\title{
SEISMIC INVESTIGATIONS OF THE LITHOSPHERE IN AN AMAGMATIC BACK-ARC REGION: NORTH ISLAND, NEW ZEALAND
}

BY

JESSE-LEE DIMECH

\begin{abstract}
A thesis
submitted to the Victoria University of Wellington in fulfilment of the requirements for the degree of Doctor of Philosophy
\end{abstract}

Victoria University of Wellington

2016 


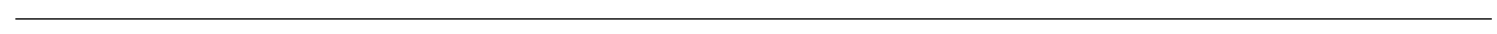




\section{Abstract}

New seismic constraints on crustal and upper mantle structures, kinematics, and lithospheric rheology are reported from an amagmatic back-arc region: the southwest North Island of New Zealand. Robust earthquake locations reveal a hypocentre 'downwarp' beneath the east-west trending Taranaki-Ruapehu Line. These earthquakes occur in the uppermost mantle, at depths of $30-50 \mathrm{~km}$, and are distinct from shallower 8-25 km-deep earthquakes near Mt. Ruapehu in terms of focal mechanisms and principal stress directions.

A receiver function CCP stack shows that the mantle earthquakes occur beneath a large change in crustal thickness, where the Moho 'steps' from 28 to $35 \mathrm{~km}$-deep and the steepest part of that step has a $20-50^{\circ}$ dip. The mantle earthquakes are dominated by strike-slip fault movement and have a maximum compressive stress direction of NE-SW. The existence of mantle earthquakes beneath a steeply-dipping Moho step implies some sort of dynamic modification is occurring in the mantle lithosphere. One possibility to explain these features is the convective removal of the mantle lithosphere due to a Rayleigh-Taylor-type instability.

South of the Taranaki-Ruapehu Line, the Moho conversion weakens on both the receiver function CCP stack, and marine seismic reflection data under most of the Wanganui Basin (SAHKE02 and GD100 seismic lines). However, localised bright reflections at Moho depths can be seen in both near-vertical and wide-angle seismic data. Attribute analysis of near-vertical seismic reflections suggests that the rocks beneath the reflectivity are strongly-attenuating $(\mathrm{Q} \sim 20)$ with a negative velocity contrast relative to the lower crust. These observations are interpreted to be related to the presence of serpentinite (antigorite) and/or high pore fluid pressures in the mantle wedge.

The links between hydration of amagmatic back-arcs, serpentinisation and/or high pore fluid pressures, rock viscosity, and mantle instabilities are documented here for the southwest North Island of New Zealand. These associations may be applicable to other amagmatic back-arcs around the world. 


\section{Acknowledgements}

I am very grateful to my primary supervisor, Tim Stern, for his excellent guidance and support over the last four years. I would also like to thank my secondary supervisors Simon Lamb and Huw Horgan for providing both expert advice and unique perspectives which helped shape both the content of this thesis and the direction of the PhD.

At Victoria University I would like to thank Rachel Heckels, Laura-May Baratin, Francesco Civilini, Dominic Evanzia, Konrad Weaver, and many others who have made my time more enjoyable. A special thanks go to all the people who helped me in the field, including Adrian Benson, Aaron Wech, Calum Chamberlain, Emily Warren-Smith, Cecile Massiot, Sapthala Karalliyadda, and Ernestynne Walsh. Thank you to Martha Savage and Richard Arnold for helping me with seismic analysis.

Outside the university, I am grateful to Stuart Henrys at GNS, particularly for his help in the formative stages of my PhD. I would also like to thank Guy Maslen and the rest of the Globe Claritas team for helping me with technical matters while processing the SAHKE02 line. Thank you to Oliver Boyd at the USGS for help on synthetic receiver functions, to Michelle Salmon at ANU for her help with receiver function method in general, and to the Marsden Fund for covering field expenses and for additional financial support. Thank you also to Laura Wallace for providing slow-slip earthquake locations.

I have used seismic data from the GeoNet network and would like to acknowledge the people who provide and maintain this invaluable scientific resource. Similarly, I have used data from the Seismic Array HiKurangi Project (SAHKE) and would like to thank the team responsible for providing me with interesting project data. A special thanks to ANSIR for providing broadband seismic equipment for this study.

Lastly, I would like to thank my family, especially my mother Carol who kept me going during the final stretch, and my father Wayne, a geologist, who first sparked my interest in geophysics. 


\section{Contents}

Abstract $\quad$ i

Acknowledgements $\quad$ iii

1 Introduction $\quad 1$

1.1 Tectonics and geology of the study area . . . . . . . . . . . 2

1.1.1 Taranaki-Ruapehu Line . . . . . . . . . . . . . . . . 4

1.1.2 Wanganui Basin . . . . . . . . . . . . . . . 6

1.1.3 Taranaki Basin and Taranaki Fault Zone . . . . . . . . . . . . 10

2 Ruapehu And Taranaki Teleseismic Imaging Line (RATTIL) 15

2.1 Seismic station locations . . . . . . . . . . . . . . . . . . . . . 15

2.2 Equipment and configuration . . . . . . . . . . . . . . . . 17

2.3 Instrument response profiles . . . . . . . . . . . . . . . . . . . 19

2.4 Orientation and polarity . . . . . . . . . . . . . . 21

2.5 Performance of RATTIL stations . . . . . . . . . . . . . 21

3 Microseismic study 33

3.1 Microseismic abstract . . . . . . . . . . . . . . . . . . 33

3.2 Previous work and study context . . . . . . . . . . . . . 33

3.3 Microseismic theory . . . . . . . . . . . . . . . . . . . 37

3.3.1 Earthquake locations . . . . . . . . . . . . . . 37

3.3.2 Geiger's location method . . . . . . . . . . . . . 37

3.3.3 Probabilistic non-linear earthquake locations . . . . . . . . . . 39

3.3.4 Focal mechanisms . . . . . . . . . . . . . . . . . . . . . 41

3.3.5 Stress inversion . . . . . . . . . . . . . . . . 45

3.3.6 Seismic moment tensor . . . . . . . . . . . . . . . . . . . 47

3.4 Data collection and analysis . . . . . . . . . . . . . . . . . 49

3.4 .1 Station selection . . . . . . . . . . . . 50

3.4.2 Event selection . . . . . . . . . . . . . . . 51

3.4.3 Preliminary earthquake locations . . . . . . . . . . . . 51

3.4.4 Final earthquake locations . . . . . . . . . . . . . 54

3.4.5 Focal mechanisms . . . . . . . . . . . . . . . . . . 55

3.4 .6 Stress inversion . . . . . . . . . . . . . . . 57

3.5 Results . . . . . . . . . . . . . . . . . 58

3.5.1 Earthquake distribution ................ 58 
3.5.2 Focal mechanisms comparisons . . . . . . . . . . . . . 60

3.5.3 Stress direction comparisons . . . . . . . . . . . . . 63

3.5.4 Fault plane orientations from focal mechanisms . . . . . . . . 64

3.5.5 Moment tensor summation and strain-rate . . . . . . . . . . 67

3.6 Discussion . . . . . . . . . . . . . . . . . . 69

3.6.1 Analysis of downwarped earthquake hypocentres . . . . . . . . 71

3.6.2 Variation of focal mechanisms with depth . . . . . . . . . 71

3.6.3 Inconsistent stress directions near Mt. Ruapehu . . . . . . . . 72

4 Receiver function study $\quad 73$

4.1 Abstract . . . . . . . . . . . . . . . . . . 73

4.2 Previous work and study context . . . . . . . . . . . . 73

4.3 Receiver function theory . . . . . . . . . . . . . . 76

4.3.1 Introduction to P-wave receiver functions . . . . . . . . . 76

4.3 .2 LQT reference frame . . . . . . . . . . . . . . . . 78

4.3.3 Multiple-Taper Spectral Correlation . . . . . . . . . . . . 79

4.3.4 Common Conversion Point stacking . . . . . . . . . . . . . 81

4.3.5 Synthetic receiver functions . . . . . . . . . . . . . . 82

4.4 Dataset and analysis . . . . . . . . . . . . . . . . 83

4.4.1 Earthquake event selection . . . . . . . . . . . . . . . . 84

4.4.2 Receiver function pre-processing . . . . . . . . . . . 86

4.4.3 Receiver function calculations . . . . . . . . . . . . . . . 88

4.4.4 Common Conversion Point stack . . . . . . . . . . . . . . 88

4.4.5 Synthetic receiver function calculations . . . . . . . . . . . . 91

4.5 Results . . . . . . . . . . . . . . . . . . . 93

4.5.1 Back azimuth and epicentral distance stacks . . . . . . . . 93

4.5.2 Common Conversion Point stack . . . . . . . . . . . . . . 95

4.5.3 Synthetic Common Conversion Point stacks . . . . . . . . . . 97

4.6 Discussion . . . . . . . . . . . . . . . . . . . . 100

5 Active-source seismic study $\quad 105$

5.1 Abstract . . . . . . . . . . . . . . . . . . . . . 105

5.2 Previous work and study context . . . . . . . . . . . 106

5.3 Active-source theory . . . . . . . . . . . . . . . . . 110

5.3.1 Reflection seismology . . . . . . . . . . . . . . 110

5.3 .2 Zoeppritz equations . . . . . . . . . . . . . . . . . . . 112

5.3 .3 Seismic attenuation . . . . . . . . . . . . . . . . . 113

5.3 .4 Ray tracing . . . . . . . . . . . . . . . . . . . . . . . . . . . . . . . . . . . . . . .

5.3.5 Hand-migration . . . . . . . . . . . . . . . . 115

5.4 Dataset and processing . . . . . . . . . . . . . . . . 117

5.4 .1 SAHKE02 . . . . . . . . . . . . . . . 117

5.4 .2 KIW . . . . . . . . . . . . . . . 120

5.5 Results . . . . . . . . . . . . . . . . . . . . 121

5.5.1 SAHKE02 seismic profile (unmigrated) . . . . . . . . 123

5.5.2 SAHKE02 seismic profile (migrated) . . . . . . . . . . . 123

5.5.3 Ray tracing of KIW . . . . . . . . . . . . . . . . . . 125

5.5.4 Attribute analysis of SAHKE02 bright reflections . . . . . . 128 
5.6 Composition of the mantle wedge . . . . . . . . . . . . . . . . 134

5.6.1 Zoeppritz equations and receiver functions . . . . . . . . . 136

5.7 Discussion . . . . . . . . . . . . . . . . . . . . . . 138

5.7.1 Serpentinite and slow-slip events . . . . . . . . . . . 139

5.7 .2 Thick subduction channel . . . . . . . . . . . . . . . 141

6 Discussion 143

6.1 Mantle earthquakes and dynamic processes . . . . . . . . . . . . . 144

6.2 Similarity between the Taranaki-Ruapehu Line and the Sierra Nevada

(U.S.) . . . . . . . . . . . . . . . . . . 150

6.3 Speculation on the role of serpentinite formation in the mantle . . . . 152

6.3.1 Gravitational and magnetic anomalies . . . . . . . . . 155

6.4 Key constraints for future geological models . . . . . . . . . . . . . 156

6.5 Recommendations for future work . . . . . . . . . . . . 158

$\begin{array}{lll}7 & \text { Conclusions } & 161\end{array}$

$\begin{array}{ll}\text { A Hypocentre locations } & 163\end{array}$

$\begin{array}{ll}\text { B Focal mechanism and moment tensor solutions } & 173\end{array}$

$\begin{array}{ll}\text { C Example DAS configuration file } & 179\end{array}$

D Station specific Receiver Function results 183

$\begin{array}{ll}\text { E CCP stacking code } & 193\end{array}$

$\begin{array}{lll}\text { F SAHKE02 processing flows } & 203\end{array}$

F.1 Geometry . . . . . . . . . . . . . . . . . . . . 203

F.2 Gun/cable static correction . . . . . . . . . . . . . . . 203

F.3 Trace QC . . . . . . . . . . . . . . . . . . . . . . 204

F.4 Signature deconvolution and high-cut anti-alias filter . . . . . . . 205

F.5 Low cut frequency filter . . . . . . . . . . . . . . . . . . 206

F.6 Amplitude recovery . . . . . . . . . . . . . . . . . . 206

F.7 Spatial anti-alias filter . . . . . . . . . . . . . . . . . . 207

F.8 Top mute . . . . . . . . . . . . . . . . . . . . . . . 209

F.9 Swell noise attenuation . . . . . . . . . . . . . . . . . . . . . . . . 209

F.10 High-frequency noise suppression . . . . . . . . . . . . . . . . . 210

F.11 Linear noise suppression . . . . . . . . . . . . . . . . . . . . . . . . . . . . . . . . . . . . . .

F.12 Multiple suppression in the Tau-P domain . . . . . . . . . . . . . . . 212

F.13 Brute stack . . . . . . . . . . . . . . . . . . . . . . . 213

F.14 Post-stack filtering . . . . . . . . . . . . . . . . . . . . . . . 213

F.15 Migration and time-depth conversion . . . . . . . . . . . . . 215

F.16 Claritas jobs for SAHKE02 . . . . . . . . . . . . . . 218

$\begin{array}{lr}\text { G OBS observations } & 219\end{array}$

$\begin{array}{ll}\text { Bibliography } & 225\end{array}$ 


\section{List of Figures}

1.1 Major tectonic elements of the New Zealand subcontinent . . . . . . . 3

1.2 Schematic profile of the Hikurangi Subduction Zone . . . . . . . . . . 4

1.3 Gravity and earthquake anomalies of the Taranaki-Ruapehu Line . . 5

1.4 Earthquake hypocentre profiles across the Taranaki-Ruapehu Line . . 5

1.5 Tectonic setting of New Zealand's North Island . . . . . . . . . . 7

1.6 Tectonic reconstruction of New Zealand . . . . . . . . . . . . . . . 9

1.7 Coeval uplift and subsidence in the Wanganui and King Country basins 10

1.8 Geological basement terranes of New Zealand . . . . . . . . . . . . . 11

1.9 Magnetic anomaly map of New Zealand's North Island . . . . . . . . 13

2.1 Deployment timeline for new temporary passive seismic stations . . . 16

2.2 Map of seismic stations considered in this study . . . . . . . . . . . 16

2.3 Photographs of seismic stations from the RATTIL deployment . . . . 20

2.4 Instrument response profiles for RATTIL stations . . . . . . . . . . . 22

2.5 Example teleseismic earthquake recorded by RATTIL stations . . . . 22

2.6 Power Spectral Density of RATTIL station 'vertical' components . . . 29

2.7 Power Spectral Density of RATTIL station 'north' components . . . . 30

2.8 Power spectral density of RATTIL station 'east' components . . . . . 31

3.1 GeoNet earthquake locations from 1987-2011 at depths of 0-50 km . . 34

3.2 Maximum horizontal compressive stress directions along the TR Line 36

3.3 Schematic diagram of a focal mechanism . . . . . . . . . . . . . . . . 42

3.4 Example of a probabilistic focal mechanism solution . . . . . . . . . . 44

3.5 Example of probabilistic principal stress directions . . . . . . . . . . . . 46

3.6 Map of seismic stations used for the TR Line microseismic study . . . 50

3.7 'GeoNet rapid' earthquake locations at the TR Line . . . . . . . . . . 52

3.8 SEISAN earthquake locations at the TR Line . . . . . . . . . . . . 53

3.9 NonLinLoc earthquake locations at the TR Line . . . . . . . . . 56

3.10 Kmeans clusters at the TR Line . . . . . . . . . . . . . . . 58

3.11 Probabilistic earthquake locations from NonLinLoc at the TR Line . 59

3.12 Focal Mechanisms at the TR Line . . . . . . . . . . . . . . . . . 62

3.13 Maximum horizontal compressive stress directions at the TR Line . . 65

3.14 Principal stress posterior probability densities at the TR Line . . . . 66

3.15 Rose diagram of focal plane orientations at the TR Line . . . . . . 66

$3.163 \mathrm{D}$ view of a 'seismic downwarp' in TR Line seismicity . . . . . . . . 70

4.1 Location map of a previous receiver function study . . . . . . . . 75 
4.2 Receiver function profile across the TR Line . . . . . . . . . . . . 75

4.3 Resistivity profile across the TR Line . . . . . . . . . . . . . . . . 76

4.4 Relationship between receiver functions and converted seismic waves . 77

4.5 LQT vs ZRT coordinate system . . . . . . . . . . . . . . . . . 79

4.6 Station location map for the new TR Line receiver function study . . 83

4.7 Distant earthquakes detected at RATTIL seismic stations . . . . . . . 85

4.8 Distant earthquakes detected at TRAP seismic stations . . . . . . . . 86

4.9 Distant earthquakes detected at GeoNet seismic stations . . . . . . . 86

4.10 Piercing point map of receiver functions at the TR Line . . . . . . . . 89

4.11 Earth models for synthetic receiver functions . . . . . . . . . . . . . . 91

4.12 Example of synthetic simulation run for a given azimuth and slowness 93

4.13 Groups of seismic stations used for receiver function analysis . . . . . 94

4.14 Receiver functions from north of the TR Line . . . . . . . . . . . . . 95

4.15 Receiver functions near the TR Line . . . . . . . . . . . . . . . 96

4.16 Receiver functions south of the TR Line . . . . . . . . . . . . . . . 97

4.17 Common Conversion Point (CCP) stack across the TR Line . . . . . 98

4.18 Synthetic CCP stacks for linear Moho dips of $10-90^{\circ}$. . . . . . . . 100

4.19 Synthetic CCP stack for a vertical Moho step with no trace sharing . 100

4.20 Qualitative 'best-fit' synthetic CCP stacks . . . . . . . . . . . . . . . 101

4.21 Interpreted CCP stack across the Taranaki-Ruapehu Line . . . . . . 103

5.1 The location of seismic datasets considered in this study . . . . . . 107

5.2 Line drawing of the unmigrated GD100 marine seismic profile . . . . 108

5.3 The South East South Island (SESI) marine seismic profile . . . . . . 109

5.4 Schematic diagram of the marine seismic reflection technique . . . . . 111

5.5 Partition of seismic energy at an interface . . . . . . . . . . . . 112

5.6 Quantitative analysis of the hand-migration process . . . . . . . . . 116

5.7 Geotrace SAHKE02 seismic reflection profile near Kapiti Island . . . 118

5.8 New seismic processing flow developed for SAHKE02 . . . . . . . . . 119

5.9 KIW wide-angle seismic data showing localised bright reflectivity . . 121

5.10 Wide-angle seismic reflection/refraction profile from Kapiti Island . . 122

5.11 Unmigrated stack of the SAHKE02 seismic reflection profile . . . . . 124

5.12 Migrated stack of the SAHKE02 seismic reflection profile . . . . . . 126

5.13 Hand-migration of SAHKE02 deep reflectors . . . . . . . . . . . . . 127

5.14 Ray tracing results from GeoNet station KIW at Kapiti Island . . . . 129

5.15 Ray tracing solutions for each planar surface referred to in the text . 130

5.16 Joint interpretation of near-vertical and wide-angle seismic reflections 131

5.17 Seismic attenuation calculation for SAHKE02 shot 1949 . . . . . . . . 131

5.18 Attribute analysis for phase on SAHKE02 shot 1949 . . . . . . . . . 133

5.19 Schematic model of a partially-serpentinised mantle wedge . . . . . . 135

5.20 A simple earth model solved with Zoeppritz equations . . . . . . . . . 137

5.21 Relationship between a serpentinised wedge and slow-slip events . . . 140

5.22 Reflection seismic signature of the Cascadia subduction . . . . . . . . 142

6.1 East African Rift mantle earthquakes and a proposed model . . . . . 145

6.2 Romanian Carpathian mantle earthquakes and proposed models . . . 146

6.3 Alborán region mantle earthquakes and proposed models . . . . . . . 147 
6.4 Receiver functions CCP stacks from the Sierra Nevada . . . . . . . . 151

6.5 Foundering Moho in the K-K' receiver function CCP stack . . . . . . 151

6.6 Rayleigh-Taylor-type instability model for the Taranaki-Ruapehu Line153

6.7 Speculative model of serpentinite distribution . . . . . . . . . . . 154

6.8 Wanganui Basin gravity anomaly . . . . . . . . . . . . . . . . 155

6.9 Schematic diagram showing key constraints from this study . . . . . . 157

D.1 Receiver functions at station PAR . . . . . . . . . . . . . . . . . . 184

D.2 Receiver functions at station WAI . . . . . . . . . . . . . . . . . 184

D.3 Receiver functions at station HOK . . . . . . . . . . . . . . 185

D.4 Receiver functions at station SOW . . . . . . . . . . . . . . 185

D.5 Receiver functions at station MOT . . . . . . . . . . . . 186

D.6 Receiver functions at station KUR . . . . . . . . . . . . . . 186

D.7 Receiver functions at station FUN . . . . . . . . . . . . . . . . . 187

D.8 Receiver functions at station PEP . . . . . . . . . . . . . . . 187

D.9 Receiver functions at station ERU . . . . . . . . . . . . . . . . 188

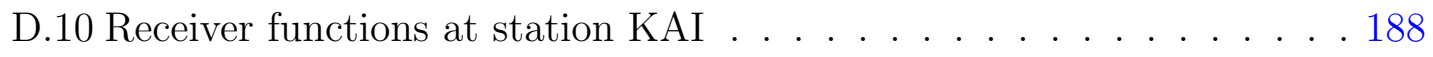

D.11 Receiver functions at station PAP . . . . . . . . . . . . . . . . 189

D.12 Receiver functions at station RAE . . . . . . . . . . . . . . . 189

D.13 Receiver functions at station SUN . . . . . . . . . . . . . . . 190

D.14 Receiver functions at station TUN . . . . . . . . . . . . . . . 190

D.15 Receiver functions at station WRR . . . . . . . . . . . . . . . 191

D.16 Receiver functions at station PKVZ . . . . . . . . . . . . . . . 191

D.17 Receiver functions at station TWVZ . . . . . . . . . . . . . . . . 192

F.1 Example of 'AREAL' display for SAHKE02 . . . . . . . . . . . . . 204

F.2 Creation and testing of signature deconvolution matching filter . . . . 205

F.3 Example of a low cut frequency filter on shot 1951 . . . . . . . . . . 206

F.4 Example of $\mathrm{T}^{2}$-type spherical divergence correction on shot 1100 . . . 207

F.5 K filter test for shot 1951 . . . . . . . . . . . . . . . . . . . 208

F.6 Shot 1951 before and after top mute . . . . . . . . . . . . . . . 209

F.7 Deswell tests for deep times in shot 1951 . . . . . . . . . . . . . . . 210

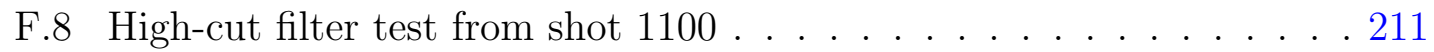

F.9 FK filter test on shot 1951 . . . . . . . . . . . . . . . . . . . 212

F.10 Shot 1951 before and after Tau-P deconvolution . . . . . . . . . . . . 213

F.11 Brute stack of the SAHKE02 line . . . . . . . . . . . . . . . 214

F.12 Stacking velocities for SAHKE02 _. . . . . . . . . . . . . 215

F.13 SAHKE02 seismic profile in time (unmigrated) . . . . . . . . . . . 216

F.14 Interval velocity model for SAHKE02 depth conversion . . . . . . . . 217

F.15 SAHKE02 seismic profile in depth (migrated) . . . . . . . . . . . . 217

F.16 Processing workflow for SAHKE02 . . . . . . . . . . . . 218

G.1 OBS17 reduced traveltime plot . . . . . . . . . . . . . . . 220

G.2 OBS18 reduced traveltime plot . . . . . . . . . . . . . . . . . . . . . . . . . . . . . . . . . . . 221

G.3 OBS19 reduced traveltime plot . . . . . . . . . . . . . . . . . 222

G.4 OBS20 reduced traveltime plot . . . . . . . . . . . . . . . . 223 


\section{List of Tables}

2.1 RATTIL station locations and instrument details . . . . . . . . . . . 18

2.2 RATTIL seismic station deployment dates . . . . . . . . . . . . 18

3.1 TR Line focal mechanisms grouped by approximate fault type . . . . 63

3.2 Seismic strain-rate tensor components at the TR Line . . . . . . . . . 68

3.3 Eigenvalues of the TR Line strain-rate tensors . . . . . . . . . . . . 69

3.4 Eigenvectors of the TR Line strain-rate tensors . . . . . . . . . . . . 69

4.1 Sediment depth estimates across the TR Line . . . . . . . . . . . . . 84

4.2 Number of receiver functions calculated per station . . . . . . . . . 87

A.1 Hypocentre locations at the TR Line $(2012-2014)$. . . . . . . . . . 172

B.1 Focal mechanisms and moment tensors at the TR Line (2012-2014) . 177

F.1 SAHKE02 acquisition parameters . . . . . . . . . . . . 203

F.2 SAHKE02 deconvolution parameters . . . . . . . . . . . . . . . 212 


\section{Chapter 1}

\section{Introduction}

The back-arc region of New Zealand's North Island has features which are not explained by conventional plate tectonic theory. For example, the east-west trending geophysical boundary known as the Taranaki-Ruapehu Line (also known as the 'Line', or 'TR Line'), is almost orthogonal to the NNE-SSW trending structures of the Hikurangi active margin [Hatherton, 1970a; Mooney, 1970; Salmon et al., 2011]. South of the TR Line arc-volcanism ceases yet subduction continues for about another $300 \mathrm{~km}$ to the SSE [Davey and Stern, 1990; Katz and Leask, 1990]. There is a growing body of evidence which suggests that unconventional processes in the mantle are deforming the western North Island lithosphere, yet this deformation may be only indirectly linked to subduction zone processes [Stern et al., 2006; Salmon et al., 2011]. The study of the Taranaki-Ruapehu Line and the amagmatic back-arc region south of the Line may provide new insights into how the continental lithosphere deforms in general.

The main objective of this thesis is to provide new constraints on crustal/upper mantle structures, kinematics, and lithospheric rheology in the southwest North Island of New Zealand. The evidence contained in this study should provide valuable inputs for future geological models. The creation of geo-and thermo-dynamic, finite-element models of subduction is not a focus of this study, which instead focuses on the acquisition and interpretation of new data in three independent seismic investigations.

This study makes use of local earthquakes, receiver functions, and active-source seismic reflection data from a region including the Taranaki-Ruapehu Line, Taranaki Basin and Wanganui Basin. The seismic analysis techniques used in this study are diverse and sample crust/mantle structures in novel ways. For example, receiver functions can detect $\mathrm{P}-$ to- $\mathrm{S}$ wave conversions from a geological layer, seismic reflec- 
tions detect the layer from above, and local earthquakes occur within a layer and provide information about intrinsic properties such as stress and strain.

The following chapters explain the acquisition of new passive-source seismic data (Chapter 2) which are then processed to detect deep earthquakes, stresses and strains associated with the Taranaki-Ruapehu Line (Chapter 3). Receiver functions from distant earthquakes are used to constrain the Moho structure associated with this feature (Chapter 4). Active-source seismic reflection data are used to identify structures in the lower crust and mantle wedge beneath the Wanganui and Taranaki basins (Chapter 5). These independent studies are brought together at the end of the thesis for a joint interpretation and discussion (Chapter 6), followed by a summary of the most important conclusions (Chapter 7).

\subsection{Tectonics and geology of the study area}

New Zealand straddles the Australian/Pacific plate boundary, where westward subduction at the Hikurangi Trough is linked to eastward subduction at the Puyseger Trench by the transpressional Alpine Fault (Figure 1.1). In an idealised subduction zone, thin ( $\sim 7 \mathrm{~km}$-thick) oceanic crust, which overlies mantle lithosphere, undergoes subduction. Yet in New Zealand, unusually thick oceanic crust subducts westward under the North Island, ranging in thickness from 5-7 km-thick north of New Zealand [Davy, 1992], to $12 \mathrm{~km}$-thick at the Hikurangi Trough [Davy, 1992], to $15 \mathrm{~km}$-thick at the Chatham Rise [Davy and Wood, 1994], by which point westward subduction ceases. The plate subducts at an angle of just $12-25^{\circ}$ beneath the eastern North Island and is only $15-25 \mathrm{~km}$ below the land surface just north of Wellington city [Henrys et al., 2013, Figure 1.1]. This is shallow in comparison to most other subduction zones around the world (e.g. Cascadia, Japan).

Along the North Island, convergence rates vary from $60 \mathrm{~mm} / \mathrm{yr}$ offshore Gisborne to $25 \mathrm{~mm} / \mathrm{yr}$ up-dip from Wellington [Wallace et al., 2012], as a subduction-dominated regime gradually translates into oblique continental collision and strike-slip. The partition of relative plate motion is partly expressed by the Marlborough Fault Zone and North Island Fault System respectively, whose structures branch out from the Alpine Fault in the South Island then continue along the east coast of the North Island (Figures 1.1 and 1.2). 


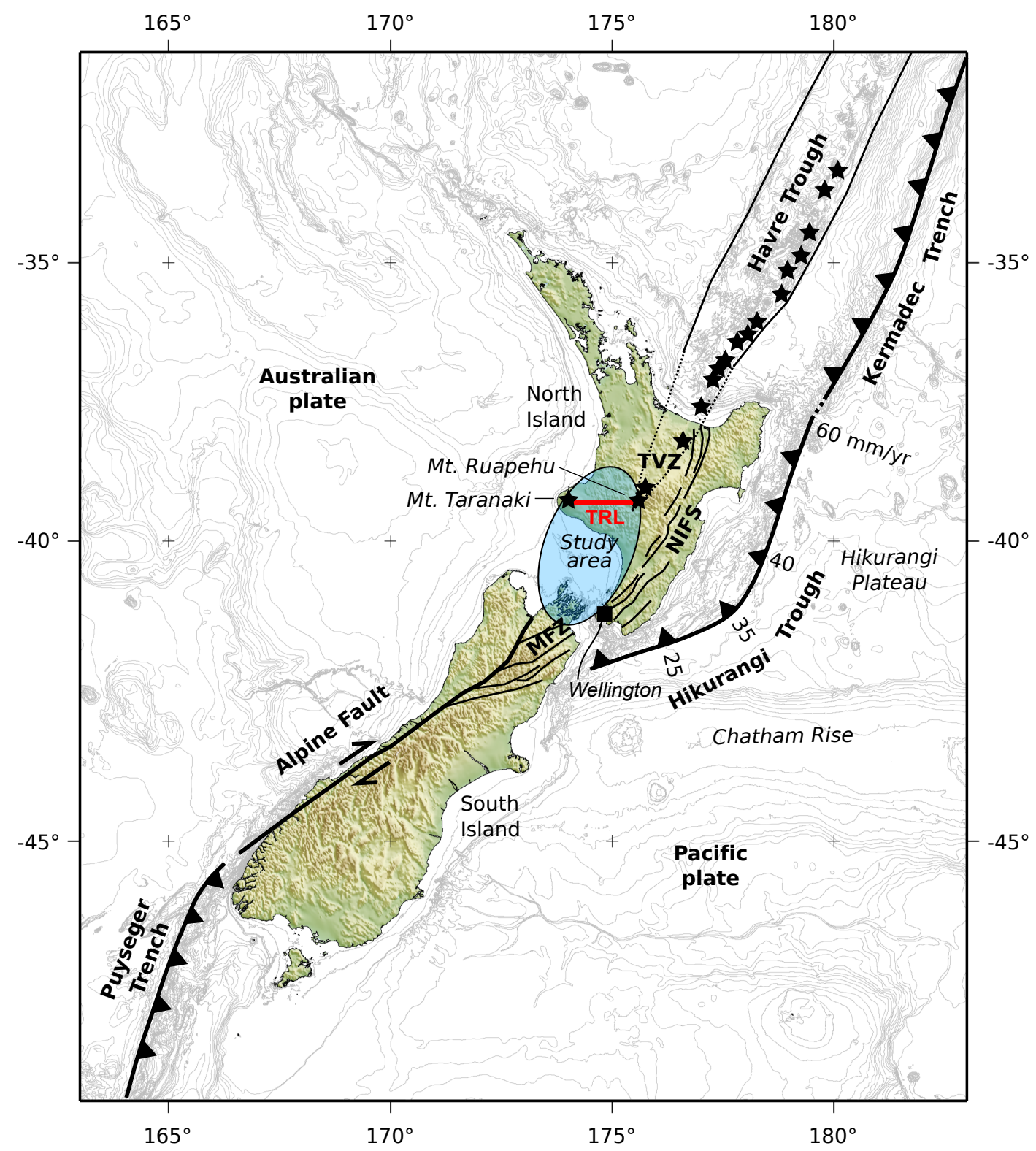

Figure 1.1: Major tectonic elements of the New Zealand subcontinent. TRL $=$ TaranakiRuapehu Line; TVZ = Taupo Volcanic Zone; MFZ = Marlborough Fault Zone; NIFS = North Island Fault System. Stars represent active andesite/dacite volcanoes of the active arc and all (except Mt. Taranaki) sit about $80-100 \mathrm{~km}$ above the Benioff zone [Stern et al., 2006]. Mt. Taranaki is distinctive in that it is a basaltic-andesite volcano with high potassium chemistry and sits about $200 \mathrm{~km}$ above the Benioff zone. Bathymetric contours are in grey [Schmidt, 2015]. Numbers represent slowing subduction rates towards the southern end of the Hikurangi Trough [Wallace et al., 2012]. 


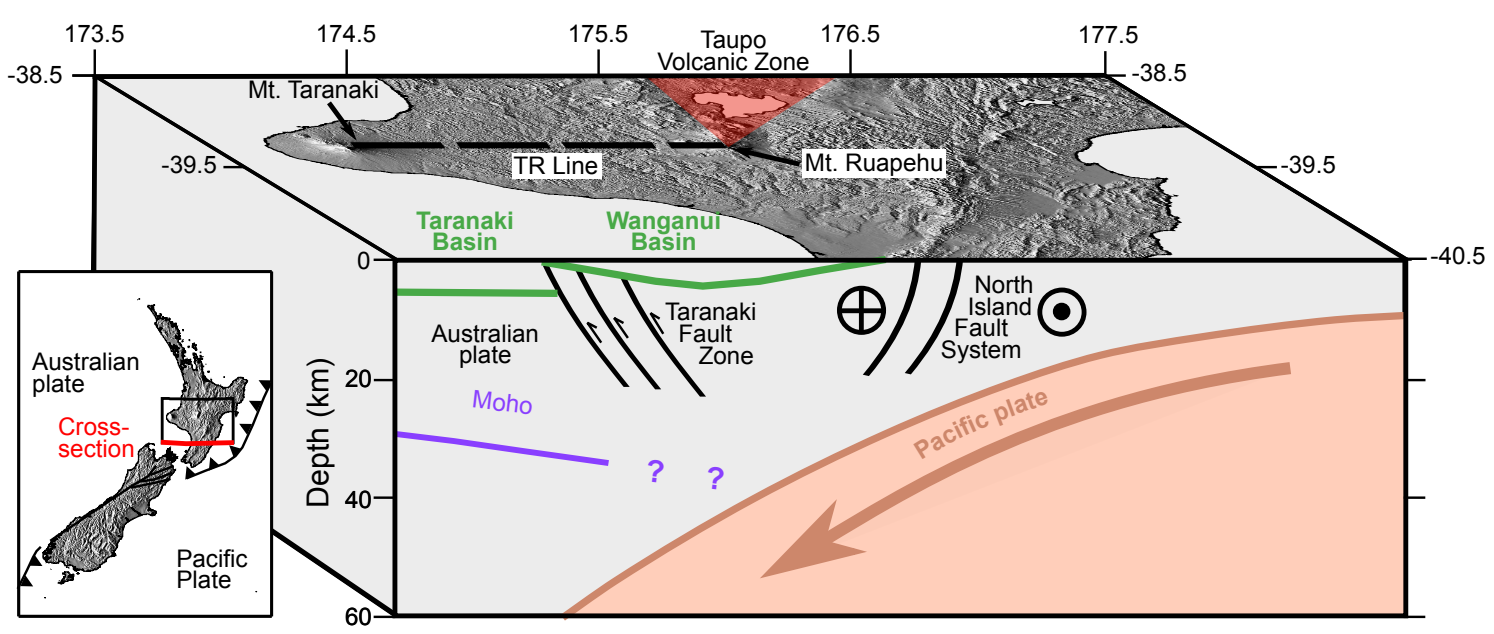

Figure 1.2: Schematic profile of the Hikurangi Subduction Zone. Profile runs through the Wanganui and Taranaki basins. All depths and locations are approximate.

\subsubsection{Taranaki-Ruapehu Line}

The Taranaki-Ruapehu Line (TRL in Figure 1.1) is a profound geophysical boundary that was first recognised more than 40 years ago as a deep boundary in the mantle across which seismic attenuation $\left(Q^{-} 1\right)$ changes abruptly [Hatherton, 1970a; Mooney, 1970]. The Taranaki-Ruapehu Line also corresponds to the southern boundary for active volcanism in New Zealand [Reyners, 1980; Price et al., 1999]. South of the Line, maximum crustal thickness is estimated at $40 \mathrm{~km}$ [Salmon et al., 2011; Holt and Stern, 1994], whereas to the north it thins to just $25 \mathrm{~km}$ [Stratford, 2006; Stratford and Stern, 2006; Salmon et al., 2011].

Gravity modelling, receiver function inversions, P-wave delay times, and wide-angle seismic data imply the presence of a $7-10 \mathrm{~km}$ crustal step across the TaranakiRuapehu Line [Stern et al., 1987; Salmon, 2008; Salmon et al., 2011; Seward et al., 2009a; Tozer, 2013]. There is also thought to be a step in the mantle lithosphere at the TR Line, such that the mantle lid is largely absent or heavily thinned under the northwest North Island [Stern et al., 1987; Seward et al., 2009b]. Despite several independent datasets detecting the presence of the TR Line, the structure and dip of the Line is not well constrained.

The exact location and geophysical significance of the Taranaki-Ruapehu Line has been the subject of much discussion. Gravity modelling by Stern et al. [1987] places the Line directly between Mt. Taranaki and Mt. Ruapehu. However, Sherburn and White [2005] suggest the Line is $25 \mathrm{~km}$ north of this location based on changes in crustal earthquake depths near Mt. Taranaki, and their assumption that earthquakes cannot exist in the mantle. Structural inversions by Reyners et al. [2006] 
(a) Gravity Anomaly Map

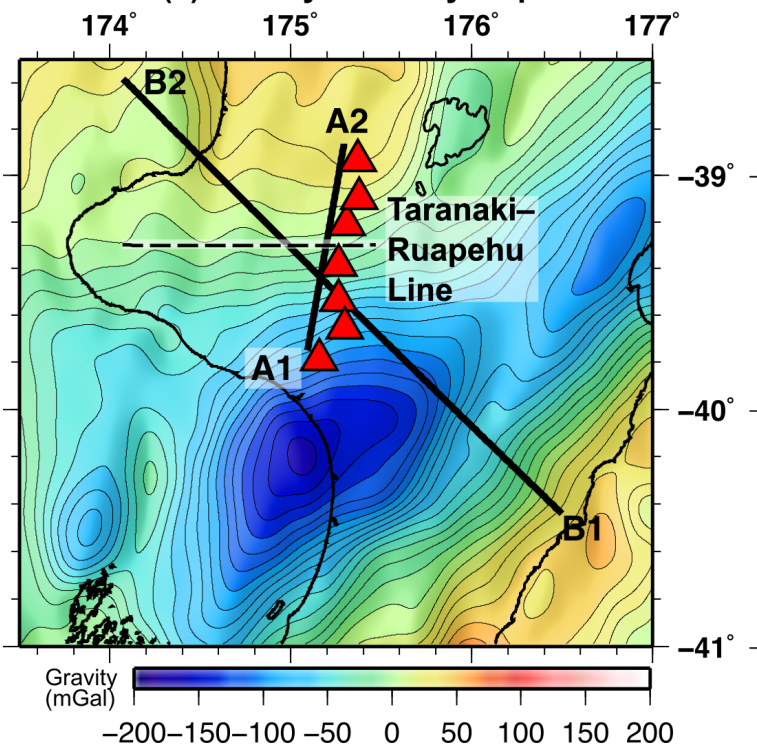

(b) Earthquake Distribution Map

$174^{\circ} \quad 175^{\circ} \quad 176^{\circ} \quad 177^{\circ}$

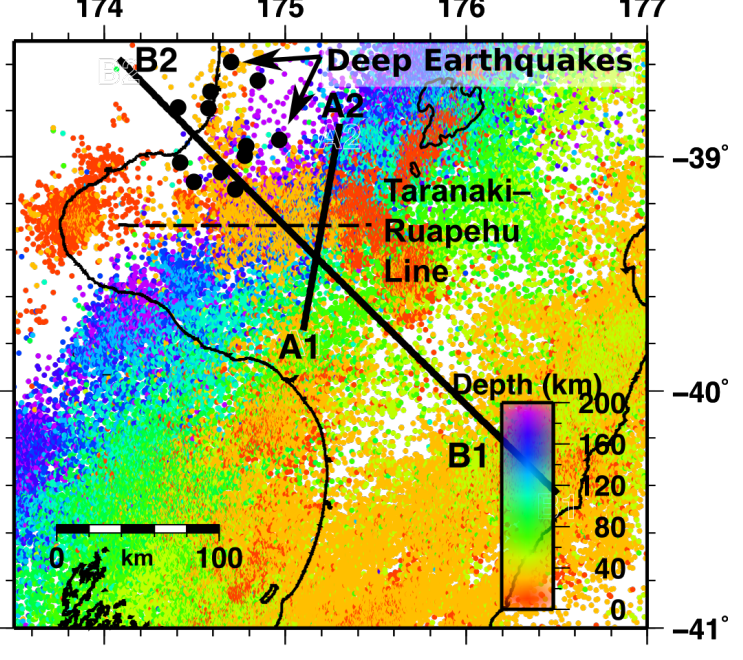

Figure 1.3: Gravity and earthquake anomalies at the Taranaki-Ruapehu Line. Black lines A1-A2 and B1-B2 are the location of earthquake hypocentre profiles in Figure 1.4. (a) Gravity anomaly map. Gravity values are isostatic (onshore) and free-air (offshore) and contours are $10 \mathrm{mGal}$ [Reilly, 1972]. Red triangles are the TRAP seismic stations from Salmon et al. [2011]. (b) Earthquake distribution map based on the GeoNet catalog [Fenaughty, 2015]. Orange hypocentres near the TR Line are the $15-40 \mathrm{~km}$ deep earthquakes referred to in the text. Note that there is a slight dip in the subducted plate Benioff zone beneath the 15-40 km deep earthquakes. The 'Deep Earthquakes' are $600 \mathrm{~km}$-deep [Boddington et al., 2004].

(a) Profile A (Salmon 2011)

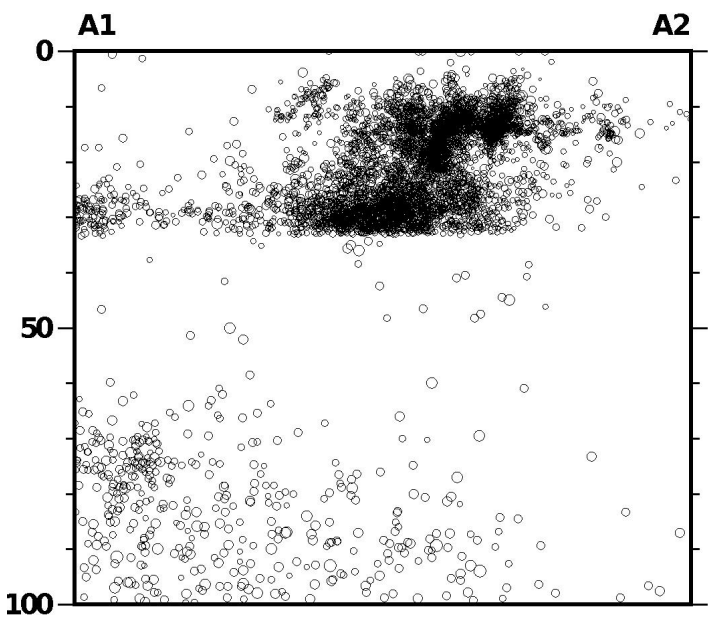

(b) Profile B (Normal to subduction)

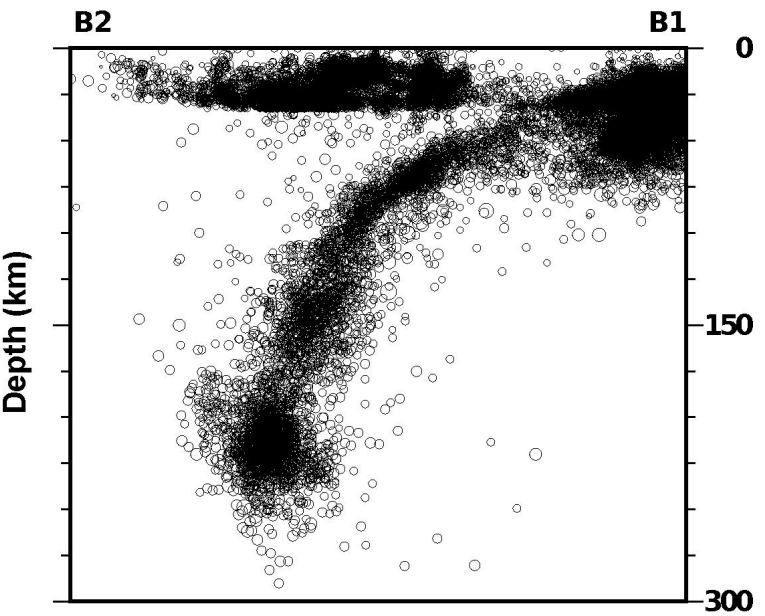

Figure 1.4: Earthquake hypocentre profiles across the Taranaki-Ruapehu Line. (a) Profile along the receiver function transect of [Salmon et al., 2011] shows diffuse crustal seismicity. It will be shown later that the sharp base of the seismicity is artificial. (b) Profile normal to the subducted Pacific plate. Profile locations shown in Figure 1.3. Earthquake hypocentres are from GeoNet [Fenaughty, 2015]. 
suggest the Line might run NW-SE between Mt. Taranaki and Mt. Ruapehu, normal to the downgoing Pacific plate. More recently, receiver function results from Salmon et al. [2011] show the Line does indeed run east-west near Mt. Ruapehu and constrain its location as a 'step' in the Moho adjacent to Mt. Ruapehu. The result from Salmon et al. [2011] is arguably the most reliable as it is based on direct measurements of the Moho. The figures in this thesis follow the convention of [Salmon et al., 2011] and show the Taranaki-Ruapehu Line as an east-west relationship.

The TR Line is associated with a steep isostatic gravity gradient whose contours trend east-west (Figure 1.3a). Extensional tectonics are observed north of the Line, while compressional tectonics are observed south of the Line [Wallace et al., 2004]. Earthquake hypocentres downloaded from the GeoNet earthquake catalog [Fenaughty, 2015] show that a band of 15-40 km deep earthquakes occur where the gravity gradient is maximum (compare Figure 1.3a and b). Immediately $\mathrm{N}$ to NW of the Line exists a second cluster of earthquakes with depths of $\sim 600 \mathrm{~km}$ (Figure 1.3b). These earthquakes are detected every few years [Boddington et al., 2004], and their relationship to the nearby Taranaki-Ruapehu Line earthquakes is unclear (Figure 1.3b).

Figure 1.4 shows two profiles across the diffuse earthquakes of the Taranaki-Ruapehu Line. The first profile, A1-A2, cuts through the transect of Salmon et al. [2011] who imaged a $\sim 7 \mathrm{~km}$ step in crustal thickness in the middle of the profile. The second profile, B1-B2, runs along the trend of the subduction zone, and shows that the Taranaki-Ruapehu Line earthquakes occur above a bend in the Benioff zone earthquakes.

Explanations for Taranaki-Ruapehu Line earthquakes are conflicting. Reyners [1989] originally suggested that the earthquakes may be due to differential stress caused by a step in crustal thickness along the Line, but later suggested that the earthquakes may be due to an anomalous amount of fluids [Reyners et al., 2006]. Other explanations include the viscous deformation and detachment of the mantle lithosphere - at unusually high strain-rates - resulting in brittle behaviour at greater depths at the Taranaki-Ruapehu Line [Stern et al., 2013].

\subsubsection{Wanganui Basin}

The Wanganui Basin is situated behind the Hikurangi Margin in the southwest North Island of New Zealand, and is effectively along-strike from the active volcanic front (Figure 1.5). It is bounded to the west by the Taranaki Fault Zone, to the east 


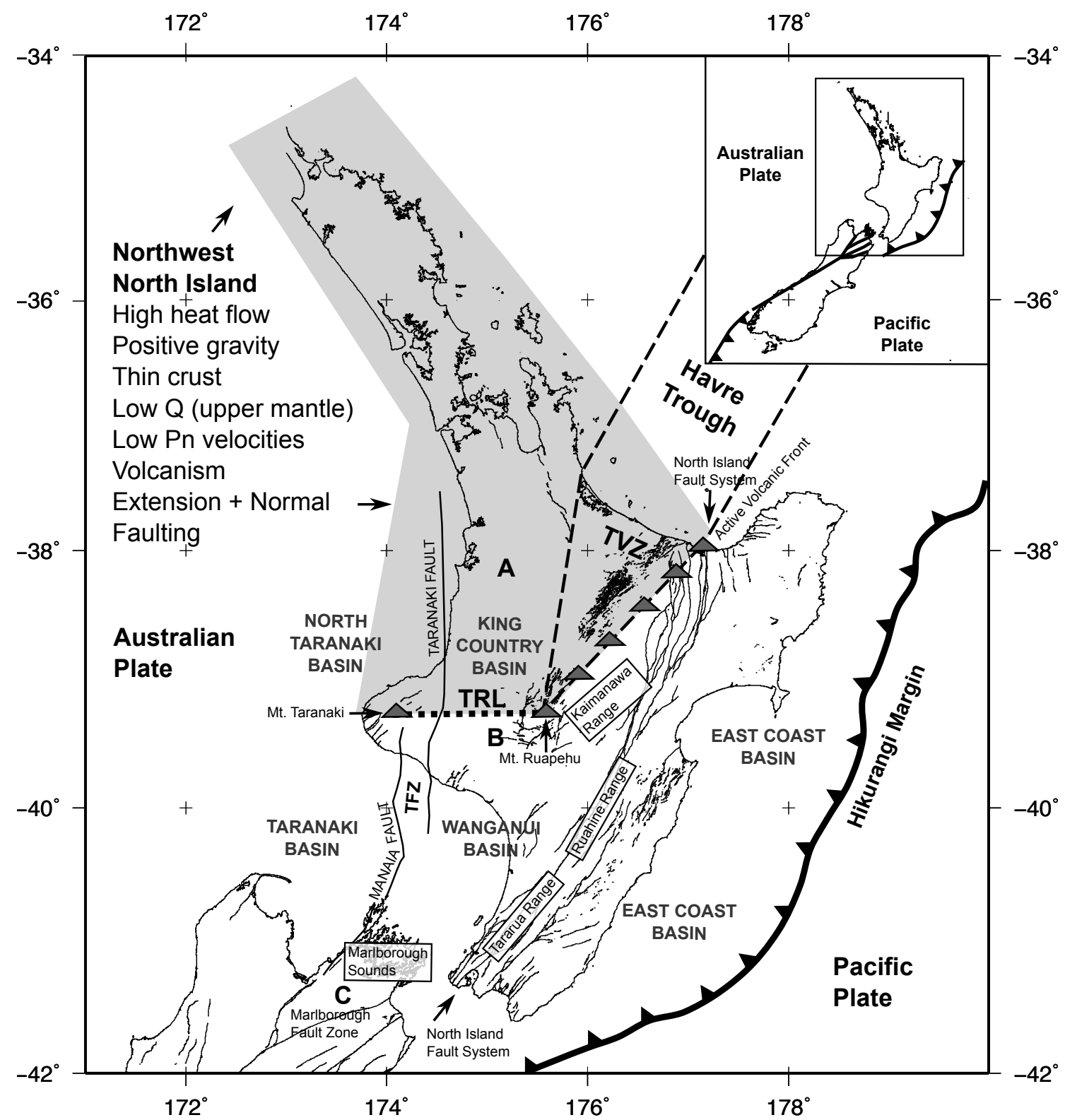

Figure 1.5: Tectonic setting of New Zealand's North Island. TVZ = Taupo Volcanic Zone; TRL $=$ Taranaki-Ruapehu Line; TFZ = Taranaki Fault Zone. Solid black lines are active faults from the Active Faults Database by GNS Science. Shaded area (northwest North Island) represents extensional back-arc properties of the northern Hikurangi Subduction Zone, in comparison to the compressional, arcless subduction zone in the south. A, B and $\mathrm{C}$ refer to corner points from Figure 1.7. Flat grey triangles along the eastern border of the TVZ represent the active volcanic front, note there is no arc-volcanism south of the TRL. Off and onshore geological mapping shows the region of extension continues $\sim 20 \mathrm{~km}$ south of the TR Line [Townsend et al., 2008] 
by the Tararua, Ruahine and Kaimanawa ranges, to the south by the Marlborough Sounds, and to the north by the Taranaki-Ruapehu Line. Cope [1966] and Cope and Reed [1967] originally divided the Wanganui Basin into the North Wanganui Basin (where Oligocene strata overlies the basement) and South Wanganui Basin (where Pliocene rocks overlie the basement), with the ridge between the two basins referred to as the Pipiriki High. Hunt [1980] first suggested that the Northern Wanganui Basin might not be a simple continuation of the South on the basis of gravity modelling. Recently, the North Wanganui Basin was amalgamated as part of the 'King Country Basin' [Kamp et al., 2002]. In this thesis the South Wanganui Basin is referred to as the Wanganui Basin, and the North Wanganui Basin as the King Country Basin.

The distance of the Wanganui Basin from the trench suggests it could be considered a retroarc foreland basin as defined by Beaumont [1981], but the absence of a volcanic arc and a deep gravity low point to a more complex origin. The Wanganui Basin was originally thought to be a rift basin, with what appeared to be extensional normal faulting interpreted from oil industry marine seismic data [Anderton, 1981]. However, migration of crustal-scale seismic datasets revealed that many apparent normal faults were actually thrust faults, and the basin is instead flexurally downwarped [Stern et al., 1992]. Frictional shear between the subducted Pacific plate and overriding Australian plate was proposed to contribute to the basin's origin [Stern et al., 1992]. In the frictional shear model, the shear force of a strongly-coupled plate interface generates a vertical, downwards pull in the overriding plate along with in-plane stresses, causing the basin to downwarp [Stern et al., 1992].

The evolution of the Wanganui Basin is linked to subduction evolution, which is believed to have started beneath the eastern North Island during the Late Oligocene [25-28 Ma Rait et al., 1991]. Plate tectonic reconstructions require substantial Miocene crustal shortening in the vicinity of the Wanganui Basin to reassemble the present day plate boundary [Walcott, 1984; King, 2000; Wood and Stagpoole, 2007; Lamb, 2011]. Wood and Stagpoole [2007]'s reconstruction equates shortening to a 'region of deformation' which collapses to form the present-day orientation of New Zealand (Figure 1.6). Up to $200 \mathrm{~km}$ of crustal shortening is predicted with maximum shortening occurring between 15-5 Ma [Furlong and Kamp, 2009]. Putting this into perspective, the Southern Alps of New Zealand are believed to have undergone just $70 \mathrm{~km}$ of shortening during the last $6 \mathrm{Ma}$ [Cande and Stock, 2004]. Deformation of the southwest North Island may have elevated a large portion of the pre-Wanganui Basin basement rock well above sea level during the Miocene [King, 2000], resulting in what is referred to informally as the 'Northern Alps' (Peter Kamp, personal com- 


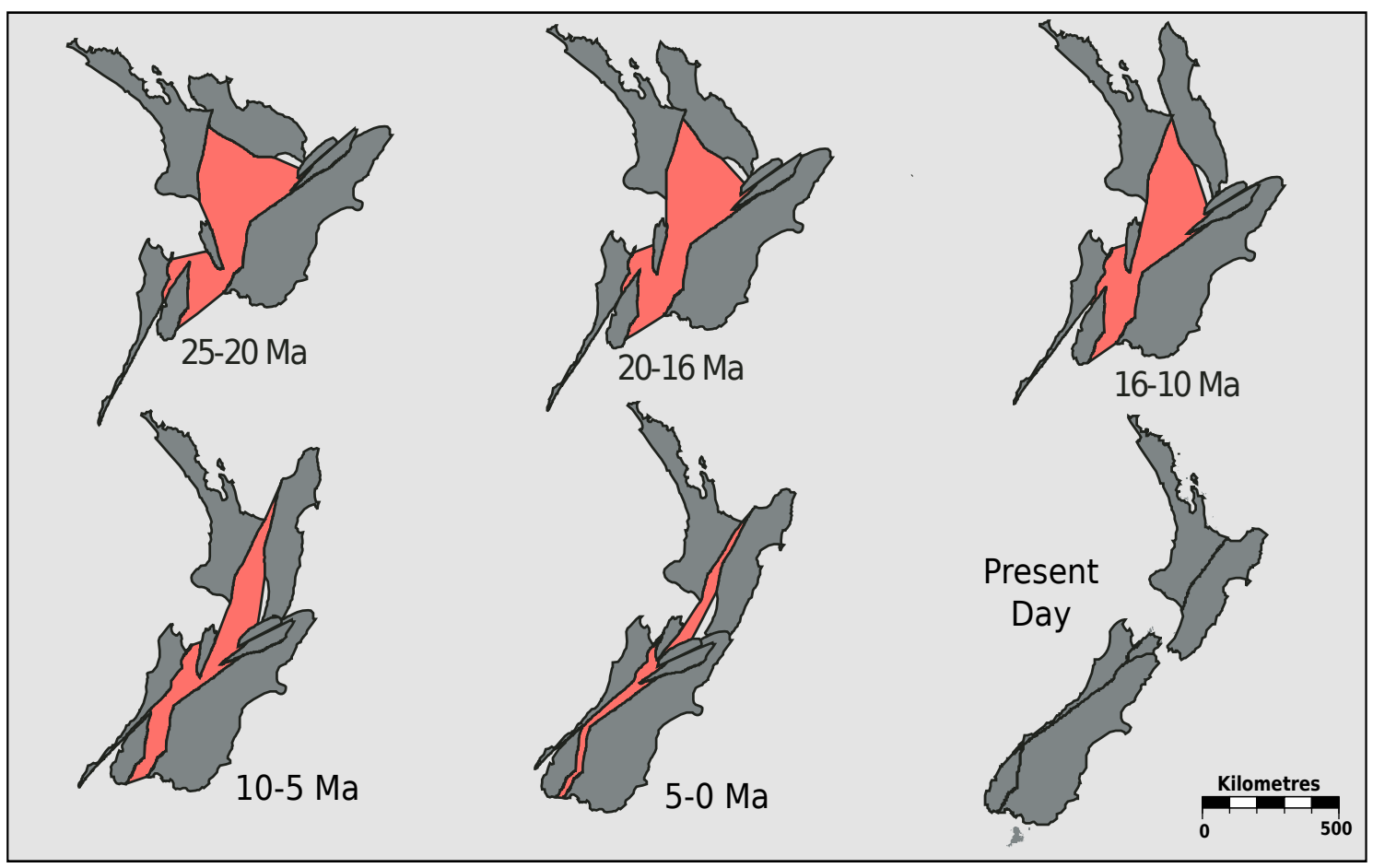

Figure 1.6: Example tectonic reconstruction from Wood and Stagpoole [2007]. In this model, major crustal shortening occurs in the Wanganui Basin region during the Miocene. Shortened crust in red is referred to as the 'central deformed region'.

munication, 2013). The Northern Alps provide a likely explanation for the irregular geometry of the Wanganui Basin basement rock, which in places has the appearance of a submerged mountain range on seismic reflection data. (See seismic data in Holt and Stern [1994], or Figure 5.7.)

The basement rock of the Wanganui Basin consists primarily of Mesozoic and Palaeozoic greywacke of the Rakaia, Morrinsville and Caples terranes (Figure 1.8). Some of the basement greywacke is altered to schist near terrane boundary interfaces. The interfaces were first identified on the basis of geological studies of the basement outcrop at surrounding basement highs, such as the Marlborough sounds [Mortimer, 1993]. The contacts were then extrapolated offshore using magnetic, marine seismic and petroleum well data [Mortimer et al., 1997], and later synthesised in a full New Zealand geological evaluation [Mortimer, 2004]. Limited direct geological observations are possible across most of the Wanganui Basin due to extensive overburden cover, meaning that structural boundaries and dips of the basement units are not well constrained and should be treated with caution.

Early Oligocene and younger sedimentary layers unconformably overlie Wanganui Basin basement terranes [Fleming, 1953]. The oldest layers are exposed at the north of the basin and youngest layers at the south, so that Pliocene sedimentary layers 


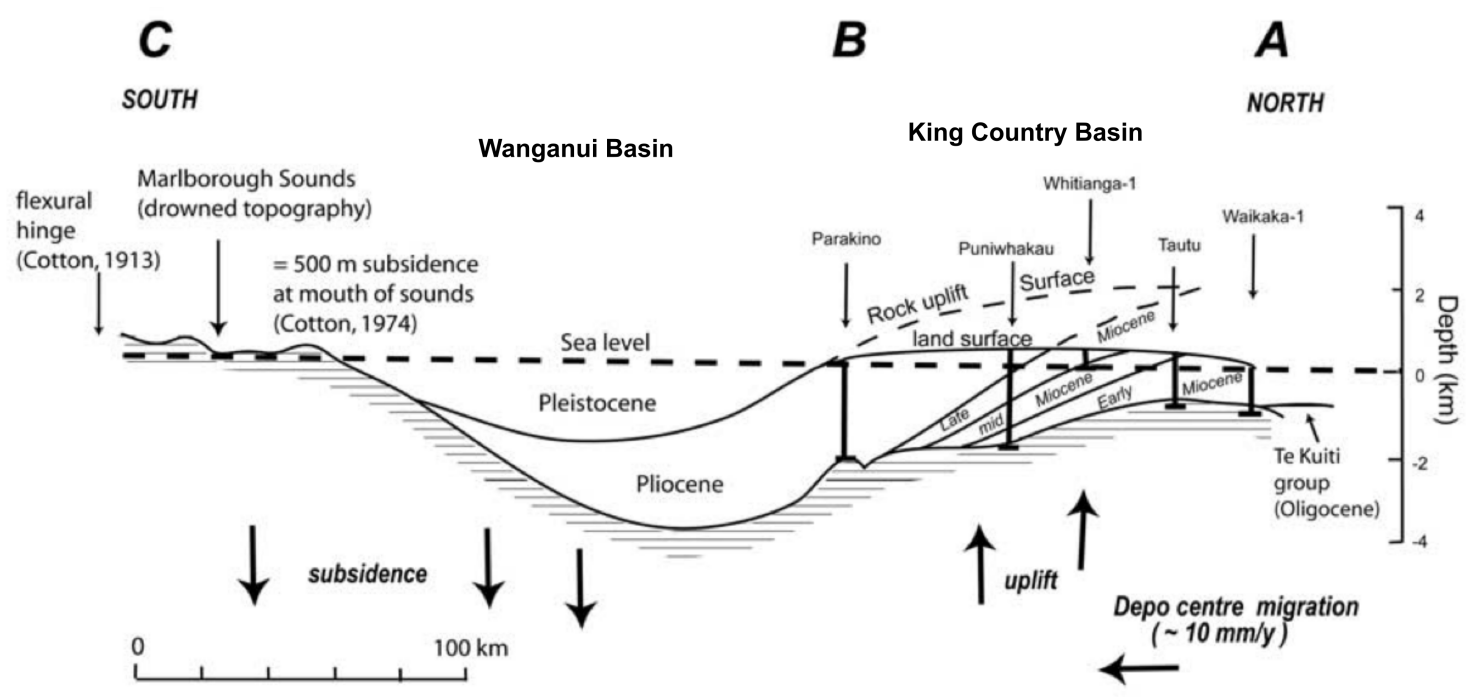

Figure 1.7: Coeval uplift and subsidence in the Wanganui and King Country basins [after Stern et al., 2006]. For the profile location, refer to points A, B and C in Figure 1.5.

directly overlie basement rocks offshore [Hunt, 1980; Stern et al., 1992]. Deposition was followed by $\sim 4 \mathrm{~km}$ of Pliocene-Recent subsidence [Hunt, 1980; Anderton, 1981; Proust et al., 2005].

A north-south cross-section through the Wanganui and King Country basins has the appearance of a 'geological standing wave' with a wavelength of $\sim 300 \mathrm{~km}$ (Figure 1.7). This region is associated with coeval uplift and subsidence and north-south migrating sedimentary depocentres. A north-south migrating Rayleigh-Taylor-type edge instability has been proposed to explain the migrating depocentres, and other features of the Taranaki-Ruapehu Line mentioned above [Stern et al., 2013].

\subsubsection{Taranaki Basin and Taranaki Fault Zone}

The Taranaki Basin is located immediately west of the Wanganui and King Country basins, its eastern boundary coincides with the easternmost portion of the Taranaki Fault Zone (Figure 1.5). The fault zone also runs subparallel to part of the Eastern Belt of the Stokes Magnetic Anomaly [Figure 1.9; Hunt, 1978], where a $<10 \mathrm{~km}$ wide, 100-200 nT magnetic anomaly is produced by Early Permian ultramafic rocks of the Dun Mountain Ophiolite Belt.

The ophiolite belt shows mélange-style deformation, and is unconformably overlain by a $6 \mathrm{~km}$-thick volcaniclastic sedimentary sequence of the Maitai terrane [Mortimer, 2004]. The Dun Mountain and Maitai terranes are grouped together as the Dun Mountain - Matai terrane in Figure 1.8. To the west of the Dun Mountain Ophiolite 


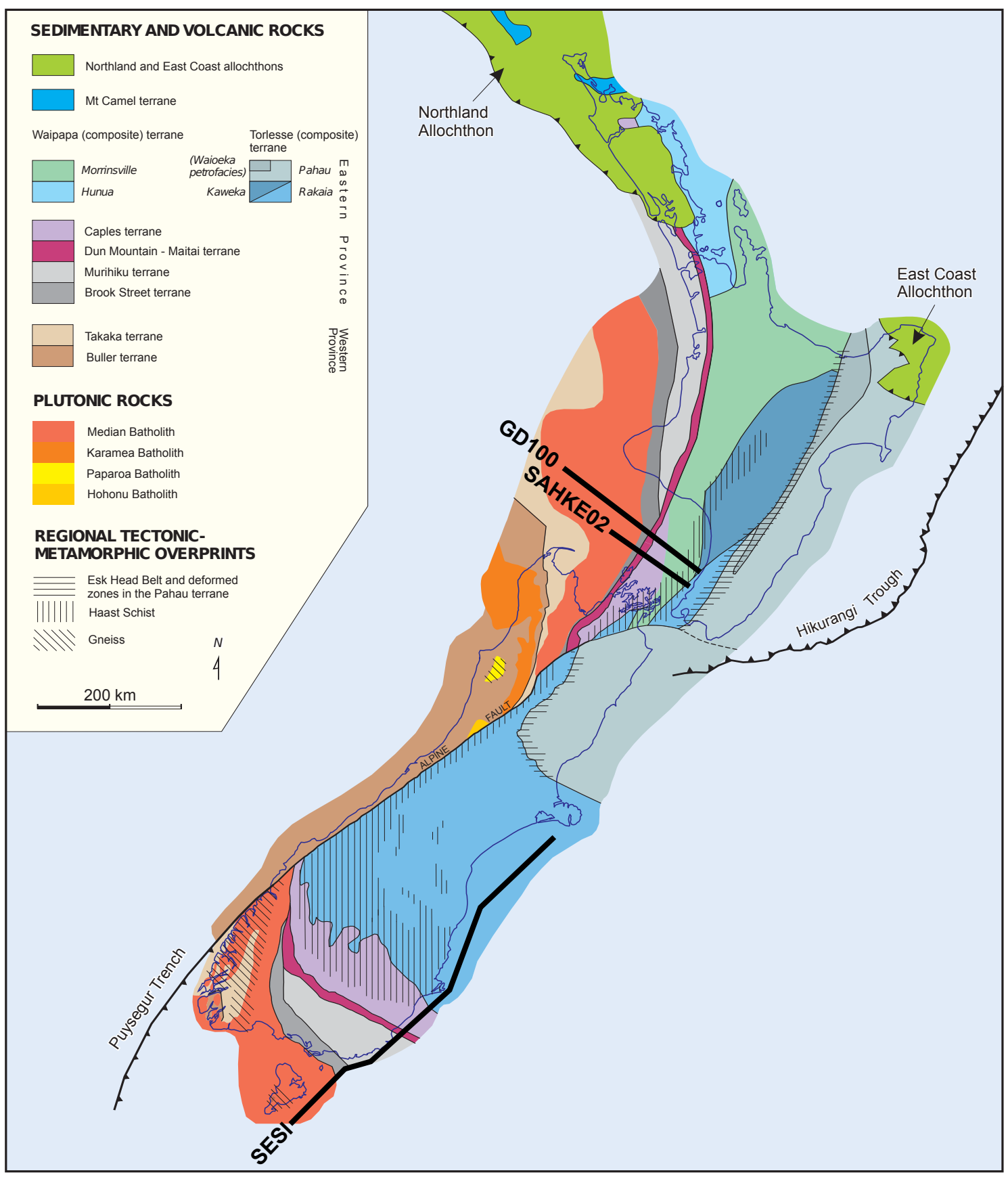

Figure 1.8: Geological basement terranes of New Zealand [from Mortimer, 2004]. Note how the GD100, SAHKE02 and SESI seismic lines cross five of the same basement terranes. 
Belt in the Taranaki Basin rests the Brook Street terrane. This terrane consists of Pyroxene-rich basalt-dominated volcanic rocks which are thought to have been deposited as a result of Permian subduction processes [Figure 1.8, Mortimer, 2004]. Further to the west, the broader Western Belt of the Stokes Magnetic Anomaly (Figure 1.9) consists of numerous, discrete magnetic anomalies associated with the plutonic and metamorphic rocks of the Median Batholith [Hunt, 1978]. The Median Batholith is also thought to be subduction-related and was intruded from 375$110 \mathrm{Ma}[$ Mortimer, 2004].

The plutonic basement rock of the Taranaki Basin is different from the sedimentary greywacke of the Wanganui Basin discussed in Section 1.1.2. The Dun Mountain Ophiolite Belt is not an arbitrary border between the Taranaki and Wanganui basins; it is thought to be a Permian crustal suture [Mortimer et al., 2002; Stern et al., 2006], whose material possibly originates from the lower crust or upper mantle [Coombs et al., 1976].

Deformation of the Taranaki Basin since the Miocene is consistent with a transition from an extensional to a compressive back-arc setting; the northern part of the basin (north of the TR Line) has undergone normal faulting and extension in this time, while the southern part (south of the TR Line) has undergone compressive deformation with reverse faulting and structural inversion [Knox, 1982].

Figure 1.2 is a cross-section across the Hikurangi Subduction Zone which shows the relationship between the Taranaki Basin, Taranaki Fault Zone, Wanganui Basin, North Island Fault System, and the subducted Pacific plate. 


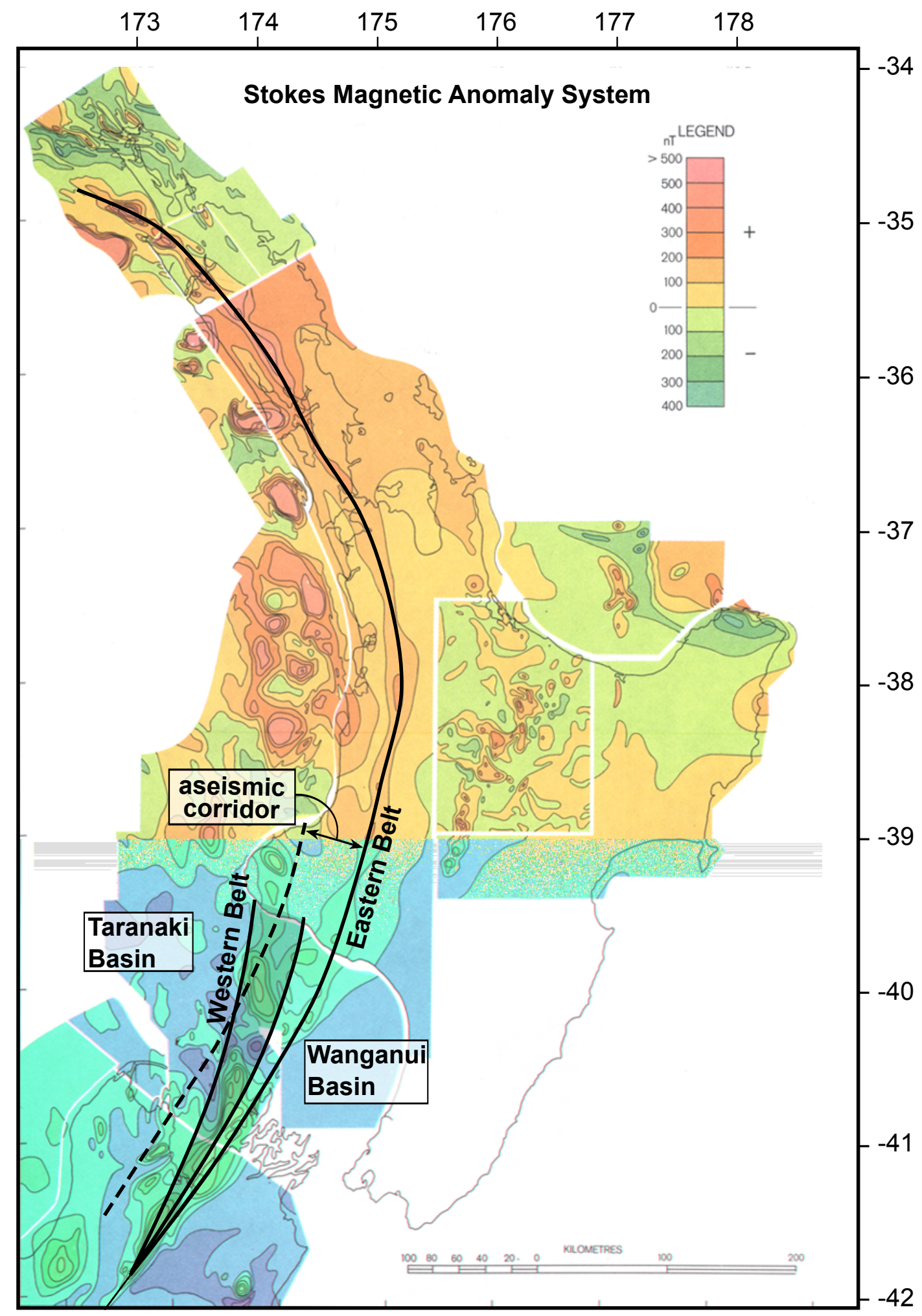

Figure 1.9: Magnetic anomaly map of New Zealand's North Island showing the location of the Stokes Magnetic Anomaly System [after Hunt, 1978]. The 'Eastern Belt' and 'Western Belt' are associated with the Dun Mountain Ophiolite Belt and Median Batholith respectively (see Figure 1.8). Also shown is an 'aseismic corridor' [Hatherton, 1970b, 1980], a region with relatively few crustal earthquakes that Hatherton ascribed to weak serpentinised rocks of the Dun Mountain Ophiolite Belt. 


\section{Chapter 2}

\section{Ruapehu And Taranaki Teleseismic Imaging Line (RATTIL)}

A key contribution of this study was the deployment of fourteen temporary broadband seismic stations across the Taranaki-Ruapehu Line. Together these stations were called the Ruapehu And Taranaki Teleseismic Imaging Line (RATTIL), which recorded passive seismic data between November 2012 and March 2014 (Figure 2.1). Most RATTIL stations were deployed north-south across the TR Line to infill a previous temporary seismic deployment called the Taranaki Ruapehu Attenuation Profile (TRAP, Figure 2.2). In later chapters, RATTIL and GeoNet stations are combined for a microseismic study of earthquakes beneath the Taranaki-Ruapehu Line (Chapter 3). RATTIL, TRAP and GeoNet stations are also combined to form a receiver function stack across the TR Line (Chapter 4).

\subsection{Seismic station locations}

A network of temporary seismic stations was deployed in some of the most inaccessible regions of the North Island of New Zealand, towards the eastern end of the east-west Taranaki-Ruapehu Line. This country is challenging for the reason it is to be studied - rapid uplift of marine sediments has created gorges and a network of rivers which transport large volumes of sediment into the Wanganui Basin [Pulford and Stern, 2004]. Seismic stations were deployed west of state highway 4 to put some distance between the stations and the volcanic influence of Mt. Ru- 


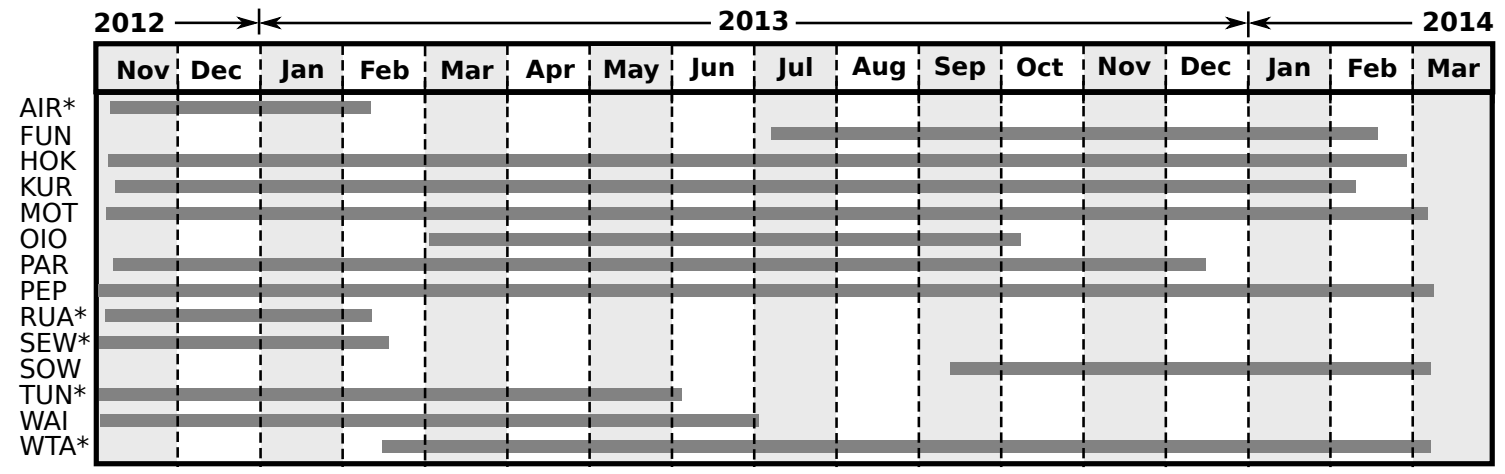

Figure 2.1: Deployment timeline for new temporary passive seismic stations. These stations comprise the Ruapehu And Taranaki Teleseismic Imaging Line (RATTIL).

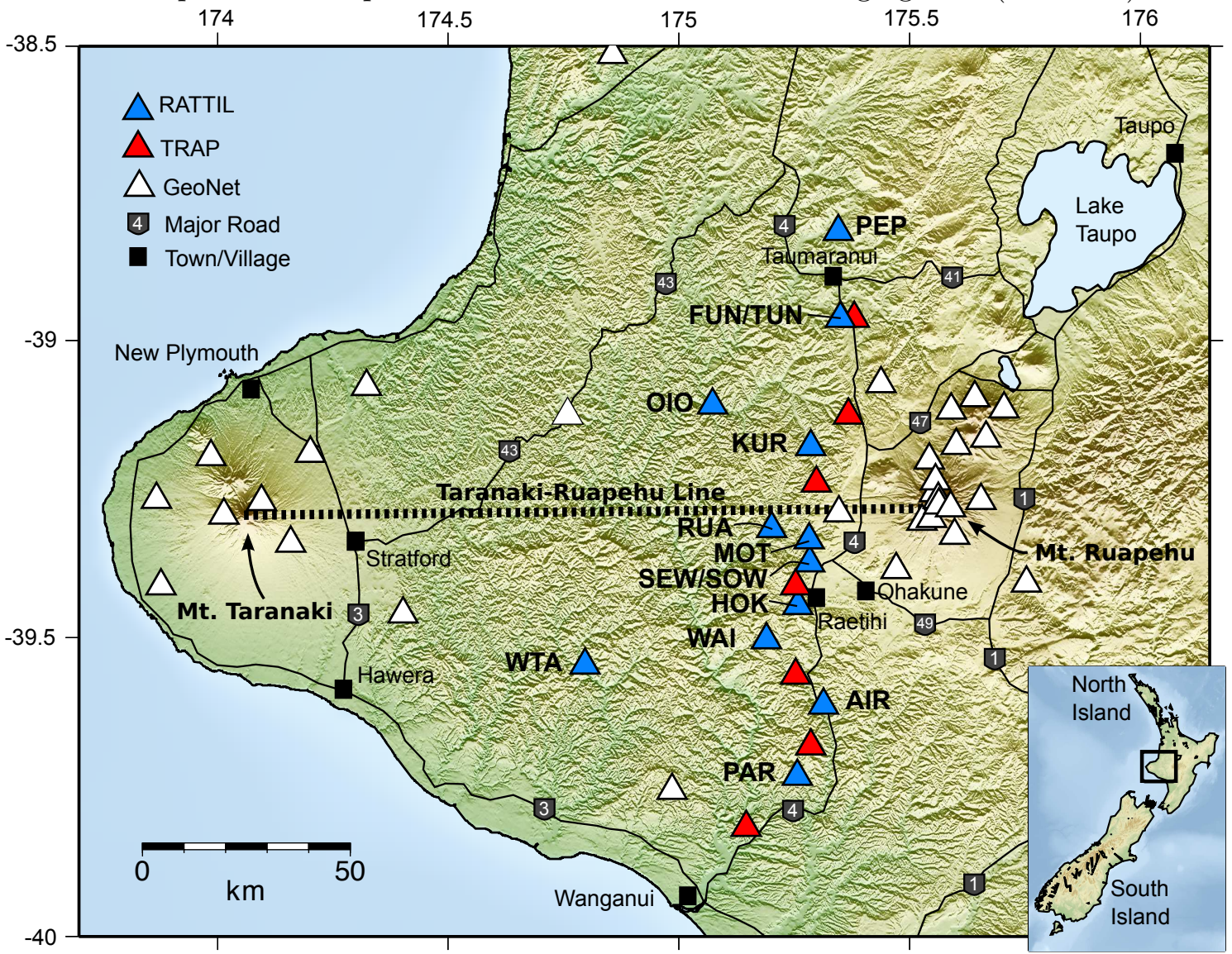

Figure 2.2: Map of seismic stations considered in this study. 'RATTIL' stations (blue triangles) were deployed in this study, while 'TRAP' stations (red triangles) were a temporary deployment from 2002-2003 [Salmon, 2008]. The remaining stations (white triangles) are permanent stations operated by GeoNet. Major roads and towns are shown. Inset shows the location of the study area. 
apehu (Figure 2.2). While a profile of stations further west, across the middle of the Taranaki-Ruapehu Line, would have been preferable, helicopter and/or boat access would be required. This region lacks roads, tracks and has heavy vegetation. The location of RATTIL and TRAP stations are a compromise between imaging the Taranaki-Ruapehu Line away from volcanic influences, whilst also being relatively easy to deploy and service.

No basement outcrop occurs along the Taranaki-Ruapehu Line, therefore site selection was based on convenience and security. Every site was situated on a farm, preferably away from public roads. Most sites were selected on the recommendation of a farmer or farm hand, often in areas that were already fenced off from livestock and were reasonably isolated. When pre-fenced sites were not available, makeshift livestock protection was fashioned using either steel waratahs and mesh wire, or an electric fence.

\subsection{Equipment and configuration}

RATTIL stations were equipped with Guralp Systems CMG-3ESP and CMG-3ESPC broadband seismometers (Table 2.1). The CMG-3ESPC (compact) is internally identical to the CMG-3ESP, but has a different arrangement of components allowing it to fit into a smaller casing. The CMG-3ESP and CMG-3ESPC units are sensitive to ground vibrations with a period of either $30 \mathrm{~s}$ or $60 \mathrm{~s}$ up to $50 \mathrm{~Hz}$. The CMG-3ESP instruments are used by GeoNet in the New Zealand National Seismograph Network, and the performance of RATTIL stations was in most cases comparable to these GeoNet stations. See Section 2.5 for an analysis on individual station performance.

Each seismometer was connected to an Earth Data PR6/24 Seismic Datalogger (DAS), which recorded continuous $100 \mathrm{~Hz}$ earthquake data to hour-long miniseed files that were saved on an external hard disk. All configuration settings were handled through the use of a 'control file', an example of which is provided in Appendix C. The DAS and seismometer were powered by a $12 \mathrm{~V}$ car battery (Figure 2.3a) which was continuously charged by a solar panel via a solar controller. Two different solar panels were used, one with a $45 \mathrm{~W}$ panel (Figure 2.3b), and another with a $90 \mathrm{~W}$ panel (Figure 2.3c). During the winter months, the $45 \mathrm{~W}$ panels were sometimes not able to maintain the battery charge, which resulted in data loss ('Days without data' in Table 2.2). It is recommended that $90 \mathrm{~W}$ solar panels be used for future deployments with the same station equipment. 
Table 2.1: RATTIL station locations and instrument details. In addition to the details in the table, every station was fitted with a PR6/24 data logger. Stations with * were removed early due to equipment or site problems.

\begin{tabular}{|l|l|l|l|l|l|l|}
\hline Name & Lat & Long & Elev & Seismometer & Serial & Corner freq \\
\hline AIR* & -39.59345 & 175.29677 & $353 \mathrm{~m}$ & CMG-3ESP & T366 & $30 \mathrm{~s} / 50 \mathrm{~Hz}$ \\
FUN & -38.95843 & 175.35565 & $374 \mathrm{~m}$ & CMG-3ESPC & T35581 & $60 \mathrm{~s} / 50 \mathrm{~Hz}$ \\
HOK & -39.44638 & 175.25773 & $555 \mathrm{~m}$ & CMG-3ESPC & T35582 & $60 \mathrm{~s} / 50 \mathrm{~Hz}$ \\
KUR & -39.17888 & 175.28573 & $285 \mathrm{~m}$ & CMG-3ESPC & T34474 & $60 \mathrm{~s} / 50 \mathrm{~Hz}$ \\
MOT & -39.33603 & 175.28248 & $634 \mathrm{~m}$ & CMG-3ESPC & T34851 & $60 \mathrm{~s} / 50 \mathrm{~Hz}$ \\
OIO & -39.10916 & 175.07277 & $119 \mathrm{~m}$ & CMG-3ESP & T3205 & $60 \mathrm{~s} / 50 \mathrm{~Hz}$ \\
PAR & -39.73289 & 175.25687 & $368 \mathrm{~m}$ & CMG-3ESP & T3136 & $30 \mathrm{~s} / 50 \mathrm{~Hz}$ \\
PEP & -38.81489 & 175.34570 & $279 \mathrm{~m}$ & CMG-3ESPC & T35579 & $60 \mathrm{~s} / 50 \mathrm{~Hz}$ \\
RUA* & -39.30814 & 175.20817 & $261 \mathrm{~m}$ & CMG-3ESP & T3205 & $60 \mathrm{~s} / 50 \mathrm{~Hz}$ \\
SEW* & -39.37473 & 175.28353 & $565 \mathrm{~m}$ & CMG-3ESPC & T35581 & $60 \mathrm{~s} / 50 \mathrm{~Hz}$ \\
SOW & -39.37473 & 175.28353 & $565 \mathrm{~m}$ & CMG-3ESPC & T35583 & $60 \mathrm{~s} / 50 \mathrm{~Hz}$ \\
TUN* & -38.96297 & 175.35691 & $393 \mathrm{~m}$ & CMG-3ESP & T3137 & $30 \mathrm{~s} / 50 \mathrm{~Hz}$ \\
WAI & -39.50412 & 175.18905 & $595 \mathrm{~m}$ & CMG-3ESPC & T35583 & $60 \mathrm{~s} / 50 \mathrm{~Hz}$ \\
WTA & -39.54598 & 174.79614 & $61 \mathrm{~m}$ & CMG-3ESPC & T34750 & $60 \mathrm{~s} / 50 \mathrm{~Hz}$ \\
\hline
\end{tabular}

Table 2.2: RATTIL seismic station deployment dates. 'Days without data' refer to full days where no data was recorded. In the case of KUR and WTA, this was caused by trees/shrubs blocking the solar panel especially during winter months. In the case of SEW, it was due to a faulty solar controller. In addition, some stations only recorded during daytime hours in winter months because of a weak solar panel. Stations with $*$ were removed early due to equipment or site problems.

\begin{tabular}{|l|l|l|c|c|}
\hline Name & Start date & End date & Days deployed & Days without data \\
\hline AIR & $07 / 11 / 2012$ & $08 / 02 / 2013$ & 94 & 0 \\
FUN & $05 / 07 / 2013$ & $18 / 02 / 2014$ & 229 & 0 \\
HOK & $04 / 11 / 2012$ & $26 / 02 / 2014$ & 480 & 1 \\
KUR & $07 / 11 / 2012$ & $08 / 02 / 2014$ & 459 & 71 \\
MOT & $04 / 11 / 2012$ & $06 / 03 / 2014$ & 488 & 0 \\
OIO & $02 / 03 / 2013$ & $07 / 10 / 2013$ & 220 & 6 \\
PAR & $07 / 11 / 2012$ & $15 / 12 / 2013$ & 404 & 6 \\
PEP & $01 / 11 / 2012$ & $08 / 03 / 2014$ & 493 & 0 \\
RUA & $05 / 11 / 2012$ & $10 / 02 / 2013$ & 98 & 0 \\
SEW & $31 / 10 / 2012$ & $19 / 02 / 2013$ & 112 & 80 \\
SOW & $11 / 09 / 2013$ & $06 / 03 / 2014$ & 177 & 0 \\
TUN & $01 / 11 / 2012$ & $04 / 06 / 2013$ & 216 & 0 \\
WAI & $02 / 11 / 2012$ & $02 / 07 / 2013$ & 243 & 40 \\
WTA & $14 / 02 / 2013$ & $06 / 03 / 2014$ & 386 & 0 \\
\hline
\end{tabular}


All stations operated with intermittent GPS recording to conserve battery power. The GPS time is updated every hour rather than continuously. Unusually high RMS timing values were not encountered for any station while calculating preliminary earthquake locations, so no attempt was made to further quantify timing errors.

The CMG-3ESP and CMG-3ESPC seismometers are designed for use in seismic vaults, typically consisting of a seismic pier constructed by moulding a poured concrete floor with a wooden frame [Guralp, 2011]. In non-ideal circumstances, such as temporary field deployments, the taller CMG-3ESP's in particular are known to go off-level easily (Michelle Salmon, personal communication, 2012). This issue was partially mitigated through the construction of seismic 'field vaults'. First a bag of quick set concrete was poured into the bottom of a hand-dug hole, then a ceramic tile and protective bucket were pressed into the setting concrete (Figure 2.3d). The seismometer was placed on top of the tile once the concrete had dried sufficiently (Figure 2.3e), and the whole system was covered with a second bucket to help keep water out (Figure 2.3f). In practice, the bucket system usually helped keep water in rather than out. This did not have any negative impact on the sensor which was waterproof. Despite the field effort, some of the 3ESP instruments continued to have levelling issues which are discussed in Section 2.5.

\subsection{Instrument response profiles}

Instrument response files were generated for the recording system (which includes both the seismometer and the data logger) using IRIS Portable Data Collection Center (PDCC) software. The corresponding frequency-amplitude-phase response curves were calculated for each station using the IRIS EVALRESP program. Both the CMG-3ESP $30 \mathrm{~s} / 50 \mathrm{~Hz}$ and CMG-3ESP $60 \mathrm{~s} / 50 \mathrm{~Hz}$ seismometer variations show a flat amplitude and phase response from about $0.2-20 \mathrm{~Hz}$ (Figure 2.4), confirming that the equipment configuration is suitable for both receiver function and microearthquake studies which use those frequencies. A Finite Impulse Response (FIR) filter applied to the response curve limits the top frequency to $50 \mathrm{~Hz}$, which is the maximum frequency of the CMG-3ESP instrument. The vertical (HHZ), north (HHN) and east (HHE) components of each RATTIL seismometer are identical, and therefore their theoretical instrument responses are identical. 


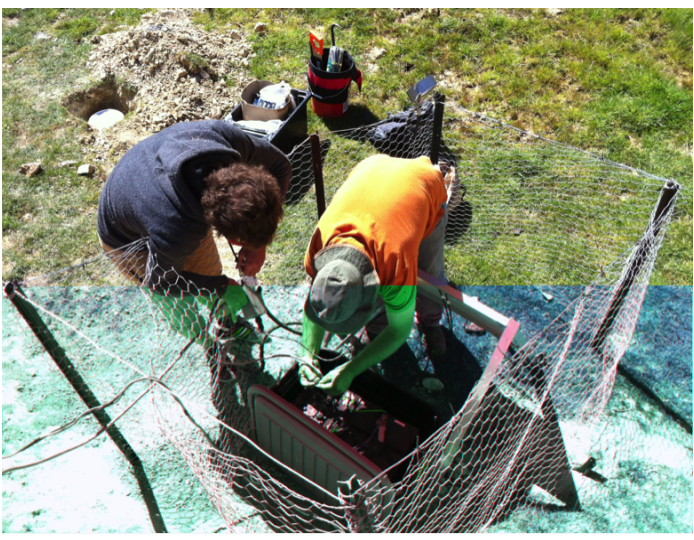

(a) DAS and batteries

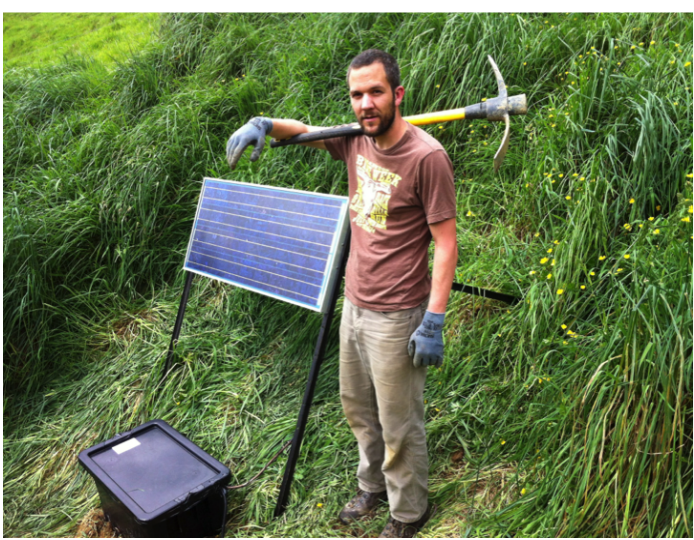

(c) 90 W solar panel

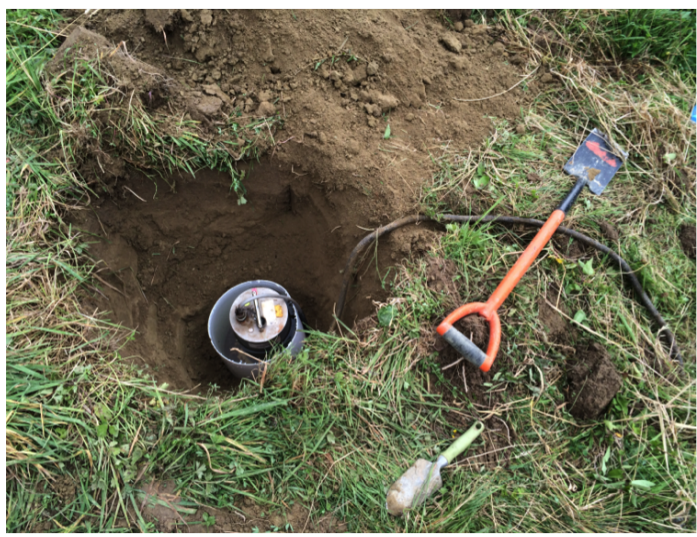

(e) Field vault with seismometer

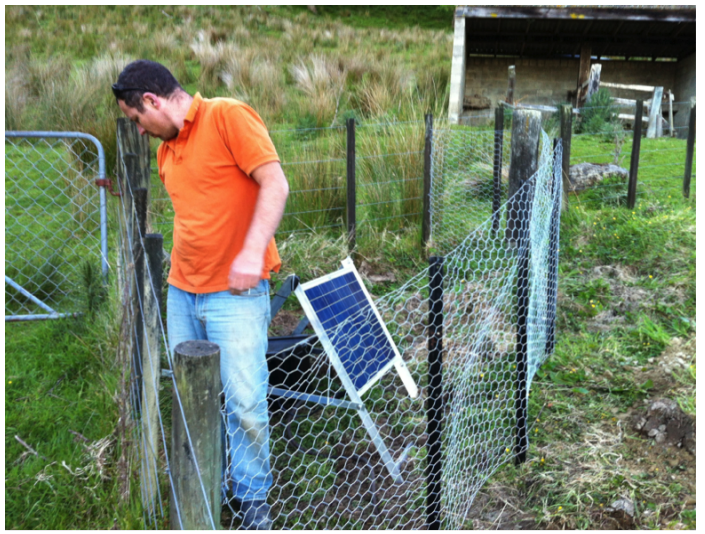

(b) $45 \mathrm{~W}$ solar panel + fencing

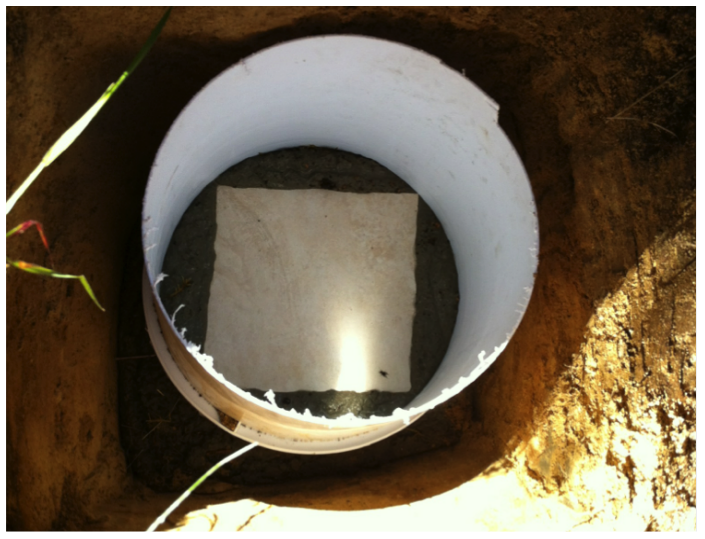

(d) "Field vault"

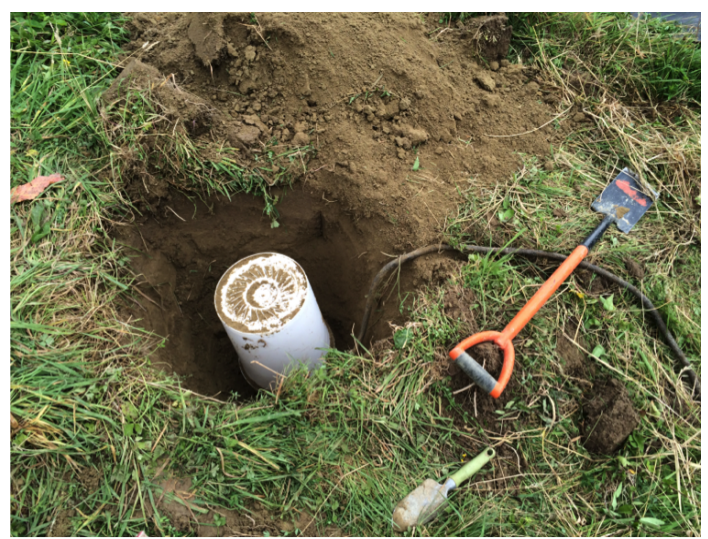

(f) Field vault sealed

Figure 2.3: Photographs of seismic stations from the RATTIL deployment. Field assistants shown are Adrian Benson, Calum Chamberlain and Aaron Wech. 


\subsection{Orientation and polarity}

Each seismometer was setup so that its three components were oriented vertical (HHZ), north (HHN), and east (HHE) respectively. Care was taken to align each seismometer's north component to true north, and to level the instrument so that all components were facing the right direction. The orientations with respect to true north were confirmed for each station when that station was removed. Nevertheless, it was still possible that components might be wrongly-oriented due to wiring issues or overlooked configuration settings.

The polarities of RATTIL stations have been checked as a side effect of calculating receiver functions (see Chapter 4). (A polarity error results in a reversed receiver function result.) Only station HOK was found to generate a reversed receiver function, which was later corrected by reversing the vertical component. The reversed vertical component is attributed to a wrongly wired connector between the seismometer and the DAS. This polarity reversal was confirmed upon inspection of a single teleseismic event detected across the network (Figure 2.5).

\subsection{Performance of RATTIL stations}

Seismic data collected at RATTIL stations were usually of high quality. In most cases, the seismic data are comparable to GeoNet station VRZ, and also fit between the NLNM/NHNM noise model curves of the Global Seismograph Network [Peterson, 1993]. (NLNM = New Low Noise Model; NHNM = New High Noise Model.) The performance of RATTIL stations was assessed by calculating the noise 'Power Spectral Density' for each component of each station [Peterson, 1993; McNamara and Buland, 2004; Petersen et al., 2011]. This was done to ensure that only data of sufficient quality were used for analysis in this thesis.

Seismic noise sources include running water, surf, volcanic activity, topographic irregularities, wind, cars, farm machinery, recording system transients and even earthquakes, all of which are station specific [McNamara and Buland, 2004]. Too much noise at a seismic station can make small or distant earthquake detection hard or even impossible, hindering many forms of data analysis. The Power Spectral Density plot allows seismic noise sources to be quantified in a useful way.

Power Spectral Density is related to the more common Fourier transform in that it decomposes a time domain signal into the frequency domain, which in turn al- 

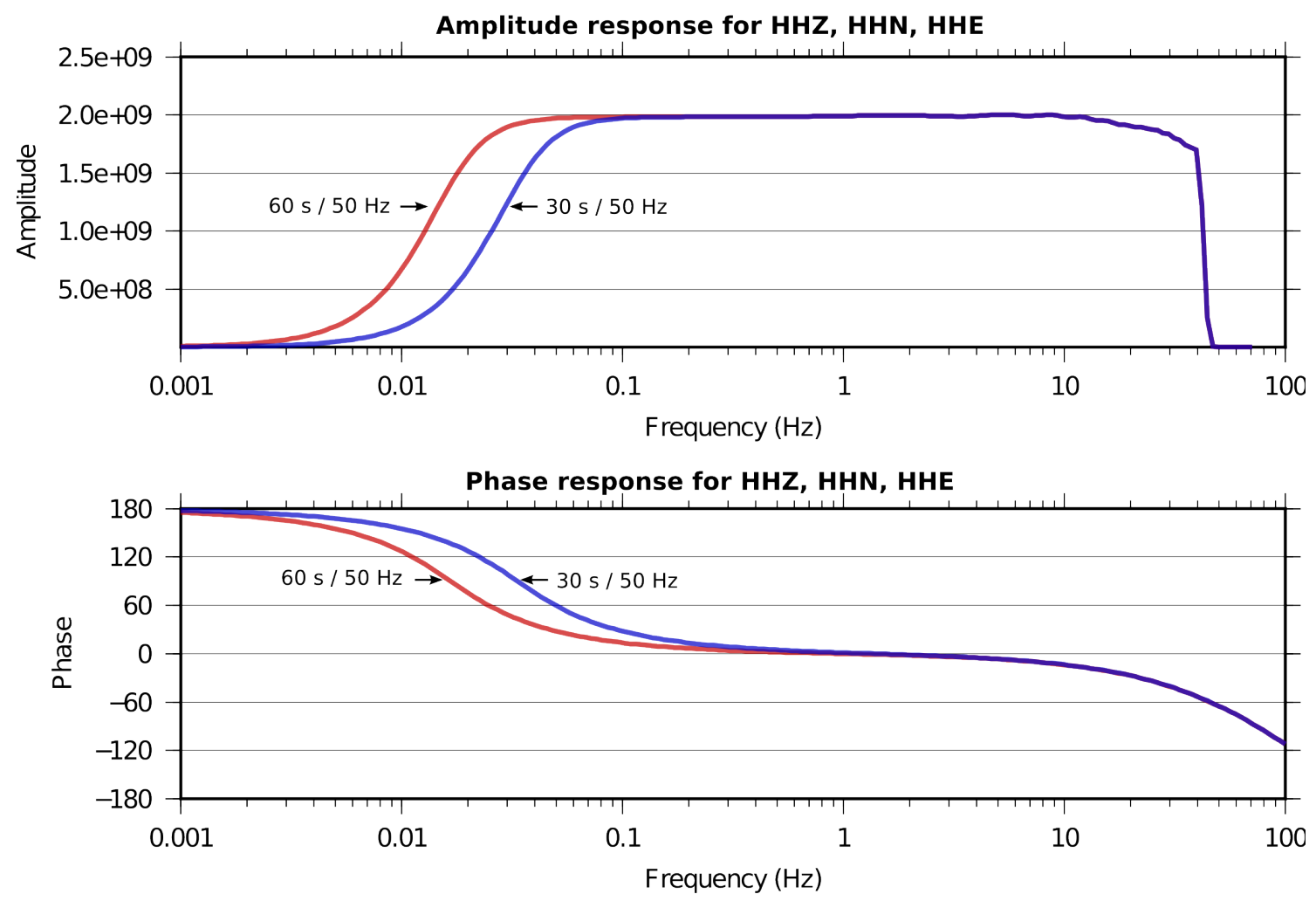

Figure 2.4: Instrument response profiles for RATTIL stations. The red and blue curves represent two variations of Guralp 3ESP seismometer (variations are annotated). Only two curves are shown because the HHZ, HHN and HHE components have equal instrument response profiles.

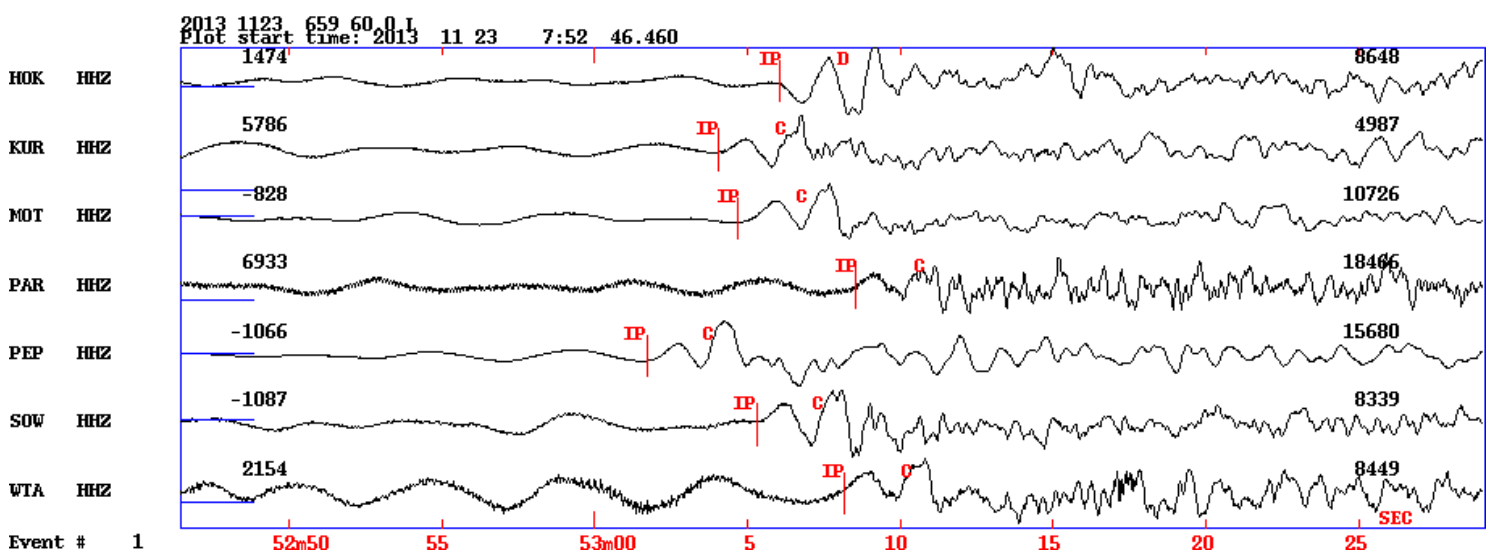

Figure 2.5: Example teleseismic earthquake recorded by RATTIL stations. The recorded event is a magnitude 6.5 earthquake near Fiji. Vertical (HHZ) channels for each station are shown with no filtering applied. Note that the dilatational (D) first break of station HOK is different to the compressional (C) first break of the other stations. This reversal in polarity is unique to station HOK and probably the result of faulty wiring. 
lows a seismic station's background noise levels to be characterised as a function of frequency. Bormann and Wielandt [2013] explained that Fourier transforms in the conventional sense can only be applied to 'transient signals' - that is, signals which decay or disappear after a period of time, such as an earthquake signal. Ambient seismic noise does not vary much over time and is instead thought of as a 'stationary signal'. To apply a Fourier transform to a stationary signal may cause the Fourier integral to diverge. Stationary signals such as ambient noise require a different mathematical treatment, hence the use of a Power Spectral Density.

McNamara and Buland [2004] utilised a 'direct Fourier transform' to calculate the Power Spectral Density. This method calculates the Power Spectral Density through a finite-range Fourier transform of input data. The finite-range Fourier transform of a periodic time series $y(t)$ is given by:

$$
Y\left(f, T_{r}\right)=\int_{0}^{T_{r}} y(t) e^{-i 2 \pi f t} d t
$$

Where $T_{r}$ is the length of the time series segment, $f$ is frequency and $t$ is time. For discrete frequency values $\left(f_{k}\right)$ the Fourier components are:

$$
Y_{k}=\frac{Y\left(f_{k}, T_{r}\right)}{\Delta t}
$$

Such that $f_{k}=k / N \Delta t$ when $k=1,2, \ldots, N-1 . \Delta t$ is the sample interval and $N$ is the number of samples in each time series segment, $N=T_{r} / \Delta t$. Therefore, given the Fourier components defined in Equation (2.2), the total Power Spectral Density estimate is defined as:

$$
P_{k}=\frac{2 \Delta t}{N}\left|Y_{k}\right|^{2}
$$

In other words, Equation (2.3) relates the total power $\left(P_{k}\right)$ to the square of the amplitude spectrum with a normalisation factor of $2 \Delta t / N$. Power (rather than energy/amplitude) versus frequency is considered because stationary signals have infinite energy and finite power.

Traditionally, the Power Spectral Density can be calculated for a relatively 'quiet' and several hour long recording from a seismic site which contains no spurious signals such as earthquakes, spikes, mass recentres or calibration pulses [Petersen et al., 2011]. McNamara and Buland [2004] used a 'Power Spectral Density estimate' of seismic noise instead of looking for a quiet period of recording. In a Power Spectral 
Density estimate, the highest probability signal is the one which characterises a site. Since spurious signals represent low probability occurrences they do not significantly contaminate high probability ambient seismic noise when large volumes of data are considered.

The PQLX package [McNamara and Boaz, 2006] is used to calculate the ambient noise characteristics of each component of each station of the RATTIL network. The PQLX package is based on the method of McNamara and Buland [2004] described above, and therefore is a Power Spectral Density estimate of the Probability Density Function (PDF). This software package is the same one used by GeoNet to characterise their network (PDF's for each GeoNet station are freely available at ftp://ftp.geonet.org.nz/qc/PDFs/). The Z, N and E components of the RATTIL network are shown in Figures 2.6 to 2.8 respectively. One month of continuous waveform data from each station are used for the Power Spectral Density estimate. The ambient noise levels of RATTIL broadband seismometers ('a-n' in Figures 2.6 to 2.8) are generally comparable to that of GeoNet station VRZ of the New Zealand National Seismograph Network ('o' in Figures 2.6 to 2.8) and the Global Seismograph Network (Figures 2.6 to 2.8 between NLNM and NHNM). A detailed discussion of each station's performance and the deployment in general is given below in alphabetical order.

\section{AIR}

Station AIR (Airport) was deployed in November 2012. Shortly after deployment the vertical component of the seismometer (CMG-3ESP Serial: T366) became 'locked' and did not function. Two attempts to re-level this instrument during routine servicing were unsuccessful; the vertical component remained locked. This station was removed in February 2013. The site was not reoccupied due to both its distance from the Taranaki-Ruapehu Line and a lack of available equipment. The E and N components ('a' in Figures 2.7 and 2.8) appear to have functioned normally, showing a background noise profile towards the upper limit of the NHNM.

\section{FUN}

Station FUN is a replacement for station TUN and is situated about $500 \mathrm{~m}$ away. It is located on flatter ground and uses the CMG-3ESPC seismometer which was found to stay on level better than the taller 3ESP. The station remained online from 
the 5th of July 2013 until the end of the deployment in early March 2014. However, the hard drive in the DAS was filled by the 18th of February, and so data after that date were lost. Station FUN has a background noise profile towards the upper limit of the NHNM ('b' in Figures 2.6 to 2.8). There is a relatively high amount of noise at about $0.2-0.6 \mathrm{~s}$ period which is in the frequency range of local earthquakes.

\section{HOK}

Station HOK (Hukaroa Road) is situated immediately south of the township of Raetihi, and was online for the full duration of the deployment from November 2012 until March 2014. The only problem was a reversed vertical component which was discussed previously. The ambient noise levels (' $c$ ' in Figures 2.6 to 2.8) are situated comfortably between the NLNM and NHNM curves and are comparable to GeoNet station VRZ ('o' in Figures 2.6 to 2.8).

\section{KUR}

Station KUR (Kurua Road) was deployed in November 2012 and remained online until March 2014. This site lost power during the winter months due to a smaller $45 \mathrm{~W}$ solar panel that was partially-obstructed by nearby trees. In addition, one of the components would occasionally go off-level. As no auto-levelling command exists for the PR6/24 data logger, the station could only be re-levelled during servicing every 2-6 months. The performance of this site when it was recording was good. The ambient noise levels ('d' in Figures 2.6 to 2.8) are situated comfortably between the NLNM and NHNM curves. Relatively high noise levels are present at $0.1 \mathrm{~s}$ period which is consistent with vehicle noise from farm machinery or a nearby private road.

\section{MOT}

Station MOT (Motete Road) was deployed in November 2012 and remained online until March 2014. This station was located near a farm building that was occasionally used to house livestock. The farm building contained a grounded electric power source, whose pulses often could be seen on low amplitude teleseismic events. Because of the electric pulses many weaker teleseismic events detected at MOT were discarded to prevent artefacts in the receiver function inversion. Station MOT has 
a background noise profile towards the upper limit of the NHNM ('e' in Figures 2.6 to 2.8). Relatively high noise levels are present at $0.1 \mathrm{~s}$ period which is consistent with vehicle noise from farm vehicles or a nearby private road.

\section{OIO}

Station OIO (Oio Road) is offset from the main RATTIL profile, roughly equidistant from GeoNet station VRZ, and RATTIL stations KUR and FUN. This station was deployed early in March 2013 and remained deployed until March 2014. A solar panel swap in October 2013 was not correctly wired, and the station lost power after this time. In addition, one of the components would occasionally go off-level. As no auto-levelling command exists for the PR6/24 data logger, the station could only be re-levelled during servicing every $2-6$ months. The performance of this site when it was recording was good. The ambient noise levels (' $f$ ' in Figures 2.6 to 2.8) are situated comfortably between the NLNM and NHNM curves. Relatively high noise levels are present at $0.1 \mathrm{~s}$ period which is consistent with vehicle noise from farm vehicles or a nearby private road.

\section{PAR}

Station PAR (Parihauhau Road) is the southernmost station in the RATTIL network. This station was deployed November 2012 and remained so until March 2014. The station lost power in December 2013 for an unknown reason and the power never returned, though it seems likely there was a problem with the battery. In addition, one of the components would occasionally go off-level. As no auto-levelling command exists for the PR6/24 data logger, the station could only be re-levelled during servicing every 2-6 months. The performance of this site when it was recording was good. The ambient noise levels (' $\mathrm{g}$ ' in Figures 2.6 to 2.8) are situated towards the NHNM curve.

\section{PEP}

Station PEP (Pepper) is the northernmost station in the RATTIL deployment. This station was online for the full duration of the deployment from November 2012 until March 2014 with no significant problems. The ambient noise levels (' $h$ ' in 
Figures 2.6 to 2.8) are situated comfortably between the NLNM and NHNM curves and are generally lower than GeoNet station VRZ ('o' in Figures 2.6 to 2.8).

\section{RUA}

Station RUA (Ruatiti Road) was deployed in November 2012 and was removed early in February 2013. This station and its equipment were relocated to site OIO in order to be further offset from the main RATTIL line. The ambient noise levels ('i' in Figures 2.6 to 2.8) are situated comfortably between the NLNM and NHNM curves, with a comparable noise profile to GeoNet station VRZ ('o' in Figures 2.6 to 2.8$)$.

\section{SEW}

Station SEW (Sewing) was the first RATTIL station deployed at the end of October 2012 and was removed in February 2013. The solar panel in this site was never able to charge the battery, and so the site lost power 1-2 weeks after every service. Three attempts were made to fix the station before it was suspended, including re-wiring the solar panel and solar controller and changing the battery. The station remained without power for several months, before being re-occupied, at which time both the seismometer and solar controller were replaced. The site was renamed 'SOW' to reflect the changes and prevent confusion. The seismometer from SEW was redeployed at station FUN with no further problems, and the solar controller was confirmed as the cause of site failure. The performance of this site when it was recording was good. The ambient noise levels (' $k$ ' in Figures 2.6 to 2.8) are situated comfortably between the NLNM and NHNM curves. Relatively high noise levels are present at $0.1 \mathrm{~s}$ period which is consistent with vehicle noise from a nearby private road that serviced the farm house.

\section{SOW}

Station SOW is a reoccupation of station SEW with a different seismometer. Station SOW was brought online in September 2013 and remained online until the end of the deployment with no further issues. The ambient noise profile for all channels at SOW is almost identical to that of station SEW (compare ' $\mathrm{j}$ ' and ' $\mathrm{k}$ ' in Figures 2.6 to 2.8$)$. 


\section{TUN}

Station TUN (Tunanui Road) is a repeat of a temporary seismic station with the same name [TUN in Salmon, 2008]. This site was deployed in November 2012 and removed in June 2013. The Salmon [2008] station went off-level a few weeks after deployment and did not record enough data to compute a good receiver function stack. The repeat station also had problems remaining level. Site TUN was located on the side of a hill, and it is speculated that soil creep resulted in the vertical component routinely going off-level after just a few weeks. Since no auto-levelling command exists for the PR6/24 data logger, the station could only be re-levelled during servicing every 2-6 months. This station was replaced in July 2013 by a new station $500 \mathrm{~m}$ away on flatter ground (FUN). The ambient noise levels (' 1 ' in Figures 2.6 to 2.8) are situated comfortably between the NLNM and NHNM curves and are generally lower than GeoNet station VRZ ('o' in Figures 2.6 to 2.8).

\section{WAI}

Station WAI (Waipuna Road) was deployed in November 2012 and removed early in July 2013 due to data quality issues. Ambient noise levels above $1 \mathrm{~s}$ period ('m' in Figures 2.6 to 2.8) are situated near the NHNM curve. Below 1s period, in the frequency range of local earthquakes, the noise levels have a sharp linear trend which indicates a problem. This site was removed early because local earthquakes could not be detected on it. Teleseismic earthquakes could be detected with their lower frequency content, and so this station's data were still useful for calculating receiver functions. The seismometer from this station was redeployed at station SOW and had no further issues. No explanation is given for the degradation of high frequencies at this site.

\section{WTA}

Station WTA (Waitotara Valley Road) is offset from the main RATTIL profile, roughly equidistant from GeoNet stations VRZ, WAZ and LREZ. This station was deployed in early February 2013 and remained so until March 2014. This site briefly lost power during the winter months due to having a smaller $45 \mathrm{~W}$ solar panel that was partially obstructed by trees. The ambient noise levels ('n' in Figures 2.6 to 2.8) are situated comfortably between the NLNM and NHNM curves, with a comparable noise profile to GeoNet station VRZ ('o' in Figures 2.6 to 2.8) 


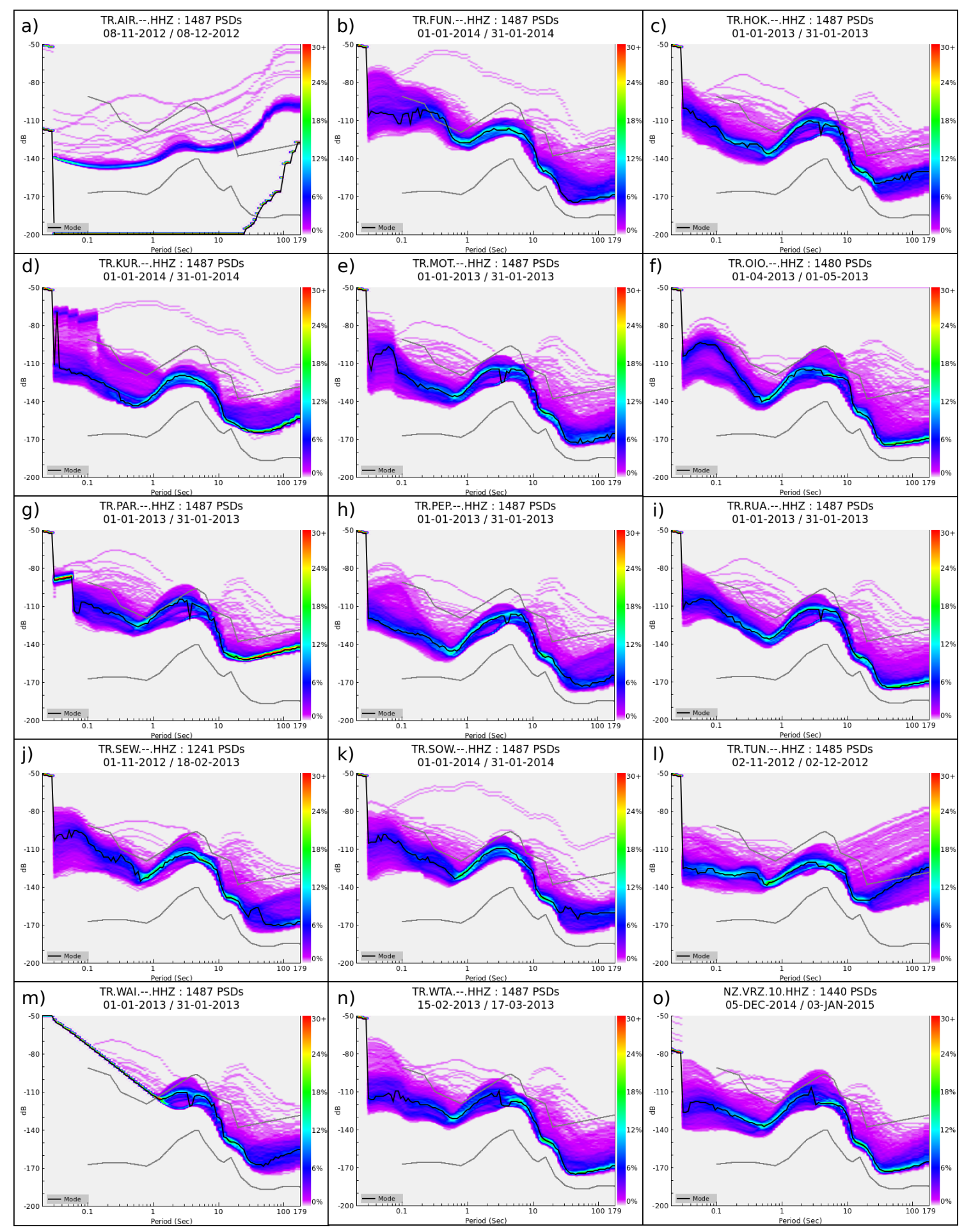

Figure 2.6: Power Spectral Density of RATTIL station 'vertical' components. These plots characterise ambient noise levels from one month of continuous data. The bottom right (o) panel is permanent GeoNet station VRZ of the National Seismograph Network. The colour bar represents Power Spectral Density probability. Grey lines represent the New Low Noise Model (NLNM) and New High Noise Model (NHNM) of Peterson [1993], which are based on the ambient noise characteristics of the 'Global Seismograph Network'. 

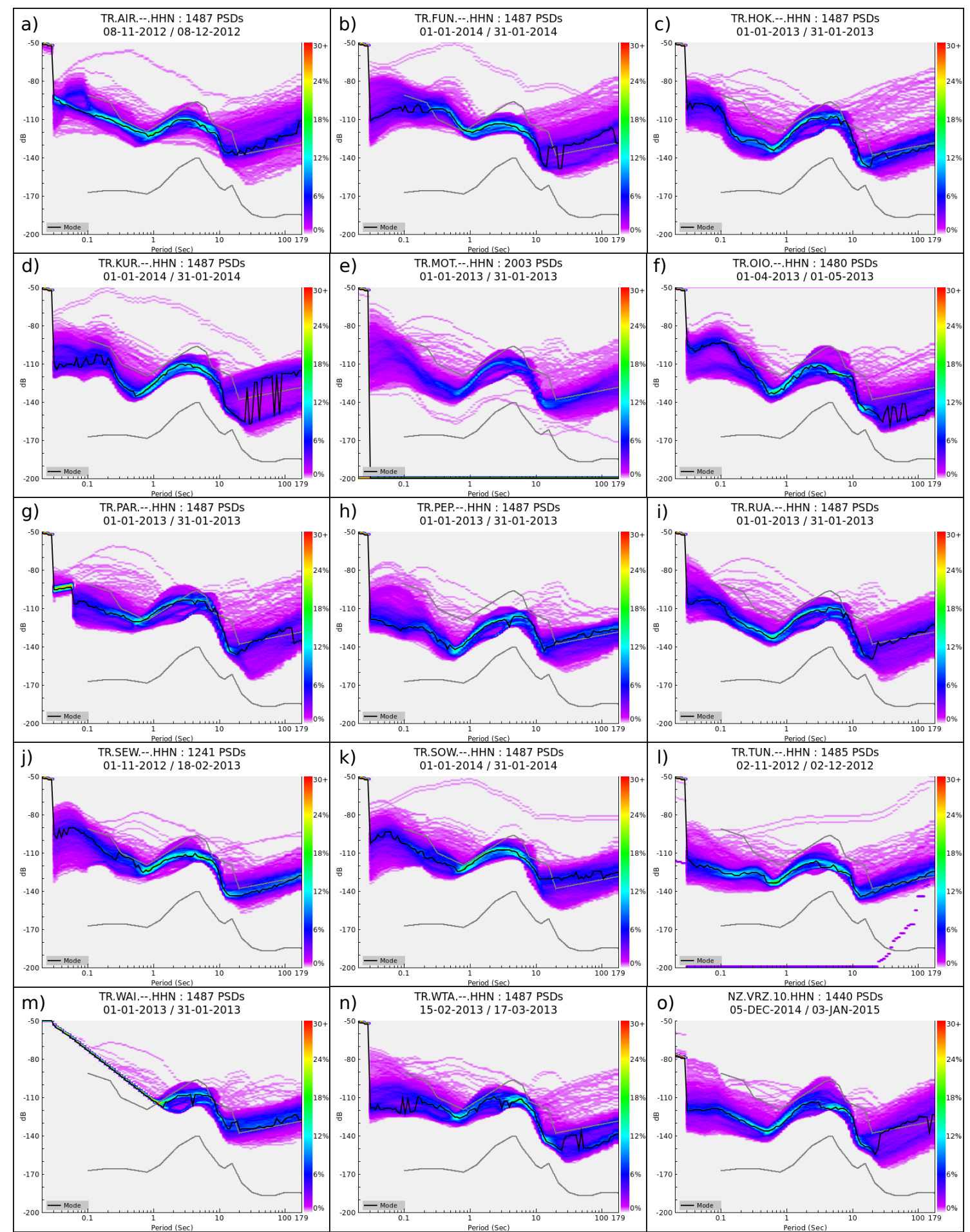

Figure 2.7: Power Spectral Density of RATTIL station 'north' components. These plots characterise ambient noise levels from one month of continuous data. The bottom right (o) panel is permanent GeoNet station VRZ of the National Seismograph Network. The colour bar represents Power Spectral Density probability. Grey lines represent the New Low Noise Model (NLNM) and New High Noise Model (NHNM) of Peterson [1993], which are based on the ambient noise characteristics of the 'Global Seismograph Network'. 


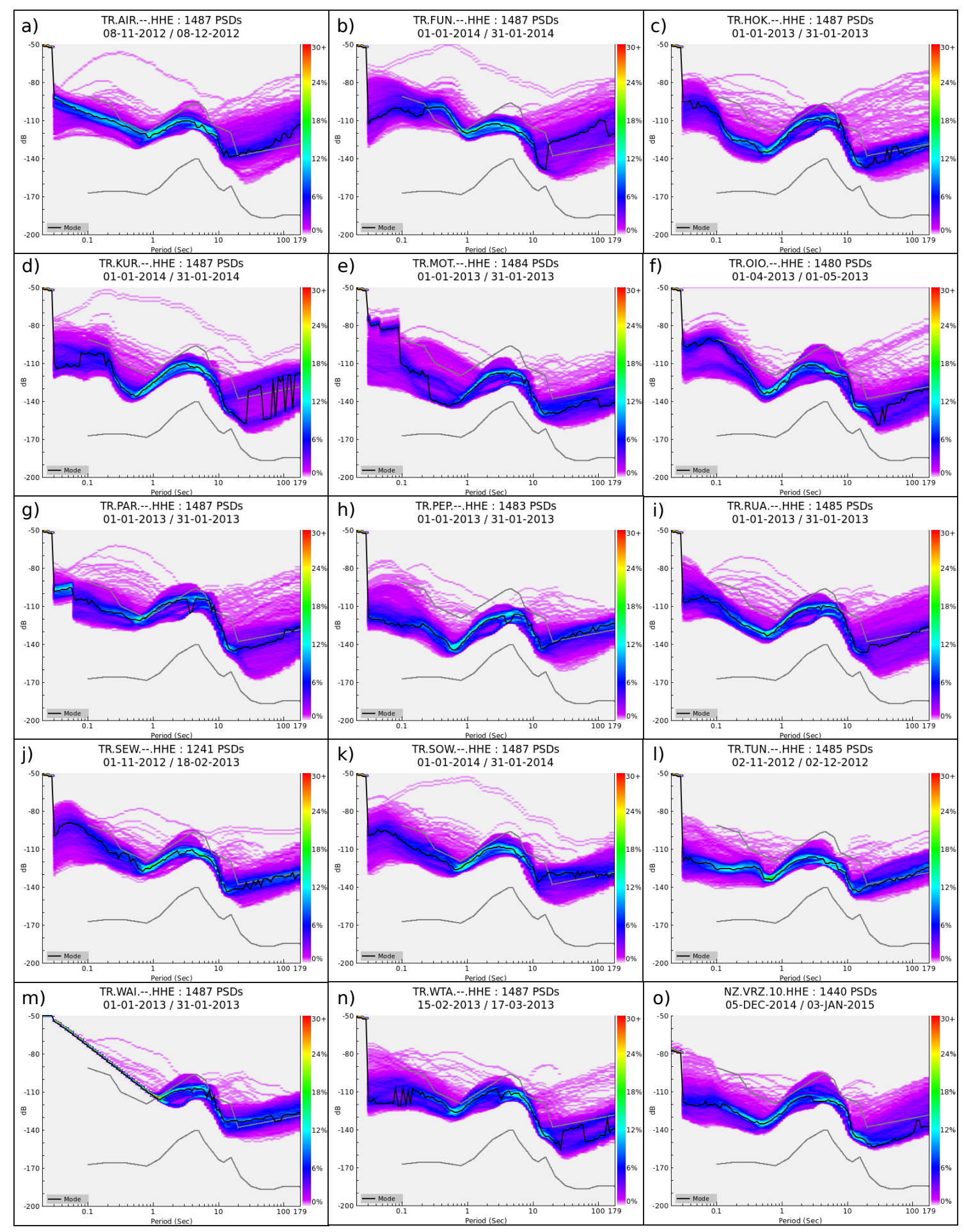

Figure 2.8: Power Spectral Density of RATTIL station 'east' components. These plots characterise ambient noise levels from one month of continuous data. The bottom right (o) panel is permanent GeoNet station VRZ of the National Seismograph Network. The colour bar represents Power Spectral Density probability. Grey lines represent the New Low Noise Model (NLNM) and New High Noise Model (NHNM) of Peterson [1993], which are in turn based on the ambient noise characteristics of the 'Global Seismograph Network'. 


\section{Chapter 3}

\section{Microseismic study}

\subsection{Microseismic abstract}

Microseismic analysis reveals a 'downwarp' of earthquake hypocentres at the base of the Taranaki-Ruapehu Line, between $30-50 \mathrm{~km}$ depth. Most of these earthquakes occur on fault planes dominated by strike-slip movement. The centre of this downwarp is at latitude 174.83 , longitude -39.25 , and is adjacent to the surface projection of several $600 \mathrm{~km}$-deep earthquakes. Near Mt. Ruapehu, relatively shallow seismicity occurs between $8-25 \mathrm{~km}$ depth, but it is not connected to the deeper seismicity containing the earthquake downwarp. The shallower seismicity is clustered and has differently oriented focal mechanisms, with roughly equal proportions of normal and strike-slip dominated fault movement. Stress directions from the deeper earthquakes are consistently NW-SE, which is the same as the regional stress field of the western North Island (see Figure 3.2). Shallower earthquakes near Mt. Ruapehu have stress directions that vary by tens of degrees between different vintages of data which may be due to active processes at the Mt. Ruapehu volcano.

\subsection{Previous work and study context}

A diffuse 'cloud' of deep earthquakes occurs between Mt. Taranaki and Mt. Ruapehu to depths exceeding $30 \mathrm{~km}$ (Figure 3.1). Everything that is known about these deep earthquakes derives from a set of side-observations rather than from focused studies [e.g. Reyners, 1980; Sherburn and White, 2006; Reyners et al., 2007; Reyners, 2010]. The absence of a focused study might be due to land access difficulties, 


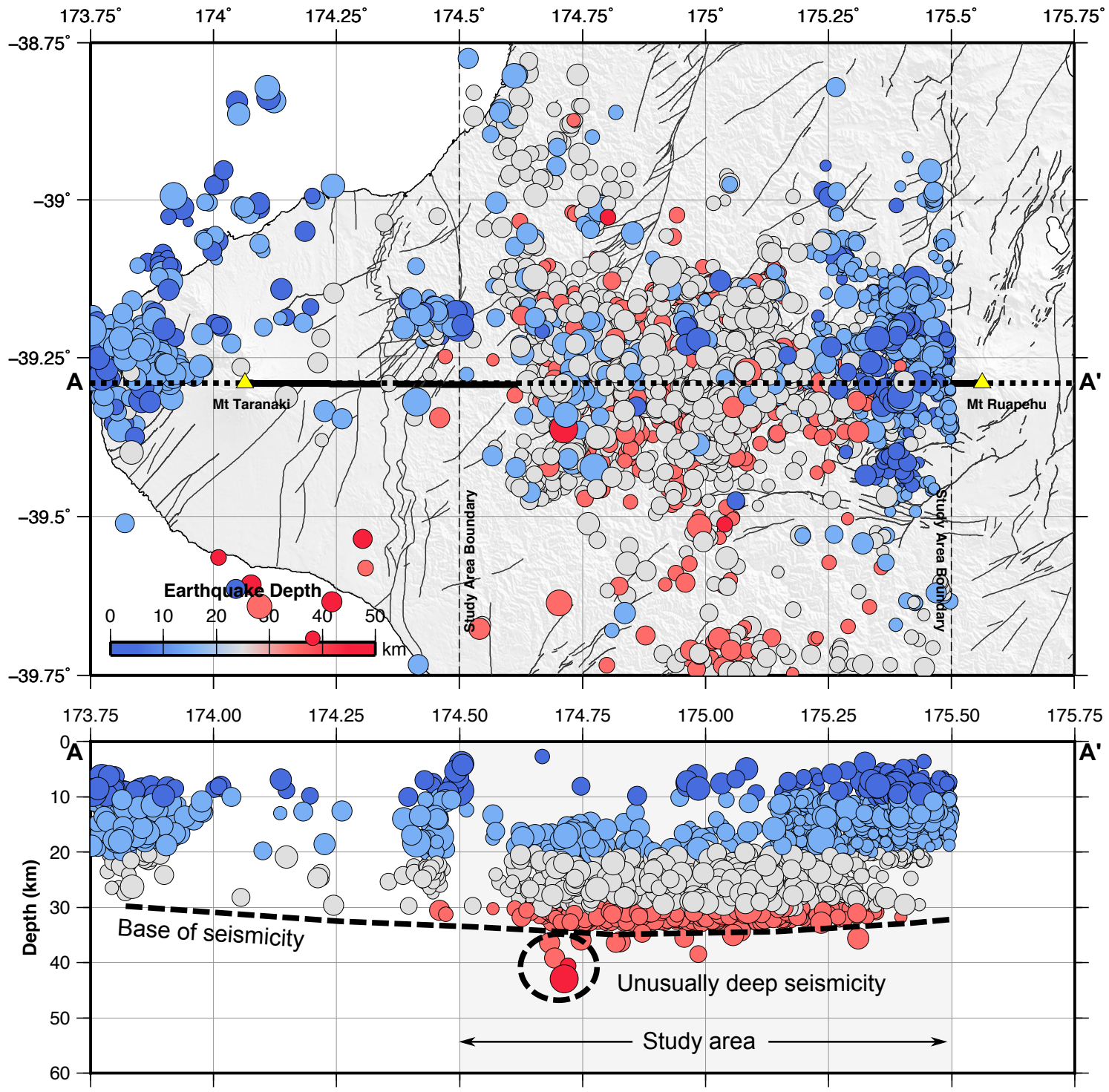

Figure 3.1: GeoNet earthquake locations from 1987-2011 at depths of 0-50 km. Parameters: minimum of 10 stations; event type 'earthquake'; reviewed by GeoNet; uses the 1D New Zealand standard velocity model [Maunder, 2002]; local magnitudes calculated; origin error $<0.3$; operator-assigned depths removed (e.g. 0, 5, 12, 15, 33 km). 
as some of the most challenging terrain in the North Island of New Zealand is found here (as discussed in Section 2.1). Whatever the reason, it is rare to have earthquakes deep in the continental lithosphere [McKenzie et al., 2005; Jackson et al., 2008], and a more detailed study might provide new information about the TR Line and deep earthquakes in general.

The Taranaki-Ruapehu Line deep earthquakes are a significant seismic feature of New Zealand, and the only seismic feature that runs at an angle (of about $40-50^{\circ}$ ) to the Hikurangi subduction zone [Hatherton, 1980]. More than 20,000 earthquakes have been located by GeoNet along the TR Line between 1987 and 2011 (Figure 3.1). These earthquakes do not appear to be directly associated with the Benioff zone of the subducting Pacific plate, and continue down to about $33 \mathrm{~km}$ depth, where they abruptly terminate along a smooth and slightly curved surface (Figure 3.1). It will be shown later that the apparent smoothness of this surface is probably not real. This study will also show that the few earthquakes visible beneath the curved surface, to depths exceeding $45 \mathrm{~km}$, are more common than they appear in the GeoNet catalog (circled in Figure 3.1).

Previous work on the TR Line deep earthquakes includes the calculation of principal stress directions (Figure 3.2). The average principal stress direction of the deep earthquakes beneath the Taranaki-Ruapehu Line (which Sherburn and White [2006] calls Taranaki 'East' in Figure 3.2) seems to be in alignment with principal stress directions from National Park, Mt. Ruapehu, and Waiouru. Sherburn and White [2006] hypothesise that the Taranaki East earthquakes are caused by a continuation of back-arc extension from the lower part of the Taupo Volcanic Zone. But it is noted here that extensional stress regime extends well to the west of the Taupo Volcanic Zone (Figure 3.2).

However, the stress field near Mt. Ruapehu may be more complicated than simple back-arc extension. Shear-wave splitting measurements show swings in polarisation that are thought to be caused by stresses from active magmatic processes and geological structures [Miller and Savage, 2001; Johnson et al., 2011]. A recent study of the Erua cluster (immediately west of Mt. Ruapehu) observed temporal changes in shear-wave splitting delay times associated with volcanic activity [Keats et al., 2011]. Later it will be shown that stress directions near Mt. Ruapehu also show swings in orientation between different studies.

The TR Line deep earthquakes are adjacent to a proposed step in the continental Moho [Salmon et al., 2011]. The relationship between the change in crustal thickness and the earthquakes is still unclear, but is thought to be caused by a rapid change in 


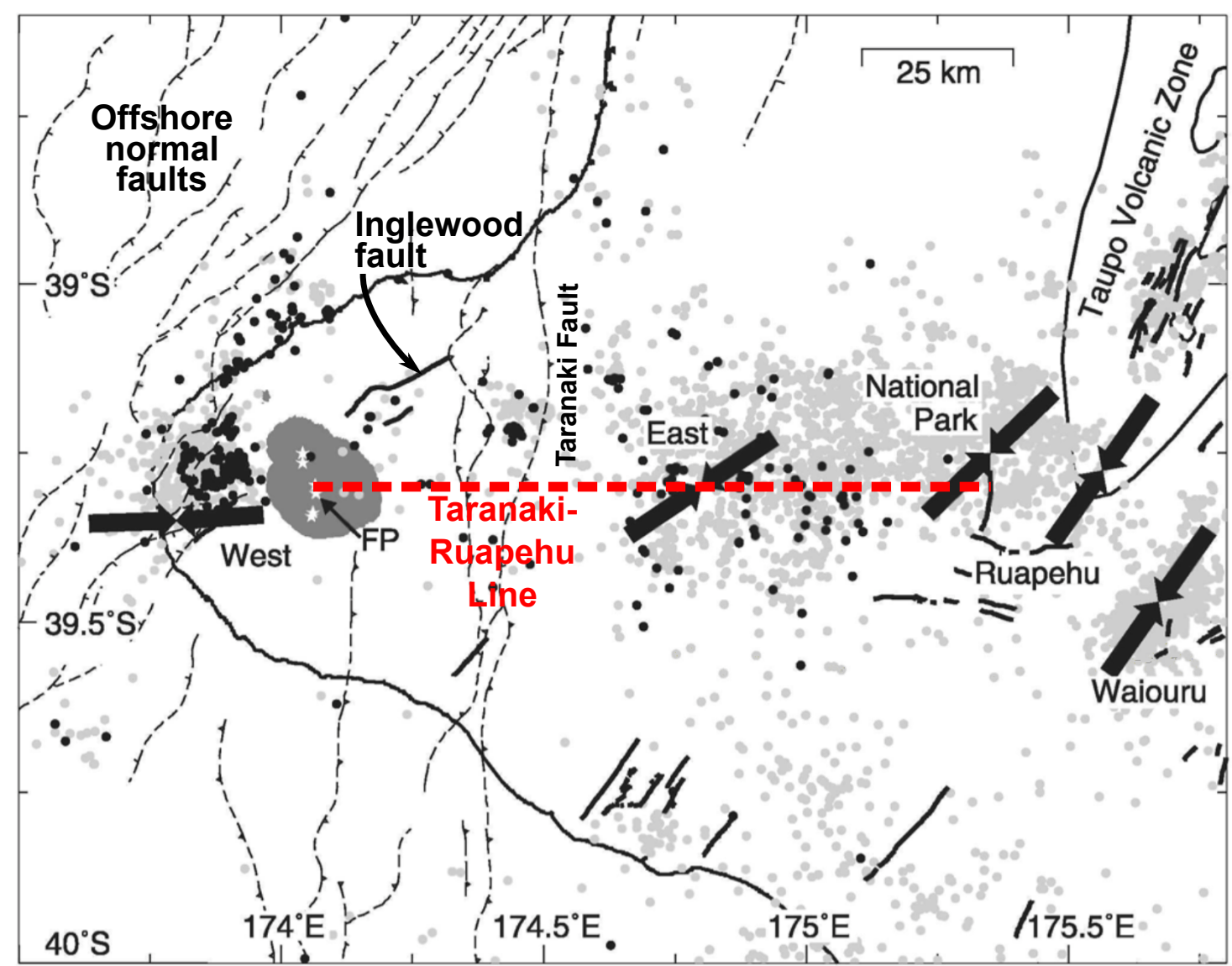

Figure 3.2: Distribution of maximum horizontal compressive stress directions along the TR Line from Sherburn and White [2006]. These include Waiouru [Hayes et al., 2004], National Park [Hurst and McGinty, 1999], Ruapehu [Darby and Meertens, 1995], and the so-called Taranaki 'East' and 'West' [Sherburn and White, 2006]. Note the active normal faults offshore to the north of Mt. Taranaki, and also the onshore Inglewood fault. Figure modified from Sherburn and White [2006].

mantle properties across the TR Line [Salmon et al., 2011]. Further work is needed to better understand the relationship between these phenomena.

In this study, GeoNet earthquake locations at the Taranaki-Ruapehu Line are further constrained using an array of temporary seismic stations (RATTIL, Chapter 2). The new locations reveal what appears to be a 'downwarp' of hypocentres beneath the Taranaki-Ruapehu Line which are interpreted as a separate cluster from the earthquakes near Mt. Ruapehu. This chapter also looks into the kinematics of faulting for both clusters by calculating focal mechanisms, seismic moment tensors, and stress directions from P-wave first motion data. The kinematic analysis provides new constraints on fault types, strain-rates, and stress directions in a region proposed to be the active front of mantle lithosphere delamination [Stern et al., 2006, 2013]. 


\subsection{Microseismic theory}

This section explains seismic theories and techniques used to study Taranaki-Ruapehu Line earthquakes.

\subsubsection{Earthquake locations}

An earthquake's location is defined by its hypocentre $\mathbf{P}=(X, Y, Z)$ which ruptured at origin time $T$. The hypocentre is the physical location where the fault rupture occurs, where $X$ is longitude, $Y$ is latitude, and $Z$ is depth below the surface. The earthquake location process has two components: (1) the forward problem of computing travel-times from a given velocity model, and (2) the inverse problem of determining the unknown parameters representing a hypocentre. For a simple homogenous medium with constant velocity $v$, the arrival times $t$ of earthquake energy at $i$ observation points $x, y, z$ can be calculated as follows:

$$
t_{c a l}^{i}=T+\frac{1}{v} \sqrt{\left(X-x_{i}\right)^{2}+\left(Y-y_{i}\right)^{2}+\left(Z-z_{i}\right)^{2}}
$$

This forward calculation can be performed for all possible hypocentre locations (e.g. all nodes in a grid for a specific region). Alternatively, the calculation can assume an initial hypocentre $\mathbf{P}_{0}=\left(X_{0}, Y_{0}, Z_{0}\right)$, such as the location of the first station to detect the earthquake, or a hypocentre from an existing catalog.

Hypocentre coordinates can then be determined by comparing the calculated arrivaltime with the observed arrival-time at each station. The best hypocentre is that which minimises the 'arrival-time residuals', i.e. the differences between the observed and calculated arrival times:

$$
r_{i}=\Delta t_{i}=t_{o b s}^{i}-t_{c a l}^{i}
$$

\subsubsection{Geiger's location method}

Equation (3.1) is highly non-linear in the sense that there is no simple linear relationship between the observed arrival times, and the desired spatial and temporal coordinates of the earthquake. One solution is to linearise the problem. Geiger [1910] introduced an iterative least-squares approach for determining earthquake lo- 
cations - if an initial hypocentre guess is close to the actual hypocentre, then the actual arrival-time residuals can be mathematically expressed as a first-order Taylor series about $\mathbf{P}_{0}$ :

$$
\begin{aligned}
r_{i} & =t_{o b s}^{i}(\mathbf{P})-\left(t_{c a l}^{i}\left(\mathbf{P}_{0}\right)+\frac{\partial t_{i}\left(\mathbf{P}_{0}\right)}{\partial \mathbf{P}}\left(\mathbf{P}-\mathbf{P}_{0}\right)+\cdots\right)+\left(T-T_{0}\right) \\
& =\frac{\partial t_{i}}{\partial x_{i}} \Delta x+\frac{\partial t_{i}}{\partial y_{i}} \Delta y+\frac{\partial t_{i}}{\partial z_{i}} \Delta z+\Delta t_{0}
\end{aligned}
$$

In the above equation, only linear terms are related. The term $\Delta t_{0}$ is the correction needed to adjust the origin time estimate. When many station are considered, a linear system of equations is formed such that:

$$
\mathbf{r}=\mathrm{G} \Delta \mathrm{p}
$$

Such that $\mathbf{r}$ is the residual vector, $\mathbf{G}$ is the matrix of partial derivatives of the arrival-time to each station with respect to the hypocentre coordinates as well as an additional column of ones which relate to the origin time correction term. The vector $\boldsymbol{\Delta} \mathbf{p}$ contains both the hypocentre and origin time corrections.

In this case, the earthquake hypocentre is determined by iteratively making small changes $\boldsymbol{\Delta} \mathbf{P}$ to successive hypocentre estimates. At least four arrival-time observations are required to determine both the hypocentre and origin time in a least-squares sense. Often an earthquake is recorded on many more stations, so the linear system is overdetermined.

Computer programs can take advantage of Geiger's method to determine earthquake hypocentres and origin times. Take, for example, SEISAN's HYPOCENTER program [Lienert et al., 1986; Lienert and Havskov, 1995]. Here, a Taylor series expansion yields a linear equation which minimises traveltime errors in a least-squares sense:

$$
d X_{4}=\left(T^{T} T\right)^{-1} T^{T} \Delta t
$$


Where $d X_{4}=\left(\Delta t_{0}, \Delta x, \Delta y, \Delta z\right), \Delta t$ is the time difference between predicted and observed arrival times, $w_{i}$ are the weighting factors normalised such that $\sum w_{i}=1$, and:

$$
T=\left[\begin{array}{cccc}
w_{1} & w_{1} \partial T_{1} / \partial x & w_{1} \partial T_{1} / \partial y & w_{1} \partial T_{1} / \partial z \\
\vdots & \vdots & \vdots & \vdots \\
w_{n} & w_{n} \partial T_{n} / \partial x & w_{n} \partial T_{n} / \partial y & w_{n} \partial T_{n} / \partial z
\end{array}\right]
$$

Linearised earthquake location algorithms like HYPOCENTER give accurate estimates of hypocentre parameters when the location problem has a single maximum concentrated in a small area with good network coverage [Presti et al., 2008]. Deep and dispersive crustal earthquakes at the Taranaki-Ruapehu Line may not fulfil these criteria, which motivates the use of non-linear, probabilistic earthquake location techniques (see Section 3.3.3).

\subsubsection{Probabilistic non-linear earthquake locations}

This study uses NonLinLoc, the non-linear probabilistic earthquake location method described by Lomax et al. [2000], to improve on preliminary earthquake locations determined by the HYPOCENTER program. The NonLinLoc method has two key advantages over the HYPOCENTER program. First, earthquake locations can be calculated using either a layered $1 \mathrm{D}$ or complex 3D velocity model. (HYPOCENTER can only use 1D models.) Second, it outputs comprehensive uncertainty information as a Posterior Density Function (PDF). This second point is especially important for this study, as the PDF describing each earthquake hypocentre is incorporated into focal mechanism solutions (as discussed in Section 3.3.4).

NonLinLoc implements the complete probabilistic PDF solution $\sigma_{p}(\mathbf{p})$ of Tarantola and Valette [1982], shown in Equation (3.7). Here, a vector of unknown parameters $\mathbf{p}$, and a vector of observed data $\mathbf{d}$, are related by $\theta(\mathbf{d} \mid \mathbf{p})$. When the density functions giving the prior information on the model parameters $\rho_{\mathbf{p}}(\mathbf{p})$ and on the observations $\rho_{\mathbf{d}}(\mathbf{d})$ are independent, and the theoretical relationship can be expressed as a conditional density function $\theta(\mathbf{d} \mid \mathbf{p}) \mu_{p}(\mathbf{p})$, then a complete probabilistic solution can be expressed as a posterior density function $(\mathrm{PDF}) \sigma_{p}(\mathbf{p})$. Here, $\mu_{p}(\mathbf{p})$ and $\mu_{d}(\mathbf{d})$ are the null information density functions specifying a state of total ignorance.

$$
\sigma_{\mathbf{p}}(\mathbf{p})=\rho_{\mathbf{p}}(\mathbf{p}) \int \frac{\rho_{\mathbf{d}}(\mathbf{d}) \theta(\mathbf{d} \mid \mathbf{p})}{\mu_{\mathbf{d}}(\mathbf{d})} \mathbf{d} \mathbf{d}
$$


In the case of an earthquake location, the unknown parameters are the hypocentral coordinates $\mathbf{x}=(x, y, z)$, the origin time $T$. The observed data are a set of arrival times $\mathbf{t}$, and the theoretical relation $\theta(\mathbf{d} \mid \mathbf{p})$ gives the predicted traveltimes $\mathbf{h}$. Assuming the theoretical relation and observed arrival times have gaussian uncertainties with covariance matricies $\mathbf{C}_{T}$ and $\mathbf{C}_{t}$ respectively, and $T$ is uniform, then it is possible to evaluate Equation (3.7) to obtain the PDF for the spatial location, $\sigma(\mathbf{x})$, as shown in Equation (3.8) below [Tarantola and Valette, 1982].

$$
\begin{aligned}
\sigma(\mathbf{x}) & =K \rho(\mathbf{x}) \cdot \exp \left[-\frac{1}{2} g(\mathbf{x})\right] \\
g(\mathbf{x}) & =\left[\hat{\mathbf{t}}_{0}-\hat{\mathbf{h}}(\mathbf{x})\right]^{T}\left(\mathbf{C}_{t}+\mathbf{C}_{T}\right)^{-1}\left[\hat{\mathbf{t}}_{0}-\hat{\mathbf{h}}(\mathbf{x})\right]
\end{aligned}
$$

Such that $K$ is a normalisation factor, $\rho(\mathbf{x})$ is a density function of prior information on the model parameters, and $g(\mathbf{x})$ is an L2 misfit function. Furthermore, $\hat{\mathbf{t}}_{0}$ is the vector of observed arrival times $\mathbf{t}$ minus their weighted mean, and $\hat{\mathbf{h}}$ is the vector of theoretical travel times $\mathbf{h}$ minus their weighted mean.

Equation (3.8) is a complete, probabilistic PDF solution to the earthquake location problem, including information on uncertainty and resolution. This includes the spatial relation between the network and event, measurement uncertainty in observed arrival times, and errors in the calculation of theoretical travel times.

NonLinLoc offers a number of grid search algorithms to estimate a location PDF within a $3 \mathrm{D}$ volume. The algorithms include a systematic grid-search, a stochastic, Metropolis-Gibbs search, or a hybrid 'Oct-Tree' method [Lomax, 2011]. This study uses the Oct-Tree method due to its speed and simplicity. Oct-Tree runs 100 times faster than the systematic grid-search algorithm with comparable robustness, yet is more global and complete than the Metropolis-Gibbs search. As discussed in Lomax et al. [2009], the Oct-Tree method first takes a set of samples on a coarse, regular grid of cells throughout the search volume. The cell with the highest probability is then subdivided into 8 child cells (hence the name Oct-Tree) from which 8 new samples of the PDF are obtained. These samples are added to a list of all previous samples, from which the highest probability cell is again identified. This process is repeated until a predetermined resolution is achieved. The Oct-Tree structure will have a larger number of smaller cells in areas of higher probability relative to areas of lower probability. 


\subsubsection{Focal mechanisms}

A focal mechanism defines the geometry of faulting during an earthquake. Focal mechanisms take advantage of characteristic patterns of radiated seismic energy around an earthquake which form compressional $(\mathrm{P})$ and tensional $(\mathrm{T})$ quadrants. Seismic stations surrounding the earthquake record an initial 'up' or 'down' motion, called the 'first motion', which correspond to the $\mathrm{T}$ and $\mathrm{P}$ quadrants respectively. The division between quadrants occurs along the 'fault plane' as well as a plane perpendicular to it, the 'auxiliary plane'. These divisions are referred to as 'nodal planes'. When the fault plane and auxiliary plane are projected onto a lowerhemisphere spherical projection a 'beach ball' diagram is created (Figure 3.3 A). The physical appearance of a beach ball is sufficient information to determine whether a fault is strike slip, normal, reverse, or more commonly, some intermediate value such as oblique reverse (Figure 3.3 B). It is not possible to resolve which plane is the fault plane and which is the auxiliary plane using just earthquake first motions. Geologic or geodetic information can sometimes be used to uniquely identify the fault plane [Stein and Wysession, 2009], but this information is often not available.

Principal stress directions and seismic moment tensors can both be derived using focal mechanism information. Theoretically, principal stress directions can be calculated using just focal mechanisms (Section 3.3.5), and the seismic moment tensor can be constructed using a combination of focal mechanisms and earthquake magnitudes (Section 3.3.6). This thesis determines principal stress directions and seismic moment tensors and uses this information to help characterise lithospheric deformation at the Taranaki-Ruapehu Line. For more background on focal mechanisms refer to Aki and Richards [1980]; Stein and Wysession [2009]; Havskov and Ottemoller [2010].

While both a fault plane and auxiliary plane are discussed above, only one of the planes needs to be known to fully define a focal mechanism as the other nodal plane is orthogonally related. All focal mechanism values recorded in this thesis refer to either the fault plane or its auxiliary plane, but not both. No special technique was used to select one nodal plane over the other. The convention of Aki and Richards [1980] is used to define the fault plane in terms of strike, dip, and rake, such that:

- The strike angle $\xi$ describes the direction of the fault line with respect to true north. It is measured clockwise from true north $0^{\circ} \leq \alpha_{s} \leq 360^{\circ}$. There are two possible values for any strike, e.g. $90^{\circ}$ and $270^{\circ}$. The strike value recorded 
A View from side

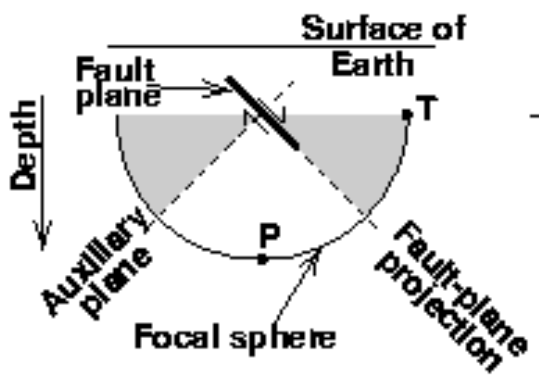

B
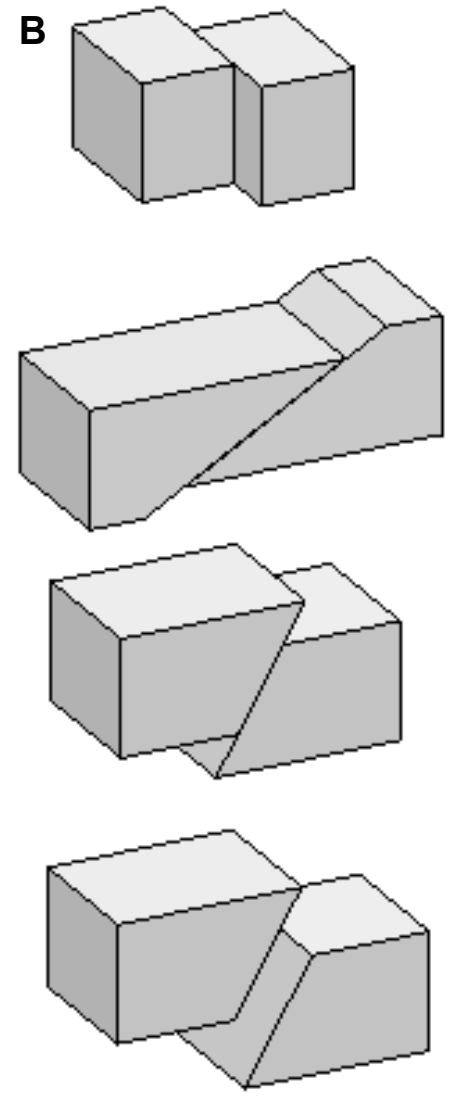

View from above

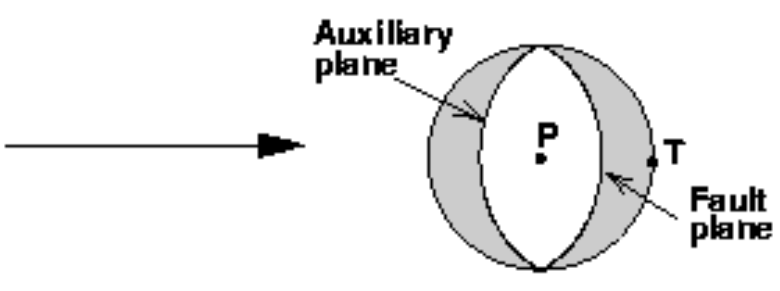

"Beach ball"

\section{Strike slip}
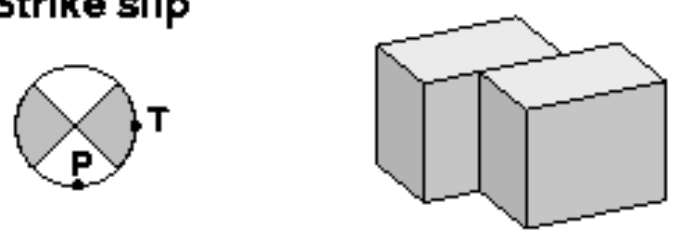

Normal
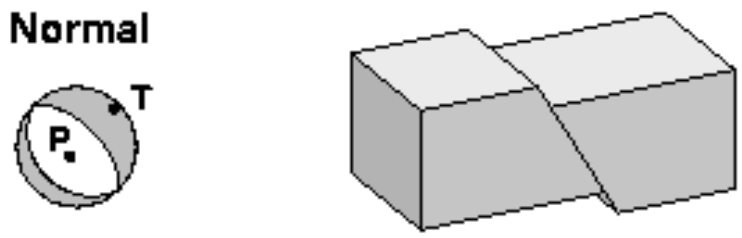

Reverse

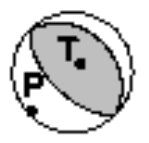

Oblique reverse

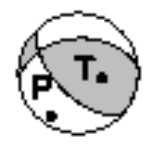

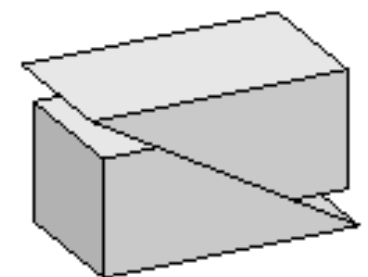

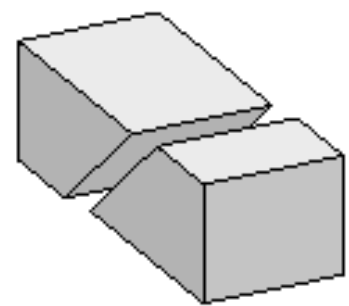

Figure 3.3: Schematic diagram of a focal mechanism [after Oppenheimer, 1996]. $\mathrm{P}$ is the compressional axis and $\mathrm{T}$ is the tensional axis. A) The fault plane and auxiliary plane of a focal mechanism are defined by the pattern of radiation surrounding an earthquake. B) The 'beach ball' representation of a focal mechanism is provided for four different fault types, each focal mechanism beach ball is flanked by block diagrams of the inferred fault plane and auxiliary plane fault movement. 
is the one where the fault plane dips to the right when looking in the strike direction.

- The dip angle $\delta$ describes the inclination of the fault plane from horizontal $0^{\circ} \leq \alpha_{s}<90^{\circ}$, such that 0 is horizontal and 90 is vertical. It is measured to the right hand side when looking along the strike direction (i.e. in the dip direction).

- The rake angle $\lambda$ describes the relative movement of the hanging wall with respect to the footwall $-180^{\circ} \leq \lambda \leq 180^{\circ}$. It is measured in the plane of the fault from the strike direction. Positive values indicate upwards movement of the hanging wall such as in reverse faulting, negative values indicate downwards movement of the hanging wall such as in normal faulting. Positive $\lambda$ values increase upwards (i.e. 1,2,3...) counterclockwise from the strike direction and negative $\lambda$ values increase downwards $(-1,-2,-3)$ clockwise from the strike direction.

In this study focal mechanisms are estimated from P-wave first motion picks using a probabilistic (Bayesian) method of Walsh [2008]; Walsh et al. [2009]. The key benefit of this method is the parameterisation of the focal mechanism posterior density function (PDF) which allows proper estimation of the uncertainties in each focal mechanism solution. The observational uncertainties are carried from the original hypocentre location and take-off angle PDF into a focal mechanism PDF (see Figure 3.4). In the simplest application of the method each focal mechanism PDF is approximated by a scalar Matrix-Fisher distribution reducing the characterisation of the uncertainty into a single parameter: the scalar concentration $\kappa$. This is used to determine the standard deviation $\sigma_{\theta}$ of the errors in strike, dip and rake of each focal mechanism. These errors are assumed equal, and can be evaluated by equation Equation (3.9), and are later used to parameterise the principal stress axis PDF (Section 3.3.5).

$$
\sigma_{\Theta}=\exp (3.9155-0.5659 \log (\kappa))
$$

The final quality of a focal mechanism depends on a number of factors, the most important of which are:

- The number of first motions picked at seismic stations. If there are too few first motion picks then any errors in those picks may result in an inaccurate focal mechanism solution. To mitigate this issue, it was suggested that focal 

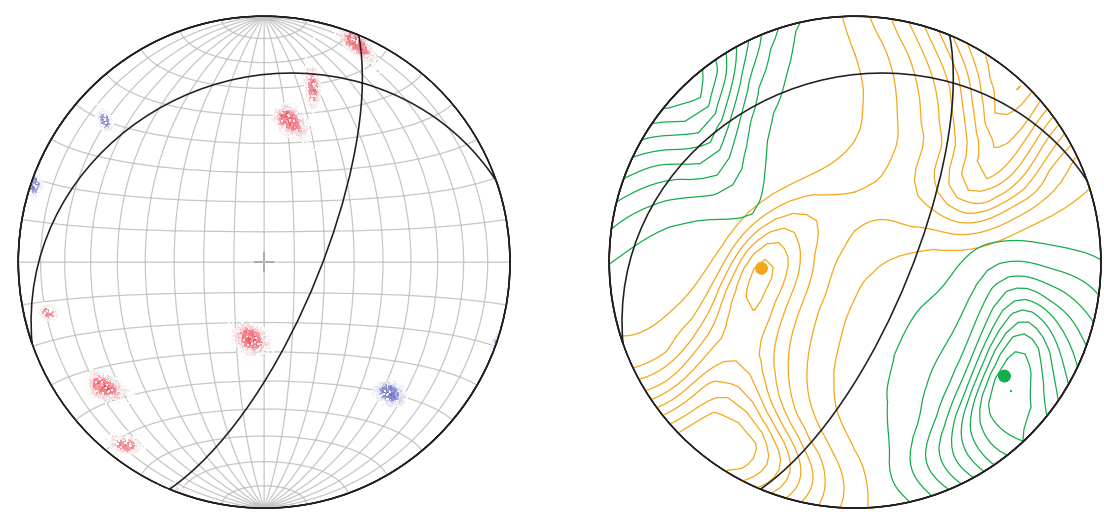

Figure 3.4: Example of a probabilistic focal mechanism solution using the Bayesian technique of Walsh et al. [2009]. The curved black lines represents the focal mechanism nodal planes. Blue points are compressions ('up' motions), red points are dilations ('down' motions). PT contour plot (right-hand side) for the same event. Orange denotes P-axis, green the T-axis. Circles denote the best fit solution using the maximum a posteriori estimate. Figure modified from Walsh et al. [2009].

mechanisms be calculated using earthquakes with at least 10 first motions ( $R$. Arnold, pers. comm., 2013.)

- The distribution of seismic stations around an earthquake's focal sphere. An accurate focal mechanism solution requires observations to be evenly distributed throughout the focal sphere (i.e. in terms of azimuth and takeoff angle). An uneven distribution can result in large uncertainties in the focal mechanism solution. Focal mechanisms in this study were picked on both GeoNet and RATTIL stations (Chapter 2) which helped close azimuthal gaps. Where gaps still exist (e.g. due to a lack of first motion picks in certain quadrants) the Walsh et al. [2009] method should capture this uncertainty in the focal mechanism PDF.

- Systematic first motion errors resulting from wrongly wired field equipment. An inverted seismogram is hard to diagnose in the field, but can be easily checked by looking at the first motion arrival of a clear teleseismic event. (They should all be the same due to the small azimuthal footprint of a local seismic network situated far from the earthquake source, e.g. Figure 2.5).

- The earthquake hypocentre location and takeoff angles. Bad hypocentre locations can be caused by an inaccurate velocity model, high background seismic noise, station timing errors, or poorly picked events. Hypocentre errors are accounted for in the Walsh et al. [2009] method by incorporating the hypocentre and takeoff angle PDF output by NonLinLoc (Section 3.3.3). 


\subsubsection{Stress inversion}

Stress is defined as force acting over some area. Quantifying stress is important because stress causes strain, and strain results in geological structures, such as faults and folds.

Stress acting on rocks in the Earth is described by a symmetric $3 \times 3$ tensor with six independent values. This can also be described in terms of three orthogonal principal stresses referred to as $\sigma_{1}$ (maximum), $\sigma_{2}$ (intermediate), and $\sigma_{3}$ (minimum), which are each orthogonal to planes with no shear stress. In most failure criterion (i.e. Coulomb-Navier) for brittle failure in unbroken homogeneous rock, the intermediate $\sigma_{2}$ axis lies in the fault plane, and slip occurs in the direction orthogonal to $\sigma_{2}-$ i.e. the intersection of the fault plane with the plane containing $\sigma_{1}$ and $\sigma_{3}$ [Ranalli, 1995].

The $\mathrm{P}$ axis of a focal mechanism is inclined $45^{\circ}$ from the fault plane, and is sometimes taken as an approximation of $\sigma_{1}$ [Gephart and Forsyth, 1984]. This approach is often used incorrectly since it assumes earthquakes occur on new faults that are oriented parallel to the planes of maximum shear stress (i.e. Tresca's criterion [Ranalli, 1995]). As McKenzie [1969] shows, earthquakes usually occur along pre-existing faults, and in this case $\sigma_{1}$ can lie anywhere in the same quadrant as the P-axis. In most geological situations, reliable stress locations require fault planes to be evenly distributed over a wide range of azimuths.

The Wallace-Bott hypothesis [after Wallace, 1951; Bott, 1959] is often used to predict the slip direction for failure on pre-existing fault planes. It states that any fault will slip parallel to the direction of maximum resolved shear stress in the fault plane. For the same ambient stress field, different fault planes will have different resolved shear stress directions. Given lots of fault planes that are randomly oriented and independent of one another, the orientation of the principal stress axis can be constrained by calculating the difference between the fault slip vector and the direction of maximum resolved shear stress in the fault plane. This value is called the 'misfit angle', and is estimated by all modern stress inversion algorithms [e.g. Gephart and Forsyth, 1984; Gephart, 1990; Michael, 1984, 1987; Rivera and Cisternas, 1990; Arnold and Townend, 2007]. In the case of focal mechanism data, where it is not known which of the two nodal planes is the fault plane, inversion algorithms usually assume equal probability for either nodal plane [Arnold and Townend, 2007].

In this study, groups of focal mechanisms are inverted for principal stress directions at the Taranaki-Ruapehu Line using the Bayesian approach of Arnold and Townend 

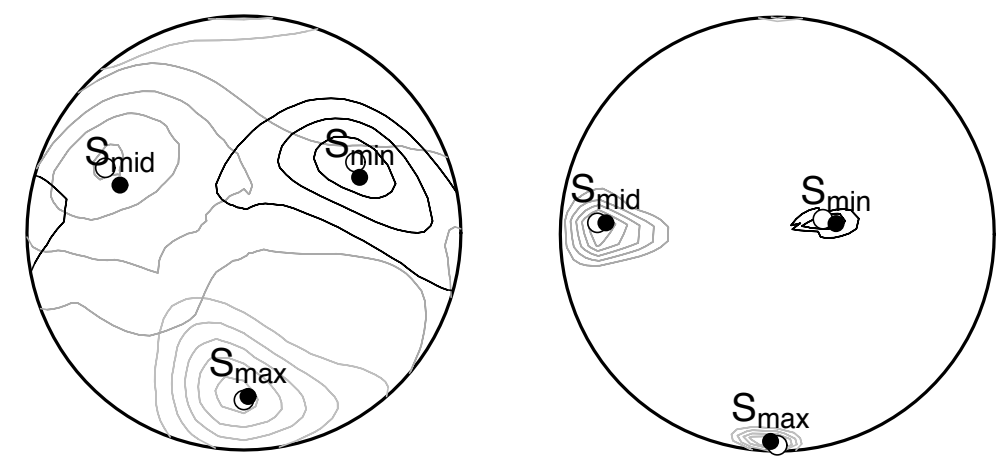

Figure 3.5: Example of probabilistic principal stress directions calculated using the Bayesian technique of Arnold and Townend [2007]. The left panel uses data from 4 focal mechanisms only, while the right panel uses 76 focal mechanisms. The filled circles show the posterior mean of all three axis. All observations are assumed to have been made with $20^{\circ}$ error. Figure modified from Arnold and Townend [2007].

[2007]. This stress inversion algorithm distinguishes itself from those mentioned previously in that it provides a rigorous measurement of uncertainty. Bayes' theorem is one of conditional probability, which provides a way to revise a prior prediction given new or additional evidence. In the implementation of Arnold and Townend [2007], the prior stress tensor has either a predefined or uniform distribution, and the fault planes are assumed to be randomly oriented. Each focal mechanism has been weighted by errors in strike, dip, and rake which are contained in a single scalar Matrix Fisher concentration parameter (as explained in Section 3.3.4). The stress tensor is revised by using the product of the individual posterior distributions of each focal mechanism which is related to the stress tensor through the WallaceBott hypothesis. As more focal mechanisms with different orientations are added to update the stress field, the uncertainty in the principal stress directions decreases (Figure 3.5).

One caveat of the Arnold and Townend [2007] approach is that it assumes equal probability of slip on either nodal plane. If most of the earthquakes occur on faults with similar orientation, or if one nodal plane is preferred over the other, the uncertainty will be underestimated.

In the Wallace-Bott hypothesis, only four of the six unique stress tensor parameters are relevant. The remaining two can't be constrained using focal mechanisms. The relevant parameters are the three principal stress directions $\sigma_{1}, \sigma_{2}, \sigma_{3}$ and the stress ratio $v=\left(\sigma_{1}-\sigma_{2}\right) /\left(\sigma_{1}-\sigma_{3}\right)$. Arnold and Townend [2007] often recast the stress tensor into three Euler orientation angles $\Phi_{S}=\left(\phi_{S}, \theta_{S}, \psi_{S}\right)$ and $v$ for use with a rotation matrix $R$ in order to facilitate conversions between the coordinate systems of the fault plane, geographic orientation and the stress tensor. The remaining two 
parameters not accounted for are the hydrostatic stress (which does not deform a body), and the stress magnitude. Therefore only the principal stress directions can be determined, and not the magnitudes of those directions.

To revise the stress tensor parameters $\left(\Phi_{s}, v\right)$, the posterior distribution $p\left[\Phi_{S}, v \mid\right.$ $\left.\left\{\Phi_{G i}^{o}, \tau_{i}\right\}\right]$ is evaluated using a set of $n$ focal mechanism observations $\left\{\Phi_{G i}^{o}\right\}(i=1 \ldots n)$ with Matrix-Fisher precisions $\left\{\tau_{i}\right\}$, as shown in Equation (3.10). (Note that the Matrix-Fisher precisions are derived from the focal mechanism errors as described in Section 3.3.4.)

$$
p\left[\Phi_{S}, v \mid\left\{\Phi_{G i}^{o}, \tau_{i}\right\}\right] \propto p\left(\Phi_{S}, v\right) \times p\left[\left\{\Phi_{G i}^{o}\right\} \mid \Phi_{S}, v,\left\{\tau_{i}\right\}\right]
$$

The marginal distribution of the principal stress axis can also be extracted. For example, $\sigma_{1}$ is the distribution of the pair of angles $\left(\phi_{S}, \theta_{S}\right)$, and is calculated by integrating the posterior distribution over $\psi_{S}$ and $v$ :

$$
p\left[\phi_{S}, \theta_{S} \mid\left\{\Phi_{G i}^{o}, \tau_{i}\right\}\right]=\iint p\left[\phi_{S}, v \mid\left\{\Phi_{G i}^{o}, \tau_{i}\right\}\right] \mathrm{d} \psi_{S} \mathrm{~d} v
$$

For plotting stress directions on maps it is often useful to compute the direction of maximum horizontal stress. This can be done even when none of the three principal stress directions are strictly horizontal. For a given stress tensor $S$ oriented at $\Phi_{S}$ in geographic coordinates, the maximum horizontal compressive stress azimuth $\phi_{G}^{m}$ can be calculated as follows:

$$
\tan \left(2 \phi_{G}^{m}\right)=\frac{2\left[R_{11} R_{21}+v R_{12} R_{22}\right]}{\left(R_{11}^{2}-R_{21}^{2}\right)+v\left(R_{12}^{2}-R_{22}^{2}\right)}
$$

Where $R_{i j}$ are the components of a transformation matrix (not shown) linking the stress coordinate frame with the geographic frame.

\subsubsection{Seismic moment tensor}

Focal mechanisms are often recorded as the strike/dip/rake of either the fault plane or the auxiliary plane. This is a useful form for the communication of structural geological information, but has limitations for understanding fault kinematics. It is common to transform the strike/dip/rake parameters into 3D cartesian coordinates. For example, in Section 3.3.5, the Bayesian stress estimate used a 'geographic' transformation to facilitate the inversion of principal stress directions. However, the 
most common way to fully parameterise a focal mechanism is to construct the seismic moment tensor $M$ [Kostrov, 1974; Jackson and McKenzie, 1988]. In the moment tensor form, an earthquake's movement is expressed as 9 generalised couples in $\mathrm{x}, \mathrm{y}, \mathrm{z}$ cartesian space, specifically:

$$
M=\left[\begin{array}{lll}
M_{x x} & M_{x y} & M_{x z} \\
M_{y x} & M_{y y} & M_{y z} \\
M_{z x} & M_{z y} & M_{z z}
\end{array}\right]
$$

In this thesis Equation (3.13) is parameterised using the approach of Aki and Richards [1980]. For each focal mechanism, a seismic moment tensor $M$ can be constructed using strike $\phi$, dip $\delta$, rake $\lambda$ from the focal mechanism as well as the earthquake moment magnitude $M_{0}$ - see Equation (3.14). The strike, dip and rake values of a focal mechanism should be those of either the fault plane or the auxiliary plane but not both. Due to symmetry (e.g. $M_{x y}=M_{y x}$ ) the value of the seismic moment tensor remains the same regardless of what nodal plane is chosen.

$$
\begin{aligned}
& M_{x x}=-M_{0}\left(\sin \delta \cos \lambda \sin 2 \phi_{s}+\sin 2 \delta \sin \lambda \sin ^{2} \phi_{s}\right), \\
& M_{x y}=M_{0}\left(\sin \delta \cos \lambda \cos 2 \phi_{s}+\frac{1}{2} \sin 2 \delta \sin \lambda \sin 2 \phi_{s}\right)=M_{y x}, \\
& M_{x z}=-M_{0}\left(\cos \delta \cos \lambda \cos \phi_{s}+\cos 2 \delta \sin \lambda \sin \phi_{s}\right)=M_{z x}, \\
& M_{y y}=M_{0}\left(\sin \delta \cos \lambda \sin 2 \phi_{s}-\sin 2 \delta \sin \lambda \cos ^{2} \phi_{s}\right), \\
& M_{y z}=-M_{0}\left(\cos \delta \cos \lambda \sin \phi_{s}-\cos 2 \delta \sin \lambda \cos \phi_{s}\right)=M_{z y}, \\
& M_{z z}=M_{0} \sin 2 \delta \sin \lambda
\end{aligned}
$$

The seismic moment $M_{0}$ of the earthquake has a scaling effect on the value of the moment tensor solution above, which essentially means the larger earthquake the larger the seismic moment in each cartesian coordinate. This is important when groups of earthquakes are considered together, as the largest earthquake(s) will tend to dominate the result.

No direct measure of $M_{0}$ was made in this study, however earthquake magnitudes automatically calculated by GeoNet ('GeoNet rapid') are available. Hanks and Kanamori [1979] derived a relationship which links the seismic moment $M_{0}$ (in N m) with the seismic moment magnitude $M_{W}$ of an earthquake, as shown below:

$$
\log _{10} M_{0}=\frac{3}{2} M_{w}+9.0
$$


GeoNet earthquakes are not reported as $M_{0}$ or $M_{W}$ but instead as $M_{L}$ or 'local' magnitudes. Ristau [2009] looked at the relationship between GeoNet $M_{L}$ magnitudes and $M_{W}$ magnitudes from the Global Centroid Moment Tensor (CMT) catalog (www.globalcmt.org). They came up with a simple linear relationship between the two forms: $M_{W}=\left(M_{L}-0.73\right) / 0.88$. This provides a way to use local GeoNet magnitudes to calculate the seismic moment $M_{0}$ of an earthquake.

Once a group of moment tensors $M$ are constructed using strike/dip/rake, inferences can be made about the strain-rate of the earthquake-containing volume. Jackson and McKenzie [1988] show that the the average strain-rate tensor $\dot{\varepsilon}_{i j}$ for a volume $V$ with shear modulus $\mu$ over a time $\Delta t$ can be calculated as a moment tensor summation:

$$
\dot{\varepsilon}_{i j}=\frac{1}{2 \mu \Delta t V} \sum_{n=1}^{N} M_{i j}^{n}
$$

Equation (3.16) is used to investigate volumes of focal mechanisms along the TaranakiRuapehu Line, including the lower crust in the vicinity of a $7-10 \mathrm{~km}$ step in crustal thickness. The principal strain components of the strain-rate matrix $\dot{\varepsilon}_{\mathbf{i j}}$ are its eigenvalues. (This equation assumes that all of the strain in the volume is expressed as brittle failure.)

\subsection{Data collection and analysis}

In this section data from 27 seismic stations are analysed in the first dedicated microseismic study of the Taranaki-Ruapehu Line (Figure 3.6). This analysis focuses on getting the best possible earthquake locations, and then inverting those earthquakes for rock properties, such as fault types, stress directions and strain-rates. First, the properties of the seismic network are explained (Section 3.4.1), then the initial catalog of earthquake events that the analysis is based on is introduced (Section 3.4.2). Those events are repicked and relocated using a simple linear technique (Section 3.4.3). Events are also located using a non-linear probabilistic location technique (Section 3.4.4). Focal mechanisms are calculated on the earthquakes with the clearest first motions (Section 3.4.5), and clusters of focal mechanisms are inverted for principal stress directions (Section 3.3.5). A comprehensive results section is provided in Section 3.5 which includes moment tensor summations and focal plane rose diagrams. 


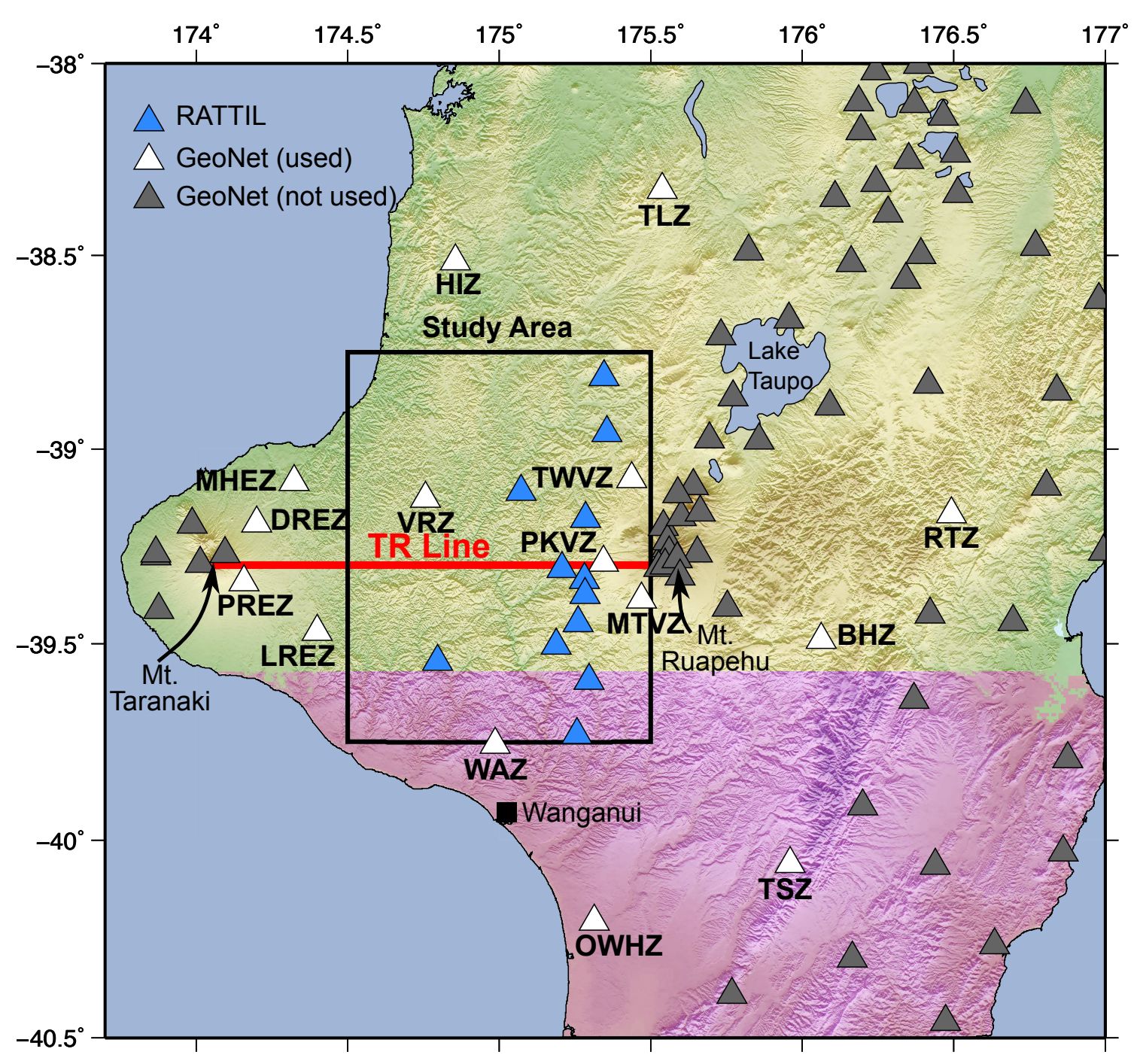

Figure 3.6: Map of seismic stations used for the TR Line microseismic study. The station codes of GeoNet stations used in this study are included; for the names of RATTIL stations see Figure 2.2.

\subsubsection{Station selection}

Of the 27 seismic stations used in this microseismic study, 15 are permanent stations operated by GeoNet and 12 were temporary deployments from the Ruapehu And Taranaki Teleseismic Imaging Line (RATTIL) (see Chapter 2). The 15 GeoNet stations were chosen on the basis of proximity to the study area, although a few that were further away were also chosen in the hope they would provide improved azimuthal coverage for some earthquakes. Continuous waveform data from these stations were downloaded directly from GeoNet (http://info.geonet.org.nz/x/ _wOD). RATTIL stations were deployed north-south across the Taranaki-Ruapehu Line for the purpose of a receiver function study (Chapter 4). They are on average closer to the TR Line earthquakes than GeoNet stations, and should be able to help 
improve earthquake locations, especially in depth. RATTIL stations are equipped with Guralp CMG-3ESP broadband seismometers. GeoNet stations are a mixture of short period (Sercel L4C-3D and Lennarz LE-3DliteMkII) and broadband (Guralp CMG-3ESP and Streckeisen STS-2) seismometers. Sampling rate for all instruments was set to $100 \mathrm{~Hz}$.

The chosen study area covers the Taranaki-Ruapehu Line immediately west of Mt. Ruapehu (Figure 3.6). The TR Line is not considered all the way to Mt. Taranaki because GeoNet seismicity in Figure 3.1, and a previous microseismic study of Mt. Taranaki region [Sherburn and White, 2006], both indicate that most TaranakiRuapehu Line deep earthquakes end before Mt. Taranaki. This gap in seismicity is consistent with the location of a known 'aseismic corridor' (Figure 1.9).

\subsubsection{Event selection}

The GeoNet rapid catalog (http://info.geonet.org.nz/x/KACD) was used to produce an initial database of earthquake locations along the Taranaki-Ruapehu Line. The GeoNet rapid catalog was chosen after comparative tests with the CONDET detection program built into SEISAN, which after several test runs detected fewer events than those from GeoNet rapid. Parameterisation of CONDET was hindered by the 2013 Seddon and Lake Grassmere earthquakes and their aftershocks, which generated about 2,000 false positives when run over 7 months of RATTIL data. A benefit of using the GeoNet rapid catalog is that it includes local magnitude estimates.

The GeoNet rapid catalog was queried for all events occurring between November 2012 and March 2014, which corresponds with the deployment window of the RATTIL array. All earthquakes are between longitudes 174.5-175.5 E and latitudes 38.75-39.75 S (corresponding to the 'study area' in Figure 3.6) were extracted from the catalog. Earthquakes were selected to a maximum depth of $50 \mathrm{~km}$ to avoid picking earthquakes associated with the underlying subduction zone. A total of 782 events fit the selection criteria, and are the basis for this microseismic study (Figure 3.7).

\subsubsection{Preliminary earthquake locations}

All 782 GeoNet rapid events were visually inspected on RATTIL and GeoNet waveform data. Those with clear waveforms were manually re-picked. A total of 29 


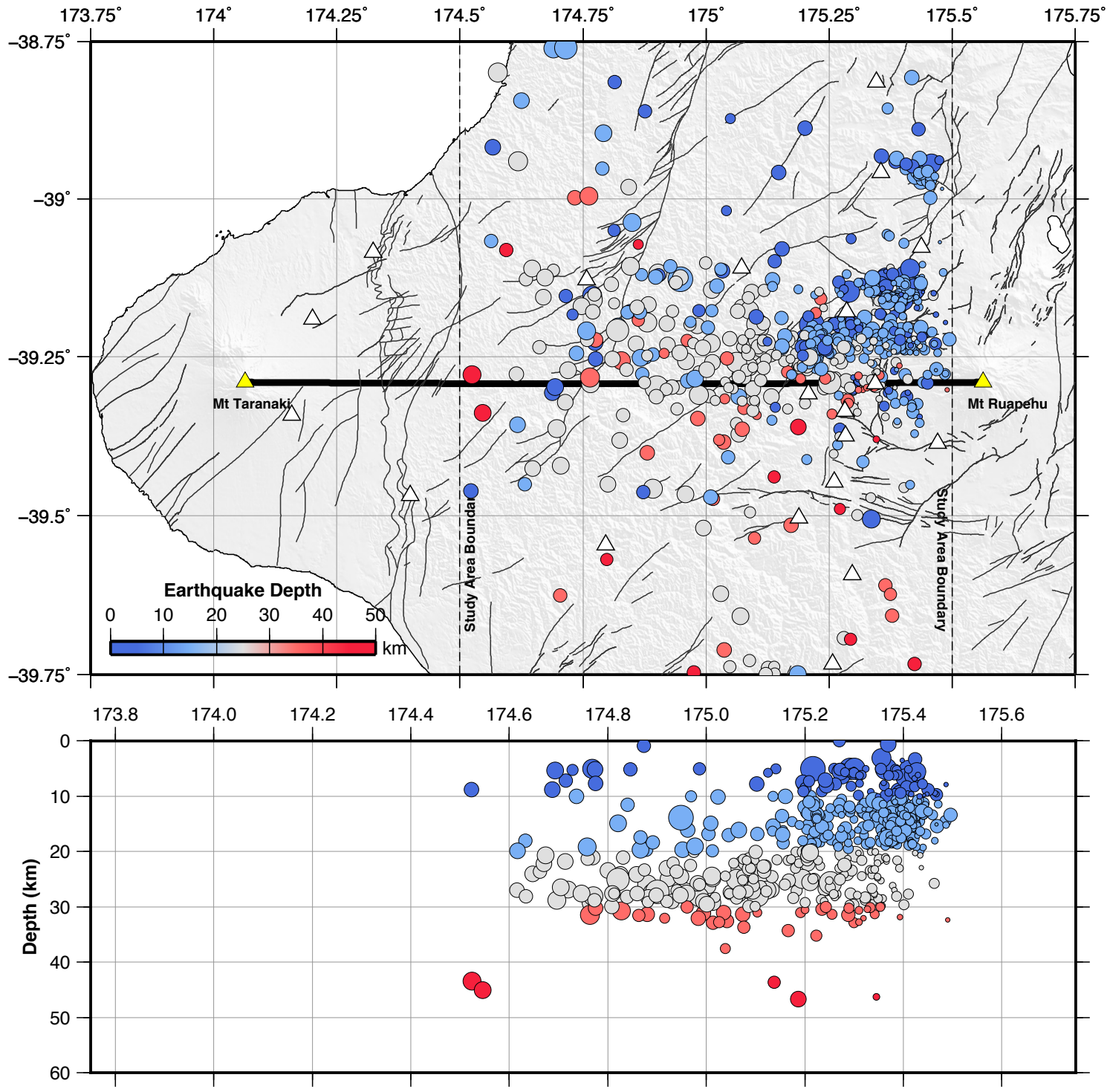

Figure 3.7: 'GeoNet rapid' earthquake locations at the TR Line. Shown are 782 earthquake hypocentres scaled by magnitude. The cross-section below is a swath of earthquakes in depth from a line running between Mt. Taranaki and Mt. Ruapehu. Earthquakes terminate along a sharp interface at $\sim 33 \mathrm{~km}$ depth, which is consistent with earthquake distribution from the long-term GeoNet catalog in Figure 3.1. 


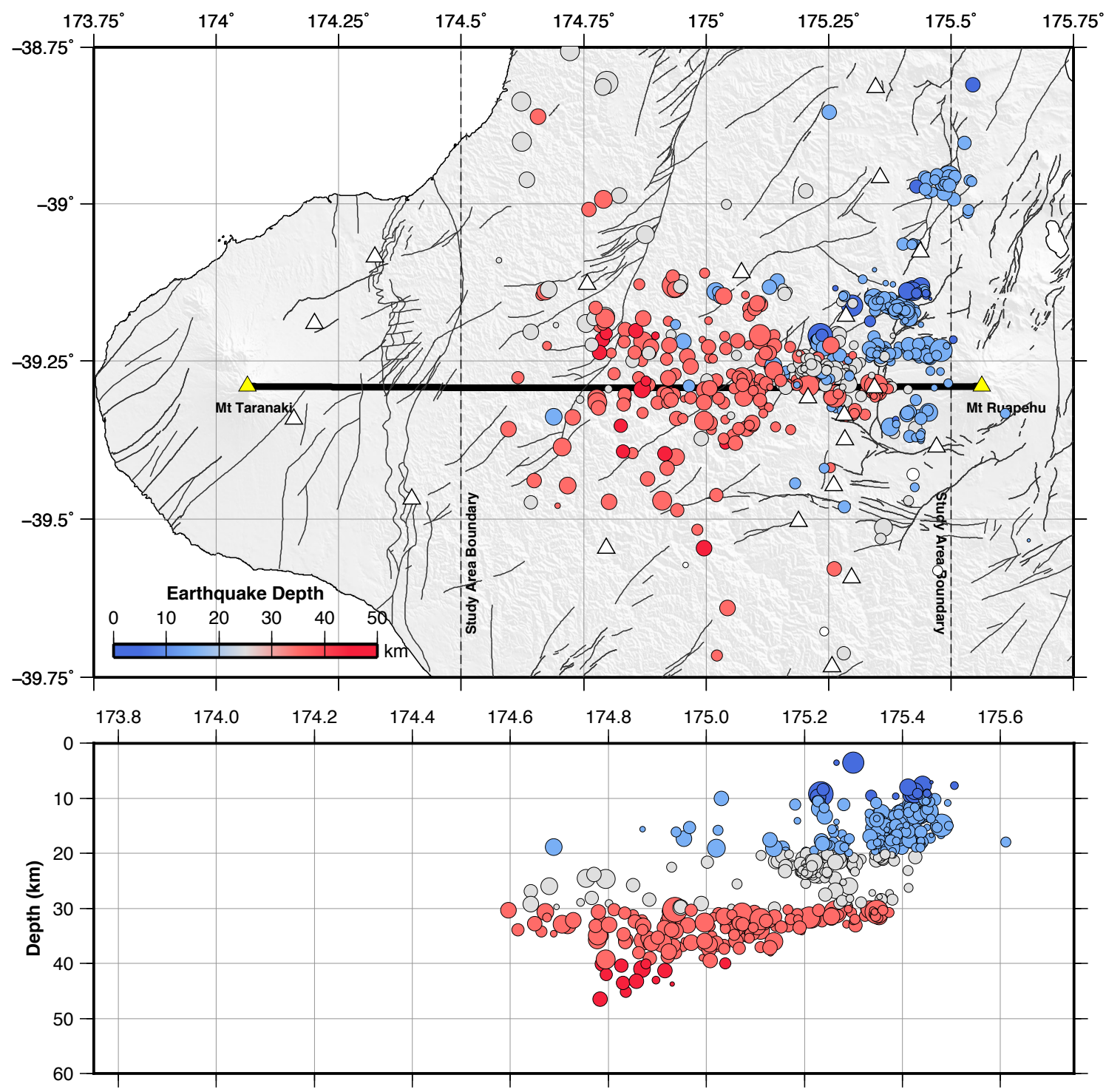

Figure 3.8: SEISAN earthquake locations. Shown are 710 earthquake hypocentres from the GeoNet rapid catalog (Figure 3.7) which have been repicked and relocated in SEISAN. The cross-section in the lower panel is a swath of earthquakes from a line running between Mt. Taranaki and Mt. Ruapehu. Note that earthquake clusters are better defined in comparison to GeoNet rapid locations, and separate into distinct groups with depth. The relocated Taranaki-Ruapehu Line earthquakes no longer form a smooth surface at $33 \mathrm{~km}$ depth, and instead reveal what appears to be a 'downwarp' of earthquake hypocentres. 
seismic stations were used in the re-picking effort, which consisted of all 14 RATTIL stations (Chapter 2) plus nearby GeoNet stations WAZ, PHWZ, TSZ, BHHZ, MTVZ, PKVZ, LREZ, PREZ, DREZ, MHEZ, VRZ, TWVZ, BKZ, HIZ and TLZ (Figure 3.6).

First, a SEISAN continuous database was constructed using continuous waveform data from both RATTIL and GeoNet stations between November 2012 and March 2014. P-phases were picked on the vertical component and S-phases on unrotated horizontal components. At least four P-phases and one S-phase were picked for each event. P-wave first motions were also picked on high-quality earthquake waveforms for the purpose of calculating focal mechanisms. This will be discussed later.

Earthquake locations were calculated using SEISAN's HYPOCENTER program (Figure 3.8). HYPOCENTER requires a $1 \mathrm{D}$ velocity model for $\mathrm{P}$ and $\mathrm{S}$ phase picks. For P velocities, the New Zealand Standard Velocity Model [Maunder, 2002] was used. $\mathrm{S}$ velocities are derived from $\mathrm{P}$ velocities using a $\mathrm{P} / \mathrm{S}$ ratio of 1.71 . This ratio is consistent with Zandt and Ammon [1995]'s value for orogenic belts such as New Zealand. In total, 710 of the GeoNet rapid events were located on seismic waveforms, the remaining 72 events were unclear (either outside the study area, or of poor quality) and therefore rejected. RMS misfit values were carefully monitored to identify bad phase picks, and most events had misfits in the range of $0.1 \mathrm{~s}$ to $0.3 \mathrm{~s}$.

The repicked event hypocentres (Figure 3.8) are different in character to the GeoNet rapid catalog events (Figure 3.7) in three ways: 1) the re-picked events show tighter clustering near Mt. Ruapehu; 2) the deepest hypocentres from repicked events are clearly separate from the shallower seismicity near Mt. Ruapehu; 3) events become even deeper and show a 'downwarp' of hypocenters at depth rather than a flat surface.

\subsubsection{Final earthquake locations}

A nonlinear earthquake location technique [NonLinLoc, Lomax et al., 2000] was used to improve on the 710 earthquake locations from the HYPOCENTER program. The NonLinLoc technique provides formal uncertainties in latitude, longitude and depth for each hypocentre, allowing for a more robust interpretation of earthquake locations. Uncertainties take the form of a probability density function, which generates a 3D 'cloud' of possible locations for each earthquake event. For a detailed description of this technique see Section 3.3.3. 
The NonLinLoc location technique is applied as a set of programs and utilities which can be downloaded from http://alomax.free.fr/nlloc/. The programs relevant to this study are Vel2Grid, Grid2Time and NLLoc:

1. Vel2Grid was used to generate a 3D velocity grid of the study area. The New Zealand Standard Velocity Model [Maunder, 2002] (also used for the SEISAN locations) was adapted into a 3D layercake velocity grid. Grid dimensions were $600 x 600$ cells in $\mathrm{x}, \mathrm{y}$ and 150 cells in $\mathrm{z}$, with a cell size of $500 \mathrm{~m}$. The grid extended well beyond the Taranaki-Ruapehu Line study area so that all the seismic stations would have a velocity grid under them. The bottom left corner of the grid was situated at geographic coordinates -40.5, 173.5, and continues north and east some $300 \mathrm{~km}$, and to $75 \mathrm{~km}$ in depth. Both $\mathrm{P}$ and $\mathrm{S}$ velocity grids were generated.

2. Grid2Time calculates travel-times from each seismic station used for earthquake picking to each cell in the velocity grid. The output is saved as a 3D travel-time grid file, which can be directly queried for travel-times without having to access the velocity grid again. This program is purely for computational efficiency.

3. NLLoc uses Grid2Time gridfiles and SEISAN phase picks (select.out file) to generate probabilistic earthquake locations for each event. The Oct-Tree location technique was chosen due to its speed and simplicity. An explanation of how this technique works and the theory behind it can be found in Section 3.3.3. The output is a complete, probabilistic PDF solution to the earthquake location problem, as well as 'best fit' earthquake hypocentres.

Figure 3.9 shows the best fit earthquake hypocentres computed with NonLinLoc. The 3D distribution of hypocentres is similar to those from SEISAN's HYPOCENTER program (Figure 3.8). However, the 'downwarping' character of the deepest hypocentres is slightly more pronounced in NonLinLoc, even though the same velocity model is used. This might be due to differences in linear and non-linear earthquake location techniques. See Section 3.5.1 for a full explanation of the hypocentre locations from NonLinLoc.

\subsubsection{Focal mechanisms}

Focal mechanisms are calculated from $\mathrm{P}$-wave first motion polarities using the Bayesian approach of Walsh et al. [2009]. Of the 710 earthquakes located with 

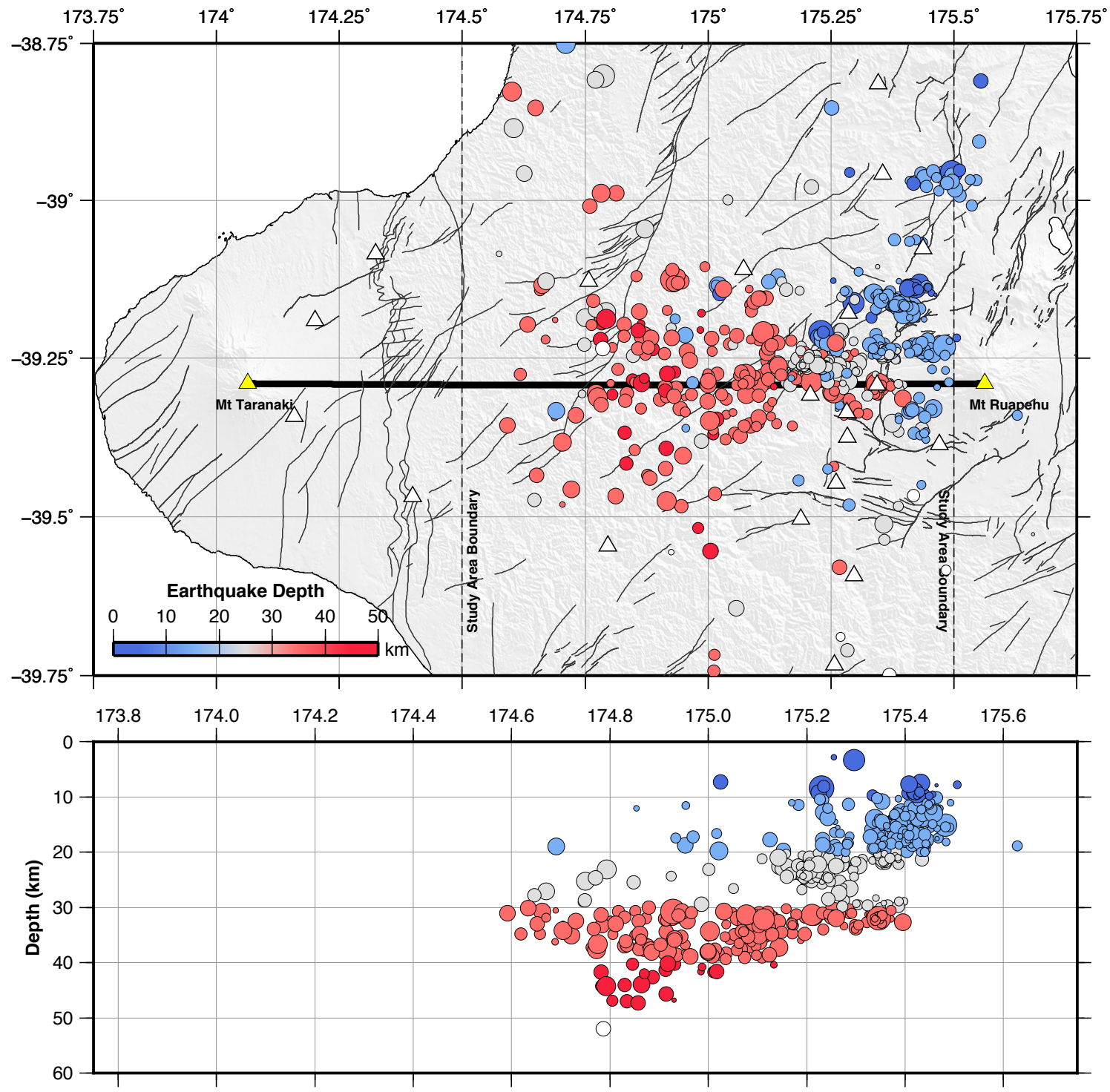

Figure 3.9: NonLinLoc earthquake locations. Shown are 710 earthquake hypocentres from SEISAN which have been relocated using NonLinLoc. Cross-section below is a swath of earthquakes from a line running between Mt. Taranaki and Mt. Ruapehu. Earthquake clusters are similar in character to the linear SEISAN locations, although the 'downwarp' of hypocentres becomes more pronounced with depth when compared to SEISAN linear locations (Figure 3.9). 
NonLinLoc in Section 3.4.4, 153 were used to calculate focal mechanism solutions. These earthquakes were used because at least 10 P-wave first motions could be identified on each earthquake, which Walsh et al. [2009] recommends as the minimum number likely to result in a 'sufficiently constrained' focal mechanism. The average number of first motions per earthquake was approximately 13 .

No attempt was made to discriminate between impulsive and emergent first motions in order to maximise first motions from the deepest earthquakes which often had an emergent character. Hardebeck and Shearer [2002], who looked at the consistency of impulsive and emergent first motions in the Northridge area in California, found that only about $10 \%$ of impulsive and $20 \%$ of emergent first motions are inconsistent after correcting for known station polarities. Assuming a similar level of uncertainty applies to Taranaki-Ruapehu Line first motions, this should not cause a significant problem, because the Walsh et al. [2009] method treats observational uncertainties probabilistically in order to account for polarity errors, assuming about $20 \%$ of all polarity picks are wrong.

The Walsh et al. [2009] method also incorporates NonLinLoc probabilistic 'earthquake cloud' locations when solving focal mechanisms (discussed in Section 3.4.4). This results in a range of possible raypaths to the hypocentre and receiver, and thus a range of possible take-off angles and azimuths in the focal sphere. The uncertainty in take-off angles and azimuths is used to calculate focal mechanism uncertainties, which are fully characterised by a Posterior Density Function (PDF). For simplicity, the PDF is simplified into a Matrix-Fisher distribution, and then into a standard deviation of strike/dip/rake focal mechanism parameters using Equation (3.9) from Arnold and Townend [2007].

\subsubsection{Stress inversion}

The Bayesian approach of Arnold and Townend [2007] is applied to estimate tectonic stress parameters from 153 focal mechanisms at the Taranaki-Ruapehu Line. The focal mechanism dataset is subdivided into $k$ clusters on the basis of each earthquake's location using a non-hierarchical clustering algorithm called 'kmeans'. This algorithm was chosen for its simplicity, and has been used for focal mechanism clustering in New Zealand previously [Townend et al., 2012]. In kmeans, each earthquake is closer to the centroid of the cluster which it belongs than to the centroid of other clusters. Kmeans clustering applied to data from this study is shown in 
(a)

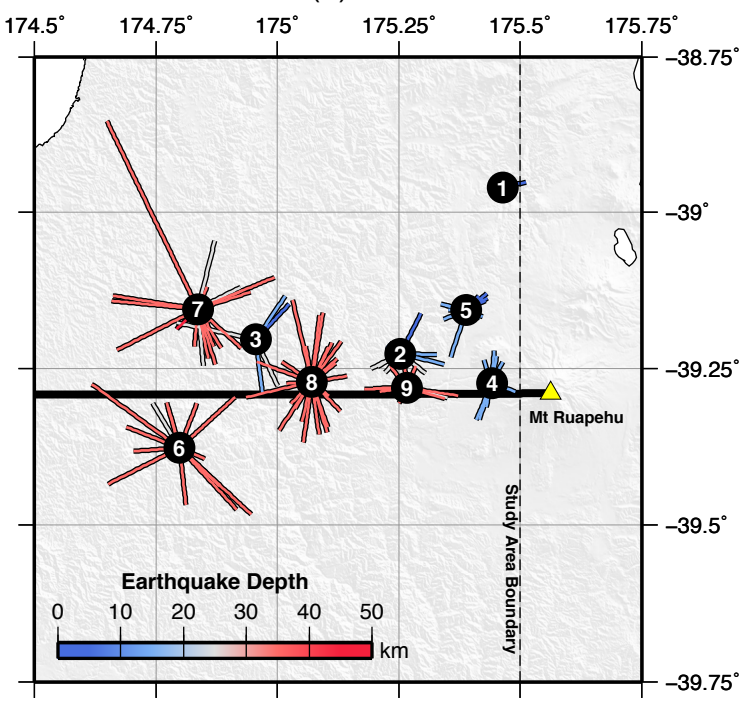

(b)

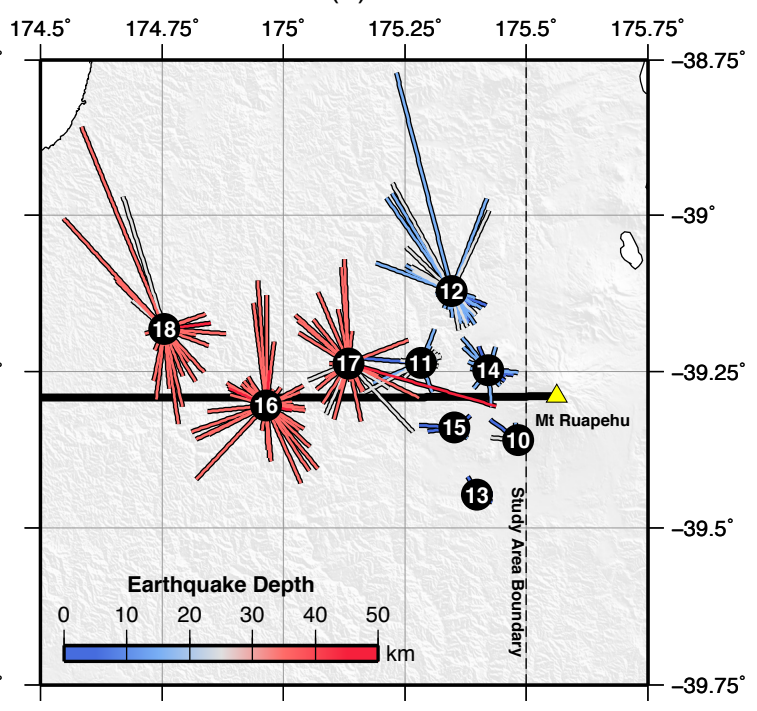

Figure 3.10: Kmeans clusters at the TR Line, (a) using focal mechanisms from this study, and (b) using focal mechanisms from Townend et al. [2012]. The number refers to a specific cluster of events used for stress inversions. (Stress inversion results are in Figure 3.14 and Figure 3.13.)

Figure 3.10. Each number represents a cluster, and the stress inversion from that cluster is shown in Figures 3.13 and 3.14.

\subsection{Results}

This section summarises key results from the microseismic study of the TaranakiRuapehu Line. First, nonlinear earthquake locations are interpreted to highlight areas of potential interest (Section 3.5.1). Focal mechanism solutions are used to determine the dominant fault type, and compared with the results from previous studies (Section 3.5.2). The principal stress directions calculated from focal mechanisms are also compared to previous studies, where the spatial distribution and temporal changes to the stress field are assessed (Section 3.5.3). Rose diagrams of the focal mechanism nodal planes are then constructed to interpret the overall orientation of fault planes (Section 3.5.4). Finally, the focal mechanisms are converted into moment tensors and used to quantify the strain-rates (Section 3.5.5).

\subsubsection{Earthquake distribution}

A total of 710 earthquake events at the Taranaki-Ruapehu Line were recorded by RATTIL and GeoNet stations between November 2012 and March 2014. Figure 3.11 


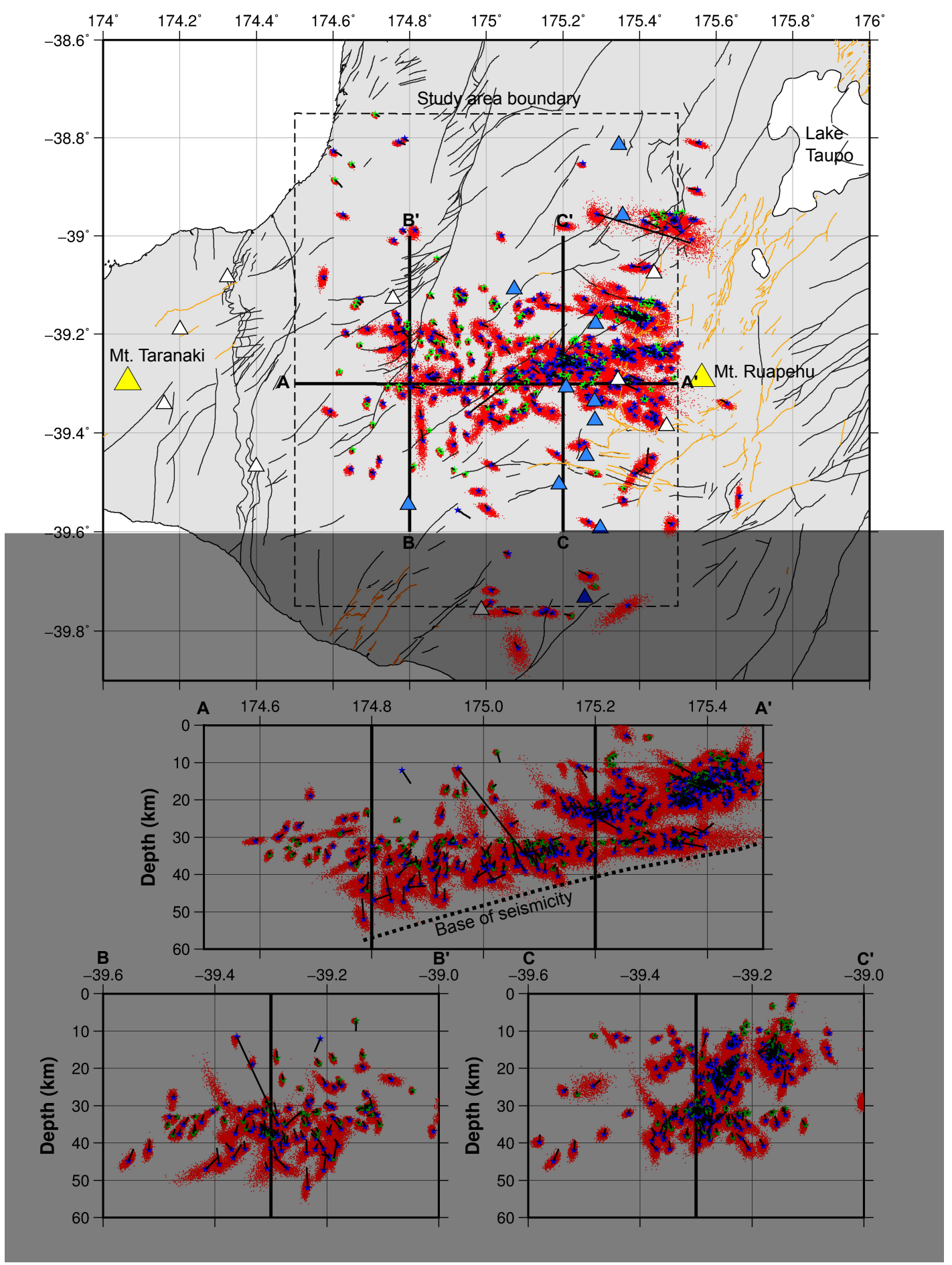

Figure 3.11: Probabilistic earthquake locations from NonLinLoc at the TR Line. Clouds of red points represent the Probability Density Function of an earthquake. The best fit hypocentre from each earthquake is shown as a star. Green stars are earthquakes which have been used for focal mechanism solutions, blue stars have not. Black lines show the difference between NonLinLoc's hypocentre location and that from SEISAN's HYPOCENTER program. Blue and white triangles show the locations of RATTIL and GeoNet seismic stations respectively. Profiles A-A', B-B' and C-C' represent swaths of earthquakes projected onto the profile from $20 \mathrm{~km}$ either side of the profile. 
shows the final location results, calculated using the probabilistic NonLinLoc location technique [Lomax et al., 2000]. The recorded earthquakes fall into two distinct 'groups'. The first group occurs as clusters of seismicity between $8-25 \mathrm{~km}$ depth immediately west of Mt. Ruapehu. The second group occurs between $30-50 \mathrm{~km}$ depth and follows the strike of the Taranaki-Ruapehu Line for about $100 \mathrm{~km}$. The second group appears to downwarp near longitude 174.8, where the deepest events increase from $30-40 \mathrm{~km}$ depth to $\sim 50 \mathrm{~km}$ depth.

Historical GeoNet catalog locations hint at the presence of a downwarp ('unusual deep seismicity ${ }^{6}$ in Figure 3.1), yet the overall earthquake pattern is diffuse, with mid/lower-crustal earthquakes that terminate at a sharp, and slightly curved boundary at $\sim 33 \mathrm{~km}$ depth (see 'base of seismicity' inFigure 3.1 ). This is suspicious for two reasons, the sharpness of the interface looks artificial, and the depth at which the interface occurs $(33 \mathrm{~km})$ is a known velocity boundary of the New Zealand Standard Velocity Model [Maunder, 2002]. It is likely that the GeoNet catalog sharp boundary is an artefact, and the true nature of the lower crust is better represented by the earthquake locations from this study. That is, earthquake hypocentres along the Taranaki-Ruapehu Line 'downwarp' to at least $50 \mathrm{~km}$ depth. This observed earthquake depth distribution is rare in continental settings [Maggi et al., 2000a,b; Jackson et al., 2008].

Two cross-sections that run normal to the Taranaki-Ruapehu Line are shown as B-B' and C-C' in Figure 3.11. C-C' is closer to the Mt. Ruapehu volcano at approximately the same location as the receiver function profile from Chapter 4. Here, the shallow and deep earthquake clusters are close together, and maximum earthquake density occurs at approximately the same depth and position as the crustal step (that is, $25-35 \mathrm{~km}$ deep). The earthquakes continue down to a maximum of just over $40 \mathrm{~km}$ depth. On the other hand, B-B' is closer to Mt. Taranaki and crosses the deepest earthquakes of the Taranaki-Ruapehu Line about $40 \mathrm{~km}$ west of the receiver function profile. There is little shallow seismicity on B-B' due to the distance from volcanic activity. However a large cluster of deep seismicity begins to form at about $30 \mathrm{~km}$ depth and continues down to at least $50 \mathrm{~km}$. First motion polarities from the deepest seismicity were difficult to pick.

\subsubsection{Focal mechanisms comparisons}

A total of 153 focal mechanism solutions were derived from 710 earthquake events detected by RATTIL and GeoNet stations at the Taranaki-Ruapehu Line (Fig- 
ure 3.12a). (A table of focal mechanism and moment tensor information is provided in Appendix B.) The focal mechanisms generally fall into one of two main groups of hypocentres discussed in Section 3.5.1: relatively 'shallow' seismicity near near Mt Ruapehu with depths of 8-25km, and a relatively 'deep' seismicity with depths greater than $30 \mathrm{~km}$. The focal mechanisms properties of these groups are analysed independently to see if their properties differ, and then are compared with an independent focal mechanism dataset calculated by Townend et al. [2012].

The shallow group ( $<25 \mathrm{~km}$-deep) contains 71 focal mechanisms, which generally fall into small clusters or 'swarms' of seismicity off the western flank of the Taupo Volcanic Zone. These clusters are well-known and presumed to be related to volcanic activity, with recent work suggesting they are sensitive to pore fluid pressure changes from volcanic eruptions [Keats et al., 2011]. The dominant fault type from the focal mechanism solutions include roughly equal numbers of strike-slip and normal faulting (Table 3.1a) with little evidence of reverse faulting. Visual inspection of the focal mechanism beach ball plot suggests that the tensional ' $\mathrm{T}$ ' axis is generally oriented in an north-south direction (Figure 3.12a).

The deep group (>25 km-deep) contains 82 focal mechanisms that are diffusely distributed in comparison to the clustered earthquakes of the shallow group. Visual inspection of the focal mechanism beach ball plots suggest that the tensional ' $\mathrm{T}$ ' axis is generally in a NW-SE direction, which is different to the north-south direction of the shallow group. The dominant fault type has a higher proportion of strike-slip faulting in comparison to normal faulting, with few reverse mechanisms. Due to these differences, the deeper group focal mechanisms are interpreted to be distinct from the shallow group focal mechanisms associated with volcanic activity near Mt Ruapehu.

Townend et al. [2012] generated a national catalog of 3483 focal mechanism solutions for all of New Zealand using GeoNet earthquake data from 2004-2011. This includes first motion data routinely picked by GeoNet duty seismologists, plus extra events picked using an automatic first-motion picker. Townend et al. [2012]'s focal mechanism solutions were also based on the Bayesian approach of Walsh et al. [2009], making their catalog an ideal comparison dataset. A total of 278 focal mechanisms match the extent of the TR Line study area (Figure $3.12 \mathrm{~b}$ ).

The dominant fault types are similar between this study and that of Townend et al. [2012] (compare Table 3.1a and b.) In both cases, the dominant fault type of the deeper mechanisms ( $>25 \mathrm{~km}$-deep) is biased towards strike-slip faults, whereas the shallower $(<25 \mathrm{~km}$-deep) mechanisms have roughly equivalent amounts of normal 
(a) Focal mechanisms from this study

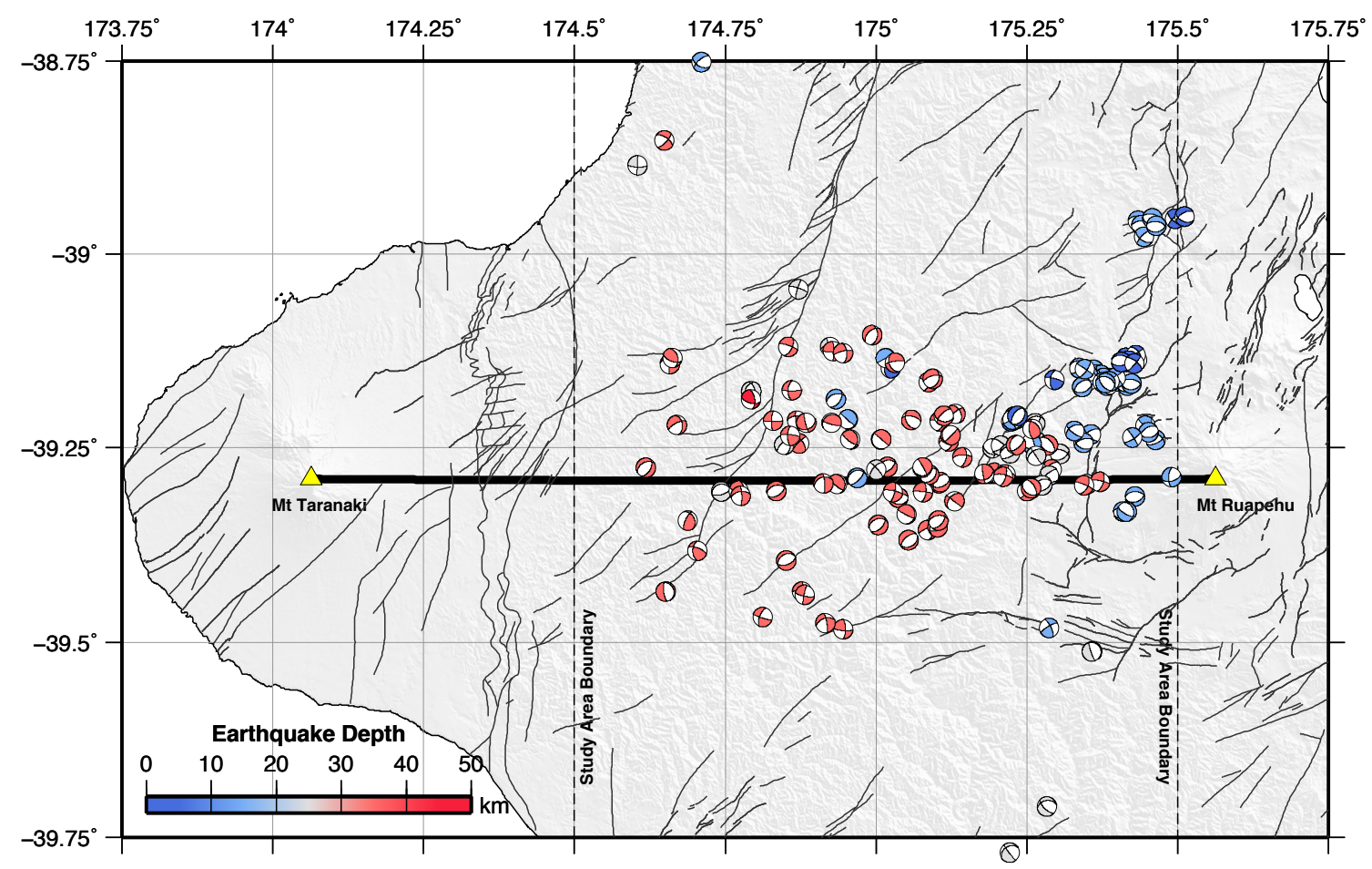

(b) Focal mechanisms extracted from Townend et al. (2012)

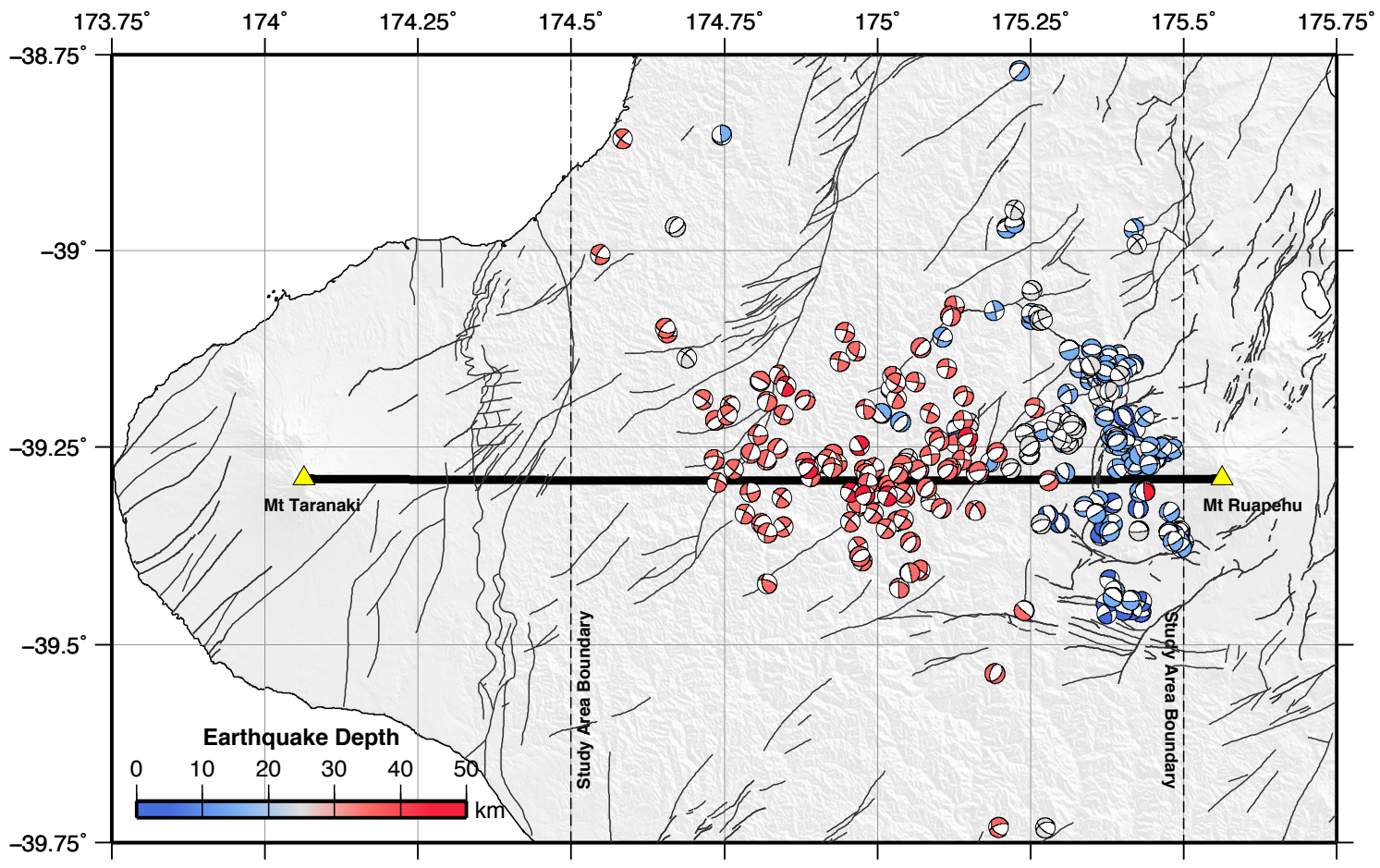

Figure 3.12: Focal Mechanisms at the TR Line, from (a) this study, and (b) the study of Townend et al. [2012]. Background faults are from QMAP [Townsend et al., 2008]. 
and strike-slip faulting. When the dominant fault type of all the focal mechanisms are considered together, the relative fault percentages are within only a few percent between studies. The $\mathrm{T}$ axes of the deep mechanisms are similarly aligned in both this study and the Townend et al. [2012] dataset. However, shallow focal mechanism $\mathrm{T}$ axes show considerably more variability in the Townend et al. [2012] study, even though the faulting type remains consistent between both sets of data.

Table 3.1: Taranaki-Ruapehu Line focal mechanisms grouped by approximate fault type. (a) Focal mechanisms from this study using GeoNet/RATTIL data, (b) Focal mechanisms from Townend et al. [2012]. 'Dominant' fault type refers to what ideal type of fault the focal mechanism is closest to. It is calculated from the rake value using the convention of Aki and Richards [1980], i.e. normal fault $\left(-45^{\circ}\right.$ to $\left.-135^{\circ}\right)$, reverse fault $\left(45^{\circ}\right.$ to $\left.135^{\circ}\right)$. Strike-slip contains both left-lateral dominant $\left(-45^{\circ}\right.$ to $0^{\circ}$ and $0^{\circ}$ to $\left.45^{\circ}\right)$ and right-lateral dominant $\left(-135^{\circ}\right.$ to $-180^{\circ}$ or $135^{\circ}$ to $\left.180^{\circ}\right)$ movements, since it is not possible to distinguish between left-lateral and right-lateral motion from focal mechanisms alone.

(a) Focal mechanisms from this study

\begin{tabular}{|l|ll|ll|ll|}
\hline Dominant & \multicolumn{2}{|c|}{ All FM } & \multicolumn{2}{|l|}{ FM <25 km-deep } & \multicolumn{2}{l|}{ FM >25 km-deep } \\
Fault Type & [count] & [\%] & [count] & [\%] & [count] & [\%] \\
\hline Strike-slip & 81 & 53 & 35 & 49 & 46 & 57 \\
Normal & 66 & 43 & 35 & 49 & 31 & 38 \\
Reverse & 6 & 4 & 1 & 1 & 5 & 6 \\
\hline total & 153 & & 71 & & 82 & \\
\hline
\end{tabular}

(b) Focal Mechanisms from Townend et al. [2012]

\begin{tabular}{|l|ll|ll|ll|}
\hline Dominant & \multicolumn{2}{|c|}{ All FM } & \multicolumn{2}{|l|}{ FM <25 km-deep } & \multicolumn{2}{|l|}{ FM >25 km-deep } \\
Fault Type & [count] & [\%] & [count] & [\%] & [count] & [\%] \\
\hline Strike-slip & 153 & 55 & 81 & 49 & 72 & 64 \\
Normal & 110 & 40 & 77 & 47 & 33 & 29 \\
Reverse & 15 & 5 & 7 & 4 & 8 & 7 \\
\hline total & 278 & & 165 & & 113 & \\
\hline
\end{tabular}

\subsubsection{Stress direction comparisons}

Maximum horizontal compressive stress directions were inverted from 18 focal mechanism clusters near the Taranaki-Ruapehu Line (Figure 3.13). The nine directions in red use focal mechanisms from this study, and the nine directions in blue use focal mechanisms from Townend et al. [2012]. These stress directions were calculated using the Bayesian approach of Arnold and Townend [2007] which is discussed in 
Section 3.3.5. Each stress direction is represented by a bow-tie symbol which broadly points in the direction of the maximum horizontal compressive stress. The bow-tie width relates to the uncertainty of the stress estimate, specifically the $80 \%$ confidence interval. Also included are petroleum borehole measurements (black bowties) and stress inversions from previous studies (purple bowties), whose uncertainty is assumed to be $\pm 10^{\circ}$ for the purpose of illustration, although their true uncertainty is unknown. The number in the middle of the red and blue bowties uniquely identifies that stress inversion, and the full Bayesian solution is shown in Figure 3.14.

Three key observations from Figure 3.13 are given below:

1. Half-way between Mt. Taranaki and Mt Ruapehu, red clusters 3, 6, 7 and 8, blue clusters 16, 17 and 18, and 'Taranaki East' stress inversion from Sherburn et al. [2006] all have a NE-SW maximum compressive stress direction. These clusters represent the deepest earthquakes of the Taranaki-Ruapehu Line and are far from volcanic processes.

2. Near Mt. Ruapehu, red clusters 1, 2, 4, 5, 9, blue clusters 10, 11, 12, 13, 14, 15 and the stress inversions of Waiouri [Hayes et al., 2004], National Park [Hurst and McGinty, 1999], and Ruapehu [Gerst and Savage, 2004] have significantly different orientations. These clusters represent the relatively shallow seismicity near Mt. Ruapehu caused by volcanic processes.

3. Petroleum borehole stress measurements are situated far from calculated stress estimates using focal mechanisms, so they must be interpreted with caution. The three most northern measurements broadly align with the 'Taranaki West' focal mechanism direction of [Sherburn et al., 2006]. The most southern measurement appears to be aligned with the deep seismicity of the TaranakiRuapehu Line.

\subsubsection{Fault plane orientations from focal mechanisms}

The Arnold and Townend [2007] stress inversion technique assumes randomly-oriented faults. When this criteria is not satisfied, the uncertainty associated with principal stress directions is high. For example, McKenzie [1969] showed that for a single fault plane with a known slip direction, the maximum principal stress axis can lie anywhere in a quadrant of the focal sphere, and therefore a single focal mechanism provides a poor constraint on stress directions. This situation is not improved if many earthquakes with similar focal mechanisms and slip directions are considered 
(a) Max horizontal compressive stress directions based on focal mechanisms from this study (red bowties, 2013-2014)

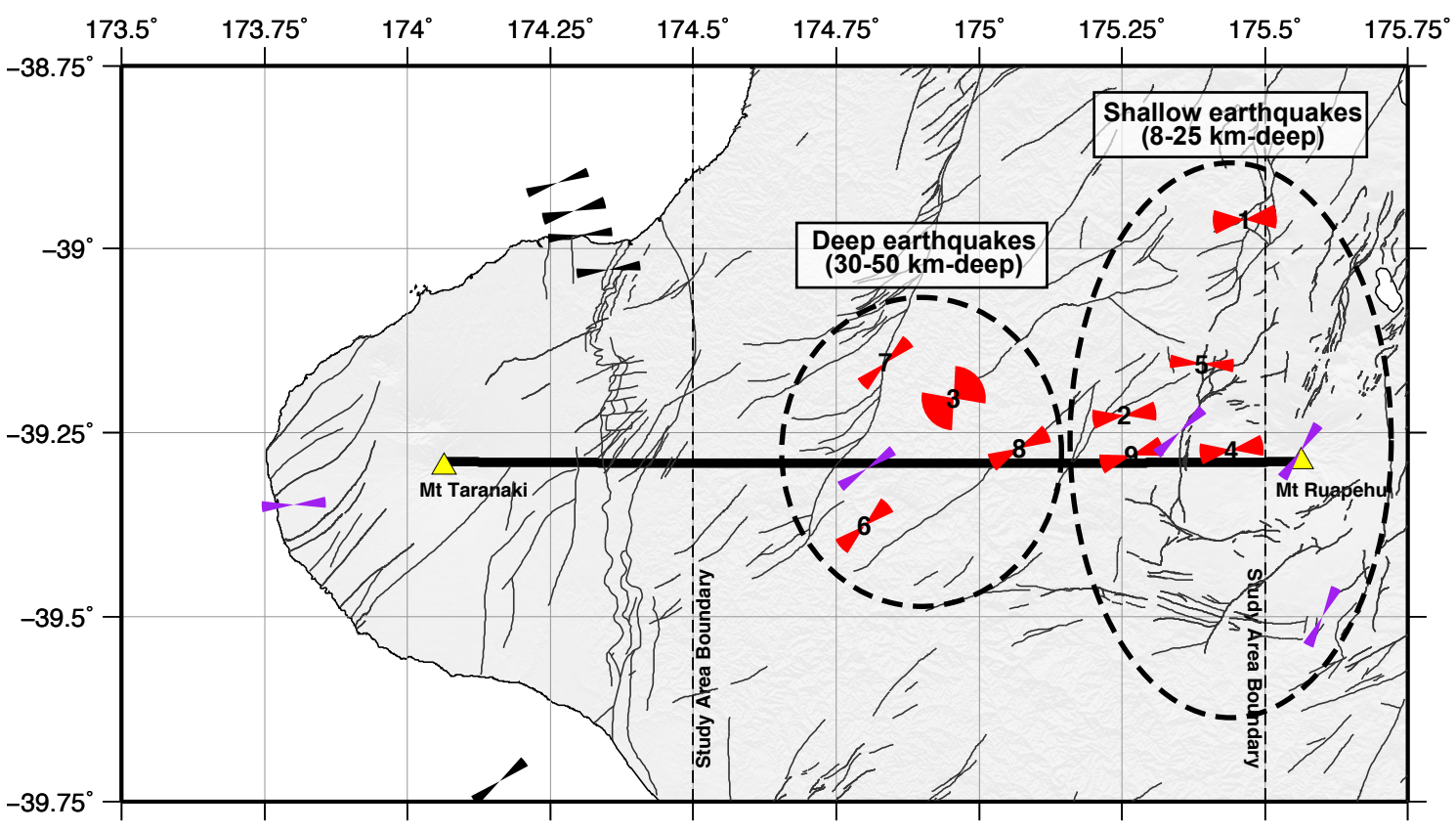

(b) Max horizontal compressive stress directions based on focal mechanisms from Townend et al. (2012) (blue bowties, 2004-2011)

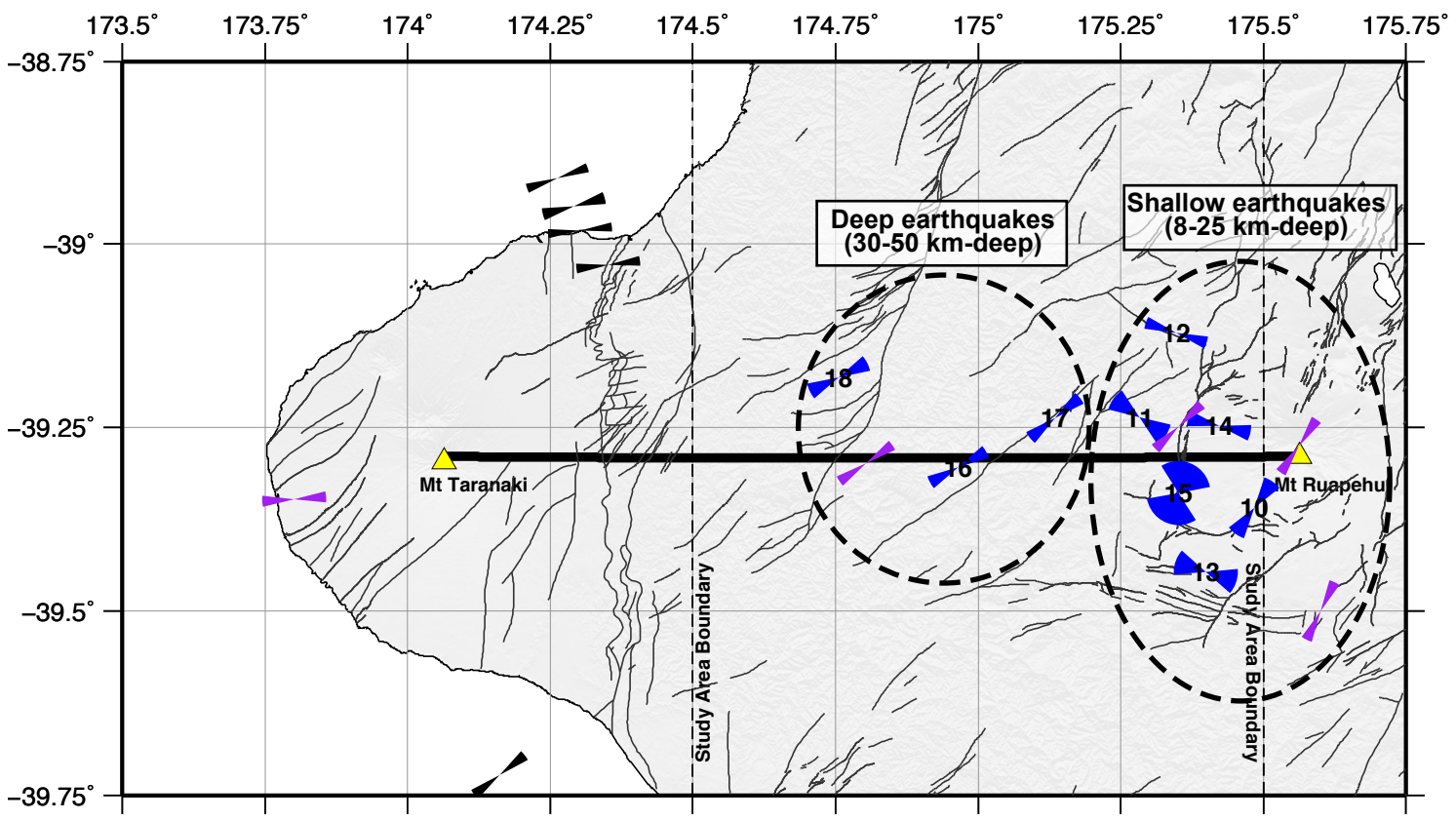

Figure 3.13: Map showing maximum horizontal compressive stress directions at the Taranaki-Ruapehu Line, based on (a) Bayesian stress inversion from this study (red bowties); (b) Bayesian stress inversion using focal mechanisms from Townend et al. [2012] (blue bowties). Bowties represent the direction and uncertainty of the maximum compressive stress. Black bowties are borehole measurements from petroleum wells [Horan, 1997; Mildren et al., 2001; Mildren and Meyer, 2005]. Purple bowties are other published stress directions derived from focal mechanism inversions as shown in Figure 3.2 and references therein. Numbers in the middle of the bowties uniquely identify the stress inversion cluster in this study. Background faults are from QMAP [Townsend et al., 2008]. Note how the red, blue and purple bowties show less agreement closer to Mt. Ruapehu. 

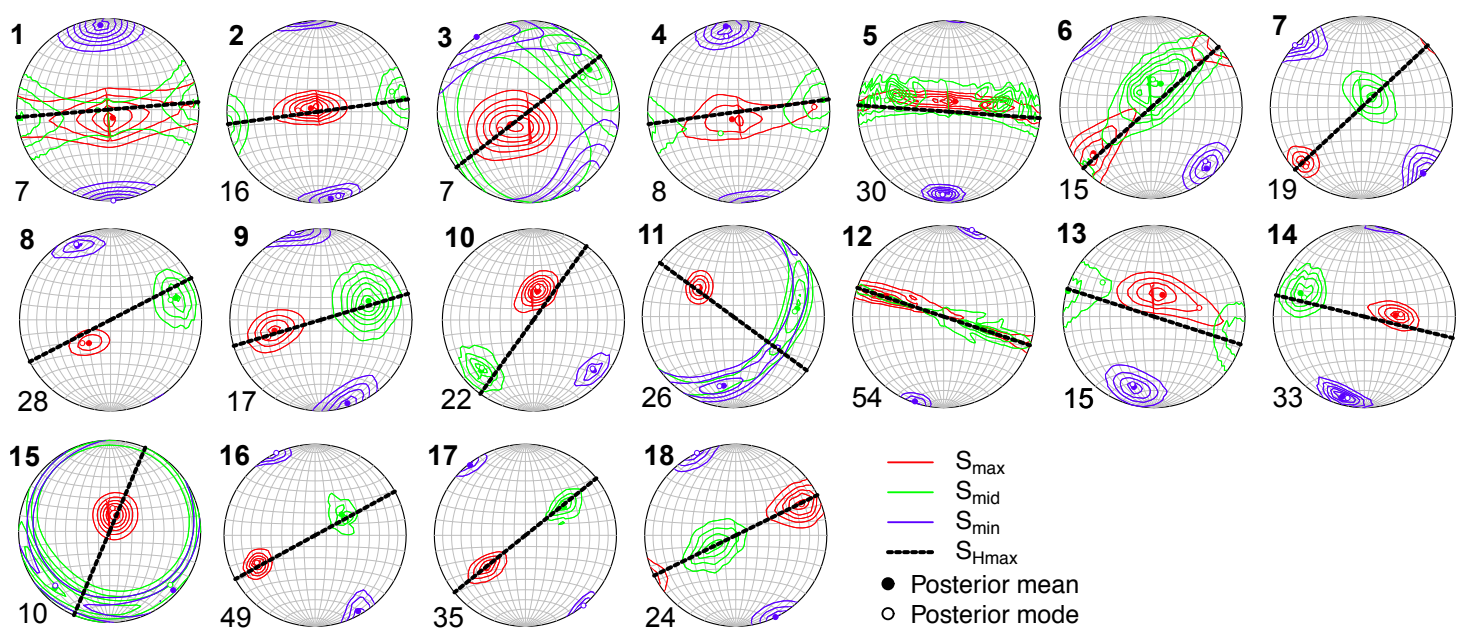

Figure 3.14: Principal stress posterior probability densities at the TR Line relating to the clusters in Figure 3.10. The cluster number is at the top left. The number of focal mechanisms used in the inversion is at the bottom left. The dark lines represent the maximum horizontal compressive stress direction.

(a) Earthquakes $<25 \mathrm{~km}$ depth NORTH

WEST

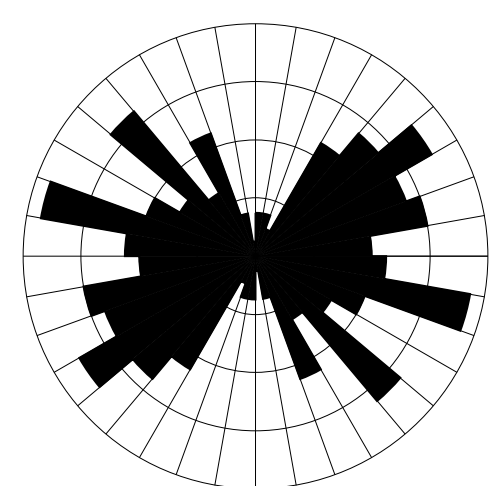

SOUTH (b) Earthquakes $>25 \mathrm{~km}$ depth NORTH
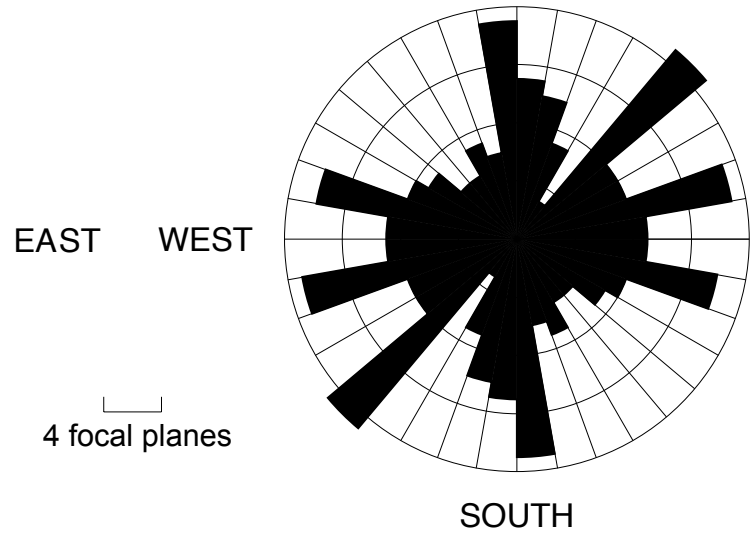

EAST

Figure 3.15: Rose diagram of focal plane orientations at the Taranaki-Ruapehu Line. (a) 'Shallow' earthquakes near Mt. Ruapehu, and (b) 'deep' earthquakes associated with the earthquake downwarp. For both shallow and deep earthquakes, there is a wide distribution of nodal planes over a range of azimuths. This is a requirement for a reliable stress inversion from a region with pre-existing faults [McKenzie, 1969].

since they bring no new information to the inversion. In this section the TaranakiRuapehu Line focal mechanism dataset is tested to see if it is randomly distributed, or if there is a bias in fault directions.

Randomly-oriented faults should have a random distribution of strike planes. To test for randomness in the Taranaki-Ruapehu Line focal mechanisms, rose diagrams of the two nodal plane strikes of all 153 focal mechanisms are calculated in Section 3.4.5; 
a total of 306 nodal planes. If the faults are randomly distributed, the nodal planes should be evenly distributed at all azimuths.

The 306 nodal planes of the full Taranaki-Ruapehu Line focal mechanism dataset have been split into two groups, representing $<25 \mathrm{~km}$ deep 'shallow' seismicity and $>25 \mathrm{~km}$ depth 'deep' seismicity (Figure 3.15 ), which correspond with the two groups of seismicity defined in Section 3.5.1.

Although the shallower nodal planes show some east-west symmetry Figure 3.15 (left), there is a wide distribution of focal planes for both shallow and deep earthquake groups. Consequently, the stress inversions using the Arnold and Townend [2007] method is likely to give a reliable stress estimate in the context of pre-existing faults.

\subsubsection{Moment tensor summation and strain-rate}

Seismic moment tensor solutions were calculated for each of the 153 focal mechanism recorded at the Taranaki-Ruapehu Line. Equation (3.14) was solved using the strike, dip, and rake values from each focal mechanism. Every moment tensor has been scaled using the earthquake's moment magnitude $\left(M_{0}\right)$ which was derived from the local earthquake magnitude $\left(M_{L}\right)$ of the GeoNet rapid catalog. (The process of converting $M_{L}$ to $M_{0}$ was explained in Section 3.3.6.) The GeoNet local magnitude values have not been assessed for accuracy. The full set of moment tensor component magnitudes $M_{i j}$ normalised by $M_{0}$ is tabled in Appendix B.

The moment tensor solutions were then split into two groups; those occurring within relatively shallow clustered seismicity near Mt. Ruapehu $(8-25 \mathrm{~km})$, and the deep diffuse seismicity which underlies it $(25-40 \mathrm{~km})$. The shallow and deep moment tensor groups were used to calculate strain-rates following the method of Kostrov [1974]. In this method, the moment tensors of each earthquake in a group are first summed, then multiplied with the shear modulus $\mu$, seismogenic volume $V$ and duration $t$ (as per Equation (3.16)) to give strain-rates. The key parameters are defined as follows:

1. For $\mu$ : Most Taranaki-Ruapehu Line earthquakes occur in the middle and lower crust and perhaps even the upper mantle, though for simplicity all earthquakes are assumed to be from the lower crust. A shear modulus $\mu$ of $3 \times 10^{10} \mathrm{~N} \mathrm{~m}^{2}$ is assumed for the lower crust based on the 'basalt' rock property from Turcotte and Schubert [1982], which should be a fair approximation 
of the composition of the lower crust as it becomes more mafic. An upper mantle shear modulus would be about twice as large, $6.3 \times 10^{10} \mathrm{~N} \mathrm{~m}^{2}$ according to Turcotte and Schubert [1982], thus a strain-rate estimate from the upper mantle would be about half as much as for the lower crust, but still within the same order of magnitude.

2. For $V$ : Rectangular volumes for the shallow and deep earthquake groups were estimated by interpreting Figure 3.11. The volume of the shallow seismicity is approximately $2.5 \times 10^{13} \mathrm{~m}^{3}$, representing a horizontal cross-section bound by coordinates -39.1 and -39.5 latitude, 174.6 and 175.5 longitude, between depths of 8 and $25 \mathrm{~km}$. The deep earthquakes are estimated to occur within a volume of $5.2 \times 10^{13} \mathrm{~m}^{3}$, bounded by coordinates -38.9 and -39.4 latitude, 175.2 and 175.5 longitude, between depths of 25 and $40 \mathrm{~km}$.

3. For $t$ : Moment tensors were calculated for earthquakes between November 2012 and March 2014, representing about 1.33 years, which is about $4.2 \times 10^{7}$ seconds.

The summed seismic strain-rate tensor components [Kostrov, 1974] are shown in Table 3.2. The highest strain-rates are in the order of $10^{-17} \mathrm{~s}^{-1}$ for both the shallow (8-25 km-deep) and deep (17-40 km-deep) earthquakes. These strain rates are calculated over a 16-month period, as such they are likely to be underestimated due to a lack of high magnitude events which might occur outside the time range of this study. The eigenvalues and eigenvectors of the two strain-rate tensors were also calculated (Tables 3.3 and 3.4). The three eigenvalues $\dot{\epsilon}_{1}, \dot{\epsilon}_{2}$, and $\dot{\epsilon}_{3}$ correspond to the maximum compression (-), intermediate, and maximum extension $(+)$ rates respectively [Lorinczi and Houseman, 2009].

Table 3.2: Seismic strain-rate tensor components for shallow $(8-25 \mathrm{~km})$ and deep (25-40 km) earthquakes at the Taranaki-Ruapehu Line. The AR cartesian coordinate system of Aki and Richards [1980] is used, such that the x-axis is north, y-axis is east and z-axis is downwards.

\begin{tabular}{|c|l|c|c|c|c|c|}
\hline $\begin{array}{c}\text { Depth } \\
{[\mathrm{km}]}\end{array}$ & $\begin{array}{c}\epsilon_{\mathrm{xx}} \\
{\left[10^{-17} \mathrm{~s}^{-1}\right]}\end{array}$ & $\begin{array}{c}\epsilon_{\mathrm{xy}} \\
{\left[10^{-17} \mathrm{~s}^{-1}\right]}\end{array}$ & $\begin{array}{c}\epsilon_{\mathrm{xz}} \\
{\left[10^{-17} \mathrm{~s}^{-1}\right]}\end{array}$ & $\begin{array}{c}\epsilon_{\mathrm{yy}} \\
{\left[10^{-17} \mathrm{~s}^{-1}\right]}\end{array}$ & $\begin{array}{c}\epsilon_{\mathrm{yz}} \\
{\left[10^{-17} \mathrm{~s}^{-1}\right]}\end{array}$ & $\begin{array}{c}\epsilon_{\mathrm{zz}} \\
{\left[10^{-17} \mathrm{~s}^{-1}\right]}\end{array}$ \\
\hline $8-25$ & 0.3403 & -0.0902 & -0.0935 & -0.0750 & -0.0896 & -0.2653 \\
$25-40$ & 0.0506 & -0.2549 & 0.0407 & 0.0216 & 0.0471 & -0.0722 \\
\hline
\end{tabular}


Table 3.3: Eigenvalues corresponding to the two strain-rate tensors in Table 3.2. The eigenvalues give principal strain-rates, such that $\dot{\epsilon}_{1}<\dot{\epsilon}_{2}<\dot{\epsilon}_{3}$.

\begin{tabular}{|c|c|c|c|}
\hline $\begin{array}{c}\text { Depth } \\
{[\mathrm{km}]}\end{array}$ & $\begin{array}{c}\dot{\epsilon}_{1} \\
{\left[10^{-17} \mathrm{~s}^{-1}\right]}\end{array}$ & $\begin{array}{c}\dot{\epsilon}_{2} \\
{\left[10^{-17} \mathrm{~s}^{-1}\right]}\end{array}$ & $\begin{array}{c}\dot{\epsilon}_{3} \\
{\left[10^{-17} \mathrm{~s}^{-1}\right]}\end{array}$ \\
\hline $8-25$ & -0.3229 & -0.0450 & 0.3679 \\
$25-40$ & -0.2420 & -0.0494 & 0.2914 \\
\hline
\end{tabular}

Table 3.4: Eigenvectors corresponding to the eigenvalues in Table 3.3.

\begin{tabular}{|l|ccc|ccc|ccc|}
\hline $\begin{array}{c}\text { Depth } \\
{[\mathrm{km}]}\end{array}$ & $\mathrm{N}$ & $\dot{\epsilon}_{1}$ & \multicolumn{3}{|c|}{$\dot{\epsilon}_{2}$} & \multicolumn{3}{c|}{$\dot{\epsilon}_{3}$} \\
\hline $8-25$ & 0.1805 & 0.3917 & 0.9022 & 0.1109 & 0.9033 & -0.4144 & 0.9773 & -0.1749 & -0.1196 \\
$25-40$ & 0.6435 & 0.6838 & -0.3439 & 0.2417 & 0.2448 & 0.9390 & -0.7262 & 0.6874 & 0.0078 \\
\hline
\end{tabular}

\subsection{Discussion}

In previous sections, the location and kinematics of earthquakes along the TaranakiRuapehu Line were successfully constrained using new data from a network of temporary seismometers. Known earthquakes were re-picked and re-located using linear and non-linear earthquake location techniques to provide reliable locations. Focal mechanisms were calculated for the clearest events, and the dominant types of faulting were determined. Stress inversions and strain-rates calculations provide new information about the properties of rocks in the crust adjacent to Mt. Ruapehu, and at the base of the Taranaki-Ruapehu Line. The most significant new contribution is the observation of a 'downwarp' of earthquake hypocentres at depths of 30-50 km. These constraints are critical to any future studies which attempt to model the geological mechanisms responsible for the Taranaki-Ruapehu Line.

The following discussion explores key findings from the results section. Note that 'shallow' seismicity refers to all earthquakes ( $<25 \mathrm{~km}$-deep), and typically forms in swarms immediately west of Mt. Ruapehu and Taupo Volcanic Zone. 'Deep' seismicity refers to earthquakes $>25 \mathrm{~km}$-deep, which are diffusely distributed along the Taranaki-Ruapehu Line at the base of the crust and/or upper mantle. 

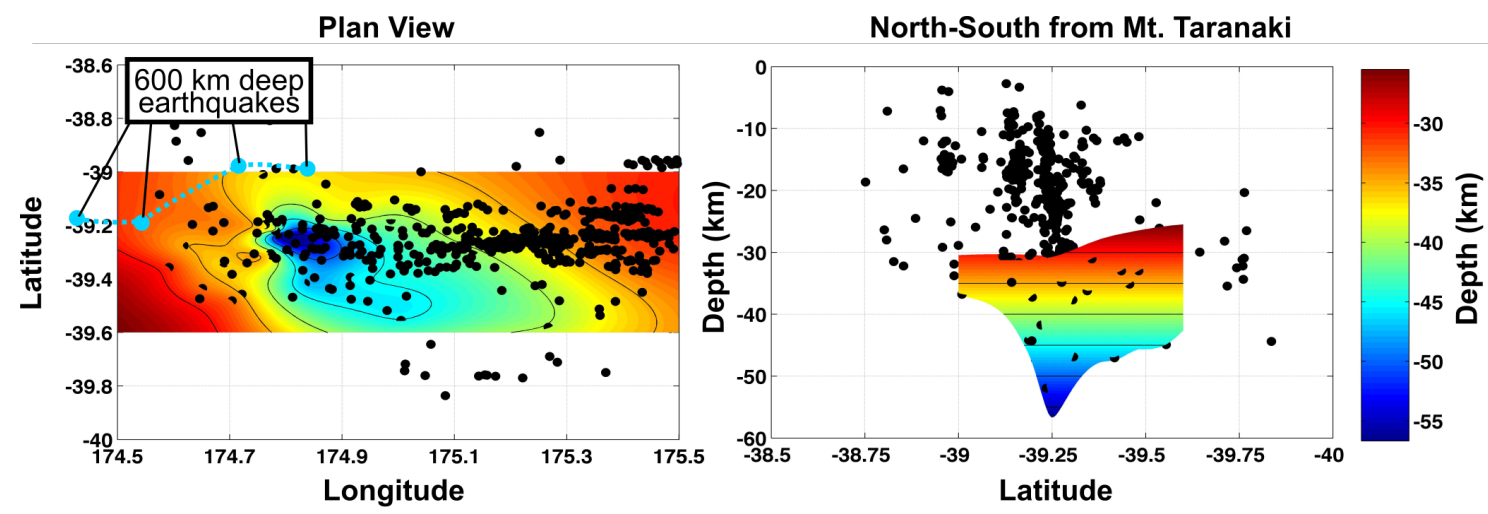

3D View

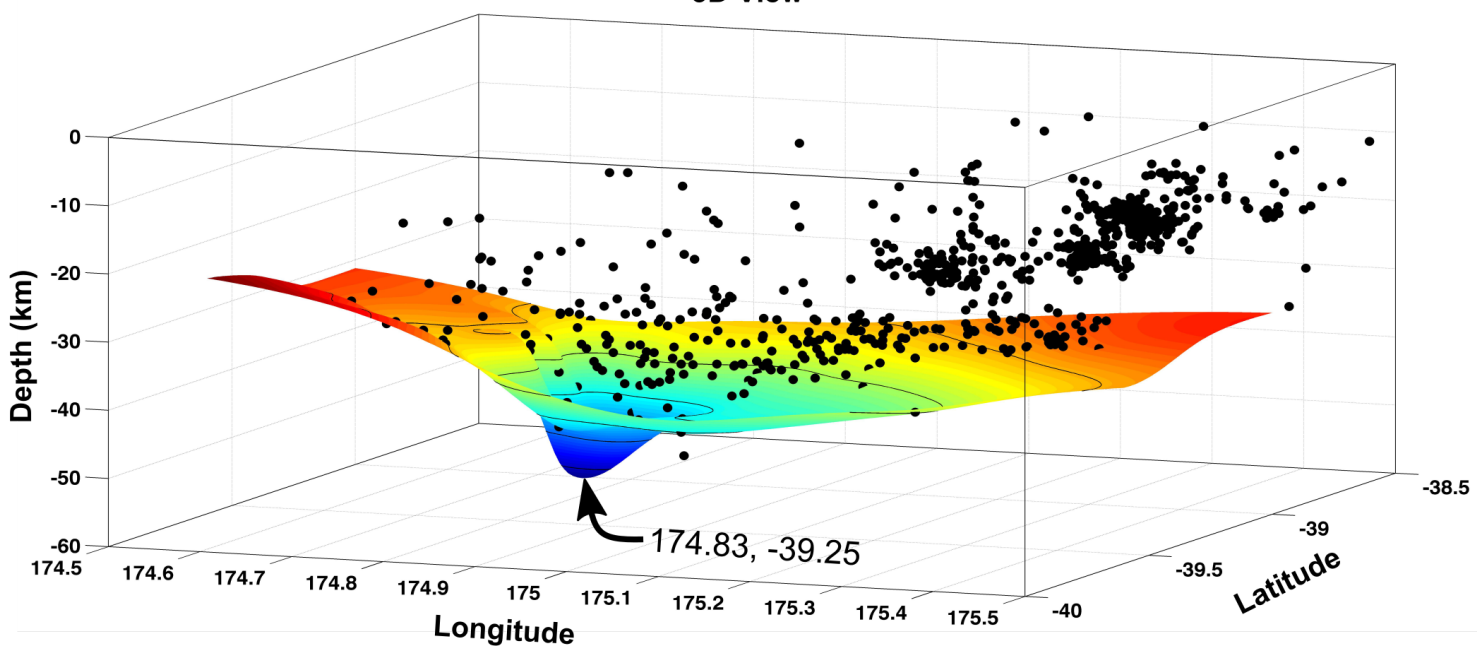

Figure 3.16: 3D view of a 'seismic downwarp' in Taranaki-Ruapehu Line seismicity. Coloured surface is an 'envelope' of the base of the deep seismicity, which helps visualise its structure. Black dots are earthquake hypocentres from Section 3.5.1. Blue dots in the top-left panel are $\sim 600 \mathrm{~km}$ deep earthquakes from Boddington et al. [2004]. 


\subsubsection{Analysis of downwarped earthquake hypocentres}

Deep seismicity at the base of the Taranaki-Ruapehu Line has a distinctive downwarp centred near longitude 174.8 (Figures 3.9 and 3.11). To further aid in visualising the geometry of this feature, a 3D surface was fit to 29 earthquake hypocentres which were manually selected from the base of the deep seismicity from Figure 3.11. The surface was created with Matlab's GRIDDATA function using the biharmonic spline interpolation method. Figure 3.16 shows this surface along with the distribution of seismicity at the Taranaki-Ruapehu Line.

The surface contains a local depression centred at longitude 174.83 latitude -39.25, at about $56 \mathrm{~km}$ depth; the earthquake downwarp. However, earthquake locations is based on an initial catalog of events which exclude earthquakes deeper than $50 \mathrm{~km}$ depth in order to avoid subduction zone effects (Section 3.4.2). It is therefore possible that earthquakes deeper than $56 \mathrm{~km}$ exist. But how deep can these events go?

Boddington et al. [2004] relocated six $600 \mathrm{~km}$-deep earthquakes in the vicinity of the Taranaki-Ruapehu Line earthquake downwarp. These events occurred between 1991 and 1998 and were recorded by temporary deployments. Four of these earthquakes are shown as blue dots in the top-left panel of Figure 3.16. (The remaining two earthquakes are further west.) The proximity of the $600 \mathrm{~km}$-deep earthquakes to the Taranaki-Ruapehu Line seismic downwarp raises the possibility that these two features are connected. If this is true, it would represent a $600 \mathrm{~km}-\mathrm{long}$, nearly vertical slither of material that is almost certainly interacting with the subducting Pacific plate. A 'kink' in Benioff zone seismicity at about $200 \mathrm{~km}$ depth is shown in Figure 1.3. This kink is directly down dip on the plate from the deep seismic downwarp. It's possible that the kink forms in response to the weight of a slither, such as that proposed by Stern et al. [2013], but this idea will not be investigated further in this thesis.

\subsubsection{Variation of focal mechanisms with depth}

The Taranaki-Ruapehu Line, as the name suggests, runs between and beneath the Mt. Taranaki and Mt. Ruapehu volcanos, so that the Line runs east of Mt. Taranaki and west of Mt. Ruapehu. Reyners [1980] observed a change in focal mechanisms with depth west of Mt. Ruapehu, however when Sherburn et al. [2006] looked for evidence of focal mechanism changes east of Mt. Taranaki they did not find any- 
thing conclusive. The new focal mechanism results resolve what initially appeared to be two conflicting observations. In agreement with Reyners [1980], changes in focal mechanisms with depth are observed west of Mt. Ruapehu, and these changes are associated with two separate groups of seismicity, one on top of the other. The shallow group only extends about $30 \mathrm{~km}$ west from Mt. Ruapehu, while the deeper group continues about $100 \mathrm{~km}$ west of Mt. Ruapehu, which is about two-thirds of the way to Mt. Taranaki. Thus, the seismic network from Sherburn et al. [2006] was too far west to observe the shallow focal mechanisms near Mt. Ruapehu, and that is why they did not record the change of focal mechanisms with depth that Reyners [1980] observed.

\subsubsection{Inconsistent stress directions near Mt. Ruapehu}

Stress directions from this study, the study of Townend et al. [2012], Waiouri [Hayes et al., 2004], National Park [Hurst and McGinty, 1999], and Ruapehu [Darby and Meertens, 1995] have different orientations near Mt. Ruapehu (Figure 3.13). Temporal and spatial variations in seismic anisotropy attributed to stress are also observed in shear-wave splitting results [Miller and Savage, 2001; Johnson et al., 2011; Keats et al., 2011], suggesting that the shear-wave splitting measurements and focalmechanism-derived stress directions may be related.

One possibility is that the differences in stress directions could be caused by temporal changes in the stress field due to the migration of volcanic fluids from Mt. Ruapehu. This idea was proposed by Keats et al. [2011] following a shear-wave splitting study of the Erua swarm, which sits immediately west of Mt. Ruapehu. Stress directions derived from focal mechanisms near Mt. Ruapehu span about 20 years, with no two studies using earthquakes form the same time period. From oldest to newest: 1994-1995 [Hurst and McGinty, 1999], 2001 [Hayes et al., 2004], 20042011 [Townend et al., 2012], 2012-2014 (this study). The stresses between studies vary so much because the stress field itself has changed between those studies. 


\section{Chapter 4}

\section{Receiver function study}

\subsection{Abstract}

Receiver function analysis provides new constraints on crustal structure across the Taranaki-Ruapehu Line. North of the Line, a strong, flat $P s$ conversion at $\sim 28 \mathrm{~km}$ depth is interpreted as the Moho. South of the Line, the Ps conversion becomes $\sim 35 \mathrm{~km}$-deep before it weakens and disappears. At the Line, an apparent Moho offset of $7-10 \mathrm{~km}$ is visible in a Common Conversion Point (CCP) stack. The true dip of the apparent offset was tested by comparing real and synthetic CCP stacks. The synthetic earth models which most closely resembled the field data suggest a dip of $20-50^{\circ}$. Directly beneath the dipping Moho, earthquake swaths projected onto the CCP stack reveal the presence of mantle earthquakes.

\subsection{Previous work and study context}

This chapter builds on the groundwork laid by Michelle Salmon [Salmon, 2008; Salmon et al., 2011], who undertook a geophysical investigation of the western North Island of New Zealand using receiver function, magnetotelluric, and seismic attenuation techniques (Figure 4.1 ). The key finding was a $\sim 7 \mathrm{~km}$ change in crustal thickness at the Taranaki-Ruapehu Line. Specifically, a receiver function CCP stack reveals a step-like change in the Moho between TRAP stations ERU and RAE (Figure 4.2). Meanwhile, the mantle south of the step shows lateral variations in resistivity and temperature (Figure 4.3). 
The true geometry of the Moho at the Taranaki-Ruapehu Line remains unconstrained. Salmon et al. [2011] argues that the CCP stack shows a nearly vertical Moho offset, but due to Fresnel zone considerations the true dip could be anywhere between $45-90^{\circ}$. Accurately constraining the Moho geometry is important because the Taranaki-Ruapehu line is not associated with any mapped faulting or strike-slip zones [Townsend et al., 2008]. The Moho geometry might thus hold clues to the origin of unconventional back-arc phenomenon. For example, the Taranaki-Ruapehu Line is proposed to be the active front of a Rayleigh-Taylor-type instability [Stern et al., 2006, 2013]. A structural constraint such as the Moho dip can help refine numerical models. If the Taranaki-Ruapehu Line is not a dynamic feature, then the geometry of the Moho might show the structure of a residual geological feature whose surface expression has long eroded away. Finally, there is some evidence for mantle seismicity just beneath the Moho at the Taranaki-Ruapehu Line [Figure 4.2, Salmon et al., 2011]. Mantle earthquakes are rare and poorly understood [McKenzie et al., 2005]. A detailed Moho structure combined with reliable earthquake hypocentres from Section 3.5.1 may provide new insights.

Salmon [2008] deployed seven short-period (1 Hz) seismometers between 2001-2002 for up to 10 months with a station spacing of approximately $20 \mathrm{~km}$ (Figure 4.1). This deployment is called the Taranaki-Ruapehu Attenuation Profile (TRAP). TRAP recorded a total of 67 teleseismic events and 12 regional events that were used for receiver function analysis. The station coverage is poor over the Moho step and to the north. Some stations recorded more events than others. Deploying more stations to infill the TRAP array was recommended (Michelle Salmon, personal communication, 2012).

In this study, a new receiver function CCP stack is constructed across the TaranakiRuapehu Line. TRAP stations from Figure 4.1 are infilled with eight additional seismic stations. This second deployment is called the Ruapehu And Taranaki Teleseismic Imaging Line (RATTIL, Chapter 2), and when combined with TRAP reduces the average station spacing from $\sim 20 \mathrm{~km}$ to $\sim 5 \mathrm{~km}$. This is a comparable receiver density to the Marlborough Fault Zone receiver function study of Wilson et al. [2004], who compared their calculated CCP stack with synthetic CCP stacks to help with interpretation. In this study synthetic CCP stacks will also be calculated to help constrain the Moho structure of the Taranaki-Ruapehu Line. 


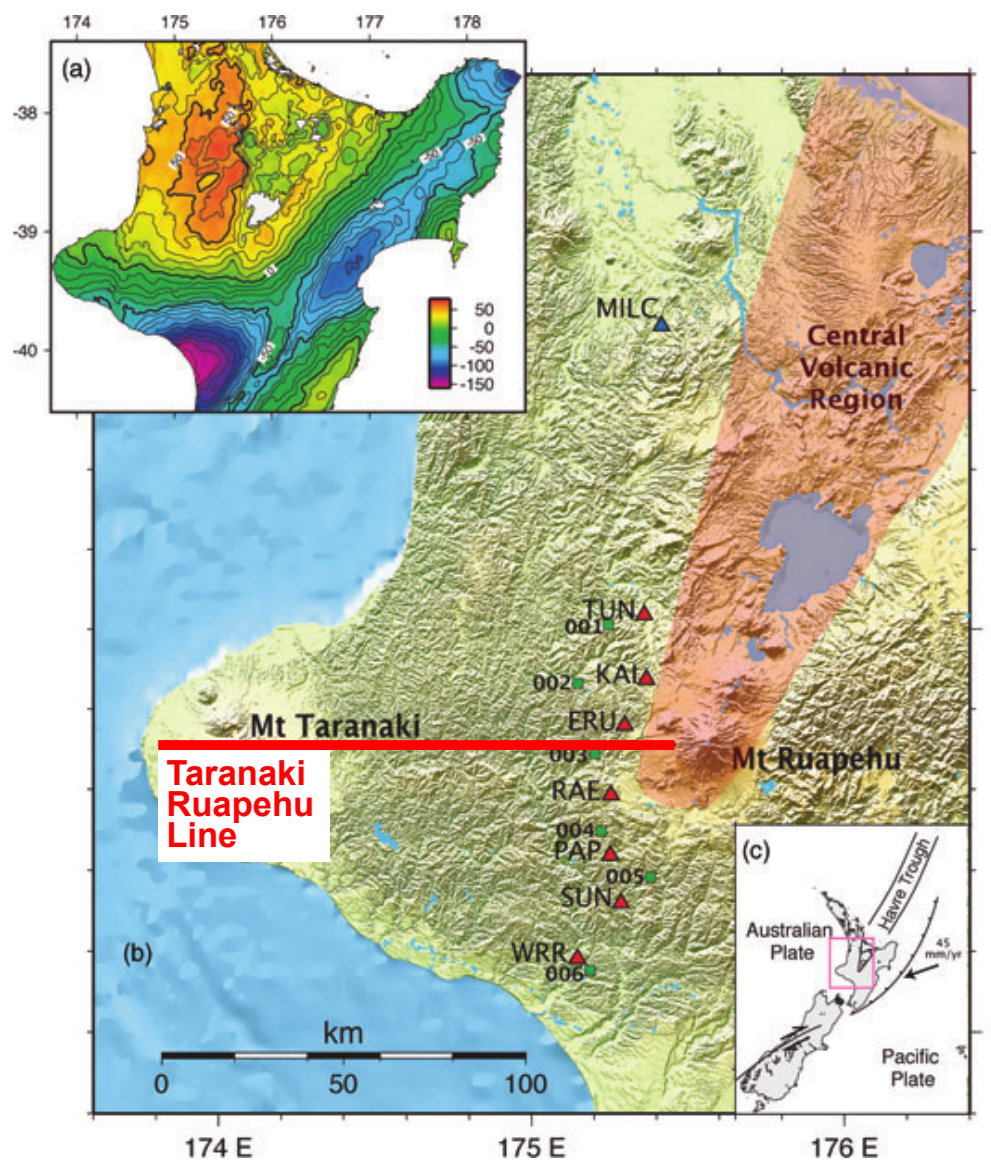

Figure 4.1: Location map showing equipment deployed by 38 S Salmon [2008]; Salmon et al. [2011]. (a) Isostatic gravity map for New Zealand's North Island. Units $=\mathrm{mGal}$. (b) Location map. Red triangles are seven temporary seismographs of the TRAP array. Green squares are sites of magnetotelluric stations. (c) Plate tectonic location map for New Zealand showing the position of the study area relative to the Hikurangi Subduction Zone. Figure modified from [Salmon et al., 2011].

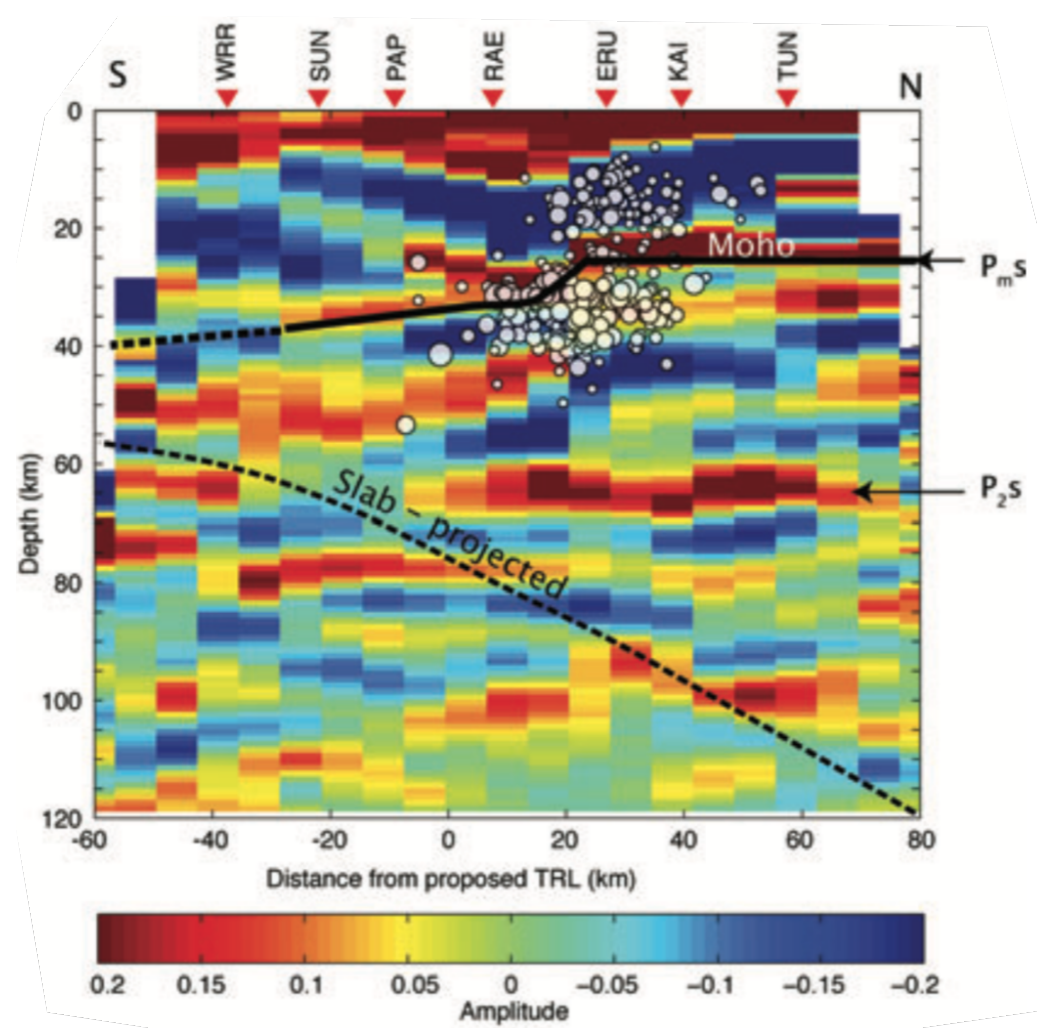

Figure 4.2: Receiver function Common Conversion Point (CCP) stack [after Salmon et al., 2011] showing a $\sim 7 \mathrm{~km}$ 'step' in the Moho Ps conversion at $\sim 30 \mathrm{~km}$ depth (white dashed circle). The black dashed line is the projected surface of the subducted $\mathrm{Pa}$ cific plate. $P_{m} s$ is the conversion associated with the Moho. $P_{2} s$ is interpreted as a deeper conversion from the mantle. A swath of GeoNet earthquakes is projected onto the profile, magnitudes range from $0.5-4$. 


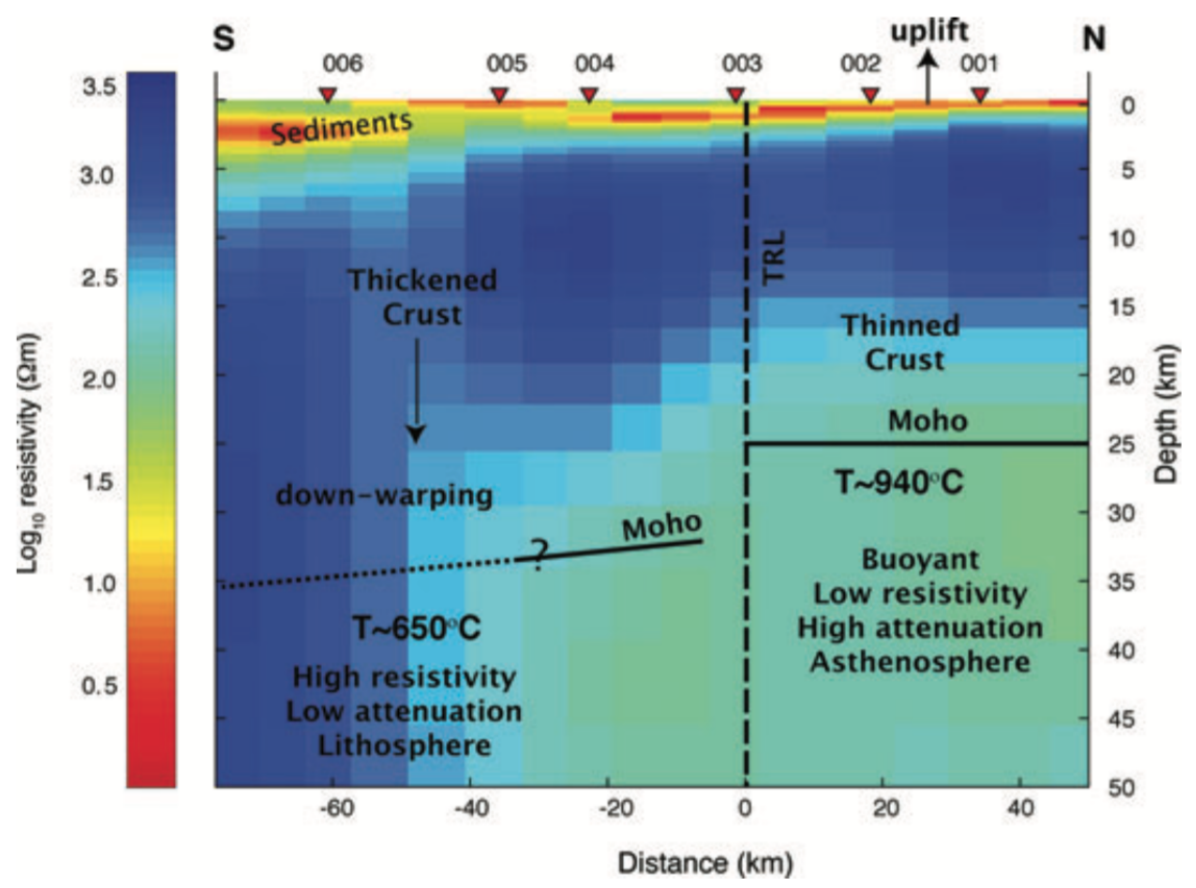

Figure 4.3: Resistivity profile across the Taranaki-Ruapehu Line [after Salmon et al., 2011]. The Moho interpretation is from receiver function analysis (Figure 4.2). The region north of the TR-line is thought to be where the mantle lid has been replaced by asthenosphere [Stern et al., 2006].

\subsection{Receiver function theory}

\subsubsection{Introduction to $\mathrm{P}$-wave receiver functions}

The receiver function method has long been used to investigate crustal and upper mantle structure using three-component seismic stations [Langston, 1977, 1979; Ammon et al., 1990]. The method takes advantage of mode conversions at seismic boundaries, where an incident $P$-wave produces a set of converted, transmitted and reflected $P$ and $S$ phases (see Figure 4.4). Using traveltime differences between the converted phases and the $P$-phase of a teleseismic earthquake, the seismic boundary depth can be solved for given velocity constraints [Gurrola et al., 1994]:

$$
\begin{gathered}
t_{P_{s}}=H\left(\sqrt{\frac{1}{V_{s}^{2}}-p^{2}}-\sqrt{\frac{1}{V_{p}^{2}}-p^{2}}\right) \\
t_{P_{p} P_{s}}=H\left(\sqrt{\frac{1}{V_{s}^{2}}-p^{2}}+\sqrt{\frac{1}{V_{p}^{2}}-p^{2}}\right)
\end{gathered}
$$


(a)
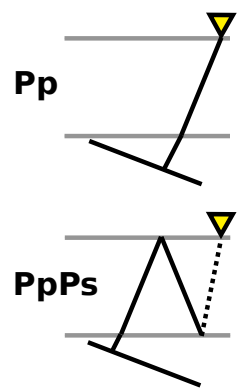
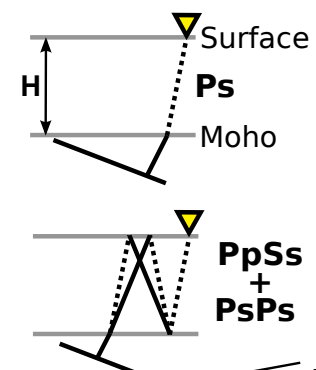

(b)

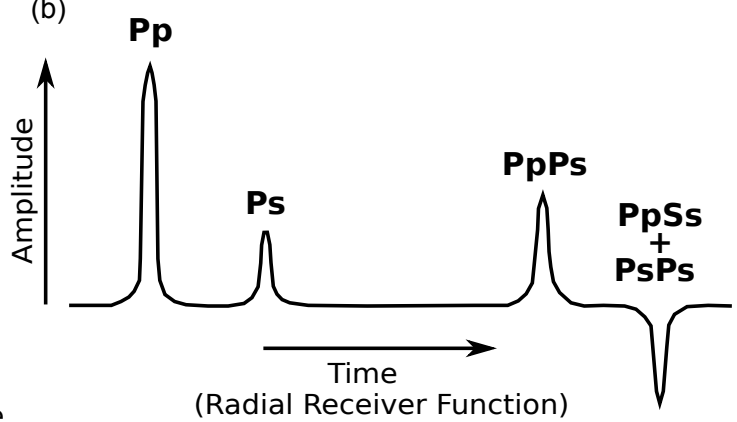

Figure 4.4: Relationship between receiver functions and converted seismic waves. (a) An incident $\mathrm{P}$-wave $(P p)$ on a flat Moho interface will produce $P s, P p P s, P p S s$ and PsPs converted phases, as the energy reverberates between the Moho and the surface. (b) Converted phases at a seismic station can be identified on the radial receiver function. The converted phases are separated in time, forming a coda to the refracted $P p$ arrival.

$$
t_{P_{s} P_{s}+P p S s}=2 H\left(\sqrt{\frac{1}{V_{s}^{2}}-p^{2}}\right)
$$

Where $t$ is the delay time between the $P p$ and either the Ps, PpPs,PsPs or PpSs phases. With the exception of the first letter, the capitalisation of $\mathrm{P}$ and $\mathrm{S}$ relates to whether the wave is travelling up or down. $V_{s}$ and $V_{p}$ are the $\mathrm{S}$ - and $\mathrm{P}$-wave velocities, and $p=D T / d \Delta$ is the ray parameter. Finally, $H$ is the depth to the seismic boundary where the conversion occurs, such as the Moho interface. Most parameters can be easily estimated, but the accurate measurement of the delay time is essential. The receiver function technique makes it easier to find the delay time by isolating and enhancing P-to-S conversions on one seismic component.

First, three-component seismograms from a teleseismic earthquake are rotated into a coordinate system which maximises $S$ phases on a horizontal component and $P$ phases on a vertical component. The most common coordinate system for receiver function calculation is vertical-radial-transverse (Z-R-T), where the vertical $Z$ component is normal to the Earth's surface, the radial $R$ component is aligned along the backazimuth of the earthquake, and the transverse $T$ is normal to the other components.

For a perfect P-to-S conversion in an isotropic layer cake earth, all of the converted $S$ energy will be found on the radial component, and none on the transverse component. But the converted energy will still be contaminated by source and travelpath information. The receiver function technique overcomes this using deconvolution. There are many deconvolution techniques available for receiver functions. Some operate in the time domain, some in the frequency domain, and others use multitaper 
spectral estimates. These techniques have pros and cons (discussed in Section 4.3.3), but they all attempt to do the same thing: isolate P-to-S converted energy on the radial component.

Lin [1995] describes the vertical $D_{Z}(t)$, radial $D_{R}(t)$ and transverse $D_{T}(t)$ particle motions recorded at the seismometer as follows:

$$
\begin{aligned}
& D_{Z}(t)=I(t) * S(t) * E_{Z}(t), \\
& D_{R}(t)=I(t) * S(t) * E_{R}(t), \\
& D_{T}(t)=I(t) * S(t) * E_{T}(t),
\end{aligned}
$$

Where $I(t)$ is the instrument response, $S(t)$ contains the effect of the source and deep mantle, and $E(t)$ is the effect of the crust and upper mantle structures. Assuming that no crustal multiples and converted phases are on the vertical component, then $E_{Z}(t)=\delta(t)$. Therefore $D_{Z}(t)=I(t) * S(t)$.

Deconvolving the radial with the vertical component should isolate the crust and upper mantle conversions, while deconvolving transverse with the vertical component should isolate no energy. In practice, unwanted energy is found on both the deconvolved radial and transverse components, caused by residual P-wave energy, anisotropy, coordinate rotation problems, dipping layers, or simply bad data. It is useful to bin and stack receiver functions from multiple events to try and improve the signal-to-noise ratio. The most common binning specifications are backazimuth and epicentral distance (e.g. Section 4.5.1), or geographical coordinates (e.g. Section 4.5.2).

\subsubsection{LQT reference frame}

The LQT reference frame is an alternative to the ZRT reference frame that accounts for source-receiver geometry. If a $\mathrm{P}$-wave arrives at a seismic station with vertical incidence, all of the P-wave energy will be on the $\mathrm{Z}$ component for the ZRT frame. However, at non-vertical incidence, some of this energy will spill over and contaminate the radial component. The LQT reference frame overcomes this by orienting the vertical component to be parallel to the P-wave (Figure 4.5), which is now called the $L$ component. Similarly, the radial $R$ component from the ZRT system becomes the $Q$ component. This is a useful coordinate system for regional earthquakes $(10-$ 

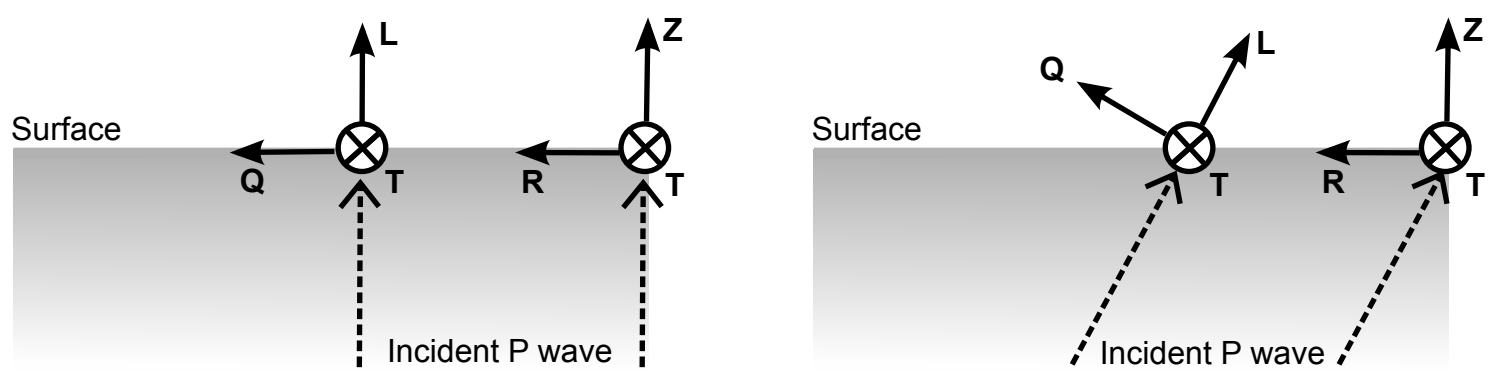

Figure 4.5: LQT vs ZRT coordinate system. LQT $=$ ZRT for a vertically incident P-wave. At non-vertical incidence, the ZRT frame remains the same but the LQT frame rotates so that the $\mathrm{L}$ component is parallel to the $\mathrm{P}$-wave direction.

$30^{\circ}$ away) which are closer to the seismometer than teleseismic earthquakes (30-110 away), and so their raypath deviates more from vertical. There are two ways to rotate into the LQT domain. The first is to simply rotate the $Z$ and $R$ components to maximise the energy of the $\mathrm{P}$-wave on the $L$ component. This only works on events with little noise in the $Z$ and $R$ components. The second way is to rotate based on the ray parameter for the station-event pair, or the angle of the $\mathrm{P}$-wave at the station location. This requires a velocity structure to be known at the station.

\subsubsection{Multiple-Taper Spectral Correlation}

The simplest way to calculate a receiver function is by spectral division, where the frequency spectrum of the radial (or transverse) component is divided by the frequency spectrum of the vertical component. This is numerically unstable when the denominator is close to zero. Enforcing a water level minimum value is one way to mitigate this issue [e.g. Ammon, 1991; Clayton and Wiggins, 1976], yet lowamplitude spectrum components are ignored. Deconvolution in the time domain is also possible [e.g. Abers et al., 1995; Gurrola et al., 1995], though the receiver functions produced tend to be biased towards the frequency components with the largest amplitudes.

The Multi-Taper Correlation (MTC) method of Park and Levin [2000] has several advantages over the methods above. It is capable of handling high-frequency data, factors in in pre-signal noise, and weighs individual receiver functions before stacking. The MTC method is attractive as it has a proven track record in the noisy island environment of New Zealand [e.g. Horspool et al., 2006; Savage et al., 2007; Bannister et al., 2007; Ewig, 2009], and was used by Salmon [2008] whose receiver function work forms the basis for this study. 
Creating a receiver function with the MTC method begins by calculating MultipleTaper Spectrum (MTS) estimates. Starting with three time series $\left[u_{R}(n \tau), u_{T}(n \tau), u_{Z}(n \tau)\right]=$ $\left\{u_{n}^{R}, u_{n}^{T}, u_{n}^{Z}\right\}_{n=0}^{N-1}$, representing the radial, transverse and vertical particle motions, and with sampling interval $\tau$ and duration $T=N \tau$. For each frequency $f$, the $K$ MTS estimates are:

$$
Y_{\gamma}^{k}(f)=\sum_{n=0}^{N-1} u_{n}^{\gamma} w_{n}^{(k)} e^{i 2 \pi f n \tau}
$$

where $\gamma$ denotes either $(\mathrm{Z}, \mathrm{R}, \mathrm{T})$ or (L,Q,T) respectively, $N$ is the number of samples and $w_{n}^{k}$ is the $K$ th taper for a user-defined time-bandwidth product $p$. The choices of $K$ and $p$ quantify a trade-off between resolution and variance of spectral estimates. For crustal investigations less than $100 \mathrm{~km}$ in depth, the usage of three tapers $(K=$ 3 ) and a $p$ value of 2.5 are identified as reasonable starting parameters [Park and Levin, 2000]. These parameters were used by Salmon [2008] and are used in this study.

With the MTS estimates from Equation (4.5), the radial and transverse receiver functions $\left(E_{R}(f)\right.$ and $E_{T}(f)$ respectively), can be calculated in the frequency domain using damped spectral correlation estimators:

$$
\begin{aligned}
& E_{R}(f)=\frac{\sum_{k=0}^{K-1}\left(Y_{Z}^{(k)}(f)\right) * Y_{R}^{(k)}(f)}{\left(\left(\sum_{k=0}^{K-1}\left(Y_{Z}^{(k)}(f)\right) * Y_{Z}^{(k)}(f)\right)+S_{0}(f)\right)} \\
& E_{T}(f)=\frac{\sum_{k=0}^{K-1}\left(Y_{Z}^{(k)}(f)\right) * Y_{T}^{(k)}(f)}{\left(\left(\sum_{k=0}^{K-1}\left(Y_{Z}^{(k)}(f)\right) * Y_{Z}^{(k)}(f)\right)+S_{0}(f)\right)}
\end{aligned}
$$

Here, $S_{0}(f)$ is the damping factor, which is a spectral estimate of the pre-event noise on the vertical component. The coherency between the vertical $Z$ and horizontal components $R$ and $T$ can be calculated as follows:

$$
\begin{aligned}
& C_{R}(f)=\frac{\sum_{k=0}^{K-1}\left(Y_{Z}^{(k)}(f)\right) * Y_{R}^{(k)}(f)}{\left(\left(\sum_{k=0}^{K-1}\left(Y_{R}^{(k)}(f)\right) * Y_{R}^{(k)}(f)\right)\left(\sum_{k=0}^{K-1}\left(Y_{Z}^{(k)}(f)\right) * Y_{Z}^{(k)}(f)\right)\right)^{1 / 2}} \\
& C_{T}(f)=\frac{\sum_{k=0}^{K-1}\left(Y_{Z}^{(k)}(f)\right) * Y_{T}^{(k)}(f)}{\left(\left(\sum_{k=0}^{K-1}\left(Y_{T}^{(k)}(f)\right) * Y_{T}^{(k)}(f)\right)\left(\sum_{k=0}^{K-1}\left(Y_{Z}^{(k)}(f)\right) * Y_{Z}^{(k)}(f)\right)\right)^{1 / 2}}
\end{aligned}
$$


Such that $C_{R}(f), C_{T}(f)$ are the coherences for the radial and transverse components respectively. The coherence values range between $0-1$, where 1 represents perfect coherence and 0 represents no correlation. Receiver Function uncertainties can now be derived using the coherency estimates as follows:

$$
\begin{aligned}
& \operatorname{var}\left(E_{R}(f)\right)=\left(\frac{1-\left(C_{R}(f)\right)^{2}}{(K-1)\left(C_{R}(f)\right)^{2}}\right)\left|E_{R}(f)\right|^{2} \\
& \operatorname{var}\left(E_{T}(f)\right)=\left(\frac{1-\left(C_{T}(f)\right)^{2}}{(K-1)\left(C_{T}(f)\right)^{2}}\right)\left|E_{T}(f)\right|^{2}
\end{aligned}
$$

Weighting of individual receiver functions $E_{R}(f), E_{T}(f)$ is proportional to the inverse of the variances $\operatorname{var}\left(E_{R}(f)\right), \operatorname{var}\left(E_{T}(f)\right)$. When receiver functions are stacked together, those with good correlation between vertical and horizontal components contribute more to the bin than those with a relatively low correlation. For a given seismic station, stacking occurs both as a function of epicentral distance, as well as backazimuth.

The last step involves the application of a cosine-squared $\left(\cos ^{2}\left(\pi f / 2 f_{c}\right)\right)$ low-pass filter to prevent Gibbs-effect ringing, where $f_{c}$ is the cut-off frequency. To preserve amplitudes, the filtered receiver functions are then normalised with the factor $2 f_{N} / f_{c}$, where $f_{N}=1 /(2 \tau)$ is the Nyquist frequency.

\subsubsection{Common Conversion Point stacking}

Receiver functions from multiple seismic stations can be geographically binned to form a common conversion point (CCP) stack [Dueker and Sheehan, 1997, 1998]. This method is analogous to common midpoint (CMP) stacking used in seismic reflection exploration, and is a powerful tool for analysing lateral changes in subsurface structure. The CCP procedure has three steps; (1) a moveout correction, (2) binning, and (3) stacking.

1. The moveout correction compensates for variations in source-receiver offset which result in a systematic variation in $P_{d} S$ ( $\mathrm{P}$ to $\mathrm{S}$ conversion at depth $\left.\mathrm{d}\right)$ arrival times. $P_{d} S$ moveout can be calculated as follows [Gurrola et al., 1994; Dueker and Sheehan, 1997]:

$$
T_{P_{d} S}(p)=\int_{D}^{0}\left[\sqrt{V_{s}(z)^{-2}-p^{2}}-\sqrt{V_{P}(z)^{-2}-p^{2}}\right] d z
$$


Here, $p$ is the $\mathrm{P}$-wave ray parameter in $\mathrm{s} / \mathrm{km}, D$ is the depth of the discontinuity, $V_{p}(z)$ and $V_{s}(z)$ are the $\mathrm{P}$ and $\mathrm{S}$ wave velocities respectively for a $1 \mathrm{D}$ velocity model at depth $z$. The corrected term is the time difference between the predicted travel-time (for ray parameter $p$ ), and its predicted zero-offset travel-time (where $p$ is set to 0 ):

$$
\Delta T_{P_{d} S}(p)=T_{P_{d} S}(p)-T_{P_{d} S}(0)
$$

2. The ray set is then binned geographically, with bin widths of $2-10 \mathrm{~km}$ being common for Moho studies (e.g. $5 \mathrm{~km}$ in Wilson et al. [2004], 2 and $10 \mathrm{~km}$ in Chen et al. [2006], $7 \mathrm{~km}$ in Salmon et al. [2011]). Binning occurs after ray tracing the converted $S$ ray paths through a one-dimensional velocity model to the approximate depth of the converted interface being studied (e.g. the Moho, at approximately $30 \mathrm{~km}$ depth). These paths are known as 'piercing points', which can be estimated using Snell's law:

$$
x=\frac{z V_{s} p}{\sqrt{1-v_{s}^{2} p^{2}}}
$$

The piercing point is the horizontal offset $x$ of the raypath from the receiver, and is a function of $z$ the conversion boundary depth, $V_{s}$ the average shear wave velocity between the conversion boundary and the receiver, and $p$ the ray parameter.

3. Stacking takes place once the binning process is complete. Each bin should contain piercing points that are in close geographical proximity to one another at a particular depth. It is common for traces to be shared between bins when not enough traces are available, or to help produce a cleaner image by smoothing out high frequency noise [e.g. Wilson et al., 2004; Salmon et al., 2011].

\subsubsection{Synthetic receiver functions}

To model anisotropic elastic wave propagation in three dimensions, Boyd [2006] developed a second-order finite-difference solution to the anisotropic elastic wave equation in Matlab. The code allows synthetic receiver functions to be generated for any arbitrary source-receiver pair and earth model, regardless of complexity. More simple analytic solutions to the elastic wave equaton do exist [e.g. Frederiksen and 
Bostock, 2000], yet these are designed for horizontal or gently-dipping layers. The finite difference solution allows any arbitrary earth model geometry to be considered, including those with steeply-dipping layers. The ability to model steep dips is an essential requirement for this study which aims to more accurately image a potential 'step' in the continental lithosphere that was previously observed by Salmon [2008]. For more information on this technique, refer to Boyd [2006].

\subsection{Dataset and analysis}

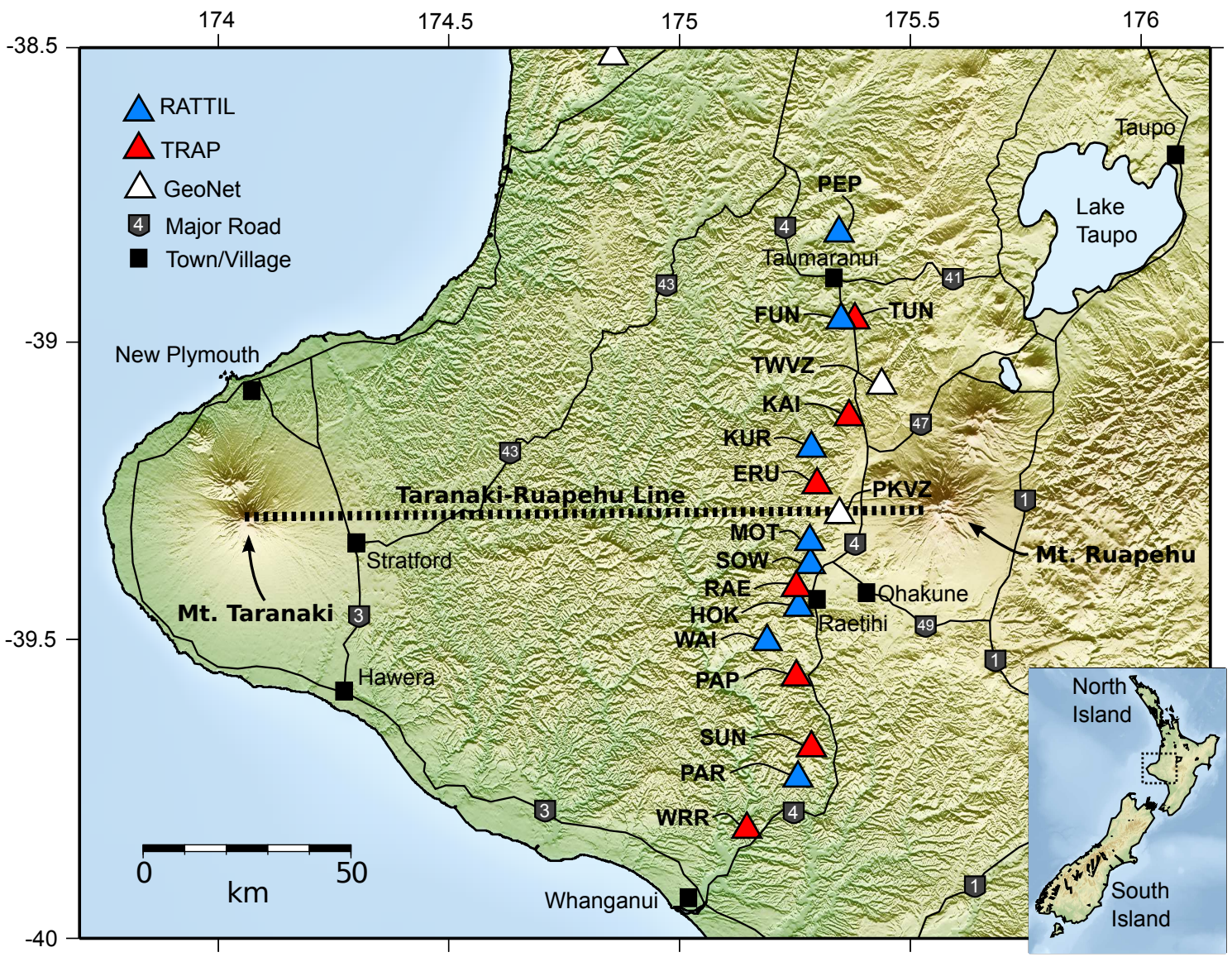

Figure 4.6: Station location map for the new Taranaki-Ruapehu Line receiver function study. RATTIL stations are temporary broadband seismic stations deployed as part of this study (as discussed in Chapter 2). TRAP stations are temporary short period $(1 \mathrm{~Hz})$ seismic stations deployed by Salmon [2008]. GeoNet stations are permanent short period $(1 \mathrm{~Hz})$ seismic stations which are part of the Tongariro National Park Volcano Seismic Network. Major roads and key towns are included as reference points.

Teleseismic and regional earthquake data from 17 stations were used for a receiver function study across the Taranaki-Ruapehu Line (Figure 4.6). Eight stations are from the Ruapehu And Taranaki Teleseismic Imaging Line (RATTIL, Chapter 2), 
seven stations are from the Taranaki-Ruapehu Attenuation Project [TRAP, Salmon, 2008], and the final two stations belong to the Tongariro National Park volcano seismic network (GeoNet). Due to accessibility issues, most of these stations are situated adjacent to state highway 4 . While a profile directly across the middle of the Taranki-Ruapehu line would be desirable, this region lacks roads, tracks and is heavily bushed.

The TRAP and GeoNet stations are short period instruments (1 Hz seismometers), while the RATTIL stations are broadband instruments. All stations are situated on the Pliocene-Miocene, shallow marine mudstones of the Wanganui Basin. Station elevations and sediment thicknesses are given in Table 4.1, with a general trend of increasing sediment thickness from north to south.

Table 4.1: Sediment depth estimates across the TR Line. Sediments are those under the station, not below sea level. Values are interpolated from [Salmon, 2008].

\begin{tabular}{|l|c|c|}
\hline Station & $\begin{array}{c}\text { Elevation } \\
(\mathrm{m})\end{array}$ & $\begin{array}{c}\text { Sediments } \\
(\mathrm{m})\end{array}$ \\
\hline PEP & 300 & 300 \\
FUN & 385 & 385 \\
TUN & 390 & 390 \\
TWVZ & 1085 & 1085 \\
KAI & 680 & 1100 \\
KUR & 285 & 900 \\
ERU & 698 & 1700 \\
PKVZ & 770 & 1770 \\
MOT & 648 & 1750 \\
\hline
\end{tabular}

\begin{tabular}{|l|c|c|}
\hline Station & $\begin{array}{c}\text { Elevation } \\
(\mathrm{m})\end{array}$ & $\begin{array}{c}\text { Sediments } \\
(\mathrm{m})\end{array}$ \\
\hline SOW & 570 & 1670 \\
RAE & 582 & 2300 \\
HOK & 648 & 2050 \\
WAI & 595 & 2100 \\
PAP & 364 & 2100 \\
SUN & 350 & 2400 \\
PAR & 377 & 2600 \\
WRR & 70 & 2300 \\
& & \\
\hline
\end{tabular}

\subsubsection{Earthquake event selection}

Distant earthquakes were selected from the USGS Advanced National Seismic System Comprehensive Catalog (ANSS ComCat). The selection criteria of Savage et al. [2007] was used for teleseismic earthquakes, i.e. epicentral distances of 30-60 and $60-110^{\circ}$ for magnitudes $>5.4$ and $>6.3$ respectively. Regional earthquakes were also selected with epicentral distances of $20-30^{\circ}$ for magnitudes $>5.4$. The regional earthquakes were included to increase azimuthal coverage. Regional events closer than $20^{\circ}$ were not selected, as interactive travelpath simulations with the Tau-P toolkit [Crotwell et al., 1999] showed that energy did not leave the Earth's crust, and thus 
P-to-S converted phases at the base of the crust are theoretically not possible. The inclusion of $20-30^{\circ}$ regional earthquakes is consistent with Salmon [2008], who found them to be valuable additions to her dataset. Regional earthquakes have shallower incidence angles than teleseismic events and should be rotated into the LQT domain (Section 4.3.2).

Events were cut from RATTIL and GeoNet continuous waveform data using phase data from the AK135 velocity model [Kennett et al., 1995], resulting in a $200 \mathrm{~s}$ window centred on the P-phase arrival time. Earthquakes kept for further analysis had a clear P-arrival on the vertical channel, which was either visible on the raw unfiltered data, or when aided by a $0.5-2 \mathrm{~Hz}$ bandpass filter. For TRAP stations, previously cut events from Salmon [2008] were included for consistency. The TRAP catalog used similar selection criteria, except it focused on magnitudes $>6$ which limited the number of regional earthquakes they could detect.

RATTIL stations were deployed for up to 15 months, and during this time 109 earthquakes met the criteria above (Figure 4.7). Of these 68 were teleseismic (30$\left.110^{\circ}\right)$ and 41 were regional $\left(20-30^{\circ}\right)$. The number of events per station varied from 70 (at station PEP) to 22 (at station HOK). The most distant teleseimic events originate from subduction zones near Japan and beneath the Andes, but the majority come from subduction zones near Indonesia and Papua New Guinea, which are situated to the northwest of the study area. Regional events come from the north near Tonga and Samoa, providing extra azimuthal coverage.

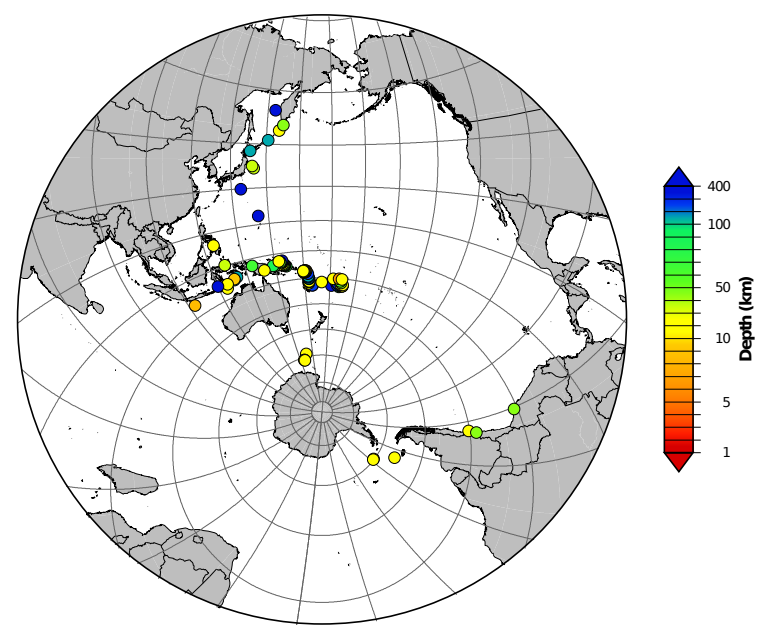

Figure 4.7: Distant earthquakes detected at RATTIL seismic stations. Events are colour coded based on earthquake focus depth.

TRAP stations were deployed for up to 10 months, and during this time 79 earthquakes were detected (Figure 4.8). Of these 67 were teleseismic (30-110 ${ }^{\circ}$ ) and 12 were regional $\left(20-30^{\circ}\right)$. The distribution of events were comparable to the RATTIL deployment, although there were fewer regional earthquakes due to the differences 
in selection criteria mentioned previously. The number of events per station varied from 59 (at station KAI) to 15 (at station TUN).

Figure 4.8: Distant earthquakes detected at TRAP seismic stations. Events are colour coded based on earthquake focus depth.

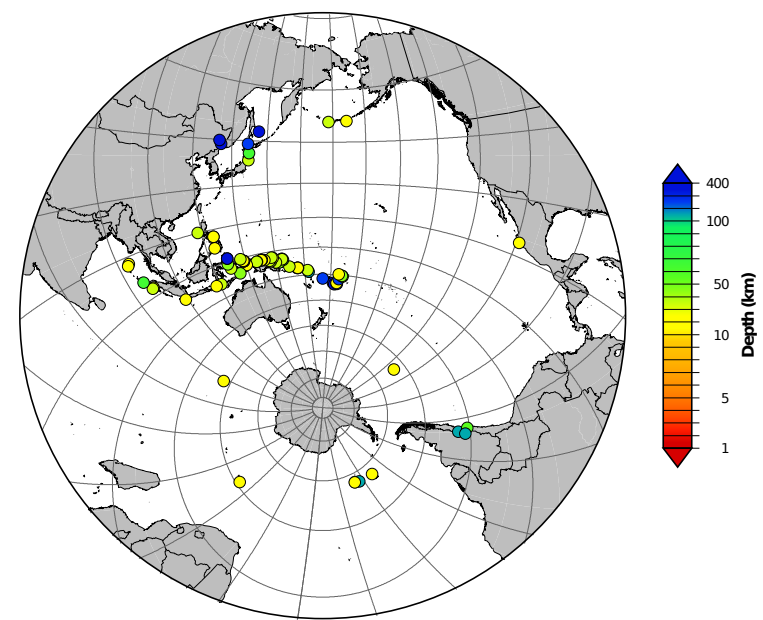

GeoNet stations TWVZ and PKVZ have been operational since 2004 and 2005 respectively. Data from the initial start of the network to March 2014 have been used for receiver functions. GeoNet waveform data were downloaded directly from the Continuous Waveform Buffer [GeoNet, 2014] java client. A total of 692 earthquakes met the criteria above (Figure 4.9). Of these, 462 were teleseismic $\left(30^{\circ}-110^{\circ}\right)$ and 230 were regional $\left(20-30^{\circ}\right)$. The distribution of events is dominated by subduction zones from the north and northwest, representing more than 7 years of earthquake data.

Figure 4.9: Distant earthquakes detected at GeoNet seismic stations. Events are colour coded based on earthquake focus depth.

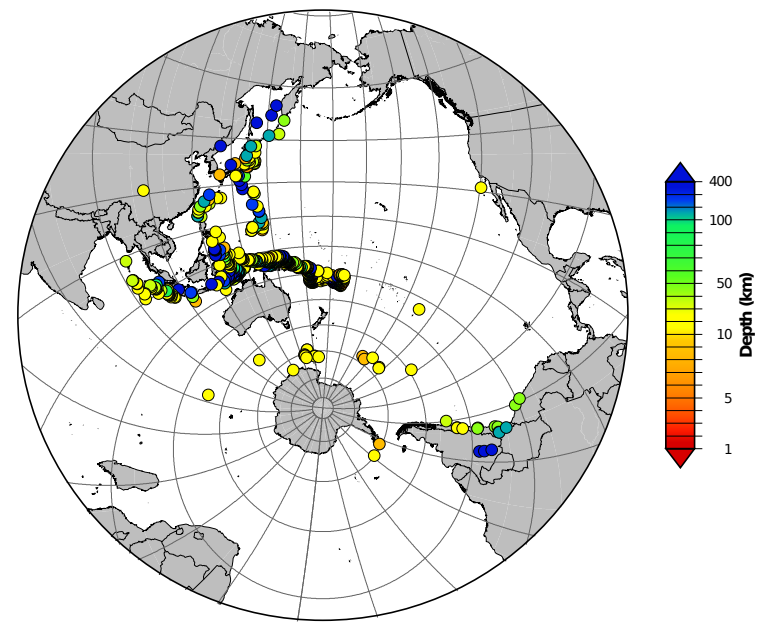

\subsubsection{Receiver function pre-processing}

Preprocessing of cut events from RATTIL and GeoNet stations followed the documentation supplied with the Park and Levin multitaper crosscorrelation codes [Park 
and Levin, 2000]. The first step was to detrend and demean the events, and apply a high-pass filter $(0.02 \mathrm{~Hz})$ to remove long wavelength noise. The events were then rotated from the coordinate system of the seismometer into to the ZRT coordinate system (gcp reversed), using the event origins extracted from the ANSS ComCat. Downsampling to $50 \mathrm{~Hz}$ was needed to match the sampling rate of the pre-cut TRAP events from Salmon [2008]. The downsampling process included a temporal antialias filter. TRAP events were supplied in a raw, unfiltered form, and were also subject to the preprocessing mentioned in this section.

Rotation into the LQT reference system (see Section 4.3.2) is useful when regional earthquakes are included in receiver function analysis. The angle of incidence of regional events is further from vertical than teleseismic events, and P-wave energy bleeds into the radial channel. Sediments beneath the seismometer (Table 4.1) can further distort the incident raypath away from vertical. Transformation into the LQT reference frame helps compensate for this, as the L axis (replacement for vertical) is aligned in the direction of the incident $\mathrm{P}$-wave, and so the $\mathrm{Q}$ axis (replacement for radial) should contain the P-to-S converted energy. By rotating the $\mathrm{Z}$ and $\mathrm{R}$ components of the ZRT reference frame by a fixed value, the LQT coordinate system is achieved. The angle of rotation $i$ was estimated using the

Table 4.2: Number of receiver functions calculated per station. Bracketed numbers for PKVZ and TWVZ show the number of receiver functions for the year 2012.

\begin{tabular}{|l|l|l|l|l|}
\hline Station & Duration (days) & Teleseismic & Regional & Total \\
\hline PAR & 401 & 31 & 18 & 49 \\
WAI & 246 & 23 & 9 & 32 \\
HOK & 485 & 29 & 12 & 41 \\
SOW & 180 & 11 & 9 & 20 \\
MOT & 493 & 40 & 22 & 62 \\
KUR & 394 & 23 & 22 & 45 \\
FUN & 233 & 16 & 15 & 31 \\
PEP & 313 & 25 & 36 & 61 \\
ERU & 236 & 42 & 6 & 48 \\
KAI & 301 & 45 & 6 & 51 \\
PAP & 299 & 36 & 5 & 41 \\
RAE & 301 & 24 & 3 & 27 \\
SUN & 237 & 42 & 8 & 50 \\
TUN & 41 & 13 & 2 & 15 \\
WRR & 240 & 24 & 6 & 30 \\
PKVZ & $3279(366)$ & $329(39)$ & $184(25)$ & $513(64)$ \\
TWVZ & $3576(366)$ & $323(27)$ & $171(12)$ & $494(39)$ \\
\hline
\end{tabular}


station-event ray parameter $p$, the P-wave velocity $c$, and Snell's law $(\sin i) / c=p$. A P-wave velocity of $3.5 \mathrm{~km} / \mathrm{s}$ was set for $v$ to compensate for the sediments of the Wanganui Basin, whereas the ray parameter was calculated using the AK135 travel time tables [Kennett et al., 1995].

Following rotation to LQT, two analysis windows of $80 \mathrm{~s}$ duration were defined from each 200 s earthquake event window. The two windows consisted of, respectively, the pre-event noise used for spectral weighting, as well as the signal window used to create the receiver function. The pre-event noise window ends $5 \mathrm{~s}$ before the P-phase arrival, which also defines the start of the signal window. An $80 \mathrm{~s}$ analysis window corresponds to a delay time of up to $16 \mathrm{~s}$, capable of imaging about $100 \mathrm{~km}$ below the surface.

\subsubsection{Receiver function calculations}

Receiver functions were created using the multitaper cross-correlation technique of Park and Levin [2000]. Three tapers are used $(K=3)$ alongside a $p$ value of 2.5 (not to be mistaken with ray parameter $p$ ) on an $80 \mathrm{~s}$ window, the meaning and appropriateness of these values is discussed in Section 4.3.3. Receiver functions with dominant frequencies of $0.5,1.0$ and $1.5 \mathrm{~Hz}$ were calculated. Table 4.2 shows the total number of receiver functions calculated from each station.

Two different version of the [Park and Levin, 2000] codes were used. The first is the official version available from the IRIS website. These codes output average receiver functions which have been binned by azimuth and epicentral distance (Section 4.5.1). The binned receiver functions have been spectrally weighted based on the pre-event noise spectrum so that the highest signal/noise ratio events contribute the most to the stacks. This is useful for looking at individual stations or collections of nearby stations. The second version used was modified by Nick Horspool in 2004 to output individual receiver functions in SAC format. The SAC files were used as inputs for CCP stacking in Section 4.4.4.

\subsubsection{Common Conversion Point stack}

Radial receiver functions from Section 4.4.3 were geographically binned to produce a pseudo-cross-section of the Taranaki-Ruapehu Line using the Common Conversion Point (CCP) stacking technique [Dueker and Sheehan, 1997, 1998]. Figure 4.10 shows the location of a CCP stack across the Taranaki-Ruapehu Line with piercing 


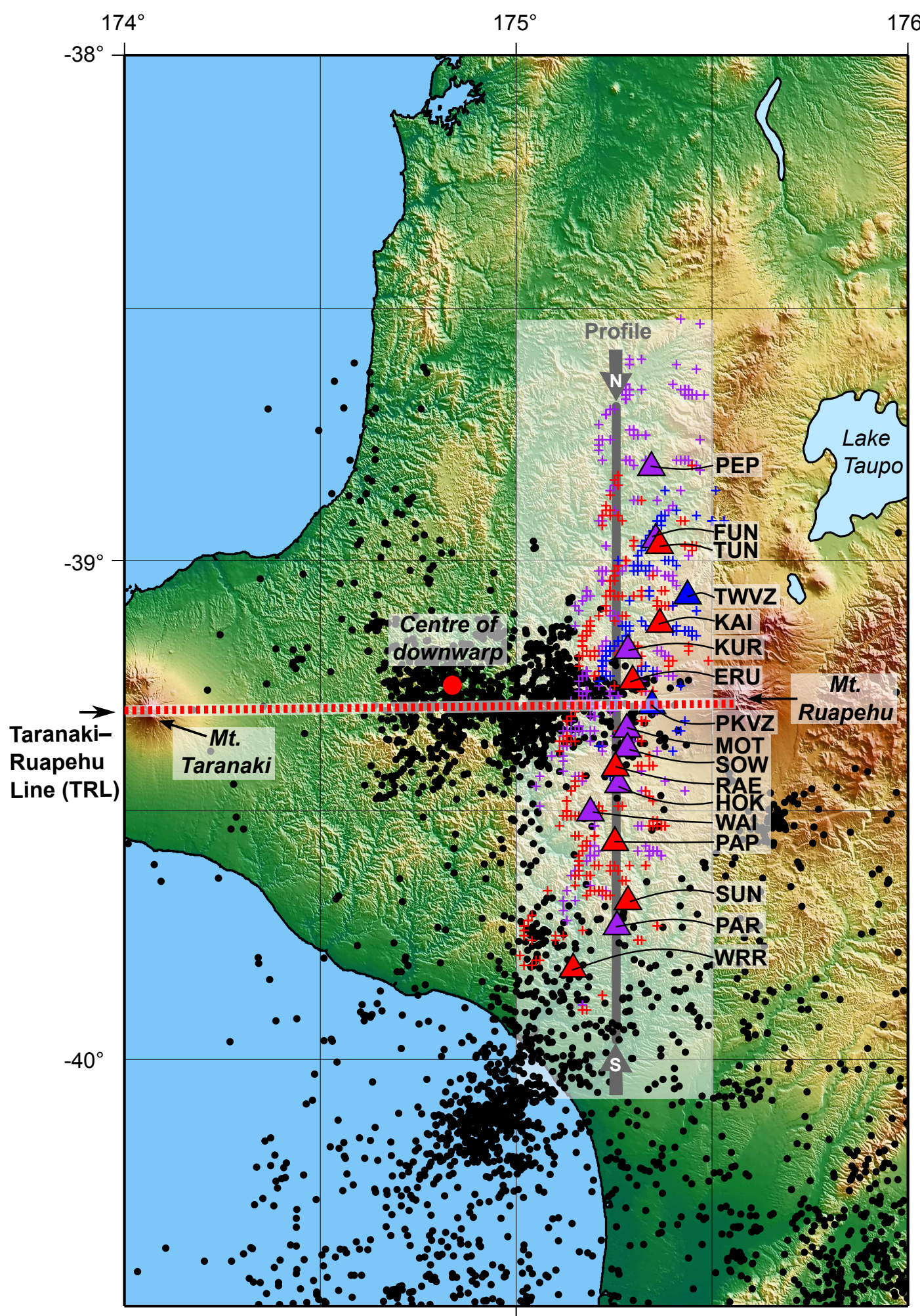

Figure 4.10: Piercing point map of receiver functions at the Taranaki-Ruapehu Line. Red, purple and blue triangles represent TRAP, RATTIL and GeoNet seismic stations respectively. The coloured pluses represent teleseismic piercing points for each network calculated at $30 \mathrm{~km}$ depth using the Tau-P toolkit [Crotwell et al., 1999]. Black dots show $15-50 \mathrm{~km}$ depth local earthquakes from the GeoNet catalog [Fenaughty, 2015]. The centre of the earthquake downwarp from fig. 3.16 is also shown. The teleseismic profile runs north-south as indicated by the grey arrows. 
points from $30 \mathrm{~km}$ depth (pluses). Matlab codes that were successful in previous investigations [e.g. Wilson et al., 2004; Boyd, 2006; Salmon, 2008] were used for the CCP stack. This source code, including all processing parameters, is included in Appendix E.

The processing parameters used are the same as in Salmon [2008], except that a $5 \mathrm{~km}$ bin spacing is chosen instead of $7 \mathrm{~km}$. The input receiver functions have a dominant period of $1 \mathrm{~Hz}$. Extra frequency filtering $(0.2-1.5 \mathrm{~Hz}$ corner frequencies) was applied to remove any residual high and low frequency noise. The geographical bin width was set to a large value $(800 \mathrm{~km})$ out of the profile plane (y-direction), so that any traces off the profile line are still considered. Traces in a bin are shared with two adjacent bins (trace sharing), which helps smooth out random noise. Ray tracing was based on the New Zealand Standard (NZST) P Velocity Model [Maunder, 2002], with $\mathrm{S}$ velocities defined by a simple $\mathrm{P} / \mathrm{S}$ ratio of 1.71 which is consistent with global averages for orogenic belts such as New Zealand [Zandt and Ammon, 1995]. (This value is also close to the $1.73 \pm 1 \mathrm{P} / \mathrm{S}$ ratio for the crust sampled by the TRAP array across the Taranaki-Ruapehu Line [Salmon, 2008].)

A static correction was applied to receiver functions from each seismic station. This correction compensated for sediment thickness and station elevations (Table 4.1) which might manifest as a step-like changes in crustal thickness. Again, the technique of Salmon [2008] is reproduced. Here, an expected delay time is calculated for the sediment layer using a $V_{p}$ of $3.4 \mathrm{~km} / \mathrm{s}$, and a $V_{p} / V_{s}$ of 1.85 . These values are approximations of the Wanganui Basin sediment layer based on the work of Watson and Allen [1964] and Eberhart-Phillips et al. [2005]. The difference between this delay time and that from the NZST P Velocity Model above gives a sediment time correction (Equation (4.12)). Similarly, the elevation time correction is given by the time taken to travel through a certain thickness of basin sediments above sea level (Equation (4.13)). The sediment thickness correction is by far the more significant of the two.

$$
\begin{gathered}
\Delta t_{P_{s}}(\text { sediments })=H_{s}\left(\frac{1}{v_{s}}-\frac{1}{v_{c}}\right) \\
\Delta t_{P_{s}}(\text { elevation })=H_{e}\left(\frac{1}{v_{c}}\right)
\end{gathered}
$$

For both equations above, $v_{s}$ and $v_{c}$ are the $\mathrm{P}$-wave velocities of the sediment and crustal layers respectively, and $H_{e}$ and $H_{s}$ are the elevation of the seismometer 

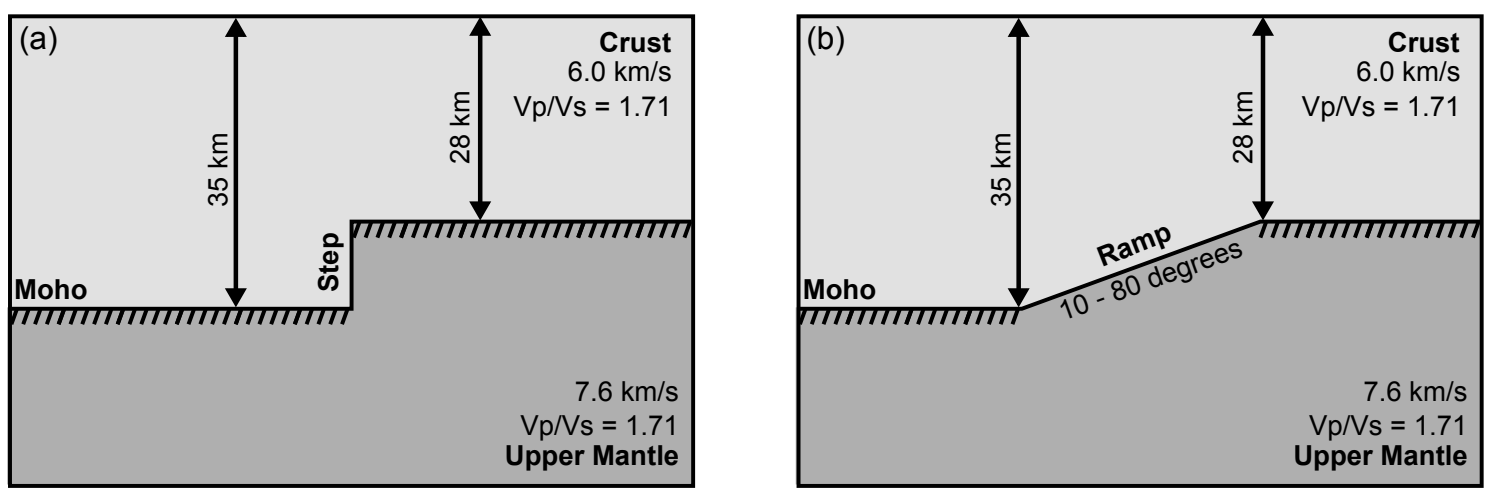

Figure 4.11: Earth models for synthetic receiver functions. (a) 'Step' end member, representing a vertical offset through the earths crust. (b) 'Ramps' for various dips between $10-80^{\circ}$ were also tested. Each model is a simple 2-layer problem, with velocities based off the New Zealand Standard Velocity Model [Maunder, 2002]. Crustal thickness is constrained by flat Moho conversions from receiver function CCP stacking results in this study.

and thickness of the sediments beneath the seismometer respectively. The static correction was applied before the CCP stack was calculated. The correction does not significantly change the resulting image of the CCP stack.

\subsubsection{Synthetic receiver function calculations}

Synthetic receiver functions were computed for simple dipping earth models to help with interpretation of observed receiver functions. The earth models tested are shown in Figure 4.11. Every observed event-receiver pair was solved using a finite difference solution to the anisotropic wave equation [Boyd, 2006]. An equivalent to the radial receiver function was output, and used to calculate a synthetic CCP stack. The same CCP processing parameters were used for both real and synthetic data.

First, an earth model was paramaterised to represent the expected structure of the Taranaki-Ruapehu Line based on the results of [Salmon et al., 2011]. The model width was set to $500 \mathrm{~km}$ wide by $250 \mathrm{~km}$ deep, with node spacings of $500 \mathrm{~m}$ horizontal and $250 \mathrm{~m}$ vertical. The extra width is was necessary to reduce edge effects. These parameters are similar to those of Wilson et al. [2004] and Boyd [2006].

Second, the earth model grid was assigned velocity values (Figure 4.11). The New Zealand Standard Velocity Model was adapted into a fit-for-purpose two-layer model, representing the crust and upper mantle respectively. The crustal $\mathrm{P}$ velocity was set to $6.0 \mathrm{~km} / \mathrm{s}$, and the upper mantle crustal $\mathrm{P}$ velocity was set to $7.6 \mathrm{~km} / \mathrm{s}$, with 
a $\mathrm{Vp} / \mathrm{Vs}$ ratio of 1.71 . The model crust thickens from $28 \mathrm{~km}$ in the north to $35 \mathrm{~km}$ in the south over a horizontal distance controlled by a dip value ranging between $10-90^{\circ}$.

A synthetic teleseismic wave with a dominant frequency of $1 \mathrm{~Hz}$ was then passed through the velocity model. The incident teleseismic wave was setup to be a $2 \mathrm{D}$ representation of a 3D system. Hence, teleseismic wave propagation direction was defined by both an azimuth and a slowness. The azimuth was set to $270^{\circ}$ or $90^{\circ}$ depending on whether the teleseismic event originated to the north or south of the earth model. The slowness was fudged as a function of ray parameter and earthquake backazimuth, so that events that are out-of-plane come in at the correct angle of incidence in $2 \mathrm{D}$.

It took roughly 30 minutes to do each simulation run, and there were almost 800 source-receiver pairs to simulate, which can take more than 5 months of processing time for the 10 tested dip geometries. To reduce computation time, only a subset of 50 equally-spaced slownesses for incident azimuths of $270^{\circ}$ or $90^{\circ}$ were considered, and the rest of the values were linearly interpolated from this set.

For each simulation run, surface displacements were recorded in the ' $x$ ', ' $y$ ' and ' $z$ ' directions. The surface displacements are directly related to what a 3-component seismometer would record at each of the $500 \mathrm{~m}$ spaced surface nodes. As such, the ' $\mathrm{x}$ ' direction displacement is related to the "radial" receiver function. An example ' $\mathrm{x}$ ' component from a simulation run is given in Figure 4.12a. Note that a wide model is needed to keep edge effects away from the centre of the model containing the Moho step.

Synthetic receiver functions for a given source-receiver geometry are extracted from the P-aligned synthetic sumulation runs (Figure 4.12b). The method of extraction is to select the nearest trace corresponding to the surface location of a seismometer along the profile, which would be within $500 \mathrm{~m}$ of the true seismometer location.

The extracted synthetic traces have no P-reverberations, and are immediately equivalent to receiver functions without needing deconvolution. The synthetics were calculated for each dip $10-90^{\circ}$ at $10^{\circ}$ increments, and then directly transplanted into the CCP code developed in Section 4.4.4. The results of the synthetic CCP stacks are presented in Figure 4.18. 

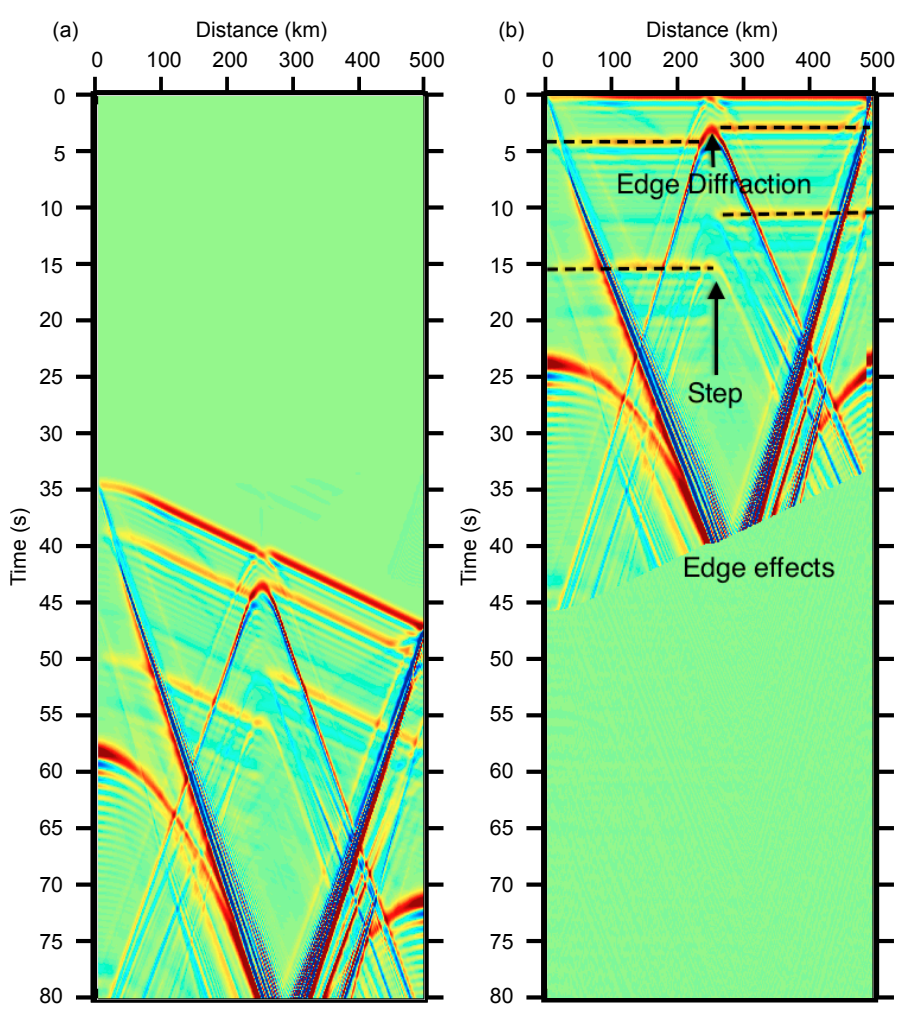

Figure 4.12: Example of synthetic simulation run for a given azimuth and slowness. (a) The ' $x$ ' (radial) component of surface displacement is shown, which contains the P-to-S converted phases. Panel (b) is the same as (a) except that it has been aligned to the first $\mathrm{P}$-arrival. The P-to-S conversion and its multiple are indicated by dashed lines. Note the presence of an edge diffraction which is not usually resolved in receiver function CCP stacks due to its steep dip.

\subsection{Results}

In this section radial and transverse receiver functions from 17 seismic stations are used to constrain a major offset in the continental lithosphere across the TaranakiRuapehu Line. First, back azimuth and epicentral distance plots are created for three groups of receiver functions, those north of the Line, near the Line, and well south of the Line. The reason for this is to identify the $P s$ conversion from the Moho and confirm that it is changing from north-south as expected. Second, a receiver function CCP stack across the Taranaki-Ruapehu Line is created to assess lateral changes in Moho depth. The CCP stack is then compared with the equivalent stack from Salmon [2008]. Finally, synthetic receiver function profiles are created to aid with interpretation.

\subsubsection{Back azimuth and epicentral distance stacks}

Receiver functions from 17 seismometers were divided into 3 groups (Figure 4.13). Those from stations north of the Taranaki-Ruapehu Line (red group stations: PEP, FUN, TUN, TWVZ, KAI, KUR, ERU and PKVZ), those situated at or adjacent to the Line (blue group stations: MOT, SOW, RAE, HOK and WAI), and those to the south of the Line (green group stations: PAP, SUN, PAR, and WRR). The stations 
Figure 4.13: Groups of seismic stations used for receiver function analysis. The red group has piercing points which are north of the Taranaki-Ruapehu Line, the blue group has piercing points which are at/south of the Line, the green group has piercing points which are far south of the Line. For each group, receiver functions are plotted in terms of backazimuth and epicentral distance. Stations names for each group are at the bottom of the figure, and are ordered from north-south. Black dots represent long-term seismicity recorded by GeoNet at depths of $15-50 \mathrm{~km}$ [Fenaughty, 2015]. Stations are from RATTIL, TRAP and GeoNet deployments.

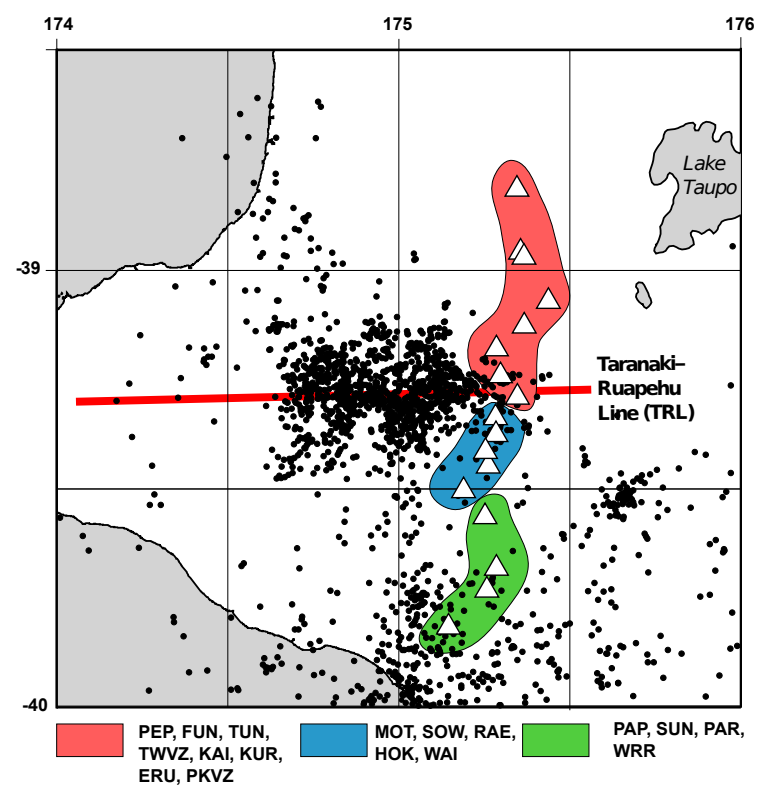

which comprise each group have similar receiver functions (based on an interpretation of station-specific receiver functions in Appendix D). Receiver functions were binned according to back azimuth and epicentral distance, and incorporate spectral weighting which gives a higher contribution to receiver functions with the greatest signal/noise ratio (explained in Section 4.3.3).

Receiver functions from the 'red group' stations north of the Taranaki-Ruapehu Line (Figure 4.14) have a crisp positive (red) wavelet centred at 0 time, interpreted to be the refracted $P p$ arrival. The $P p$ arrival tends to be stronger for closer events. A second positive (red) wavelet occurs between 3-4s time. This is interpreted to be the Ps conversion from the Moho boundary. There is little coherent energy on the transverse component, which is expected from a flat Moho interface with little sedimentary overburden.

Receiver functions from the 'blue group' stations adjacent to or slightly south of the Taranaki-Ruapehu Line (Figure 4.15) have a $P p$ arrival that is slightly offset from 0 time. This observation is consistent with an increase in sedimentary basin thickness. A second positive wavelet occurs between 4 and $6 \mathrm{~s}$ time and is often double-peaked in nature. Significant energy bleed can be observed in the transverse back azimuth stack from about $4 \mathrm{~s}$ time which might be the result of a dipping layer.

Receiver functions from 'green group' stations well south of the Taranaki-Ruapehu Line (Figure 4.16) have a broad positive wavelet that is offset $\sim 1$ s from 0 time. This is consistent with a further increase in sedimentary basin thickness. A second positive wavelet occurs at about 6 to $8 \mathrm{~s}$ time and is also double-peaked in nature. 

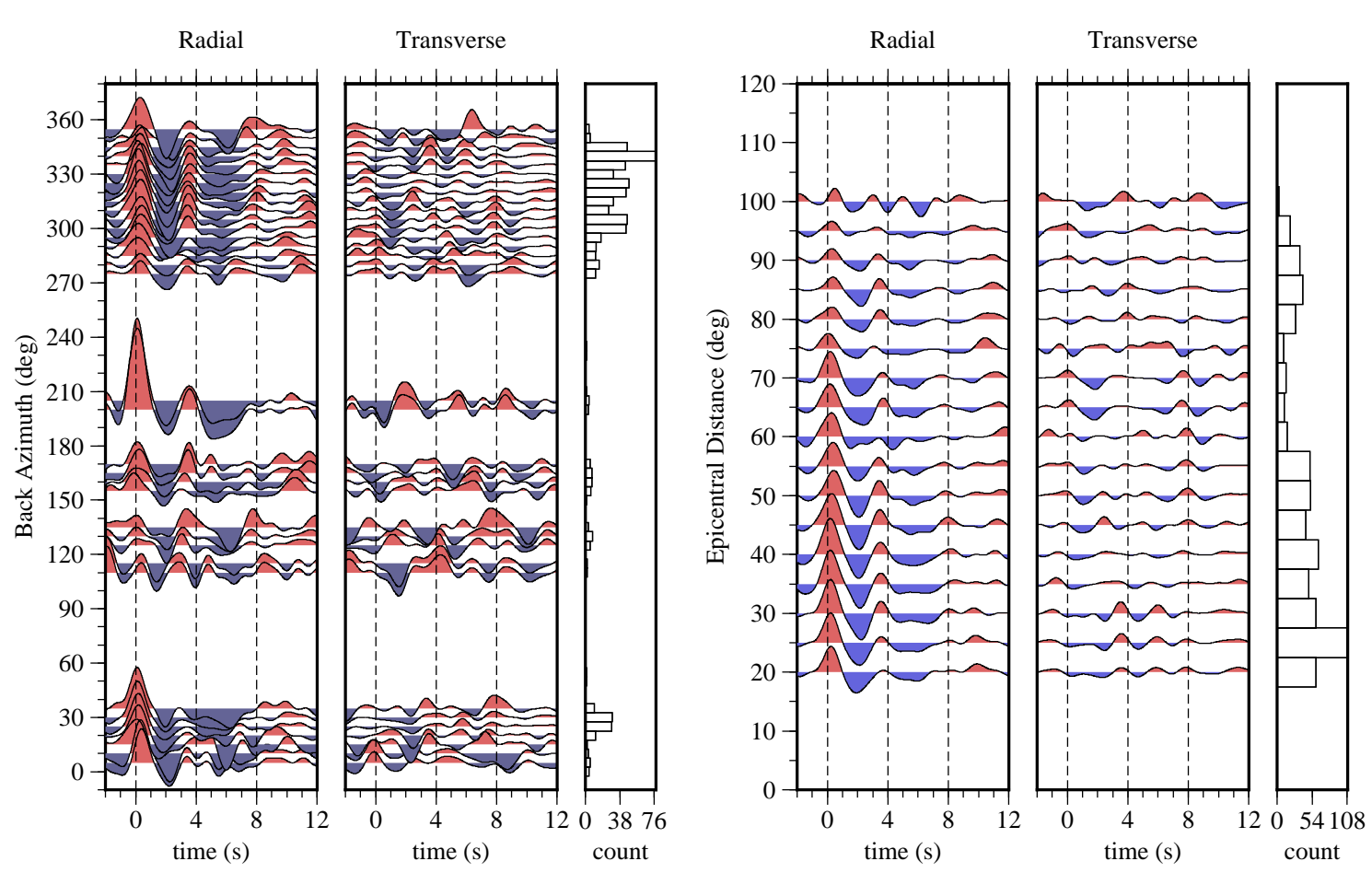

Figure 4.14: Back azimuth (left) and Epicentral distance (right) plots of ZRT receiver functions from north of the Taranaki-Ruapehu Line (stations PEP, TUN, FUN, TWVZ, KAI, KUR, ERU and PKVZ). Receiver functions were low-pass filtered $(1 \mathrm{~Hz})$ and binned every $10^{\circ}$ in back azimuth and $5^{\circ}$ in epicentral distance. Colours represent phase, red is positive, blue is negative.

There is significant energy bleed on the transverse back azimuth plot at all times, consistent with relatively thick basin sediments and a dipping Moho.

In summary, a sharp Ps conversion at 4 s north of the Taranaki-Ruapehu Line turns into a broad 6-8 s peak south of the Taranaki-Ruapehu Line. This is interpreted to be a major change in crustal thickness.

\subsubsection{Common Conversion Point stack}

A $140 \mathrm{~km}$-long receiver function stack across to the Taranaki-Ruapehu Line is shown in Figure 4.17. The top panel is a reproduction of Figure 4.2, which was published in Salmon et al. [2011]. The bottom panel is a revision of the top panel which includes receiver functions from 10 extra seismic stations. In this section, the top panel will be referred to as the 'original' stack and the bottom panel as the 'revised' stack.

The most important observation in the revised stack is that Moho beneath the Wanganui Basin appears to be flat rather than dipping. The Moho then significantly 

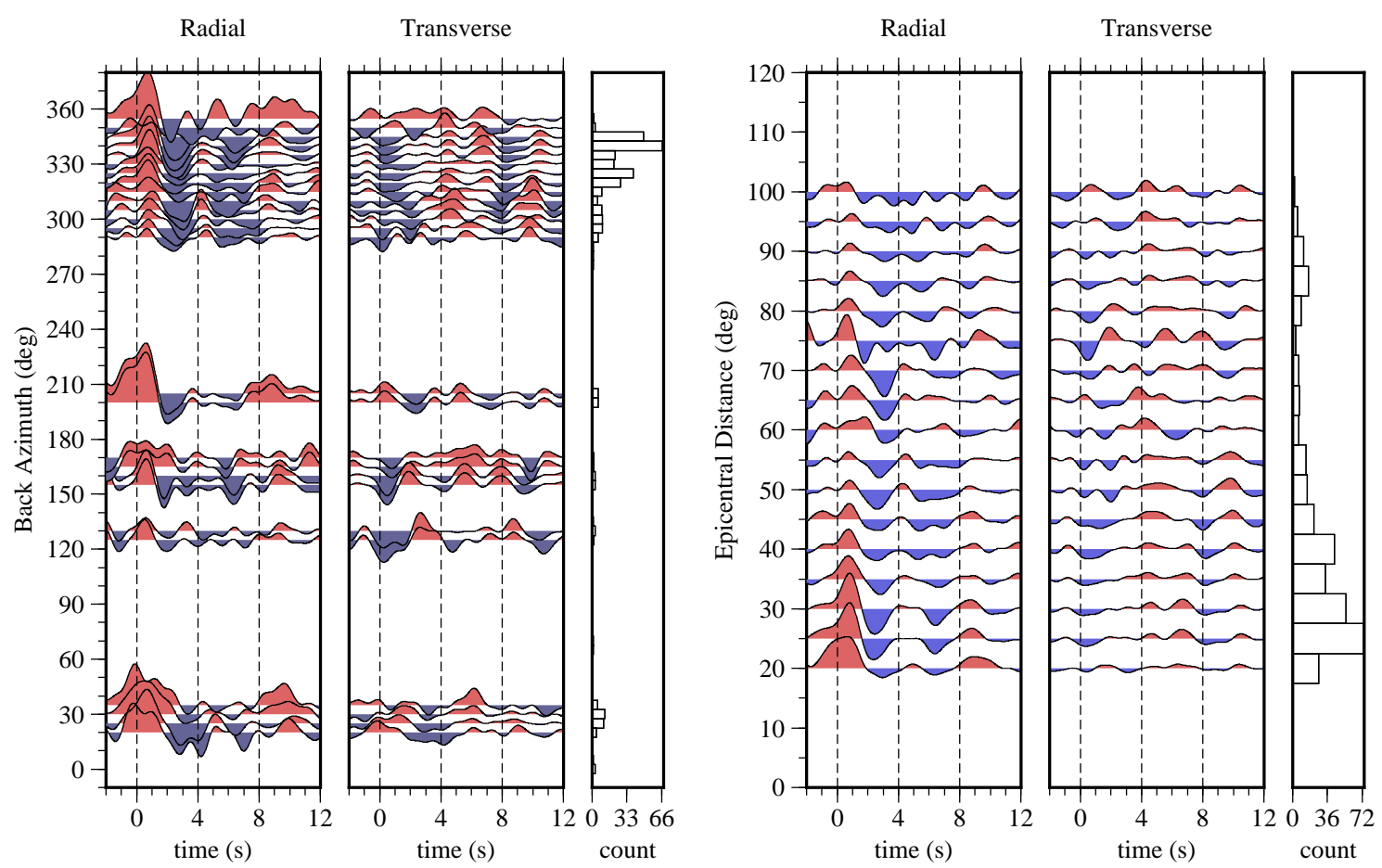

Figure 4.15: Back azimuth (left) and epicentral distance (right) plots of ZRT receiver functions near the Taranaki-Ruapehu Line (stations MOT, SOW, RAE, HOK and WAI). Receiver functions were low-pass filtered $(1 \mathrm{~Hz})$ and binned every $10^{\circ}$ in back azimuth and $5^{\circ}$ in epicentral distance. Colours represent phase, red is positive, blue is negative.

weakens towards the southern end of both stacks ('Vanishing Moho' in Figure 4.17). The importance of a flat and vanishing Moho will be discussed in relation to activesource seismic observations in Chapter 5 , and then compared to a similar feature called a 'Moho hole' in the Sierra Nevada in Chapter 6. The Moho conversion can also be seen continuing to the north due to extra station coverage.

Another important observation is that the amplitude of several features in the revised stack has been enhanced or diminished (a few prominent examples are identified in Figure 4.17). This is a well-known property of seismic stacking with extra data, where primary energy is strengthened and multiple energy is attenuated. This property is significant to the revised CCP stack because more than twice the number of seismic stations and receiver function events are used compared to the original stack. Circled in Figure 4.17, 'multiple energy' in the original stack has been diminished in the revised stack, as has a shallower 'dipping crustal layer'. Towards the bottom of the profile, what Salmon et al. [2011] interpreted as a mantle conversion is attenuated in the revised profile, suggesting that it might be a multiple. Conversely, a deeper conversion on the southern end of the profile has been strengthened. This feature, which has the appearance of a second Moho conversion, will be discussed later. 

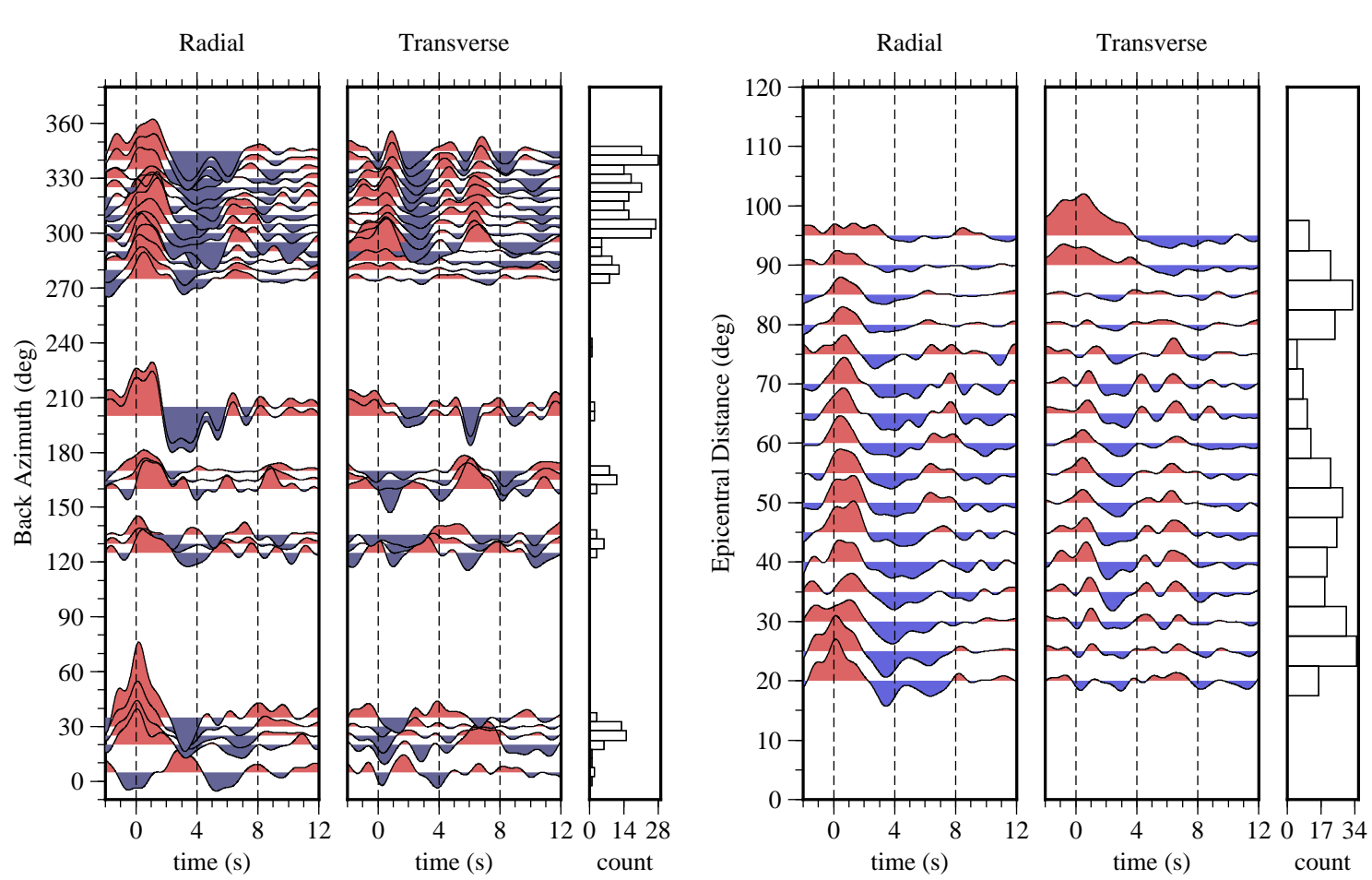

Figure 4.16: Back azimuth (left) and epicentral distance (right) plots of ZRT receiver functions from stations south of the Taranaki-Ruapehu Line (stations PAP, SUN, PAR and WRR). Receiver functions were low-pass filtered $(1 \mathrm{~Hz})$ and binned every $10^{\circ}$ in back azimuth and $5^{\circ}$ in epicentral distance. Colours represent phase, red is positive, blue is negative.

The Moho step (at $\sim 30 \mathrm{~km}$ depth, $\sim 0 \mathrm{~km}$ distance) is better defined in the revised profile. The depth to the Moho increases from $28 \mathrm{~km}$ north of the Taranaki-Ruapehu Line to $35 \mathrm{~km}$ deep south of the Line. In the next section, these structural constraints are used as parameters for forward modelling, where synthetic CCP stacks are created using simple earth models which are then compared to the observed CCP stack to aid with interpretation (Section 4.5.3).

\subsubsection{Synthetic Common Conversion Point stacks}

Synthetic receiver functions were created from a 2-layer earth model. The top layer represents the crust, and the bottom layer the upper mantle (Figure 4.11). The synthetic Moho is the interface between the two layers. The Moho was assigned dips of $10-90^{\circ}$ resulting in nine separate earth models, and rays were passed through each model. The incidence angles and station spacing of synthetic earthquakes are chosen to reflect those of the actual earthquakes. The output includes a 'radial' seismic trace which is equivalent to a receiver function. Synthetic receiver functions were then been binned and stacked in the same manner as the observed data to 

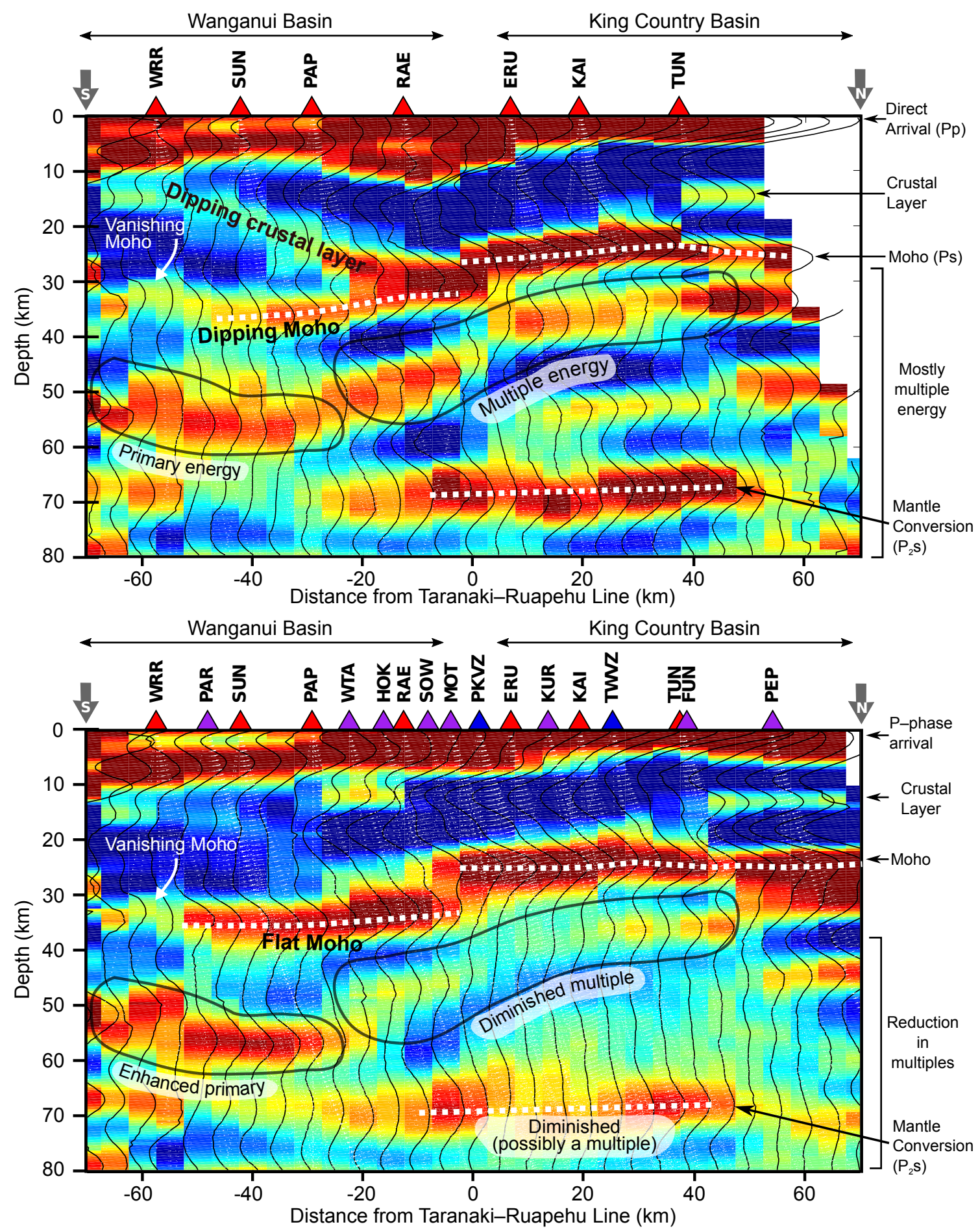

Figure 4.17: Common Conversion Point (CCP) stack across the Taranaki-Ruapehu Line. Top: Reproduction of Salmon et al. [2011] using pre-cut events provided by the author (compare with Figure 4.2). Bottom: Iteration of the above CCP stack which includes receiver functions from 10 additional seismic stations along the profile. Fine, white-dotted lines indicate the raypath of individual teleseismic events. Triangles represent seismic station locations at the surface and are colour-coded by network. Red = TRAP; blue $=$ GeoNet; purple = RATTIL . 
form CCP stacks (as discussed in Section 4.4.4). Note: no sediment/elevation static correction was applied as there was no sedimentary basin or topography to account for in the synthetic earth model.

Nine synthetic CCP stacks are shown in Figure 4.18. For each stack, there is a positive (red) peak centred at $0 \mathrm{~km}$ depth, followed by a second positive peak between $28-35 \mathrm{~km}$. The first peak is the $P p$ phase. The second peak is a $P s$ converted phase from a velocity discontinuity representing the Moho discontinuity.

Only the $10^{\circ}$ synthetic Moho has the appearance of a ramp on a synthetic CCP stack. This is due to frequency limitations of $1 \mathrm{~Hz}$ receiver functions, combined with CCP processing parameters such as 'bin sharing' (where traces are shared between one or more adjacent bins). Dips that are $20^{\circ}$ and higher have a step-like appearance in the CCP stack. An apparent step at low dips highlights the importance of synthetic modelling in the interpretation of receiver function results.

For dips $>50^{\circ}$, a characteristic 'double-peak' occurs at the synthetic Moho step. The double-peak is a manifestation of strong edge diffraction caused by a step-like offset. The diffraction, and other high-angle events, are not clearly visible in the CCP stack due to trace sharing between adjacent bins which acts as a dip filter. If trace sharing is turned off, the diffractions become clearer (Figure 4.19). However, trace sharing remains necessary for attenuating noise on the observed data.

A comparison between synthetic and observed CCP stacks is shown in Figure 4.20. Here, the observed CCP stack is interpreted to be best fit by synthetic earth models dipping $20-50^{\circ}$. This is not a quantitative best-fit value, but instead a qualitative interpretation which uses synthetic CCP stacks as a visual guide to interpret the Moho dip on the observed CCP stack. This approach is similar to Wilson et al. [2004] who constrained the dip of the Moho in the Marlborough Fault System by qualitative comparison between observed and synthetic CCP stacks.

In Figure 4.18, note that dips $>50^{\circ}$ or $<20^{\circ}$ have the appearance of a double-peak or ramp respectively. In other words, a smaller $10^{\circ}$ dip should produce a smooth ramp in a CCP stack. While dips $>50^{\circ}$ should produce a strong double-peak caused by edge diffractions from a step-like offset, yet only a weak double-peak is observed. It is for these reasons that the dip of the Moho at the Taranaki-Ruapehu Line is judged to be between $20-50^{\circ}$. 

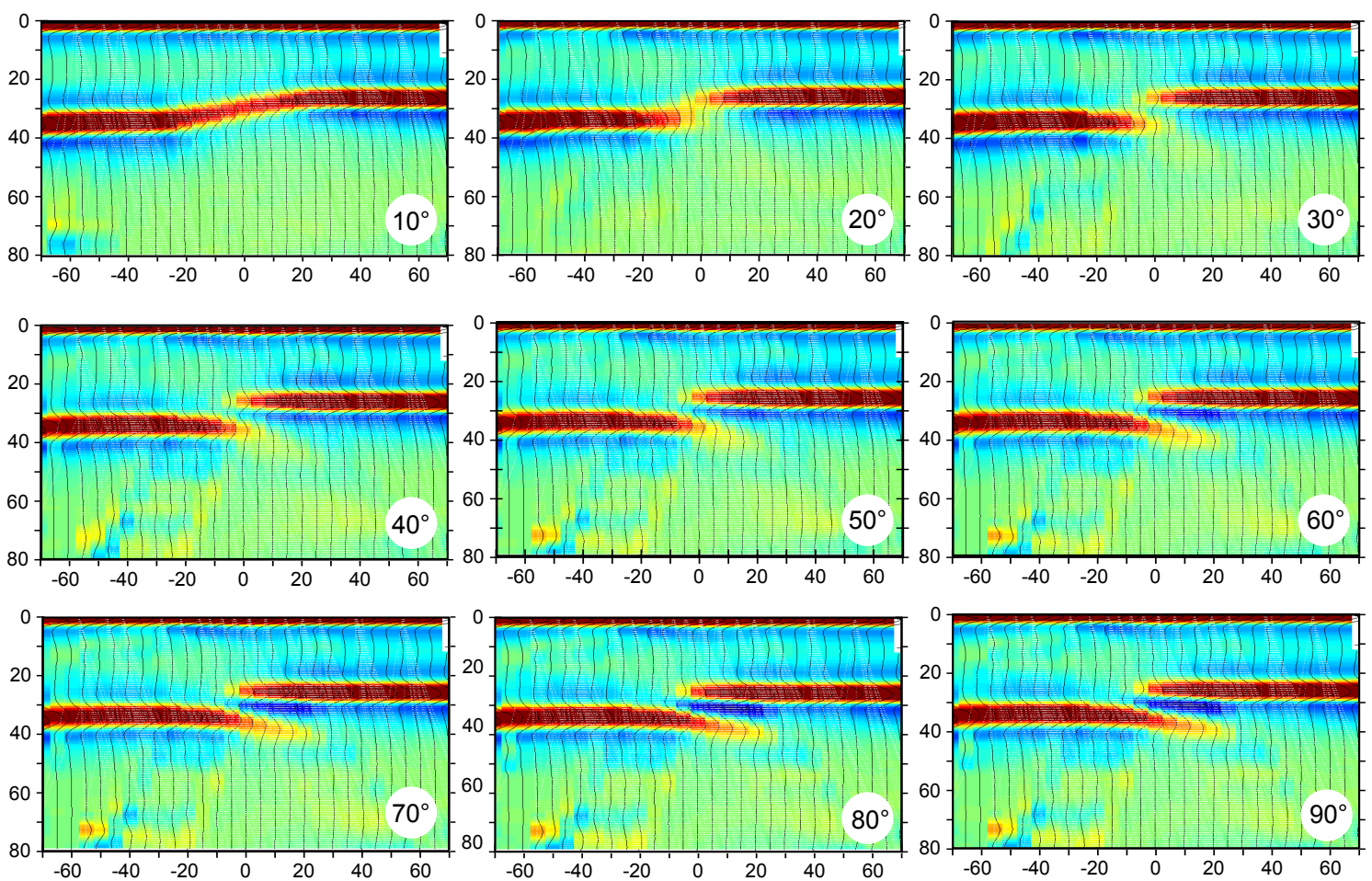

Figure 4.18: Synthetic CCP stacks for linear Moho dips of $10-90^{\circ}$. These receiver functions have a dominant frequency of $1 \mathrm{~Hz}$. Note that even at low dips, a synthetic Moho conversion has a step-like appearance. Distance from the Taranaki-Ruapehu Line $(\mathrm{km})$ is on the $\mathrm{x}$-axis, while depth $(\mathrm{km})$ is on the y-axis.

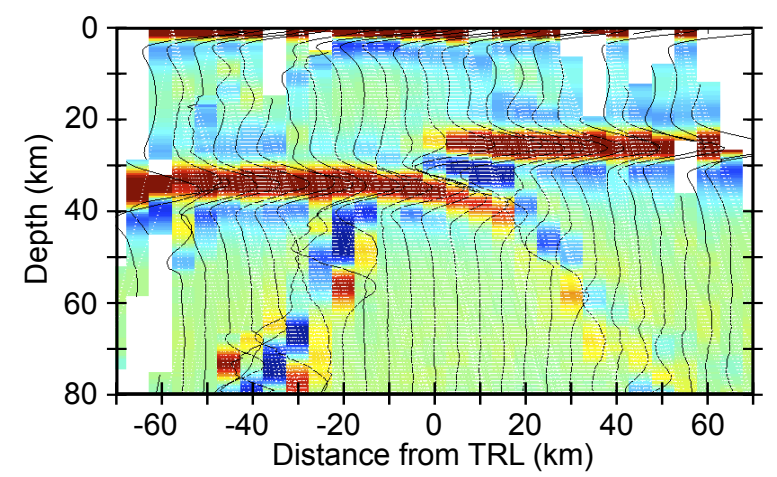

Figure 4.19: Synthetic CCP stack for a $90^{\circ}$ 'vertical step' in a synthetic Moho with no trace sharing between adjacent bins. Note the edge diffractions below $30 \mathrm{~km}$ depth. Diffractions like these cannot be observed in the TR Line receiver function stack due to trace sharing between adjacent bins (compare with the $90^{\circ}$ synthetic stack in Figure 4.18.)

\subsection{Discussion}

The receiver function CCP stack provides a further constraint on the geometry of the Taranaki-Ruapehu Line Moho, which was the primary objective of this chapter. The CCP stack has important implications that future studies of the TR Line should consider. For example, a 'downwarp' of earthquake hypocentres occurs beneath the 
(a) Qualitative 'best fit' synthetic models $\left(20^{\circ}-50^{\circ}\right)$
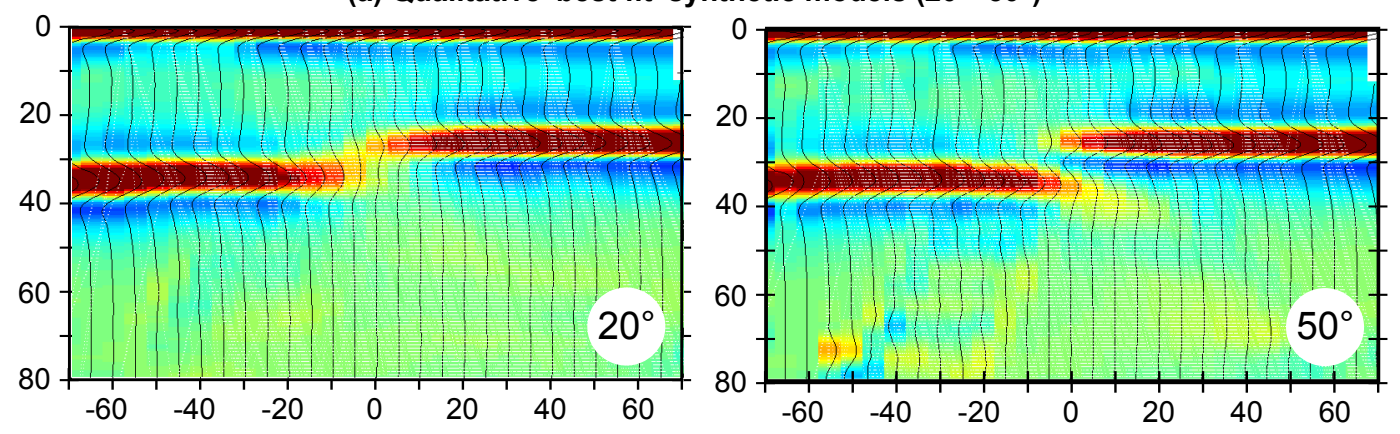

(b) Field data

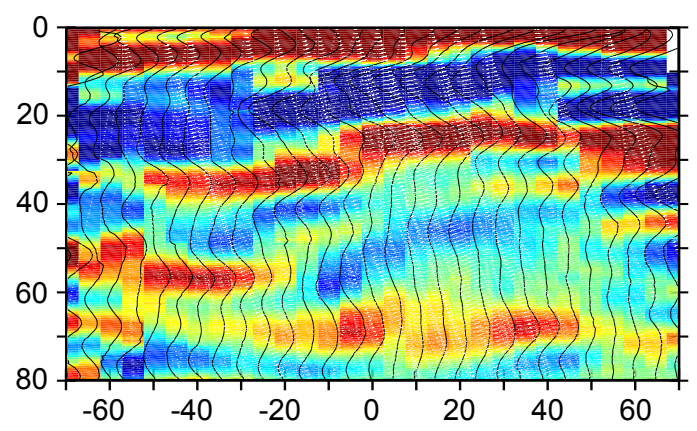

(c) Poorly-fitting synthetic models
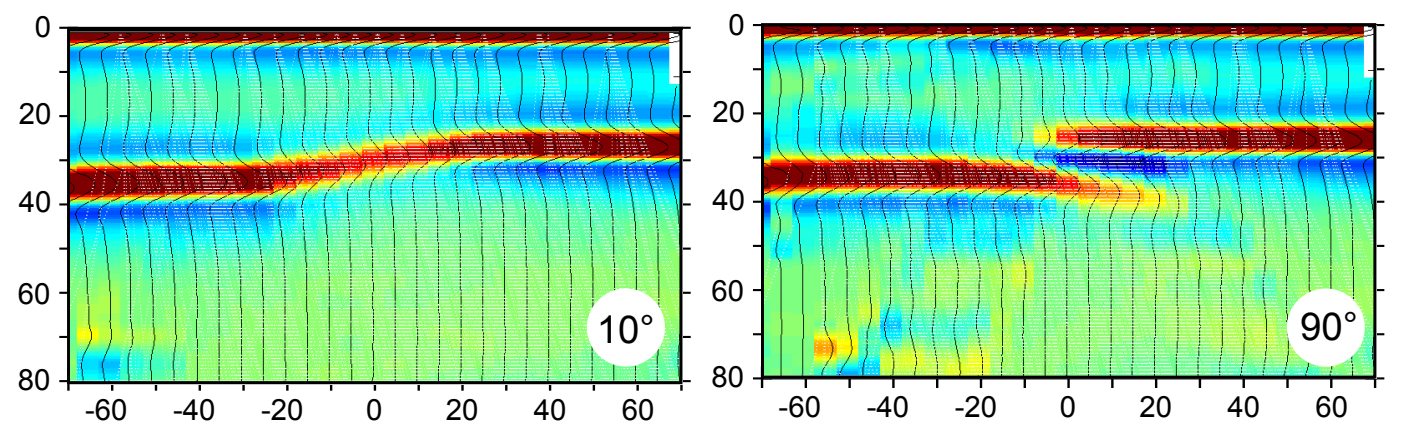

Figure 4.20: Qualitative 'best-fit' synthetic CCP stacks. (a) End-members of synthetic models judged to resemble the observed field data; (b) observed field data; (c) end-members of synthetic models judged to not match the field data. Distance from the TaranakiRuapehu Line $(\mathrm{km})$ is on the $\mathrm{x}$-axis, while depth $(\mathrm{km})$ is on the $\mathrm{y}$-axis. 
TR Line to depths in excess of $50 \mathrm{~km}$ (Figure 3.11). The hypocentres representing this downwarp occur directly beneath and to the west of the CCP stack profile, such that the receiver function piercing points at $30 \mathrm{~km}$ depth intersect the eastern portion of the downwarped deep earthquakes (Figure 4.10). These downwarped earthquakes have been projected onto the CCP stack in Figure 4.21. Note that these earthquakes are observed below the receiver function Moho conversion, and therefore occur in the uppermost mantle. The observation of mantle earthquakes is rare in the continental lithosphere and requires a special explanation [McKenzie et al., 2005; Jackson et al., 2008].

Most mantle earthquakes occur in material that is cooler than $600^{\circ} \mathrm{C}[$ McKenzie et al., 2005]. One possible implication is that the mantle beneath the TaranakiRuapehu Line is unusually cool. Yet the opposite has been implied from geophysical observations. Salmon et al. [2011] estimated mantle temperature on the basis of attenuation and resistivity measurements, and calculated that the region where mantle earthquakes are occurring has a temperature up to $\sim 940^{\circ} \mathrm{C}$ with up to $2 \%$ partial melt.

McKenzie et al. [2005] noted a few cases where earthquakes occurred at temperatures above $600^{\circ} \mathrm{C}$. These events were all in the mantle of oceanic lithosphere beneath the outer rises of trenches and were the result of high strain-rates. However, the mantle earthquakes beneath the Taranaki-Ruapehu Line occur within a continental lithosphere so a different explanation is required. One possibility is that a dynamic process in the mantle is causing localised high strain-rates, such as a Rayleigh-Taylor-type instability. The topic of mantle earthquakes will be revisited the final discussion chapter (Chapter 6), where the observations at the TR Line will be compared to other regions around the world. 


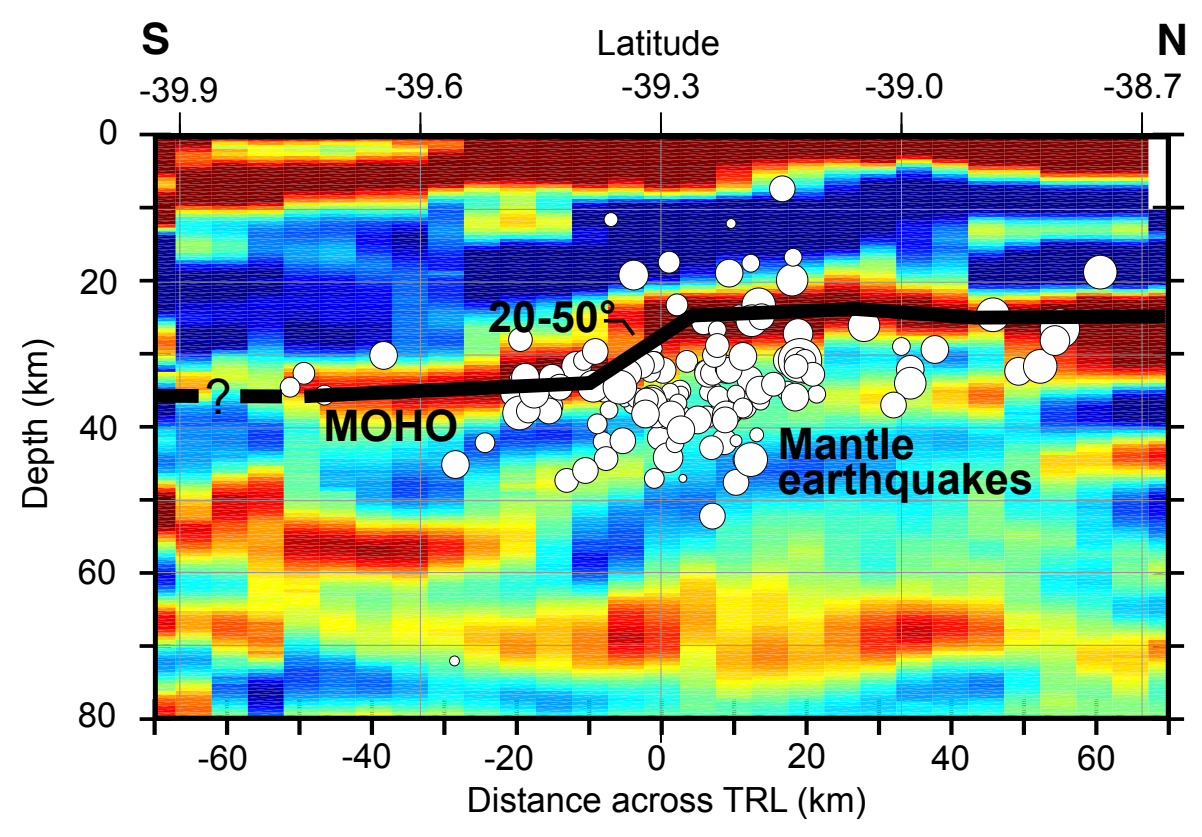

Figure 4.21: Interpreted CCP stack running N-S across the Taranaki-Ruapehu Line. Earthquake hypocentres are from this thesis (Section 3.5.1), and represent a swath beneath the CCP stack and west to the hypocentre downwarp (Figure 4.10). Earthquake magnitudes are between 0.5 and 3.7. 


\section{Chapter 5}

\section{Active-source seismic study}

\subsection{Abstract}

Active-source seismic data from the Seismic Array HiKurangi Experiment (SAHKE) have been analysed to provide new constraints on lower crustal and upper mantle structures beneath the Taranaki and Wanganui basins. The key finding is localised bright reflectivity at Moho depths beneath the Wanganui Basin. This reflectivity is seen on two marine seismic lines (GD100 and SAHKE02), as well as wide-angle seismic reflection/refraction data from Kapiti Island (KIW). Attribute analysis of SAHKE02 shot gathers indicates that this bright reflectivity is associated with relatively low $V_{p}$ and low $Q$, and is probably a soft and weak material in the mantle wedge. Either side of the localised bright reflectivity is a distinctive lack of Moho reflectivity under the Wanganui Basin. Two possibilities are considered to explain this evidence. 1) High pore fluid pressure within the regular mantle, and 2) serpentinisation of the upper mantle wedge. Given that upper mantle temperatures in the Wanganui area are predicted to be low enough to be in the serpentinite stability zone, the latter interpretation is preferred. However, it is possible that both serpentinite and high pore fluid pressures are occurring, in which case it is not easy to separate the contributing effects. If serpentinite is forming, this could have a profound effect on the upper mantle strength and dynamics of the region. 


\subsection{Previous work and study context}

Chapters 3 and 4 investigated the Taranaki-Ruapehu Line at the northern boundary of the Wanganui Basin. Here, the Moho is interpreted to deepen from $25 \mathrm{~km}$ to $35 \mathrm{~km}$ south of the TR Line on the basis of a receiver function CCP stack (Figure 4.21). A key observation is that the $P s$ conversion (which defines the Moho) weakens and disappears at the southern end of the profile under the Wanganui Basin. Why does the Moho disappear? Do other studies of the Wanganui Basin reveal a Moho? This chapter shifts the investigation 140-180 km south of the Taranaki-Ruapehu Line, to the southern end of the Wanganui Basin, to look for answers (Figure 5.1).

The marine seismic reflection profile 'GD100' (Figure 5.1) was the first to image structures from the lower crust and upper mantle of the offshore Wanganui Basin [Davey, 1987; Stern and Davey, 1990]. A key feature of this profile is weak-tovanishing Moho reflectivity under the Wanganui Basin (Figure 5.2). Beneath the adjacent Taranaki Basin a strongly-dipping Moho is clearly imaged, but it disappears under the Taranaki Fault Zone. On the southeast end of the GD100 profile, cross-cutting reflections are observed which is where the subducting Pacific plate is interpreted to be impinging on the Australian plate [Stern and Davey, 1989]. Note the localised bright reflectivity in the Australian plate at Moho depths (red arrow in Figure 5.2). This reflectivity will be investigated in more detail later.

A new marine seismic reflection profile with $15 \mathrm{~s}$ of two-way travel-time information (SAHKE02) has recently been shot that runs parallel to, and $\sim 20 \mathrm{~km}$ southwest of, GD100 (Figure 5.1). SAHKE02 was collected as part of the Seismic Array HiKurangi Experiment [SAHKE, Henrys et al., 2013] and has a more powerful source airgun than GD100, which means more energy that might reflect back from deep structures in the Earth. In this study, raw data from SAHKE02 are processed and compared to GD100 to test whether the missing Moho observation remains. It will again be shown that the Moho has little reflectivity under the Wanganui Basin in SAHKE02.

On the other side of the country, the South East South Island (SESI) deep seismic reflection profile [Godfrey et al., 2001] extended from near Christchurch to near Stewart Island (Figure 5.1 inset). This profile is far from the Wanganui and Taranaki basins, yet SESI crosses 5 of the 6 same basement terranes as GD100 and SAHKE02 (Figure 1.8). SESI is essentially GD100 or SAHKE02 without an active subduction zone. Continuous lower-crustal reflectivity (the base of which defines the Moho) can be tracked across the SESI line (Figure 5.3). The character of these reflectors is thought to be related to changes in basement terranes [Mortimer et al., 2002]. 


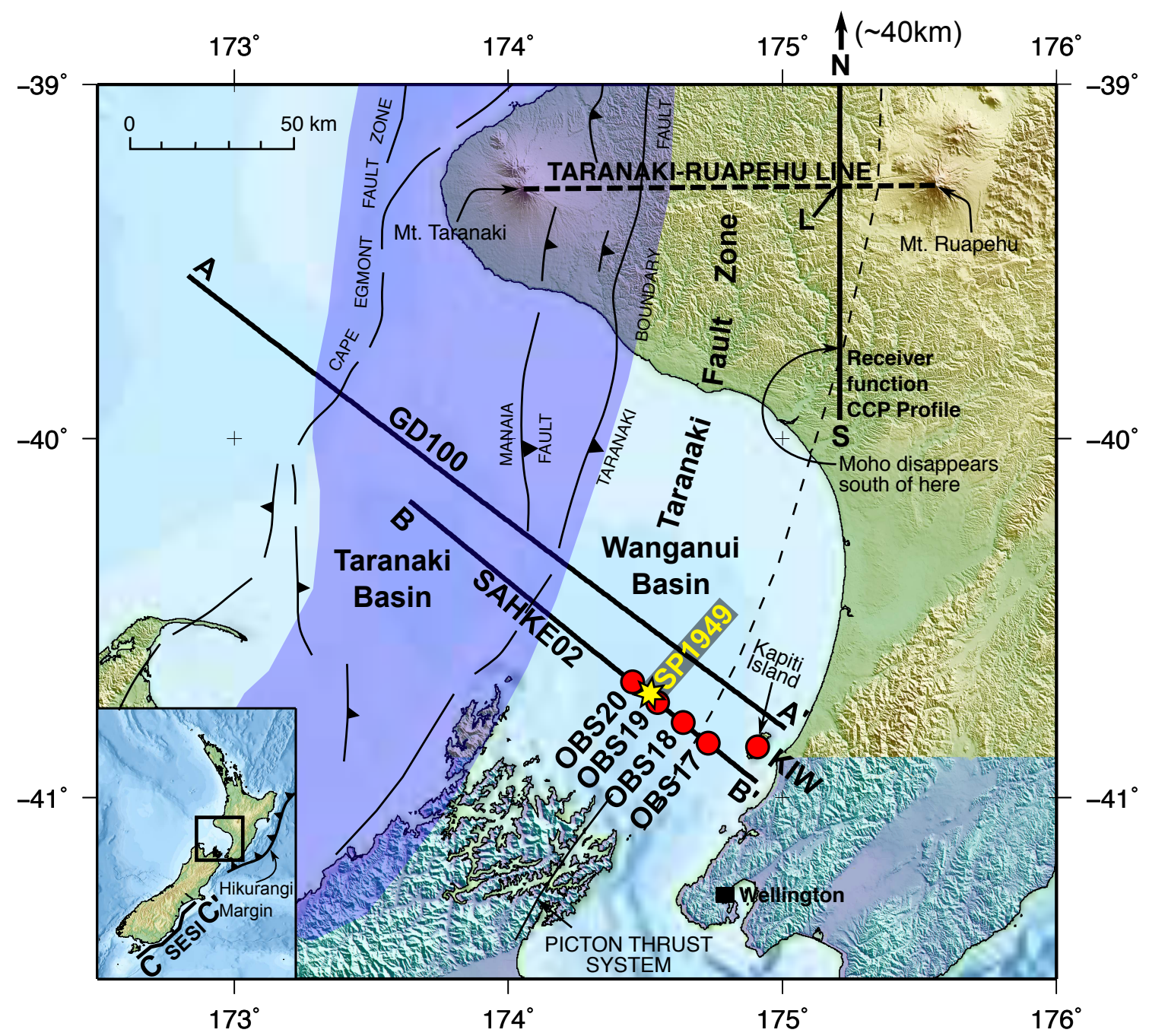

Figure 5.1: The location of seismic datasets considered in this study. The receiver function profile is from Section 4.5.1. GD100 [Stern and Davey, 1990], SESI [Mortimer et al., 2002] and SAHKE02 [Henrys et al., 2013] are marine seismic surveys which image the lower crust and upper mantle. OBS17-20 are ocean bottom seismometers, and KIW is a permanent seismometer of the New Zealand National Seismograph Network. OBS17-20 and KIW recorded airgun blasts from SAHKE02. SP1949 is the shot point location of a single SAHKE02 shot gather used for attribute analysis. Basement faults and the 'Taranaki Fault Zone' region (shaded in purple) after Stern and Davey [1990]. 


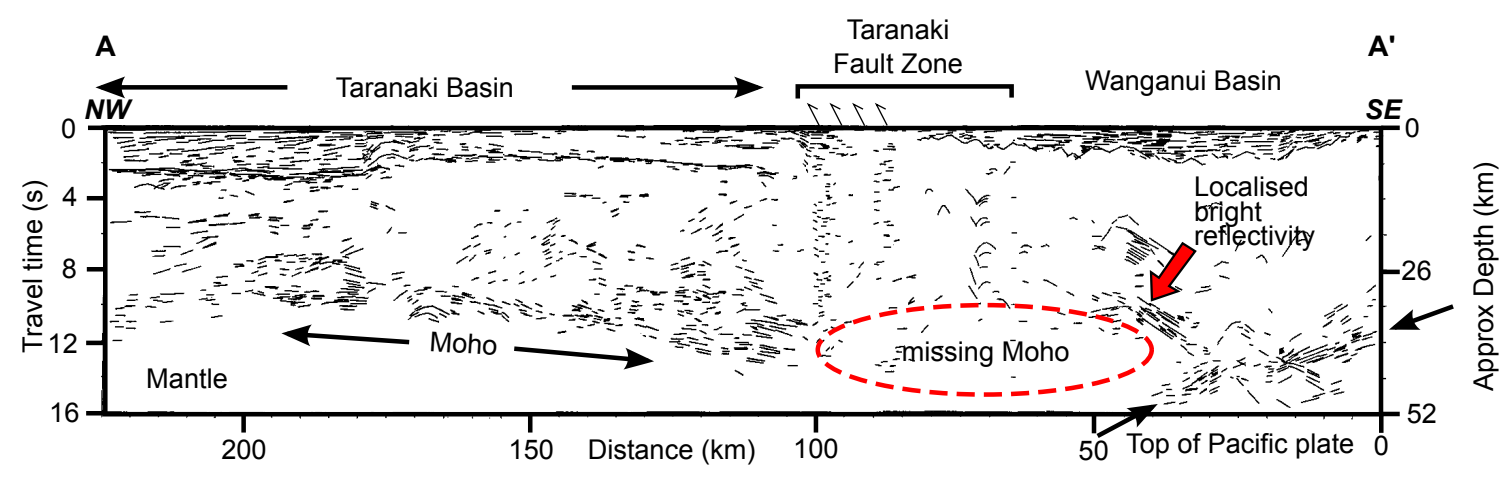

Figure 5.2: Line drawing of the unmigrated GD100 marine seismic profile, [after Stern and Davey, 1990]. The Moho is interpreted to dip landward under the Taranaki Basin. The Moho disappears under the Wanganui Basin. There is also cross-cutting reflectivity between the top of the subducted plate and localised bright reflectivity beneath the centre of the Wanganui Basin (red arrow).

Why do the same basement terranes that contain Moho reflectivity in the southeast South Island seem to contain no Moho reflectivity below the Wanganui Basin?

One possibility is that the cool upper mantle beneath the Wanganui Basin contains an anomalous amount of water derived from the subducted Pacific plate. Fluids travelling through the upper mantle are likely to have pressures close to lithostatic [Christensen, 2004], and so high pore pressure becomes a factor. High pore pressures in crystalline rocks are known to reduce seismic velocities. For example, measurements from Christensen [1989] on a relatively high-porosity (3.6\%) lherzolite xenolith showed that at a confining pressure of $150 \mathrm{MPa}$, an increase of pore pressure from atmospheric to $85 \%$ of confining pressure decreased $V_{p}$ by $8 \%$ and $V_{s}$ by $24 \%$. Therefore, increasing pore pressure would cause the mantle velocity to be closer to that of the lower crust, reducing the strength of the Moho reflection.

Lamb [2015], based on a full geodynamic and thermal model, calculated that the temperature along the subducted Pacific plate interface beneath the Wanganui Basin is $\sim 400^{\circ} \mathrm{C}$, and so the mantle wedge immediately above is probably a similar temperature. This is too cold for partial melt formation. In these conditions free water can exist for a period of time, but will eventually react with olivine to create serpentinite minerals [Constable, 2015].

This leads to another possible explanation for weak-to-missing Moho reflectivity in the Wanganui Basin: partial or pervasive serpentinisation of the mantle wedge, which can diminish, erase, or even invert the seismic contrast associated with the Moho of the overriding plate [Bostock, 2013]. Mantle wedge serpentinisation is a globally-observed phenomenon for mantle wedges that are 'cold', i.e. within the 

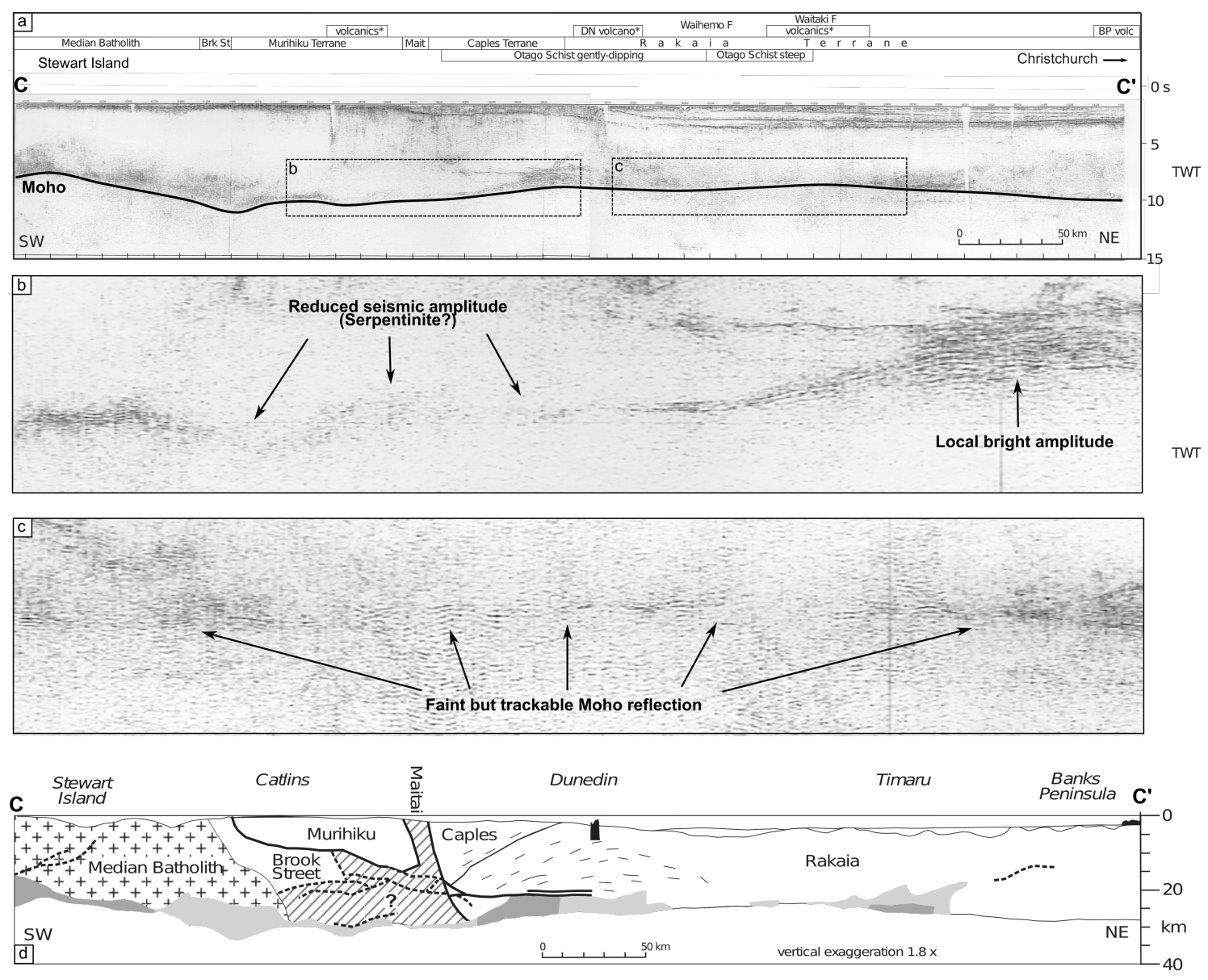

Figure 5.3: The South East South Island (SESI) marine seismic profile (after Mortimer et al. [2002]). SESI is relevant to SAHKE02 and GD100 because it crosses most of the same basement terranes (see Figure 1.8). (a) The SESI profile. The black line represents the Moho discontinuity which can be traced across the entire seismic profile. Two insets are also included which zoom in on the Moho. (b) Shows variations in Moho reflectivity which are interpreted to be caused by changes in basement terrane. Here, the reduced seismic amplitude is associated with the Maitai terrane, which contains the partially-serpentinised Dun Mountain Ophiolite Belt. (c) Shows the fabric of the Rakaia terrane, which is dominated by Greywacke, and is analogous to the basement of the Wanganui Basin. (d) A geological and tectonic interpretation of the SESI profile shows the relationship between Moho reflectivity and basement terranes. Dashed lines are schist foliations; heavy lines are interpreted faults; black shading represents Neogene volcanics; light and dark grey shading represents high seismic reflectivity zones; diagonal shading represents possible imbrication of the Maitai and/or Brook Street ophiolite and metasediments. 
serpentinite stability zone $\left[<600^{\circ} \mathrm{C}\right.$, Hacker et al., 2003; Christensen, 2004]. Serpentinisation has significant effects on the physical and mechanical properties of the mantle wedge, including changes in seismic velocity and reflectivity, an increase in magnetisation, reduction in density, increase in electrical conductivity, and reduction in mechanical strength [Hyndman and Peacock, 2003]. Dehydration processes in the subducting plate progressively alter mantle peridotite to serpentinite, which over millions of years can result in complete serpentinisation of the mantle wedge.

In this study, near-vertical and wide-angle seismic reflection data will be analysed to constrain structures in the lower crust and upper mantle beneath the Taranaki and Wanganui basins. It will be shown that the Wanganui Basin Moho is weakto-absent in near-vertical and possibly wide-angle seismic reflection/refraction data. The exception is one localised region of bright reflectivity at Moho depths which is associated with low $Q$ and low $P_{s}$, which was determined using the spectral ratio method and polarity analysis respectively. Interpretations for both the weak-toabsent and bright reflectivity include high pore fluid pressure and the presence of a serpentinised mantle wedge.

\subsection{Active-source theory}

This section explains active-source seismic theories and techniques used to study the Wanganui and Taranaki basins.

\subsubsection{Reflection seismology}

When shockwaves pass through the Earth some energy will reflect back to the surface after impinging on an acoustic impedance boundary (e.g. rock layers with different density and velocity characteristics). In reflection seismology, the shockwave is typically produced by an airgun (at sea), or vibroseis, weight drop, dynamite or hammer (on land). Energy is recorded at the surface by way of a seismic transducer, usually a geophone, hydrophone or seismometer (Figure 5.4).

The recorded data are then processed on a workstation or supercomputer, and the final deliverable is in the form of a 'stacked' seismic section which is a pseudogeological cross-section of the Earth showing variations in seismic reflectivity which usually correlate with geological layering. Reflection seismology is primarily used by oil and gas exploration companies to characterise sedimentary basins before and 


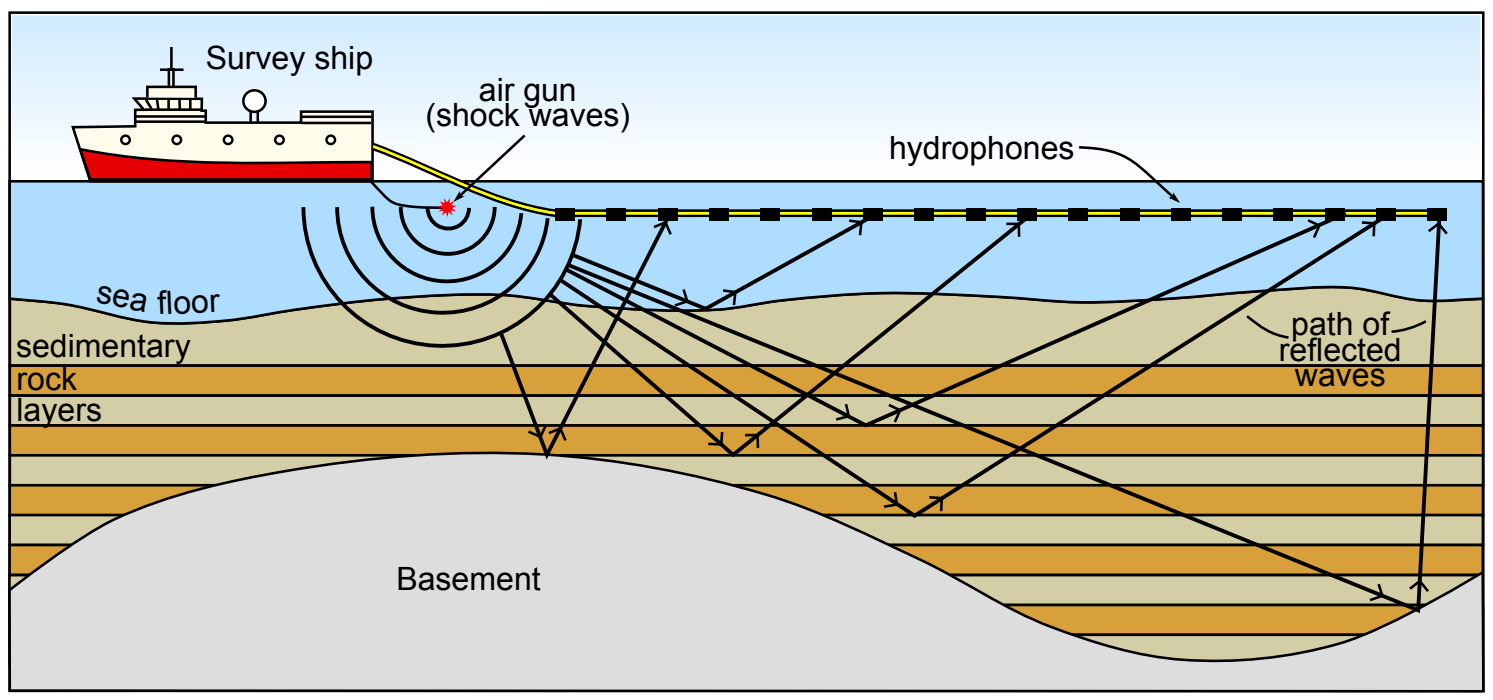

Figure 5.4: Schematic diagram of the marine seismic reflection technique. Shockwaves of sound energy penetrate the subsurface and are reflected back from rock layers to hydrophones towed behind a seismic vessel.

after drilling. Consequently, most seismic processing software and techniques have been developed with oil exploration in mind.

The seismic reflection technique has also proved useful for imaging the Earth's crust and upper mantle. This work was pioneered by groups such as the Consortium for Continental Reflection Profiling (COCORP), and the British Institutions Reflection Profiling Syndicate (BIRPS) [e.g. Cook et al., 1979; Matthews et al., 1990; Oliver, 1998]. One of the key findings from early reflection studies is that it is possible to detect features such as thrust faults in the lower crust and upper mantle [Brewer et al., 1983]. Reflection seismology also has the power to look beneath mountain ranges [Stern et al., 2001], into subduction zones [Matsuzawa et al., 1980; Clowes et al., 1987], and has recently been used to study the seismic reflection character of regions containing slow-slip events [Nedimović et al., 2003; Bell et al., 2010].

In this study, SAHKE02 marine seismic reflection data are processed and interpreted to constrain lower crust and upper mantle structures beneath the Taranaki and Wanganui basins. The processing effort takes advantage of commercial seismic processing software and employs techniques that are widely used in the oil and gas industry. A detailed 'processing workbook' is kept to explain how and why each technique was applied (Appendix F). For a theoretical review of common geophysical processing techniques see Sheriff [2002], and for a practical review refer to Yilmaz [2001]. 


\subsubsection{Zoeppritz equations}

The seismic reflection technique works because at most geological boundaries a small fraction of seismic energy will reflect back to the surface. Zoeppritz equations explain this phenomenon by describing the partitioning of seismic wave energy at an interface as a function of incidence angle [Zoeppritz, 1919; Sheriff and Geldart, 1995]. An incident P-wave which impinges on a seismic boundary can have its energy partitioned into a transmitted $\mathrm{P}$-wave, transmitted $\mathrm{S}$-wave, reflected $\mathrm{P}$-wave and reflected S-wave (Figure 5.5).

Figure 5.5: Partition of seismic energy at an interface. For each layer, $V_{P}$ is the Pwave velocity, $V_{S}$ is the $\mathrm{S}$-wave velocity, and $\rho$ is density. The two layers must have different velocities and/or densities for there to be a acoustic impedance contrast between them. Angle $\theta_{P}$ relates to $\mathrm{P}$-wave angles and $\theta_{S}$ relates to S-wave angles. Zoeppritz equations link all of these variables together (Equation (5.2)).

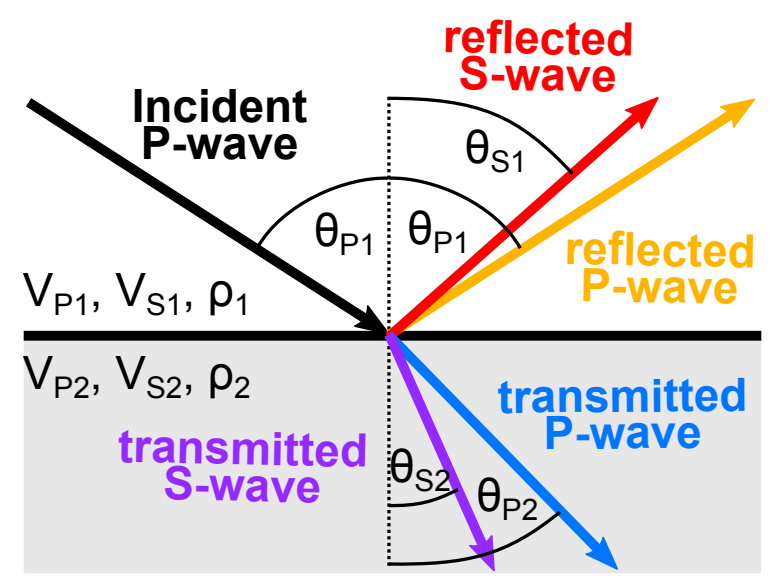

First, the angles of each wave are calculated (Snell's law):

$$
\frac{\sin \theta_{P 1}}{V_{P 1}}=\frac{\sin \theta_{S 1}}{V_{S 1}}=\frac{\sin \theta_{P 2}}{V_{P 2}}=\frac{\sin \theta_{S 2}}{V_{S 2}}
$$

Second, reflection and transmission coefficients are solved (Zoeppritz equations, Sheriff and Geldart [1995]):

$\left[\begin{array}{cccc}\cos \theta_{P 1} & -\sin \theta_{S 1} & \cos \theta_{P 2} & \sin \theta_{S 2} \\ \sin \theta_{P 1} & \cos \theta_{S 1} & -\sin \theta_{P 2} & \cos \theta_{S 2} \\ Z_{1} \cos 2 \theta_{S 1} & -W_{1} \sin 2 \theta_{S 1} & -Z_{2} \cos 2 \theta_{S 2} & -W_{2} \sin 2 \theta_{S 2} \\ \frac{V_{S 1}}{V_{P 1}} W_{1} \sin 2 \theta_{P 1} & W_{1} \cos 2 \theta_{S 1} & \frac{V_{S 2}}{V_{P 2}} W_{2} \sin 2 \theta_{P 2} & -W_{2} \cos 2 \theta_{S 2}\end{array}\right]\left[\begin{array}{c}R_{P} \\ R_{S} \\ T_{P} \\ T_{S}\end{array}\right]=\left[\begin{array}{c}\cos \theta_{P 1} \\ -\sin \theta_{S 1} \\ -Z_{1} \cos 2 \theta_{S 1} \\ \frac{V_{S 1}}{V_{P 1}} W_{1} \sin 2 \theta_{P 1}\end{array}\right]$

Here, $Z_{i}=\rho_{i} V_{P i}, W_{i}=\rho_{i} V_{S i}$, while $R_{P}, R_{S}, T_{P}$, and $T_{S}$ are the amplitudes of the reflected and transmitted $\mathrm{P}$ - and $\mathrm{S}$-waves and the transmitted $\mathrm{P}$ - and $\mathrm{S}$-waves respectively. 
This information is relevant to crustal seismic studies for at least two reasons: 1) Transmitted and reflected seismic energy can disappear or strengthen based on incidence angle. In other words, a reflection seen in wide-angle seismic data might not be visible on near-vertical seismic data. 2) The acoustic properties of the two layers can change so that a reversal in impedance contrast (or polarity) occurs. In this thesis the 'CREWES Zoeppritz Explorer', which implements the Zoeppritz equations, will be used to characterise the Moho interface in terms of reflection and transmission coefficients.

\subsubsection{Seismic attenuation}

As seismic waves propagate through the Earth their elastic energy is attenuated by absorption and scattering. Absorption relates to elastic energy loss by anelastic processes which produce heat due to friction or viscosity. Geological examples include fluid movement [Dvorkin and Nur, 1993] and friction between grains or crack faces [Johnston et al., 1979]. Scattering relates to the distortion of the wavefront caused by small-scale random heterogeneities or other obstacles found in Earth materials. Geological examples include topographic irregularities [Gilbert and Knopoff, 1960] and karsts or vugs in carbonate rocks [Hackert and Parra, 2003]. Attenuation is described in terms of the seismic quality factor $(Q)$, which is essentially the energy lost per oscillation cycle [Fowler, 1990]:

$$
Q=-\frac{2 \pi E}{T \frac{d E}{d t}}
$$

Where $E$ is the peak energy, $T$ is the period of the seismic wave, and $t$ is time. Integrating this equation gives attenuation as the variation of energy with time:

$$
E(t)=E_{0} e^{\frac{-2 \pi t}{Q T}}
$$

Such that $E_{0}$ is the energy at $t=0$. This equation can be recast in terms of motion rather than energy which is more useful in seismology. Here, displacement amplitudes are proportional to the square root of the energy [Fowler, 1990]:

$$
A(t)=A_{0} e^{\frac{-\pi t}{Q T}}=A_{0} e^{\frac{-\pi f t}{Q}}
$$


Where $A_{0}$ is the displacement amplitude at $t=0$ and $f$ is the frequency. Equation (5.5) describes the exponential decay of seismic amplitude due to attenuation. Note that the rate of decay increases with decreasing $Q$ and increasing $f$. Therefore, low $Q$ materials are highly attenuating, and higher seismic frequencies are attenuated more than lower seismic frequencies.

On a seismic reflection profile, attenuation $\left(Q^{-1}\right)$ manifests as a decay of seismic energy and seismic frequency $f$ as a function of travelling distance, which is independent of geometrical spreading and energy partition at interfaces [Zhou, 2014]. In this study, crustal/mantle reflections are compared to each other to see how much attenuation has occurred between those reflections.

One of the most popular and robust ways to calculate $Q$ from seismic data is the spectral ratio method [Raikes and White, 1984; White, 1992]. Here, the natural logarithm of the ratio between amplitude spectra of subjacent reflectors $A(f)_{2} / A(f)_{1}$ separated by two-way traveltime difference $\Delta t$ is linearly related to $Q$ as follows:

$$
\ln \left[A_{2}(f) / A_{1}(f)\right]=\pi(\Delta t) f / Q
$$

In other words, $\ln \left[A_{2}(f) / A_{1}(f)\right]$ against frequency $f$ yields a negative slope $p$ from which $Q$ can be calculated:

$$
p=-\pi(\Delta t) / Q
$$

White [1992] also proposed a guide to standard error $E$ determination for $Q$, which can be parameterized as follows:

$$
\begin{aligned}
& E=\sqrt{6 Q^{2} /\left[\pi^{2}(\Delta t)^{2} B^{3} T\right]} \\
& B=f_{h}+(b / 2)-\left(f_{i}-(b / 2)\right)
\end{aligned}
$$

Where $T$ is the duration of the data segment, and $b$ is the bandwidth of the spectral window, defined as the difference between the upper and lower frequency bounds, $f_{h}$ and $f_{i}$, respectively.

\subsubsection{Ray tracing}

Ray tracing determines the raypath of a seismic wave through a specified velocity model. Ray tracing is particularly useful for unraveling seismic traveltime measure- 
ments which have been distorted by velocity complications [May and Covey, 1981]. In this study travel-time measurements of prominent seismic features have been made on a wide-angle receiver gather, and ray tracing is used to help discover the true subsurface location of this energy.

The interactive MacRay program [Lienert et al., 1986] is used for ray tracing. Velocity models in MacRay are defined by two or more interfaces extending across the model. Any pair of successive interfaces describe a layer. The ray tracing algorithm that is used calculates the propagation of rays within a layer by the stepwise integration of a set of first order differential equations:

$$
\begin{aligned}
\frac{d}{d t} x(t) & =V(x, z) \sin \theta \\
\frac{d}{d t} z(t) & =V(x, z) \cos \theta \\
\frac{d}{d t} \theta(t) & =\frac{d V}{d x} \cos \theta-\frac{d V}{d z} \sin \theta
\end{aligned}
$$

Where $\theta$ is the ray's angle from vertical. By supplying a definition of the $V(x, z)$ and initial values for $x, z, t$, and $\theta$, subsequent values of $x, z, t$, and $\theta$ may be calculated by simultaneously integrating the above three equations over small steps in time. At the boundary between layers, Snell's law is applied (Equation (5.1)) and the calculation is continued.

\subsubsection{Hand-migration}

In reflection seismology, migration is an inversion operation which repositions seismic information so that reflections and diffractions are plotted at their true subsurface locations [Sheriff, 2002]. The need for this process arises because seismic elements are recorded at surface positions different from their actual subsurface position due to variable velocities and dipping horizons.

Most modern migration techniques are data-driven and designed for high signal/noise ratio seismic reflection data. For deep crustal/mantle reflectors, the signal/noise ratio assumption breaks down and the migration procedure often behaves poorly, producing artefacts such as 'migration smiles' which obscure the true reflectivity [Warner, 1987]. One way around this is to apply a simple hand-migration technique to deep reflectors picked on unmigrated seismic profiles [e.g. Stern and Davey, 1989]. Later in this chapter, hand-migration formula in Yilmaz [2001] will be ap- 
plied to marine line SAHKE02 to migrate $\sim 30 \mathrm{~km}$-deep reflectors located beneath the Wanganui Basin. This formula can be explained as follows:

Consider reflector segment $C D$ in Figure 5.6a. Assume that $C D$ migrates to $C^{\prime} D^{\prime}$, and point $E$ on $C D$ migrates to point $E^{\prime}$ on $C^{\prime} D^{\prime}$. The horizontal and vertical (time) displacements, $d_{x}$ and $d_{t}$, and the dip $\Delta \tau / \Delta x$, all measured on the migrated time section (Figure 5.6b), can be expressed in terms of medium velocity $v$, traveltime $t$, and apparent $\operatorname{dip} \Delta t / \Delta x$ as measured on the unmigrated time section (Figure 5.6a). The following formula can then be derived [Chun and Jacewitz, 1981; Yilmaz, 2001]:

(a)

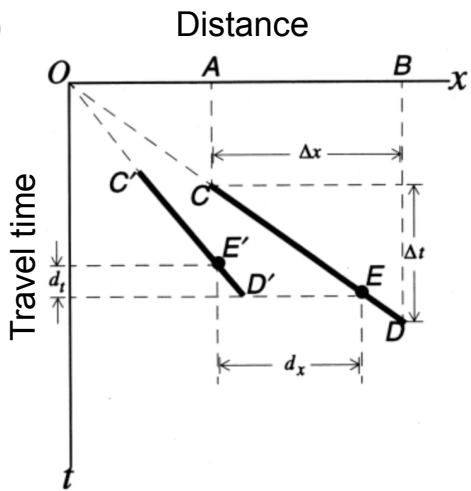

(b)

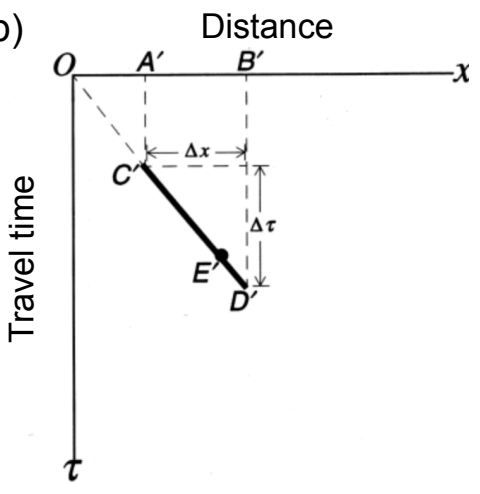

Figure 5.6: Quantitative analysis of the hand-migration process for a seismic reflection event [after Yilmaz, 2001]. Dipping event $A B$ on the unmigrated cross-section (a) is moved to $A^{\prime} B^{\prime}$ on the migrated cross-section (b). The event after migration is also superimposed on the unmigrated section so that the relative position of the event before and after migration can be compared. Point $C$ on dipping reflector $A B$ is moved to $C^{\prime}$ after migration. The amount of horizontal displacement $d_{x}$, vertical displacement $d_{t}$, and the dip $\Delta \tau / \Delta x$ after migration is calculated from Equation (5.10).

$$
\begin{aligned}
d_{x} & =\frac{v^{2} t}{4} \frac{\Delta t}{\Delta x} \\
d_{t} & =t\left[1-\sqrt{1-\left(\frac{v \Delta t}{2 \Delta x}\right)^{2}}\right] \\
\frac{\Delta \tau}{\Delta x} & =\frac{\Delta t}{\Delta x} \frac{1}{\sqrt{1-\left(\frac{v \Delta t}{2 \Delta x}\right)^{2}}}
\end{aligned}
$$

Specifically, adding or subtracting $d_{x}$ and $d_{t}$ to the unmigrated $x$ and $\tau$ defines their migrated position. 


\subsection{Dataset and processing}

The analysis in this chapter is based on active-source seismic reflection data acquired by the Seismic Array HiKurangi Experiment [SAHKE, Henrys et al., 2013]. A total of 1382 seismic airgun shots were fired along the profile marked 'SAHKE02' in Figure 5.1. The profile is situated offshore from the southwest North Island of New Zealand, and crosses both the Taranaki and Wanganui basins. The shots were recorded on a single hydrophone streamer towed behind the seismic vessel, and this dataset is called SAHKE02. Airgun shots were also detected onshore by a permanent GeoNet seismic station at Kapiti Island (KIW), as well as ocean bottom seismometers placed beneath the shot path (OBS17, OBS18, OBS19 and OBS20).

\subsubsection{SAHKE02}

The SAHKE02 marine seismic line was first processed by Geotrace [2010]. Their final migrated profile shows a detailed sequence of sedimentary layers down to $3 \mathrm{~s}$ two-way traveltime (twt) out of a total $15 \mathrm{~s}$ twt (Figure 5.7). Sub-horizontal sediments overlie a flat basement in the Taranaki Basin with gentle rolling structures and bright amplitudes that might be of interest to petroleum explorers. In the Wanganui Basin, drill-hole and seismic reflection data show that Pliocene-Pleistocene sedimentary rocks onlap deformed, metamorphosed Permian-Jurassic basement rock, similar to the Torlesse greywacke of the adjacent onshore Tararua Range and Marlborough Sounds [Anderton, 1981]. The basement floor is irregular with up to $1.5 \mathrm{~s}$ twt of vertical offset (enlarged in Figure 5.7), representing what would have been a subaerial erosion surface with similar relief $(\sim 1500 \mathrm{~m})$ to parts of the adjacent Tararua mountain range. Below the basement floor, no reflectivity is preserved between $3-15 \mathrm{~s}$ twt.

The processing report for SAHKE02 [Geotrace, 2010] includes a number of processing steps which were not optimised to preserve deep reflectivity, such as migration with inaccurate velocities beneath the basement. Because of its unusually long traveltimes, and proximity to the GD100 seismic profile, SAHKE02 is expected to contain deep structural information that might be recovered by a different processing workflow.

For this study, a new processing workflow was developed for SAHKE02 with the goal of preserving/enhancing reflections from the lower crust and upper mantle. No consideration was given to preserving shallow reflectivity, as that is already well- 


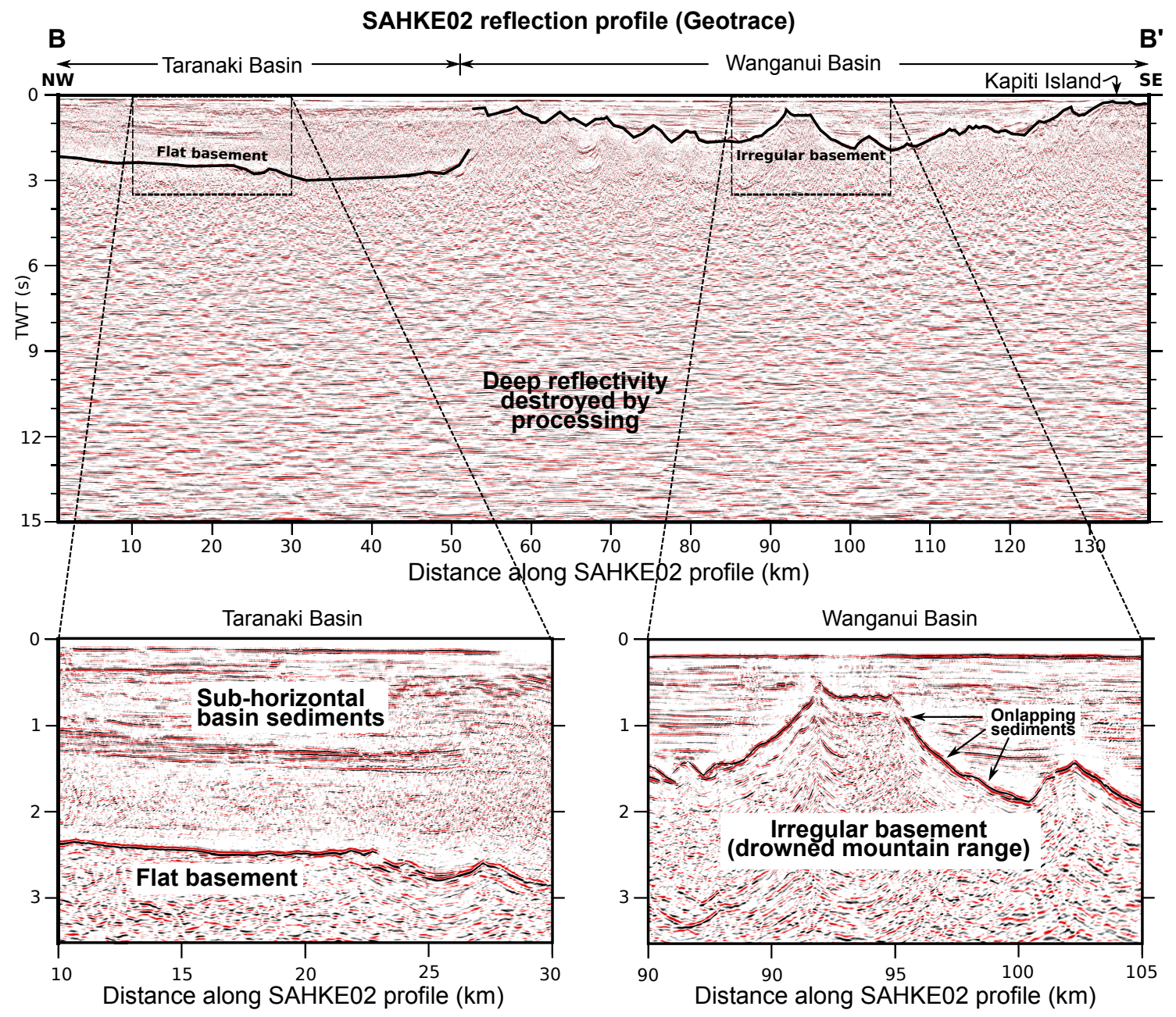

Figure 5.7: Geotrace SAHKE02 seismic reflection profile near Kapiti Island [Geotrace, 2010]. The profile location is shown as B-B' in Figure 5.1. The solid black line is the top basement interpretation. Examples of shallow reflectivity are shown as insets. Note that deep reflectivity is destroyed, probably due to migration smearing. 


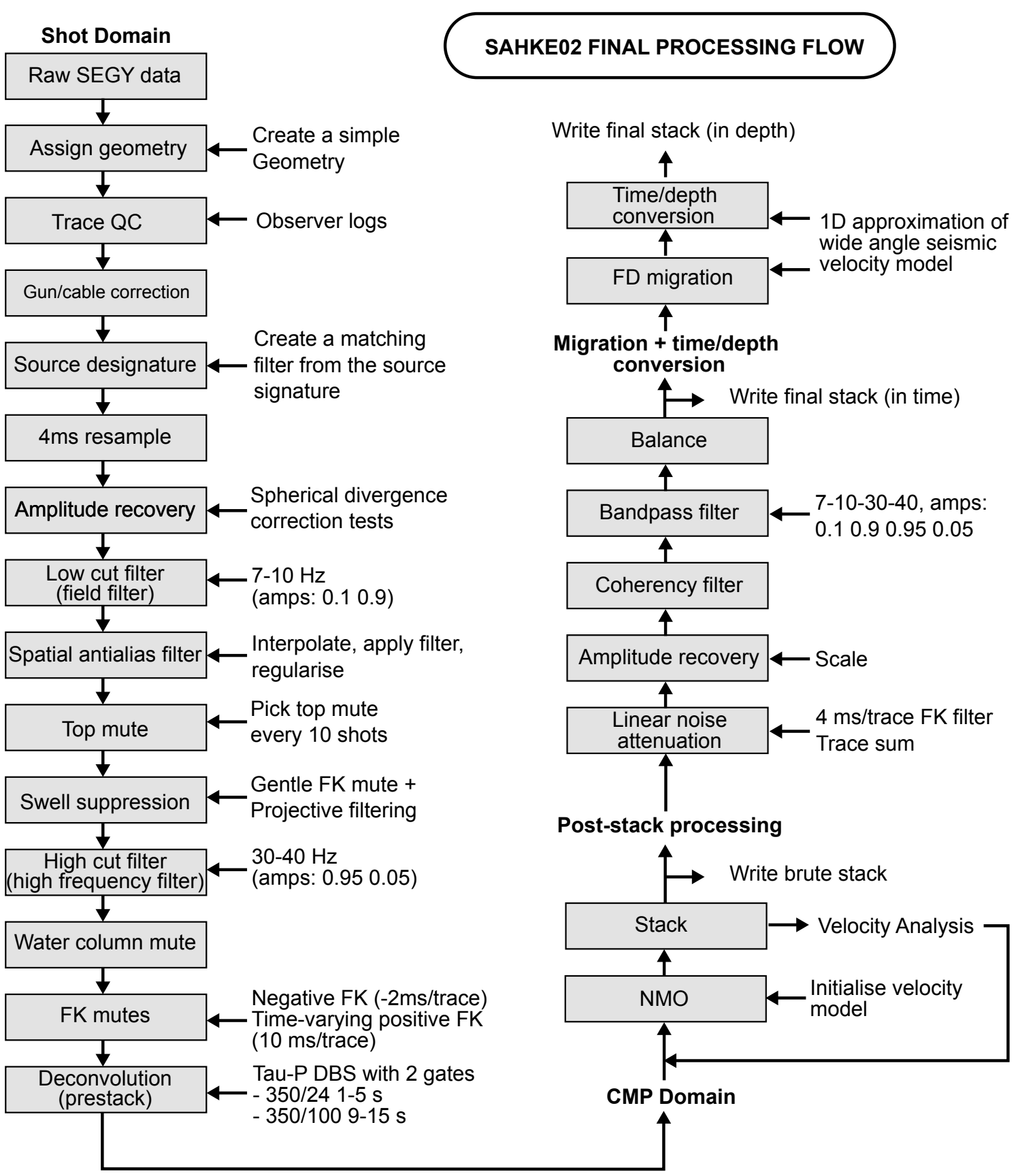

Figure 5.8: New processing flow developed for SAHKE02. Note that three outputs were produced: (1) A brute stack, (2) a final unmigrated stack in time, and (3) a migrated stack in depth. Key processing steps are discussed in detail in Appendix F. 
defined in the Geotrace seismic profile (Figure 5.7). The new processing workflow was created using GLOBE Claritas ${ }^{\mathrm{TM}}$ (Claritas), a commercial seismic processing suite commonly used by oil and gas companies. Simple, well-established techniques were chosen to minimise processing time and reduce artefacts. Complex techniques such as surface-related multiple elimination were tested, but they did not enhance deep reflections, and in many cases introduced artefacts, so they were dropped from the final processing flow. The workflow was influenced by the study of Hutchinson and Lee [1989], who processed deep crustal reflection data from the Gulf of Maine on the east coast of North America. Their processing flow was simple, as was most processing from the 1980's due to computational limitations, and relied mostly on frequency filters, FK-filters and deconvolution.

The final processing flow is summarised in Figure 5.8, and fully explained in Appendix F. Like Hutchinson and Lee [1989], frequency and FK filters are the primary means of suppressing random noise for the SAHKE02 processing flow. Deconvolution is used to remove repeating signals, such as short-period multiples. These are standard processing techniques used in seismic reflection processing. Refer to Yilmaz [2001] for more information.

\section{4 .2 KIW}

Two previous wide-angle seismic studies recorded airgun shots from along the SAHKE02 profile which show what appear to be Moho reflections beneath the Wanganui Basin [Henrys et al., 2013; Tozer, 2013]. Henrys et al. [2013] interpret the Moho to deepen westward under the Taranaki Basin and continue under the Wanganui Basin after being offset by an unknown fault (possibly the Taranaki Fault). Using the same dataset, Tozer [2013] finds a constant Moho-like surface under the Wanganui Basin at a constant depth of about $35 \mathrm{~km}$. In other words, both studies model wide-angle reflections/refractions at Moho depths beneath the Wanganui Basin, yet reflections are weak-to-absent on near-vertical seismic data and receiver function data.

In this thesis the KIW wide-angle reflection/refraction data from Henrys et al. [2013] are revisited, and ray tracing is used to constrain features in the wide-angle data which may also be seen in marine like SAHKE02. Wide-angle reflections and refractions generated by SAHKE02's airgun were recorded by a seismometer at Kapiti Island (KIW in Figure 5.1). Henrys et al. [2013] analysed these data as part of an investigation of crustal and subduction zone structure. In their study, bright localised reflectors were observed near the base of the Australian plate crust (Figure 5.9). 


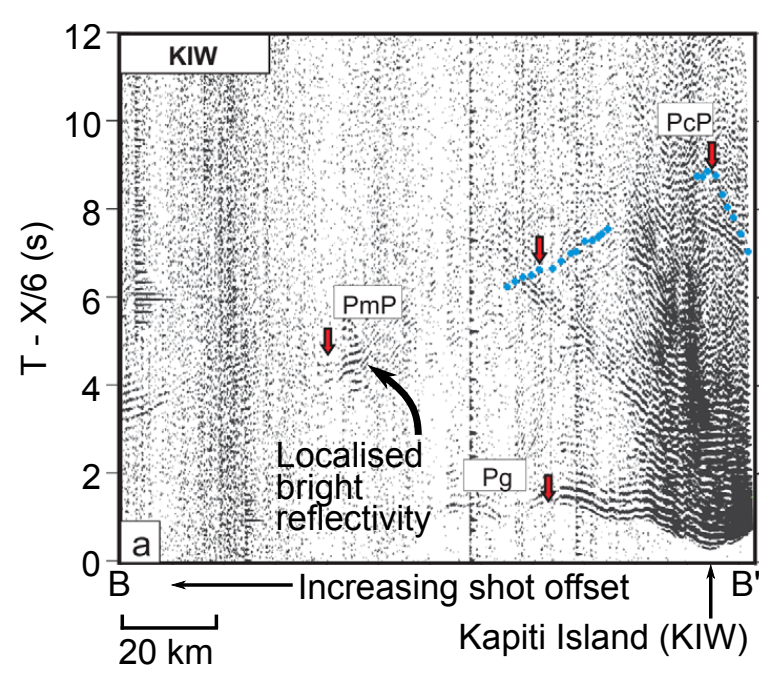

Figure 5.9: Kapiti Island wide-angle seismic data showing localised bright reflectivity beneath the Wanganui Basin [after Henrys et al., 2013]. Vertical axis is 'reduced traveltime', T-X/6 (s). PcP is associated with the Pacific plate subducting crust. PmP is the base of the Australian plate crust. Pg are considered to be diving waves in the Australian continental crust. Blue dots are phase picks which were migrated. Profile is approximately oriented along the SAHKE02 marine seismic line, from point ' $\mathrm{B}$ ' on the left to Kapiti Island (KIW) towards the right (Figure 5.1).

The cause of these reflections is still unknown, but since they occur at Moho depths they could provide important clues to understanding geological processes close to a subducted plate.

A more detailed profile of the KIW seismic data is shown in Figure 5.10, where key structural elements are interpreted. The Australian plate Moho and subducted Pacific plate were interpreted by Henrys et al. [2013] to occur along the surface labelled 'irregular reflection surface' in Figure 5.10b.

Note: Four ocean-bottom seismometers also recorded airgun energy from SAHKE02 (OBS17-20 in Figure 5.1). A full analysis of these stations was not undertaken, however, because the data were of poor quality. A basic interpretation of these datasets is provided in Appendix G.

\subsection{Results}

This section provides new constraints on lower crustal and upper mantle structures beneath the Taranaki and Wanganui Basins. The constraints are based on newly-processed seismic reflection data from SAHKE02, as well as wide-angle seismic reflection/refraction data recorded by GeoNet station KIW at Kapiti Island (Figure 5.1). Seismic profiles from SAHKE02 show that the Moho appears missing beneath the Wanganui Basin, yet localised bright reflectivity exists at Moho depths (Sections 5.5.1 and 5.5.2). Ray tracing of wide-angle seismic reflections and refractions constrains this localised reflectivity in depth, and identifies what appears to be the down-dip extension of the Taranaki Fault (Section 5.5.3). The localised bright 

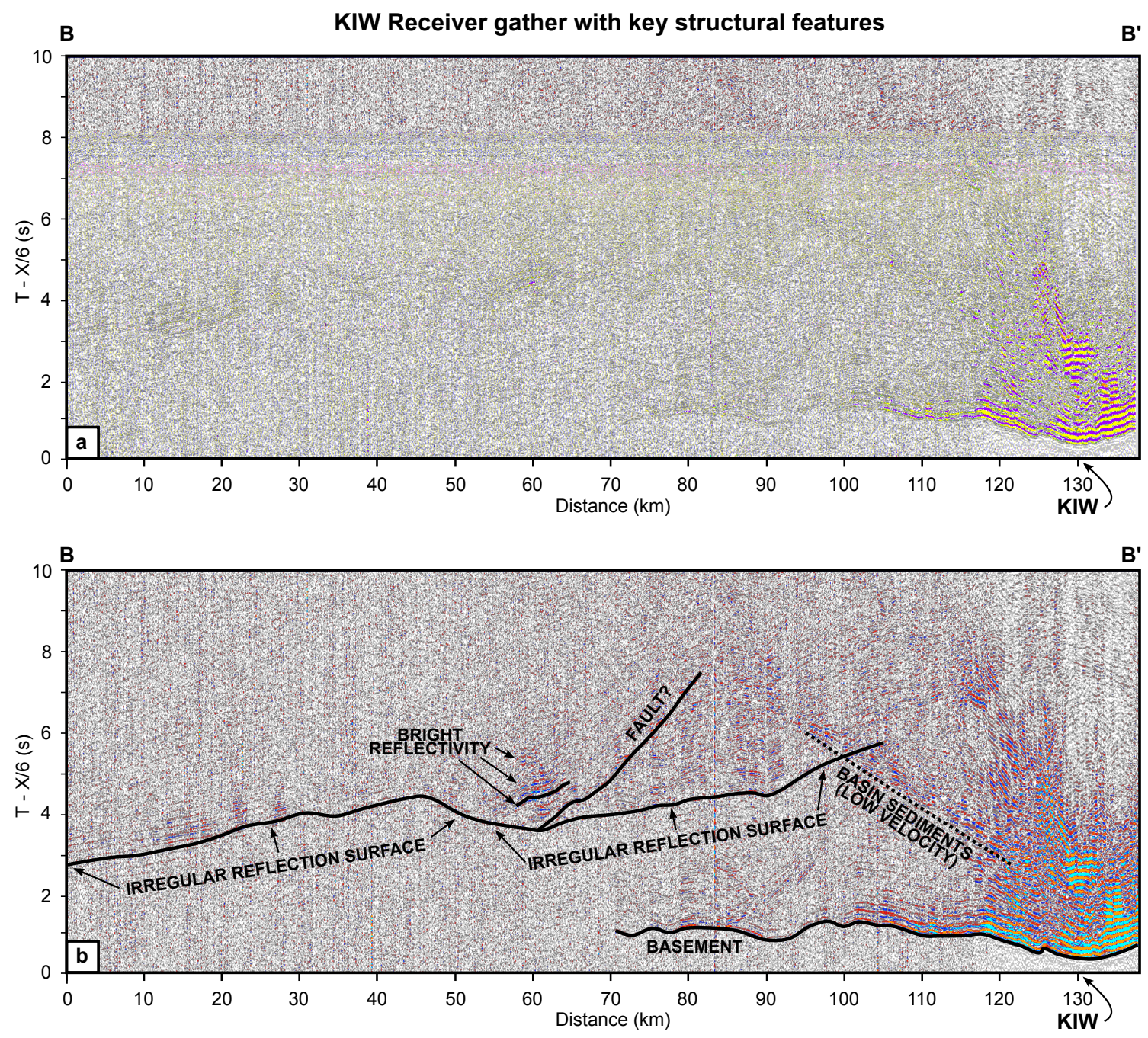

Figure 5.10: An uninterpreted (a) and interpreted (b) wide-angle seismic reflection/refraction profile from Kapiti Island (KIW) (after Henrys et al. [2013]). Vertical axis is reduced traveltime, T-X/6(s). Horizontal axis is the approximate distance along the SAHKE02 profile, defined as B to B' in Figure 5.1. Note that shot offset increases either side of KIW at distance $131 \mathrm{~km}$. Processing: Zero-phase 2-4-12-16 Hz butterworth bandpass filter; $6 \mathrm{~km} / \mathrm{s}$ linear moveout correction. What's labelled as the 'irregular reflection surface' is thought to relate to the Australian plate Moho and the top of the subducting Pacific plate [Henrys et al., 2013]. 
reflectors from SAHKE02 are evaluated for their seismic attributes, which include high attenuation (low $Q$ ) and indications of a polarity reversal (Section 5.5.4).

\subsubsection{SAHKE02 seismic profile (unmigrated)}

The newly-processed SAHKE02 marine seismic profile reveals the seismic character of the lower crust and upper mantle beneath the Taranaki and Wanganui basins (Figure 5.11). This profile is unmigrated. At the NW end of the profile, the Moho is interpreted to be at the base of a 3-4 s-thick two-way time (twt) package of deep reflectors at distances $0-30 \mathrm{~km}$ along the SAHKE02 profile. The maximum depth of these reflectors is about $14 \mathrm{~s}$ or $\sim 40 \mathrm{~km}$ deep, and they dip strongly to the SE. Similar reflectivity can be seen on GD100 (Figure 5.2) at distances of 100-125 km. From $30-80 \mathrm{~km}$ along the SAHKE02 profile, the band of lower-crustal reflectivity dims and there is no clear Moho reflection, just like in GD100 (between 100-50 km distance in Figure 5.2). What remains of the lower-crustal fabric appears to reach a maximum depth at the boundary between the Taranaki and Wanganui basins, and then appears to shallow under the Wanganui Basin (dashed line).

Relatively bright reflectivity at distances of $80-110 \mathrm{~km}$ is enlarged in Figure 5.11. These reflectors appear to be buckled or warped, with evidence of cross-cutting which might be due to the data being unmigrated. Stern and Davey [1990] observed similar cross-cutting in GD100 (Figure 5.2) which they attributed to the subducting Pacific plate abutting the Australian Moho [Davey, 1987]. The attributes of these reflectors are investigated in Section 5.5.4.

\subsubsection{SAHKE02 seismic profile (migrated)}

The final migrated and depth-converted SAHKE02 marine seismic profile (Figure 5.12) repositions deep reflectivity by tens of kilometres when compared to the unmigrated profile (Figure 5.11). Reflectivity band ' 1 ' is interpreted as localised bright reflectivity at Moho depths, and reflectivity band ' 2 ' is interpreted as being near the top of the subducting Pacific plate. These reflectors have untied into two separate packages in the migrated profile and are now separated by about $10-15 \mathrm{~km}$ of distance along profile. The untied reflectors have an unusual appearance.

Unusual migration results are common in deep seismic reflection data. As explained by Warner [1987], conventional migration of deep seismic reflection data often produces disappointingly poor results even when the crustal data are of high quality. 


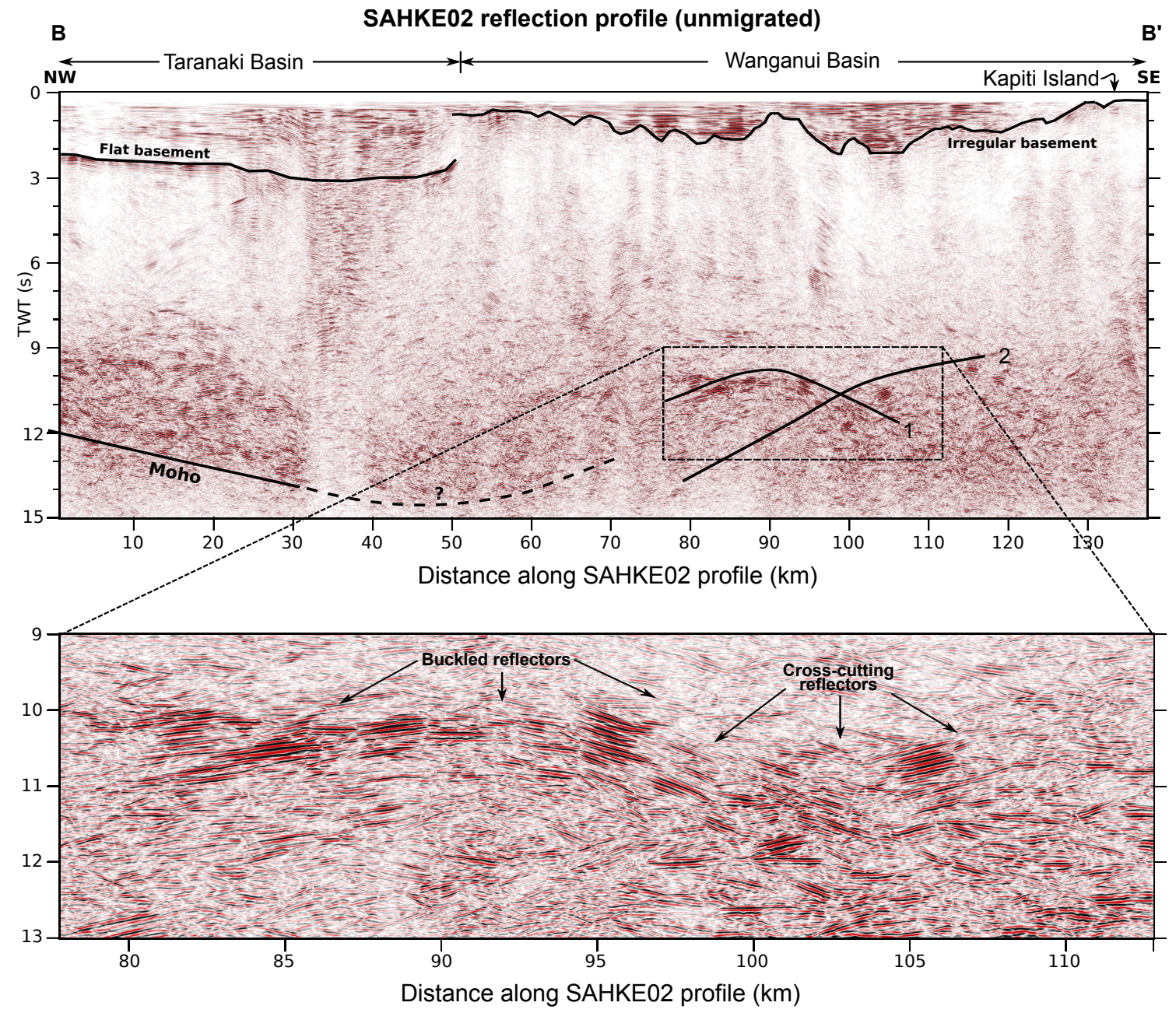

Figure 5.11: Stacked, unmigrated images of the SAHKE02 seismic reflection profile near Kapiti Island. The profile location is shown as B-B' in Figure 5.1. Key structural features are shown as thick black lines. Those numbered 1 and 2 represent buckled and crosscutting reflectivity interpreted by Davey [1987] to be where the Australian crust (1) abuts the subducting Pacific plate (2). Deep section inset shows an increase in reflectivity at about $10 \mathrm{~s}$ twt. Bottom panel is an enlargement of bright buckled and cross-cutting reflectors. Note that the cross-cutting between 1 and 2 unties with migration. 
Near-surface features tend to distort and attenuate the seismic wavefield and this has an effect on the deeper reflections. Warner [1987] suggested that hand-migration of deep reflectors might be helpful for artefact reduction. In this section, the handmigration formula of Yilmaz [2001] is applied to the two picked deep reflectors from Figure 5.11 and the result is shown in Figure 5.13. Note that the migration result varies significantly as the migration velocity is changed. A $4 \mathrm{~km} / \mathrm{s}$ velocity would perfectly untie the reflectors, but $4 \mathrm{~km} / \mathrm{s}$ is unrealistically slow for lower-crustal reflections. A more realistic lower-crustal velocity is $6.5 \mathrm{~km} / \mathrm{s}$ [Maunder, 2002] which results in reflector 1 appearing incorrectly migrated (bow-tie effect). One possibility is that distortion of the deep reflectors is occurring due to uncompensated velocity effects such as the irregular geometry of the Wanganui Basin basement surface.

An attempt was made to compensate for velocity effects by depth-converting with a $2 \mathrm{D}$ velocity model, which incorporates variability in basement depth, especially in the Wanganui Basin (details in Appendix F). The combination of depth conversion and migration yields a final migrated image that looks better than the hand-migrated results, but which is probably still inaccurate due to uncompensated effects. It is also possible that the reflectors are out-of-profile.

Recall that localised bright reflectivity also shows up in GD100 (Figure 5.2). Later it will be shown that a similar bright feature exists on a wide-angle seismic reflection/refraction profile recorded at Kapiti Island (KIW). Therefore, this reflectivity is likely to be a significant geophysical observation that requires a special explanation.

\subsubsection{Ray tracing of KIW}

Ray tracing through a specified velocity model was used to constrain features identified from wide-angle seismic reflection/refraction data at GeoNet station KIW (Figure 5.14). The velocity model used is a $2 \mathrm{D}$ representation of the lithosphere beneath the Taranaki and Wanganui basins along the SAHKE02 transect. Sediment depths for the Taranaki and Wanganui basins were picked directly from the SAHKE02 marine seismic profile (Figure 5.7). Sedimentary basin velocities are based on refraction modelling of SAHKE02 [Tozer, 2013], while crustal velocities are from the New Zealand Standard Velocity Model [Maunder, 2002].

Most of the prominent features from the wide-angle seismic data can be explained in terms of 4 planar reflecting layers (Figure 5.14). The individual ray tracing solutions for each of these reflections is shown in Figure 5.15. An interesting observation is that 


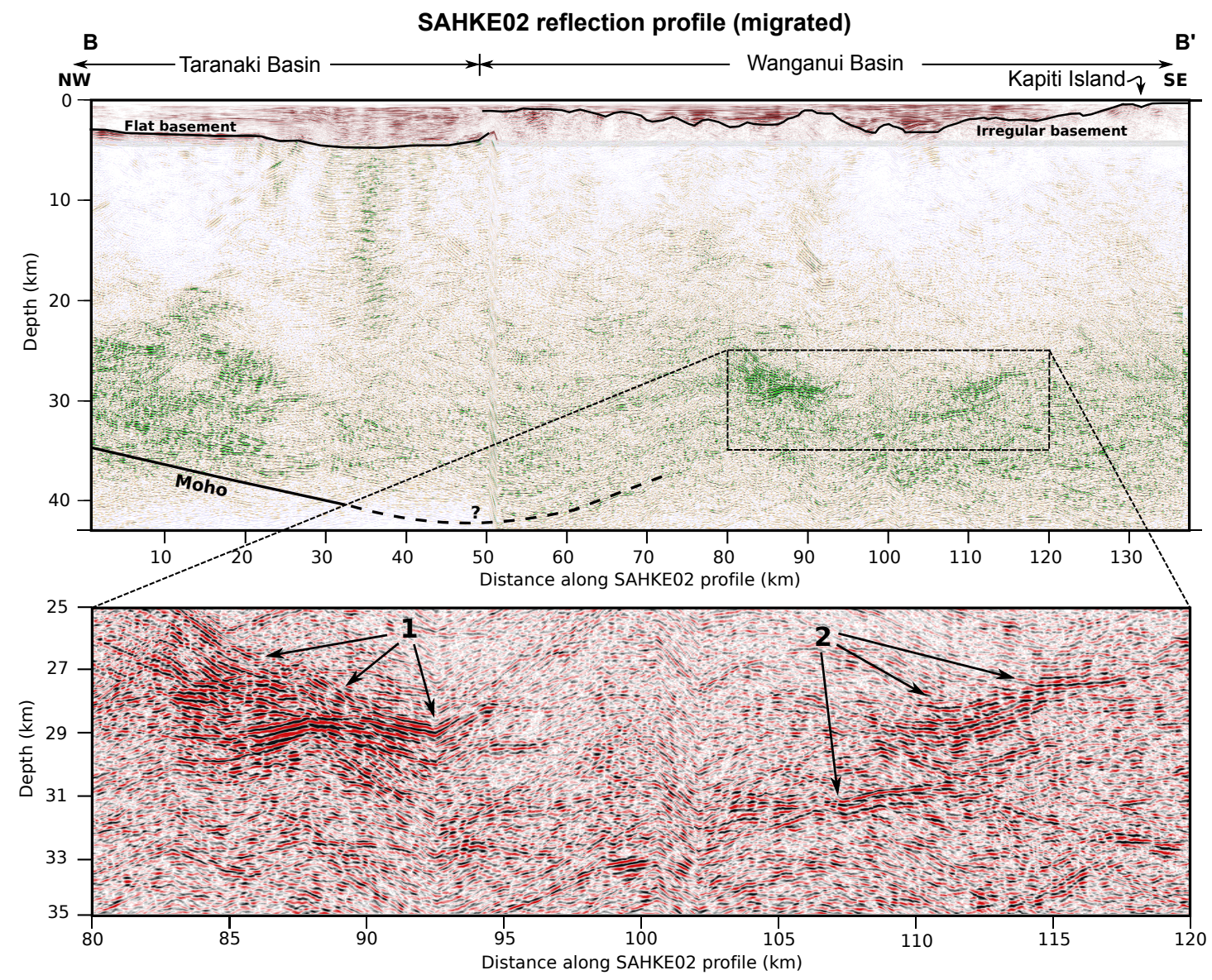

Figure 5.12: Migrated stack of the SAHKE02 seismic reflection profile near Kapiti Island. The profile location is shown as B-B' in Figure 5.1. Key structural features are shown as thick black lines. Those numbered 1 and 2 represent buckled and cross-cutting reflectivity from the unmigrated profile (Figure 5.11) which have been hand migrated at $6.5 \mathrm{~km} / \mathrm{s}$ (refer to Figure 5.13). Deep section inset is an enlargement of migrated deep reflectivity, note the unusual appearance of the migration. 
Unmigrated

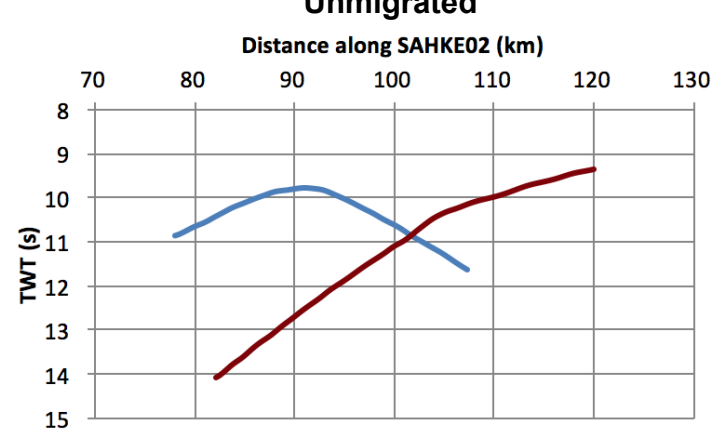

$4 \mathrm{~km} / \mathrm{s}$

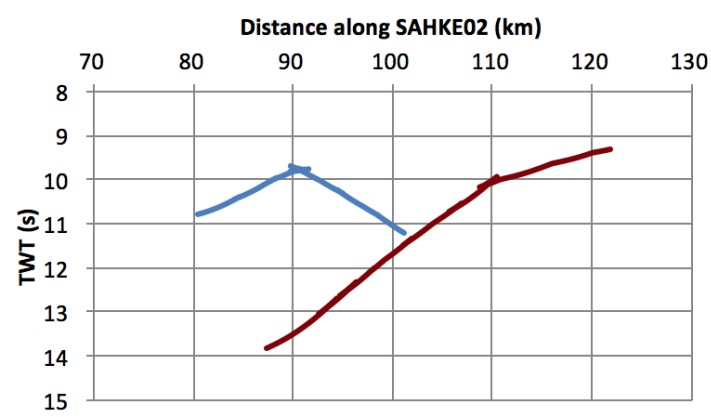

$6 \mathrm{~km} / \mathrm{s}$

Distance along SAHKEO2 (km)

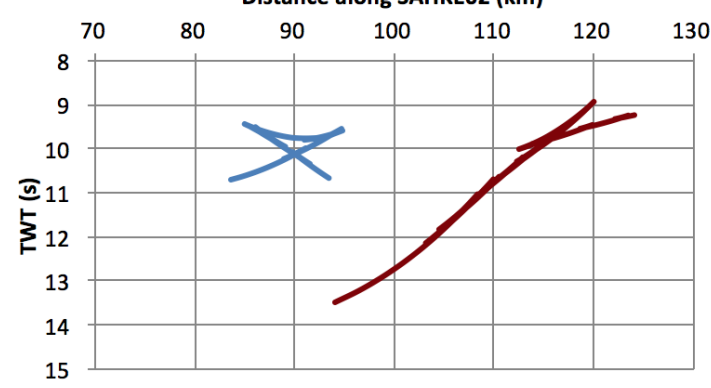

$3 \mathrm{~km} / \mathrm{s}$

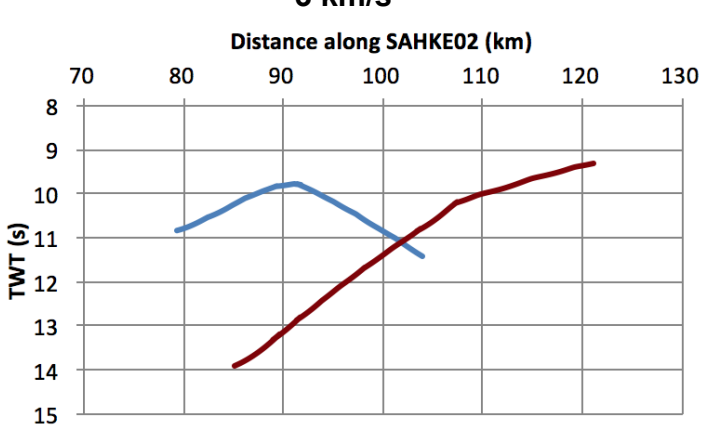

$5 \mathrm{~km} / \mathrm{s}$

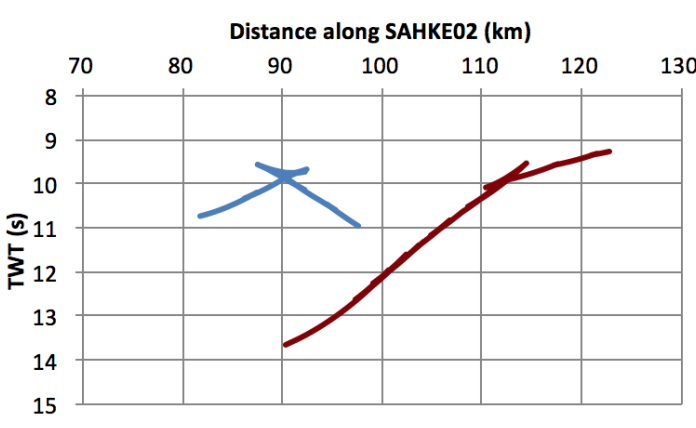

$6.5 \mathrm{~km} / \mathrm{s}$

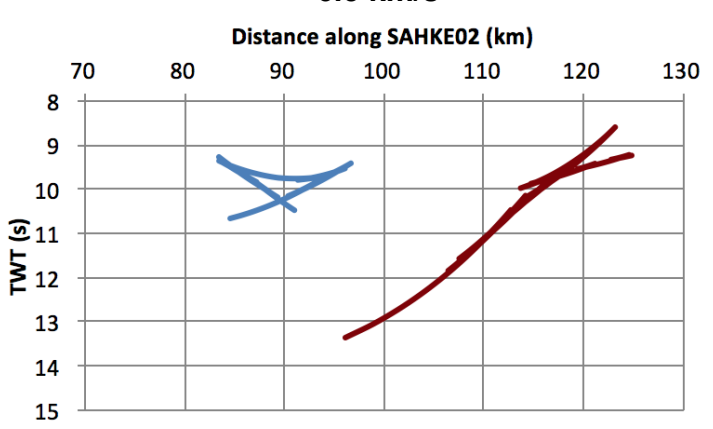

Figure 5.13: Hand-migration of SAHKE02 deep reflectors. Blue and red lines correspond to reflectors 1 and 2 respectively from Figure 5.11. Velocity values have a significant impact on the migration. A velocity of $6.5 \mathrm{~km} / \mathrm{s}$ is realistic for lower crust [Maunder, 2002], but produces an undesirable migration 'bow-tie' effect for the blue reflector. One possibility is that velocity effects in the lower crust have distorted the deep reflectors. 
a 'single dipping layer' can explain the surface that Henrys et al. [2013] and Tozer [2013] attribute to the top of the Pacific plate and the Australian plate Moho.

The 'Moho' reflection from Tozer [2013] has also been reproduced, which appears horizontal at a depth of $\sim 35 \mathrm{~km}$. It overlaps with the 'single dipping layer' in Figure 5.14a. In other words, the KIW wide-angle seismic data can be interpreted with or without a Moho reflection.

Next, the surface labelled 'deep fault' corresponds to the PdP event from Henrys et al. [2013]. Migration of the PdP event resolved to a single steeply-dipping $\left(>60^{\circ}\right)$ plane that might correspond to a portion of the Taranaki Fault in the lower crust. The ray tracing result in this section suggests that this fault might actually be shallower $\left(\sim 36^{\circ}\right)$.

Finally, a localised 'bright patch' appears in the wide-angle seismic data which have been ray traced to Moho depths $(\sim 33 \mathrm{~km})$. This feature appears to be flat and narrow, and is situated near where the Australian plate Moho abuts the Pacific plate. This is interpreted as the corner of a mantle wedge.

The migrated SAHKE02 seismic reflection profile (Figure 5.12) and KIW ray tracing planar layers (Figure 5.15) have been combined into a single interpreted diagram which shows the relationships between the two datasets (Figure 5.16). There are three key observations. 1) The red 'single dipping layer' matches well with the location of the reflectors labelled ' 2 ' in Figure 5.12. This layer is situated parallel and about $8 \mathrm{~km}$ above the Pacific plate interface. 2) The yellow 'bright patch' from the ray-tracing, and the reflectors labeled ' 1 ' in the migrated SAHKE02 profile (i.e. localised bright reflectivity), occur in the same general region suggesting that the two techniques are imaging the same phenomenon. Together they are referred to in Figure 5.16 as 'bright reflectivity'. 3) A deep fault, possibly the Taranaki Fault, is plunging deep into the base of the crust and perhaps even the upper mantle as imaged by Stern et al. [2015] on land shot gathers.

\subsubsection{Attribute analysis of SAHKE02 bright reflections}

Localised seismic reflectivity that is significantly brighter than its surroundings is observed beneath the Wanganui Basin on marine seismic surveys GD100 (Figure 5.2) and SAHKE02 (Figure 5.11). Ray-traced wide-angle seismic reflection/refraction data from KIW also implies a localised bright feature at Moho depths (Figure 5.14). The bright reflectivity from KIW, SAHKE02 and GD100 profiles, occur in close 

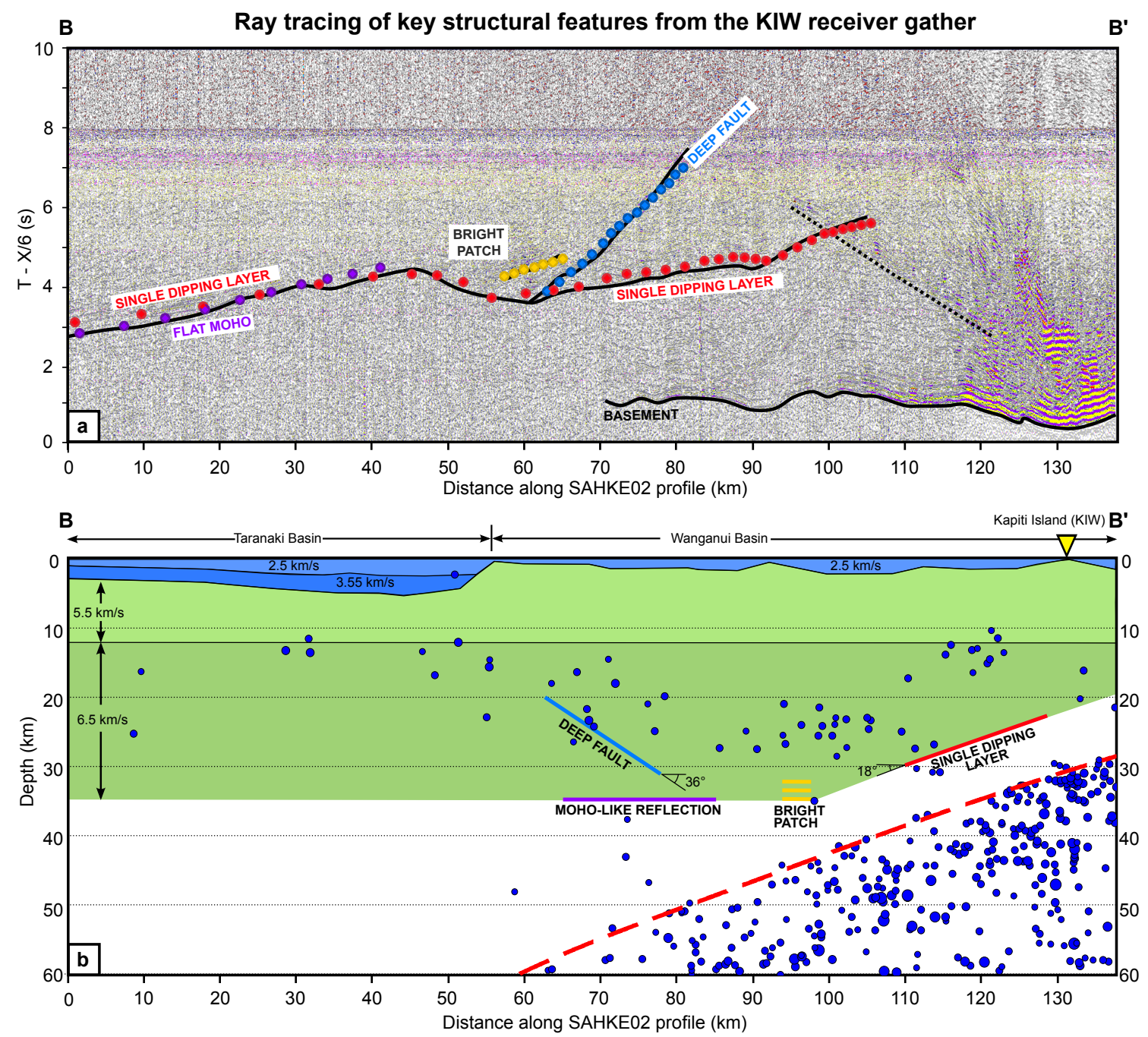

Figure 5.14: Ray tracing results from GeoNet station KIW at Kapiti Island. (a) Reduced travel-time plot of wide-angle seismic data which use the SAHKE02 airgun source. (Dataset from Henrys et al. [2013].) 'Single dipping layer', 'flat Moho', 'deep fault' and 'bright patch' are four planar layers which fit the observed data and the circles for each represent individual rays traced. (b) Profile along SAHKE02 showing the four ray traced layers with the ray tracing velocity model in the background. Blue dots are earthquake locations from Reyners et al. [2011]; dashed red lines are the top of the Pacific plate from Williams et al. [2013]. 

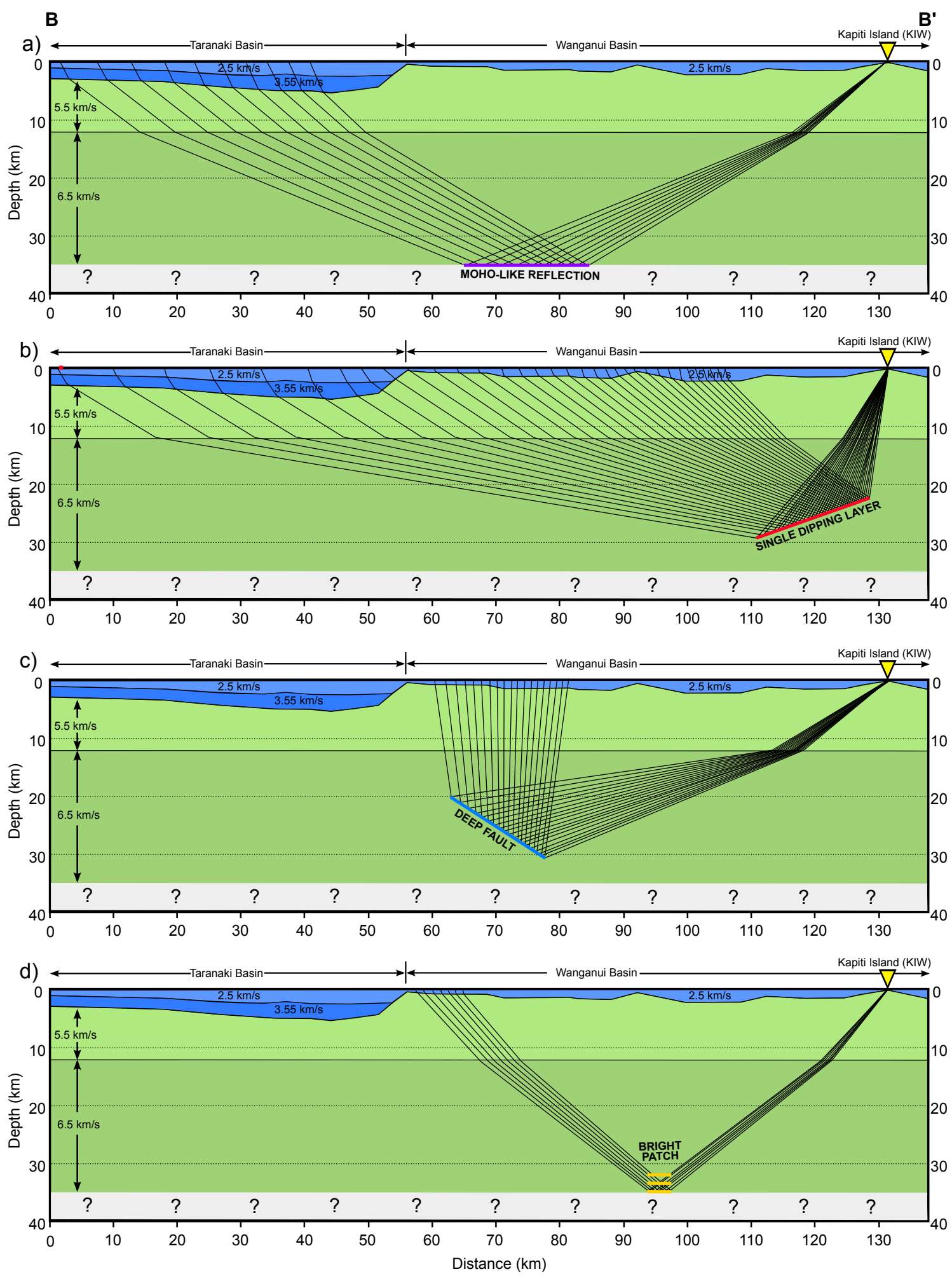

Figure 5.15: Ray tracing solutions for each planar surface referred to in Figure 5.14. 


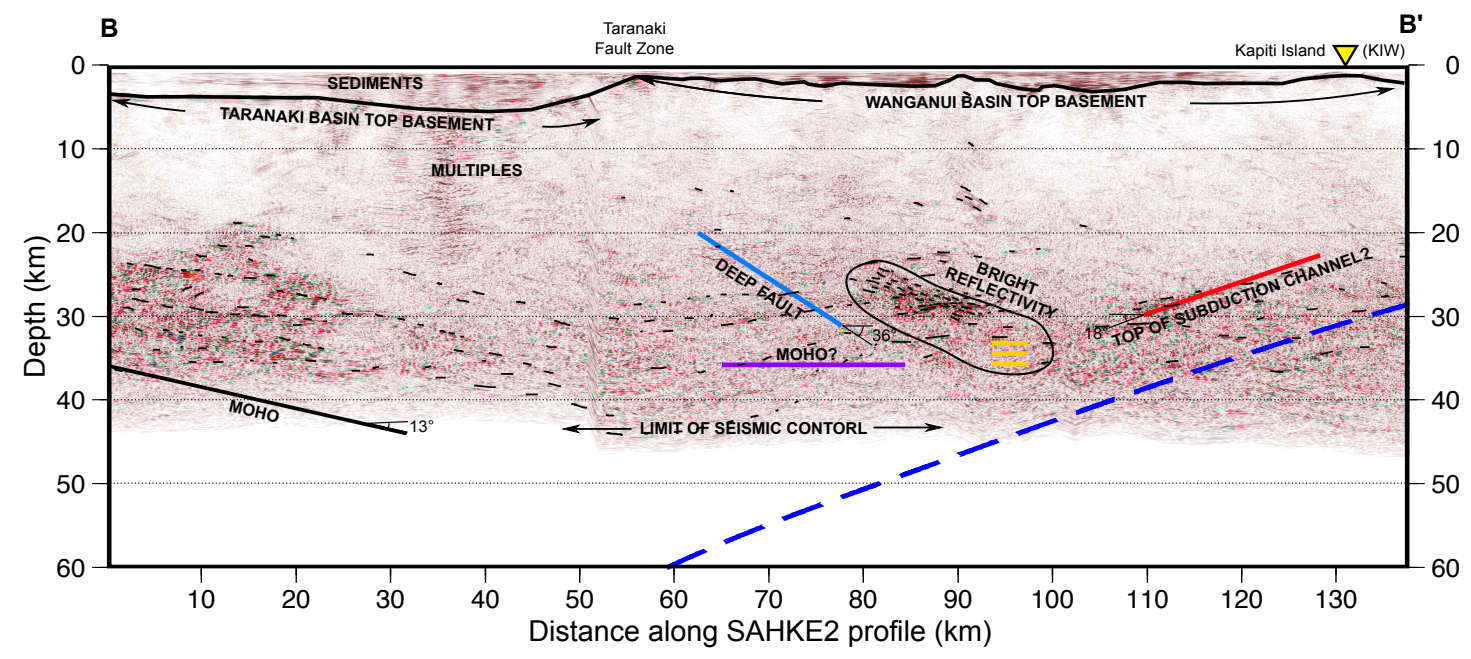

Figure 5.16: Joint interpretation of near-vertical and wide-angle seismic reflections from SAHKE02 and KIW respectively (profile B-B' in Figure 5.1). Ray traced wide-angle reflections from Figure 5.15 are shown here as bold coloured lines. Blue dashed line is top of subducted Pacific plate [Williams et al., 2013]. Note that the localised bright reflections from SAHKE02 are close to the ray traced 'bright patch' from KIW, suggesting the two features are related. (Together they are called 'bright reflectivity'.)
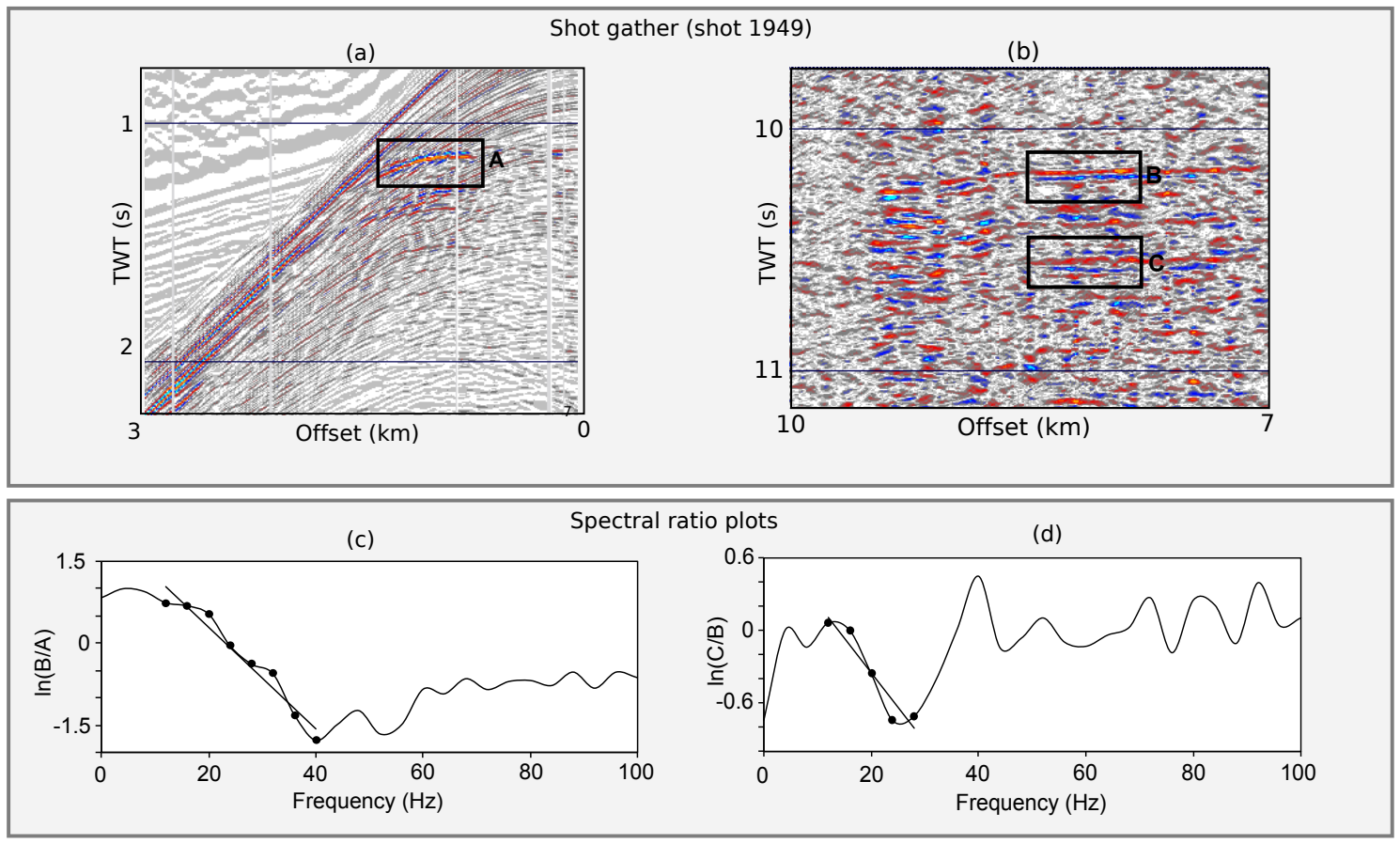

Figure 5.17: Seismic attenuation calculation for SAHKE02 shot 1949. (a,b) Frequency amplitude spectra extracted from averaged windows of the basement reflector $\mathrm{A}$, as well as two deeper reflections B and C. Note that the deeper reflections are associated with the bright reflectivity inset from Figure 5.11. The gradient of the spectral ratio plots in (c) and (d) are used to calculate $Q$. 
proximity to each other (Figure 5.16) and therefore might be different images of the same feature. In this section, the seismic attributes of this reflectivity will be investigated using SAHKE02 'shot gathers'.

Strong seismic reflections at Moho depths are well known in the continental lithosphere and have been ascribed to either free water, shear zones, or mafic intrusions in the lower crust [Warner, 1990]. Cooled mafic intrusions should produce alternating zones of impedance contrast but with the dominant sign being a positive impedance contrast with respect to the lower crust, and these rocks types should be relatively rigid. If, on the other hand the deep reflectivity were due to either free water or hydrous mineralogy in the lower crust/upper mantle then a negative impedance contrast and a relatively soft rheology would be expected. The zone of high reflectivity in Figure 5.11 is tested for these competing origins for the observed Moho-depth reflectivity by examining the seismic quality factor $Q$ and the impedance contrast.

Deep seismic reflectivity from Figure 5.11 is visible on 120 seismic shot gathers from SAHKE02 (Shot ID: 1801-1808, 1813-1816, 1818-1834, 1840-1846, 1856-1873, 1885, 1891, 1897-1900, 1907-1932, 1938-1939, 1941-1955, and 1974-1990). These shot gathers were shortlisted by visual inspection to just nine: 1805, 1830, 1856, 1857, 1866, 1929, 1948, 1949 and 1952. Of these, the clearest reflections were seen on shot 1949. Estimations of $Q$ and its associated standard error were all based shot 1949 because seismic attenuation and reflection polarity estimates are sensitive to data quality. For example, $Q$ estimation from surface seismic reflection data requires a signal/noise ratio better than 3:1 to be considered 'reasonable quality' [Dasgupta and Clark, 1998].

The only processing applied to shot 1949 was a $5-10-50-70 \mathrm{~Hz}$ bandpass filter and a $14 \mathrm{~ms} /$ trace FK filter, followed by a $\mathrm{t}^{2}$ type spherical divergence correction. Frequency amplitude spectra for each reflector were then extracted from a $\sim 0.2 \mathrm{~s}$ long rectangular window by means of a Fast Fourier Transform (FFT), averaged over 120 channels. The spectral ratio method (Section 5.3.3) was used to compare reflectors from different depths to find the $Q$ between them.

Spectral ratio plots, and the windows they were derived from, are shown in Figure 5.17. From the spectral ratios at the base of the Wanganui Basin (A) and the top of the deep reflectivity package (B), a crustal Q of $\sim 300 \pm 40$ is calculated for a frequency band of $12-40 \mathrm{~Hz}$. This is in agreement with the earthquake-derived $Q_{p}$ of Eberhart-Phillips et al. [2008], where the back-arc crust towards the southern end of the Hikurangi subduction zone typically has a $Q$ of 300-400. In contrast, the top 


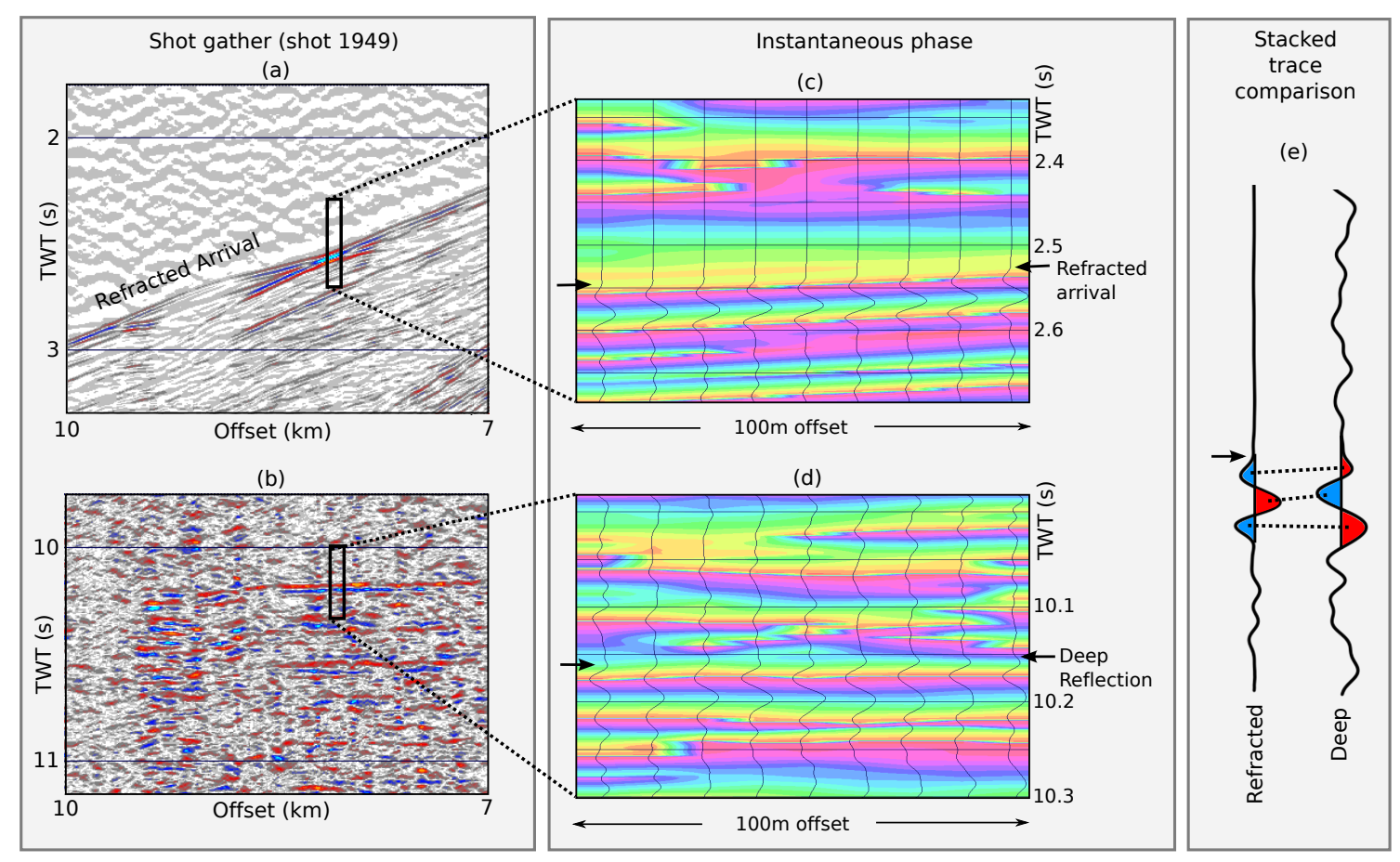

Figure 5.18: Attribute analysis for phase on SAHKE02 shot 1949. Analysis windows are extracted to compare the refracted arrival (a) and deep reflectors (b) for a given offset. The instantaneous phase of these windows (calculated using Claritas) is shown in (c) and (d) respectively, where the colours are linked to whether the seismic trace deflects left or right. The refracted arrival deflects slightly to the left (yellow) then strongly to the right, representing a positive acoustic impedance contrast. However, the deep reflectors deflect slightly to the right (blue) then strongly to the left. This indicates a negative impedance contrast for this part of the deep crustal reflectors. (e) Stacked seismic traces for refracted and deep reflectors are aligned at the first deflection as indicated by the arrow. Dotted lines link a mismatched pattern of peaks and troughs, further indicating a negative impedance contrast for the deep crustal reflectors. 
of the 'localised bright reflectivity' at Moho depths has a noticeably sharper wavelet to subsequent reflectors (Figure 5.17). Comparing a deeper reflection (C) with the top of the reflectivity (B) yields a comparatively low $Q$ of $\sim 20 \pm 10$ for frequencies of $12-28 \mathrm{~Hz}$. This implies considerable attenuation over a small distance, which is interpreted as free fluids or hydrated minerals in the mantle wedge.

Using this same shot gather, instantaneous phase attributes from the refracted basement arrival of a known positive impedance contrast (Figure 5.18a) were compared with the localised bright reflectivity (Figure 5.18b), to help determine the sign of the impedance contrast. The seismic traces and instantaneous phase of the refractors (Figure 5.18c) both appear to deflect opposite to that of the localised bright reflectivity (Figure 5.18d), suggesting a negative acoustic impedance contrast (reversed polarity).

Stacked seismic traces of both the refracted arrival and top of the localised bright reflectivity are aligned at the first break (Figure 5.18e). This provides another visual representation of the polarity reversal. A reversal in polarity is interpreted to result from reduced acoustic impedance in the mantle wedge relative to the lower crust. In other words, the upper mantle in this region is interpreted to have a lower seismic P-wave velocity than the lower crust.

\subsection{Composition of the mantle wedge}

This study proposes that the mantle wedge beneath the Wanganui Basin contains a significant volume of hydrated minerals such as serpentine (Figure 5.19). However, free water remains another possible source of the localised bright reflectivity, but this is not likely from a petrophysical perspective [Frost and Bucher, 1994]. Serpentinite is formed by hydration of depleted peridotite in the mantle wedge. The dominant form of serpentinite found in mantle wedges, antigorite, is stable at temperatures of $350-600^{\circ} \mathrm{C}$ at forearc mantle pressures [Christensen, 2004]. It has the unusual properties of dropping (for $100 \%$ serpentinisation) seismic wave speeds by up to $20 \%$ from its parent peridotite and the density can drop by up to $20 \%$ from 3350 to $2700 \mathrm{~kg} / \mathrm{m}^{3}$ [Christensen, 2004]. The water that drives the hydration process is thought to come from the eclogisation of oceanic crust, which involves a volume change and the release of about 1.2-2.3 weight \% of water [Bostock et al., 2002]. Serpentine also exhibits the property of stable-sliding behaviour at plate velocities and an inability to accumulate elastic strain [Bostock et al., 2002]. 


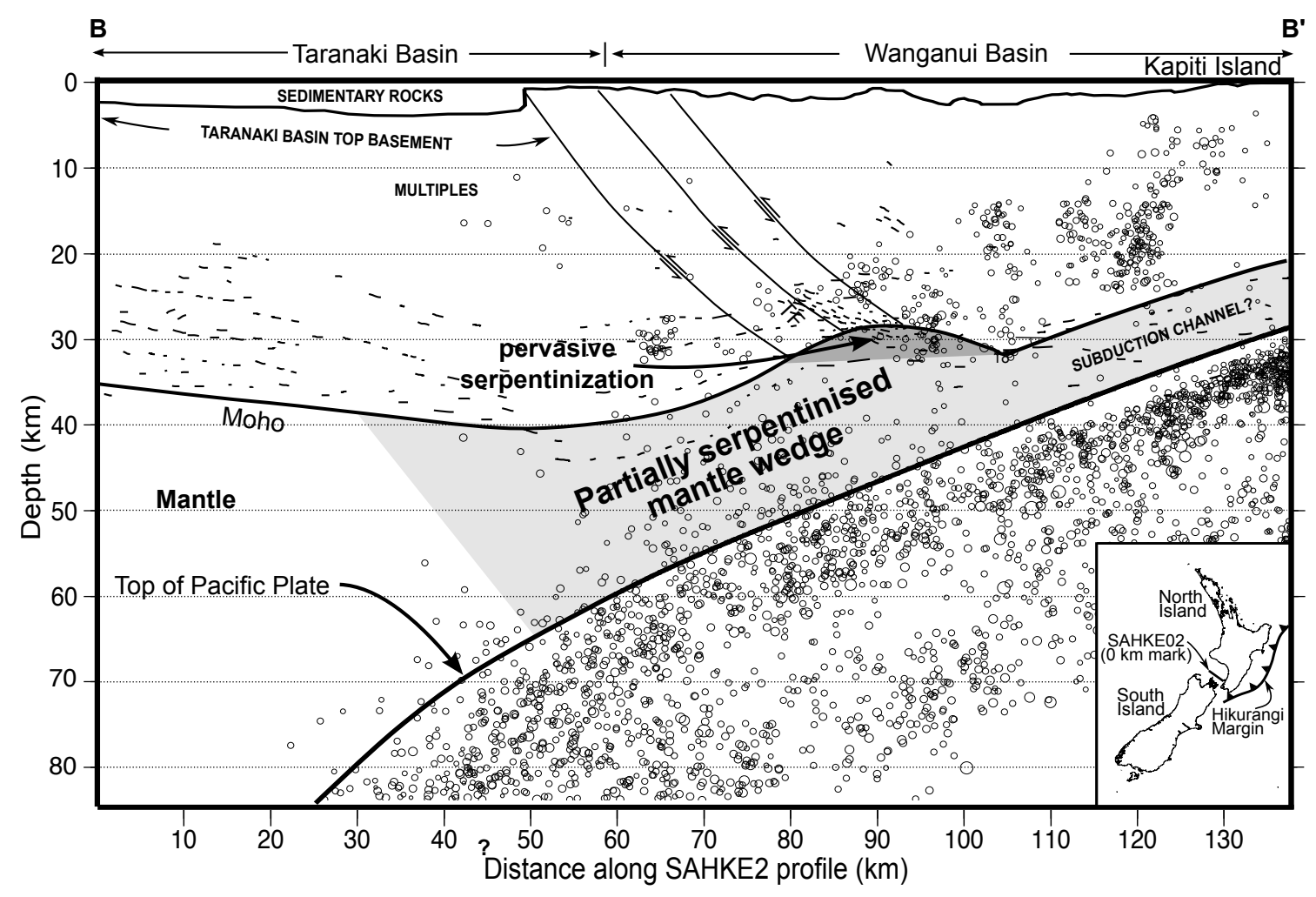

Figure 5.19: Schematic model showing the proposed structure of a partially-serpentinised mantle wedge in the Hikurangi Subduction Zone. Shading is indicative of relative amount of serpentinisation. Earthquake hypocenters are from [Reyners et al., 2011]. Depths are approximate.

Serpentinisation in southwestern North Island has been previously proposed by Hatherton [1980]. Hatherton had noted an association between the Eastern Belt of the Stokes Magnetic Anomaly and a gap in earthquake seismicity called the 'aseismic corridor' (Figure 1.9). The Eastern Belt is limited to an older surface exposure of ophiolites of Permian age. Hatherton was trying to relate these observations to an old crustal suture belt, and not the mantle wedge. The serpentinisation proposed in this study is different because it relates to active subduction zone processes.

Supporting evidence for a serpentinised mantle wedge comes from: diminished Moho reflectivity beneath the Wanganui Basin observed in GD100 and SAHKE02 (Figures 5.2 and 5.16); a vanishing P-to-S Moho conversion beneath the Wanganui Basin in the revised receiver function CCP stack (Figure 4.17); high attenuation measurements $(\mathrm{Q} \sim 20)$ from rocks interpreted to be in the mantle wedge (Figure 5.17); and the indication of a negative impedance contrast associated with these same rocks (Figure 5.18). These observations are consistent with those of Bostock et al. [2002] for a serpentinised Moho of the forearc in Cascadia. 
However, why does serpentine appear to produce blank seismic reflectivity over some large ( $\sim 50 \mathrm{~km}$-wide) areas yet high reflectivity is seen in just one localised area (Figure 5.12)? One possibility is shearing in the high-differential strain zone immediately adjacent to the subducted Pacific plate. Shearing will cause localisation [Holtzman et al., 2003], or focusing, such that layers of serpentinised mantle and host peridotite separate out to form a banding. Reflectivity due to shearing in serpentinised mantle of forearcs has been recognised elsewhere [Brocher et al., 2003].

Another possibility is a change in basement terranes. Some of the weakest Moho reflectivity across the SESI line corresponds with the Maitai Terrane ('Mait' and 'Maitai' in Figure 5.3), which includes the partially-serpentinised Dun Mountain Ophiolite Belt. While the Maitai Terrane is $10-15 \mathrm{~km}$-wide at the surface, Mortimer et al. [2002] interprets it to be some $50 \mathrm{~km}$-wide at the base of the crust (Figure 5.3d). In SAHKE02, it is possible that the Maitai terrane has become preferentially serpentinised in comparison to other basement terranes, which would explain the limited spatial extent of the bright reflectivity.

Serpentinisation results in a drop in density of up to $24 \%$ and volume increase of up to 30-40\% [Guillot et al., 2015], which will cause localised positive buoyancy. This could be the cause of the apparent up-warp of the reflectors (Figure 5.19) as the enhanced buoyancy might induce a diapir-like behaviour. However, it can't be ruled out that these reflectors are being buckled due to applied in-plane compression.

\subsubsection{Zoeppritz equations and receiver functions}

The southern half of the receiver function CCP stack from Chapter 4 is reproduced in Figure 5.20. Here, the Moho vanishes towards the southern end of the profile ('vanishing Moho' in Figure 5.20a). About $20 \mathrm{~km}$ below this surface is another positive P-to-S conversion with the appearance of a second 'seismic Moho'. Salmon et al. [2011] speculated that this deeper feature might be a multiple of a lower crustal reflector in the Wanganui Basin. However, since the extra station coverage in the revised $\mathrm{CCP}$ profile enhances this conversion rather than diminishes it, this feature is more likely to be a primary conversion.

A partially-serpentinised mantle wedge has the necessary properties to be able to explain the seismic Moho observation. Serpentinisation effectively lowers the seismic velocity of the upper mantle, which reduces the impedance contrast of the Moho, which could theoretically cause the Moho to disappear, hence the 'vanishing Moho' in Figure 5.20a. At the base of the serpentinised wedge, a contrast may exist with 


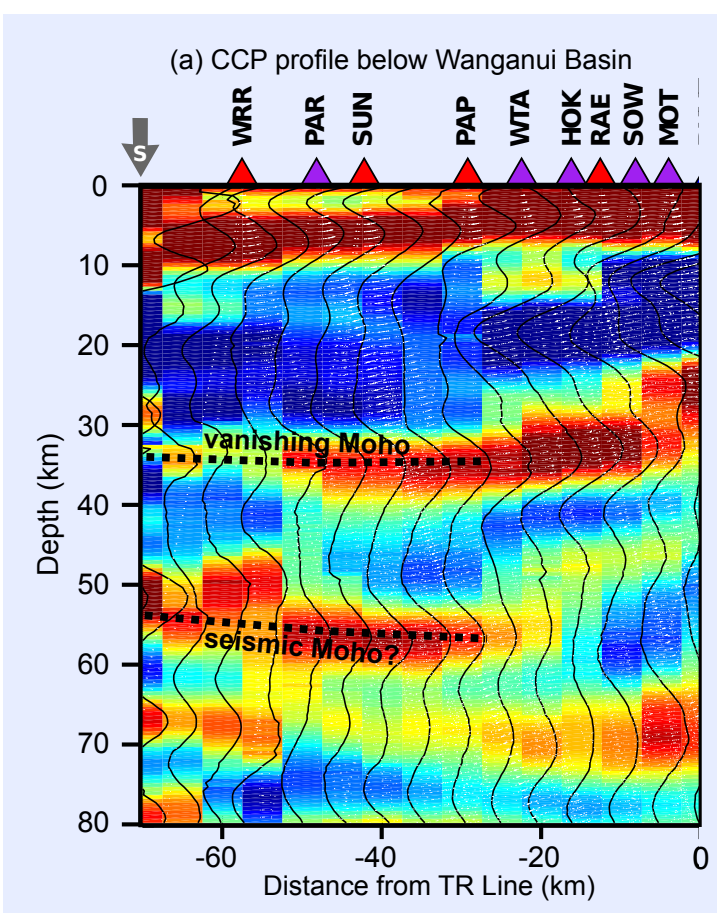

(c) Serpentinised mantle wedge to base of crust

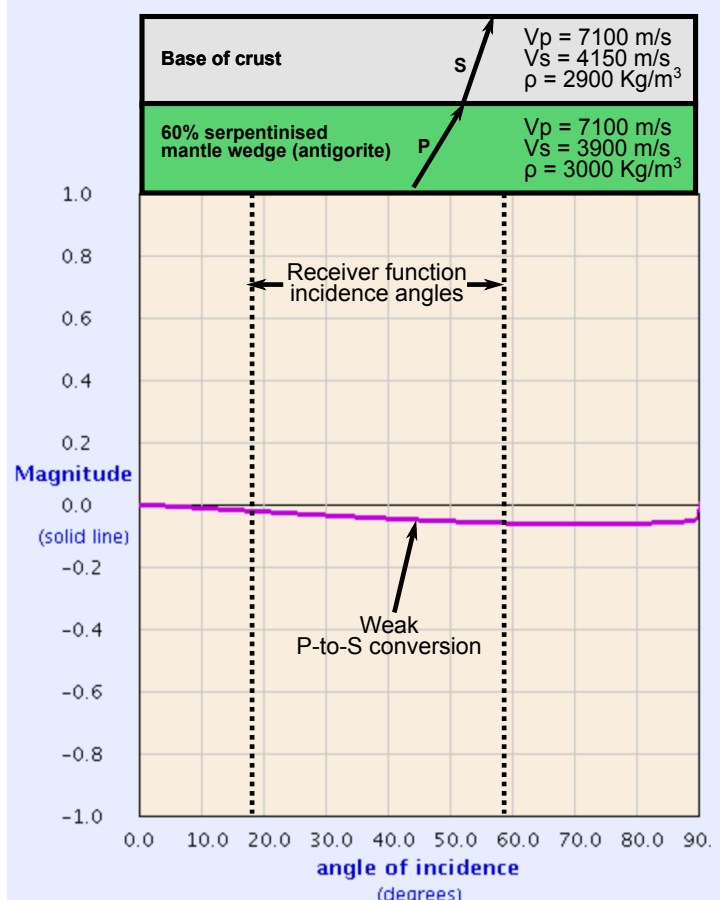

(b) CCP profile below Wanganui Basin (model)

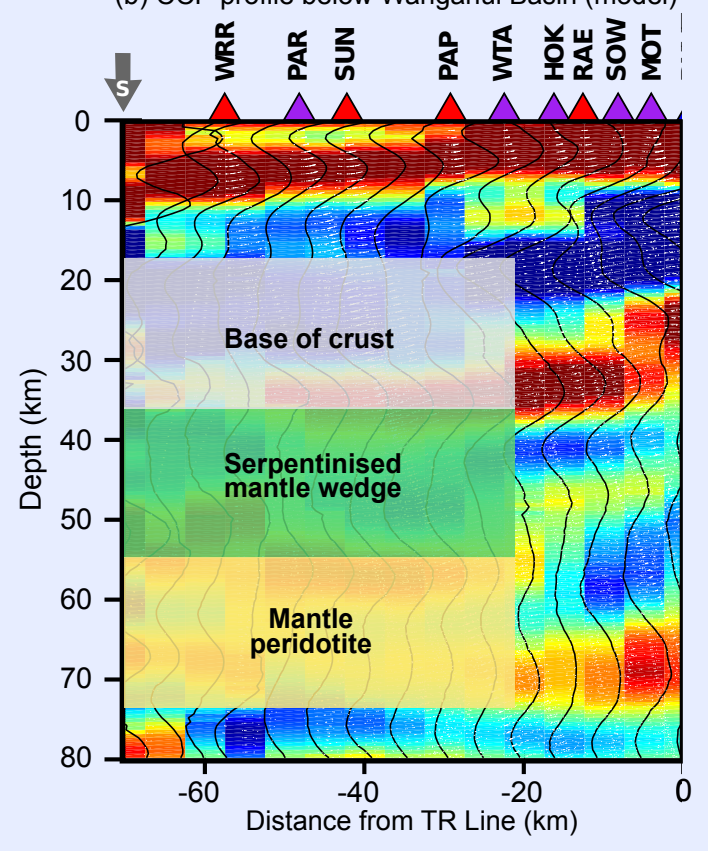

(d) Mantle peridotite to serpentinised mantle wedge

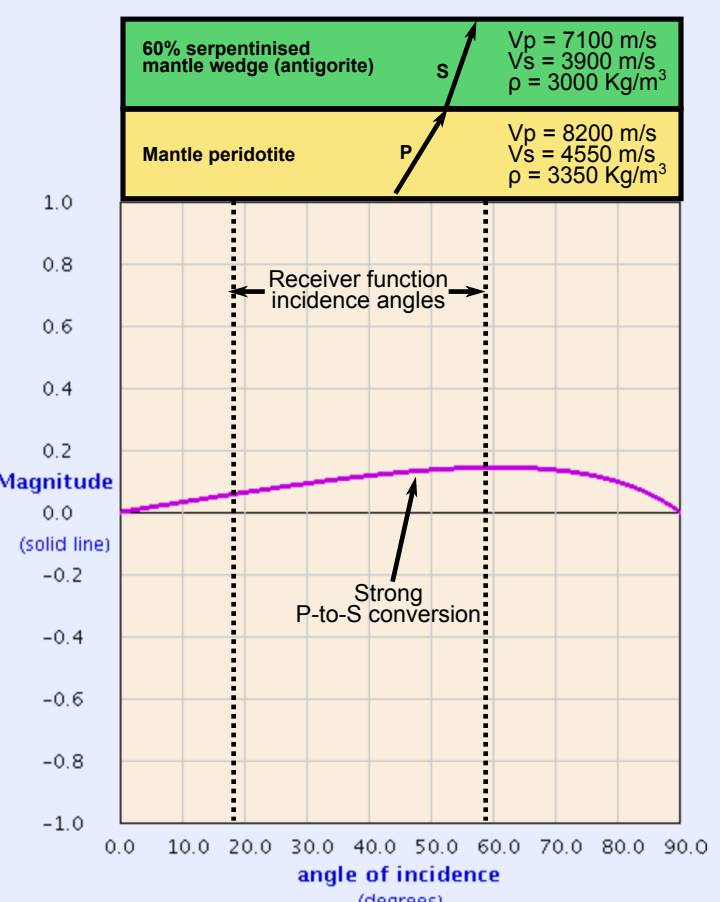

Figure 5.20: A simple earth model solved with Zoeppritz equations. (a) Receiver function CCP stack showing a 'vanishing Moho', and 'seismic Moho' beneath it. (b) This might be explained by a three-layer model, where the base of the crust and an unaltered upper mantle are separated by a serpentinised mantle wedge. (c) Zoeppritz equation solution for a P-to-S conversion going from the serpentinised mantle wedge to the lower crust. (d) Zoeppritz equation solution for a P-to-S conversion going from unaltered mantle into serpentinised mantle. 
the unaltered mantle peridotite below. Such a contrast would create a positive P-to-S conversion, hence the 'seismic Moho' Figure 5.20a.

For a serpentinised mantle wedge to have similar seismic properties to the base of the lower crust, approximately $60 \%$ alteration of mantle peridotite to serpentinite (antigorite) is required. This was determined by matching $\mathrm{Vp}, \mathrm{Vs}$ and $\rho$ values of different ratios of serpentinite/peridotite from Christensen [2004] with expected values from the base of the crust: $V_{p}=7100 \mathrm{~m} / \mathrm{s} ; V_{s}=4150 \mathrm{~m} / \mathrm{s} ; \rho=3000 \mathrm{~kg} / \mathrm{m}^{3}$. This results in serpentinised mantle wedge having: $V_{p}=7100 \mathrm{~m} / \mathrm{s}, V_{s}=3900 \mathrm{~m} / \mathrm{s}$, $\rho=2900 \mathrm{~kg} / \mathrm{m}^{3}$. Note that the base of crust P-wave velocity is faster than the $6500 \mathrm{~m} / \mathrm{s}$ used in ray tracing. The reason for this is that the ray tracing value was an average of the lower crust, while the $7100 \mathrm{~m} / \mathrm{s}$ value (and the Vs and $\rho$ ) are more realistic for the base of the lower crust in New Zealand [Stern et al., 2001].

Consider a simple 1D three layer model, where the base of the lower crust overlies a serpentinised mantle wedge, which overlies unaltered mantle peridotite (Figure 5.20b). The crust and serpentinite values are described above. The peridotite values are $V_{p}=8200 \mathrm{~m} / \mathrm{s} ; V_{s}=4550 \mathrm{~m} / \mathrm{s} ; \rho=3550 \mathrm{~kg} / \mathrm{m}^{3}$ [from Ringwood, 1969]. With Zoeppritz equations it is possible to determine the theoretical P-to-S transmission coefficients from the lower layer into a higher layer. This is analogous to the P-to-S conversions detected by the receiver function technique.

Synthetic reflection/transmission coefficients are calculated using the CREWES Zoeppritz explorer: Figure 5.20c refers to the case of the vanishing Moho at the interface between the base of the crust and the serpentinised wedge; Figure 5.20d to the seismic Moho at the base of the serpentinised mantle wedge and unaltered mantle peridotite. Note that the vanishing Moho in Figure 5.20c is weak, the seismic Moho in Figure 5.20d shows a strong positive P-to-S conversion.

The results above suggest that a serpentinised mantle wedge beneath the Wanganui Basin might act seismically like an extension of the lower crust, and a seismic Moho might exist at the base of the serpentinised mantle wedge.

\subsection{Discussion}

The analysis of SAHKE02 marine seismic and KIW wide-angle reflection/refraction data has provided new constraints on crustal and upper-mantle structures beneath the Taranaki and Wanganui basins, which is the overall main objective of this thesis. Key findings beneath the Wanganui Basin include: 
1. Localised bright seismic reflectivity at Moho depths which are associated with low $V_{p}$ and low $Q$. This is interpreted to be a relatively soft and weak material in the corner of the mantle wedge, adjacent to the subducted Pacific plate interface.

2. With the exception of the localised bright reflectivity mentioned above, there is a general 'dimming' of Moho reflectivity beneath the basin as a whole.

3. The presence of a Moho from wide-angle seismic reflection/refraction data at Kapiti Island is unclear, because the key features of the dataset can be ray traced without requiring a Moho.

4. Ray tracing models a deep fault in the lower crust which is dipping southeast at $\sim 36^{\circ}$. This fault is interpreted to be the down-dip extent of the Taranaki Fault.

Key findings beneath the Taranaki Basin from SAHKE02 include:

1. The Moho is dipping $\sim 13^{\circ}$ southeast at depths of $35-40 \mathrm{~km}$.

2. A significant loss of Moho reflectivity occurs beneath the Taranaki Fault Zone.

The idea of a weak mantle wedge beneath the Wanganui Basin is particularly interesting because this might have significant geodynamic consequences. The preferred explanation for both the weak material, and dimming of the Moho reflection, is partial serpentinisation of the mantle wedge.

\subsubsection{Serpentinite and slow-slip events}

The proposed partially-serpentinised mantle wedge is spatially associated with repeated slow-slip events (Figure 5.21). Slow-slip events are aseismic earthquakes with long rupture times which are detected by continuous GPS measurements instead of seismometers [e.g. Hirose et al., 1999; Bürgmann et al., 2001; Lowry et al., 2001; Dragert et al., 2004; Douglas et al., 2005]. Unlike regular earthquakes, slow-slip events can release their energy over days to years, typically releasing the equivalent energy of a magnitude 6-7 earthquake [Schwartz and Rokosky, 2007], at depths of 20-45 km [e.g. Dragert et al., 2004; Hirose and Obara, 2005; Kawasaki, 2004; Kostoglodov et al., 2003], often recurring in the same location with a repeat interval of months to years [e.g. Miller et al., 2002; Kostoglodov et al., 2003; Szeliga et al., 2004; Hirose and Obara, 2005]. At least five slow-slip events have been observed along the southern Hikurangi subduction zone in 2003, 2005, 2008 and 2013 and have re- 


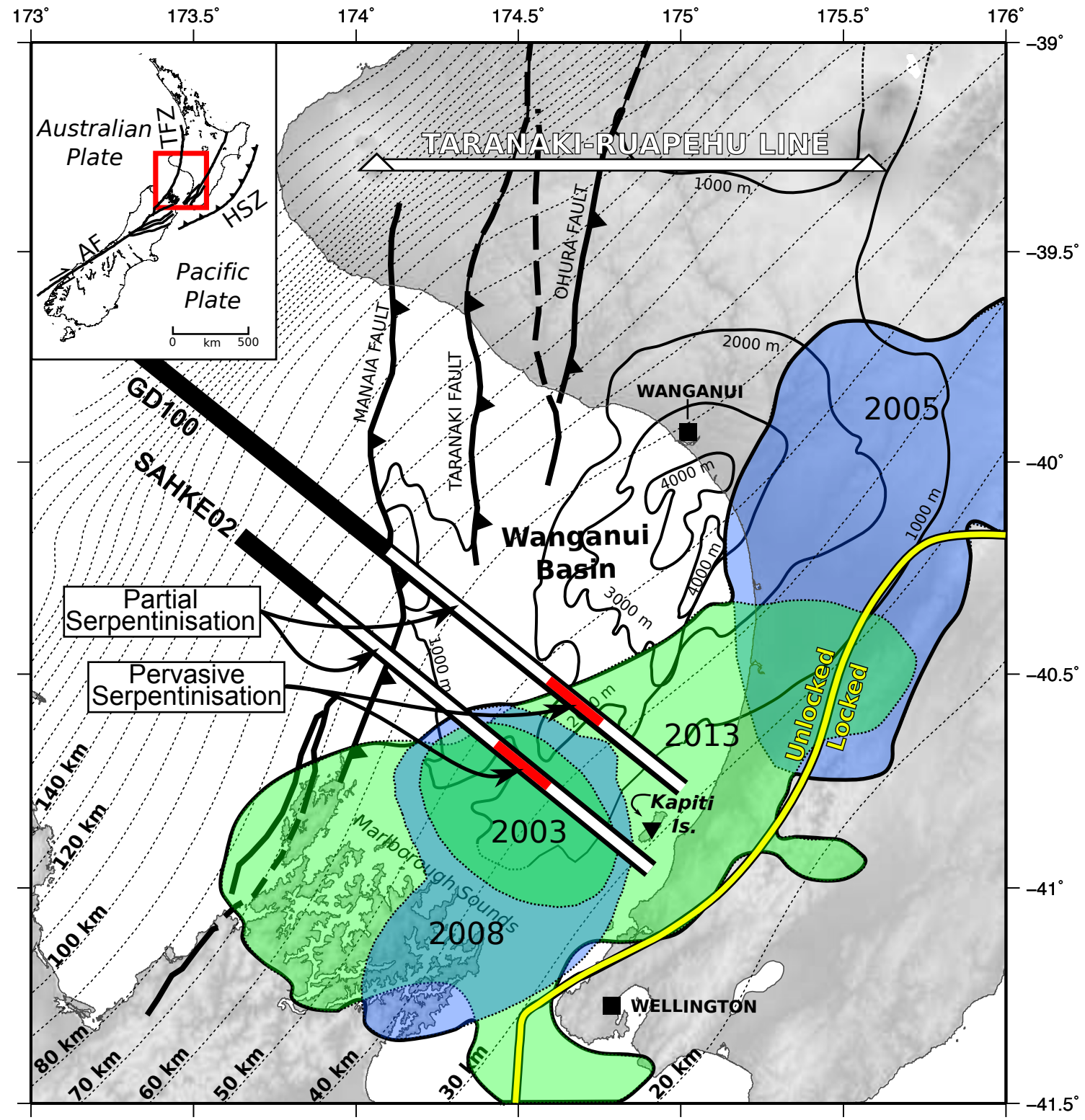

Figure 5.21: Spatial relationship between a proposed partially-serpentinised mantle wedge and slow-slip events along the southern end of the Hikurangi Subduction Zone. Slowslip events are numbered by year of initiation and are coloured green/blue to distinguish between events. GD100 and SAHKE02 cross through repeated slow-slip events near Kapiti Island, and the approximate extent of proposed partial and pervasive serpentinisation are shown as white and red lines respectively. Slow-slip events from 2003, 2005 and 2008 are from [Wallace and Beavan, 2010], while the 2013 slow-slip event is from Laura Wallace (Personal communication, 2015). Contours to base of Wanganui Basin are shown [Anderton, 1981]. The slow-slip events appear to avoid the deepest part of the Wanganui Basin. Dashed contours are the top of the subducted Pacific plate [Williams et al., 2013]. 
sulted in year-long moment releases comparable to magnitude 6.3-7.0 earthquakes at depths of 30-40 km [Wallace and Beavan, 2010].

The cause of slow-slip events like those along the southern Hikurangi subduction zone is not fully understood. They are thought to occur at the subduction zone interface within the transition from stick-slip to stable-sliding behaviour [Schwartz and Rokosky, 2007]. Some authors suggest that slow-slip initiation and size might be sensitive to changes in plate geometry [e.g. Kato, 2003; Liu and Rice, 2007] and/or pore fluid pressure [Segall et al., 2010]. Others argue that hydration of peridotite to serpentinite in a cold mantle wedge may explain both the presence of slow-slip and associated tectonic tremor [Bostock, 2013; Poulet et al., 2014]. The presence of a partially-serpentinised mantle wedge along the Hikurangi subduction zone might therefore be related to the origin of these events.

\subsubsection{Thick subduction channel}

Strongly-dipping reflectivity parallel to the top of the subducted Pacific plate is noted on both near-vertical and wide-angle seismic reflection data. ('Top of a subduction channel' in Figure 5.16). This reflectivity is situated about $8 \mathrm{~km}$ above the top of the Pacific plate (Figure 5.19).

The unusual thickness of this layer is similar to the $5-7 \mathrm{~km}$-thick 'E-reflection band' on top of the subducted slab in Cascadia (Figure 5.22). Several interpretations for the E-reflection band were suggested, including: 1) interlayered mafic and/or sedimentary rocks; 2) intensely sheared sediments that trap fluids; 3) dipping lenses of high porosity, where fluid is supplied by dehydration reactions.

In the New Zealand setting, one possibility is that this layer is a continuation of the thick underplated sediments identified in Henrys et al. [2013]. It is also possible that a hydrated mantle mineral such as serpentinite has been forced under hydraulic pressure up into the subduction channel [e.g. Hyndman and Peacock, 2003]. 
(a) Study area map

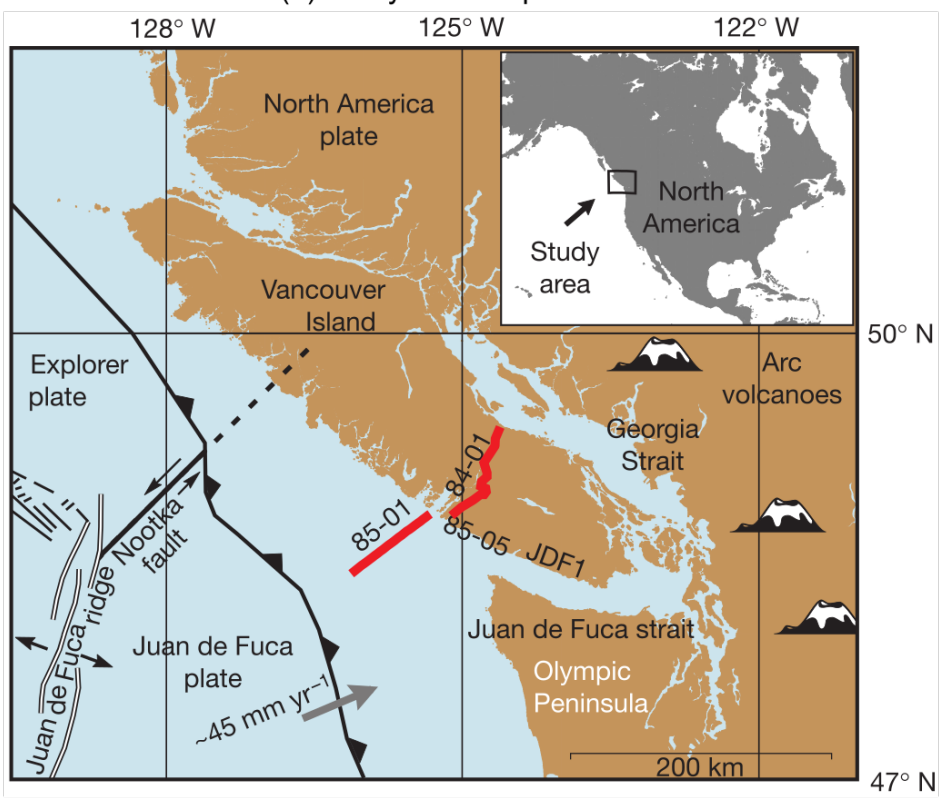

(b) Line 85-01

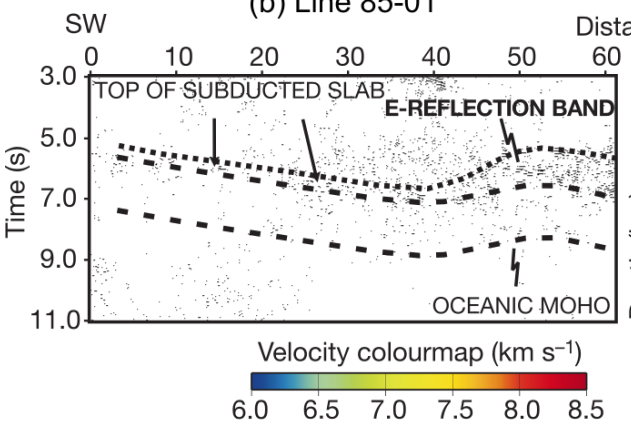

(c) Line $85-02$

Figure 5.22: Reflection seismic signature of the Cascadia subduction interface [after Nedimović et al., 2003]. (a) Study area map. Red lines represent the two seismic profiles shown below. Two adjacent seismic lines are shown in (b) and (c). Note the interpretation of the 'E-reflection band' which is directly on top of the subducted slab. 


\section{Chapter 6}

\section{Discussion}

In this chapter new findings from this thesis are summarised and discussed in the context of how the continental lithosphere might be deforming in the southwest North Island of New Zealand. The key observations are compared to similar structures seen elsewhere in the world. Four key points are highlighted:

1. A 'downwarp' of earthquakes $30-50 \mathrm{~km}$-deep is observed in the mantle beneath the Taranaki-Ruapehu Line. Is this rare? What are the implications of this finding? (Discussed in Section 6.1.)

2. The revised receiver function CCP stack across the Taranaki-Ruapehu Line shows the Moho deepening by $\sim 8 \mathrm{~km}$ and then disappearing under the Wanganui Basin. A similar situation exists in the Sierra Nevada (U.S.). How do the two settings compare? (Discussed in Section 6.2.)

3. A mantle wedge enriched in serpentinite could be expected to swell, yet the Wanganui Basin has been progressively subsiding since the Miocene. What could cause this behaviour? (Discussed in Section 6.3.)

4. Chapters 3 to 5 provide many new constraints on crustal/mantle structures, fault kinematics, and rheology. What are the key constraints for future geological models? (Discussed in Section 6.4.)

This chapter will conclude with recommendations for future work. (Discussed in Section 6.5.) 


\subsection{Mantle earthquakes and dynamic processes}

The occurrence of earthquakes in the mantle beneath the Taranaki-Ruapehu Line is difficult to explain. Most earthquakes occur in the brittle rocks of the upper crust, and mantle earthquakes are believed to be rare in continental settings [Maggi et al., 2000a,b; Jackson et al., 2008]. The unambiguous observation of mantle earthquakes at the Taranaki-Ruapehu Line, where the crustal structure is tightly constrained by a receiver function CCP stack, is a significant result that requires a special explanation.

At least three continental regions have mantle earthquakes with similar characteristics to those of the Taranaki-Ruapehu Line, including the East African Rift [e.g. Lindenfeld and Rümpker, 2011], the Romanian Carpathians [e.g. Lorinczi and Houseman, 2009], and the Alborán region of the western Mediterranean [e.g. Calvert et al., 2000]. Earthquake profiles for each of these regions, and examples of proposed geodynamic models, are shown in Figures 6.1 to 6.3. Note that the mantle earthquakes occur at depths of 53-60 km (East African Rift), 70-200 km (Romanian Carpathians), and 50-150 km (Alborán region) [Lindenfeld and Rümpker, 2011; Lorinczi and Houseman, 2009; Seber et al., 1996]. Earthquakes from all three regions were detected by long-term or high-density seismic deployments, either temporary or permanent in nature, thus the recorded earthquake hypocentres are well-constrained at mantle depths.

Like the Taranaki-Ruapehu Line earthquakes, those in the mantle beneath the East African Rift are small in magnitude $\left(M_{L}=1.4-2.4\right)$, are separated from shallower seismicity, and are dominated by strike-slip focal mechanisms [Lindenfeld and Rümpker, 2011]. It is unclear what caused these earthquakes to occur in the mantle. Three possible explanations have been proposed. 1) Rift-induced delamination of mantle lithosphere [Wallner and Schmeling, 2010, Figure 6.1c-d], where advecting heat weakens the lower crust and parts of the mantle lithosphere detach and drop down. This model is proposed to explain the extreme uplift of the Rwenzori mountains, and the downwelling provides a mechanism for seismogenic conditions at greater depth. 2) Magmatic impregnation of the lithosphere [Foley, 2008], which is observed in volcanic areas such as Monserrat, Afar and Iceland. In this model, earthquakes are associated with transient high strain-rates caused by rapid magma movements. 3) Earthquakes are induced by stresses of magmatic origin on preexisting mantle faults [e.g. Wolfe et al., 2003]. 
a) Study area

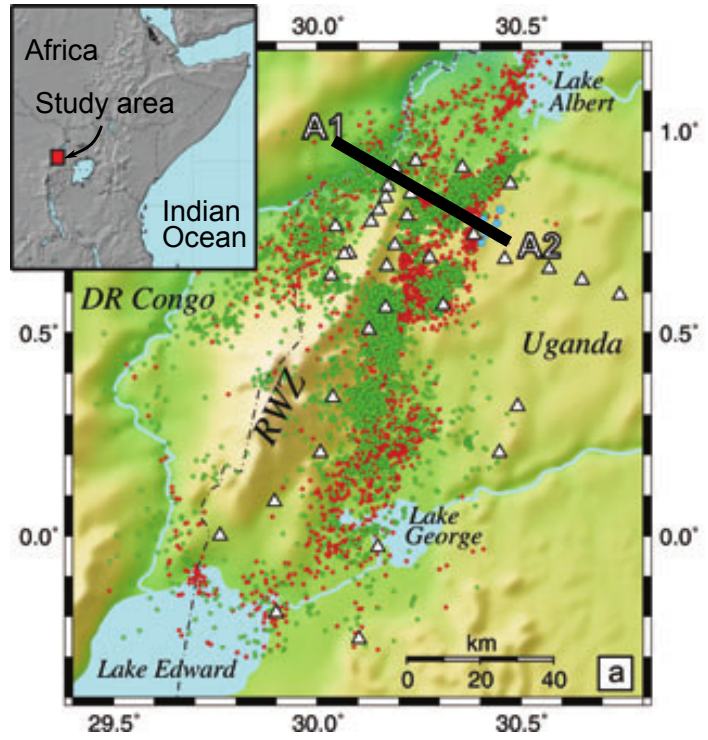

c) Rayleigh-Taylor-type instability (temperature)

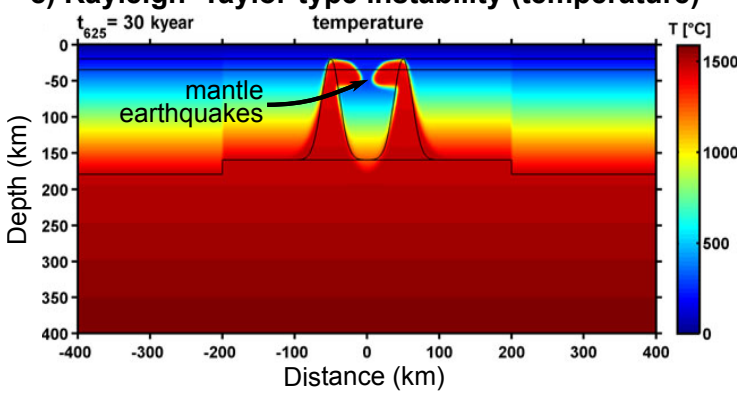

b) Crust and mantle earthquakes

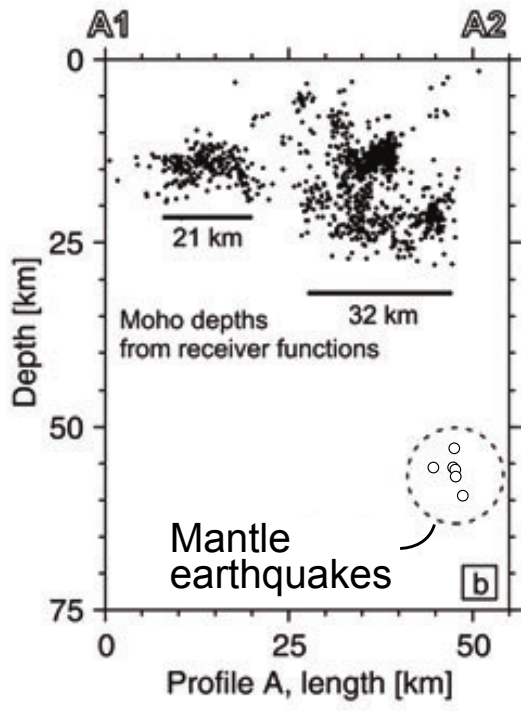

d) Rayleigh-Taylor-type instability (stress)

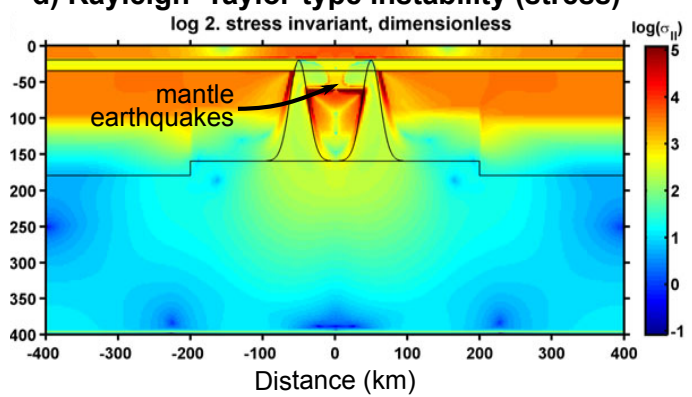

Figure 6.1: East African Rift mantle earthquakes and a proposed model. (a) Study area map showing the location of a profile containing mantle earthquakes in the East African Rift. Red and green dots represent earthquake hypocentres, white triangles are seismic station locations. (b) Crustal and mantle earthquakes along profile A1-A2 from (a). The mantle earthquakes are circled at the bottom right of the figure. (c) RayleighTaylor-type instability model for the formation of the Rwenzori mountains (RWZ). (d) Stress associated with the same Rayleigh-Taylor-type instability. Figures 1 and 2 after Lindenfeld and Rümpker [2011]; figures 3 and 4 after Wallner and Schmeling [2010]. 

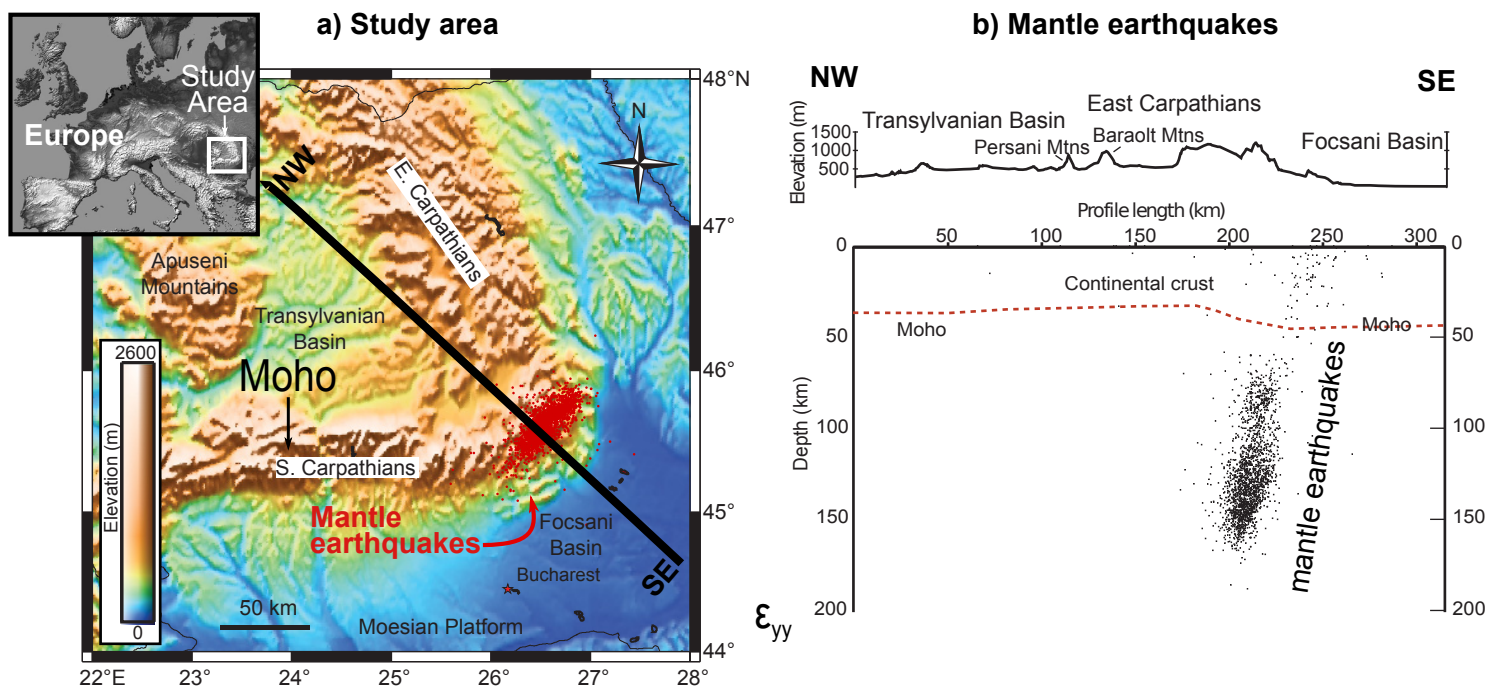

d) Delamination model

c) Rayleigh-Taylor instability model
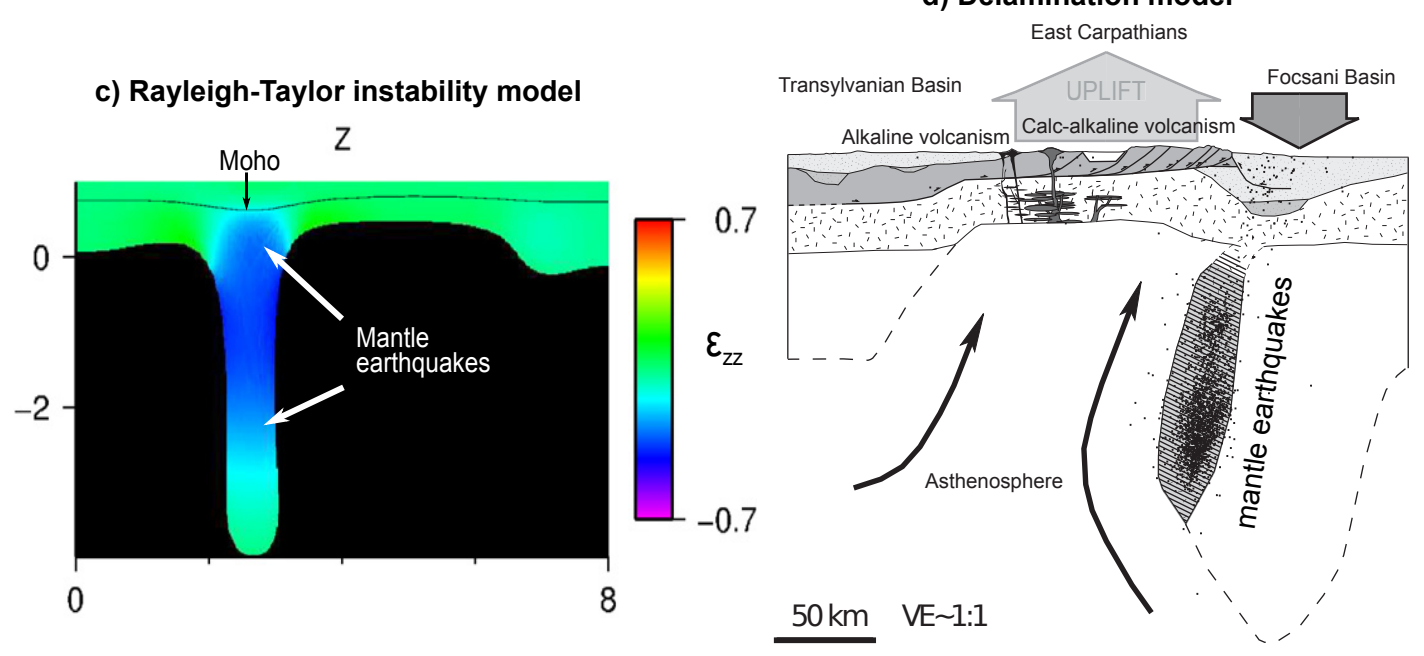

Figure 6.2: Romanian Carpathian mantle earthquakes and proposed models. (a) Study area map showing the location of a profile containing mantle earthquakes in the Romanian Carpathians. Red dots represent earthquake hypocentres. (b) Crustal and mantle earthquakes along profile NW-SE. (c) Rayleigh-Taylor-type instability model proposed by Lorinczi and Houseman [2009], here mantle earthquakes are associated with high strainrates. (d) Delamination model proposed by Fillerup et al. [2010], here the earthquakes occur within a partially-detached eclogised crustal root. Figures (a), (b) and (d) after Fillerup et al. [2010]; figure (c) after Lorinczi and Houseman [2009]. 
a) Study area

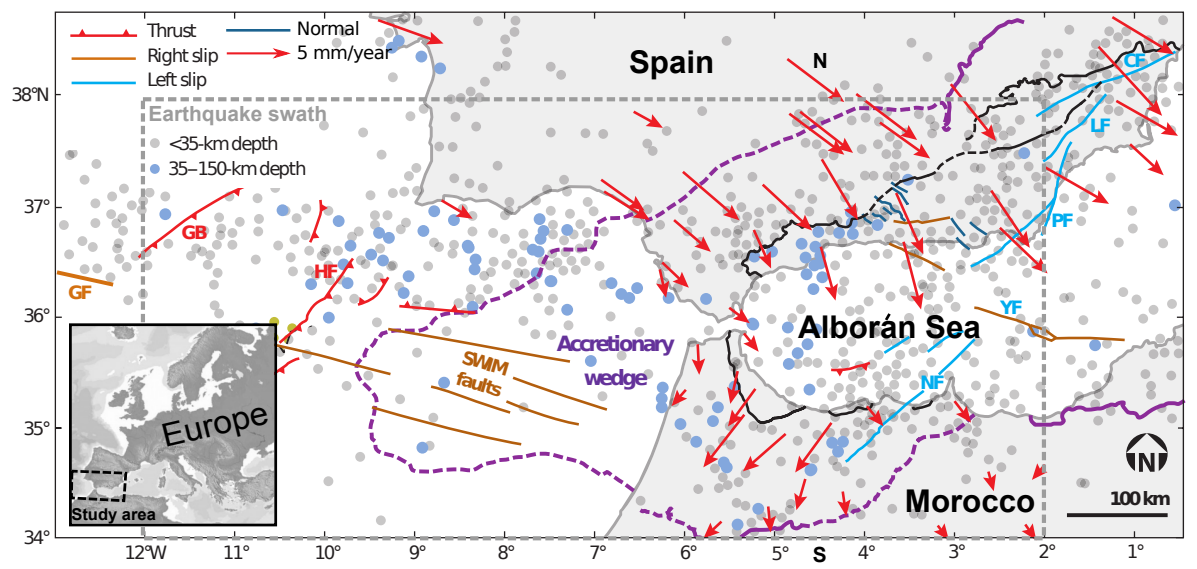

b) Mantle earthquakes

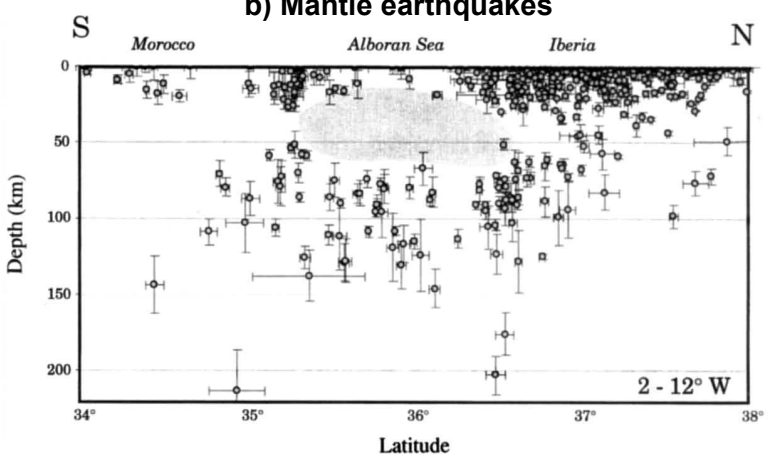

c) Proposed models

1 Slab break-of

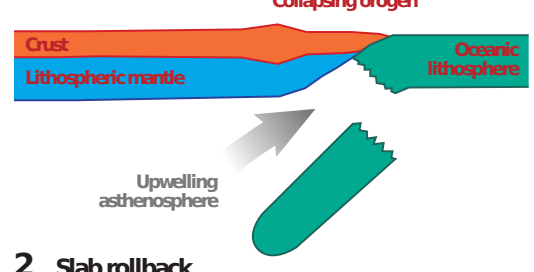

2 Slabrollback

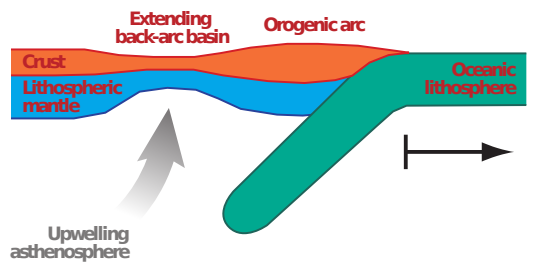

3 Delamination

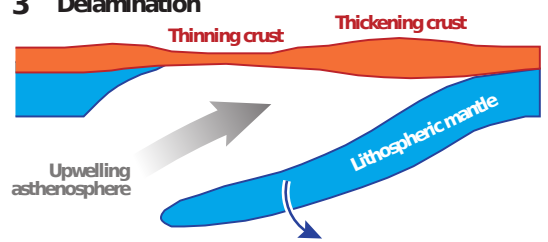

4 Convective removal of lithosphere

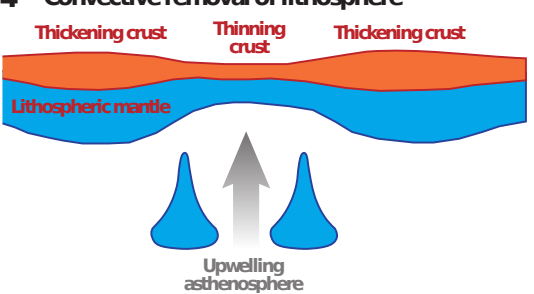

Figure 6.3: Alborán region mantle earthquakes and proposed models. (a) Location map. Blue and grey dots are earthquake hypocentres, the blue dots represent earthquakes that are 35-150 km-deep. (b) Earthquake profile representing a swath of earthquakes from the dashed region in (a). Shaded area marks the approximate location where an aseismic gap is observed. (c) Proposed geological models which attempt to explain the Alborán region. Figures (a) and (c) after Platt et al. [2013]; figure (b) after Seber et al. [1996]. 
New ideas which attempt to explain mantle earthquakes beneath the Romanian Carpathians include a Rayleigh-Taylor-type instability of the continental mantle lithosphere [Lorinczi and Houseman, 2009, Figure 6.2c], and delamination of an eclogised crustal root [Fillerup et al., 2010, Figure 6.2d]. In the case of a RayleighTaylor-type instability, the mantle lithosphere is modelled as denser than the asthenosphere and becomes gravitationally unstable when perturbed by a process such as crustal shortening. In the case of delamination, crustal shortening is instead thought to have thickened the crustal root into the eclogite stability field. A metamorphic phase change then took place and the eclogised root became increasingly unstable. Sometime during the Late Miocene-Early Pliocene, the root may have partially detached from the lower crust, and then descended into the upper mantle at a high angle. The earthquakes observed today are thought to occur as a result of high strain-rates accompanying a Rayleigh-Taylor-type instability, or within a partially-detached eclogised root in the case of delamination.

Finally, in the Alborán region of the western Mediterranean, mantle earthquakes occur within a high-velocity anomaly in the upper mantle [Calvert et al., 2000]. The geologic history of the Alborán domain is controversial, and there are several incompatible explanations for the opening of the Algerian basin and extension of the Alborán terrane (Figure 6.3C). These include: (1) slab break-off [Fillerup et al., 2010]; (2) slab rollback [Faccenna et al., 2004]; (3) a Rayleigh-Taylor-type instability of the Alborán lithosphere [Platt and Vissers, 1989; Houseman, 1996]; and (4) delamination of the mantle lithosphere [Docherty and Banda, 1995; Calvert et al., 2000; Platt et al., 1998; Seber et al., 1996]. Explanations 1 and 2 relate to subduction processes which are fundamentally different mechanisms to 3 and 4 which relate to gravitational instabilities. Whatever the true cause, complete slab break-off or lithospheric detachment seems unlikely, otherwise there would be no clear mechanism to produce the aforementioned earthquakes [Calvert et al., 2000].

The East African Rift, Romanian Carpathians and the Alborán region all point to some form of dynamic modification of the mantle lithosphere to explain mantle earthquakes. It seems reasonable that a similar explanation should be needed for the Taranaki-Ruapehu Line mantle earthquakes. In all three regions, some form of gravitational instability is proposed (delamination or Rayleigh-Taylor-type). Likewise, a Rayleigh-Taylor-type instability has been proposed beneath Taranaki-Ruapehu Line which implies earthquakes in the mantle due to high strain-rates [Stern et al., 2006, 2013]. 
The observed mantle earthquakes in this thesis are interpreted to be direct evidence of a dynamic process in the mantle lithosphere beneath the Taranaki-Ruapehu Line. Other evidence includes north-south migrating sedimentary depocentres [Stern et al., 2006], and a steeply-dipping Moho 'step' beneath the Taranaki-Ruapehu Line. Ray-traced wide-angle seismic data [Tozer, 2013], and the receiver function CCP stack from this thesis (Section 4.5.1), suggest that the Moho step is dipping at $\geq 30^{\circ}$ and $20-50^{\circ}$ respectively. These dips are unusually steep for the Moho and are difficult to maintain without invoking a dynamic explanation.

The earthquake constraints in Chapter 3 might be useful for understanding dynamic processes in the mantle lithosphere. For example, Taranaki-Ruapehu Line mantle earthquakes appear to have a relatively low strain-rate $\left(10^{-17} s^{-1}\right.$, Table 3.3) which is considerably less than the high strain-rate $\left(10^{-13} s^{-1}\right)$ proposed for a RayleighTaylor-type instability at the TR Line [Stern et al., 2013]. Since the discrepancy is several orders of magnitude it seems unlikely to be a result of the seismic strain-rate being underestimated. (Although it is possible that the strain-rate is underestimated, as parameters such as the seismogenic volume $V$ are difficult to accurately estimate.) One possibility is that the strain is dominantly aseismic and the seismic component is only a small fraction of the total strain-rate. A similar explanation was proposed for the Rayleigh-Taylor-type instability model of the Romanian Carpathians by Lorinczi and Houseman [2009]. Here, the instability time constant $T_{0}$ was an order of magnitude different between a calculation based on the observed strainrate and a calculation based on the viscosity constant, suggesting that the observed strain-rate might be too small.

The Taranaki-Ruapehu Line mantle earthquakes have a maximum horizontal compressive stress direction in a NE-SW direction ('Deep earthquakes' in Figure 3.13), or alternatively extensional axes oriented NW-SE. This latter direction is the same as extension in the western North Island [Sherburn et al., 2006]. Thus, the TR Line mantle earthquakes appear to align with the regional stress field. Bak and Tang [1989]; Cowie et al. [1993]; King [2000] and others suggest that the brittle crust is always primed and ready to fail. One possibility is that a dynamic process such as a Rayleigh-Taylor-type instability is maintaining a brittle asperity in the upper mantle, creating a focal point for the regional stress field of the western North Island to generate earthquakes. 


\subsection{Similarity between the Taranaki-Ruapehu Line and the Sierra Nevada (U.S.)}

One of the best analogues for the Taranaki-Ruapehu Line in terms of the time and space scale of deformation is the Sierra Nevada of eastern California (Figure 6.4). This is another continental region where dynamic modification of the mantle lithosphere has been proposed [e.g. Zandt et al., 2004; Le Pourhiet et al., 2006; Frassetto et al., 2011]. Although the Sierra Nevada lacks an association with mantle earthquakes like the regions mentioned previously, it does contain clusters of anomalous deep crustal earthquakes [Frassetto et al., 2011]. However, it is the structure of the Moho which bears the closest resemblance to the Taranaki-Ruapehu Line (Figures 6.4 and 6.5).

In the Sierra Nevada, the Moho depth increases from 25-35 km-deep to 45-55 kmdeep over a profile distance of tens of kilometres (Figure 6.4b). The shallower Moho provides a strong P-to-S conversion on receiver function CCP stacks (Figure 6.4b). The strength of this conversion is thought to be related to a delamination process, where asthenosphere has upwelled following the foundering of a dense crustal root [Frassetto et al., 2011]. Since the seismic velocity contrast between asthenosphere and mid-crust is greater than the contrast between the lower crust and mantle lithosphere, a stronger P-to-S conversion results. (Strictly speaking, this is not a Moho conversion, hence the name 'Reset "delamination" Moho' in Figure 6.4.) The observation of a strong P-to-S conversion from a delaminated Moho is important for the Taranaki-Ruapehu Line. In the northwest North Island of New Zealand, gravity modelling, studies of regional Sn wave speeds, and rock uplift rates, suggest that the mantle lid and possibly the lower crust are missing north of the Taranaki-Ruapehu Line, and have been replaced with material from the asthenosphere [Stern et al., 2006].

Consider the receiver function CCP stacks in Figure 6.5c. For both the TaranakiRuapehu Line and the Sierra Nevada, Moho amplitude is brightest where asthenosphere is in direct contact with mid-crustal rocks. Another similarity is a decrease in seismic amplitude on the left of both profiles which Frassetto et al. [2011] refers to as a 'Moho hole'. This feature was modelled with synthetic receiver functions by Zandt et al. [2004], and it is proposed to be a Moho cusp created by a foundering lithospheric root. This is one possible explanation from the Taranaki-Ruapehu Line Moho disappearing. However, recall that by using Zoeppritz equations a weakening 
Moho could also be caused by partial serpentinisation of the mantle lithosphere (see Section 5.6.1).

(a) Study area map

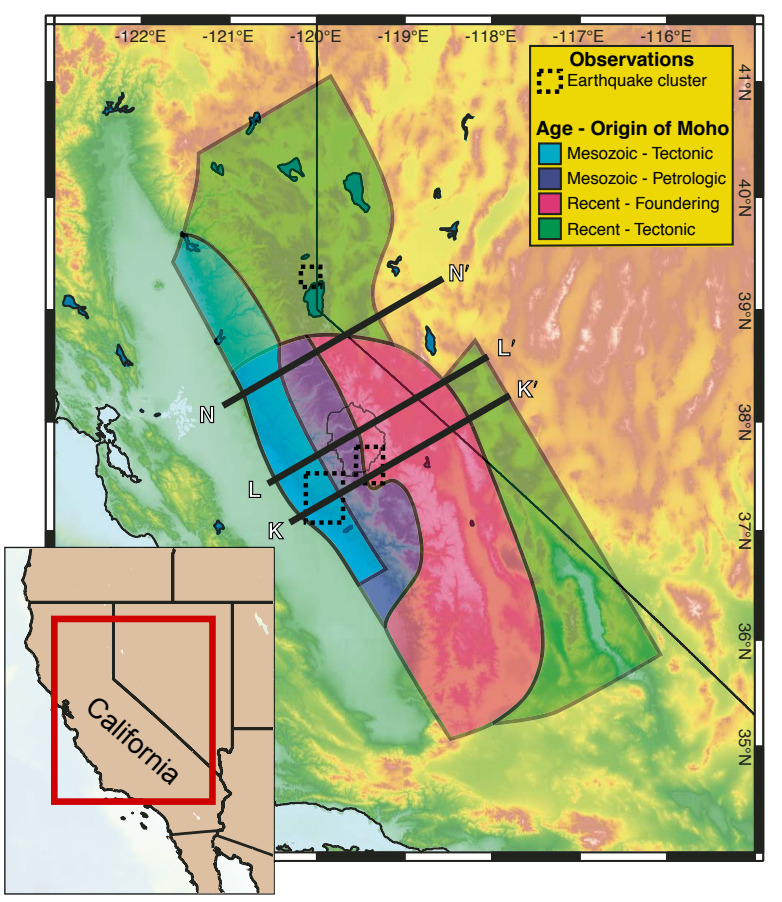

(b) Key receiver function profiles

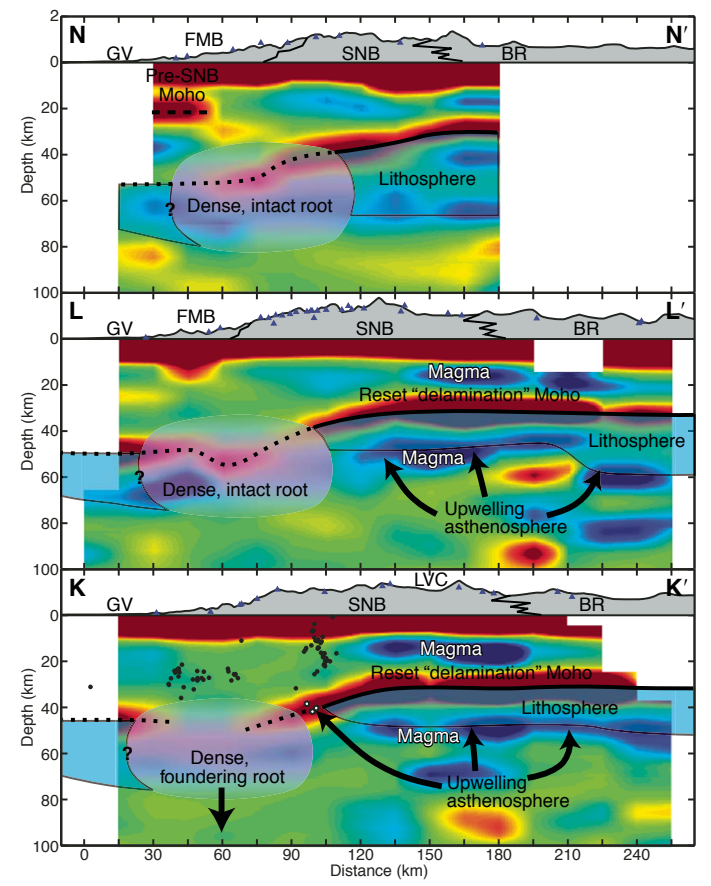

Figure 6.4: Receiver function CCP stacks from the Sierra Nevada [after Frassetto et al., 2011]. (a) Study area showing the location of three receiver function profiles, K-K', L-L', $\mathrm{N}-\mathrm{N}$ '. (b) Interpreted receiver function profiles. Note that the Moho becomes sharper where the asthenosphere is shown to have upwelled.
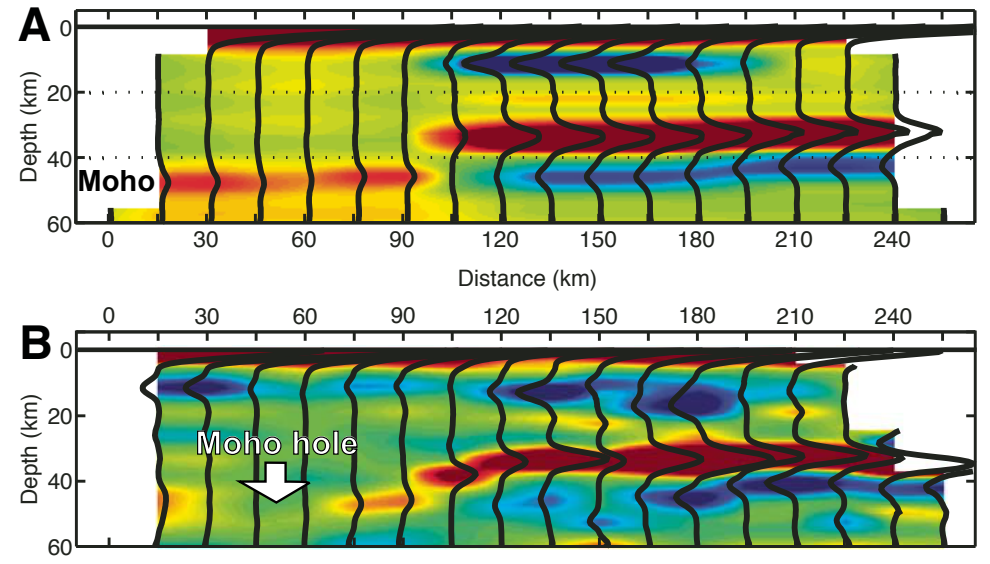

C

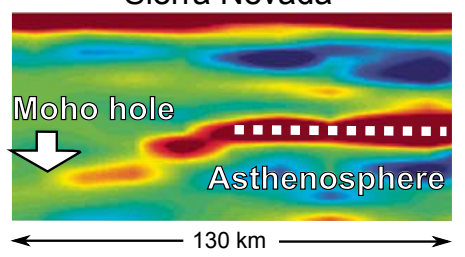

Taranaki-Ruapehu Line

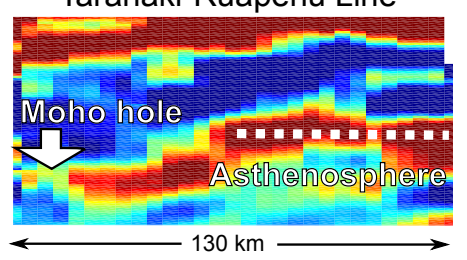

Figure 6.5: $\quad$ Foundering Moho in the $\mathrm{K}-\mathrm{K}$ ' receiver function CCP stack [after Frassetto et al., 2011]. (A) A synthetic CCP stack shows a bright, sharp Moho where the lower crust is thought to overlie asthenosphere (>100 km distance). (B) Observed stacks are similar to synthetics, except a foundering lithospheric root is thought to cause a 'Moho hole'. (C) Comparing Sierra Nevada to Taranaki-Ruapehu Line shows similar features including a 'Moho hole' and a bright asthenosphere Moho. 


\subsection{Speculation on the role of serpentinite forma- tion in the mantle}

In Chapter 5, a significant volume of serpentinite was proposed to occur in the mantle wedge beneath the Wanganui Basin. Alteration of mantle peridotite to serpentinite causes a density drop along with a concurrent volume increase as large as $40 \%$ [Guillot et al., 2015]. Yet the Wanganui Basin is not rising in response to a swelling mantle lithosphere, and neither are other regions whose mantle wedges are thought to be enriched with serpentinite (e.g. Alaska, Aleutians, central Andes, Cascadia, Izu-Bonin-Mariana, and central Japan). Rather, the Wanganui Basin shows evidence of being progressively downwarped (discussed in Section 1.1.2). If pervasive serpentinisation exists in the mantle wedge there might be a process in the mantle which counteracts the effect of the swelling, and possibly even causes the observed downwarp.

One possibility is that the serpentinite in the mantle lithosphere is flowing away from where it was formed. A plausible mechanism to explain this behaviour is smallscale convection in a serpentinised mantle wedge [e.g. Richter, 1973; Richter and Parsons, 1975]. Mantle wedge viscosity exerts the strongest control of any parameter regarding whether a small-scale convection develops [Wirth and Korenaga, 2012]. The viscosity of fully serpentinised mantle peridotite is around $10^{19} \mathrm{~Pa}$ at $550^{\circ} \mathrm{C}$ and ambient pressure [Carter and Tsenn, 1987; de Bremond d'Ars et al., 1999]. The viscosity of a mixture of peridotite and serpentinite has been estimated at $10^{20} \mathrm{~Pa}$ for $50 \%$ and $10^{21} \mathrm{~Pa}$ for $12 \%$ serpentinisation respectively [Schwartz et al., 2001]. For comparison, a cold anhydrous mantle has a viscosity of $10^{23} \mathrm{~Pa}$ [Carminati et al., 1999] which is comparable to continental crust. In other words, serpentinite is at least an order of magnitude less viscous than normal mantle lithosphere, and might provide the right conditions for small-scale convection.

Stern et al. [2013] required a maximum upper mantle viscosity of $5 \times 10^{20} \mathrm{~Pa}$ s to explain the north to south movement of a putative step-driven instability in the mantle lid of the western North Island (Figure 6.6). This is a lower than the regular viscosity of the continental upper mantle, but was required to explain the time scale of the migration of sedimentary basin depocentres that were linked to the migrating instability (Figure 6.6, right panel). Their value of $5 \times 10^{20} \mathrm{Pas}$ is consistent with partial serpentinisation of the mantle wedge as discussed above. Therefore, it is possible that the link between arc hydration, serpentinisation, and instability development is a generalised process, and not just linked to the New Zealand setting. 

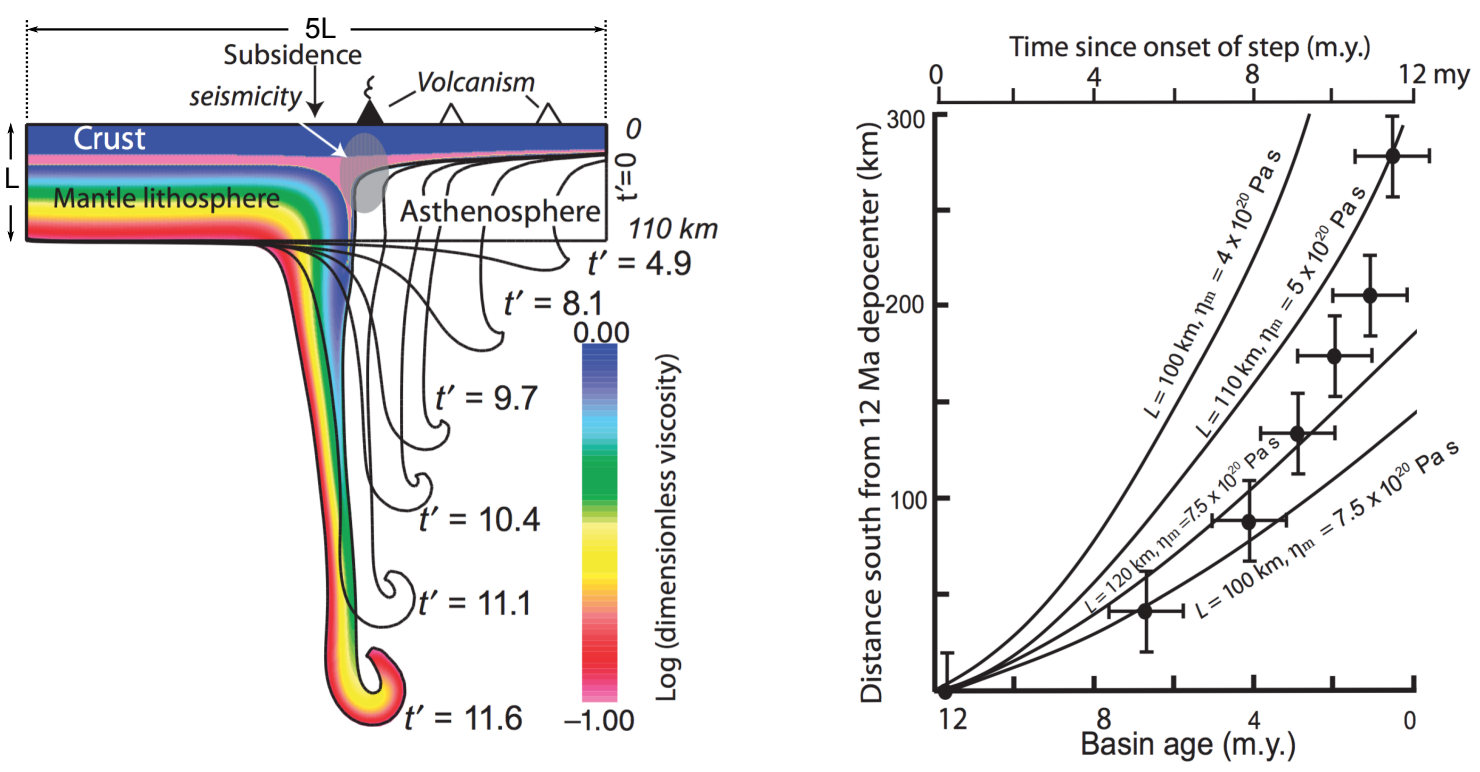

Figure 6.6: Rayleigh-Taylor-type instability model for the Taranaki-Ruapehu Line [after Stern et al., 2013]. Colour scale is dimensionless viscosity $(\eta), t^{\prime}$ is dimensionless time, $\mathrm{L}$ is lithospheric thickness. The right panel relates models of instability migration path (solid lines) to the observed migration of depocentres (black dots). The rate of depocentre migration was best fit with an uppermost mantle viscosity $\left(\eta_{m}\right)$ of $5 \times 10^{20} \mathrm{~Pa}$. If $\mathrm{L}$ is set to $110 \mathrm{~km}$ and $\eta_{m}=5 \times 10^{20} \mathrm{~Pa}$ s, the dimensionless time $t^{\prime}$ is equivalent to millions of years.

A quantitative analysis of small-scale convection or some other corner flow mechanism is beyond the scope of this thesis. However, this thesis has constraints that would be needed in modelling this sort of phenomenon. The following is speculation on a possible model. It was previously proposed that water ejected from the subducting plate is causing serpentinisation of the mantle wedge (Section 5.6). Relatively low-viscosity serpentinite might flow down-dip along the subducted Pacific plate, away from the corner of the mantle wedge. At some depth the serpentinite breaks down. The breakdown of serpentinite contains $13 \%$ of water by weight to depths of 150-200 km in subduction zones, which could then re-enter the subduction zone and cause further serpentinisation [Ulmer and Trommsdorff, 1995].

Figure 6.7 is a speculative model of where mantle wedge serpentinisation might be occurring beneath the Wanganui Basin and regions to the northeast. The eastern bound is the $30 \mathrm{~km}$ depth contour which specifies the top of the subducted Pacific plate [Williams et al., 2013]. The mantle wedge is unlikely to be any shallower than this under the Wanganui Basin [Henrys et al., 2013; Tozer, 2013]. It is bound by SAHKE02, GD100 and the receiver function CCP stack, all of which show reduced Moho reflectivity. It is also confined to regions of the mantle wedge likely to be $<650^{\circ} \mathrm{C}$ (i.e. it avoids the TVZ). 
(a) Proposed extent of a serpentinised mantle wedge
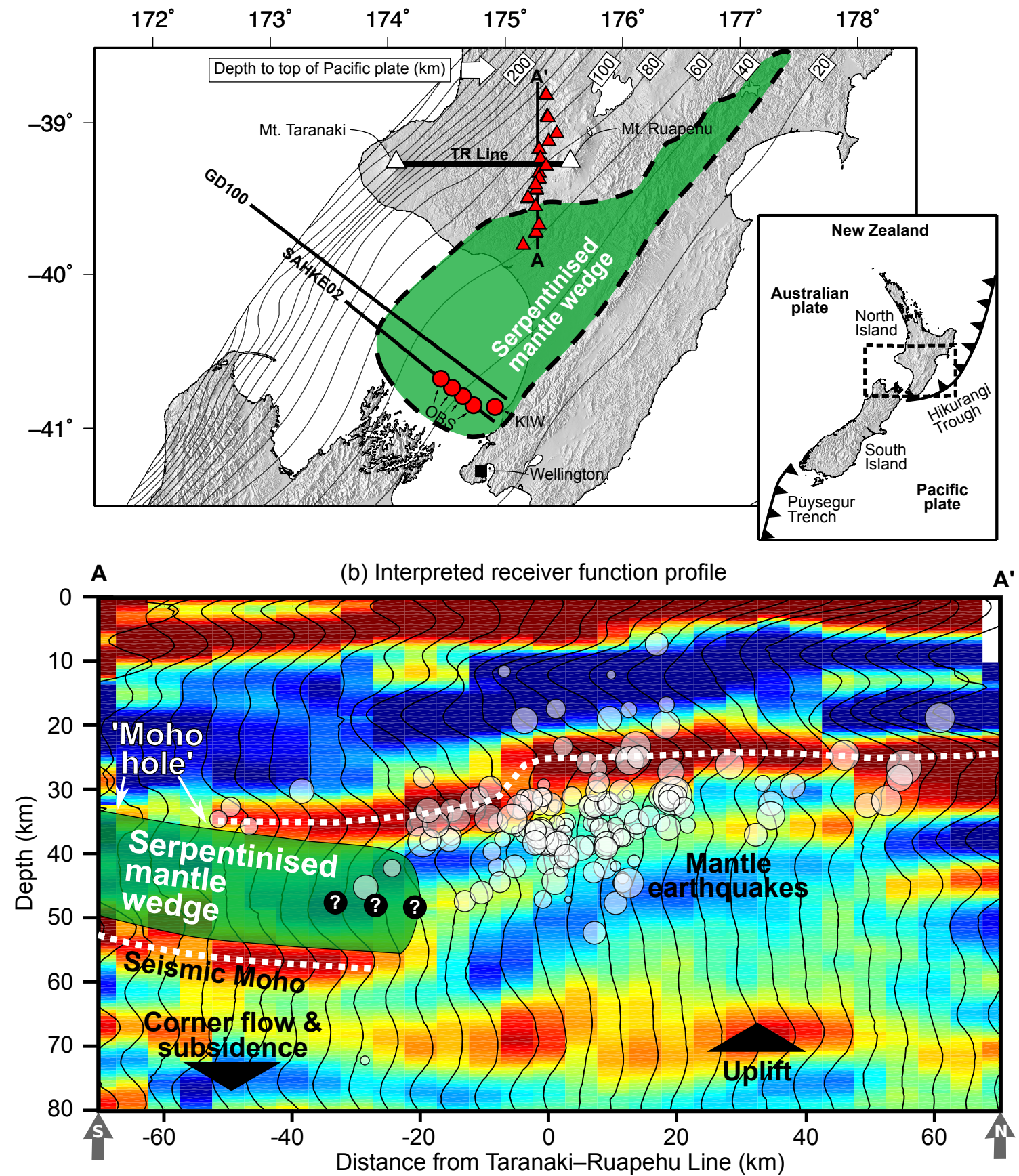

Figure 6.7: Speculative model of serpentinite distribution. (a) A partially-serpentinised mantle wedge is proposed to occur in the Wanganui Basin and possibly extends to the northeast. Red triangles are seismic stations used for receiver functions. Red circles are ocean-bottom seismometers and GeoNet station KIW. GD100 and SAHKE02 are marine seismic profiles. The 'top of Pacific plate' contours are from Williams et al. [2013]. (b) Receiver function profile across the TR Line with interpretation. White circles are earthquakes scaled by magnitude. 


\subsubsection{Gravitational and magnetic anomalies}

The region of proposed serpentinisation is associated with a distinctively low ($160 \mathrm{mGal}$ ) isostatic gravity anomaly (Figure 1.3a). Ewig [2009] modelled the gravitational effect of Wanganui Basin sediment fill and found that only about -80 mGal can be explained by the sediments alone, leaving another $-80 \mathrm{mGal}$ to be explained by deeper sources. While a detailed interpretation of the gravity anomalies is beyond the scope of this study, it is noted that the low density of serpentinite could provide a simple explanation for the long standing problem of explaining this anomaly [Robertson and Reilly, 1958]. Even a modest 25\% serpentinisation of peridotite brings with it approximately $-200 \mathrm{~kg} / \mathrm{m}^{3}(6 \%)$ in density reduction. For an infinite Bouguer slab of this density contrast and say $17 \mathrm{~km}$ thick (Figure 5.20), the predicted gravity effect would be about $-140 \mathrm{mGal}$ [Kearey et al., 2013]. The 3D configuration of the proposed serpentinite body is not an infinite slab, and would reduce this estimate by up to $50 \%$, yet still make a considerable contribution to explaining the $-160 \mathrm{mGal}$ Wanganui Basin gravity anomaly.

(a) Gravity anomaly due Wanganui Basin sediments

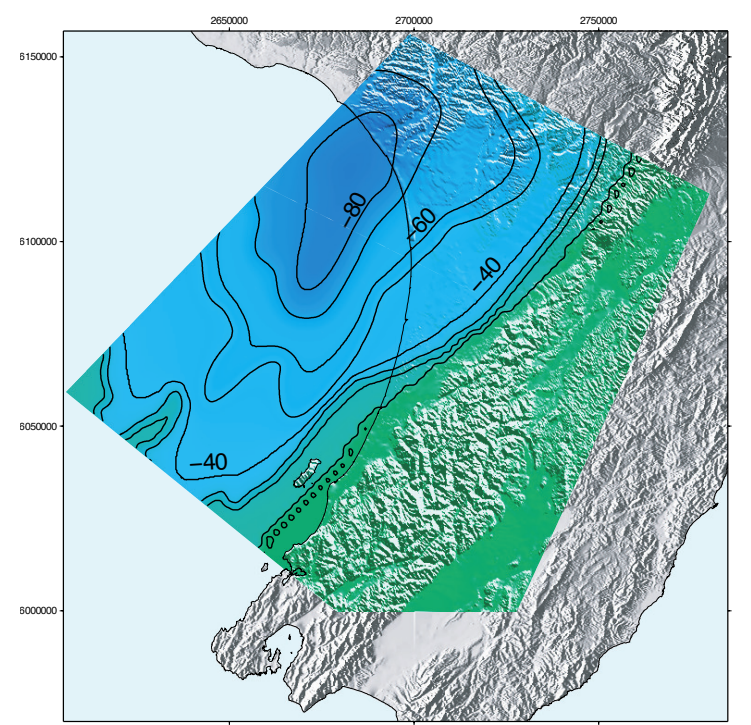

(b) Observed gravity anomaly

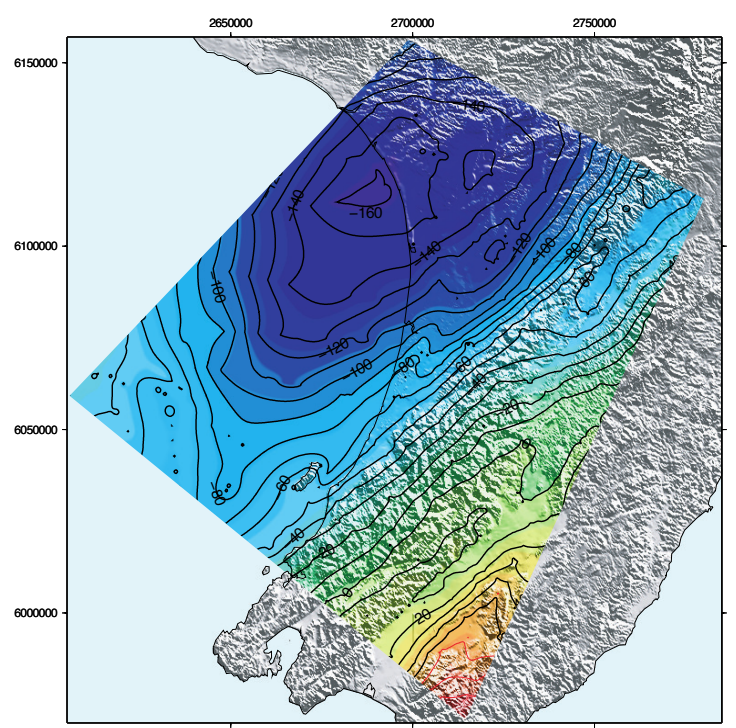

$\mathrm{mGal}$

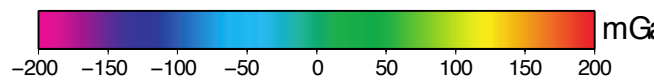

Figure 6.8: Wanganui Basin gravity anomaly [after Ewig, 2009]. (a) Modelled gravitational anomaly due to the sediments of the Wanganui Basin. (b) Observed isostatic/free air gravity anomaly. Note that the sediments can only explain about half of the observed anomaly, the remaining half must come from deeper sources.

Serpentinite is often magnetic due to the precipitation of small amounts of Fe rich materials such as magnetite. Blakely et al. [2005] show that a serpentinised mantle 
wedge could show a broad magnetic anomaly of about $80 \mathrm{nT}$. The Wanganui Basin region appears to lack a strong magnetic signature (Figure 1.9). However, the magnetic coverage for the offshore Wanganui Basin is sparse with just a few ship tracks to rely on (NOAA Marine Trackline Geophysical Database), so it is hard to be conclusive if there is a significant magnetic anomaly present or not.

Moreover, magnetisation of serpentinite is a complex and temperature dependent process [Hunt, 1978; Blakely et al., 2005; Evans, 2010]. A lack of magnetisation does not necessarily mean there is no antigorite in the mantle wedge. As discussed by Evans [2010], the serpentinisation of peridotite operates according to two endmember mechanisms, lizardite predominates in low-temperature environments (50$\left.300^{\circ} \mathrm{C}\right)$ while antigorite dominates at higher temperatures $\left(400-600^{\circ} \mathrm{C}\right)$. At higher temperatures, such as in forearc mantle wedges, it is less likely that there will be an accompanying precipitation of magnetite, and therefore less potential for a magnetic anomaly. For example, Smith [2010] described an antigorite-rich metaperidotite from the Green Knobs diatreme in the Navajo volcanic field, which has no magnetite present. However, this issue is complicated and highly dependent on the chemistry of the mantle wedge. This topic needs further research.

\subsection{Key constraints for future geological models}

The interaction between back-arc extension to the north of the Taranaki-Ruapehu Line, amagmatic back-arc processes to the south, and the strong possibly of dynamic mantle processes such as a gravitational instability and/or mantle wedge corner flow, are complex to model. Key input parameters to such a model would be crustal structure, lithospheric rheology, and kinematics. The three seismic investigations in this thesis provide several constraints which future geological models of the North Island should consider. A summary of the most important constraints is illustrated in Figure 6.9 and provided in bullet form below:

- A 'downwarp' of earthquake hypocentres exist at depths of 30-50 km beneath the Taranaki-Ruapehu Line which place them in the mantle. They are dominated by strike-slip focal mechanisms, and like the rest of the western North Island are associated with NW-SE extension. In this study, these earthquakes are proposed to be associated with some sort of dynamic process in the mantle lithosphere. 

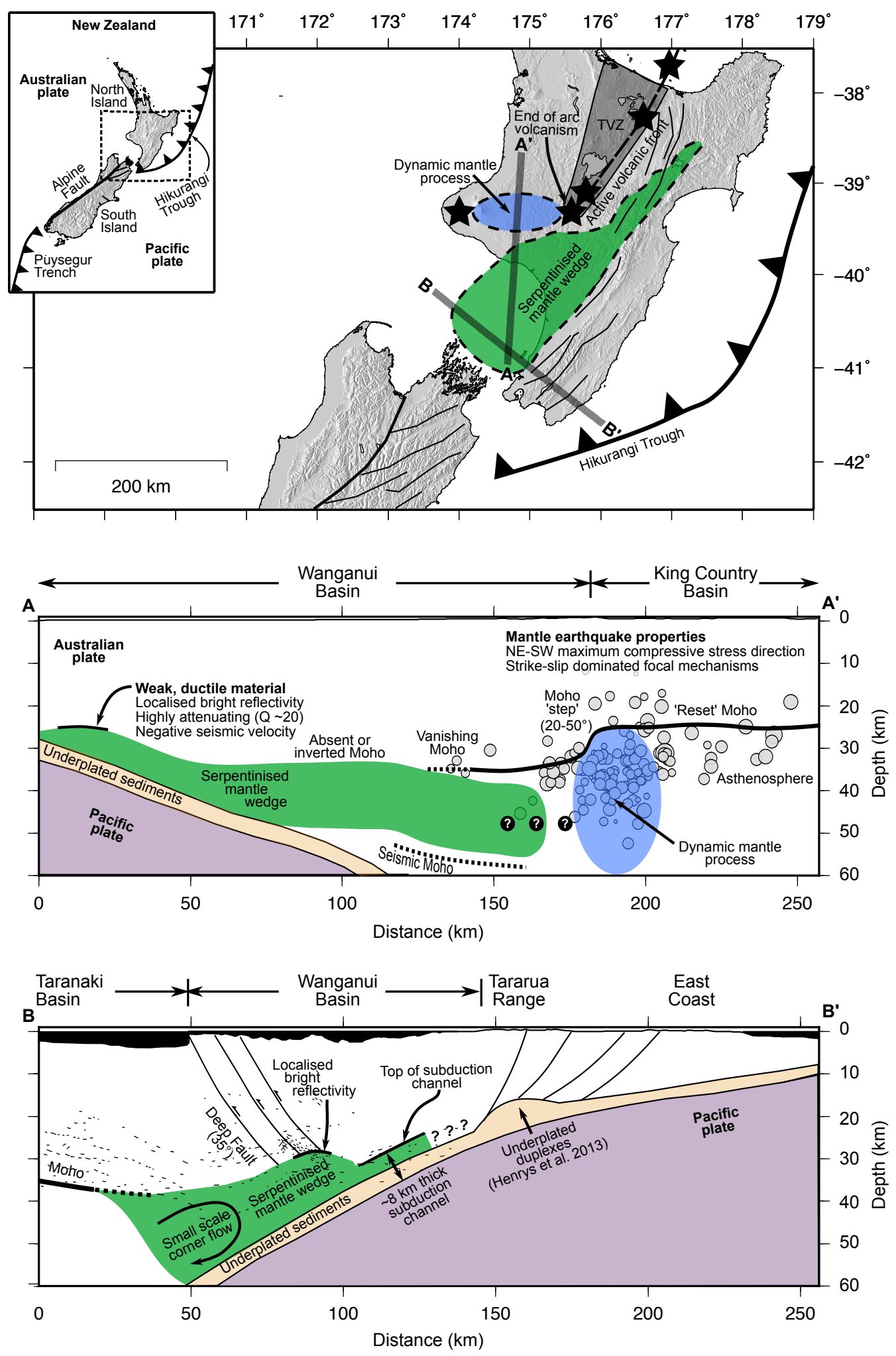

Figure 6.9: Schematic diagram showing key constraints from this study. Stars represent active volcanoes. TVZ = Taupo Volcanic Zone. In profile A-A', the serpentinised mantle wedge is proposed to trend NE, except near the active volcanic front. The serpentinised mantle wedge might also impinge upon a dynamic mantle process such as the RayleighTaylor type instability [Stern et al., 2013]. In profile B-B', serpentinite is thought to be riding up against a shallow subducting Pacific plate, perhaps even being forced up into a thick subduction channel under hydraulic pressure. 
- The Moho depth across the Taranaki-Ruapehu Line increases from $28 \mathrm{~km}$ north of the Line to $35 \mathrm{~km}$ south of the Line. The steepest part of the Moho dips at $20-50^{\circ}$. A geological model for the Taranaki-Ruapehu Line would need a mechanism to maintain these dips.

- The Moho under the northern end of the Wanganui Basin appears to be reasonably flat. It was previously assumed to be dipping or even downwarped [e.g. Salmon et al., 2011; Ewig, 2009]. The presence of a conventional thick crustal root beneath the Wanganui Basin seems unlikely due to the flat Moho.

- Weak, ductile material exists beneath the Wanganui Basin at Moho depths, and likely comes from the mantle wedge. The preferred explanation for this material is serpentinite (antigorite) for reasons discussed previously, although free-water can't be ruled out. This material is likely to have relatively lowviscosity when compared to mantle periodotite allowing it to more easily deform and has created a new and unconventional crustal root beneath the Wanganui Basin to a depth of $\sim 50 \mathrm{~km}$.

\subsection{Recommendations for future work}

This thesis leaves much room for follow-on investigations on a number of important topics. The following future work is recommended:

1. A high-density temporary deployment of seismometers across and along the Taranaki-Ruapehu Line, especially west of the RATTIL network and east of the Taranaki Fault. This area is one of the most inaccessible parts of New Zealand's North Island, and would require helicopter and/or boat access as well as permits to deploy in Wanganui National Park. Geological field work should also be considered. Seismic stations should be deployed for at least a year so that enough local and teleseismic earthquakes are recorded.

2. Further work on receiver functions, such as joint inversion of receiver functions and ambient noise data to constrain the velocity model and structure associated with the Taranaki-Ruapehu Line Moho offset. Furthermore, the Taranaki-Ruapehu Line presents itself as an ideal testbed for receiver functions using local earthquakes from the subducted Pacific plate which can be compared to the results in this study. Both of these studies can be done with existing data, but would be ideally combined with the high density micro- 
seismic study proposed above, to provide better constraints for lithospheric structure in an area undergoing dynamic deformation.

3. Construction of geodynamic finite-element models which use constraints from this thesis and previous work. For example, modelling the gravitational, magnetic, and deformational properties of a serpentinised mantle wedge. Another example is modelling a dynamic mantle process which can explain low strainrate mantle earthquakes while being able to sustain a Moho dipping $20-50^{\circ}$. 


\section{Chapter 7}

\section{Conclusions}

Crust and upper mantle properties of the southwest North Island of New Zealand have been investigated using microseismic, receiver function, and active-source seismic techniques. Key observations from this study include:

1. A 'downwarp' of earthquakes is observed at depths of 30-50 km east-west along the Taranaki-Ruapehu Line. The downwarp is centred at latitude 174.83, longitude -39.25. A receiver function CCP stack constrains the Moho depth in this region requiring the downwarped earthquakes to occur in the mantle. Maximum horizontal compressive stress directions of these earthquakes are in a NE-SW, or alternatively NW-SE extension, which is consistent with NW-SE extension of the Taupo Volcanic Zone and western North Island. The mantle earthquakes appear to be in a separate cluster from earthquakes in the crust near Mt. Ruapehu, and have differently-oriented focal mechanisms and stress directions.

2. A receiver function CCP stack reveals a change in continental Moho depth from $25 \mathrm{~km}$-deep north of the Taranaki-Ruapehu Line to $35 \mathrm{~km}$-deep south of the Line. Synthetic models help constrain the change in thickness to dips of 20-50 degrees. The downwarped mantle earthquakes occur directly beneath where the Moho is steepest.

3. The Moho appears to be missing south of the Taranaki-Ruapehu Line on both the receiver function profile and marine seismic reflection data. However, a localised region of bright seismic reflectivity is identified in the mantle wedge beneath the Wanganui Basin on near-vertical and wide-angle seismic datasets. Attribute analysis suggests that the region of the upper mantle between two 
dominant reflectors is strongly attenuating $(\mathrm{Q} \sim 20)$ and possibly associated with a reversal in acoustic impedance.

Observations 1 and 2 are interpreted to be associated with some sort of dynamic mantle processes, such as a Rayleigh-Taylor-type instability (discussed in Section 6.1). Observation 3 was interpreted to be caused by serpentinisation of the mantle wedge (Section 5.7), which might in turn be associated with some type of mantle cornerflow process (discussed in Sections 6.2 and 6.3).

The link between the three key observations listed above is one where hydration of an amagmatic arc will cause, via serpentinisation and/or high pore fluid pressure, a weakening within the mantle wedge. This should permit a range for deformations from corner flow and downwarping of the crust to a wholesale gravitational instability of the upper mantle lid. 


\section{Appendix A}

\section{Hypocentre locations}

The following table lists all 710 hypercentres recorded by GeoNet and RATTIL stations at the Taranaki-Ruapehu Line for the period of November 2012 to March 2014. Earthquake locations (lat, long, depth) and their quality parameters (RMS, Stations, Gap) were calculated using NonLinLoc (see Section 3.3.3). Earthquake magnitudes (Mag) are from the GeoNet Rapid earthquake analysis system which uses SeisComP3 [Olivieri and Clinton, 2012], and has been the official source of earthquake information in New Zealand since September 2012. Local magnitudes $\left(\mathrm{M}_{\mathrm{L}}\right)$ have not been been re-evaluated during this study and are included below for reference purposes. The Event ID refers to the origin time of the earthquake, and is given as YYYYMMDD.HHMMSS. 


\begin{tabular}{|c|c|c|c|c|c|c|c|c|c|c|c|c|c|c|c|}
\hline $\begin{array}{c}\text { Event ID } \\
\text { yyyymmdd.hhmmss }\end{array}$ & $\begin{array}{c}\text { Longitude } \\
{\left[{ }^{\circ}\right]}\end{array}$ & $\begin{array}{c}\text { Latitude } \\
{\left[{ }^{\circ}\right]} \\
\end{array}$ & $\begin{array}{c}\text { Depth } \\
{[\mathrm{Km}]}\end{array}$ & $\begin{array}{c}\mathrm{RMS} \\
{[\mathrm{s}]}\end{array}$ & Stations & $\begin{array}{c}\text { Gap } \\
{\left[{ }^{\circ}\right]}\end{array}$ & $\mathrm{M}_{\mathrm{L}}$ & Event ID & $\begin{array}{c}\text { Longitude } \\
{\left[{ }^{\circ}\right]}\end{array}$ & $\begin{array}{c}\text { Latitude } \\
{\left[{ }^{\circ}\right]}\end{array}$ & $\begin{array}{c}\text { Depth } \\
{[\mathrm{Km}]}\end{array}$ & $\begin{array}{c}\mathrm{RMS} \\
{[\mathrm{s}]}\end{array}$ & Stations & $\begin{array}{c}\text { Gap } \\
{\left[{ }^{\circ}\right]}\end{array}$ & $\mathrm{M}_{\mathrm{L}}$ \\
\hline 20121101.125246 & 175.342 & -39.213 & 16.65 & 0.33 & 15 & 84 & 1.92 & 20130523.074820 & 175.001 & -39.278 & 23.09 & 0.20 & 15 & 99 & 1.89 \\
\hline 20121101.154149 & 175.387 & -39.484 & 24.76 & 0.06 & 5 & 261 & 1.45 & 20130524.084214 & 175.149 & -39.269 & 23.02 & 0.12 & 9 & 116 & 2.02 \\
\hline 20121102.151511 & 174.782 & -39.221 & 41.75 & 0.09 & 7 & 277 & 2.23 & 20130524.185028 & 175.207 & -39.247 & 21.66 & 0.34 & 20 & 69 & 1.87 \\
\hline 20121103.105233 & 175.142 & -39.120 & 11.01 & 0.26 & 12 & 112 & 2.24 & 20130527.032113 & 175.226 & -39.214 & 10.47 & 0.34 & 25 & 38 & 1.71 \\
\hline 20121106.114010 & 175.391 & -39.164 & 12.88 & 0.37 & 26 & 68 & 2.68 & 20130529.205423 & 175.211 & -39.287 & 31.40 & 0.29 & 30 & 51 & 3.30 \\
\hline 20121106.114720 & 175.405 & -39.165 & 16.45 & 0.09 & 9 & 189 & 0.78 & 20130531.033638 & 175.287 & -39.286 & 26.56 & 0.21 & 25 & 59 & 2.55 \\
\hline 20121106.164228 & 175.401 & -39.165 & 16.45 & 0.08 & 7 & 184 & 1.27 & 20130531.120101 & 174.914 & -39.424 & 34.39 & 0.09 & 6 & 133 & 2.14 \\
\hline 20121107.010304 & 175.405 & -39.165 & 16.59 & 0.09 & 6 & 191 & 1.28 & 20130601.142330 & 175.054 & -39.369 & 34.88 & 0.23 & 23 & 97 & 1.91 \\
\hline 20121107.073456 & 175.381 & -39.161 & 15.76 & 0.33 & 25 & 63 & 2.61 & 20130604.170046 & 174.924 & -39.120 & 29.79 & 0.25 & 20 & 88 & 2.01 \\
\hline 20121107.080531 & 175.366 & -39.160 & 16.67 & 0.09 & 11 & 138 & 1.77 & 20130606.121238 & 175.419 & -39.232 & 11.69 & 0.13 & 10 & 160 & 2.73 \\
\hline 20121107.090352 & 175.421 & -39.168 & 16.98 & 0.09 & 13 & 197 & 1.39 & 20130606.121238 & 175.407 & -39.229 & 11.45 & 0.13 & 12 & 118 & 1.51 \\
\hline 20121108.113204 & 175.371 & -39.153 & 18.30 & 0.15 & 11 & 130 & 1.51 & 20130606.135046 & 175.410 & -39.065 & 14.61 & 0.05 & 7 & 148 & 1.45 \\
\hline 20121108.115924 & 175.333 & -39.246 & 19.06 & 0.08 & 13 & 118 & 1.21 & 20130606.161359 & 174.871 & -39.046 & 25.92 & 0.35 & 27 & 94 & 2.67 \\
\hline 20121109.082048 & 175.329 & -39.145 & 15.82 & 0.26 & 14 & 138 & 1.92 & 20130606.185242 & 175.449 & -39.240 & 14.18 & 0.02 & 6 & 296 & 0.66 \\
\hline 20121110.072616 & 175.358 & -39.153 & 17.84 & 0.06 & 10 & 147 & 1.38 & 20130607.033808 & 175.159 & -39.280 & 30.23 & 0.11 & 11 & 117 & 1.53 \\
\hline 20121110.165721 & 175.361 & -39.239 & 20.27 & 0.08 & 14 & 130 & 1.62 & 20130609.170833 & 175.088 & -39.175 & 33.97 & 0.21 & 12 & 96 & 1.94 \\
\hline 20121110.222121 & 175.372 & -39.157 & 16.15 & 0.09 & 10 & 158 & 2.29 & 20130609.192959 & 175.264 & -39.218 & 21.38 & 0.25 & 23 & 71 & 1.90 \\
\hline 20121111.114708 & 174.854 & -39.212 & 12.05 & 1.45 & 13 & 183 & 0.85 & 20130610.155737 & 175.033 & -39.205 & 35.27 & 0.04 & 5 & 169 & 1.59 \\
\hline 20121111.152839 & 175.352 & -39.241 & 21.87 & 0.07 & 9 & 164 & 0.76 & 20130610.172157 & 174.830 & -39.368 & 44.06 & 0.22 & 7 & 164 & 2.00 \\
\hline 20121111.200728 & 175.352 & -39.236 & 20.84 & 0.08 & 10 & 163 & 1.72 & 20130610.200144 & 174.834 & -39.417 & 47.02 & 0.22 & 6 & 174 & 2.00 \\
\hline 20121112.060844 & 175.419 & -39.174 & 17.73 & 0.00 & 4 & 205 & 1.05 & 20130612.030027 & 174.710 & -38.752 & 18.64 & 0.42 & 24 & 164 & 2.94 \\
\hline 20121112.192037 & 175.287 & -39.482 & 11.30 & 0.17 & 11 & 130 & 1.92 & 20130617.095623 & 174.926 & -39.218 & 31.89 & 0.35 & 20 & 63 & 2.31 \\
\hline 20121113.012520 & 175.345 & -39.239 & 20.97 & 0.10 & 11 & 156 & 1.58 & 20130619.174633 & 175.086 & -39.356 & 35.91 & 0.21 & 18 & 121 & 2.37 \\
\hline 20121113.044439 & 175.120 & -39.255 & 32.78 & 0.11 & 10 & 224 & 1.91 & 20130619.212032 & 174.986 & -39.381 & 29.45 & 0.03 & 5 & 235 & 2.24 \\
\hline 20121114.090434 & 175.402 & -39.164 & 16.08 & 0.11 & 10 & 182 & 1.53 & 20130621.175422 & 175.415 & -39.330 & 18.64 & 0.02 & 8 & 137 & 2.05 \\
\hline 20121114.095543 & 174.869 & -39.215 & 37.16 & 0.20 & 20 & 65 & 2.95 & 20130622.113310 & 175.404 & -39.230 & 12.49 & 0.11 & 8 & 198 & 1.29 \\
\hline 20121114.121725 & 175.368 & -39.244 & 19.94 & 0.10 & 12 & 173 & 1.75 & 20130622.231734 & 175.384 & -39.164 & 14.10 & 0.32 & 16 & 78 & 1.81 \\
\hline 20121114.162811 & 175.409 & -39.169 & 15.42 & 0.08 & 8 & 189 & 1.14 & 20130623.072960 & 175.344 & -39.301 & 32.63 & 0.05 & 10 & 113 & 1.40 \\
\hline 20121114.163605 & 175.402 & -39.168 & 15.64 & 0.09 & 8 & 186 & 1.01 & 20130623.092618 & 175.413 & -39.329 & 18.64 & 0.03 & 7 & 137 & 1.02 \\
\hline 20121115.065845 & 175.355 & -39.244 & 21.06 & 0.04 & 8 & 168 & 1.48 & 20130623.212444 & 175.094 & -39.161 & 31.63 & 0.23 & 24 & 65 & 2.27 \\
\hline 20121118.235817 & 175.337 & -39.147 & 14.01 & 0.33 & 20 & 98 & 2.93 & 20130626.083858 & 175.424 & -39.235 & 14.36 & 0.00 & 5 & 162 & 0.82 \\
\hline 20121119.045824 & 175.295 & -39.162 & 3.33 & 0.27 & 20 & 58 & 3.22 & 20130628.080133 & 175.340 & -39.151 & 14.65 & 0.09 & 5 & 209 & 1.15 \\
\hline 20121119.143344 & 175.431 & -39.239 & 14.03 & 0.05 & 7 & 211 & 0.59 & 20130628.161825 & 174.649 & -38.853 & 32.18 & 0.32 & 23 & 157 & 2.38 \\
\hline 20121119.210736 & 175.361 & -39.231 & 18.77 & 0.08 & 11 & 131 & 1.42 & 20130630.224438 & 175.000 & -39.274 & 35.27 & 0.16 & 7 & 203 & 1.42 \\
\hline 20121120.122609 & 174.887 & -39.236 & 42.59 & 0.09 & 13 & 133 & 2.02 & 20130701.144118 & 175.361 & -39.158 & 15.20 & 0.06 & 8 & 157 & 1.39 \\
\hline 20121121.053243 & 174.859 & -39.288 & 37.50 & 0.01 & 5 & 312 & 2.00 & 20130702.065708 & 175.397 & -39.160 & 14.04 & 0.41 & 21 & 70 & 2.08 \\
\hline 20121121.055051 & 175.440 & -39.238 & 14.50 & 0.06 & 5 & 234 & 0.83 & 20130703.154940 & 174.851 & -39.288 & 35.01 & 0.09 & 7 & 147 & 1.54 \\
\hline 20121121.082030 & 175.383 & -39.160 & 14.47 & 0.29 & 19 & 64 & 2.23 & 20130704.094015 & 175.403 & -39.166 & 14.69 & 0.01 & 5 & 315 & 1.05 \\
\hline 20121121.152409 & 175.352 & -39.239 & 21.87 & 0.10 & 10 & 164 & 2.01 & 20130704.094015 & 175.398 & -39.181 & 17.14 & 0.09 & 7 & 167 & 2.87 \\
\hline 20121122.103939 & 175.402 & -39.166 & 15.93 & 0.11 & 7 & 185 & 0.95 & 20130705.140320 & 175.511 & -38.952 & 7.08 & 0.64 & 34 & 103 & 1.79 \\
\hline 20121122.173620 & 175.358 & -39.512 & 26.98 & 0.21 & 22 & 53 & 2.79 & 20130705.214858 & 175.493 & -38.967 & 16.89 & 0.12 & 9 & 240 & 1.13 \\
\hline 20121123.001409 & 175.373 & -39.164 & 13.04 & 0.05 & 5 & 161 & 0.74 & 20130706.145205 & 175.436 & -39.240 & 14.19 & 0.08 & 9 & 169 & 2.07 \\
\hline 20121123.072942 & 175.374 & -39.241 & 20.57 & 0.11 & 12 & 174 & 1.31 & 20130707.040043 & 175.497 & -38.970 & 15.99 & 0.16 & 10 & 242 & 2.19 \\
\hline
\end{tabular}




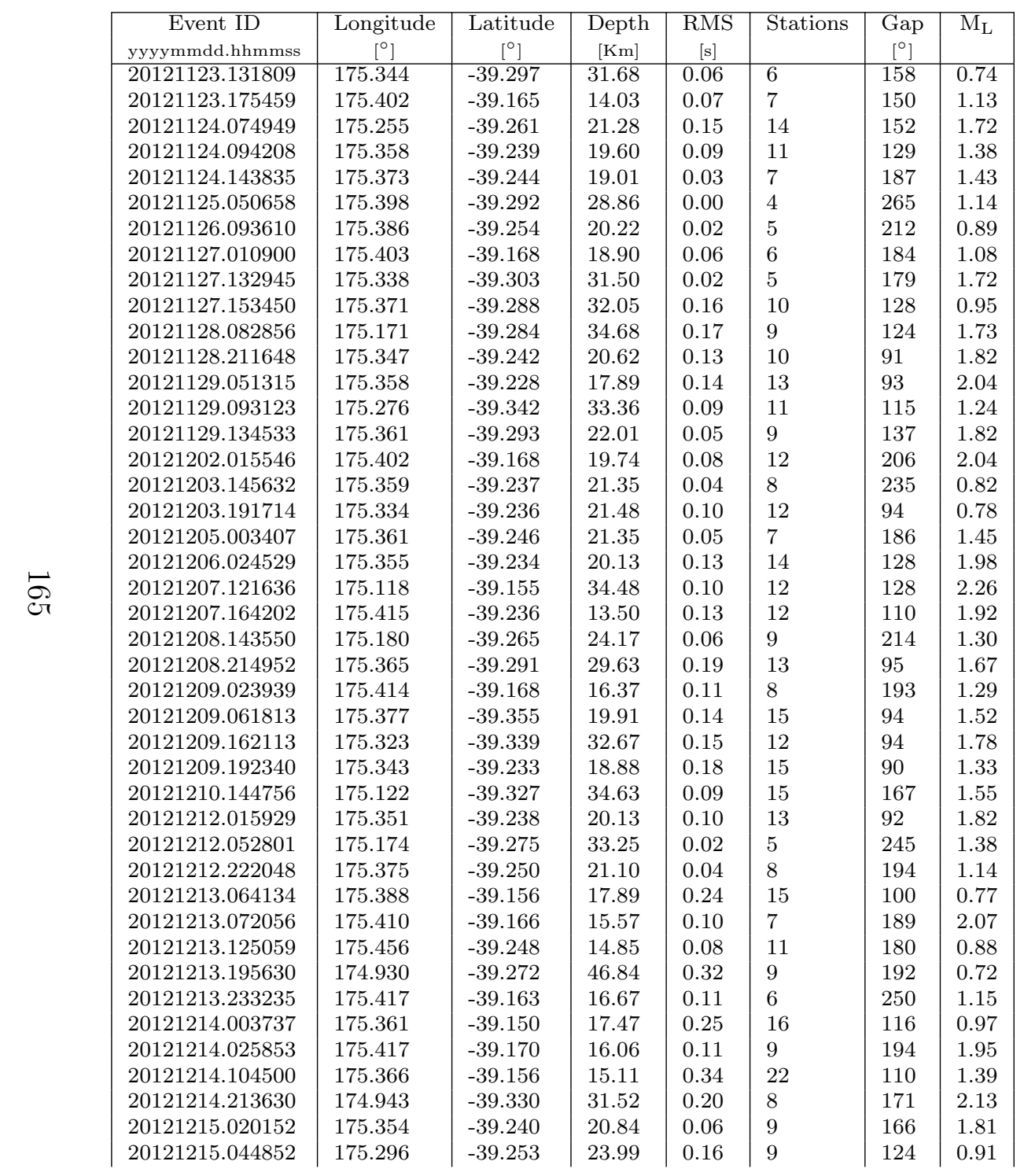

\begin{tabular}{|c|c|c|c|c|c|c|c|}
\hline Event ID & $\begin{array}{c}\text { Longitude } \\
{\left[{ }^{\circ}\right]}\end{array}$ & $\begin{array}{c}\text { Latitude } \\
{\left[{ }^{\circ}\right]}\end{array}$ & $\begin{array}{c}\text { Depth } \\
{[\mathrm{Km}]}\end{array}$ & $\begin{array}{c}\mathrm{RMS} \\
{[\mathrm{s}]}\end{array}$ & Stations & $\begin{array}{c}\text { Gap } \\
{\left[{ }^{\circ}\right]}\end{array}$ & $\mathrm{M}_{\mathrm{L}}$ \\
\hline 20130707.103919 & 175.444 & -38.978 & 14.52 & 0.23 & 17 & 162 & 1.78 \\
\hline 20130707.141653 & 175.489 & -38.970 & 16.37 & 0.07 & 8 & 235 & 1.12 \\
\hline 20130708.040331 & 175.184 & -39.443 & 11.48 & 0.21 & 7 & 138 & 1.67 \\
\hline 20130708.062216 & 175.452 & -39.230 & 15.80 & 0.18 & 18 & 114 & 1.06 \\
\hline 20130708.063328 & 175.440 & -39.236 & 18.81 & 0.31 & 11 & 171 & 1.90 \\
\hline 20130710.002932 & 175.021 & -39.135 & 19.74 & 0.24 & 10 & 151 & 2.76 \\
\hline 20130710.190655 & 175.122 & -39.283 & 32.51 & 0.20 & 21 & 75 & 2.00 \\
\hline 20130713.013501 & 175.201 & -39.264 & 24.36 & 0.07 & 9 & 161 & 2.00 \\
\hline 20130713.015929 & 174.704 & -39.481 & 33.00 & 0.37 & 12 & 133 & 0.91 \\
\hline 20130713.060820 & 175.458 & -39.245 & 12.49 & 0.07 & 7 & 222 & 2.28 \\
\hline 20130715.171451 & 174.969 & -39.289 & 17.23 & 0.60 & 26 & 41 & 1.93 \\
\hline 20130716.200631 & 175.416 & -39.332 & 17.06 & 0.32 & 19 & 101 & 2.04 \\
\hline 20130717.122919 & 174.952 & -39.312 & 38.29 & 0.17 & 13 & 114 & 1.01 \\
\hline 20130717.223542 & 175.220 & -39.260 & 23.77 & 0.14 & 9 & 143 & 1.85 \\
\hline 20130718.091703 & 174.688 & -39.344 & 36.20 & 0.36 & 18 & 84 & 0.94 \\
\hline 20130719.014702 & 175.356 & -39.239 & 29.19 & 0.07 & 9 & 168 & 0.87 \\
\hline 20130720.203518 & 175.424 & -39.236 & 14.05 & 0.04 & 9 & 163 & 2.03 \\
\hline 20130722.150250 & 174.925 & -39.556 & 71.69 & 1.15 & 22 & 108 & 0.85 \\
\hline 20130722.195900 & 175.481 & -39.231 & 15.13 & 0.06 & 8 & 195 & 3.41 \\
\hline 20130723.210206 & 174.829 & -39.215 & 31.77 & 0.29 & 19 & 106 & 1.85 \\
\hline 20130723.224532 & 175.361 & -39.150 & 14.61 & 0.13 & 6 & 161 & 1.50 \\
\hline 20130724.221241 & 175.340 & -39.286 & 31.41 & 0.09 & 13 & 123 & 2.70 \\
\hline 20130725.164247 & 174.855 & -39.120 & 32.50 & 0.24 & 24 & 85 & 1.64 \\
\hline 20130727.114743 & 175.198 & -39.261 & 23.70 & 0.08 & 6 & 189 & 2.28 \\
\hline 20130728.084904 & 175.465 & -38.964 & 15.88 & 0.36 & 20 & 98 & 1.49 \\
\hline 20130728.132321 & 175.108 & -39.151 & 21.19 & 0.08 & 12 & 168 & 1.56 \\
\hline 20130730.152157 & 175.166 & -39.299 & 21.99 & 0.22 & 12 & 111 & 0.49 \\
\hline 20130730.154456 & 175.343 & -39.153 & 20.40 & 0.04 & 9 & 166 & 1.20 \\
\hline 20130730.160242 & 175.487 & -38.972 & 17.00 & 0.06 & 8 & 217 & 1.95 \\
\hline 20130731.201653 & 175.484 & -39.584 & 69.84 & 0.09 & 9 & 152 & 1.58 \\
\hline 20130802.132032 & 175.242 & -39.226 & 13.74 & 0.09 & 6 & 120 & 2.30 \\
\hline 20130802.234645 & 175.387 & -39.165 & 15.07 & 0.23 & 16 & 122 & 2.52 \\
\hline 20130803.030251 & 174.858 & -39.235 & 32.50 & 0.37 & 19 & 48 & 2.10 \\
\hline 20130803.123111 & 174.934 & -39.187 & 17.42 & 0.21 & 15 & 98 & 1.47 \\
\hline 20130803.143136 & 175.429 & -39.229 & 18.28 & 0.09 & 8 & 209 & 2.15 \\
\hline 20130803.171238 & 175.435 & -39.225 & 13.39 & 0.19 & 12 & 86 & 1.83 \\
\hline 20130804.054615 & 175.206 & -39.249 & 21.00 & 0.32 & 19 & 63 & 1.96 \\
\hline 20130804.143224 & 175.050 & -39.336 & 30.70 & 0.28 & 24 & 63 & 1.14 \\
\hline 20130804.200905 & 175.387 & -39.342 & 10.28 & 0.05 & 7 & 115 & 0.96 \\
\hline 20130804.232942 & 175.346 & -39.292 & 31.94 & 0.05 & 9 & 116 & 3.58 \\
\hline 20130807.033424 & 174.913 & -39.296 & 32.06 & 0.46 & 33 & 47 & 2.16 \\
\hline 20130807.210444 & 174.902 & -39.315 & 36.73 & 0.17 & 8 & 130 & 2.04 \\
\hline 20130809.100504 & 175.256 & -39.303 & 31.16 & 0.19 & 22 & 89 & 3.38 \\
\hline
\end{tabular}




\begin{tabular}{|c|c|c|c|c|c|c|c|}
\hline $\begin{array}{c}\text { Event ID } \\
\text { yyyymmdd.hhmmss }\end{array}$ & $\begin{array}{c}\text { Longitude } \\
{\left[{ }^{\circ}\right]}\end{array}$ & $\begin{array}{c}\text { Latitude } \\
{\left[{ }^{\circ}\right]}\end{array}$ & $\begin{array}{l}\text { Depth } \\
{[\mathrm{Km}]}\end{array}$ & $\begin{array}{c}\mathrm{RMS} \\
{[\mathrm{s}]}\end{array}$ & Stations & $\begin{array}{c}\text { Gap } \\
{\left[{ }^{\circ}\right]}\end{array}$ & $\mathrm{M}_{\mathrm{L}}$ \\
\hline 20121215.134151 & 175.405 & -39.164 & 16.23 & 0.10 & 8 & 184 & 1.28 \\
\hline 20121215.150703 & 175.368 & -39.243 & 21.15 & 0.06 & 11 & 133 & 0.67 \\
\hline 20121215.151408 & 175.370 & -39.243 & 21.28 & 0.07 & 11 & 185 & 0.74 \\
\hline 20121215.192628 & 175.367 & -39.242 & 21.10 & 0.07 & 11 & 180 & 1.44 \\
\hline 20121216.011524 & 175.356 & -39.233 & 18.91 & 0.29 & 21 & 93 & 0.65 \\
\hline 20121216.014411 & 175.192 & -39.262 & 23.77 & 0.05 & 7 & 218 & 1.92 \\
\hline 20121216.125537 & 175.188 & -39.288 & 35.89 & 0.09 & 7 & 221 & 1.04 \\
\hline 20121216.132007 & 175.368 & -39.242 & 19.94 & 0.11 & 13 & 133 & 1.48 \\
\hline 20121217.131842 & 175.139 & -39.353 & 34.37 & 0.08 & 13 & 111 & 1.45 \\
\hline 20121217.204441 & 175.380 & -39.250 & 20.36 & 0.02 & 5 & 200 & 1.44 \\
\hline 20121217.221925 & 175.400 & -39.165 & 15.62 & 0.24 & 20 & 105 & 1.96 \\
\hline 20121218.014913 & 175.387 & -39.299 & 29.85 & 0.09 & 7 & 204 & 1.92 \\
\hline 20121218.091751 & 175.334 & -39.236 & 21.48 & 0.11 & 11 & 94 & 1.16 \\
\hline 20121218.120522 & 175.335 & -39.227 & 19.21 & 0.26 & 15 & 92 & 1.79 \\
\hline 20121219.005133 & 175.385 & -39.160 & 15.47 & 0.34 & 23 & 65 & 1.84 \\
\hline 20121219.014127 & 175.388 & -39.160 & 17.32 & 0.10 & 7 & 200 & 2.70 \\
\hline 20121219.071737 & 174.863 & -39.196 & 43.40 & 0.19 & 10 & 248 & 1.19 \\
\hline 20121219.083254 & 175.351 & -39.234 & 19.30 & 0.13 & 15 & 124 & 2.08 \\
\hline 20121219.084949 & 175.400 & -39.165 & 15.73 & 0.11 & 12 & 181 & 1.90 \\
\hline 20121219.105529 & 174.805 & -39.233 & 34.88 & 0.31 & 12 & 89 & 1.47 \\
\hline 20121219.105727 & 175.363 & -39.244 & 19.96 & 0.10 & 9 & 197 & 2.32 \\
\hline 20121219.122242 & 175.363 & -39.251 & 21.57 & 0.04 & 7 & 181 & 0.66 \\
\hline 20121219.221525 & 175.362 & -39.245 & 21.21 & 0.07 & 7 & 130 & 0.96 \\
\hline 20121220.000953 & 175.373 & -39.156 & 15.99 & 0.32 & 20 & 77 & 0.84 \\
\hline 20121220.095804 & 175.457 & -39.245 & 13.83 & 0.11 & 14 & 181 & 2.23 \\
\hline 20121220.105713 & 175.367 & -39.244 & 20.40 & 0.07 & 8 & 182 & 1.37 \\
\hline 20121220.115134 & 175.458 & -39.243 & 14.61 & 0.08 & 13 & 182 & 0.59 \\
\hline 20121220.134644 & 175.420 & -39.167 & 16.19 & 0.08 & 7 & 221 & 1.15 \\
\hline 20121220.142155 & 175.420 & -39.167 & 16.48 & 0.10 & 7 & 221 & 0.62 \\
\hline 20121220.172332 & 175.390 & -39.170 & 13.96 & 0.06 & 6 & 143 & 0.77 \\
\hline 20121221.113533 & 174.906 & -39.295 & 38.71 & 0.14 & 12 & 178 & 0.93 \\
\hline 20121221.141617 & 175.456 & -39.245 & 14.01 & 0.11 & 13 & 180 & 1.82 \\
\hline 20121221.150035 & 175.266 & -39.242 & 21.73 & 0.32 & 26 & 73 & 0.91 \\
\hline 20121221.182309 & 175.392 & -39.160 & 15.57 & 0.09 & 8 & 174 & 2.01 \\
\hline 20121221.212159 & 175.470 & -39.240 & 12.01 & 0.04 & 8 & 188 & 0.95 \\
\hline 20121222.174016 & 175.254 & -39.128 & 2.75 & 0.12 & 6 & 236 & 0.78 \\
\hline 20121223.030236 & 175.381 & -39.253 & 20.47 & 0.05 & 5 & 203 & 1.41 \\
\hline 20121223.033134 & 175.363 & -39.237 & 20.11 & 0.04 & 8 & 175 & 1.31 \\
\hline 20121223.172508 & 175.366 & -39.241 & 18.77 & 0.16 & 17 & 96 & 1.73 \\
\hline 20121223.211136 & 175.359 & -39.244 & 21.72 & 0.03 & 10 & 129 & 1.92 \\
\hline 20121223.221718 & 175.354 & -39.250 & 21.50 & 0.04 & 8 & 145 & 1.70 \\
\hline 20121224.054029 & 175.358 & -39.240 & 20.40 & 0.10 & 11 & 170 & 1.88 \\
\hline 20121224.125838 & 175.013 & -39.718 & 35.45 & 0.18 & 10 & 132 & 1.66 \\
\hline
\end{tabular}

\begin{tabular}{|c|c|c|c|c|c|c|c|}
\hline Event ID & $\begin{array}{c}\text { Longitude } \\
{\left[{ }^{\circ}\right]}\end{array}$ & $\begin{array}{c}\text { Latitude } \\
{\left[{ }^{\circ}\right]}\end{array}$ & $\begin{array}{c}\text { Depth } \\
{[\mathrm{Km}]}\end{array}$ & $\begin{array}{c}\mathrm{RMS} \\
{[\mathrm{s}]}\end{array}$ & Stations & $\begin{array}{c}\text { Gap } \\
{\left[{ }^{\circ}\right]}\end{array}$ & $\mathrm{M}_{\mathrm{L}}$ \\
\hline 20130809.104930 & 175.275 & -39.298 & 28.73 & 0.44 & 39 & 51 & 1.71 \\
\hline 20130809.105614 & 175.250 & -39.306 & 31.76 & 0.20 & 21 & 90 & 2.17 \\
\hline 20130810.133216 & 175.024 & -39.147 & 7.28 & 0.55 & 22 & 72 & 2.19 \\
\hline 20130810.164456 & 175.016 & -39.135 & 16.61 & 0.38 & 22 & 77 & 1.53 \\
\hline 20130810.235310 & 175.262 & -39.237 & 19.47 & 0.12 & 11 & 188 & 2.07 \\
\hline 20130811.102547 & 175.120 & -39.242 & 34.19 & 0.22 & 18 & 73 & 2.33 \\
\hline 20130812.040816 & 175.102 & -39.352 & 35.24 & 0.40 & 25 & 52 & 1.94 \\
\hline 20130812.142800 & 175.346 & -39.149 & 13.97 & 0.31 & 17 & 102 & 1.48 \\
\hline 20130812.152418 & 175.365 & -39.151 & 15.13 & 0.12 & 8 & 153 & 1.84 \\
\hline 20130815.062215 & 175.270 & -39.690 & 71.69 & 0.26 & 11 & 116 & 1.31 \\
\hline 20130815.140830 & 175.161 & -39.288 & 22.40 & 0.17 & 10 & 80 & 2.10 \\
\hline 20130816.175909 & 175.257 & -39.302 & 31.33 & 0.16 & 19 & 59 & 1.48 \\
\hline 20130818.151830 & 175.392 & -39.168 & 16.01 & 0.11 & 8 & 146 & 1.67 \\
\hline 20130821.142050 & 175.377 & -39.168 & 13.20 & 0.20 & 8 & 121 & 1.48 \\
\hline 20130821.175600 & 175.405 & -39.135 & 9.29 & 0.17 & 9 & 143 & 2.05 \\
\hline 20130822.071142 & 174.670 & -39.221 & 31.89 & 0.33 & 22 & 74 & 1.31 \\
\hline 20130822.120733 & 175.256 & -39.420 & 32.17 & 0.09 & 12 & 124 & 1.46 \\
\hline 20130822.225636 & 175.050 & -39.229 & 26.55 & 0.03 & 6 & 210 & 1.45 \\
\hline 20130823.080516 & 175.167 & -39.292 & 23.93 & 0.16 & 10 & 110 & 1.96 \\
\hline 20130823.092512 & 175.376 & -39.166 & 14.71 & 0.30 & 19 & 99 & 1.06 \\
\hline 20130824.015255 & 175.352 & -39.159 & 14.47 & 0.07 & 5 & 163 & 2.14 \\
\hline 20130825.064328 & 175.058 & -39.214 & 32.00 & 0.29 & 20 & 79 & 2.24 \\
\hline 20130826.121840 & 175.372 & -39.294 & 30.50 & 0.26 & 27 & 96 & 1.56 \\
\hline 20130827.033341 & 175.242 & -39.256 & 21.83 & 0.06 & 8 & 142 & 2.01 \\
\hline 20130827.113406 & 175.490 & -39.288 & 15.47 & 0.31 & 27 & 78 & 1.30 \\
\hline 20130828.194157 & 175.361 & -39.157 & 15.20 & 0.09 & 8 & 152 & 1.10 \\
\hline 20130830.125654 & 175.458 & -39.330 & 12.93 & 0.01 & 6 & 174 & 2.79 \\
\hline 20130831.180840 & 174.835 & -39.306 & 36.86 & 0.39 & 27 & 59 & 1.96 \\
\hline 20130903.132602 & 175.234 & -39.209 & 8.05 & 0.40 & 21 & 65 & 1.86 \\
\hline 20130904.101227 & 175.179 & -39.284 & 31.22 & 0.14 & 18 & 67 & 1.76 \\
\hline 20130905.192428 & 175.088 & -39.285 & 37.08 & 0.17 & 17 & 55 & 2.04 \\
\hline 20130906.051600 & 174.987 & -39.179 & 40.84 & 0.16 & 10 & 262 & 1.15 \\
\hline 20130906.065337 & 175.170 & -39.222 & 33.00 & 0.08 & 9 & 144 & 1.70 \\
\hline 20130906.102236 & 175.419 & -39.369 & 11.96 & 0.10 & 10 & 127 & 1.80 \\
\hline 20130907.001538 & 175.031 & -39.140 & 30.76 & 0.34 & 26 & 74 & 2.46 \\
\hline 20130907.012208 & 175.279 & -39.245 & 21.19 & 0.20 & 11 & 180 & 1.12 \\
\hline 20130907.102416 & 174.793 & -39.177 & 23.16 & 0.45 & 28 & 48 & 2.80 \\
\hline 20130908.013015 & 175.418 & -39.467 & 71.96 & 0.51 & 13 & 187 & 1.91 \\
\hline 20130908.020507 & 175.255 & -39.254 & 23.00 & 0.09 & 6 & 198 & 1.55 \\
\hline 20130908.172208 & 175.142 & -39.260 & 20.97 & 0.15 & 11 & 86 & 2.54 \\
\hline 20130909.125137 & 174.954 & -39.361 & 11.51 & 0.85 & 10 & 114 & 1.26 \\
\hline 20130911.202546 & 175.416 & -39.172 & 16.52 & 0.12 & 16 & 159 & 2.00 \\
\hline 20130912.213552 & 175.392 & -39.165 & 16.37 & 0.12 & 11 & 176 & 1.04 \\
\hline
\end{tabular}




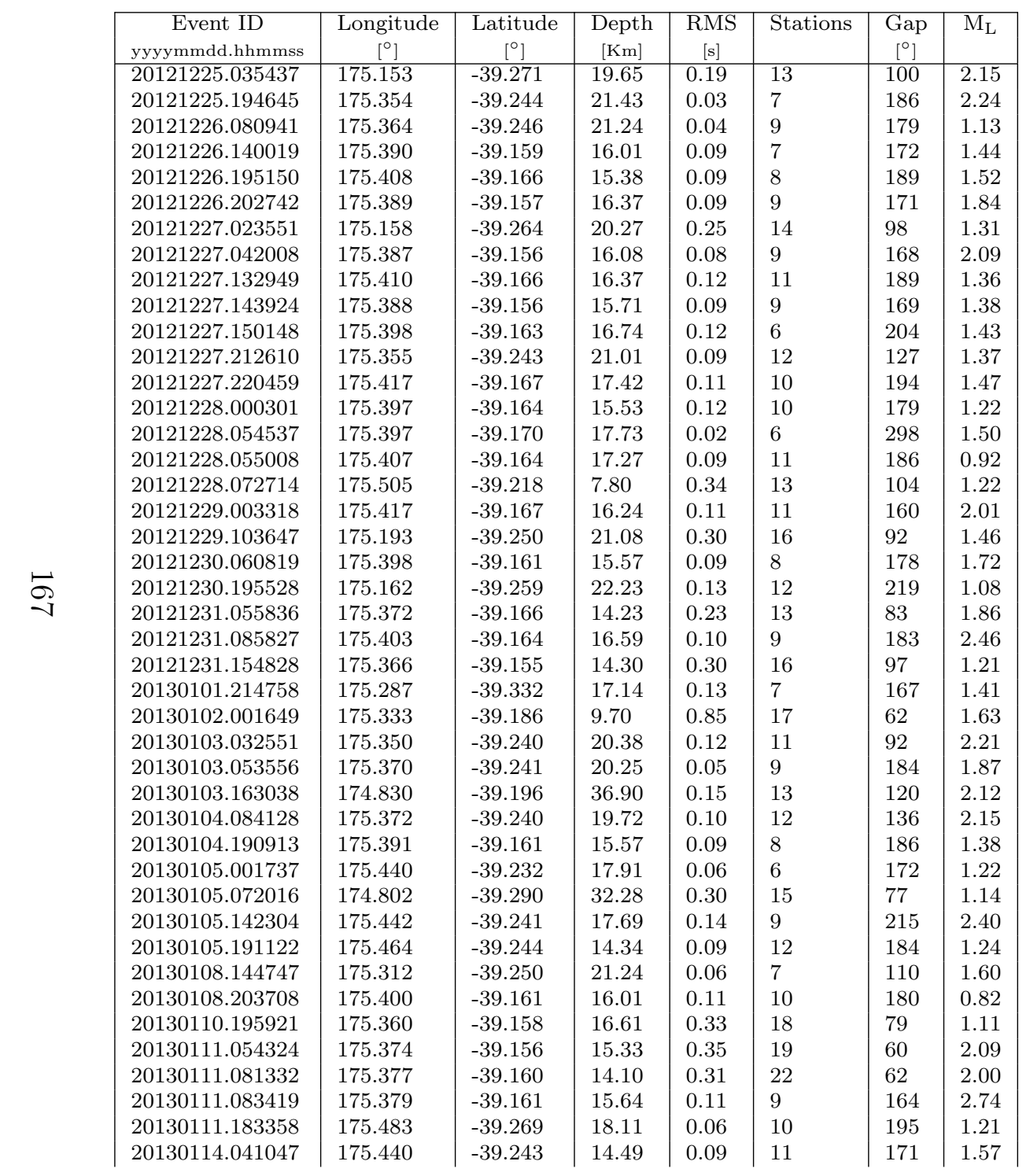

\begin{tabular}{|c|c|c|c|c|c|c|c|}
\hline Event ID & $\begin{array}{c}\text { Longitude } \\
{\left[{ }^{\circ}\right]}\end{array}$ & $\begin{array}{c}\text { Latitude } \\
{\left[{ }^{\circ}\right]}\end{array}$ & $\begin{array}{l}\text { Depth } \\
{[\mathrm{Km}]}\end{array}$ & $\begin{array}{c}\mathrm{RMS} \\
{[\mathrm{s}]}\end{array}$ & Stations & $\begin{array}{c}\text { Gap } \\
{\left[{ }^{\circ}\right]}\end{array}$ & $\mathrm{M}_{\mathrm{L}}$ \\
\hline 20130913.114425 & 175.380 & -39.167 & 15.47 & 0.24 & 21 & 72 & 1.79 \\
\hline 20130913.210548 & 175.397 & -39.165 & 16.35 & 0.09 & 12 & 147 & 1.71 \\
\hline 20130914.014826 & 175.433 & -39.137 & 9.03 & 0.20 & 14 & 122 & 1.72 \\
\hline 20130915.140118 & 175.399 & -39.166 & 16.30 & 0.10 & 9 & 149 & 0.83 \\
\hline 20130918.171923 & 174.915 & -39.312 & 32.34 & 0.13 & 10 & 126 & 1.63 \\
\hline 20130920.171157 & 175.425 & -39.237 & 10.58 & 0.34 & 17 & 148 & 1.66 \\
\hline 20130920.172138 & 175.359 & -39.536 & 26.10 & 0.13 & 8 & 148 & 1.75 \\
\hline 20130921.010435 & 175.078 & -39.307 & 32.61 & 0.21 & 19 & 84 & 2.72 \\
\hline 20130923.083355 & 175.404 & -39.130 & 17.87 & 0.09 & 8 & 176 & 0.80 \\
\hline 20130923.091036 & 175.346 & -39.308 & 31.95 & 0.12 & 17 & 90 & 1.72 \\
\hline 20130923.183856 & 175.406 & -39.168 & 16.94 & 0.12 & 13 & 153 & 1.51 \\
\hline 20130923.200239 & 175.454 & -39.331 & 12.11 & 0.10 & 10 & 170 & 1.71 \\
\hline 20130927.073425 & 175.449 & -39.244 & 11.15 & 0.10 & 12 & 176 & 1.52 \\
\hline 20130928.104112 & 175.410 & -39.242 & 13.33 & 0.07 & 9 & 169 & 1.54 \\
\hline 20130928.130140 & 175.065 & -39.373 & 37.52 & 0.13 & 12 & 127 & 2.24 \\
\hline 20130929.083524 & 175.210 & -39.248 & 25.23 & 0.13 & 10 & 224 & 1.96 \\
\hline 20130929.143629 & 175.352 & -39.297 & 32.91 & 0.08 & 8 & 117 & 1.56 \\
\hline 20130929.200257 & 175.278 & -39.144 & 19.96 & 0.15 & 11 & 186 & 1.41 \\
\hline 20130930.193744 & 175.397 & -39.170 & 13.66 & 0.05 & 5 & 183 & 0.83 \\
\hline 20131001.081609 & 175.345 & -39.298 & 31.63 & 0.11 & 21 & 90 & 1.48 \\
\hline 20131001.082705 & 175.222 & -39.257 & 20.19 & 0.31 & 21 & 66 & 1.30 \\
\hline 20131001.170736 & 175.465 & -39.296 & 15.71 & 0.08 & 9 & 192 & 0.97 \\
\hline 20131003.000647 & 175.171 & -39.278 & 33.15 & 0.04 & 8 & 246 & 1.36 \\
\hline 20131003.064116 & 174.626 & -38.957 & 29.17 & 0.27 & 8 & 139 & 2.38 \\
\hline 20131004.144752 & 175.232 & -39.247 & 31.01 & 0.22 & 27 & 68 & 1.92 \\
\hline 20131004.150925 & 175.344 & -39.244 & 18.51 & 0.14 & 19 & 122 & 1.49 \\
\hline 20131006.180317 & 175.337 & -39.294 & 32.78 & 0.03 & 8 & 154 & 0.82 \\
\hline 20131009.025339 & 175.343 & -39.309 & 31.90 & 0.06 & 9 & 120 & 1.58 \\
\hline 20131009.072440 & 174.913 & -39.301 & 41.27 & 0.09 & 11 & 125 & 2.07 \\
\hline 20131009.094211 & 174.864 & -39.290 & 43.97 & 0.31 & 16 & 90 & 2.56 \\
\hline 20131009.101944 & 175.295 & -39.223 & 24.47 & 0.13 & 10 & 165 & 1.31 \\
\hline 20131009.215332 & 174.670 & -39.128 & 27.08 & 0.41 & 19 & 93 & 2.61 \\
\hline 20131013.011211 & 174.915 & -39.393 & 45.67 & 0.32 & 13 & 123 & 2.14 \\
\hline 20131013.131152 & 174.879 & -39.233 & 30.05 & 0.15 & 11 & 93 & 2.01 \\
\hline 20131017.094413 & 175.419 & -39.139 & 8.74 & 0.32 & 21 & 113 & 2.88 \\
\hline 20131018.033018 & 175.104 & -39.344 & 36.24 & 0.28 & 18 & 53 & 2.30 \\
\hline 20131018.035812 & 175.423 & -39.138 & 9.17 & 0.18 & 20 & 115 & 2.98 \\
\hline 20131018.171002 & 175.414 & -39.134 & 8.91 & 0.29 & 18 & 109 & 2.09 \\
\hline 20131018.184658 & 175.267 & -39.580 & 39.74 & 0.11 & 14 & 145 & 2.17 \\
\hline 20131019.052632 & 175.084 & -39.836 & 44.39 & 0.14 & 7 & 283 & 1.97 \\
\hline 20131019.115217 & 175.382 & -39.236 & 17.49 & 0.16 & 13 & 100 & 1.70 \\
\hline 20131019.173226 & 175.252 & -38.853 & 16.52 & 0.16 & 14 & 84 & 2.22 \\
\hline 20131020.010854 & 174.750 & -39.186 & 25.29 & 0.13 & 11 & 142 & 2.65 \\
\hline
\end{tabular}




\begin{tabular}{|c|c|c|c|c|c|c|c|}
\hline $\begin{array}{c}\text { Event ID } \\
\text { yyyymmdd.hhmmss }\end{array}$ & $\begin{array}{c}\text { Longitude } \\
{\left[{ }^{\circ}\right]}\end{array}$ & $\begin{array}{c}\text { Latitude } \\
{\left[{ }^{\circ}\right]}\end{array}$ & $\begin{array}{c}\text { Depth } \\
{[\mathrm{Km}]}\end{array}$ & $\begin{array}{c}\mathrm{RMS} \\
{[\mathrm{s}]}\end{array}$ & Stations & $\begin{array}{c}\text { Gap } \\
{\left[{ }^{\circ}\right]}\end{array}$ & $\mathrm{M}_{\mathrm{L}}$ \\
\hline 20130115.172554 & 175.399 & -39.164 & 12.51 & 0.43 & 24 & 71 & 1.60 \\
\hline 20130115.172822 & 175.413 & -39.170 & 16.59 & 0.12 & 14 & 192 & 3.30 \\
\hline 20130115.173140 & 175.370 & -39.144 & 18.04 & 0.17 & 12 & 128 & 1.68 \\
\hline 20130115.173926 & 175.398 & -39.171 & 17.98 & 0.06 & 6 & 191 & 1.94 \\
\hline 20130115.184539 & 175.417 & -39.166 & 17.38 & 0.17 & 9 & 199 & 1.05 \\
\hline 20130115.200520 & 175.394 & -39.166 & 17.73 & 0.08 & 6 & 203 & 1.85 \\
\hline 20130115.204936 & 175.420 & -39.235 & 12.84 & 0.13 & 13 & 112 & 1.58 \\
\hline 20130115.222102 & 175.388 & -39.163 & 16.19 & 0.08 & 7 & 171 & 1.75 \\
\hline 20130116.084120 & 175.424 & -39.242 & 14.03 & 0.17 & 14 & 112 & 0.87 \\
\hline 20130117.054516 & 175.373 & -39.154 & 14.71 & 0.28 & 16 & 84 & 1.55 \\
\hline 20130118.061939 & 175.345 & -39.224 & 16.81 & 0.27 & 11 & 83 & 2.26 \\
\hline 20130118.115729 & 175.417 & -39.170 & 16.76 & 0.18 & 17 & 160 & 1.38 \\
\hline 20130118.143903 & 174.917 & -39.174 & 36.18 & 0.15 & 8 & 143 & 1.55 \\
\hline 20130119.183919 & 175.218 & -39.275 & 22.12 & 0.08 & 7 & 195 & 0.74 \\
\hline 20130121.031248 & 175.257 & -39.307 & 16.41 & 0.06 & 7 & 103 & 1.47 \\
\hline 20130121.101924 & 175.221 & -39.256 & 21.44 & 0.22 & 13 & 172 & 1.18 \\
\hline 20130122.143303 & 175.131 & -39.207 & 31.85 & 0.17 & 20 & 93 & 1.91 \\
\hline 20130124.101414 & 175.435 & -39.361 & 21.28 & 0.07 & 7 & 162 & 2.04 \\
\hline 20130124.102135 & 175.172 & -39.357 & 32.56 & 0.07 & 8 & 187 & 1.50 \\
\hline 20130124.222551 & 175.444 & -39.248 & 14.61 & 0.02 & 6 & 235 & 1.46 \\
\hline 20130127.115517 & 175.258 & -39.308 & 14.45 & 0.22 & 15 & 69 & 0.80 \\
\hline 20130128.014356 & 175.010 & -39.370 & 41.75 & 0.10 & 9 & 255 & 1.69 \\
\hline 20130128.181957 & 175.297 & -39.258 & 22.69 & 0.12 & 12 & 120 & 1.56 \\
\hline 20130129.082322 & 174.743 & -39.306 & 29.10 & 0.22 & 15 & 82 & 1.22 \\
\hline 20130129.133739 & 175.305 & -39.258 & 22.38 & 0.11 & 15 & 105 & 2.50 \\
\hline 20130129.134040 & 175.293 & -39.263 & 23.18 & 0.12 & 10 & 121 & 1.56 \\
\hline 20130131.145941 & 175.345 & -39.105 & 20.25 & 0.07 & 6 & 149 & 0.60 \\
\hline 20130131.192711 & 175.387 & -39.365 & 22.09 & 0.08 & 10 & 125 & 1.65 \\
\hline 20130131.212059 & 174.805 & -39.307 & 46.88 & 0.07 & 8 & 317 & 1.75 \\
\hline 20130201.081337 & 175.401 & -39.168 & 16.01 & 0.10 & 10 & 182 & 2.26 \\
\hline 20130201.173502 & 175.454 & -39.247 & 14.23 & 0.07 & 9 & 179 & 1.26 \\
\hline 20130201.235441 & 175.386 & -39.212 & 21.43 & 0.23 & 6 & 185 & 0.91 \\
\hline 20130202.081007 & 175.425 & -39.239 & 14.12 & 0.16 & 14 & 113 & 0.88 \\
\hline 20130206.144314 & 174.980 & -39.518 & 41.93 & 0.08 & 11 & 157 & 1.71 \\
\hline 20130206.175433 & 174.846 & -39.284 & 40.25 & 0.15 & 9 & 236 & 1.92 \\
\hline 20130207.082722 & 175.373 & -39.157 & 14.47 & 0.07 & 7 & 170 & 1.94 \\
\hline 20130207.115507 & 175.351 & -39.146 & 15.59 & 0.25 & 12 & 156 & 0.84 \\
\hline 20130207.145751 & 175.406 & -39.166 & 16.50 & 0.13 & 13 & 153 & 1.71 \\
\hline 20130207.164054 & 175.087 & -39.165 & 32.19 & 0.21 & 18 & 91 & 1.92 \\
\hline 20130208.053600 & 175.409 & -39.335 & 17.01 & 0.13 & 13 & 101 & 2.24 \\
\hline 20130208.094722 & 175.410 & -39.332 & 17.45 & 0.15 & 15 & 101 & 1.82 \\
\hline 20130209.192605 & 175.420 & -39.174 & 16.45 & 0.11 & 10 & 214 & 1.57 \\
\hline 20130212.010516 & 175.009 & -39.239 & 34.96 & 0.22 & 19 & 118 & 1.48 \\
\hline
\end{tabular}

\begin{tabular}{|c|c|c|c|c|c|c|c|}
\hline Event ID & $\begin{array}{c}\text { Longitude } \\
{\left[{ }^{\circ}\right]}\end{array}$ & $\begin{array}{c}\text { Latitude } \\
{\left[{ }^{\circ}\right]}\end{array}$ & $\begin{array}{c}\text { Depth } \\
{[\mathrm{Km}]}\end{array}$ & $\begin{array}{c}\mathrm{RMS} \\
{[\mathrm{s}]}\end{array}$ & Stations & $\begin{array}{c}\text { Gap } \\
{\left[{ }^{\circ}\right]}\end{array}$ & $\mathrm{M}_{\mathrm{L}}$ \\
\hline 20131020.121701 & 175.233 & -39.266 & 21.57 & 0.09 & 10 & 211 & 1.14 \\
\hline 20131020.132900 & 175.388 & -39.128 & 17.14 & 0.09 & 7 & 164 & 0.87 \\
\hline 20131022.152307 & 175.430 & -39.131 & 7.46 & 0.59 & 24 & 86 & 2.69 \\
\hline 20131023.094614 & 175.419 & -39.138 & 8.96 & 0.33 & 21 & 112 & 2.48 \\
\hline 20131023.172514 & 175.349 & -39.298 & 32.17 & 0.12 & 9 & 97 & 1.32 \\
\hline 20131026.083709 & 175.385 & -39.238 & 20.99 & 0.11 & 9 & 209 & 1.09 \\
\hline 20131027.070053 & 175.445 & -39.137 & 11.25 & 0.12 & 13 & 180 & 1.88 \\
\hline 20131028.143546 & 175.011 & -39.363 & 37.47 & 0.10 & 7 & 186 & 1.46 \\
\hline 20131029.113149 & 175.198 & -39.263 & 23.40 & 0.11 & 10 & 209 & 1.36 \\
\hline 20131030.004336 & 175.082 & -39.283 & 34.04 & 0.12 & 12 & 113 & 1.92 \\
\hline 20131030.080127 & 175.169 & -39.282 & 10.99 & 0.11 & 7 & 149 & 0.99 \\
\hline 20131030.143204 & 175.142 & -39.226 & 32.61 & 0.23 & 14 & 69 & 2.26 \\
\hline 20131102.035400 & 175.096 & -39.277 & 37.03 & 0.08 & 9 & 176 & 1.52 \\
\hline 20131102.163316 & 174.928 & -39.126 & 30.76 & 0.24 & 30 & 80 & 3.75 \\
\hline 20131102.170102 & 174.945 & -39.128 & 30.78 & 0.31 & 22 & 78 & 2.41 \\
\hline 20131102.171326 & 175.275 & -39.290 & 26.26 & 0.12 & 14 & 130 & 1.03 \\
\hline 20131102.184345 & 174.941 & -39.119 & 30.65 & 0.12 & 8 & 139 & 1.90 \\
\hline 20131105.190355 & 175.455 & -39.268 & 14.91 & 0.15 & 12 & 125 & 1.42 \\
\hline 20131106.185804 & 175.434 & -39.450 & 12.20 & 0.08 & 9 & 182 & 1.43 \\
\hline 20131110.042613 & 174.771 & -39.173 & 24.67 & 0.28 & 10 & 121 & 2.17 \\
\hline 20131111.015256 & 175.388 & -39.291 & 28.90 & 0.11 & 7 & 130 & 1.29 \\
\hline 20131112.130821 & 175.265 & -39.260 & 27.41 & 0.13 & 15 & 133 & 2.34 \\
\hline 20131112.145314 & 175.304 & -39.271 & 29.48 & 0.03 & 10 & 143 & 1.52 \\
\hline 20131113.184617 & 174.646 & -39.474 & 27.80 & 0.37 & 13 & 137 & 2.04 \\
\hline 20131114.042415 & 174.786 & -39.234 & 51.93 & 0.25 & 12 & 111 & 2.27 \\
\hline 20131114.050919 & 175.182 & -39.250 & 22.43 & 0.17 & 15 & 180 & 1.98 \\
\hline 20131114.095925 & 175.211 & -39.258 & 23.61 & 0.14 & 12 & 146 & 1.39 \\
\hline 20131114.181224 & 175.443 & -39.141 & 9.08 & 0.07 & 6 & 178 & 0.60 \\
\hline 20131115.223938 & 175.406 & -39.139 & 7.64 & 0.31 & 14 & 79 & 2.62 \\
\hline 20131116.053612 & 175.265 & -39.270 & 31.04 & 0.21 & 12 & 186 & 1.25 \\
\hline 20131116.100421 & 175.353 & -39.292 & 31.48 & 0.11 & 14 & 92 & 1.48 \\
\hline 20131116.122058 & 174.763 & -39.197 & 37.25 & 0.03 & 6 & 249 & 1.66 \\
\hline 20131117.011708 & 175.338 & -39.294 & 31.94 & 0.02 & 6 & 154 & 0.79 \\
\hline 20131119.070050 & 175.244 & -39.425 & 12.00 & 0.14 & 9 & 215 & 1.44 \\
\hline 20131120.042751 & 175.271 & -39.270 & 29.85 & 0.07 & 11 & 183 & 1.64 \\
\hline 20131120.121541 & 174.927 & -39.110 & 32.58 & 0.18 & 17 & 92 & 2.03 \\
\hline 20131120.184621 & 174.870 & -39.282 & 42.04 & 0.15 & 7 & 139 & 1.56 \\
\hline 20131120.184750 & 174.931 & -39.132 & 35.65 & 0.18 & 15 & 82 & 2.33 \\
\hline 20131121.121307 & 175.074 & -39.357 & 39.06 & 0.24 & 19 & 76 & 1.90 \\
\hline 20131121.152826 & 175.339 & -39.307 & 32.34 & 0.08 & 13 & 103 & 1.55 \\
\hline 20131122.193258 & 174.857 & -39.206 & 47.32 & 0.09 & 10 & 126 & 2.14 \\
\hline 20131123.211733 & 174.931 & -39.310 & 35.87 & 0.31 & 14 & 72 & 2.24 \\
\hline 20131124.035203 & 175.209 & -39.261 & 24.76 & 0.09 & 10 & 146 & 1.60 \\
\hline
\end{tabular}




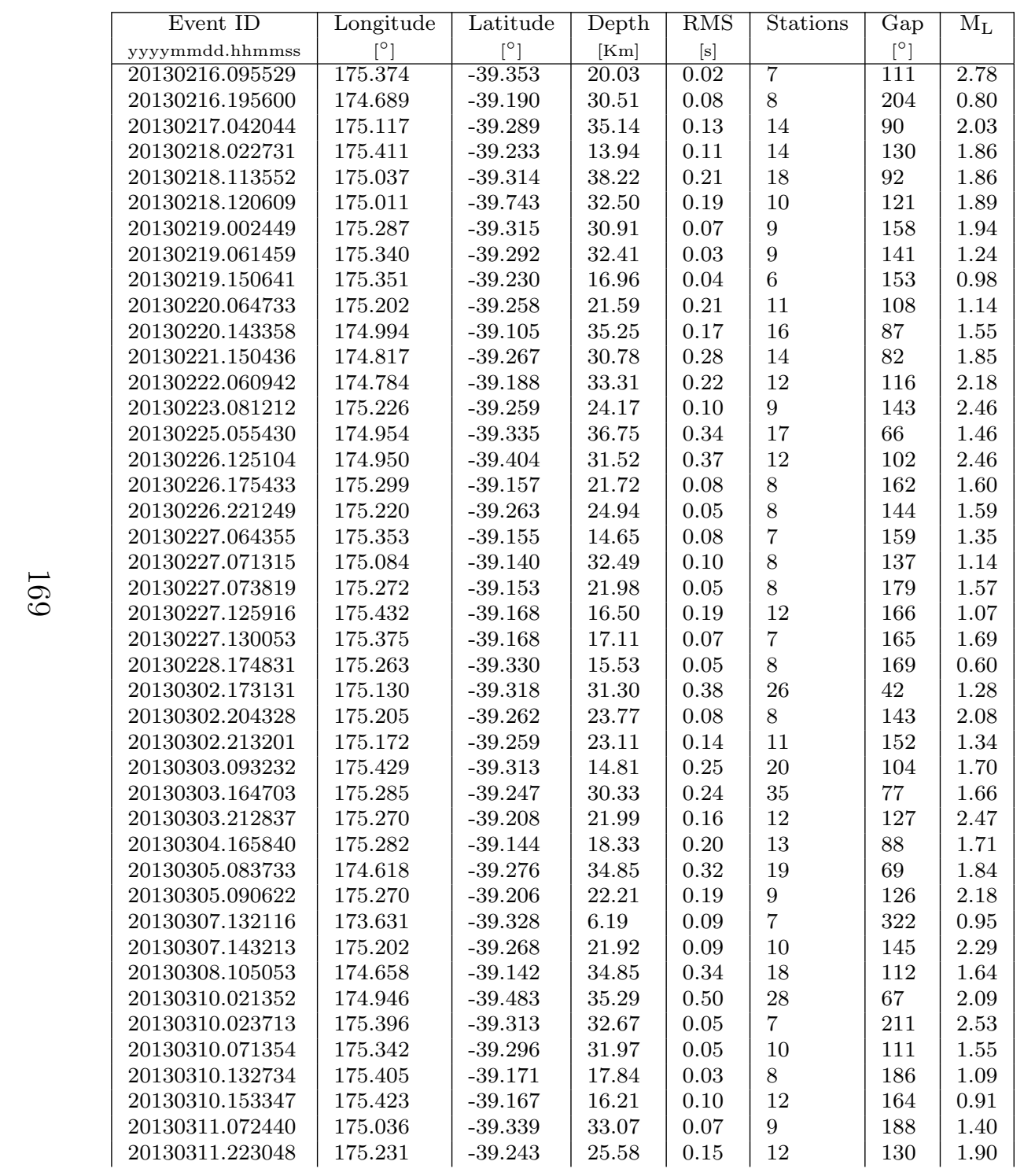

\begin{tabular}{|c|c|c|c|c|c|c|c|}
\hline Event ID & $\begin{array}{c}\text { Longitude } \\
{\left[{ }^{\circ}\right]}\end{array}$ & $\begin{array}{c}\text { Latitude } \\
{\left[{ }^{\circ}\right]}\end{array}$ & $\begin{array}{c}\text { Depth } \\
{[\mathrm{Km}]}\end{array}$ & $\begin{array}{c}\mathrm{RMS} \\
{[\mathrm{s}]}\end{array}$ & Stations & $\begin{array}{c}\text { Gap } \\
{\left[{ }^{\circ}\right]}\end{array}$ & $\mathrm{M}_{\mathrm{L}}$ \\
\hline 20131124.040304 & 174.939 & -39.131 & 31.48 & 0.17 & 11 & 82 & 2.04 \\
\hline 20131127.033350 & 175.357 & -39.153 & 17.76 & 0.08 & 9 & 122 & 1.25 \\
\hline 20131127.170134 & 175.221 & -39.261 & 23.40 & 0.10 & 9 & 220 & 1.95 \\
\hline 20131128.022455 & 175.244 & -39.279 & 31.26 & 0.18 & 11 & 199 & 1.48 \\
\hline 20131129.101943 & 175.077 & -39.275 & 31.36 & 0.36 & 27 & 46 & 3.01 \\
\hline 20131130.150730 & 175.015 & -39.464 & 37.61 & 0.20 & 13 & 153 & 1.98 \\
\hline 20131201.123520 & 174.861 & -39.176 & 34.77 & 0.18 & 18 & 72 & 2.39 \\
\hline 20131201.142619 & 175.244 & -39.261 & 21.06 & 0.12 & 12 & 179 & 1.83 \\
\hline 20131202.013255 & 175.283 & -39.711 & 28.18 & 0.31 & 16 & 108 & 2.09 \\
\hline 20131203.034617 & 175.219 & -39.246 & 23.18 & 0.12 & 7 & 201 & 1.63 \\
\hline 20131203.055456 & 175.000 & -39.292 & 38.07 & 0.23 & 22 & 68 & 2.58 \\
\hline 20131204.060226 & 174.633 & -39.196 & 30.12 & 0.33 & 12 & 104 & 2.42 \\
\hline 20131204.094321 & 175.222 & -39.255 & 24.37 & 0.10 & 13 & 145 & 1.91 \\
\hline 20131207.230125 & 174.813 & -38.989 & 31.90 & 0.06 & 7 & 167 & 2.33 \\
\hline 20131209.141706 & 174.966 & -39.308 & 30.93 & 0.10 & 7 & 113 & 1.84 \\
\hline 20131211.153727 & 175.087 & -39.220 & 36.37 & 0.09 & 10 & 155 & 1.31 \\
\hline 20131211.190201 & 175.196 & -39.241 & 34.85 & 0.17 & 16 & 114 & 2.05 \\
\hline 20131212.005704 & 175.133 & -39.295 & 40.40 & 0.14 & 6 & 176 & 1.05 \\
\hline 20131212.042502 & 175.492 & -39.223 & 11.01 & 0.14 & 8 & 201 & 1.02 \\
\hline 20131213.062449 & 175.358 & -39.238 & 20.25 & 0.14 & 16 & 129 & 1.09 \\
\hline 20131213.112332 & 175.058 & -39.292 & 37.74 & 0.12 & 14 & 107 & 1.71 \\
\hline 20131215.134629 & 174.863 & -39.330 & 35.78 & 0.18 & 7 & 152 & 1.66 \\
\hline 20131216.000442 & 175.124 & -39.129 & 17.75 & 0.39 & 13 & 179 & 2.23 \\
\hline 20131216.000638 & 175.187 & -39.143 & 24.43 & 0.09 & 7 & 241 & 1.40 \\
\hline 20131217.161557 & 175.035 & -39.379 & 39.41 & 0.10 & 10 & 209 & 1.63 \\
\hline 20131217.163021 & 175.062 & -39.277 & 36.51 & 0.15 & 12 & 112 & 1.52 \\
\hline 20131217.204012 & 175.195 & -39.254 & 25.09 & 0.10 & 9 & 237 & 1.35 \\
\hline 20131218.002550 & 175.226 & -39.260 & 23.42 & 0.11 & 12 & 171 & 2.24 \\
\hline 20131218.030822 & 175.098 & -39.358 & 38.64 & 0.13 & 7 & 118 & 1.57 \\
\hline 20131218.072715 & 175.247 & -39.254 & 24.45 & 0.17 & 13 & 110 & 1.49 \\
\hline 20131218.082142 & 175.340 & -39.275 & 28.27 & 0.10 & 9 & 141 & 1.04 \\
\hline 20131218.160951 & 174.773 & -39.305 & 37.67 & 0.41 & 23 & 81 & 2.67 \\
\hline 20131218.165412 & 174.775 & -39.312 & 36.61 & 0.44 & 22 & 82 & 2.83 \\
\hline 20131219.182157 & 175.194 & -39.261 & 24.65 & 0.07 & 9 & 227 & 1.76 \\
\hline 20131220.033804 & 174.748 & -39.229 & 28.68 & 0.20 & 6 & 203 & 2.05 \\
\hline 20131220.184948 & 174.793 & -39.188 & 44.20 & 0.25 & 15 & 137 & 2.82 \\
\hline 20131221.022919 & 175.300 & -39.328 & 33.82 & 0.11 & 12 & 118 & 2.11 \\
\hline 20131222.044119 & 175.248 & -39.263 & 25.34 & 0.06 & 7 & 192 & 1.54 \\
\hline 20131222.205427 & 175.451 & -39.139 & 10.88 & 0.10 & 11 & 186 & 0.97 \\
\hline 20131223.112015 & 175.340 & -39.237 & 19.25 & 0.13 & 12 & 121 & 1.30 \\
\hline 20131224.053914 & 175.143 & -39.263 & 37.23 & 0.29 & 24 & 49 & 2.73 \\
\hline 20131224.110900 & 174.602 & -38.827 & 31.50 & 0.24 & 14 & 179 & 2.80 \\
\hline 20131226.095548 & 175.159 & -39.142 & 24.39 & 0.04 & 11 & 173 & 2.04 \\
\hline
\end{tabular}




\begin{tabular}{|c|c|c|c|c|c|c|c|c|c|c|c|c|c|c|c|}
\hline $\begin{array}{c}\text { Event ID } \\
\text { yyyymmdd.hhmmss }\end{array}$ & $\begin{array}{c}\text { Longitude } \\
{\left[{ }^{\circ}\right]}\end{array}$ & $\begin{array}{c}\text { Latitude } \\
{\left[{ }^{\circ}\right]} \\
\end{array}$ & $\begin{array}{c}\text { Depth } \\
{[\mathrm{Km}]}\end{array}$ & $\begin{array}{c}\mathrm{RMS} \\
{[\mathrm{s}]}\end{array}$ & Stations & $\begin{array}{c}\text { Gap } \\
{\left[{ }^{\circ}\right]}\end{array}$ & $\mathrm{M}_{\mathrm{L}}$ & Event ID & $\begin{array}{c}\text { Longitude } \\
{\left[{ }^{\circ}\right]}\end{array}$ & $\begin{array}{c}\text { Latitude } \\
{\left[{ }^{\circ}\right]}\end{array}$ & $\begin{array}{c}\text { Depth } \\
{[\mathrm{Km}]}\end{array}$ & $\begin{array}{c}\mathrm{RMS} \\
{[\mathrm{s}]}\end{array}$ & Stations & $\begin{array}{c}\text { Gap } \\
{\left[{ }^{\circ}\right]}\end{array}$ & $\mathrm{M}_{\mathrm{L}}$ \\
\hline 20130312.050116 & 175.190 & -39.231 & 26.81 & 0.10 & 7 & 234 & 1.59 & 20131226.192024 & 175.231 & -39.256 & 25.34 & 0.10 & 8 & 215 & 0.87 \\
\hline 20130315.060222 & 174.575 & -39.084 & 23.04 & 0.15 & 6 & 181 & 0.84 & 20131226.202647 & 175.329 & -39.228 & 17.20 & 0.25 & 17 & 86 & 2.19 \\
\hline 20130316.141450 & 174.873 & -39.245 & 32.00 & 0.37 & 23 & 48 & 1.74 & 20131227.110500 & 175.410 & -39.186 & 15.55 & 0.09 & 11 & 193 & 0.95 \\
\hline 20130316.170954 & 175.400 & -39.168 & 17.73 & 0.12 & 10 & 279 & 2.41 & 20131228.041703 & 175.555 & -38.810 & 7.18 & 0.30 & 7 & 200 & 2.14 \\
\hline 20130317.144238 & 175.298 & -39.337 & 33.09 & 0.09 & 12 & 76 & 1.57 & 20131228.093029 & 175.008 & -39.219 & 38.77 & 0.25 & 16 & 116 & 2.24 \\
\hline 20130319.104053 & 175.431 & -39.171 & 16.48 & 0.01 & 5 & 301 & 1.72 & 20131228.110952 & 175.446 & -39.137 & 11.32 & 0.12 & 12 & 181 & 1.19 \\
\hline 20130320.153330 & 175.326 & -39.299 & 31.22 & 0.09 & 13 & 75 & 1.24 & 20131230.062814 & 175.206 & -39.259 & 23.84 & 0.13 & 10 & 206 & 1.75 \\
\hline 20130321.003509 & 175.340 & -39.295 & 31.97 & 0.02 & 7 & 140 & 1.29 & 20131230.195738 & 175.482 & -39.245 & 15.35 & 0.05 & 8 & 231 & 1.57 \\
\hline 20130321.110055 & 174.985 & -39.205 & 41.64 & 0.05 & 9 & 192 & 0.94 & 20131231.151230 & 175.244 & -39.258 & 23.35 & 0.14 & 14 & 169 & 1.62 \\
\hline 20130322.160736 & 175.028 & -39.307 & 31.00 & 0.43 & 27 & 43 & 1.86 & 20140101.220544 & 174.592 & -39.356 & 31.04 & 0.16 & 7 & 140 & 2.31 \\
\hline 20130322.215748 & 175.210 & -39.259 & 24.14 & 0.08 & 10 & 140 & 1.95 & 20140101.232039 & 175.103 & -39.156 & 35.25 & 0.12 & 14 & 87 & 2.29 \\
\hline 20130322.230327 & 175.282 & -39.261 & 26.41 & 0.09 & 7 & 166 & 1.24 & 20140102.174956 & 175.149 & -39.276 & 34.46 & 0.08 & 7 & 142 & 1.84 \\
\hline 20130323.105739 & 174.925 & -39.202 & 24.36 & 0.17 & 9 & 110 & 1.48 & 20140103.162657 & 175.000 & -39.286 & 38.20 & 0.09 & 11 & 129 & 2.29 \\
\hline 20130323.110640 & 174.851 & -39.395 & 30.65 & 0.46 & 28 & 63 & 1.68 & 20140105.060747 & 174.963 & -39.254 & 38.84 & 0.15 & 15 & 114 & 2.45 \\
\hline 20130323.164702 & 174.953 & -39.214 & 18.77 & 0.32 & 19 & 61 & 2.40 & 20140105.150839 & 174.722 & -39.457 & 35.14 & 0.40 & 17 & 121 & 2.56 \\
\hline 20130323.212352 & 174.878 & -39.435 & 36.88 & 0.38 & 27 & 56 & 1.83 & 20140105.234601 & 175.369 & -39.749 & 70.46 & 0.08 & 7 & 221 & 2.00 \\
\hline 20130323.212352 & 174.882 & -39.439 & 37.59 & 0.27 & 22 & 61 & 2.24 & 20140106.094447 & 175.336 & -39.300 & 31.75 & 0.03 & 7 & 167 & 1.00 \\
\hline 20130324.053603 & 174.932 & -39.272 & 40.32 & 0.47 & 11 & 117 & 1.86 & 20140107.193656 & 174.767 & -39.159 & 33.90 & 0.29 & 10 & 127 & 2.05 \\
\hline 20130324.203411 & 174.912 & -39.243 & 38.47 & 0.19 & 15 & 118 & 1.89 & 20140108.035136 & 174.783 & -38.988 & 33.79 & 0.45 & 21 & 111 & 2.78 \\
\hline 20130325.131611 & 175.551 & -38.907 & 12.00 & 0.13 & 9 & 188 & 1.97 & 20140108.041906 & 175.188 & -39.239 & 22.63 & 0.10 & 8 & 243 & 1.55 \\
\hline 20130326.143330 & 175.203 & -39.269 & 22.23 & 0.10 & 9 & 145 & 1.34 & 20140108.221449 & 175.005 & -39.554 & 44.90 & 0.11 & 10 & 152 & 2.40 \\
\hline 20130326.183530 & 175.454 & -39.238 & 12.93 & 0.13 & 6 & 180 & 0.77 & 20140109.081540 & 174.787 & -38.802 & 26.35 & 0.27 & 21 & 138 & 3.36 \\
\hline 20130327.103351 & 175.133 & -39.259 & 33.88 & 0.06 & 7 & 117 & 1.75 & 20140109.223025 & 174.771 & -38.808 & 28.00 & 0.19 & 11 & 191 & 2.57 \\
\hline 20130327.165930 & 175.109 & -39.276 & 39.06 & 0.16 & 14 & 112 & 1.72 & 20140110.055522 & 175.339 & -39.302 & 32.05 & 0.05 & 9 & 152 & 1.01 \\
\hline 20130328.061530 & 175.436 & -39.066 & 14.91 & 0.06 & 9 & 178 & 1.50 & 20140112.094532 & 174.704 & -39.383 & 34.23 & 0.42 & 26 & 101 & 2.70 \\
\hline 20130328.100259 & 175.383 & -39.170 & 13.29 & 0.45 & 27 & 66 & 2.14 & 20140113.095123 & 175.324 & -39.309 & 29.61 & 0.13 & 17 & 106 & 1.71 \\
\hline 20130328.164235 & 175.466 & -39.235 & 17.47 & 0.07 & 8 & 187 & 1.49 & 20140113.121346 & 174.918 & -39.275 & 40.16 & 0.17 & 16 & 146 & 2.31 \\
\hline 20130328.222151 & 175.267 & -39.324 & 16.67 & 0.14 & 9 & 167 & 1.29 & 20140115.055415 & 175.242 & -39.252 & 27.98 & 0.04 & 6 & 198 & 0.87 \\
\hline 20130329.075644 & 175.355 & -39.235 & 21.66 & 0.11 & 12 & 128 & 1.43 & 20140118.103233 & 175.198 & -39.259 & 23.33 & 0.11 & 10 & 208 & 1.40 \\
\hline 20130329.220122 & 175.207 & -39.263 & 23.88 & 0.07 & 9 & 98 & 1.91 & 20140118.155208 & 174.812 & -39.468 & 33.02 & 0.36 & 19 & 82 & 2.41 \\
\hline 20130401.123949 & 175.439 & -39.189 & 13.88 & 0.07 & 7 & 209 & 0.78 & 20140118.194324 & 175.040 & -39.000 & 28.86 & 0.06 & 7 & 104 & 1.60 \\
\hline 20130401.204217 & 175.378 & -39.238 & 20.75 & 0.09 & 11 & 139 & 1.15 & 20140119.091251 & 175.455 & -39.147 & 9.47 & 0.11 & 10 & 217 & 1.05 \\
\hline 20130403.140929 & 175.476 & -39.236 & 16.37 & 0.04 & 6 & 228 & 1.05 & 20140120.203951 & 175.371 & -39.235 & 18.42 & 0.07 & 6 & 164 & 1.67 \\
\hline 20130404.234930 & 174.958 & -39.240 & 32.50 & 0.40 & 25 & 48 & 2.40 & 20140121.060047 & 175.259 & -39.270 & 22.52 & 0.13 & 9 & 192 & 2.30 \\
\hline 20130407.100533 & 175.464 & -39.230 & 17.56 & 0.08 & 9 & 185 & 0.76 & 20140122.132750 & 175.067 & -39.271 & 34.32 & 0.07 & 11 & 120 & 2.05 \\
\hline 20130407.135830 & 175.361 & -39.237 & 19.72 & 0.13 & 15 & 130 & 1.44 & 20140124.023538 & 175.423 & -39.135 & 9.78 & 0.15 & 7 & 161 & 1.01 \\
\hline 20130407.144532 & 174.662 & -39.134 & 30.77 & 0.35 & 28 & 92 & 2.47 & 20140126.132739 & 175.209 & -39.258 & 23.77 & 0.13 & 11 & 205 & 1.78 \\
\hline 20130408.101623 & 175.352 & -39.157 & 10.85 & 0.55 & 26 & 52 & 2.29 & 20140126.190001 & 175.440 & -39.343 & 16.83 & 0.20 & 13 & 151 & 1.82 \\
\hline 20130408.102141 & 175.342 & -39.172 & 10.23 & 0.42 & 19 & 55 & 1.73 & 20140128.050949 & 175.259 & -39.226 & 32.00 & 0.20 & 21 & 71 & 2.47 \\
\hline 20130408.144018 & 175.463 & -39.240 & 10.12 & 0.31 & 23 & 80 & 1.94 & 20140129.131038 & 174.832 & -39.317 & 36.09 & 0.23 & 15 & 98 & 2.11 \\
\hline 20130409.140442 & 175.210 & -39.261 & 24.94 & 0.09 & 9 & 156 & 1.33 & 20140130.131347 & 175.341 & -39.231 & 19.43 & 0.09 & 12 & 122 & 1.18 \\
\hline 20130410.153049 & 175.191 & -39.245 & 20.62 & 0.08 & 8 & 227 & 1.37 & 20140131.002109 & 174.783 & -39.323 & 31.33 & 0.23 & 10 & 110 & 2.18 \\
\hline 20130411.052040 & 174.935 & -39.297 & 38.53 & 0.36 & 20 & 44 & 2.02 & 20140201.022515 & 175.443 & -39.366 & 19.63 & 0.02 & 5 & 134 & 1.11 \\
\hline
\end{tabular}




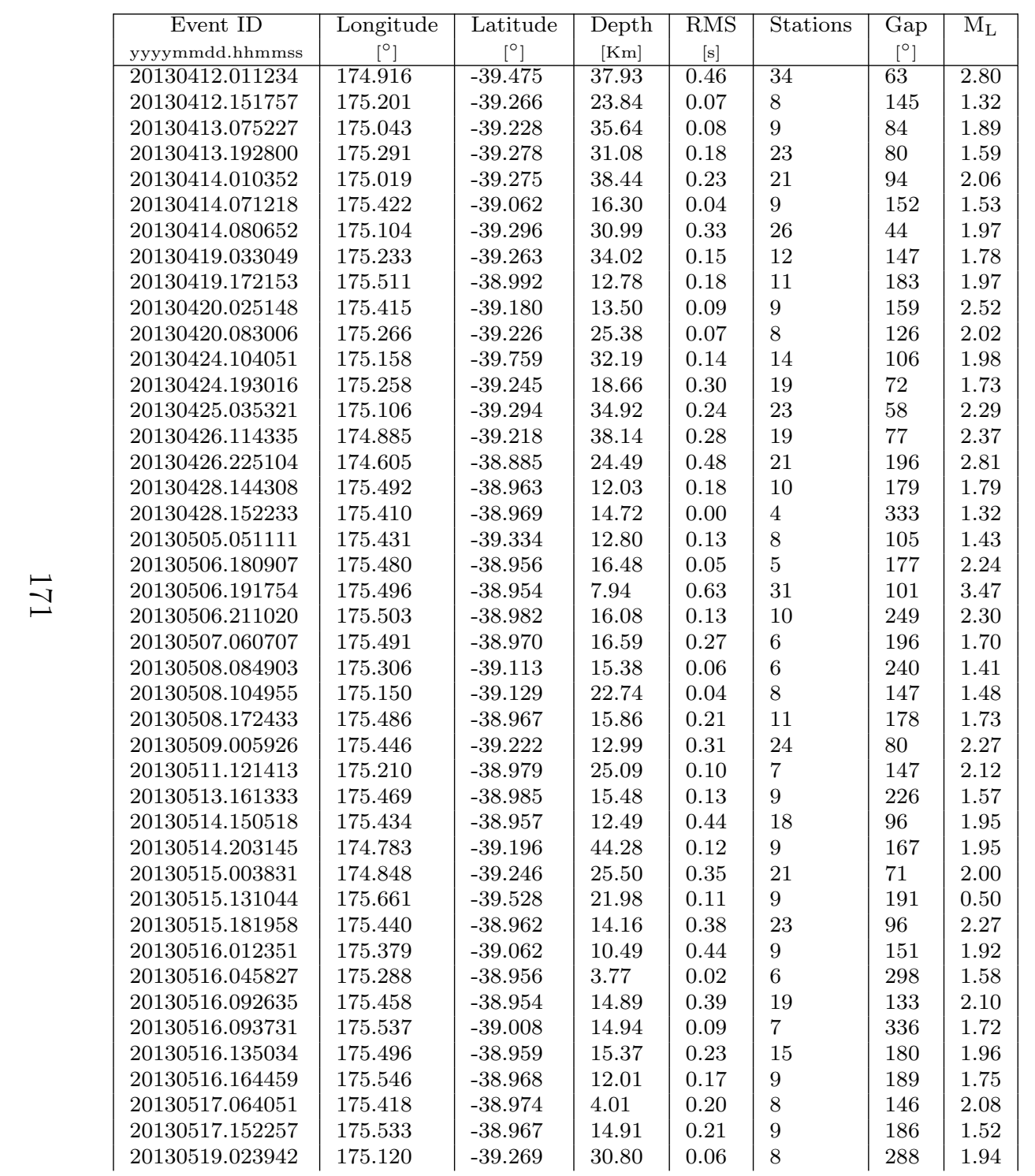

\begin{tabular}{|c|c|c|c|c|c|c|c|}
\hline Event ID & Longitude & Latitude & $\begin{array}{c}\text { Depth } \\
{[\mathrm{Km}]}\end{array}$ & $\begin{array}{c}\mathrm{RMS} \\
{[\mathrm{s}]}\end{array}$ & Stations & Gap & $\mathrm{M}_{\mathrm{L}}$ \\
\hline 20140201.151129 & 175.243 & -39.288 & 28.46 & 0.10 & 11 & 167 & 2.05 \\
\hline 20140202.162441 & 175.239 & -39.260 & 24.52 & 0.18 & 12 & 141 & 1.41 \\
\hline 20140202.200307 & 175.358 & -39.237 & 18.57 & 0.05 & 7 & 129 & 0.96 \\
\hline 20140203.193050 & 175.128 & -39.342 & 33.51 & 0.05 & 7 & 170 & 1.36 \\
\hline 20140204.115433 & 174.731 & -39.340 & 32.50 & 0.41 & 13 & 78 & 2.31 \\
\hline 20140204.125340 & 175.336 & -39.235 & 19.23 & 0.12 & 12 & 123 & 1.44 \\
\hline 20140205.130721 & 175.246 & -39.276 & 19.38 & 0.12 & 9 & 201 & 1.49 \\
\hline 20140206.232126 & 175.428 & -39.141 & 9.07 & 0.20 & 14 & 119 & 1.58 \\
\hline 20140208.014518 & 175.239 & -39.279 & 19.16 & 0.11 & 8 & 205 & 1.57 \\
\hline 20140208.132357 & 174.759 & -39.009 & 36.79 & 0.30 & 11 & 157 & 2.22 \\
\hline 20140209.002911 & 175.232 & -39.264 & 17.71 & 0.17 & 11 & 81 & 2.13 \\
\hline 20140209.110815 & 175.232 & -39.264 & 18.66 & 0.24 & 18 & 81 & 2.23 \\
\hline 20140210.190748 & 175.196 & -39.263 & 23.59 & 0.12 & 11 & 234 & 1.49 \\
\hline 20140211.020643 & 175.206 & -39.244 & 21.94 & 0.15 & 11 & 205 & 1.55 \\
\hline 20140212.040840 & 175.447 & -39.138 & 9.84 & 0.08 & 8 & 182 & 1.12 \\
\hline 20140212.234122 & 175.432 & -39.372 & 19.96 & 0.04 & 8 & 128 & 1.40 \\
\hline 20140213.091350 & 175.103 & -39.309 & 33.35 & 0.12 & 15 & 166 & 2.06 \\
\hline 20140214.060928 & 175.369 & -39.244 & 21.06 & 0.09 & 10 & 184 & 1.48 \\
\hline 20140214.101644 & 175.074 & -39.276 & 34.54 & 0.07 & 8 & 161 & 1.59 \\
\hline 20140215.052419 & 175.353 & -39.240 & 18.75 & 0.12 & 9 & 165 & 1.21 \\
\hline 20140215.120747 & 175.399 & -39.168 & 13.44 & 0.10 & 7 & 181 & 1.55 \\
\hline 20140215.204951 & 175.017 & -39.347 & 41.64 & 0.44 & 21 & 103 & 2.18 \\
\hline 20140217.002047 & 175.112 & -39.209 & 32.18 & 0.31 & 25 & 58 & 3.16 \\
\hline 20140217.044559 & 175.629 & -39.340 & 18.86 & 0.25 & 8 & 278 & 1.54 \\
\hline 20140217.074033 & 175.298 & -39.241 & 33.95 & 0.10 & 10 & 163 & 1.16 \\
\hline 20140219.045511 & 175.173 & -39.763 & 20.33 & 0.29 & 6 & 140 & 1.78 \\
\hline 20140219.060334 & 175.388 & -39.348 & 18.72 & 0.03 & 8 & 148 & 1.20 \\
\hline 20140219.090755 & 175.048 & -39.761 & 34.35 & 0.13 & 7 & 228 & 1.72 \\
\hline 20140219.123157 & 175.463 & -39.150 & 7.88 & 0.08 & 7 & 225 & 0.51 \\
\hline 20140219.133644 & 175.123 & -39.234 & 38.58 & 0.38 & 17 & 137 & 2.14 \\
\hline 20140219.154929 & 175.196 & -39.259 & 23.70 & 0.11 & 11 & 235 & 1.14 \\
\hline 20140219.174613 & 175.306 & -39.337 & 33.22 & 0.08 & 12 & 89 & 1.56 \\
\hline 20140220.032817 & 175.143 & -39.763 & 30.93 & 0.12 & 8 & 145 & 1.62 \\
\hline 20140220.093205 & 175.187 & -39.262 & 23.92 & 0.10 & 11 & 229 & 1.20 \\
\hline 20140220.113829 & 175.443 & -39.379 & 18.86 & 0.07 & 8 & 140 & 1.09 \\
\hline 20140220.205323 & 175.081 & -39.288 & 35.32 & 0.11 & 14 & 82 & 2.00 \\
\hline 20140220.214258 & 175.154 & -39.758 & 31.15 & 0.26 & 14 & 142 & 2.10 \\
\hline 20140220.234032 & 174.691 & -39.333 & 18.99 & 0.44 & 10 & 112 & 2.51 \\
\hline 20140221.100010 & 175.443 & -39.378 & 18.42 & 0.06 & 8 & 164 & 1.27 \\
\hline 20140221.110747 & 175.222 & -39.770 & 26.50 & 0.54 & 17 & 126 & 2.48 \\
\hline 20140221.120023 & 175.200 & -39.258 & 24.28 & 0.07 & 11 & 208 & 1.74 \\
\hline 20140221.210926 & 175.240 & -39.261 & 24.28 & 0.12 & 9 & 195 & 1.12 \\
\hline 20140222.044543 & 175.243 & -39.264 & 24.69 & 0.06 & 8 & 204 & 1.60 \\
\hline
\end{tabular}




\begin{tabular}{|c|c|c|c|c|c|c|c|c|c|c|c|c|c|c|c|}
\hline $\begin{array}{c}\text { Event ID } \\
\text { yyyymmdd.hhmmss }\end{array}$ & $\begin{array}{c}\text { Longitude } \\
{\left[{ }^{\circ}\right]}\end{array}$ & $\begin{array}{c}\text { Latitude } \\
{\left[{ }^{\circ}\right]}\end{array}$ & $\begin{array}{c}\text { Depth } \\
{[\mathrm{Km}]}\end{array}$ & $\begin{array}{c}\mathrm{RMS} \\
{[\mathrm{s}]}\end{array}$ & Stations & $\begin{array}{c}\text { Gap } \\
{\left[{ }^{\circ}\right]}\end{array}$ & $\mathrm{M}_{\mathrm{L}}$ & Event ID & $\begin{array}{c}\text { Longitude } \\
{\left[{ }^{\circ}\right]}\end{array}$ & $\begin{array}{c}\text { Latitude } \\
{\left[{ }^{\circ}\right]}\end{array}$ & $\begin{array}{c}\text { Depth } \\
{[\mathrm{Km}]}\end{array}$ & $\begin{array}{c}\text { RMS } \\
{[\mathrm{s}]}\end{array}$ & Stations & $\begin{array}{c}\text { Gap } \\
{\left[{ }^{\circ}\right]}\end{array}$ & $\mathrm{M}_{\mathrm{L}}$ \\
\hline 20130519.025746 & 175.105 & -39.216 & 32.10 & 0.45 & 30 & 56 & 2.66 & 20140223.173459 & 175.300 & -39.271 & 29.34 & 0.08 & 10 & 161 & 1.15 \\
\hline 20130519.125415 & 175.229 & -39.210 & 8.40 & 0.55 & 34 & 38 & 3.69 & 20140223.212536 & 175.282 & -39.274 & 18.50 & 0.17 & 8 & 182 & 1.49 \\
\hline 20130519.132342 & 175.224 & -39.216 & 9.22 & 0.46 & 29 & 62 & 2.44 & 20140224.015650 & 175.071 & -39.290 & 34.43 & 0.05 & 7 & 275 & 1.53 \\
\hline 20130519.135015 & 175.233 & -39.213 & 10.56 & 0.35 & 20 & 65 & 1.68 & 20140224.033604 & 175.440 & -39.369 & 19.96 & 0.05 & 8 & 124 & 1.38 \\
\hline 20130519.153727 & 175.234 & -39.221 & 12.78 & 0.09 & 11 & 124 & 2.46 & 20140224.085206 & 175.004 & -39.349 & 34.30 & 0.29 & 19 & 66 & 2.83 \\
\hline 20130520.054114 & 175.350 & -39.297 & 30.00 & 0.29 & 21 & 73 & 1.45 & 20140224.201817 & 175.129 & -39.230 & 34.90 & 0.16 & 15 & 127 & 2.11 \\
\hline 20130520.064052 & 175.227 & -39.214 & 10.49 & 0.37 & 22 & 58 & 1.53 & 20140225.042309 & 174.999 & -39.318 & 37.96 & 0.23 & 11 & 111 & 2.43 \\
\hline 20130520.114701 & 175.196 & -39.282 & 31.76 & 0.28 & 30 & 51 & 1.85 & 20140225.143648 & 175.058 & -39.644 & 29.95 & 0.40 & 15 & 83 & 2.42 \\
\hline 20130520.121427 & 175.215 & -39.284 & 31.51 & 0.34 & 30 & 53 & 2.92 & 20140225.233746 & 175.223 & -39.261 & 22.25 & 0.25 & 14 & 82 & 2.58 \\
\hline 20130521.004054 & 174.651 & -39.435 & 33.00 & 0.49 & 23 & 115 & 2.14 & 20140227.034542 & 175.204 & -39.250 & 22.38 & 0.04 & 8 & 148 & 1.62 \\
\hline 20130521.153235 & 175.144 & -39.269 & 22.62 & 0.07 & 9 & 117 & 2.36 & 20140227.052710 & 175.192 & -39.261 & 24.36 & 0.05 & 8 & 227 & 1.03 \\
\hline
\end{tabular}

Table A.1: Hypocentre locations for earthquakes at the Taranaki-Ruapehu Line between November 2012 and March 2014 . Table is sorted by date, which increases down the left column and then down the right column. 


\section{Appendix B}

\section{Focal mechanism and moment tensor solutions}

This appendix details focal mechanism and moment tensor solutions at the TaranakiRuapehu Line for the period November 2012 to March 2014. Data are sorted by increasing depth. 


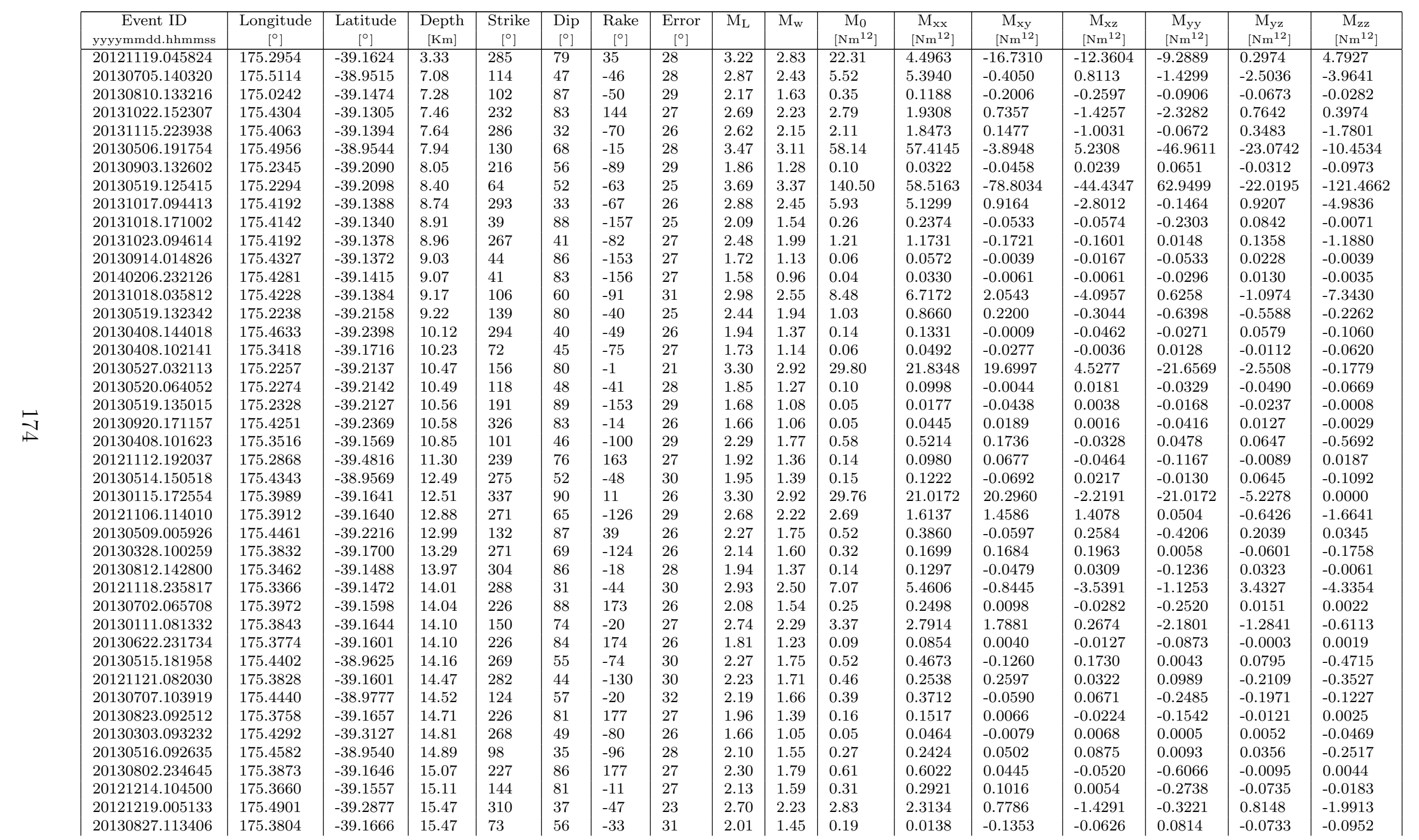




\begin{tabular}{|c|c|c|c|c|c|c|c|c|c|c|c|c|c|c|c|c|}
\hline $\begin{array}{c}\text { Event ID } \\
\text { yyyymmdd.hhmmss }\end{array}$ & $\begin{array}{c}\text { Longitude } \\
{\left[{ }^{\circ}\right]}\end{array}$ & $\begin{array}{c}\text { Latitude } \\
{\left[{ }^{\circ}\right]}\end{array}$ & $\begin{array}{c}\text { Depth } \\
{[\mathrm{Km}]}\end{array}$ & $\begin{array}{c}\text { Strike } \\
{\left[{ }^{\circ}\right]}\end{array}$ & $\begin{array}{c}\text { Dip } \\
{\left[{ }^{\circ}\right]}\end{array}$ & $\begin{array}{c}\text { Rake } \\
{\left[{ }^{\circ}\right]}\end{array}$ & $\begin{array}{c}\text { Error } \\
{\left[{ }^{\circ}\right]}\end{array}$ & $\mathrm{M}_{\mathrm{L}}$ & $\mathrm{M}_{\mathrm{w}}$ & $\begin{array}{c}\mathrm{M}_{0} \\
{\left[\mathrm{Nm}^{12}\right]}\end{array}$ & $\begin{array}{c}\mathrm{M}_{\mathrm{Xx}} \\
{\left[\mathrm{Nm}^{12}\right]}\end{array}$ & $\begin{array}{c}\mathrm{M}_{\mathrm{xy}} \\
{\left[\mathrm{Nm}^{12}\right]}\end{array}$ & $\begin{array}{c}\mathrm{M}_{\mathrm{xz}} \\
{\left[\mathrm{Nm}^{12}\right]}\end{array}$ & $\begin{array}{c}\mathrm{M}_{\mathrm{yy}} \\
{\left[\mathrm{Nm}^{12}\right]}\end{array}$ & $\begin{array}{c}\mathrm{M}_{\mathrm{yz}} \\
{\left[\mathrm{Nm}^{12}\right]}\end{array}$ & $\begin{array}{c}\mathrm{M}_{\mathrm{zz}} \\
{\left[\mathrm{Nm}^{12}\right]}\end{array}$ \\
\hline 20130913.114425 & 175.3853 & -39.1600 & 15.47 & 141 & 57 & -72 & 30 & 1.79 & 1.20 & 0.08 & 0.0475 & 0.0380 & -0.0089 & 0.0215 & -0.0323 & -0.0690 \\
\hline 20121107.073456 & 175.3809 & -39.1605 & 15.76 & 250 & 73 & -168 & 22 & 2.61 & 2.14 & 2.04 & 1.4333 & 1.3829 & 0.1306 & -1.1966 & -0.6672 & -0.2367 \\
\hline 20130708.062216 & 175.4516 & -39.2299 & 15.80 & 236 & 50 & -111 & 29 & 1.67 & 1.06 & 0.05 & 0.0441 & -0.0161 & 0.0003 & 0.0016 & -0.0140 & -0.0457 \\
\hline 20130728.084904 & 175.4646 & -38.9635 & 15.88 & 79 & 37 & -105 & 26 & 2.28 & 1.76 & 0.54 & 0.5178 & -0.0160 & 0.1634 & -0.0133 & 0.0826 & -0.5045 \\
\hline 20121220.000953 & 175.3728 & -39.1562 & 15.99 & 246 & 70 & -165 & 27 & 2.23 & 1.70 & 0.45 & 0.3668 & 0.2460 & 0.0211 & -0.2917 & -0.1724 & -0.0750 \\
\hline 20130310.153347 & 175.4234 & -39.1673 & 16.21 & 84 & 37 & -102 & 30 & 1.40 & 0.76 & 0.02 & 0.0166 & 0.0004 & 0.0050 & -0.0003 & 0.0024 & -0.0163 \\
\hline 20130810.164456 & 175.0159 & -39.1346 & 16.61 & 319 & 3 & 165 & 31 & 2.19 & 1.65 & 0.38 & -0.0235 & -0.0078 & 0.3413 & 0.0132 & -0.1669 & 0.0103 \\
\hline 20130118.115729 & 175.4167 & -39.1699 & 16.76 & 283 & 55 & -76 & 30 & 1.55 & 0.93 & 0.03 & 0.0301 & 0.0007 & 0.0092 & -0.0013 & 0.0066 & -0.0288 \\
\hline 20130716.200631 & 175.4155 & -39.3324 & 17.06 & 346 & 29 & -47 & 28 & 1.93 & 1.36 & 0.14 & 0.0267 & 0.0611 & -0.0939 & 0.0598 & -0.0323 & -0.0866 \\
\hline 20131226.202647 & 175.3286 & -39.2283 & 17.20 & 128 & 72 & -47 & 26 & 2.19 & 1.66 & 0.39 & 0.3532 & 0.0204 & -0.1326 & -0.1838 & -0.2090 & -0.1694 \\
\hline 20130715.171451 & 174.9689 & -39.2889 & 17.23 & 254 & 23 & -62 & 29 & 2.28 & 1.76 & 0.56 & 0.2719 & -0.1798 & -0.2612 & 0.0808 & 0.3245 & -0.3526 \\
\hline 20130803.123111 & 174.9335 & -39.1873 & 17.42 & 33 & 53 & -118 & 27 & 2.10 & 1.55 & 0.27 & 0.1601 & -0.1455 & 0.0281 & 0.0686 & 0.0965 & -0.2287 \\
\hline 20130208.094722 & 175.4095 & -39.3320 & 17.45 & 271 & 54 & -72 & 28 & 1.57 & 0.96 & 0.03 & 0.0315 & -0.0081 & 0.0100 & -0.0003 & 0.0064 & -0.0312 \\
\hline 20121214.003737 & 175.3608 & -39.1496 & 17.47 & 248 & 68 & -166 & 26 & 1.95 & 1.39 & 0.15 & 0.1178 & 0.0901 & 0.0039 & -0.0921 & -0.0616 & -0.0257 \\
\hline 20131004.150925 & 175.3439 & -39.2436 & 18.51 & 118 & 41 & -53 & 26 & 1.49 & 0.86 & 0.02 & 0.0231 & 0.0026 & 0.0076 & -0.0037 & -0.0085 & -0.0193 \\
\hline 20130612.030027 & 174.7104 & -38.7516 & 18.64 & 230 & 65 & -137 & 28 & 2.94 & 2.51 & 7.23 & 6.9344 & -1.0275 & 0.9913 & -3.1580 & -3.7483 & -3.7763 \\
\hline 20130424.193016 & 175.2576 & -39.2446 & 18.66 & 107 & 40 & -144 & 24 & 1.73 & 1.13 & 0.06 & 0.0150 & 0.0372 & -0.0052 & 0.0213 & 0.0390 & -0.0363 \\
\hline 20130323.164702 & 174.9531 & -39.2136 & 18.77 & 132 & 86 & 83 & 33 & 1.83 & 1.25 & 0.09 & 0.0042 & -0.0077 & 0.0692 & -0.0172 & 0.0613 & 0.0130 \\
\hline 20121216.011524 & 175.3564 & -39.2327 & 18.91 & 239 & 61 & -152 & 24 & 1.92 & 1.35 & 0.14 & 0.1319 & 0.0253 & -0.0010 & -0.0780 & -0.0670 & -0.0539 \\
\hline 20131001.082705 & 175.2220 & -39.2571 & 20.19 & 59 & 65 & -104 & 28 & 1.30 & 0.65 & 0.01 & 0.0086 & -0.0026 & -0.0056 & 0.0000 & 0.0048 & -0.0087 \\
\hline 20121229.103647 & 175.1932 & -39.2504 & 21.08 & 104 & 38 & -154 & 29 & 1.72 & 1.13 & 0.06 & 0.0087 & 0.0363 & -0.0042 & 0.0176 & 0.0440 & -0.0263 \\
\hline 20130609.192959 & 175.2639 & -39.2185 & 21.38 & 254 & 30 & -50 & 27 & 1.90 & 1.33 & 0.12 & 0.0544 & -0.0551 & -0.0264 & 0.0271 & 0.0788 & -0.0816 \\
\hline 20130524.185028 & 175.2067 & -39.2473 & 21.66 & 53 & 69 & -155 & 26 & 1.71 & 1.12 & 0.06 & 0.0594 & 0.0058 & -0.0033 & -0.0425 & 0.0268 & -0.0169 \\
\hline 20121221.150035 & 175.2659 & -39.2421 & 21.73 & 253 & 60 & -71 & 27 & 2.01 & 1.46 & 0.19 & 0.1134 & -0.0888 & 0.0959 & 0.0437 & 0.0033 & -0.1571 \\
\hline 20130129.133739 & 175.3052 & -39.2581 & 22.38 & 286 & 53 & -60 & 27 & 1.56 & 0.94 & 0.03 & 0.0318 & -0.0038 & 0.0047 & -0.0048 & 0.0115 & -0.0270 \\
\hline 20130523.074820 & 175.0007 & -39.2783 & 23.09 & 318 & 79 & 30 & 29 & 2.02 & 1.47 & 0.20 & 0.1543 & -0.0009 & -0.0877 & -0.1923 & -0.0474 & 0.0380 \\
\hline 20130907.102416 & 174.7932 & -39.1771 & 23.16 & 345 & 58 & -111 & 25 & 2.80 & 2.35 & 4.19 & -0.4016 & -0.2240 & 1.2135 & 3.9206 & 1.4517 & -3.5191 \\
\hline 20130426.225104 & 174.6046 & -38.8855 & 24.49 & 182 & 88 & -166 & 29 & 2.81 & 2.36 & 4.36 & 0.2948 & -4.2169 & -0.1107 & -0.2213 & -1.0559 & -0.0735 \\
\hline 20130515.003831 & 174.8479 & -39.2464 & 25.50 & 352 & 40 & -138 & 25 & 2.00 & 1.44 & 0.18 & -0.0218 & -0.0675 & 0.1003 & 0.1424 & -0.0356 & -0.1207 \\
\hline 20130606.161359 & 174.8712 & -39.0458 & 25.92 & 289 & 79 & 8 & 26 & 2.67 & 2.20 & 2.52 & 1.3889 & -1.9683 & -0.4619 & -1.5201 & 0.3439 & 0.1312 \\
\hline 20140221.110747 & 175.2216 & -39.7695 & 26.50 & 143 & 86 & -55 & 30 & 2.48 & 1.99 & 1.21 & 0.7146 & 0.2568 & -0.5514 & -0.5769 & -0.8121 & -0.1378 \\
\hline 20130531.033638 & 175.2867 & -39.2858 & 26.56 & 230 & 70 & -132 & 30 & 2.14 & 1.60 & 0.32 & 0.2867 & -0.0402 & 0.0921 & -0.1345 & -0.1725 & -0.1522 \\
\hline 20121122.173620 & 175.3580 & -39.5120 & 26.98 & 161 & 81 & -86 & 30 & 2.79 & 2.34 & 4.03 & 0.3028 & 0.6016 & -1.2039 & 0.9403 & -3.6316 & -1.2431 \\
\hline 20131112.130821 & 175.2655 & -39.2604 & 27.41 & 239 & 40 & 3 & 32 & 2.34 & 1.83 & 0.69 & -0.4171 & -0.1922 & 0.2771 & 0.3815 & 0.4491 & 0.0356 \\
\hline 20131202.013255 & 175.2831 & -39.7106 & 28.18 & 134 & 66 & -59 & 27 & 2.09 & 1.55 & 0.26 & 0.2104 & 0.0794 & -0.0703 & -0.0428 & -0.1445 & -0.1676 \\
\hline 20130809.104930 & 175.2753 & -39.2983 & 28.73 & 243 & 43 & -91 & 23 & 3.38 & 3.01 & 41.19 & 33.0153 & -16.3318 & -2.7986 & 8.0717 & 0.8359 & -41.0870 \\
\hline 20130129.082322 & 174.7434 & -39.3062 & 29.10 & 72 & 63 & -92 & 31 & 2.50 & 2.01 & 1.32 & 0.9869 & -0.2797 & -0.7291 & 0.0776 & 0.2588 & -1.0644 \\
\hline 20130604.170046 & 174.9238 & -39.1203 & 29.79 & 255 & 61 & 8 & 30 & 2.73 & 2.27 & 3.24 & -1.7602 & -2.3351 & 0.1718 & 1.3777 & 1.5646 & 0.3825 \\
\hline 20130520.054114 & 175.3497 & -39.2970 & 30.00 & 292 & 68 & -32 & 25 & 1.53 & 0.91 & 0.03 & 0.0254 & -0.0129 & 0.0069 & -0.0146 & 0.0129 & -0.0108 \\
\hline 20130303.164703 & 175.2850 & -39.2466 & 30.33 & 322 & 50 & -80 & 28 & 2.47 & 1.98 & 1.17 & 0.5815 & 0.5885 & 0.0203 & 0.5540 & 0.2382 & -1.1355 \\
\hline 20130826.121840 & 175.3716 & -39.2937 & 30.50 & 16 & 63 & -171 & 28 & 2.24 & 1.72 & 0.47 & 0.2243 & -0.3674 & 0.1911 & -0.1646 & 0.0999 & -0.0596 \\
\hline 20130323.110640 & 174.8511 & -39.3951 & 30.65 & 239 & 36 & -100 & 30 & 2.40 & 1.90 & 0.89 & 0.6928 & -0.3254 & -0.2966 & 0.1409 & 0.0323 & -0.8338 \\
\hline 20130804.143224 & 175.0504 & -39.3356 & 30.70 & 5 & 13 & 158 & 30 & 1.96 & 1.40 & 0.16 & 0.0055 & -0.0303 & 0.1379 & -0.0316 & 0.0656 & 0.0260 \\
\hline
\end{tabular}




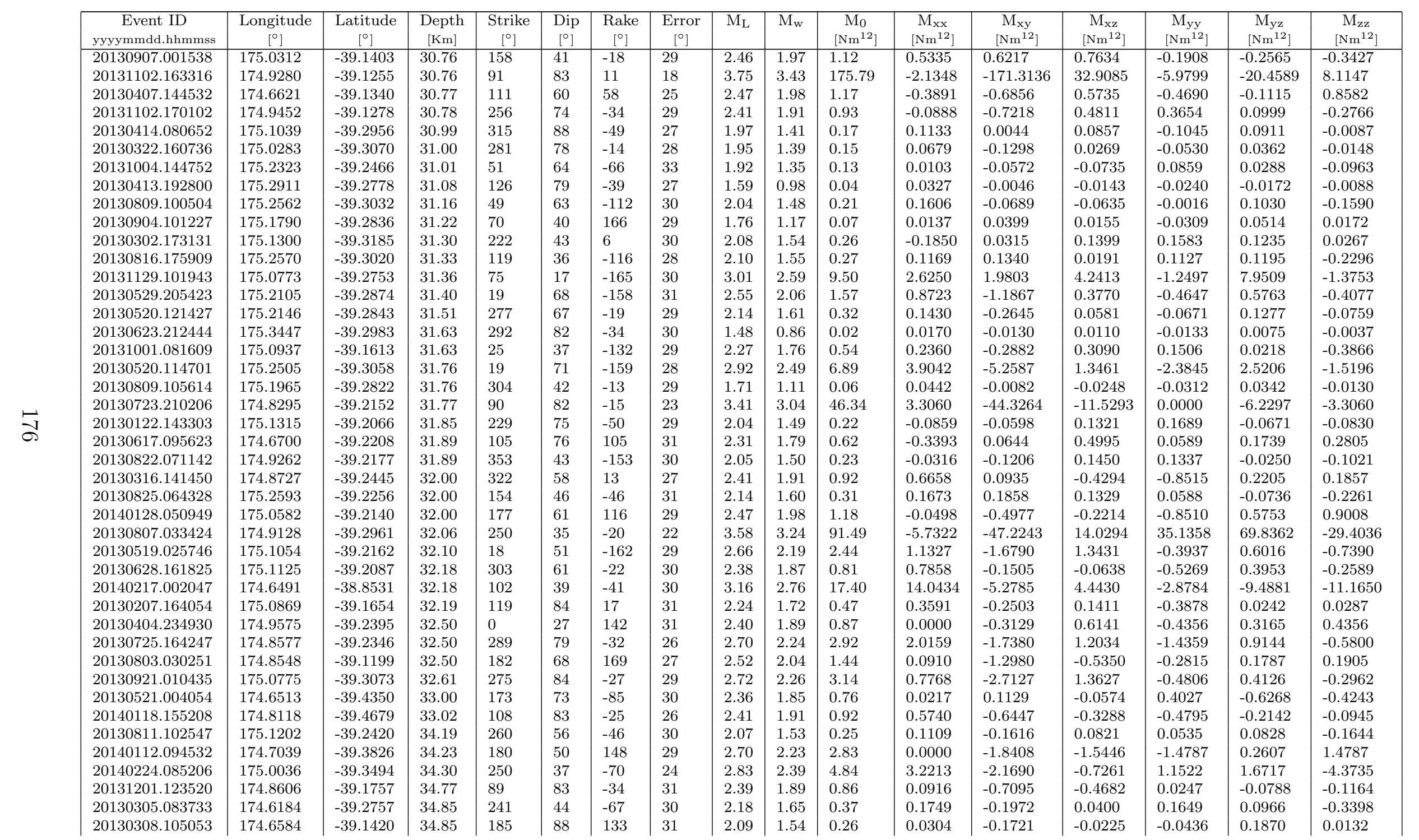




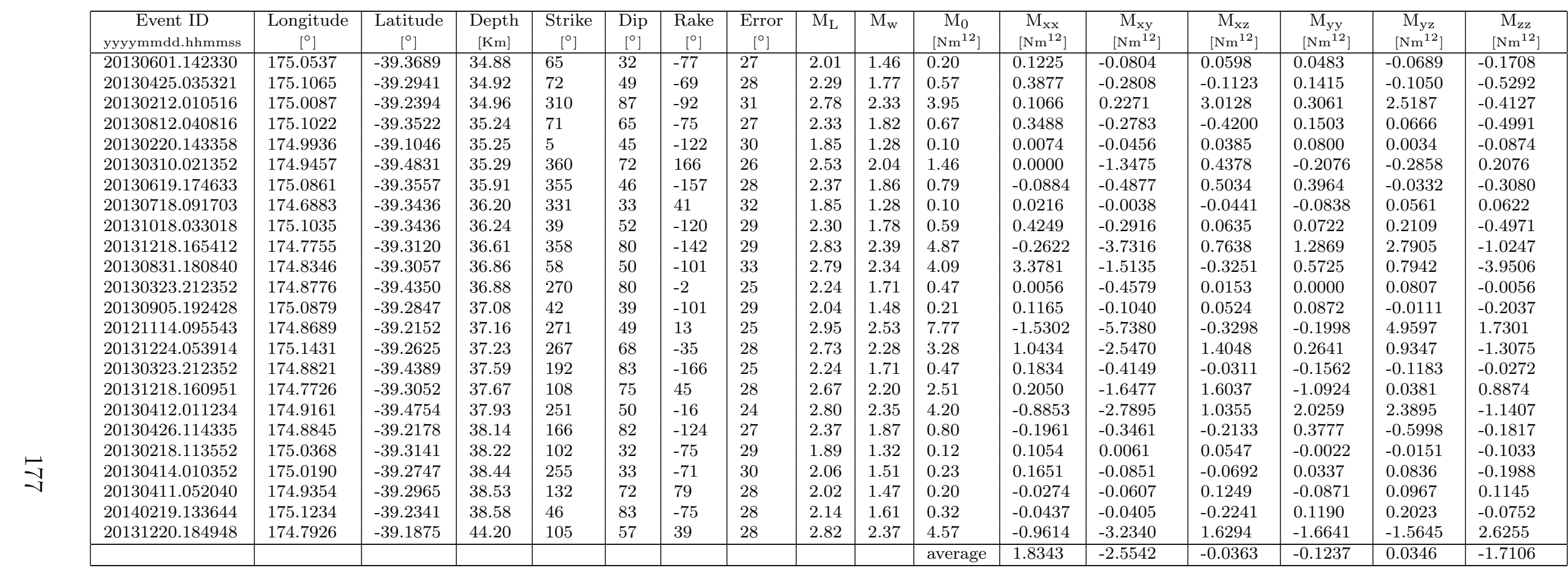

Table B.1: Focal mechanism and moment tensor solutions for earthquakes recorded between November 2012 and March 2014 at the Taranaki-Ruapehu Line with at least 10 first motions from GeoNet and RATTIL stations. The strike/dip/rake values above represent the geometry of either the fault plane OR the auxiliary plane solution for a focal mechanism. There is no intended bias towards one plane or the other. $\mathrm{M}_{\mathrm{L}}=$ local magnitude, $\mathrm{M}_{\mathrm{w}}=$ seismic moment magnitude, $\mathrm{M}_{0}=$ seismic moment. $\mathrm{M}_{\mathrm{ij}}$ represent the six independent components of the moment tensor solution, where i,j represent combinations of x,y,z cartesian coordinates. Sign convention follows Aki and Richards [1980] such that positive $\mathrm{x}$ is north, positive $\mathrm{y}$ is east, and positive $\mathrm{z}$ is down. 


\section{Appendix C}

\section{Example DAS configuration file}

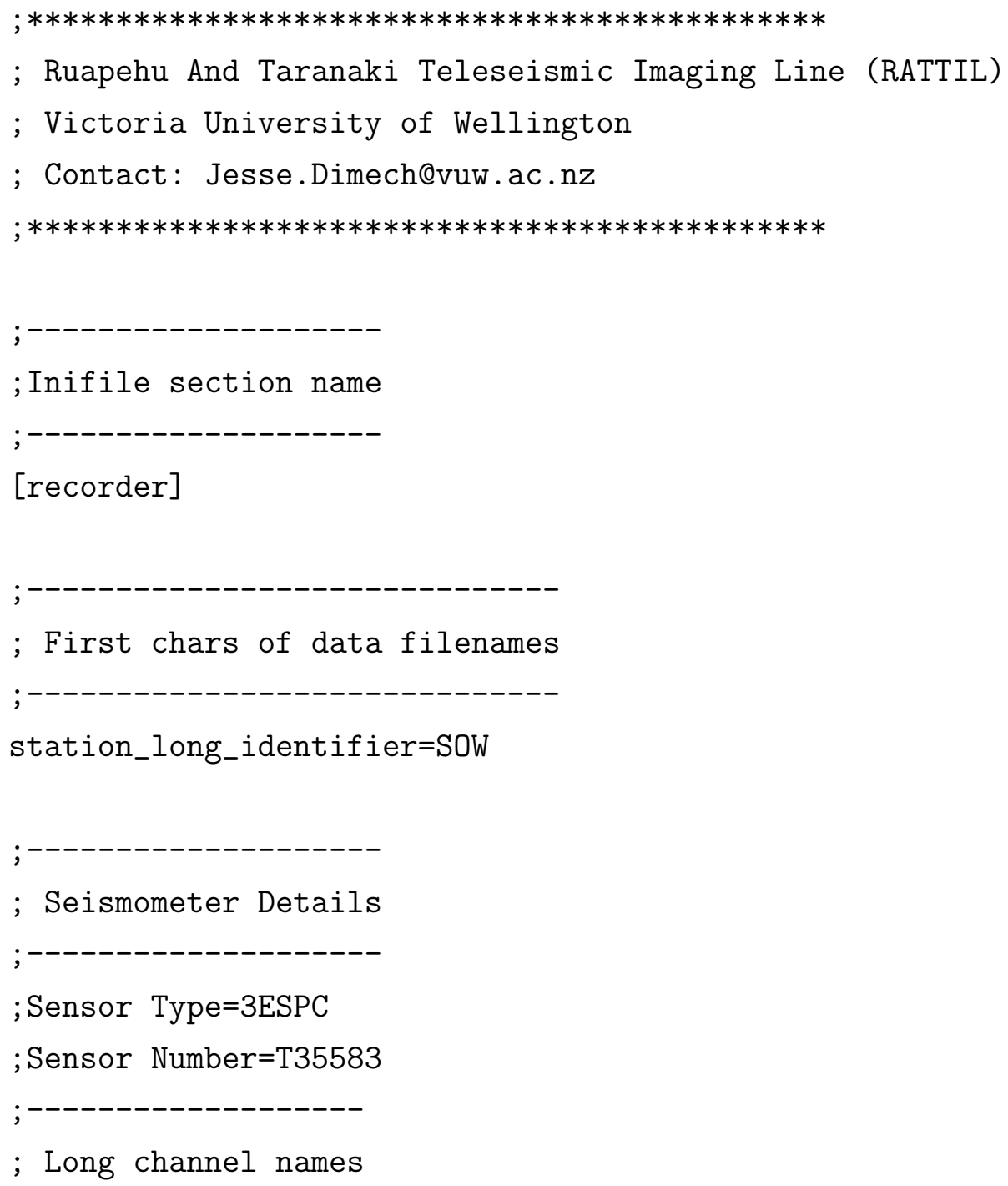


channel_0_long_id=DZ
channel_1_long_id=DN
channel_2_long_id=DE
channel_3_long_id=pri3
channel_4_long_id=pri4
channel_5_long_id=pri5
channel_6_long_id=sec0
channel_7_long_id=sec1
channel_8_long_id=sec2
channel_9_long_id=sec3
channel_10_long_id=sec4
channel_11_long_id=sec5

channel_13_long_id=ambientTemperature

channel_14_long_id=diskTemperature

channel_15_long_id=supplyCurrent

channel_16_long_id=batteryVolts1

channel_17_long_id=batteryVolts2

channel_18_long_id=externalAnalogue1

channel_19_long_id=externalAnalogue2

channel_20_long_id=externalAnalogue3

channel_21_long_id=externalAnalogue4

; Short channel names

;---------------------

channel_0_short_id=dz

channel_1_short_id=dn

channel_2_short_id=de

channel_3_short_id=p3

channel_4_short_id=p4

channel_5_short_id=p5

channel_6_short_id=s0

channel_7_short_id=s1

channel_8_short_id=s2 


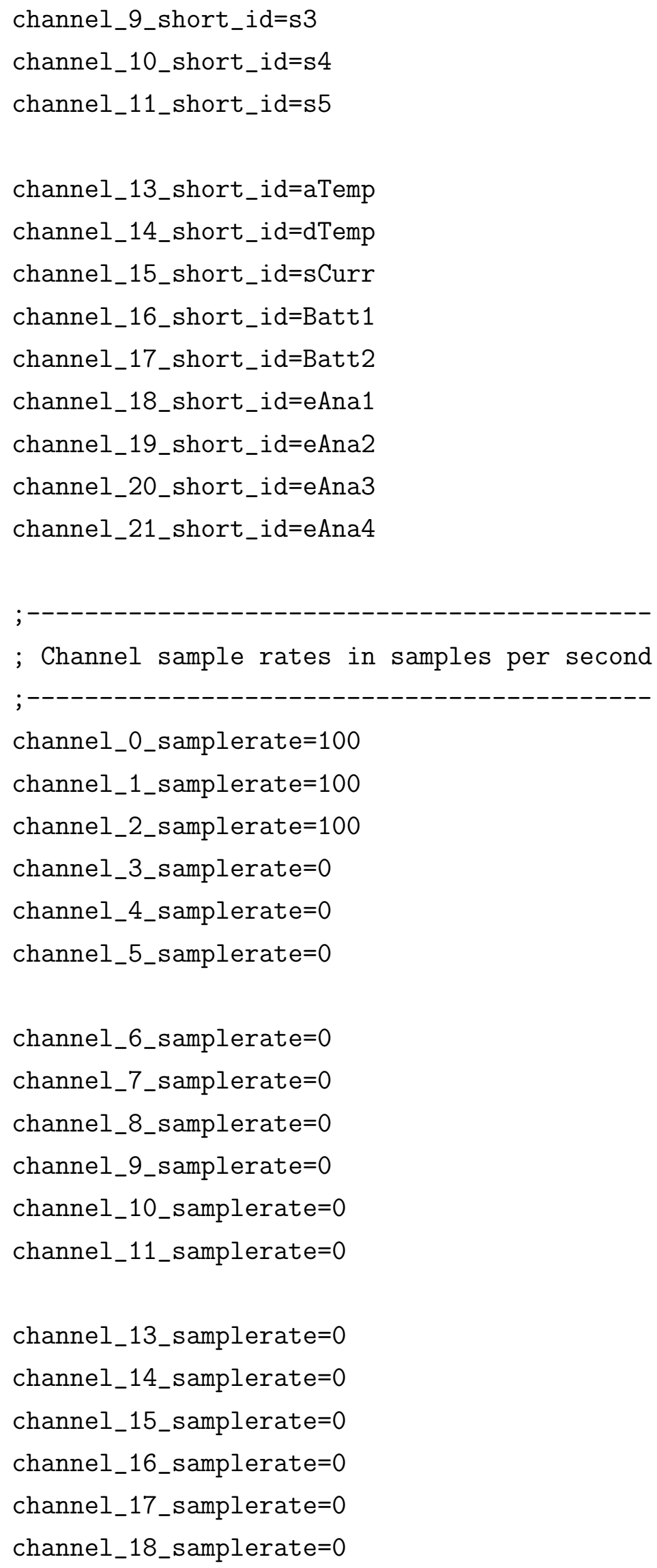




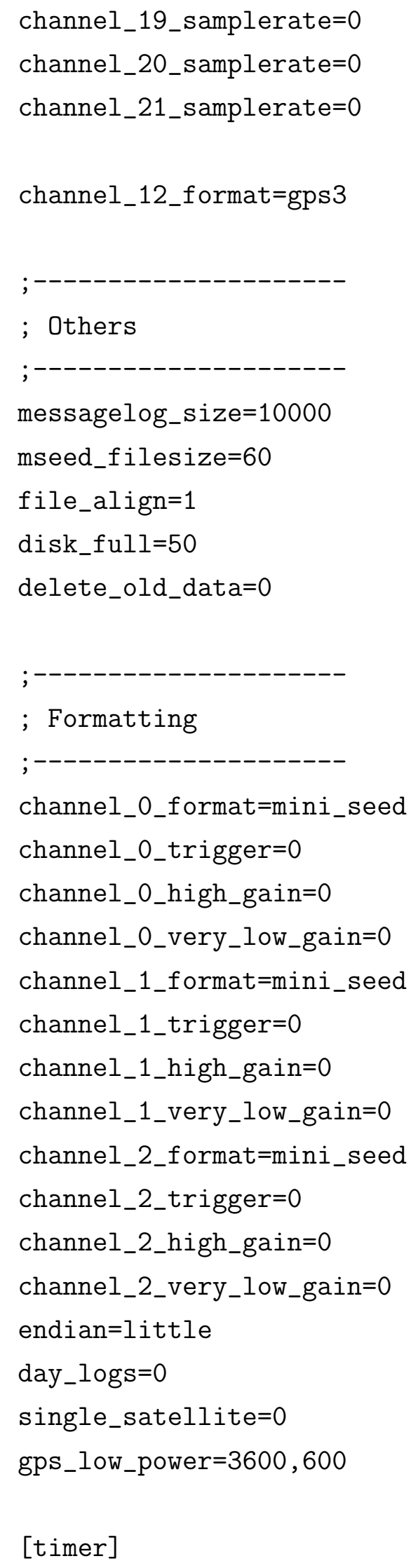




\section{Appendix D}

\section{Station specific Receiver Function results}

Back azimuth and epicentral distance plots were created for all 17 stations used in the receiver function study. Stations PAR, WAI, HOK, SOW, MOT, KUR, FUN and PEP are broadband seismometers deployed as part of this study. Stations ERU, KAI, PAP, RAE, SUN, TUN and WRR are from Salmon [2008]. Stations PKVZ and TWVZ are GeoNet stations part of the Tongariro National Park volcano seismic network. Receiver Functions were created using multi-taper spectral correlation [Park and Levin, 2000], after the components were rotated into the LQT domain (Section 4.3.2). 

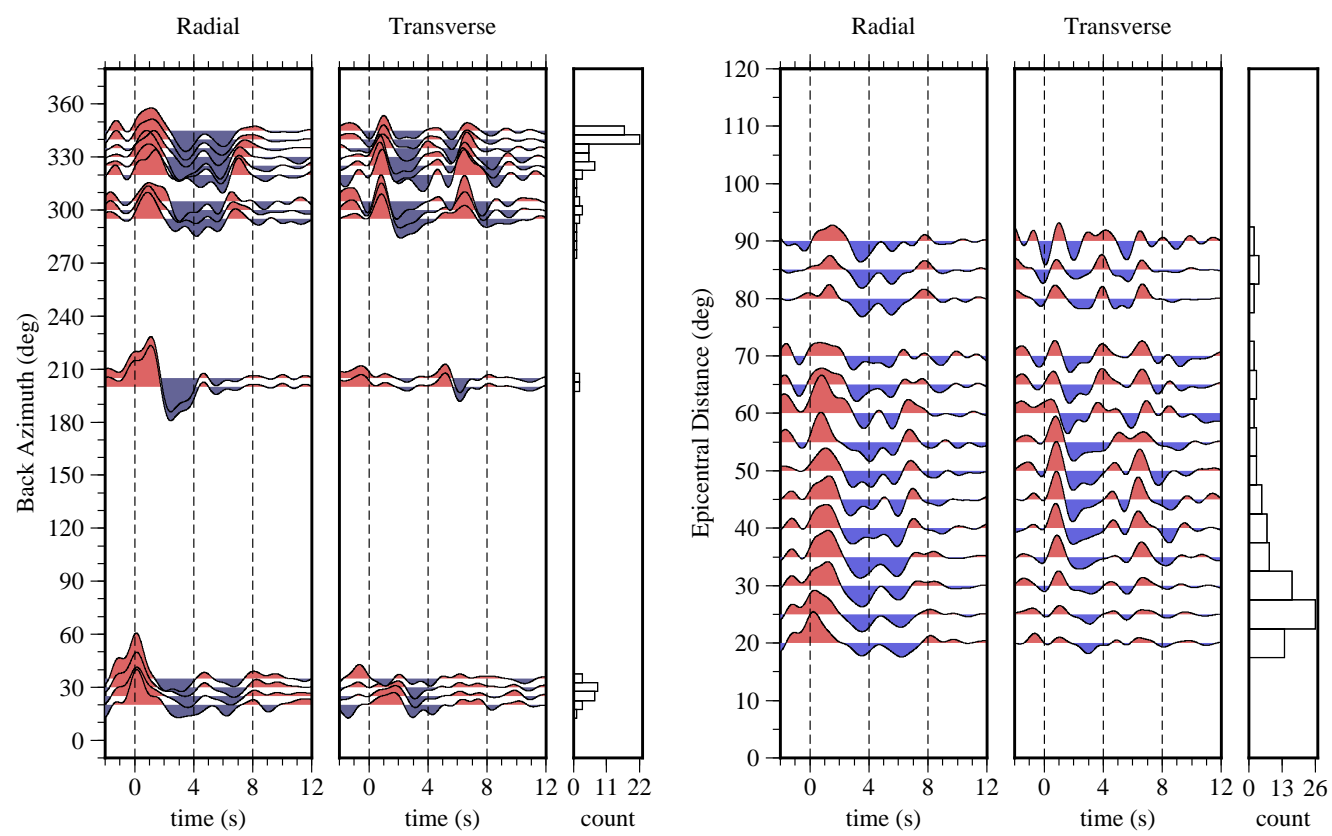

Figure D.1: Back azimuth (left) and epicentral distance (right) plots of receiver functions from station PAR. Receiver functions were low-pass filtered $(1 \mathrm{~Hz})$ and binned every $10^{\circ}$ in back azimuth and $5^{\circ}$ in epicentral distance. Colours represent phase, red is positive, blue is negative.
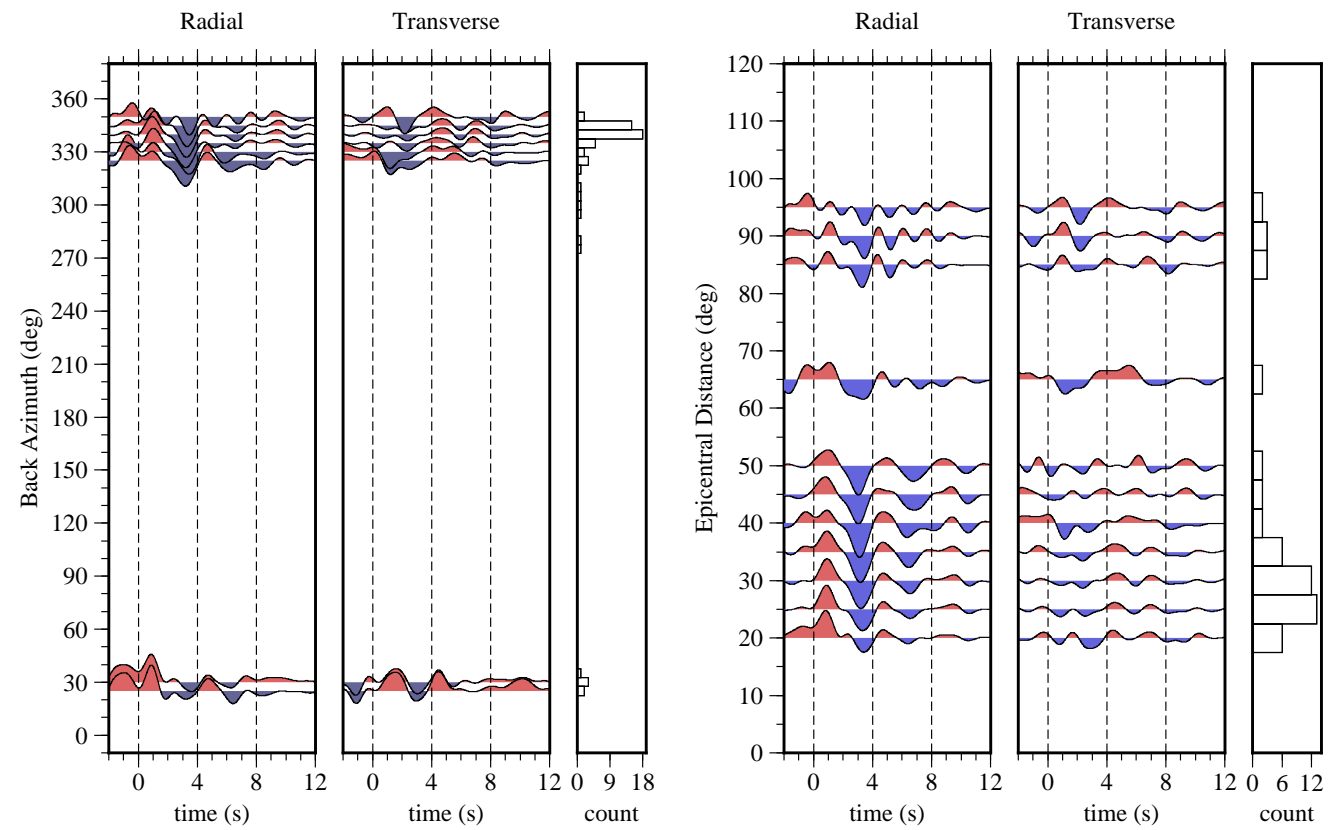

Figure D.2: Back azimuth (left) and epicentral distance (right) plots of receiver functions from station WAI. Receiver functions were low-pass filtered $(1 \mathrm{~Hz})$ and binned every $10^{\circ}$ in back azimuth and $5^{\circ}$ in epicentral distance. Colours represent phase, red is positive, blue is negative. 

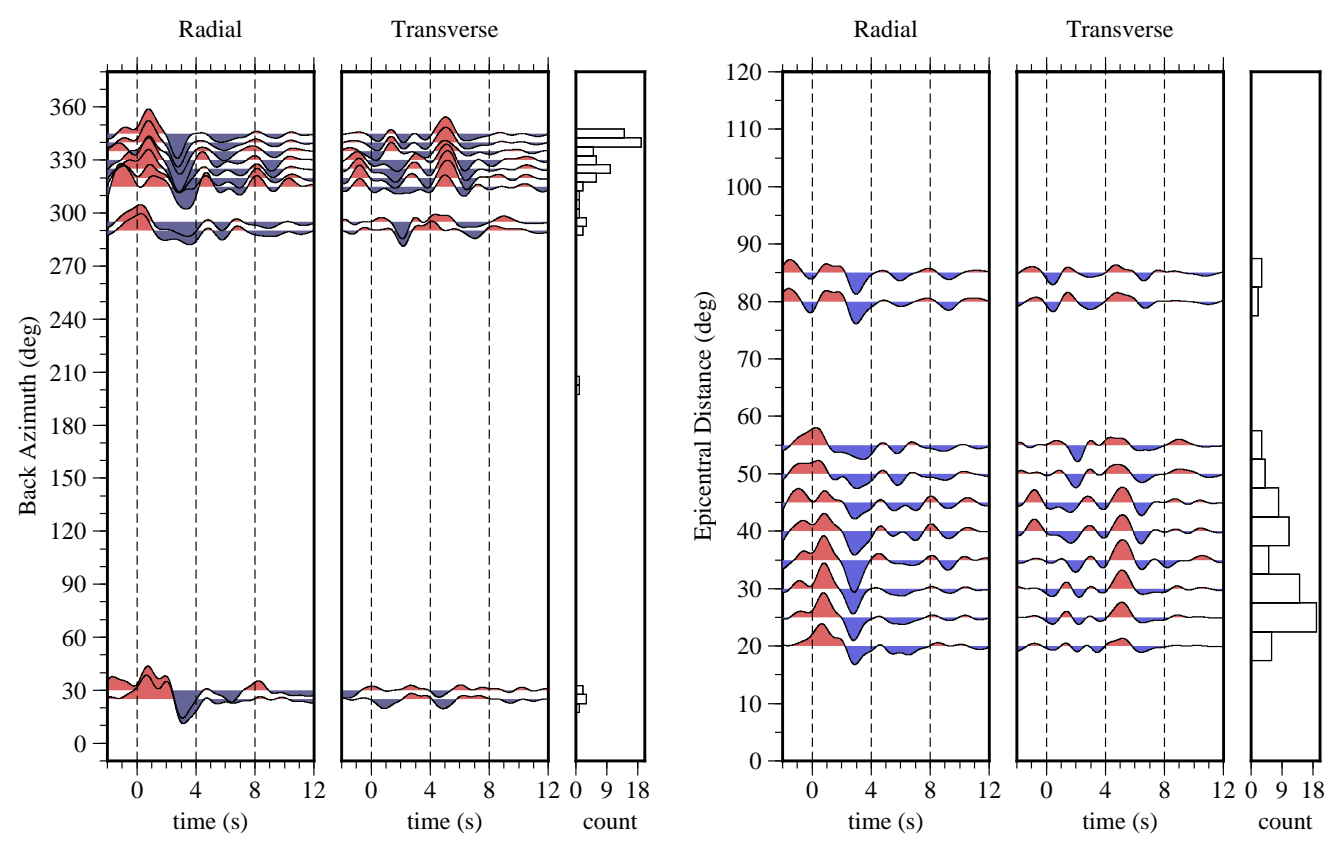

Figure D.3: Back Azimuth (left) and Epicentral Distnnce (right) plots of receiver functions from station HOK. Receiver functions were low-pass filtered $(1 \mathrm{~Hz})$ and binned every $10^{\circ}$ in back azimuth and $5^{\circ}$ in epicentral distance. Colours represent phase, red is positive, blue is negative.
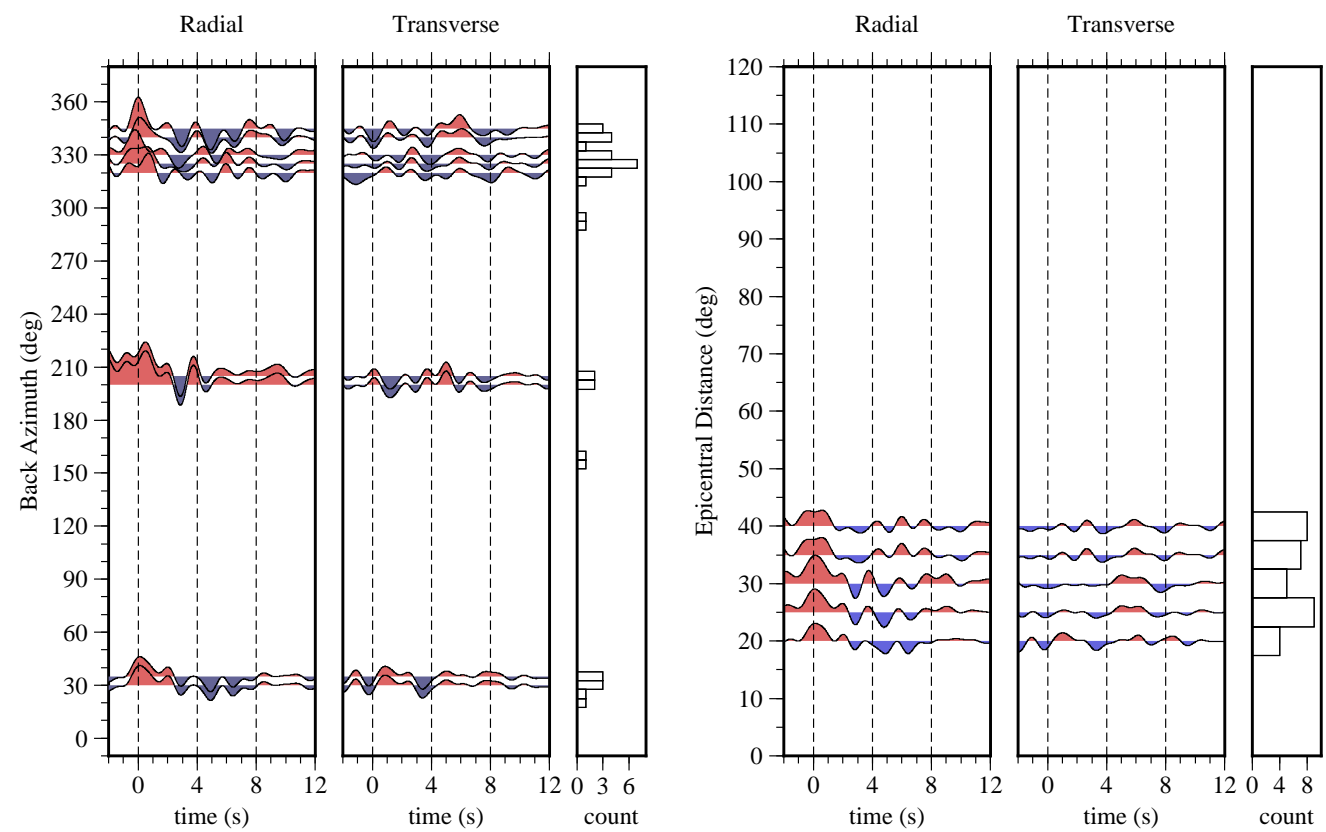

Figure D.4: Back azimuth (left) and epicentral distance (right) plots of receiver functions from station SOW. Receiver functions were low-pass filtered $(1 \mathrm{~Hz})$ and binned every $10^{\circ}$ in back azimuth and $5^{\circ}$ in epicentral distance. Colours represent phase, red is positive, blue is negative. 

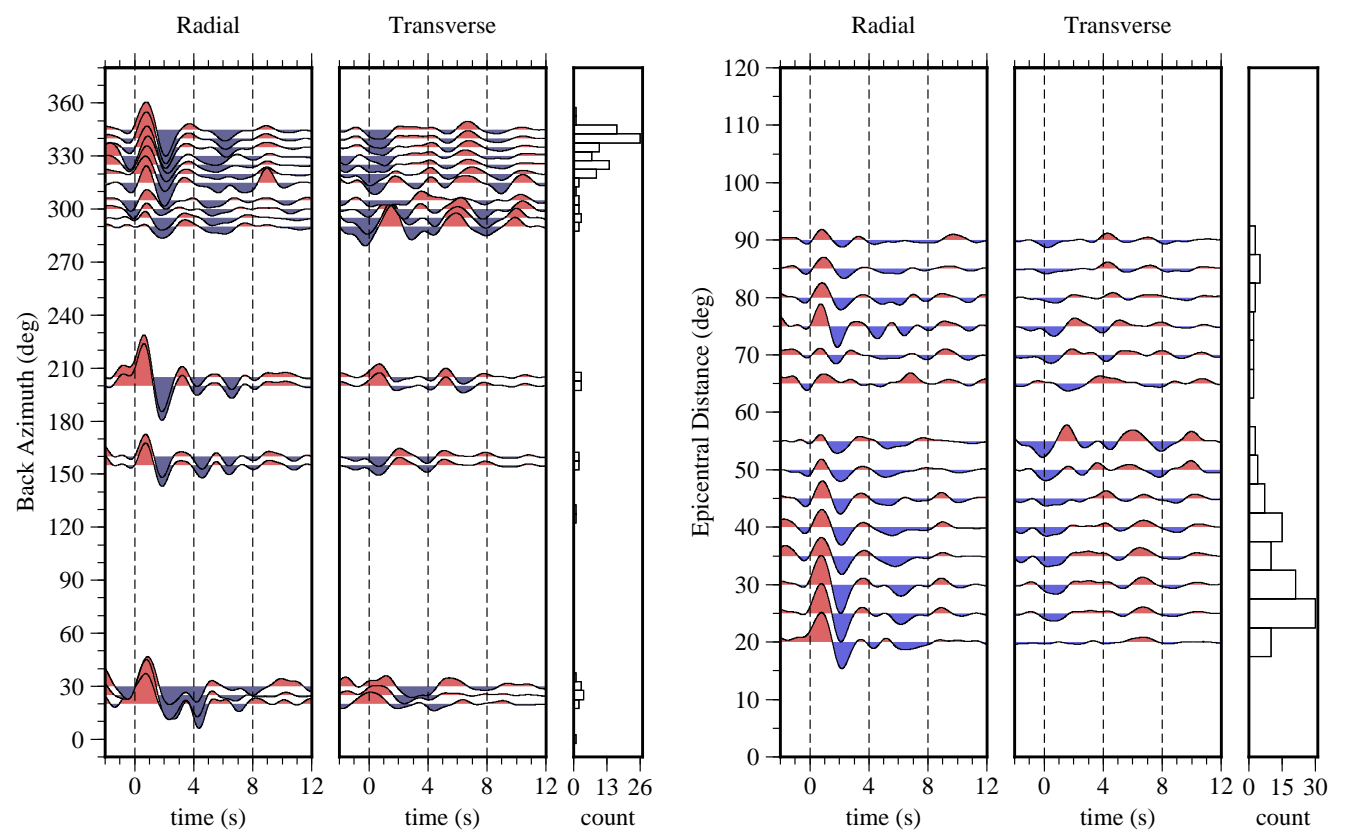

Figure D.5: Back Azimuth (left) and Epicentral Distnnce (right) plots of receiver functions from station MOT. Receiver functions were low-pass filtered $(1 \mathrm{~Hz})$ and binned every $10^{\circ}$ in back azimuth and $5^{\circ}$ in epicentral distance. Colours represent phase, red is positive, blue is negative.
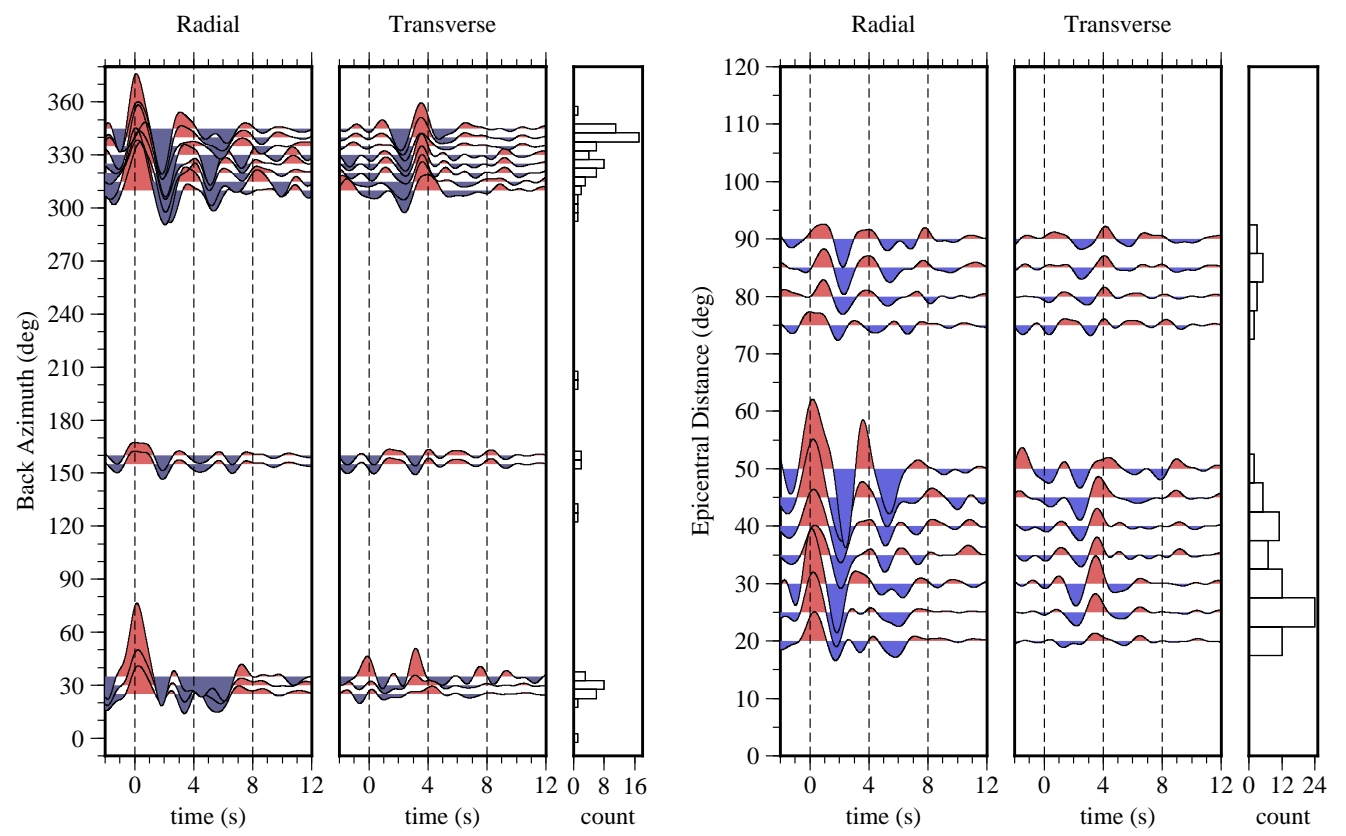

Figure D.6: Back azimuth (left) and epicentral distance (right) plots of receiver functions from station KUR. Receiver functions were low-pass filtered $(1 \mathrm{~Hz})$ and binned every $10^{\circ}$ in back azimuth and $5^{\circ}$ in epicentral distance. Colours represent phase, red is positive, blue is negative. 

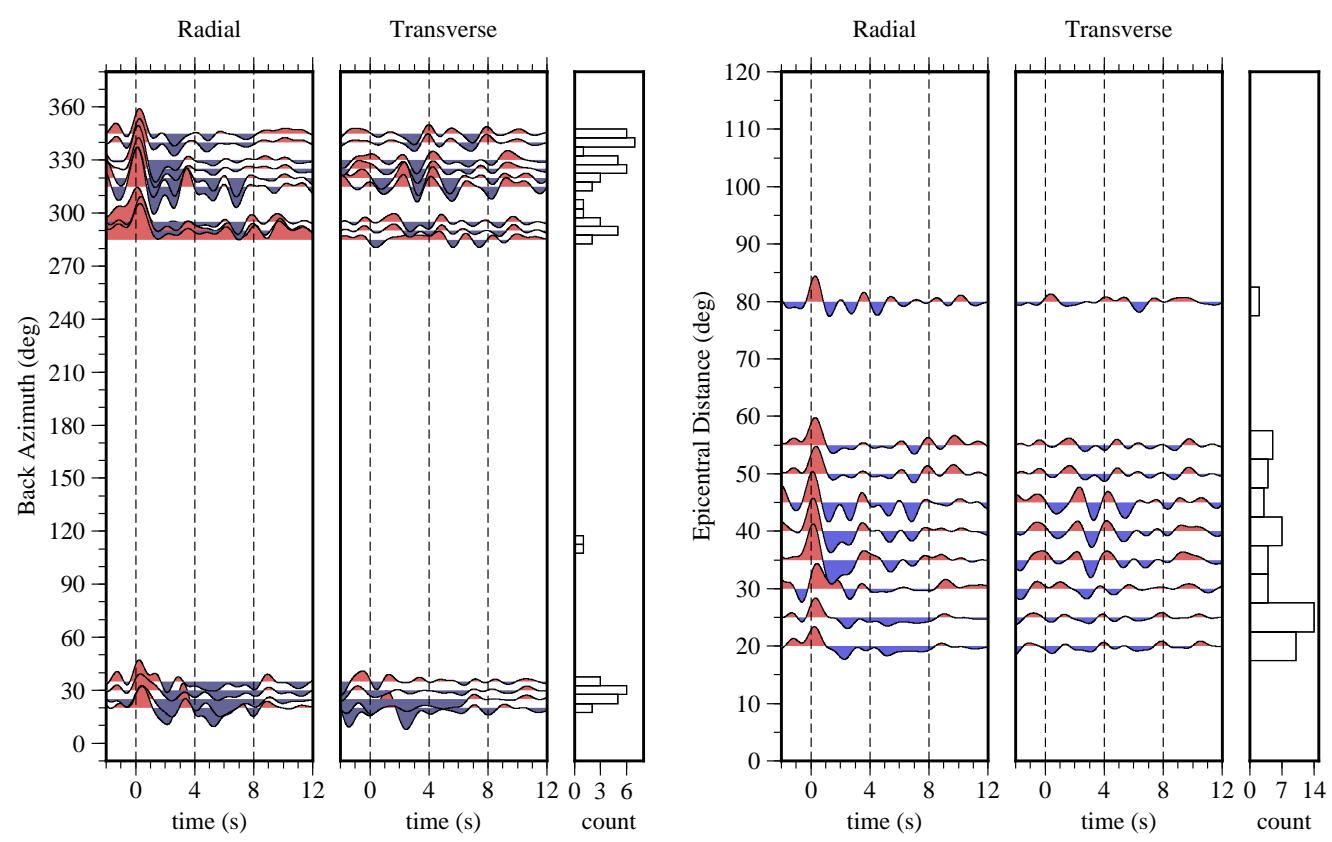

Figure D.7: Back azimuth (left) and epicentral distance (right) plots of receiver functions from station FUN. Receiver functions were low-pass filtered $(1 \mathrm{~Hz})$ and binned every $10^{\circ}$ in back azimuth and $5^{\circ}$ in epicentral distance. Colours represent phase, red is positive, blue is negative.
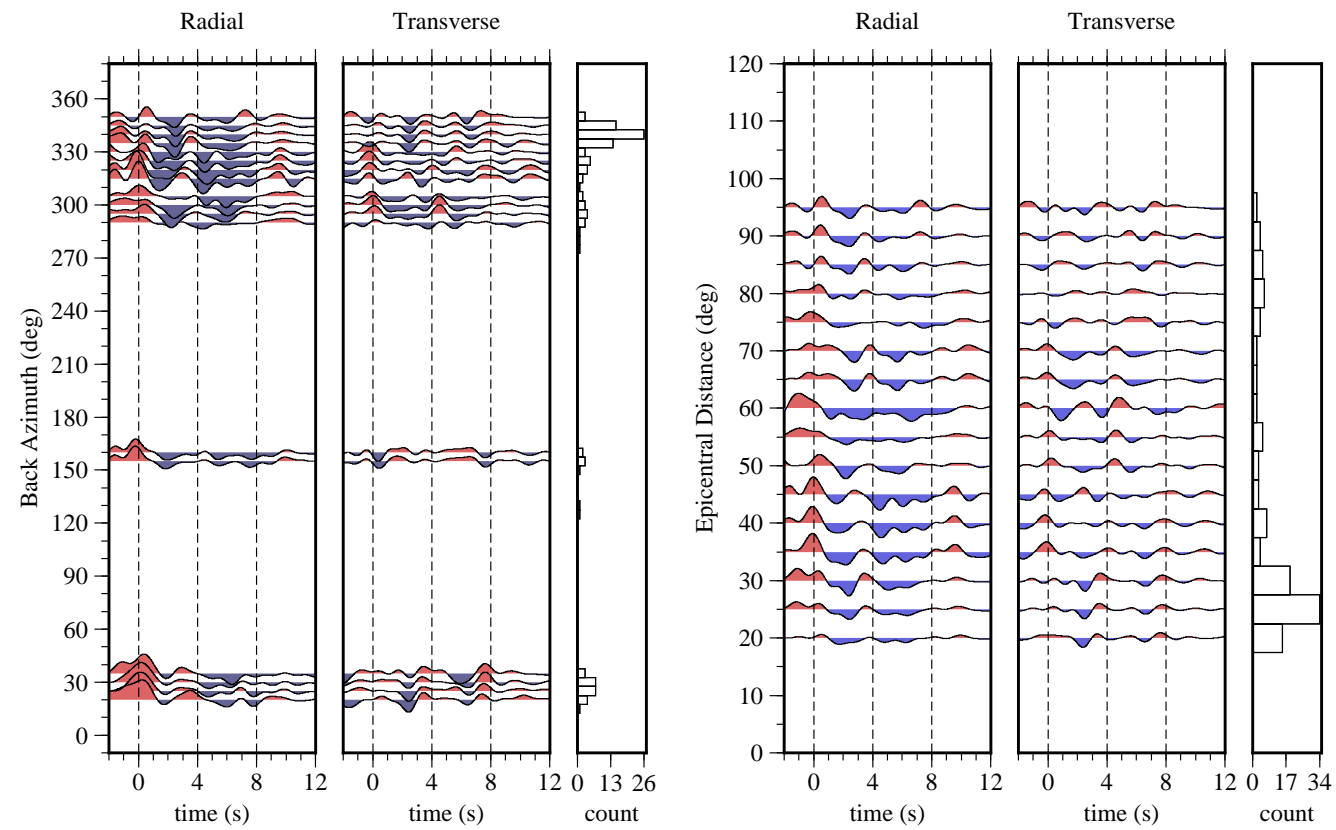

Figure D.8: Back azimuth (left) and epicentral distance (right) plots of receiver functions from station PEP. Receiver functions were low-pass filtered $(1 \mathrm{~Hz})$ and binned every $10^{\circ}$ in back azimuth and $5^{\circ}$ in epicentral distance. Colours represent phase, red is positive, blue is negative. 

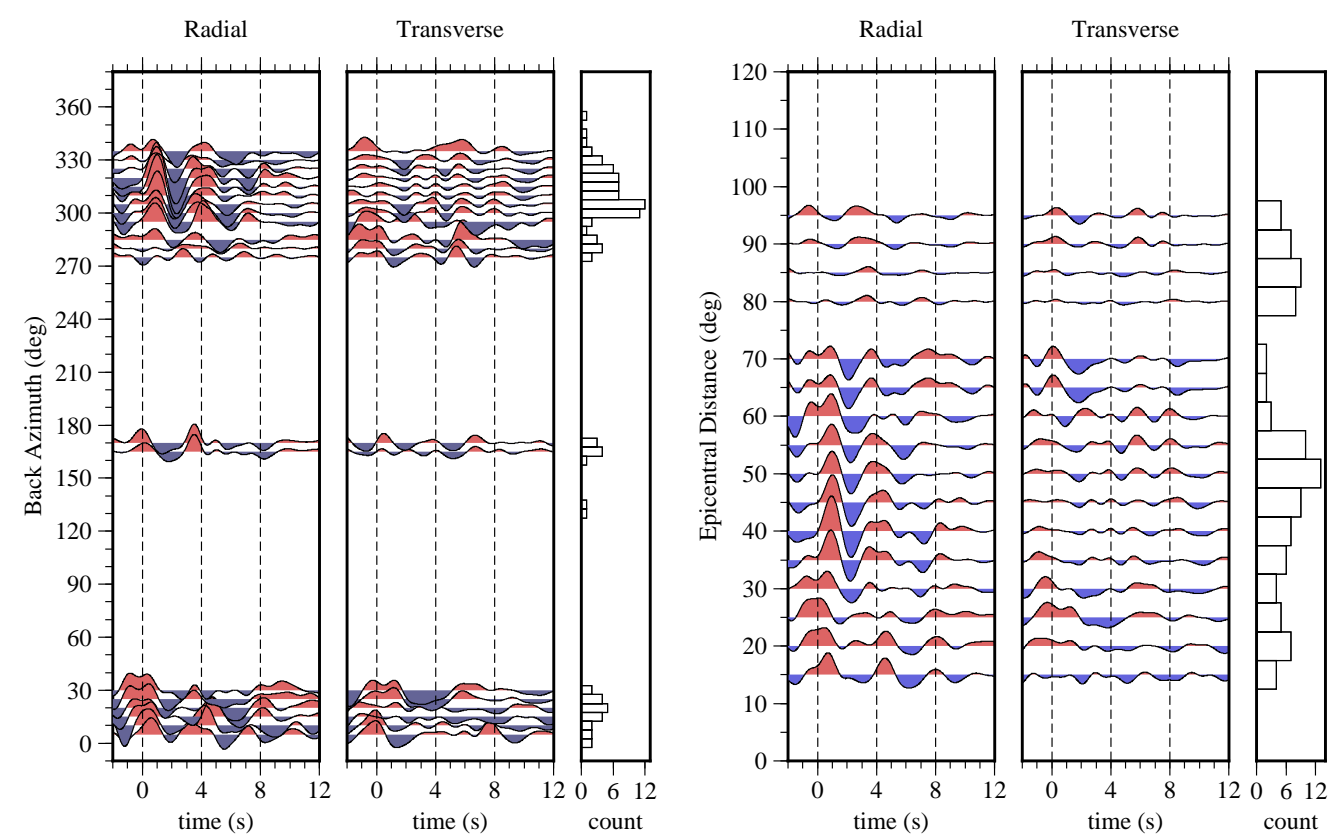

Figure D.9: Back azimuth (left) and epicentral distance (right) plots of receiver functions from station ERU. Receiver functions were low-pass filtered $(1 \mathrm{~Hz})$ and binned every $10^{\circ}$ in back azimuth and $5^{\circ}$ in epicentral distance. Colours represent phase, red is positive, blue is negative.
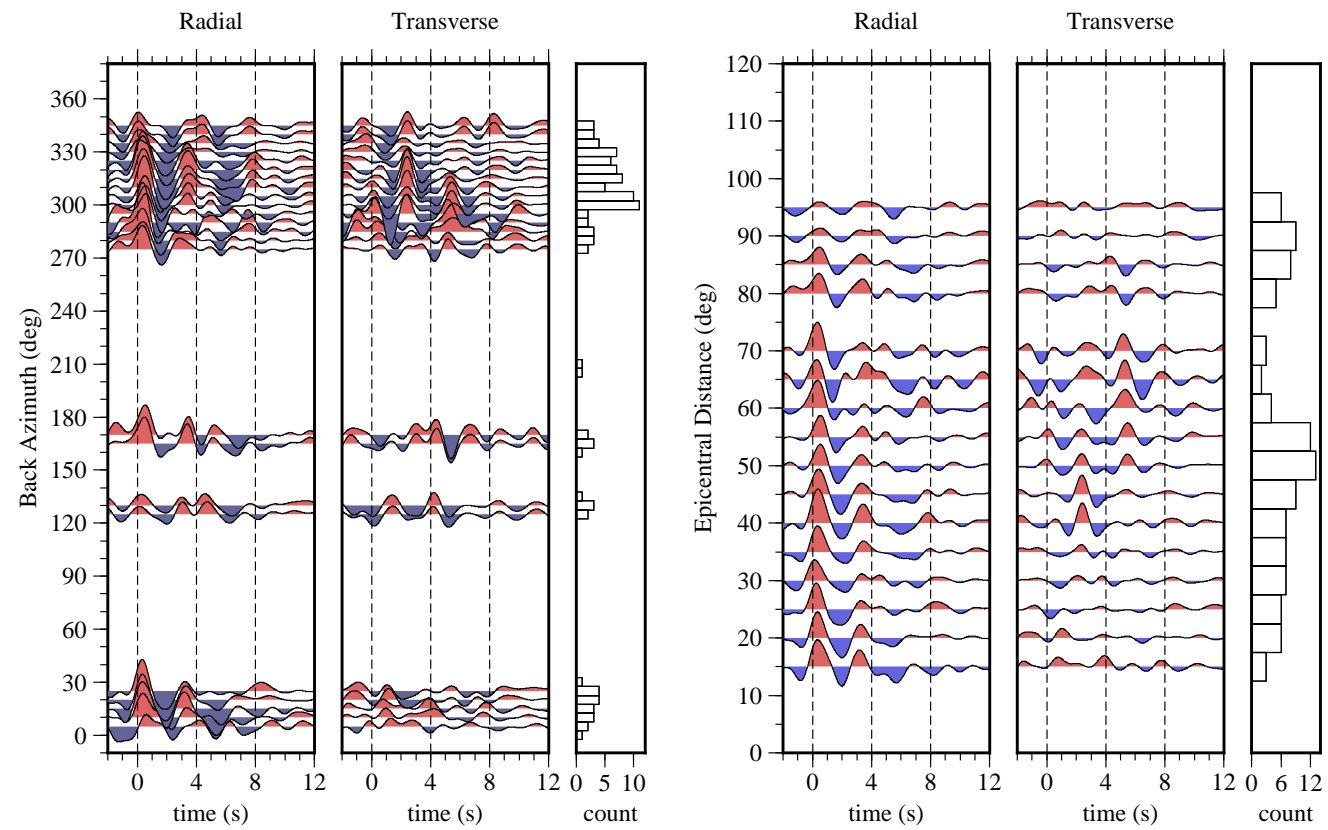

Figure D.10: Back azimuth (left) and epicentral distance (right) plots of receiver functions from station KAI. Receiver functions were low-pass filtered $(1 \mathrm{~Hz})$ and binned every $10^{\circ}$ in back azimuth and $5^{\circ}$ in epicentral distance. Colours represent phase, red is positive, blue is negative. 

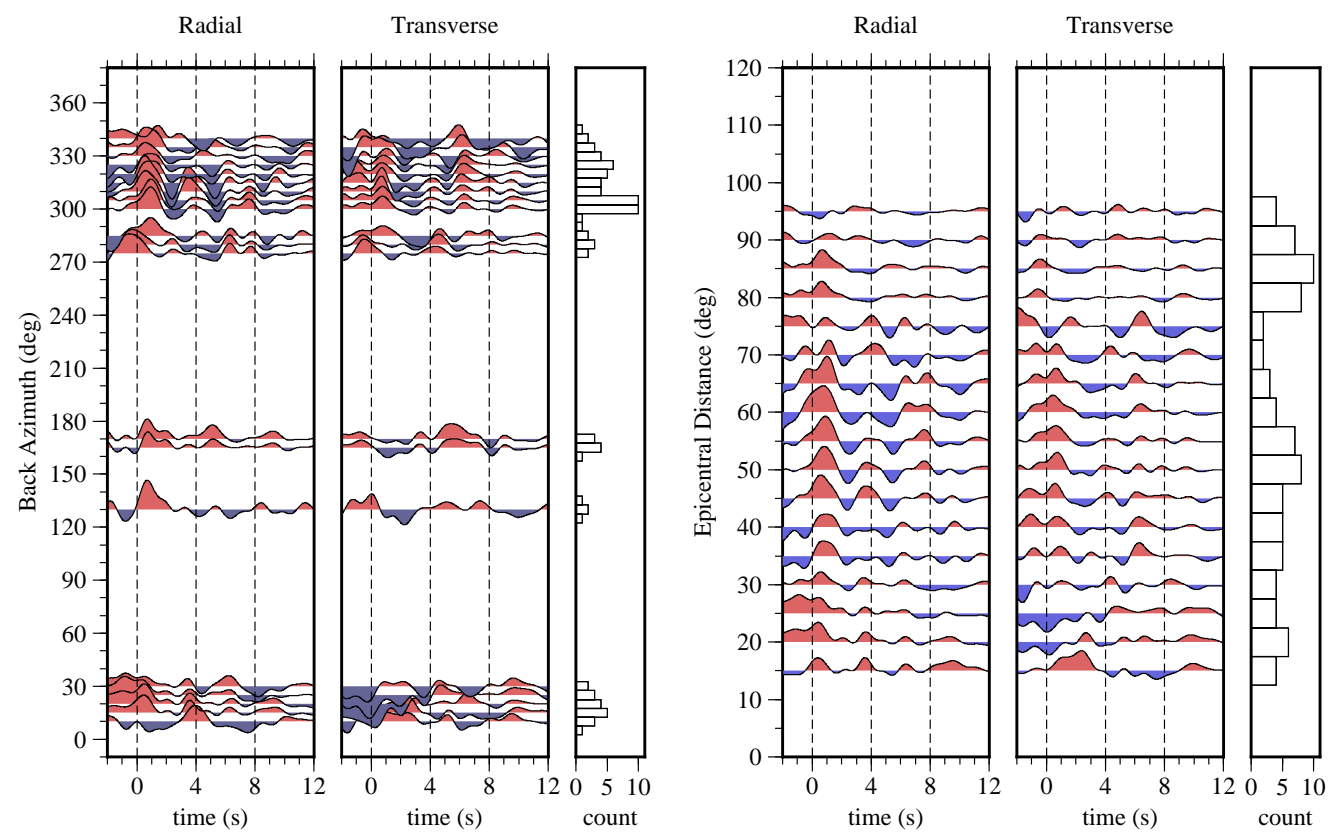

Figure D.11: Back azimuth (left) and epicentral distance (right) plots of receiver functions from station PAP. Receiver functions were low-pass filtered $(1 \mathrm{~Hz})$ and binned every $10^{\circ}$ in back azimuth and $5^{\circ}$ in epicentral distance. Colours represent phase, red is positive, blue is negative.
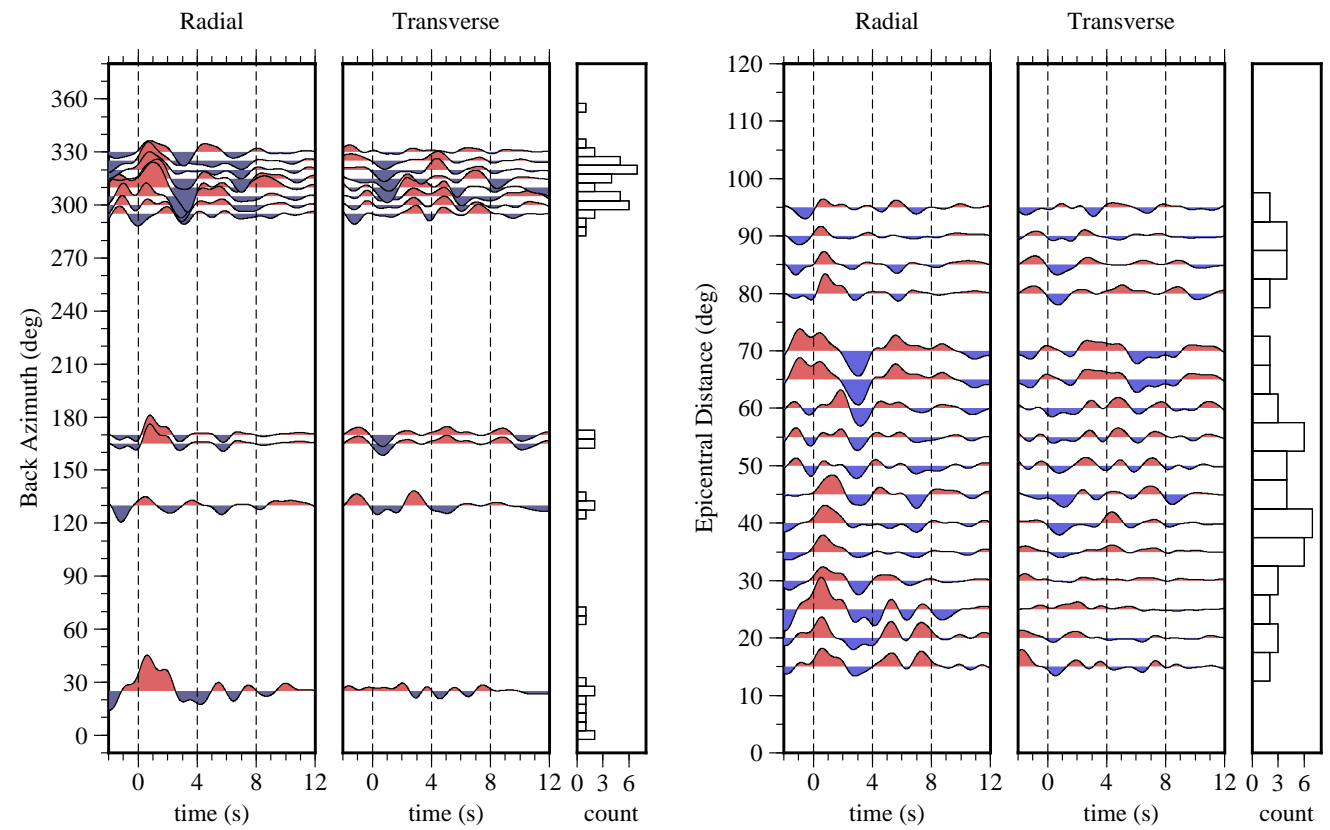

Figure D.12: Back azimuth (left) and epicentral distance (right) plots of receiver functions from station RAE. Receiver functions were low-pass filtered $(1 \mathrm{~Hz})$ and binned every $10^{\circ}$ in back azimuth and $5^{\circ}$ in epicentral distance. Colours represent phase, red is positive, blue is negative. 

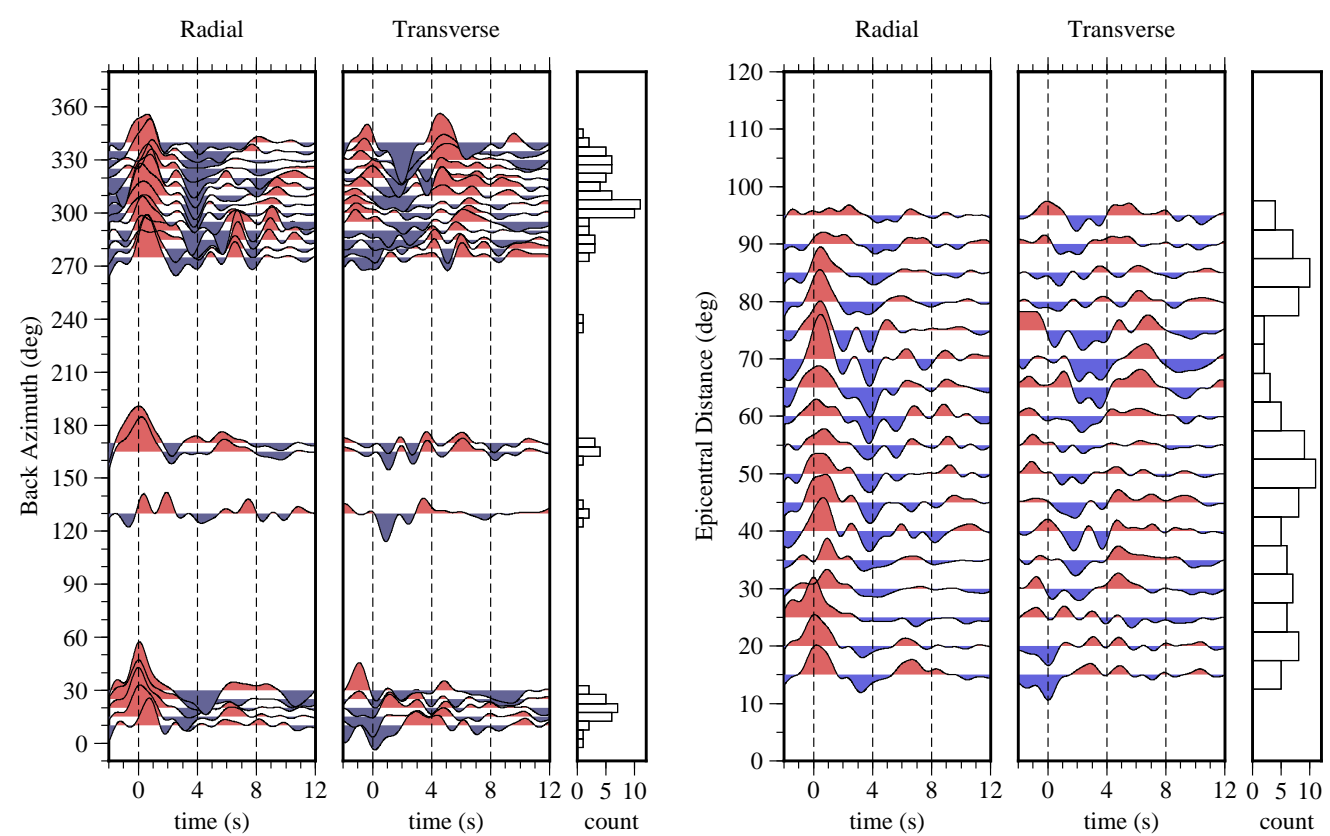

Figure D.13: Back azimuth (left) and epicentral distance (right) plots of receiver functions from station SUN. Receiver functions were low-pass filtered $(1 \mathrm{~Hz})$ and binned every $10^{\circ}$ in back azimuth and $5^{\circ}$ in epicentral distance. Colours represent phase, red is positive, blue is negative.
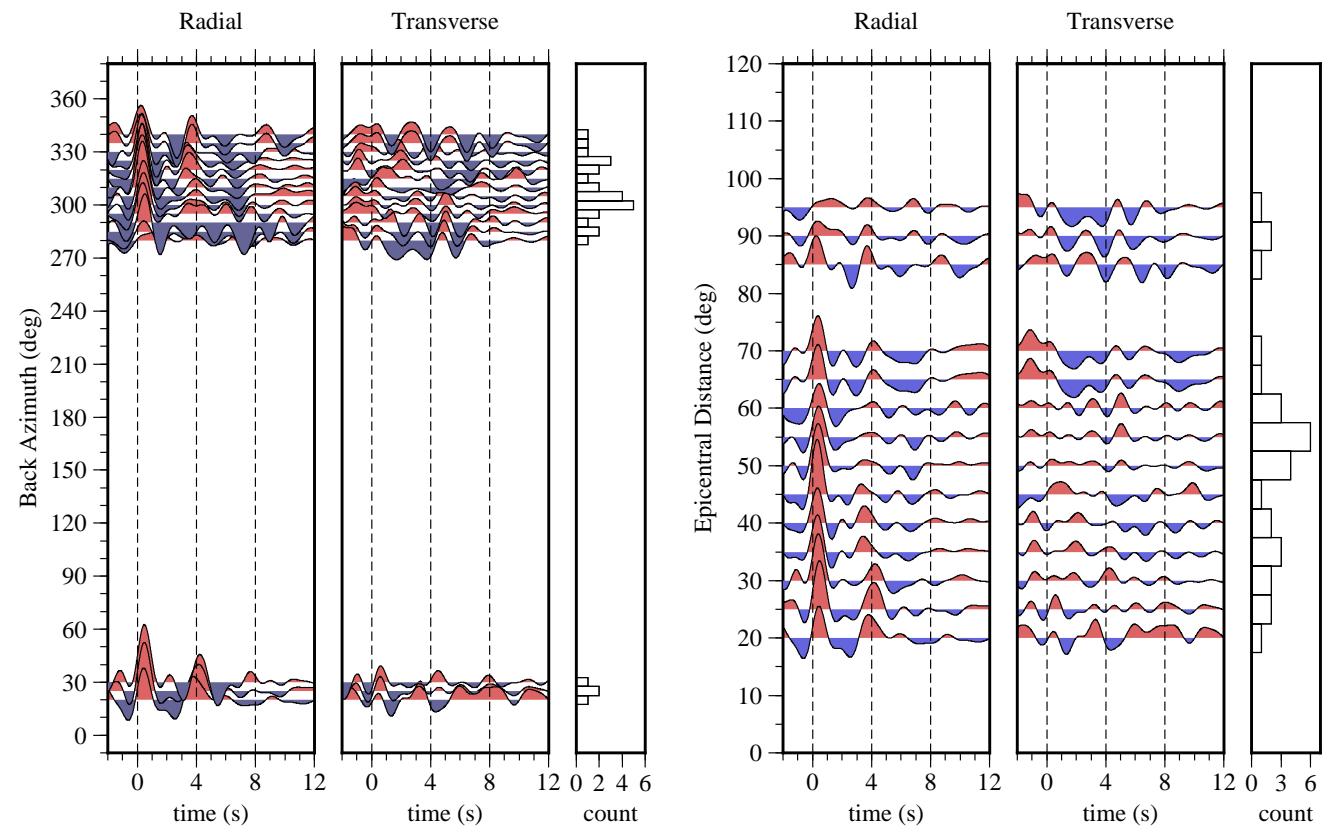

Figure D.14: Back azimuth (left) and epicentral distance (right) plots of receiver functions from station TUN. Receiver functions were low-pass filtered $(1 \mathrm{~Hz})$ and binned every $10^{\circ}$ in back azimuth and $5^{\circ}$ in epicentral distance. Colours represent phase, red is positive, blue is negative. 

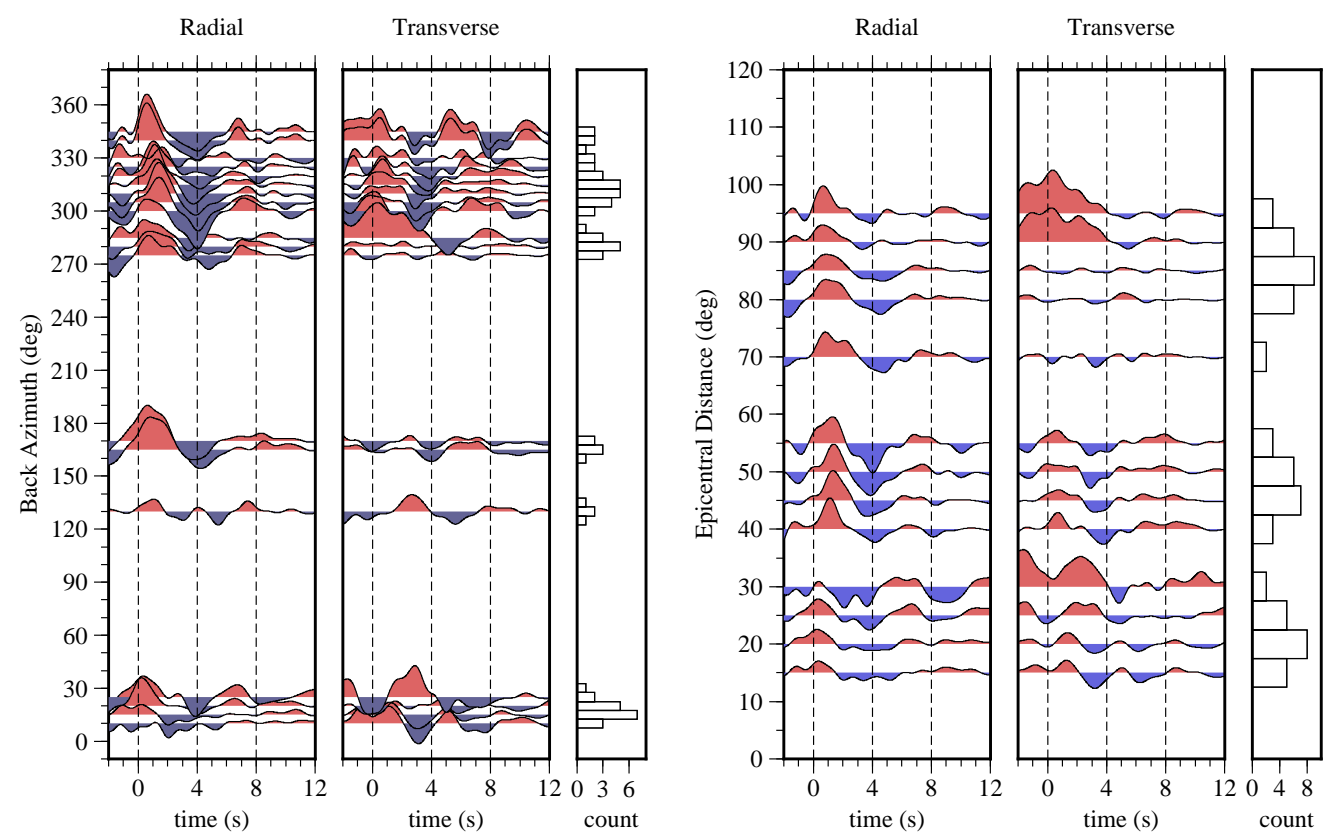

Figure D.15: Back azimuth (left) and epicentral distance (right) plots of receiver functions from station WRR. Receiver functions were low-pass filtered $(1 \mathrm{~Hz})$ and binned every $10^{\circ}$ in back azimuth and $5^{\circ}$ in epicentral distance. Colours represent phase, red is positive, blue is negative.
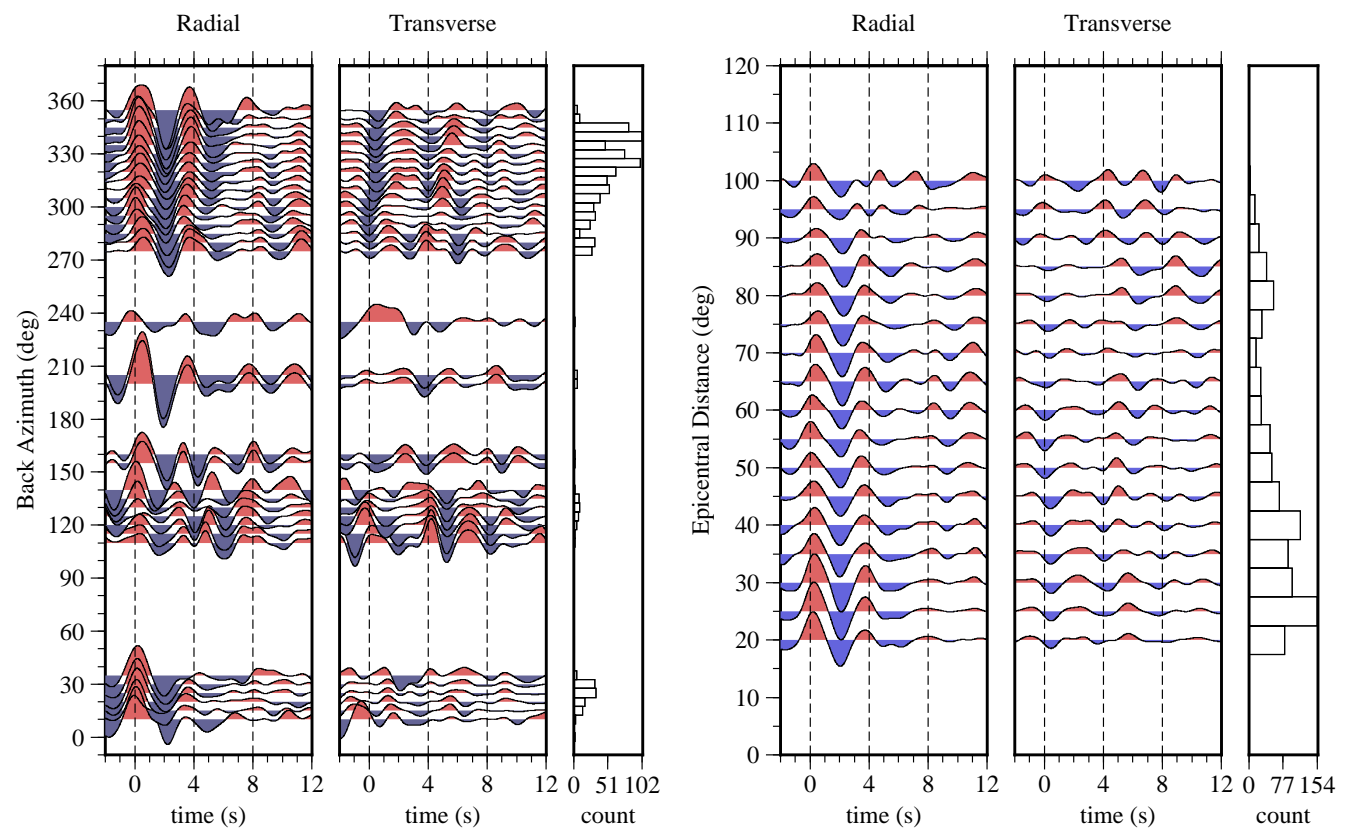

Figure D.16: Back azimuth (left) and epicentral distance (right) plots of receiver functions from station PKVZ. Receiver functions were low-pass filtered $(1 \mathrm{~Hz})$ and binned every $10^{\circ}$ in back azimuth and $5^{\circ}$ in epicentral distance. Colours represent phase, red is positive, blue is negative. 

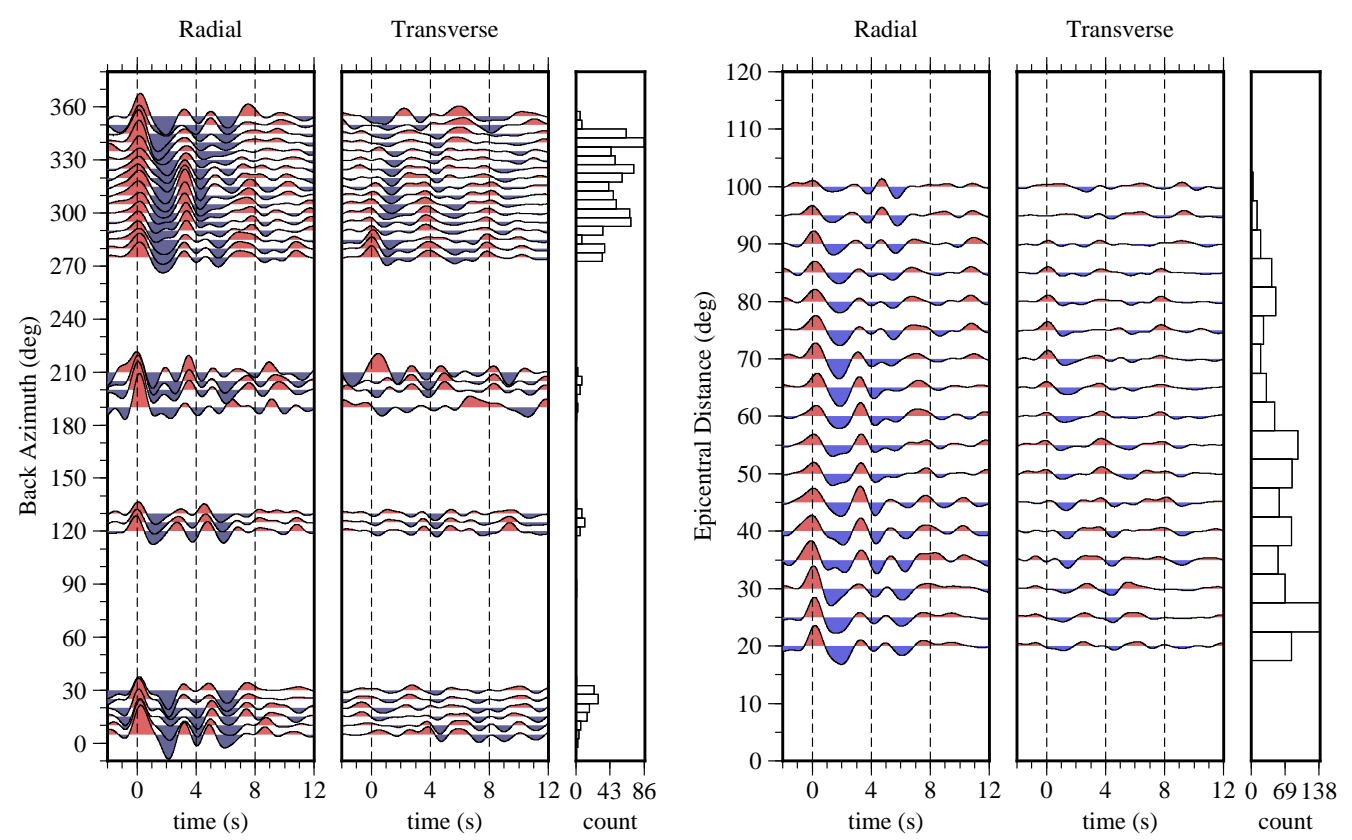

Figure D.17: Back azimuth (left) and epicentral distance (right) plots of receiver functions from station TWVZ. Receiver functions were low-pass filtered $(1 \mathrm{~Hz})$ and binned every $10^{\circ}$ in back azimuth and $5^{\circ}$ in epicentral distance. Colours represent phase, red is positive, blue is negative. 


\section{Appendix E}

\section{CCP stacking code}

This appendix contains the Matlab source code used for CCP stacking, and most importantly, detailed parameterisation.

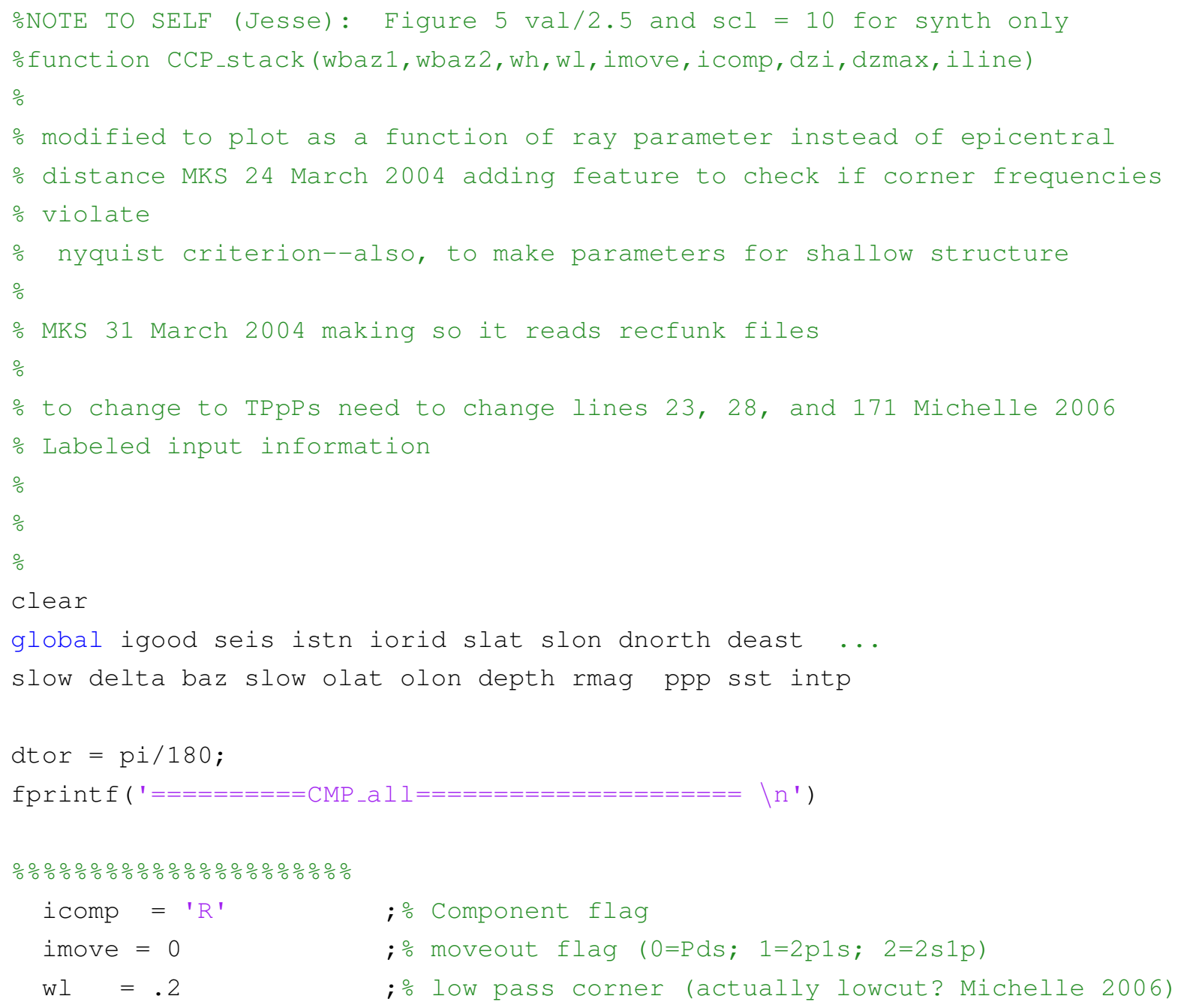




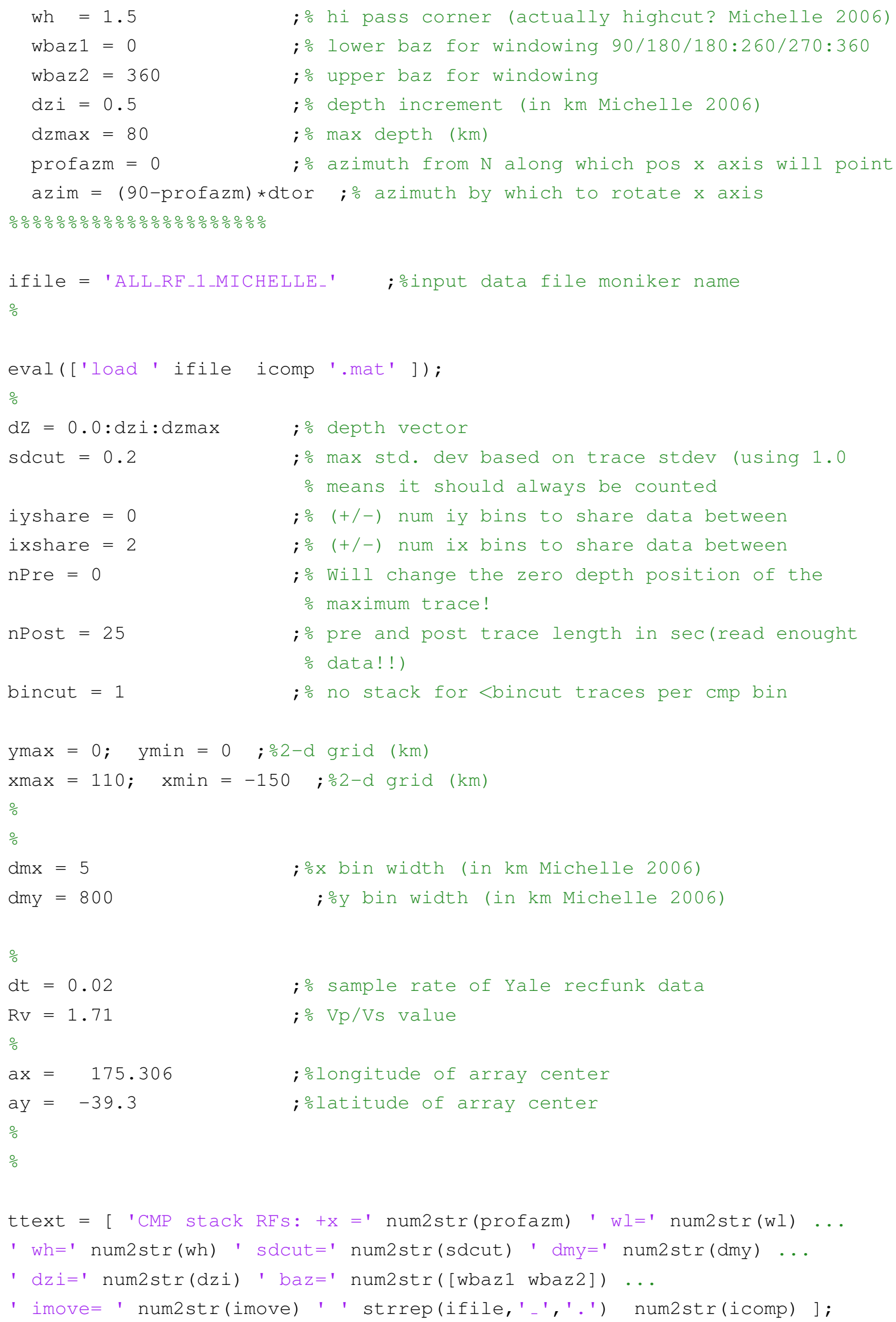




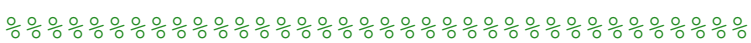

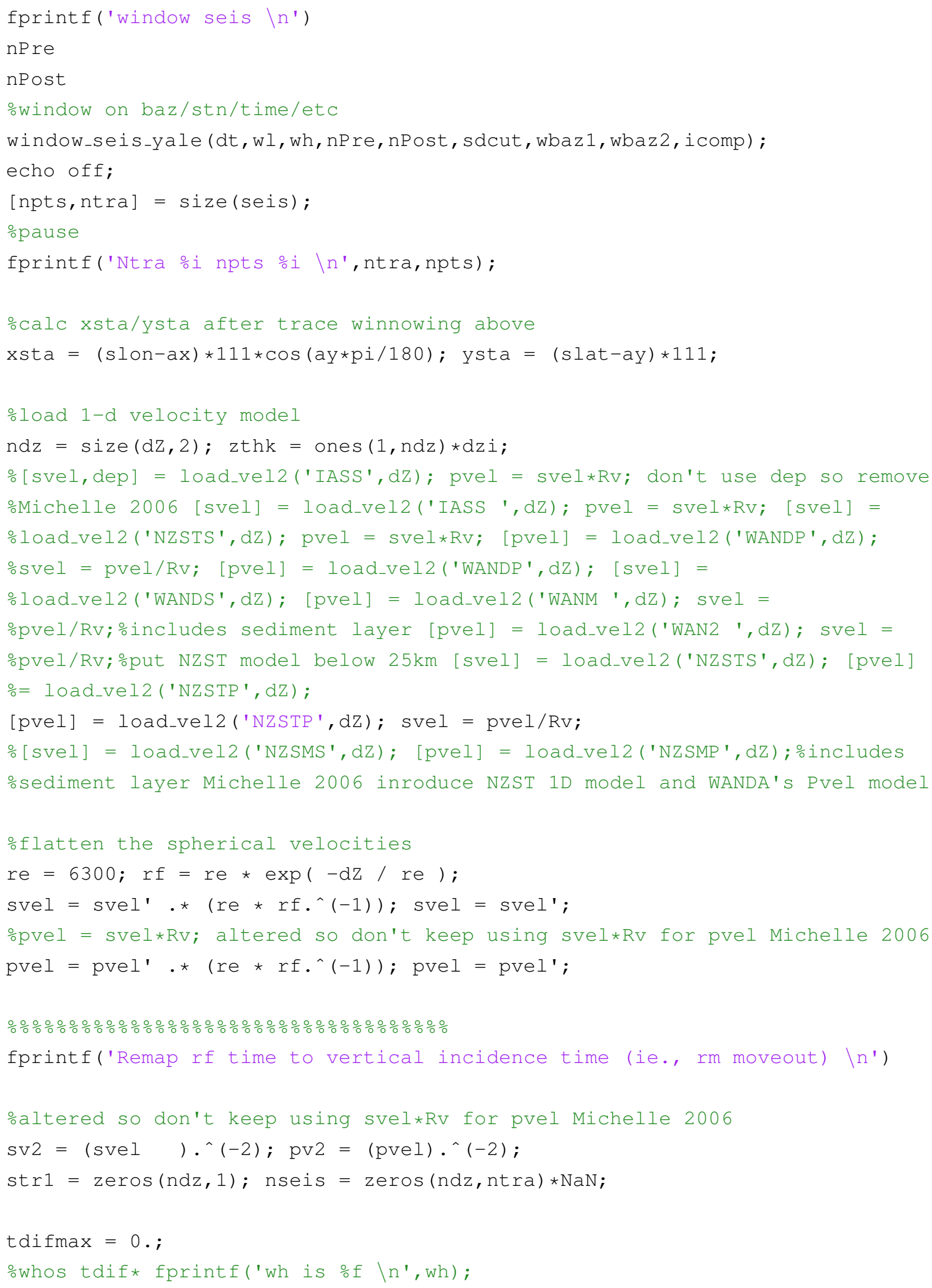




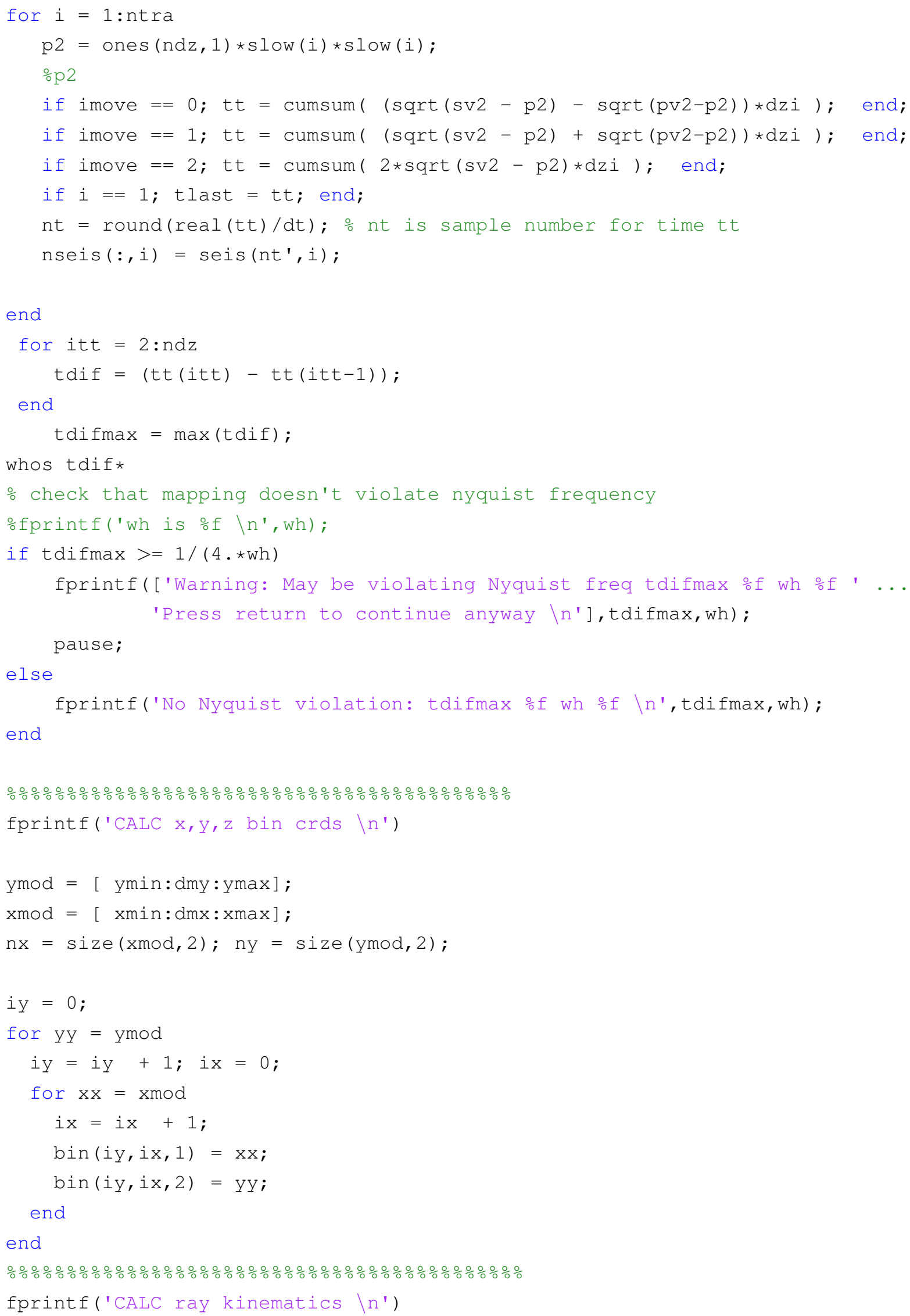




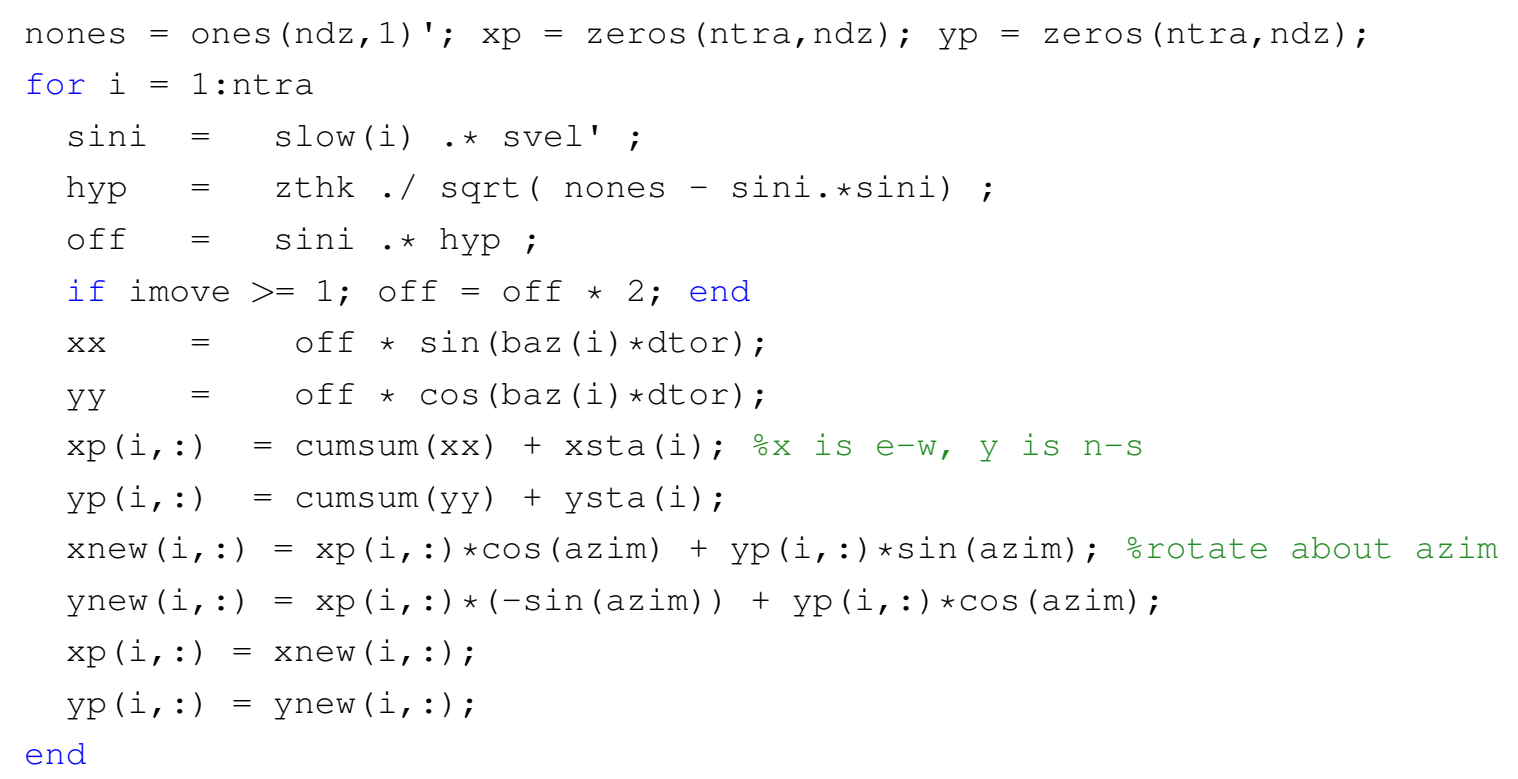

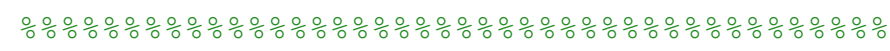

omap view plot of piercing pts

figure (1)

Clf

idep $=\operatorname{round}\left(\left[\mathrm{dzi} 3070\right.\right.$ ]/dzi); $\mathrm{cc}=\left[\mathrm{C}^{\prime} \mathrm{m}\right.$ ' $^{\prime}$ 'go'; 'rd'];

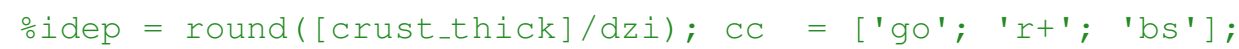

$i d e p * d z i$

for $i d=1:$ length $($ idep $)$

ipt $=i \operatorname{dep}(i d)$;

for $i=1:$ ntra

$\mathrm{p} 1=\operatorname{plot}(\mathrm{xp}(i, i p t), \operatorname{yp}(i, i p t), \mathrm{cc}(i \mathrm{~d},:))$; hold on

end

end

clear dst;

for $\mathrm{k}=1: \mathrm{ndz}$;

$\operatorname{dst}(:, \mathrm{k})=\operatorname{sqrt}\left(\mathrm{xp}(:, \mathrm{k}) \cdot{ }^{\wedge} 2+\mathrm{yp}(:, \mathrm{k}) \cdot{ }^{\wedge} 2+\mathrm{dz}(\mathrm{k}) \cdot{ }^{\wedge} 2\right) ;$

end

odst $(:, 700 / \mathrm{dzi})$

$\operatorname{an}=\operatorname{atan} 2(x p(:, n d z), y p(:, n d z)) * 180 / p i$

plot (bin $(:,:, 1)$, bin $(:,:, 2)$, 'r+'); hold on

o transform xsta and ysta into coordinates of plot again

\%xnew $(i,:)=\operatorname{xp}(i,:) \star \cos (\operatorname{azim})+y p(i,:) \star \sin (\operatorname{azim}) ;$ orotate about azim

oynew $(i,:)=\operatorname{xp}(i,:) *(-\sin (\operatorname{azim}))+\operatorname{yp}(i,:) \star \cos (\operatorname{azim}) ;$

xstanew $=$ xsta*cos $($ azim) + ysta*sin (azim);

ystanew $=x \operatorname{sta} *(-\sin (\operatorname{azim}))+$ ysta*cos $($ azim $) ;$

$\mathrm{p} 1=$ plot (xstanew, ystanew, '+k'); hold on

set (p1, 'linewidth', [3], 'markersize', [10])

set (gca, 'dataaspectratio', [ 11 1 1 ])

title([' Piercing Points sta=m* crust=go 70=rd ntra=' num2str(ntra) ])

xlabel(['distance (km) pos along az ', num2str(profazm)]); 


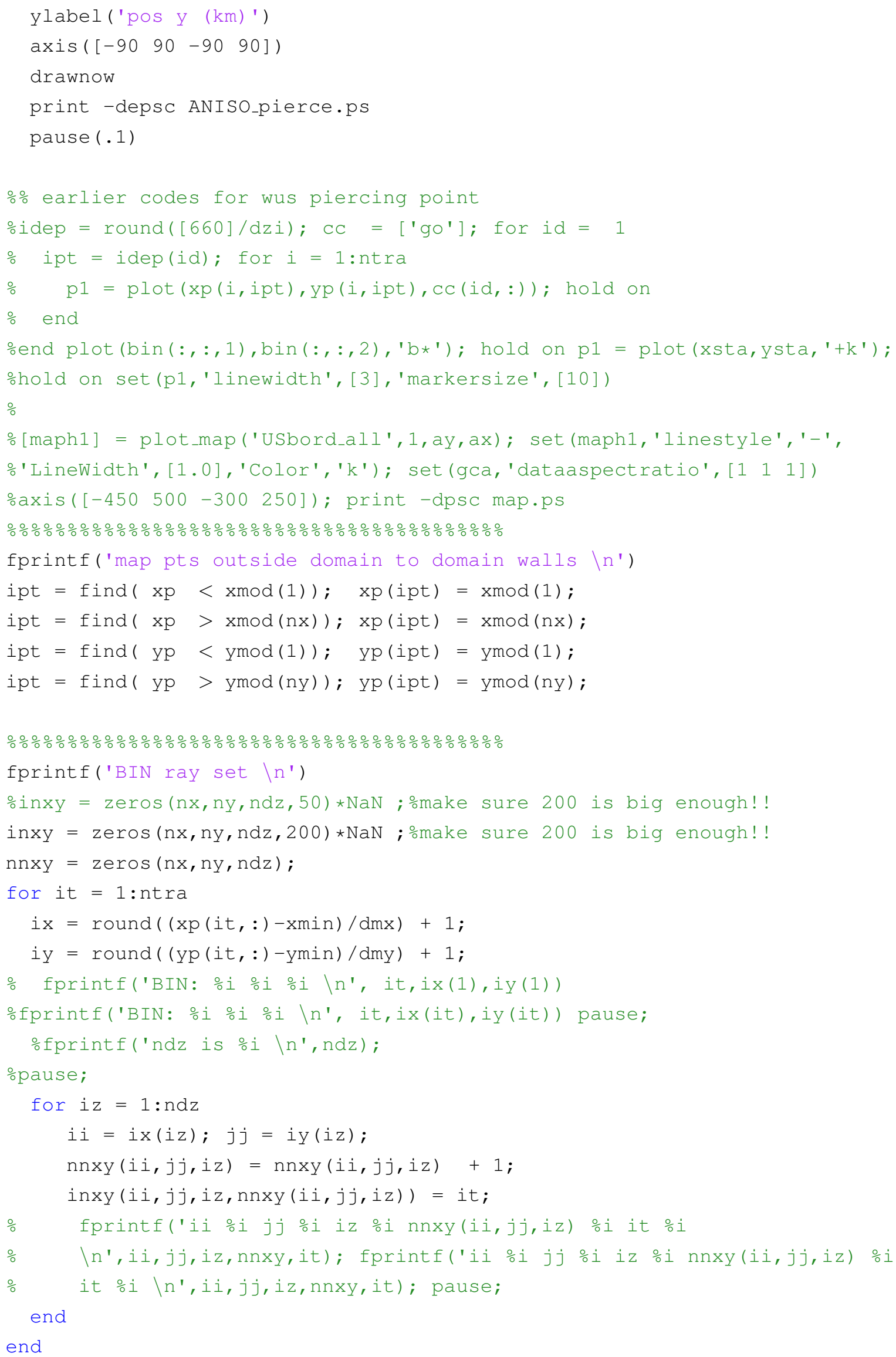




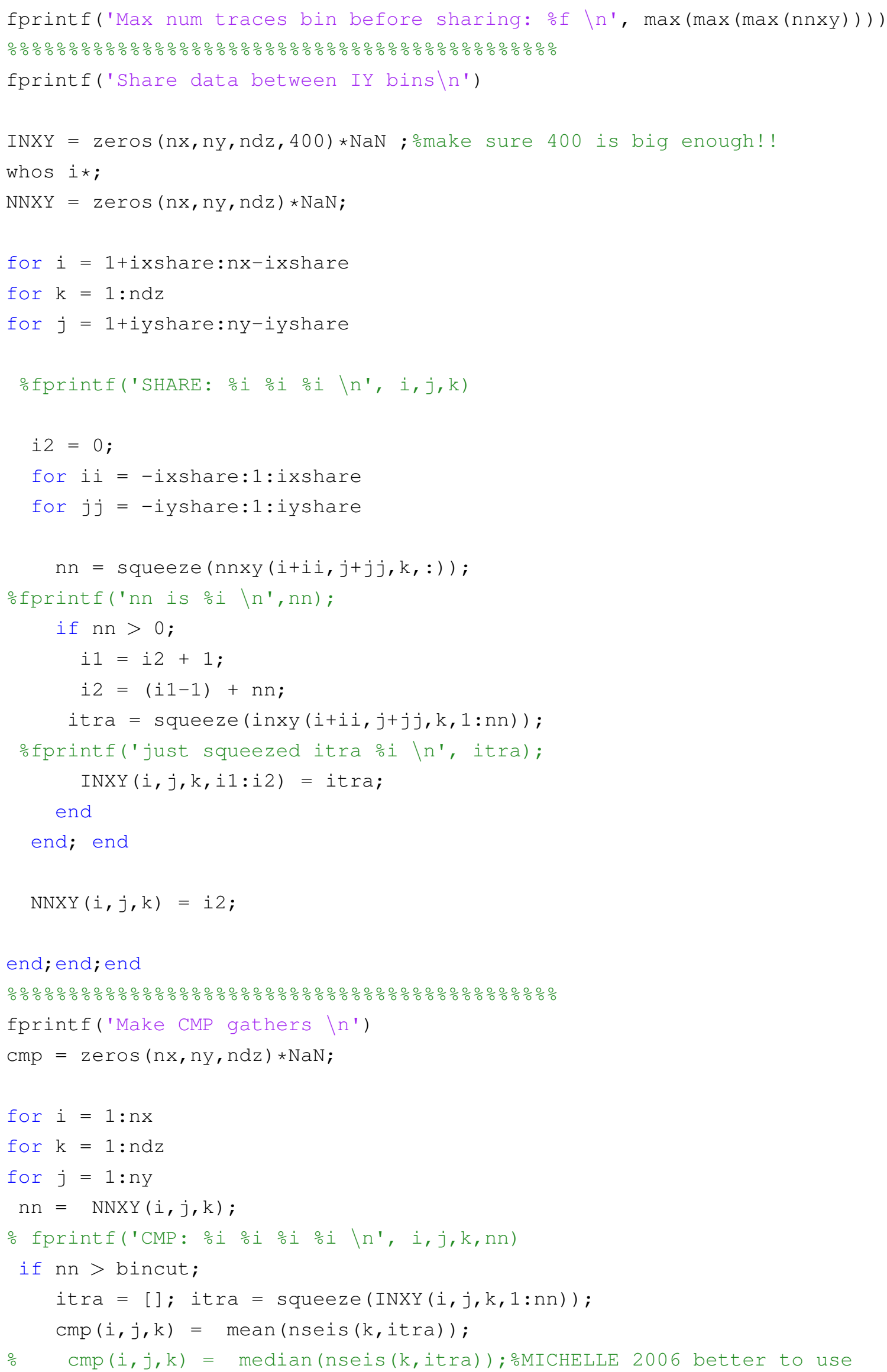




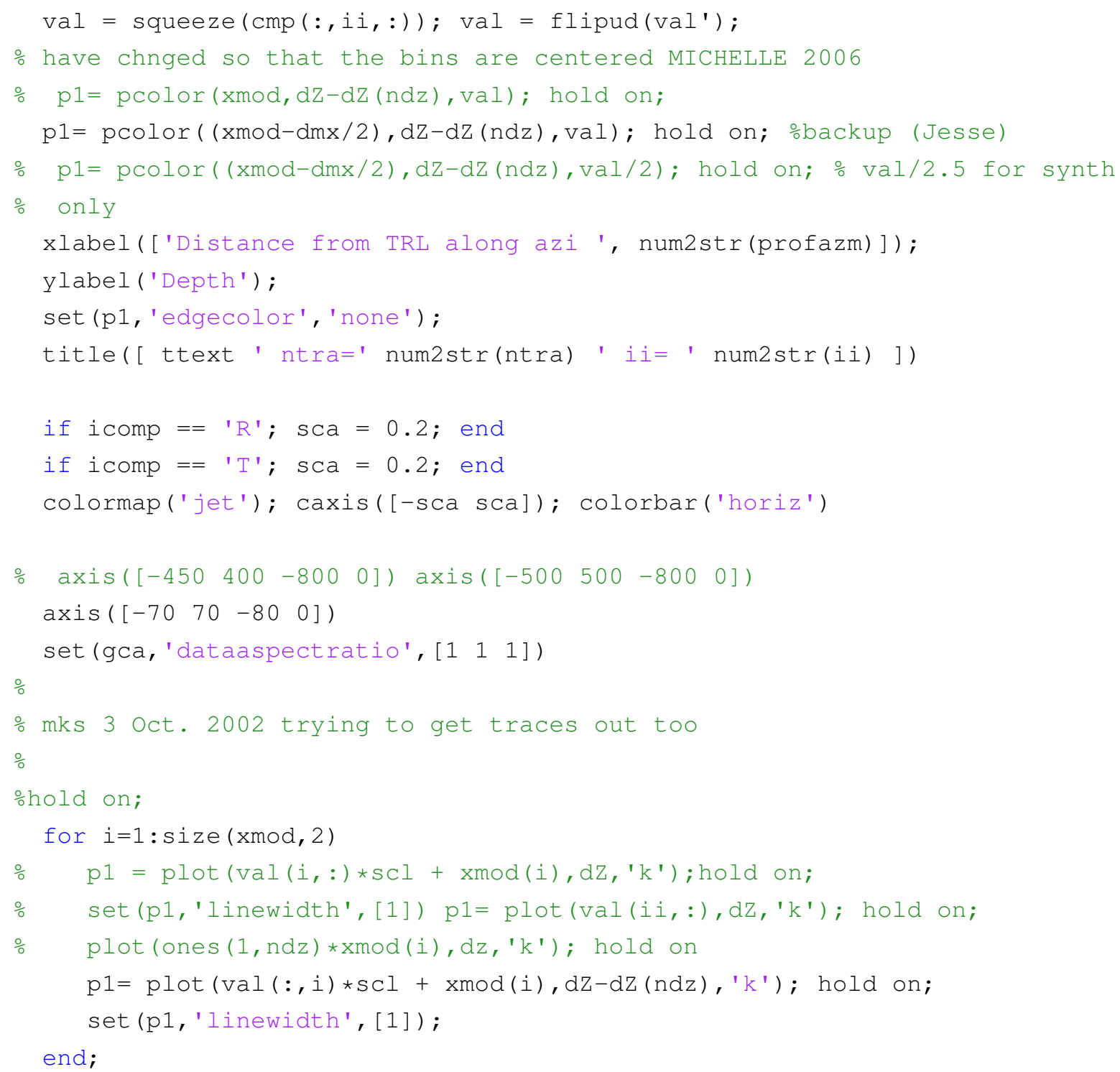




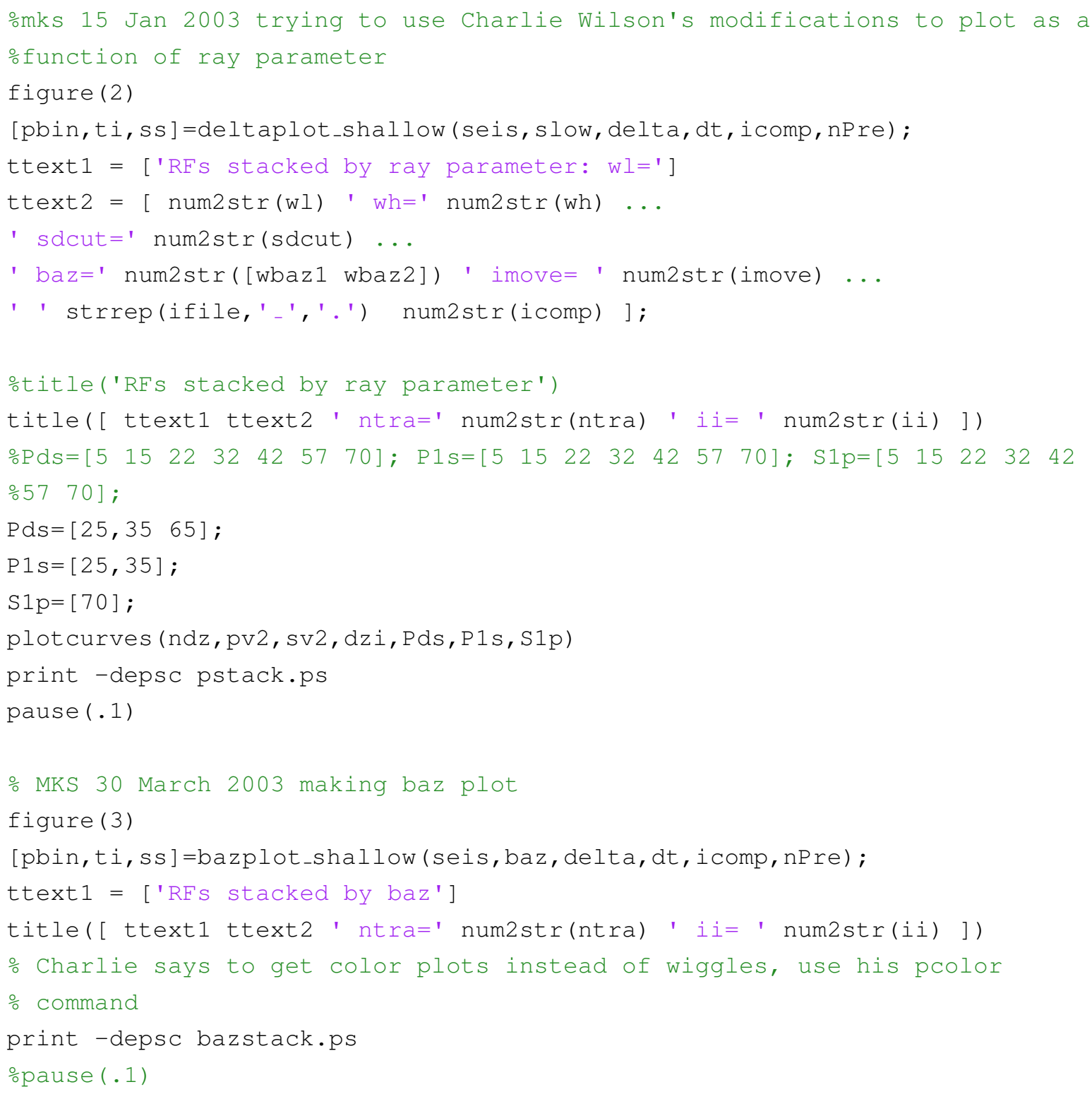




\section{Appendix F}

\section{SAHKE02 processing flows}

This appendix details the processing of marine line SAHKE02. Each processing step is presented in the order applied. Explanations and justifications are given where necessary. Visual illustrations for each step show its effect on the data.

\section{F.1 Geometry}

SAHKE02's acquisition parameters were found in the acquisition report as well as the observers logs, the key values are summarised in Table F.1. In Claritas, the MGEOM utility was able to define a basic marine geometry using just these values.

Table F.1: SAHKE02 acquisition parameters

\begin{tabular}{|l|l|}
\hline Parameter & Value \\
\hline Channels & 800 \\
Group Interval & $12.5 \mathrm{~m}$ \\
Near offset & $133 \mathrm{~m}$ \\
Far offset & $10,127.5 \mathrm{~m}$ \\
Shot spacing & $100 \mathrm{~m}$ \\
\hline
\end{tabular}

\begin{tabular}{|l|l|}
\hline Parameter & Value \\
\hline CMP spacing & $6.25 \mathrm{~m}$ \\
Streamer depth & $9 \mathrm{~m}$ \\
Source depth & $6 \mathrm{~m}$ \\
First shot ID & 1001 \\
Last shot ID & 2382 \\
\hline
\end{tabular}

\section{F.2 Gun/cable static correction}

The seismic airgun array and hydrophone cables are towed several metres beneath the surface of the ocean. A negative static correction needs to be applied to correct 


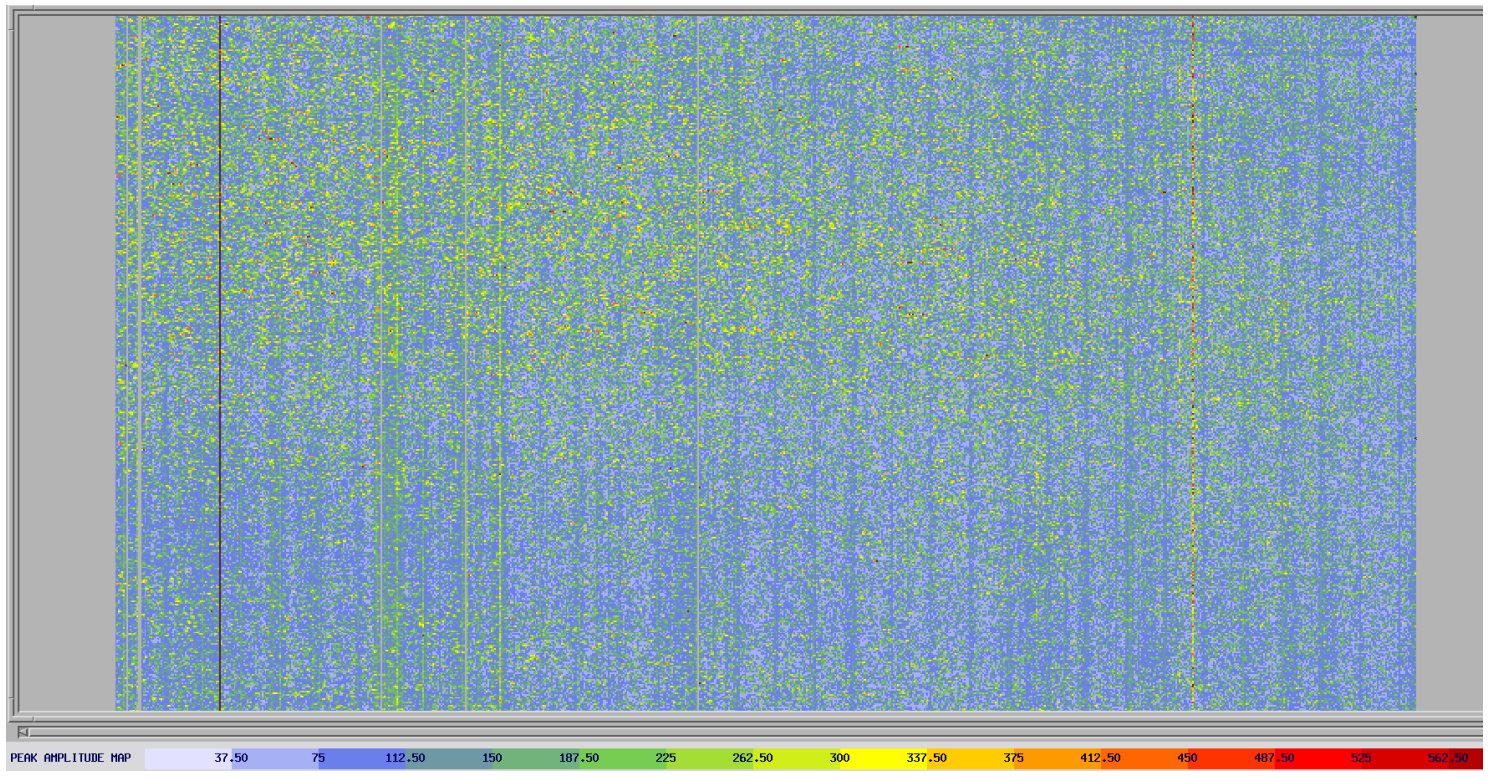

Figure F.1: Example of AREAL display for SAHKE02. The red vertical stripe is one of the channels muted.

for the delay time that would be expected between the tow depth and the surface of the ocean. For SAHKE02, a source-receiver static correction of $11 \mathrm{~ms}$ is necessary, i.e. $($ source + receiver depth)/water velocity $* 1000$ thus $(10+6) / 1500 * 1000=11 \mathrm{~ms}$. A $-10 \mathrm{~ms}$ bulk shift was applied to each trace, as this is the closest to the sampling rate.

\section{F.3 Trace QC}

Trace mutes were applied based on observer logs and QC report recommendations. Additional trace mutes were provided by using the Claritas AREAL module. In this module, peak amplitudes were calculated from the raw shot gathers between 10-12 s two-way traveltime. Peak values were autopicked and written to a trace edit file when they exceeded a threshold. This was later re-incorporated into the processing flow, with anomalously high peak amplitude traces being dropped. An example AREAL display of peak amplitudes is shown in Figure F.1. 


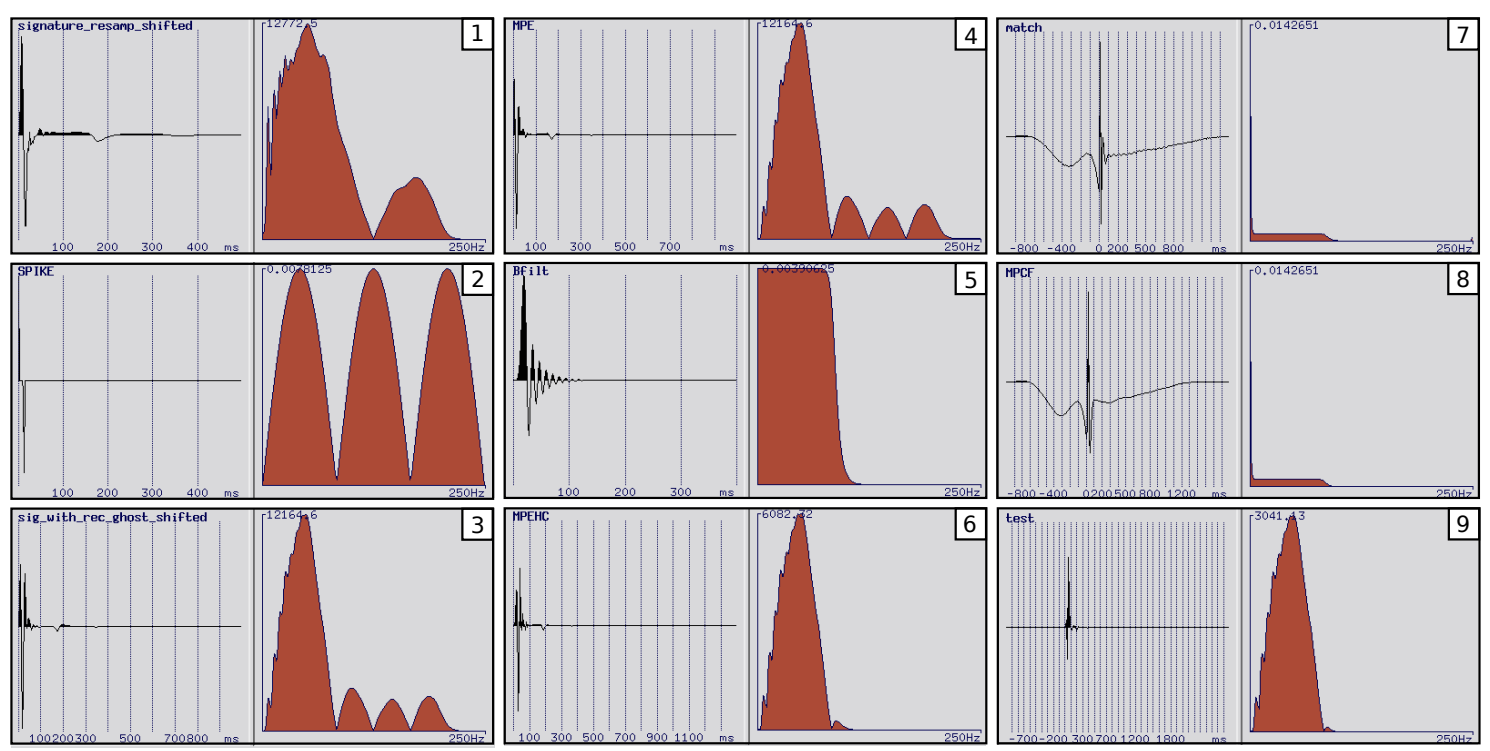

Figure F.2: : Creation and testing of signature deconvolution matching filter. (1) Supplied signature (shifted to origin and resampled to $2 \mathrm{~Hz}$ ); (2) a spike simulating the receiver ghost notch; (3) convolution of 1 and 2; (4) minimum-phase equivalent of 3; (5) butterworth highcut filter $80-120 \mathrm{~Hz}$ with 400 samples; (6) convolution of 4 and 5; (7) matching filter converting 3 to 6 ; (8) 7 convolved with 5 to remove high frequency effects; (9) test of 8 as matching filter. (8) was exported as stage1.wts to be used for signature deconvolution and as high-cut anti-alias filter preceding resampling from 2 to $4 \mathrm{~ms}$.

\section{F.4 Signature deconvolution and high-cut anti- alias filter}

Several processing steps such as butterworth bandpass filtering and Weiner deconvolution assume the input data to be minimum phase. However, most seismic data collected are mixed phase. A source signature deconvolution step can be incorporated to adjust the phase of the data to be closer to minimum-phase than it was before. For marine seismic data, this requires knowledge of the signature of the airgun array, as well as the effect of source and receiver ghosts. A modelled far-field source signature was provided by the contractor for the airgun array which incorporates a source ghost notch at $125 \mathrm{~Hz}(\sim 6 \mathrm{~m}$ source depth). However, no receiver ghost was incorporated. The Claritas WAVELET application was used to modify the modelled source signature and incorporate a receiver ghost (using receiver tow depth of 9 metres). The signature was further modified to incorporate highcut bandpass filter so that the data could be resampled from $2 \mathrm{~ms}$ to $4 \mathrm{~ms}$. The final product of the WAVELET application was a matching filter which when convolved with the input seismic data brings it closer to minimum phase, and ready for resampling. Creation and testing of the matching filter is illustrated in Figure F.2. 


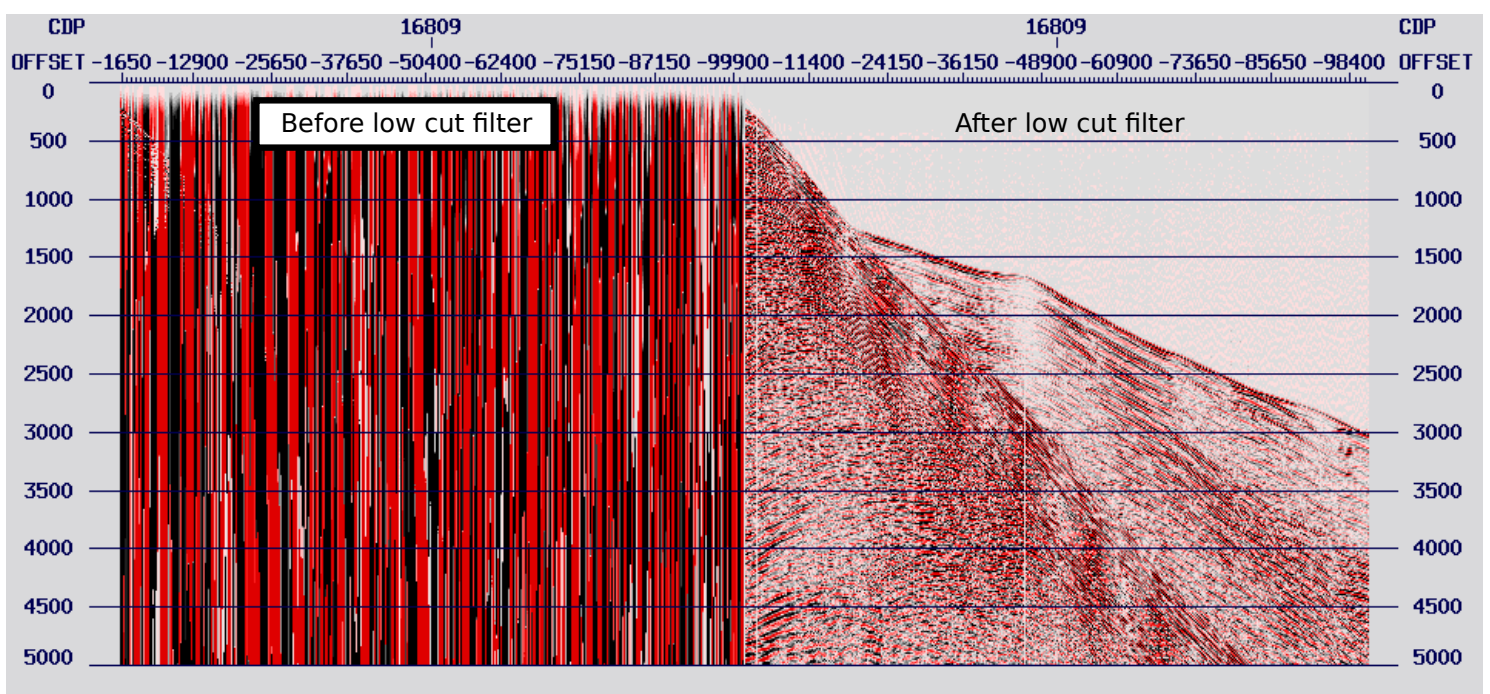

Figure F.3: Example of low cut frequency filter applied to SAHKE02 shot 1951. The filter was designed to remove low frequency noise.

\section{F.5 Low cut frequency filter}

The SAHKE02 raw shot records include no low-cut field filter, as a result lowfrequency noise contamination is evident on all shots, e.g. Figure F.3 (left). A low-cut minimum-phase butterworth filter of 7-10 Hz (amps: 0.10 .9 ) was applied across the whole survey, revealing previously hidden seismic data, e.g. Figure F.3 (right).

\section{F.6 Amplitude recovery}

Geometric spreading of the seismic wavefront results in a reduction of seismic amplitude with increasing traveltime. To recover amplitudes, a $\mathrm{T}^{2}$ (time-squared) type spherical divergence correction was applied across all data. Panel tests of various configurations for $\mathrm{T}^{2}, \mathrm{~T}^{2 *} \mathrm{~V}$ and $\mathrm{T}^{2 *} \mathrm{~V}^{2}$ were conducted, with a simple $\mathrm{T}^{2}$ power value of 2.2 providing the most even amplitude recovery (see Figure F.4). After TAR the magnitude of the amplitudes (right panel) is more balanced. A lack of amplitudes around $5 \mathrm{~s}$ is likely due to a lack of reflections in massive bedrock. 

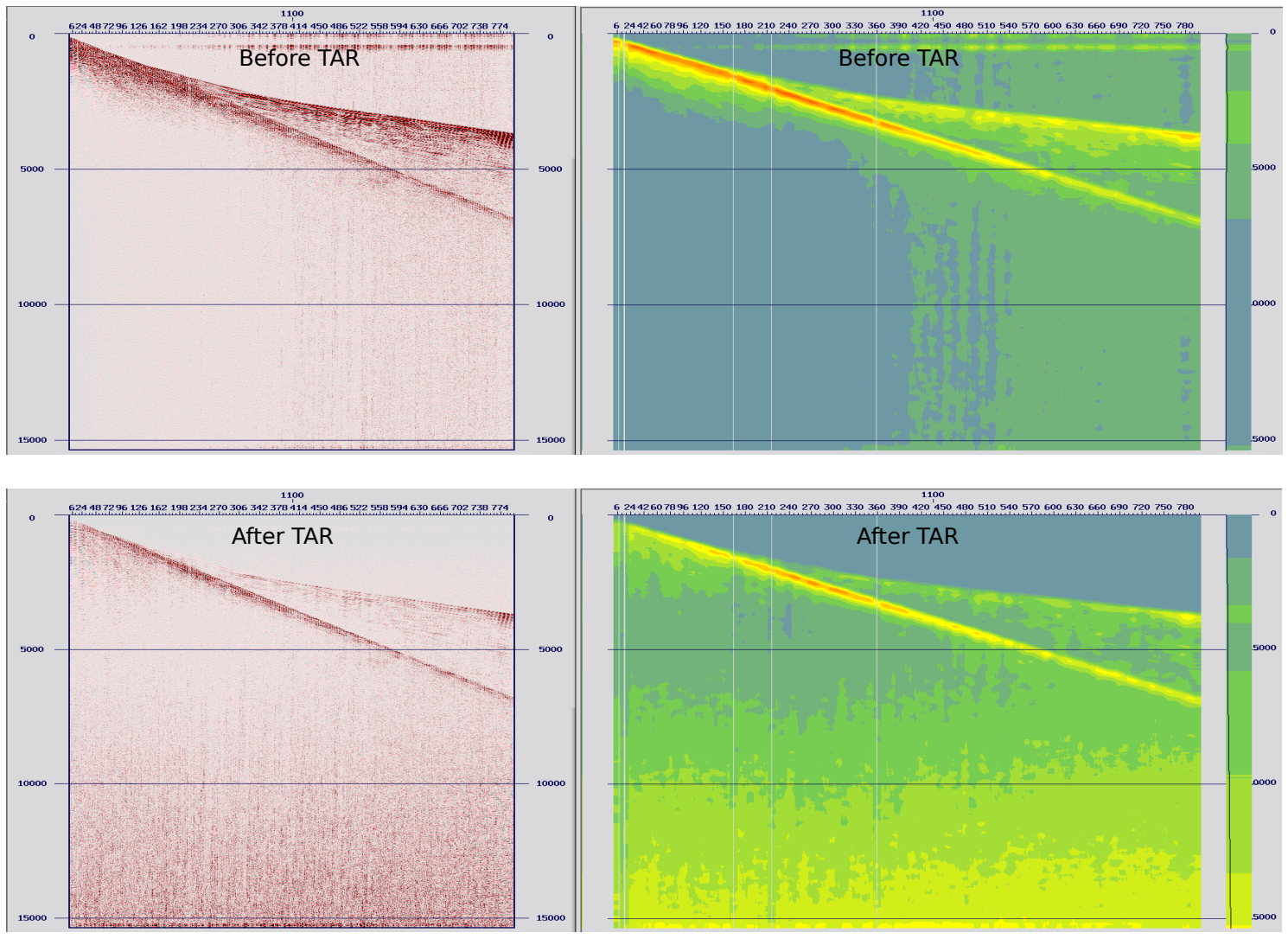

Figure F.4: Example of $\mathrm{T}^{2}$ type amplitude recovery applied to SAHKE02 shot 1100.

\section{F.7 Spatial anti-alias filter}

Spatial aliasing occurs because the hydrophones are spaced a fixed distance apart, and so the seismic wavefield is not sampled at every possible point. Spatial aliasing manifests as 'wrap around' in the FK domain, e.g. Figure F.5 (top right). In the time domain, it appears as steeply-dipping, linear, jagged signal which gets in the way of real signal, e.g. Figure F.5 (top left). The aliased signal itself cannot be recovered, and therefore must be removed. A spatial anti-alias filter was designed to attenuate wrap-around effects using a combination of trace interpolation and $\mathrm{K}$ filter (see Figure F.5, bottom). Note the reduction of aliased energy indicated by the dashed circle. The steps applied are as follows:

1) Offset regularisation $12.5 \mathrm{~m}$ to $6.25 \mathrm{~m}$ receiver spacing.

2) K filter (0.45 with a 0.05 taper.)

3) Offset regularisation $6.25 \mathrm{~m}$ to $12.5 \mathrm{~m}$ receiver spacing. 

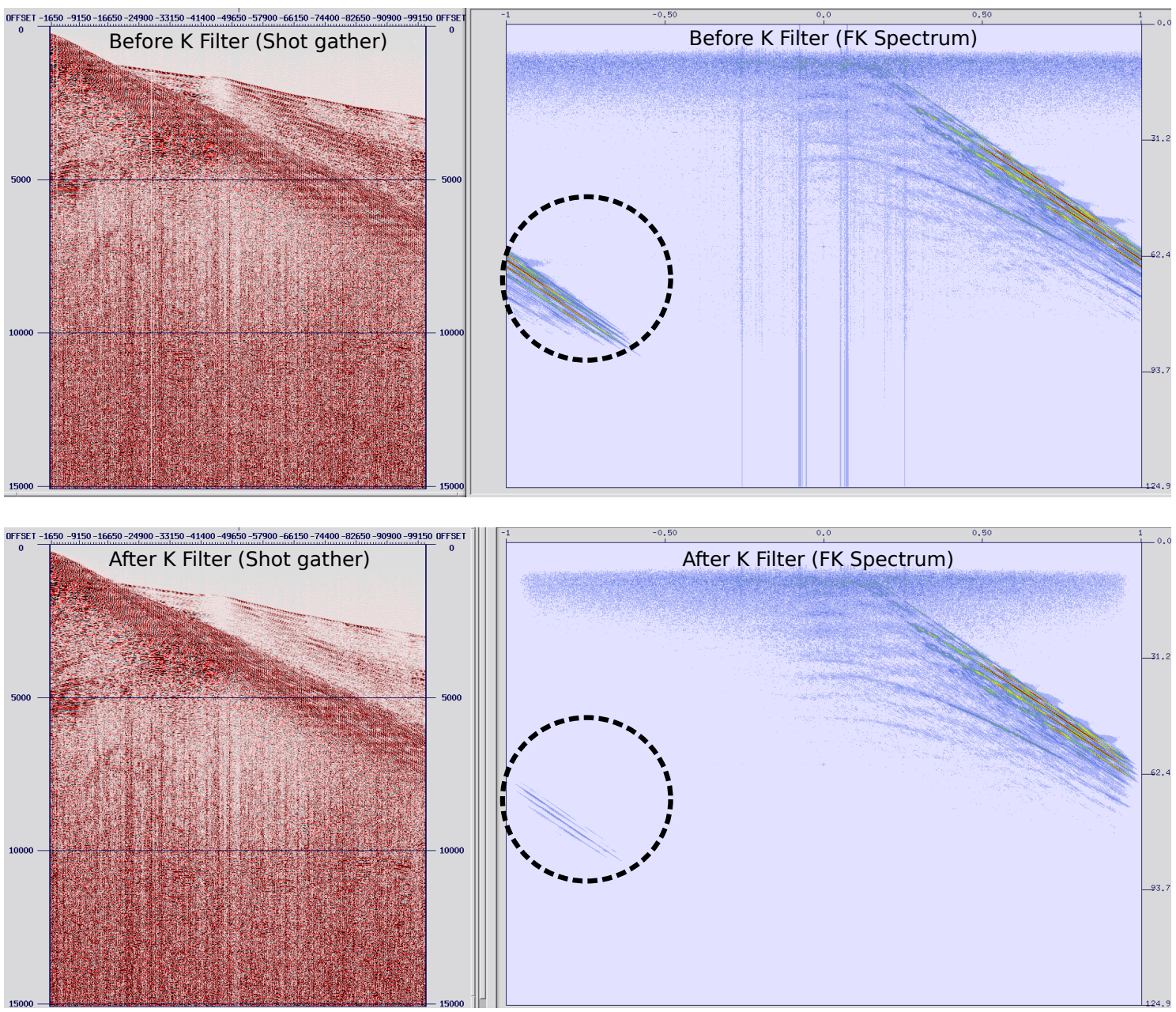

Figure F.5: K filter test for shot 1951. Top: no K filter applied. Bottom: after K filter. The left panel is the shot gather, and the right panel is its FK spectrum. 


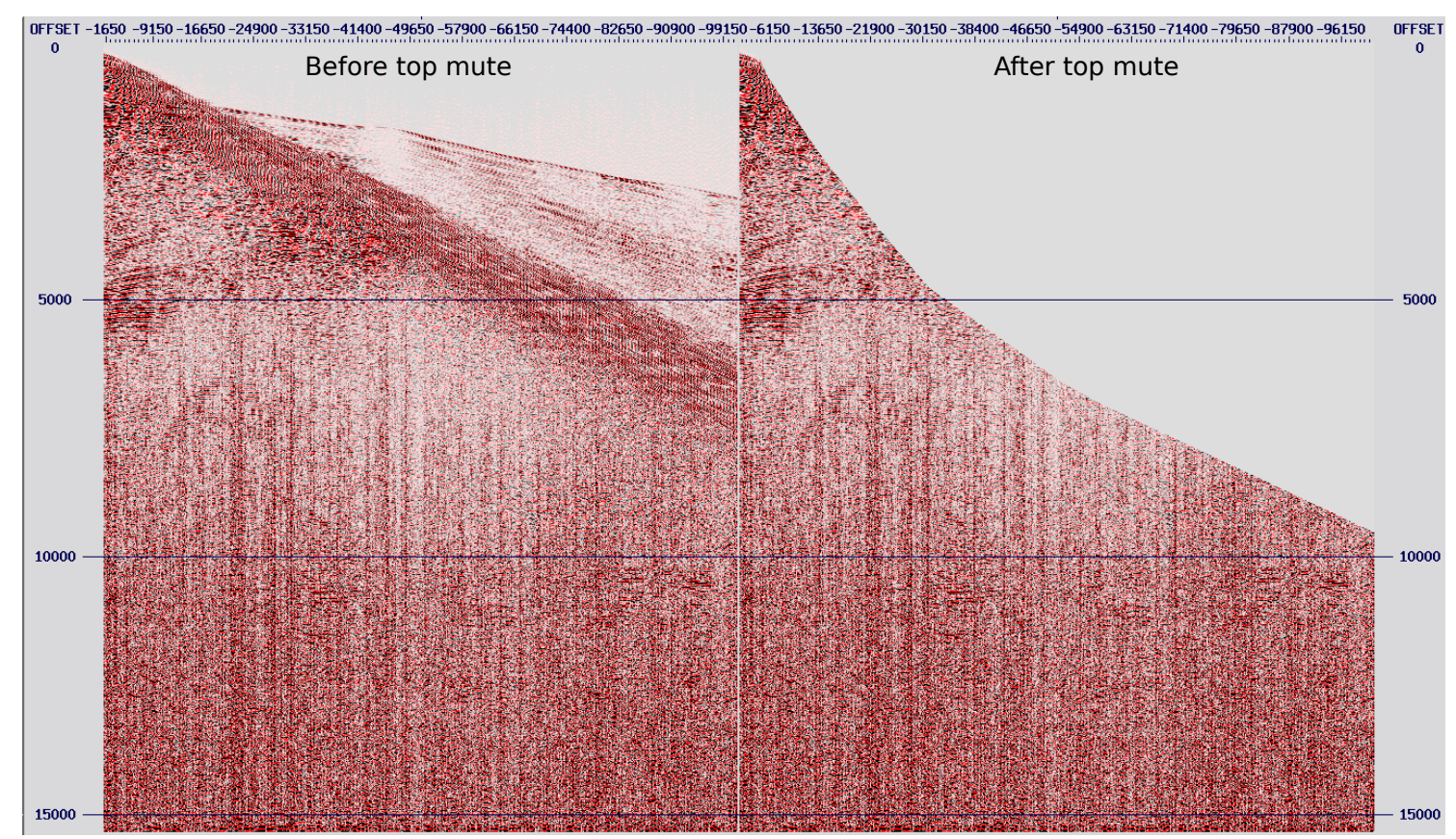

Figure F.6: Shot 1951 before and after a top mute was applied.

\section{F.8 Top mute}

The seismic reflection method also records direct and refracted energy. When the data are sorted to the CMP domain and stacked, this energy can obscure reflections. One way to remove direct and refracted energy is through the application of a top mute (see Figure F.6). Several 'near-offset' traces (close to the airgun) were saved so that the water bottom and shallow reflectors were not removed by the muting. Some of the mutes applied were 'aggressive', that is they cut deeper into time than would normally be the case. One example is shown in Figure F.6 (right), where nearsurface scattering effects near offset -33150 were also muted. Scattered energy was often a problem in SAHKE02 due to the presence of irregular basement. Removing these scatterers helped reduce the presence of linear noise in the stacked profile, but made the basement reflector less pronounced.

\section{F.9 Swell noise attenuation}

Swell is common in the South Taranaki Bight year round, including the day SAHKE02 was shot. The observer logs comment on setting the streamer depth deeper to $10 \mathrm{~m}$ due to swell noise. However, considerable swell noise, random noise bursts and other anomalous amplitudes persist. 

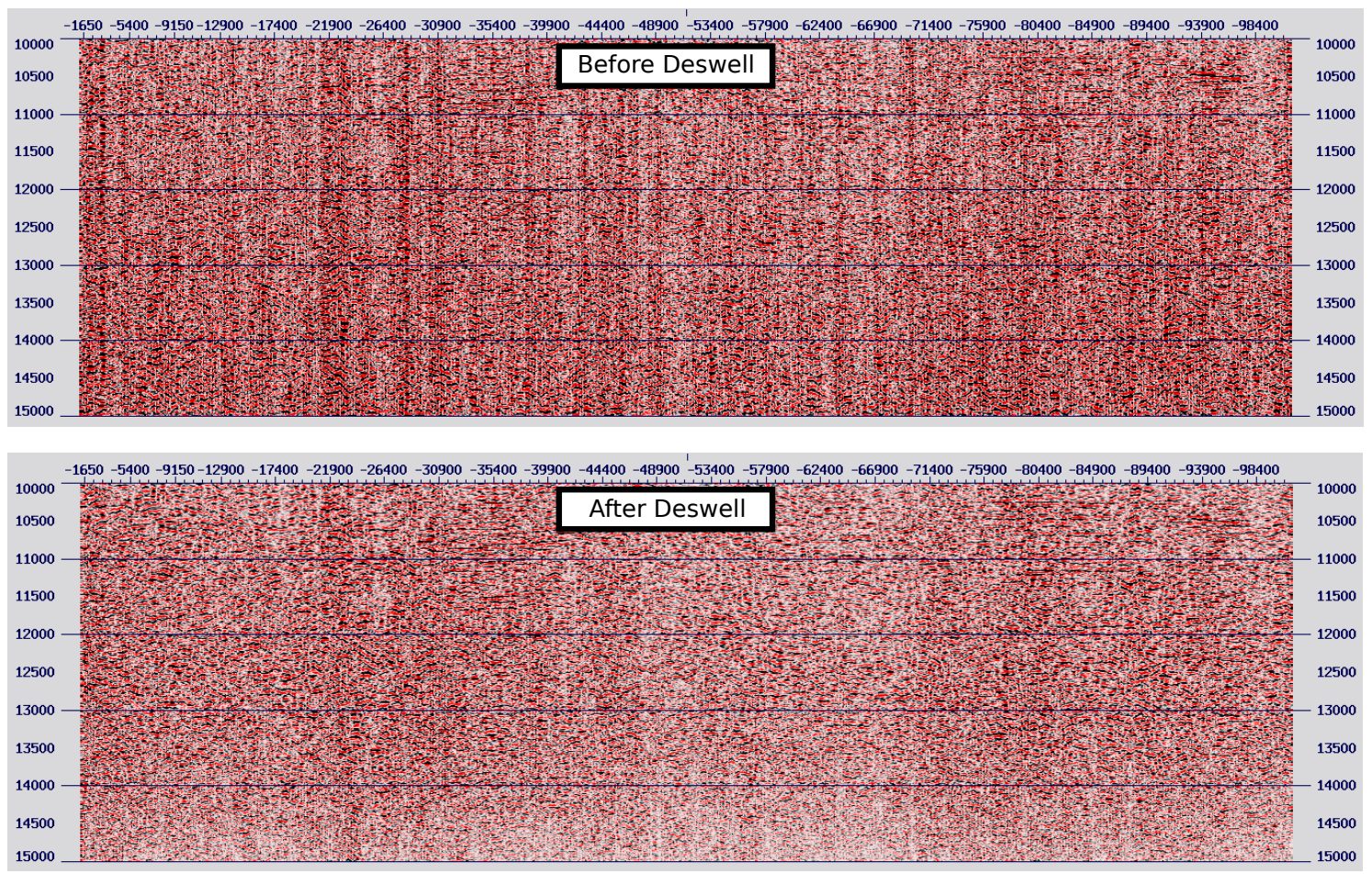

Figure F.7: Deswell tests for deep times in shot 1951. Top: Before swell noise attenuation. Bottom: After swell noise attenuation. Note the reduction in cable noise across the record.

A combination of low-cut filtering (see above), gentle FK mute, and projective filtering (DUSWELL) was used to mitigate the effect of swell noise on the data (Figure F.7). DUSWELL is an externally licensed module within Claritas designed to remove swell noise. The data records are transformed into wavelet space, and a user-defined window is run down and across the traces. Within each window, the wavelet amplitudes are ranked, if the amplitude is greater than a specified threshold value it is removed and interpolated back in. The following parameters were found to work well in the DUSWELL module:

THRESH_TOP 5; THRESH_END 1.2; V_HALFWIN 40; H_HALFWIN 20; QUANTILE 11

\section{F.10 High-frequency noise suppression}

Due to a shallow water bottom, strong energy source, near-surface faults, and a rugose high-velocity basement, high-frequency energy had a low signal-noise ratio. In particular, multiple energy was a significant issue with the SAHKE02 dataset. Spectral analysis of the deep reflectors of interest showed that their dominant frequencies were in the 10-20 Hz range, therefore the higher and even moderate frequencies 

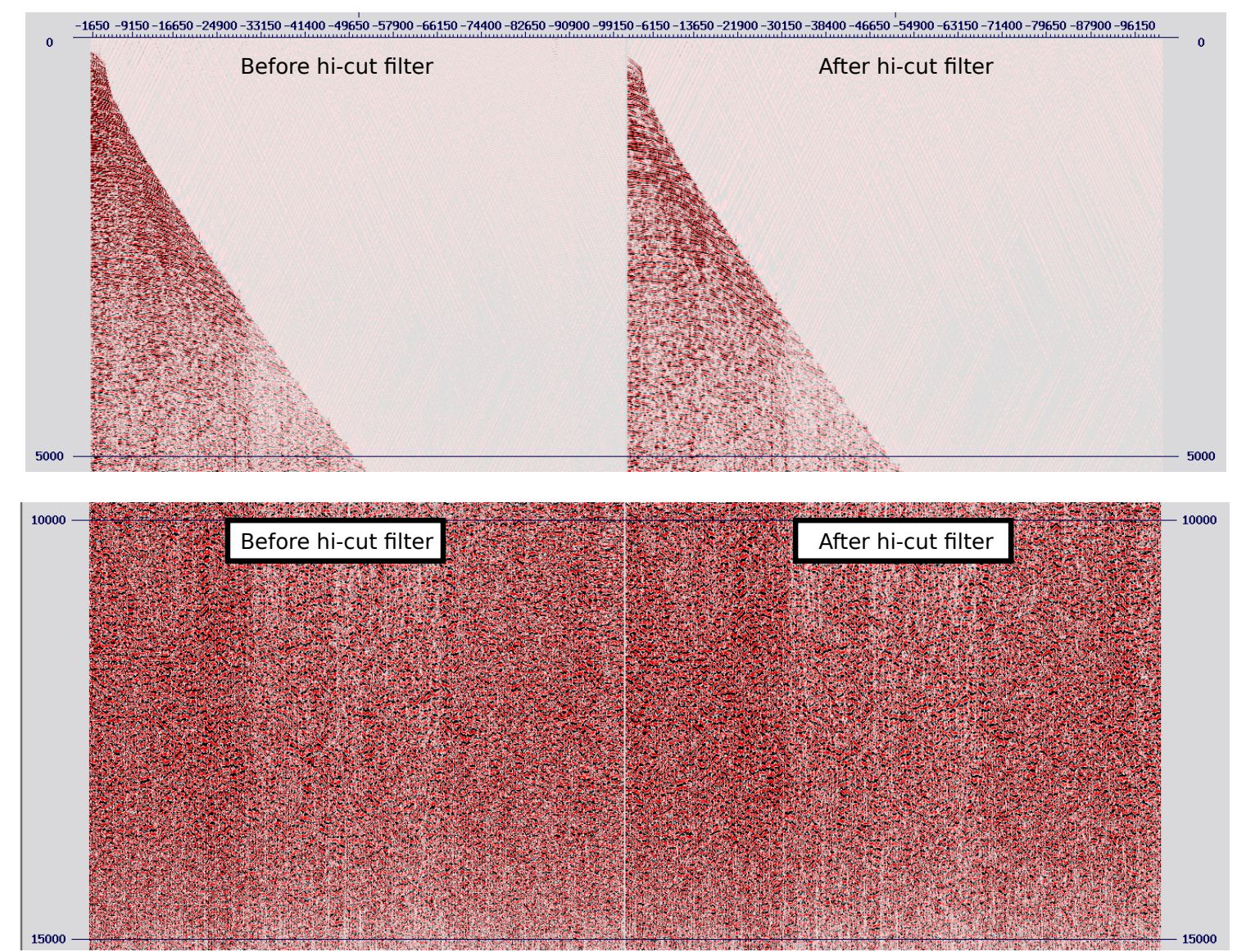

Figure F.8: High cut filter test from shot 1100. Top: $0-5 \mathrm{~s}$ of shot showing multiple attenuation effect of filter. Bottom: $10-15 \mathrm{~s}$ of shot shows how deep signal is largely unaffected.

could be safely removed with little effect on the deep energy. This unconventionally strong processing has an added benefit of attenuating multiple energy. A high-cut minimum-phase butterworth bandpass filter (30-40 Hz, amps: 0.950 .05 ) was designed and applied to the data, so that the seismic character directly under the basement could be better imaged (Figure F.8).

\section{F.11 Linear noise suppression}

Seismic energy that is negative in the FK domain is either back dipping, out-of-plane, or noise, and does not stack well. Similarly, linear energy that is strongly positivedipping in the FK domain is also likely to be noise. Hutchinson and Lee [1989], who also studied deep crustal structure in the Gulf of Maine, utilised two separate FK mutes in the shot domain to attenuate negative and positive-dipping energy respectively. This, in essence, yields a time-varying FK filter. This technique has 

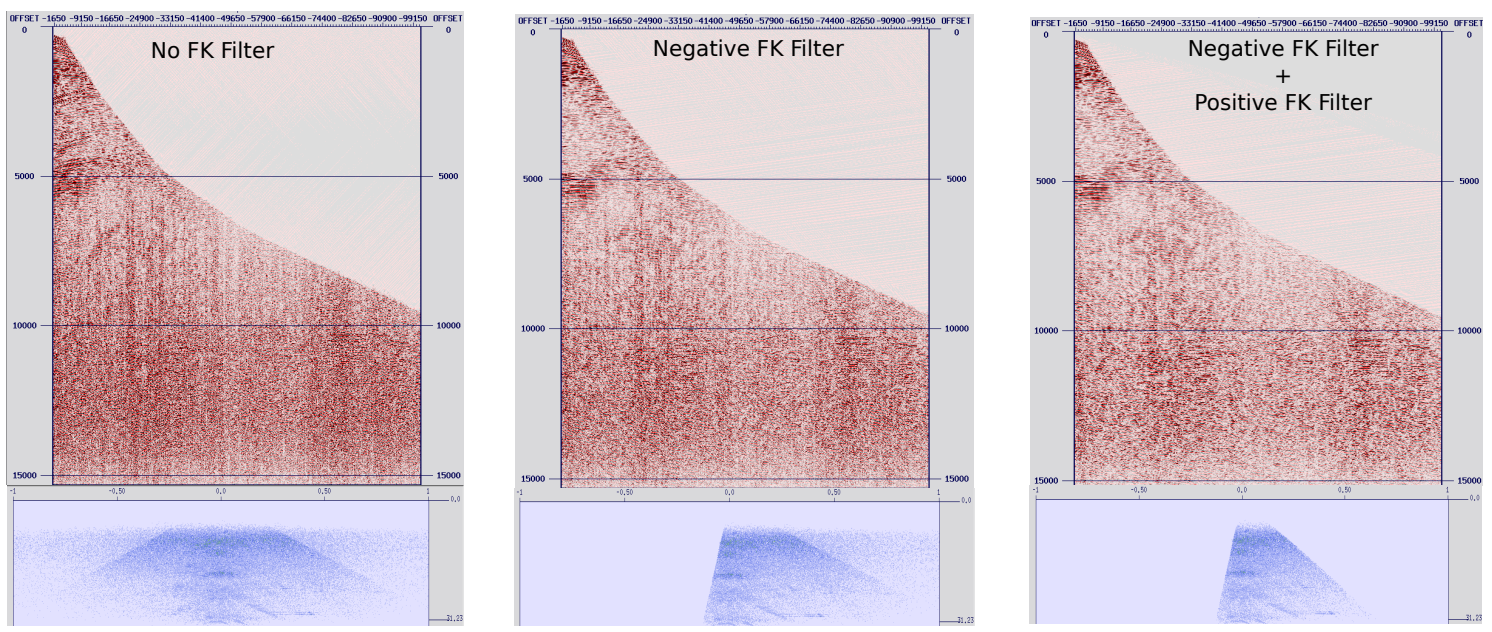

Figure F.9: FK filter test on shot 1951 showing the effect of positive and negative FK filters. Beneath each gather is its FK spectrum. Note how the reflectivity later than $10 \mathrm{~s}$ is progressively enhanced as both positive and negative FK filters are applied.

been adapted for SAHKE02. The negative FK mute was applied aggressively to all traces at $-2 \mathrm{~ms} /$ trace, under the assumption that the majority of back-dipping energy is noise and violates the basic assumptions of marine seismic processing. A positive FK mute, more gentle at $10 \mathrm{~ms} /$ trace, was wrapped by a forwards and reverse NMO correction designed to overcorrect primary reflections and under-correct multiples. The application of this filter greatly enhances deep reflectivity (Figure F.9).

\section{F.12 Multiple suppression in the Tau-P domain}

Multiples contaminated the SAHKE02 profile due to the presence of a hard, shallow water bottom. Interbed multiples from the Taranaki Fault Zone resulted in even more contamination. Weiner deconvolution in the Tau-P domain proved to be an effective method for removing short-period multiples and reverberations (see Figure F.10). Weiner deconvolution parameters were determined on the basis of panel tests, where the optimal configuration consisted of shallow and deep gates which are interpolated in between (Table F.2). It was found to be most effective to wrap the deconvolution in a removable AGC.

Table F.2: SAHKE02 deconvolution parameters

\begin{tabular}{|l|l|l|l|l|}
\hline Gate & Design window & Application window & Filter length & Operator gap \\
\hline 1 & $400-3000 \mathrm{~ms}$ & $0-5000 \mathrm{~ms}$ & 350 & 24 \\
2 & $9000-14000 \mathrm{~ms}$ & $9000-15000 \mathrm{~ms}$ & 350 & 100 \\
\hline
\end{tabular}



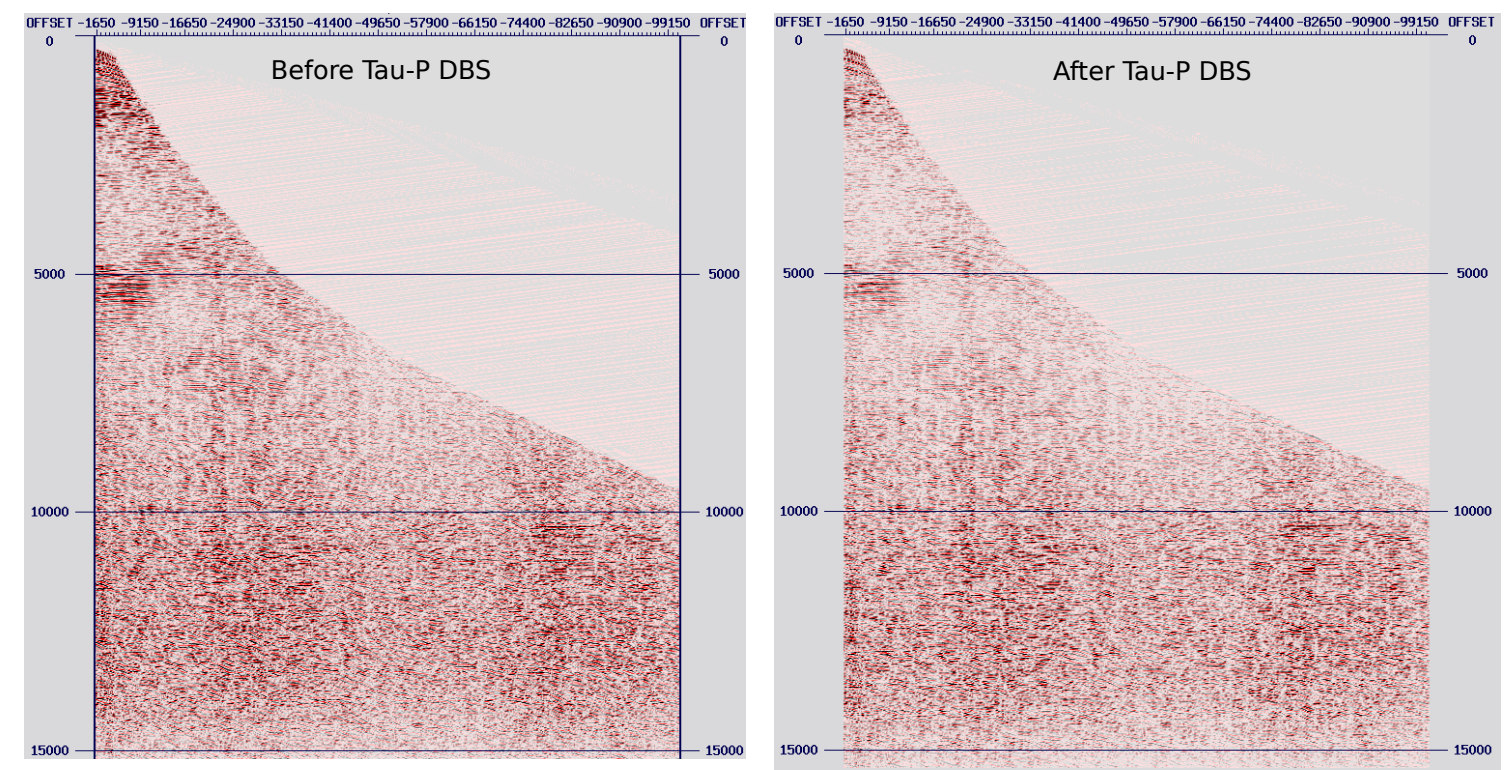

Figure F.10: Shot 1951 before and after Tau-P deconvolution.

\section{F.13 Brute stack}

The shot gathers were sorted into the CMP domain, NMO corrected using an initial 1D velocity model, and then stacked using square root normalization (better for noisy data according to the Claritas documentation). This process was then iterated following velocity analysis in the Claritas velocity analysis application to produce the brute stack in Figure F.11. The final stacking velocities are also included for reference in Figure F.12.

\section{F.14 Post-stack filtering}

Some sub-basement linear energy survived prestack processing, and persisted into the brute stack Figure F.11. A symmetrical post-stack FK-filter at $4 \mathrm{~ms} /$ trace was applied to further attenuate this energy and reveal what is beneath it. Further amplitude recovery was also applied, and consisted of a linear scale function and trace balancing based on deep reflector amplitudes.

Semblance-based coherency filtering [Milkereit and Spencer, 1989; Neidell and Taner, 1971] was also applied. This technique is commonly used for deep crustal imaging [e.g. Cook et al., 1999; Hasselgren and Clowes, 1995; Vasudevan et al., 2007] due to its ability to isolate coherent events in a high noise background typical of the lower crust. Normalised coherency of data over user-specified range of dips is first 

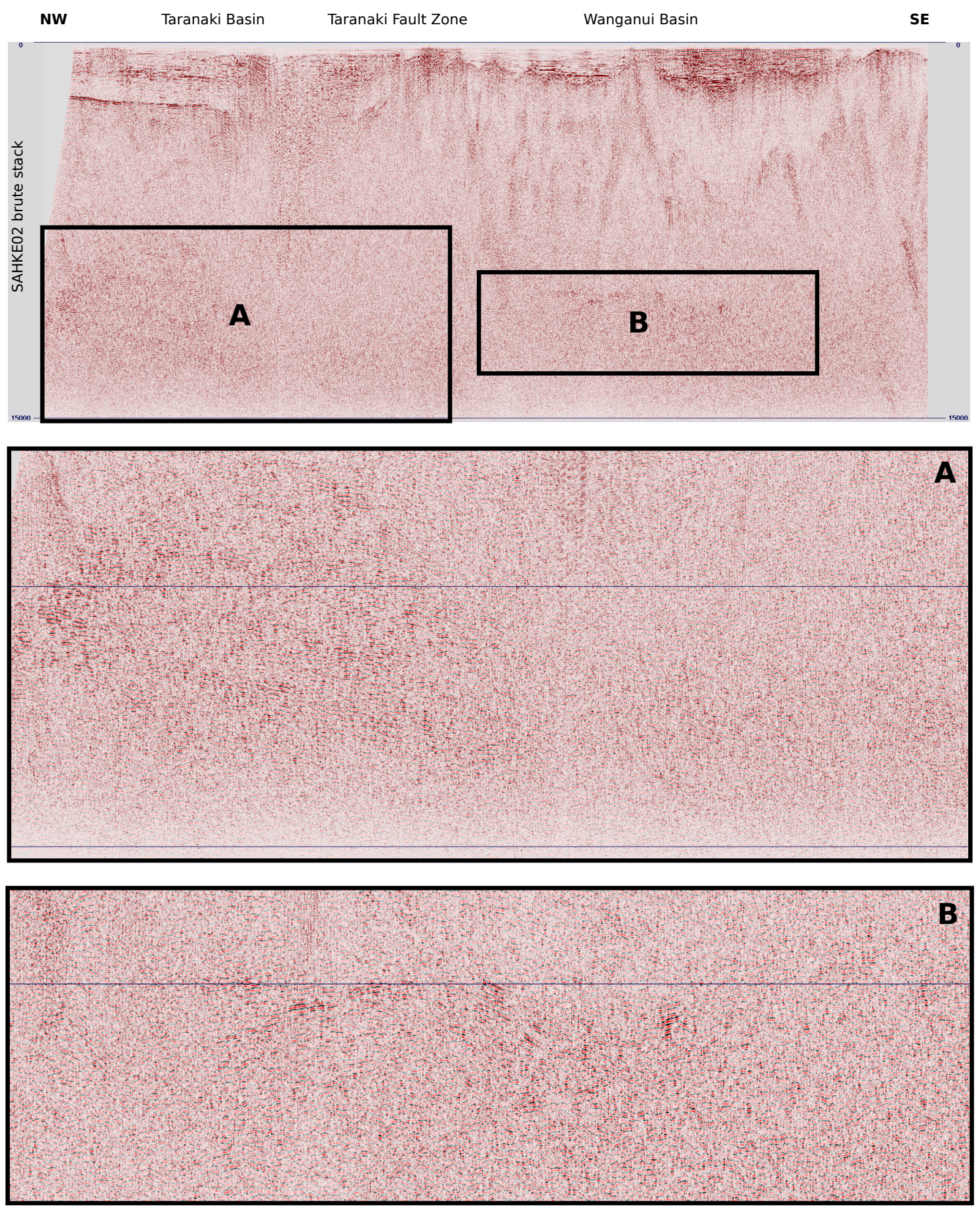

Figure F.11: Brute stack of the SAHKE02 line including insets. In inset A, note the dipping deep reflectors which go under the Taranaki Fault Zone. In inset B, note the apparently buckled deep reflectors under the Wanganui Basin 


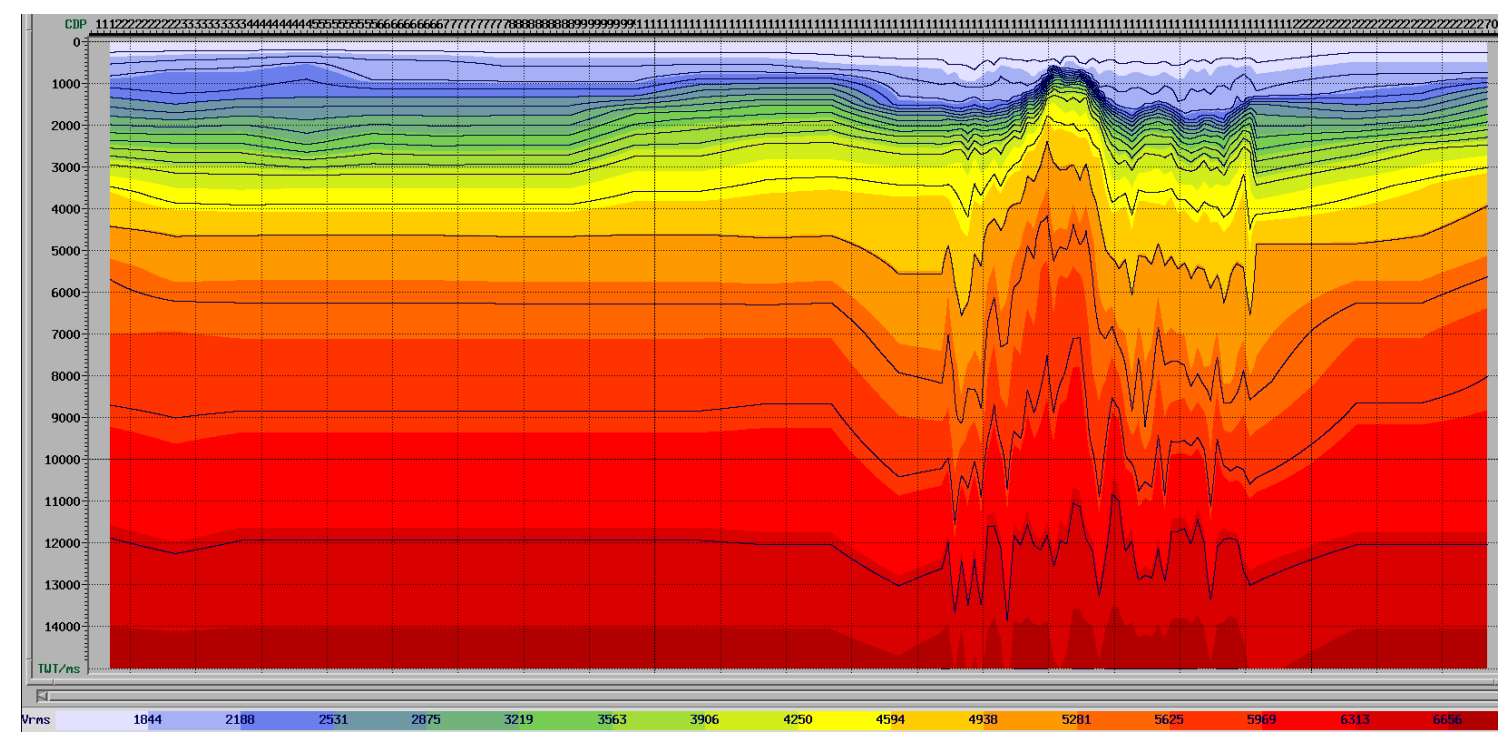

Figure F.12: Stacking Velocities for SAHKE02. Stacking velocities were created using the Claritas CVA application. Increased density is included over deep reflectors associated with Zoom B. It didn't make much of a difference to the deep reflectors if the velocity model was detailed versus if it was simple.

computed; the data are then smoothed and filtered in the direction of maximum semblance. Optimum processing values were selected by panel testing.

The application of this filter enhances deep bright reflectors, which are otherwise seen in the brute-stack above. Care was taken not to introduce any new signal which was not previously seen on the brute stack. The Claritas 'sembsmooth' module was used for this purpose with the following parameters:

NTRPANEL 30; DX 50; PMAX 0.25; NP 10; SEMEXP 1; ADDBACK 0.0

The final unmigrated stack is shown in Figure F.13.

\section{F.15 Migration and time-depth conversion}

The basement of the Wanganui Basin is essentially a drowned mountain range which is situated adjacent to the Taranaki Basin whose sediment thickness is greater in SAHKE02. This creates a complex set of velocity pull-up and push-down effects on reflectors below the basement. A $2 \mathrm{~d}$ velocity model has been created to capture this complexity (Figure F.14). Time-depth conversion with this model is intended to help undo the velocity effects caused by basin sedimentary rocks on the deep reflectors. 


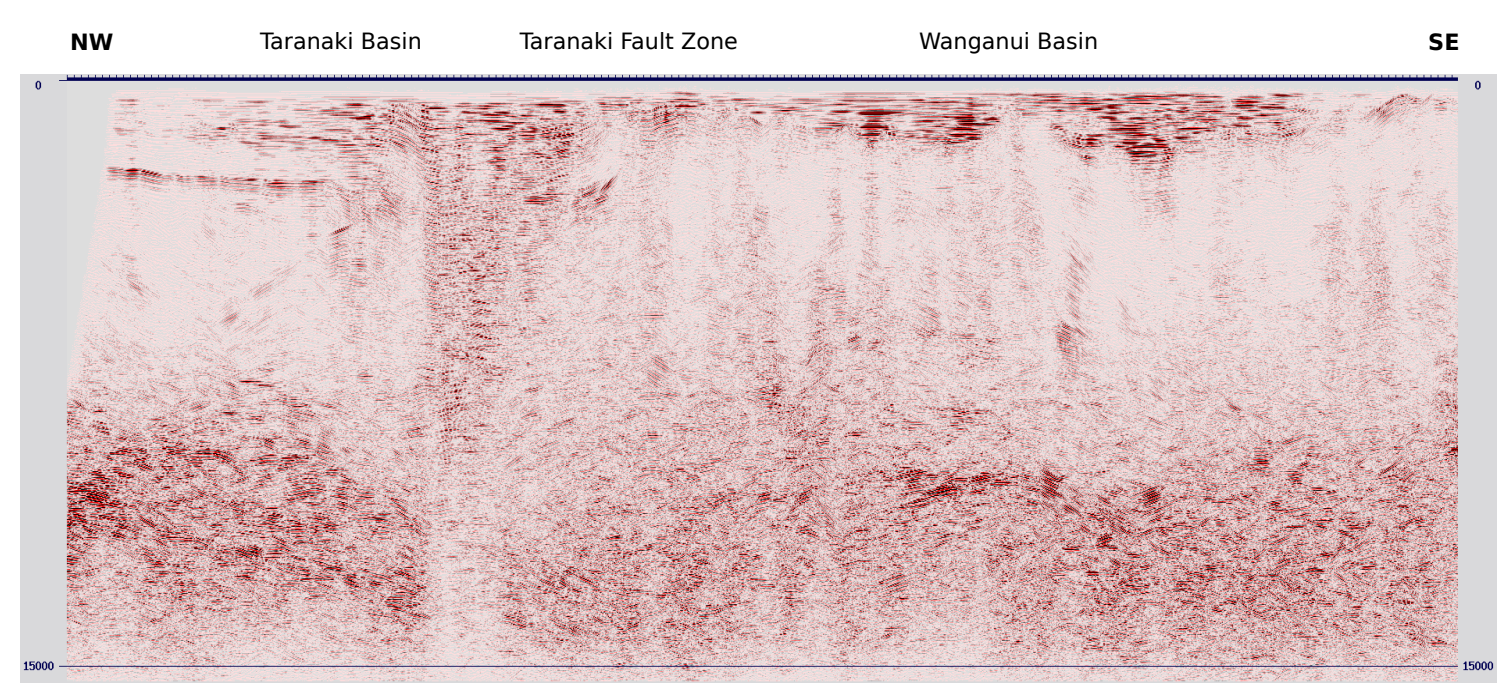

Figure F.13: SAHKE02 seismic section in time (unmigrated), with post-stack coherency filtering.

The model was constructed by first interpreting the basement floor in time (Figure 5.11). The sediments above are assigned an interval velocity of $2500 \mathrm{~m} / \mathrm{s}$, based on SAHKE02 refracted velocities calculated by Tozer [2013]. For sub-basement velocities, the New Zealand standard velocity model [Maunder, 2002] is used. No attempt is made to model the velocities of the subducted Pacific plate. This velocity model was also used for migration, as in the deep section there are no lateral changes in velocity and so the migration is simple.

Migration was applied using the Claritas FDMIG module. FDMIG is a finite difference time migration routine, based in the X-T domain with implicit 45 degree migration. Despite the 45-degree algorithm, FDMIG gives reasonable results up to about 60 degrees. The algorithm was therefore modified for 60-degree migration so that steeply-dipping energy was preserved.

The final migrated, depth-converted stack is shown in Figure F.15. Compared to Figure F.13, the apparently-buckled reflectors under the Wanganui Basin migrate to a bright patch under the centre of the Wanganui Basin. The SE dipping reflectors under the Taranaki Basin also appear slightly steeper. Finally, there is now some definition to the subducting Pacific plate towards the SE end of the profile. 
SAHKE02 interval velocity model

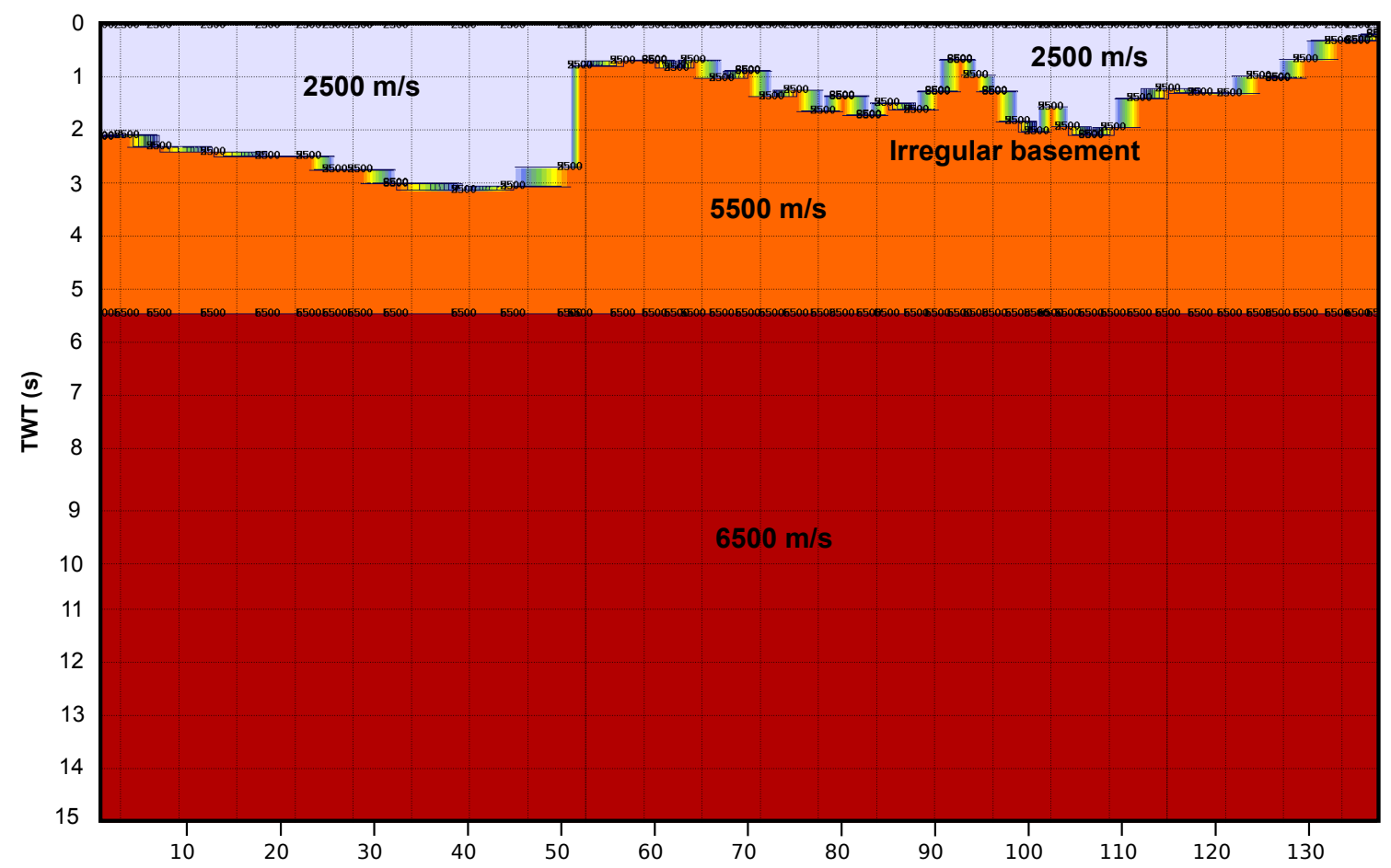

Figure F.14: Interval velocity model for SAHKE02 depth conversion. Horizontal scale is distance along SAHKE02 profile.

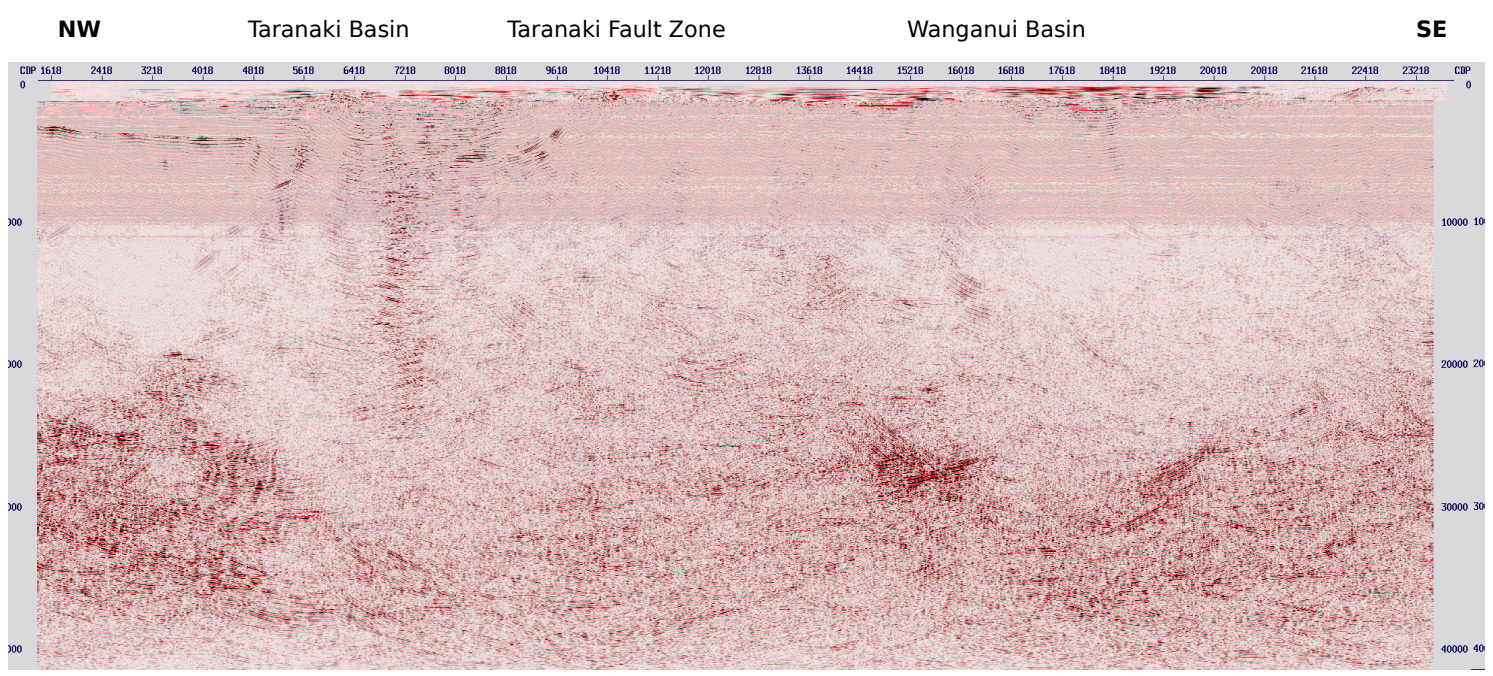

Figure F.15: SAHKE02 seismic profile in depth, including migration. Depths in metres. 


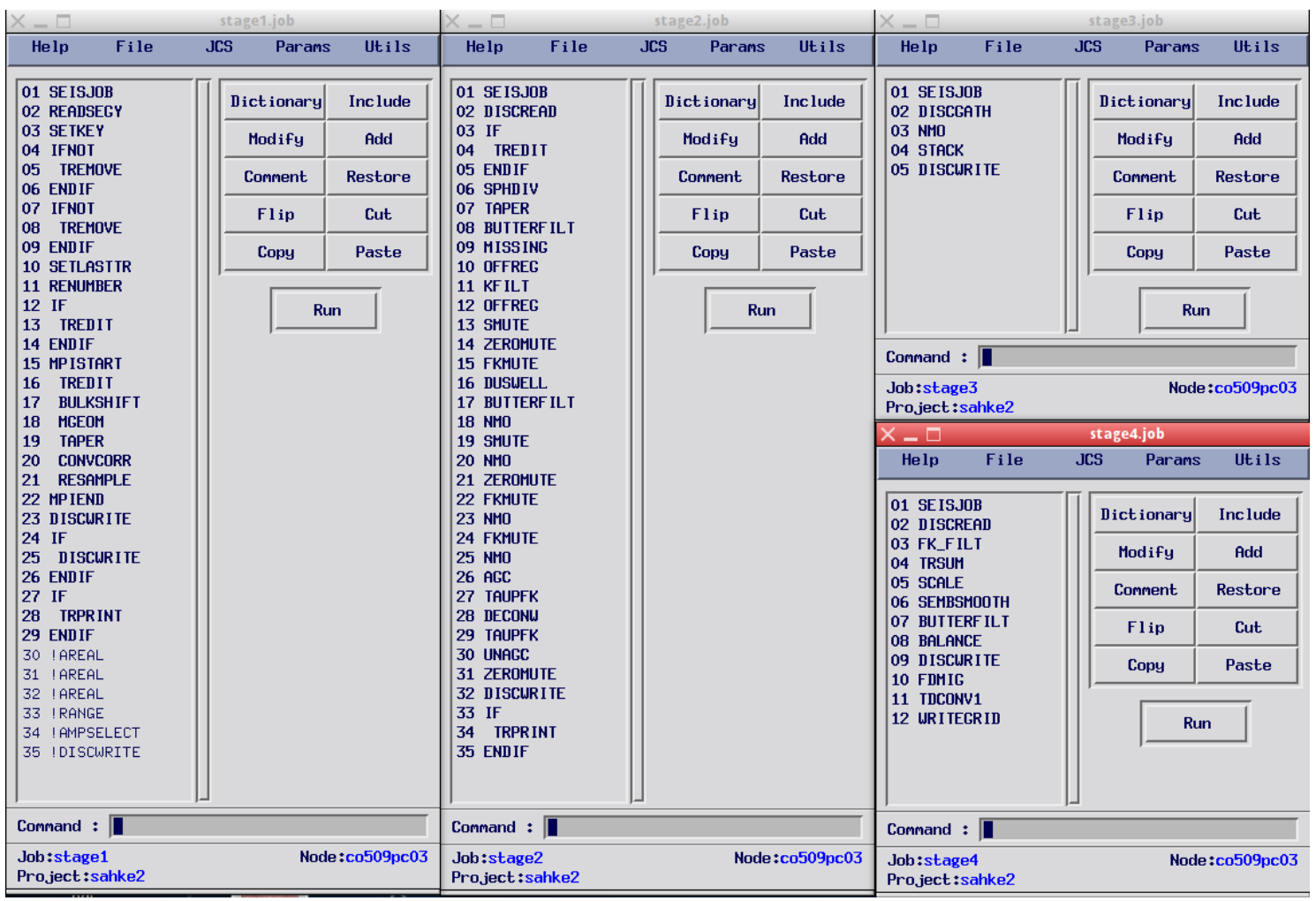

Figure F.16: Globe Claritas processing workflow for SAHKE02.

\section{F.16 Claritas jobs for SAHKE02}

The processing flow of Figure 5.8 was run through Claritas in four stages. Screenshots of the processes for each stage are shown in Figure F.16 as an alternative way of visualising the SAHKE02 processing flow. 


\section{Appendix G}

\section{OBS observations}

This appendix includes reduced traveltime plots for four OBS (Ocean Bottom Seismometer) stations deployed beneath the SAHKE02 marine seismic profile: OBS17, OBS18, OBS19, OBS20 (locations in Figure 5.1). These data have a poor signal/noise ratio in comparison to data from GeoNet station KIW, and were not suitable for ray tracing. There are some indications of deep, bright reflectivity on OBS17 and OBS20, but this is not clear. Basic interpretations for each OBS station are included below. 

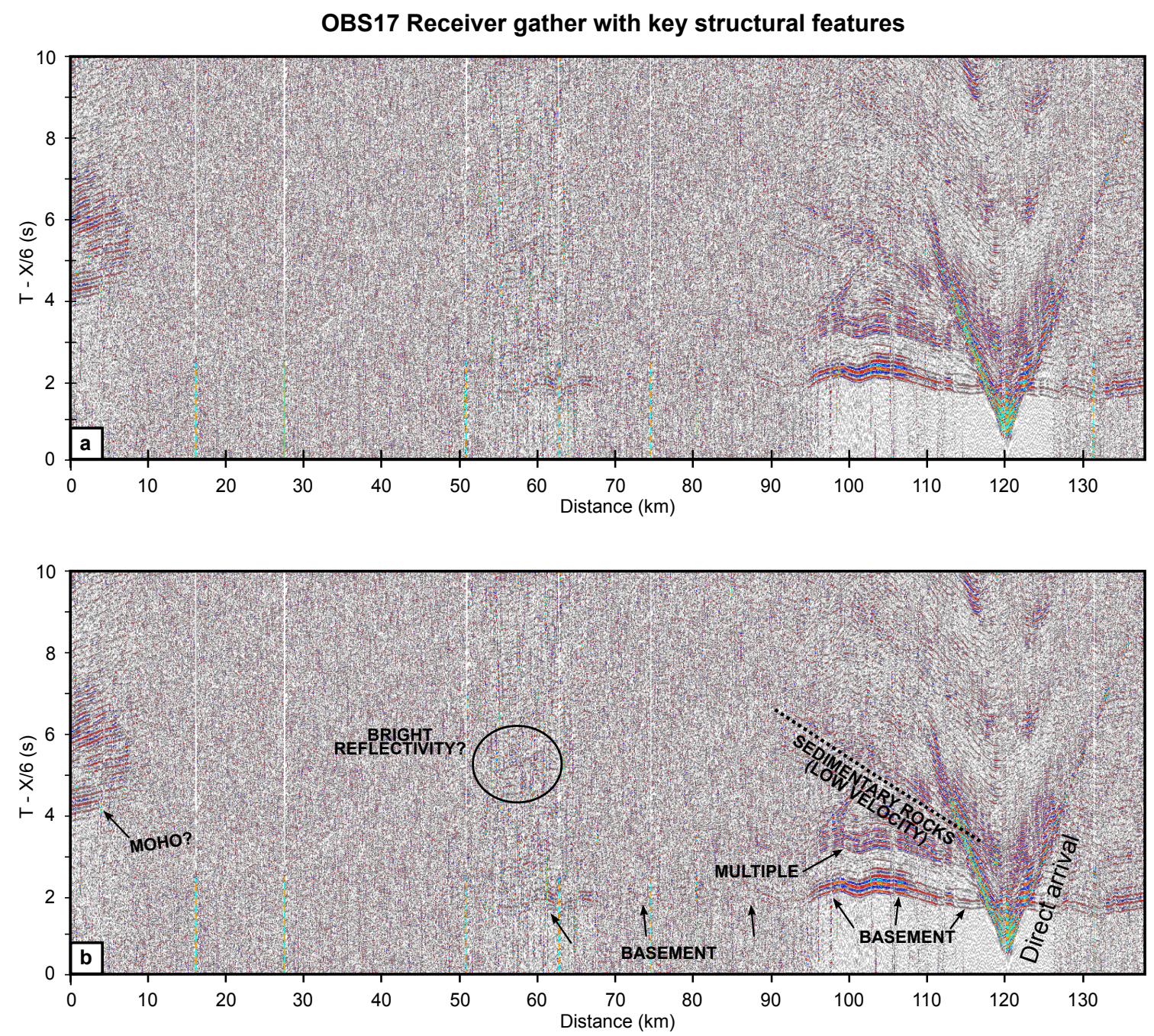

Figure G.1: OBS17 reduced traveltime plot. An uninterpreted (a) and interpreted (b) wide-angle reflection/refraction profile [after Henrys et al., 2013]. Processing: Zero-phase $2-5-10-20 \mathrm{~Hz}$ butterworth bandpass filter; $6 \mathrm{~km} / \mathrm{s}$ linear moveout correction. 

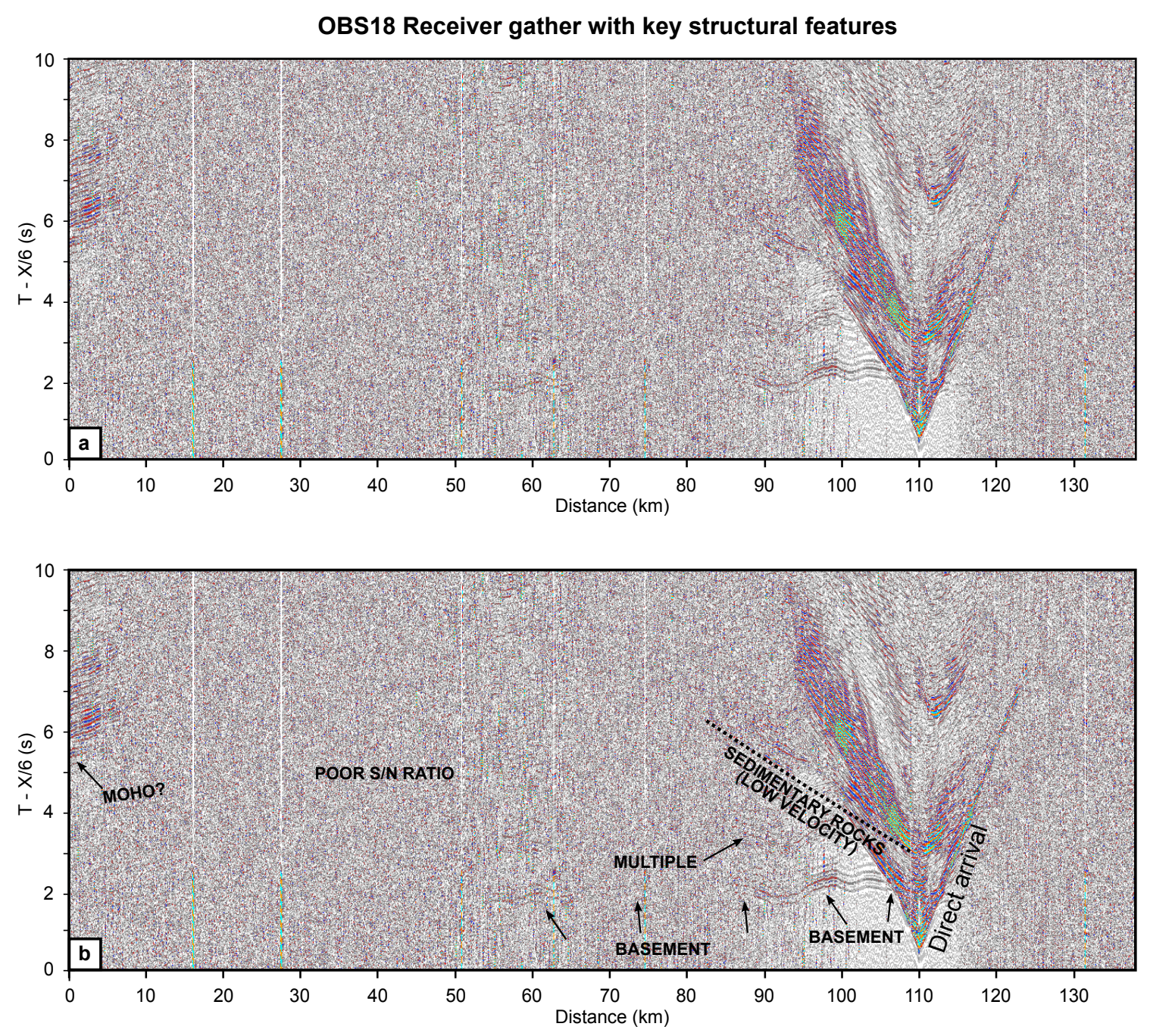

Figure G.2: OBS18 reduced traveltime plot. An uninterpreted (a) and interpreted (b) wide-angle reflection/refraction profile [after Henrys et al., 2013]. Processing: Zero-phase $2-5-10-20 \mathrm{~Hz}$ butterworth bandpass filter; $6 \mathrm{~km} / \mathrm{s}$ linear moveout correction. 

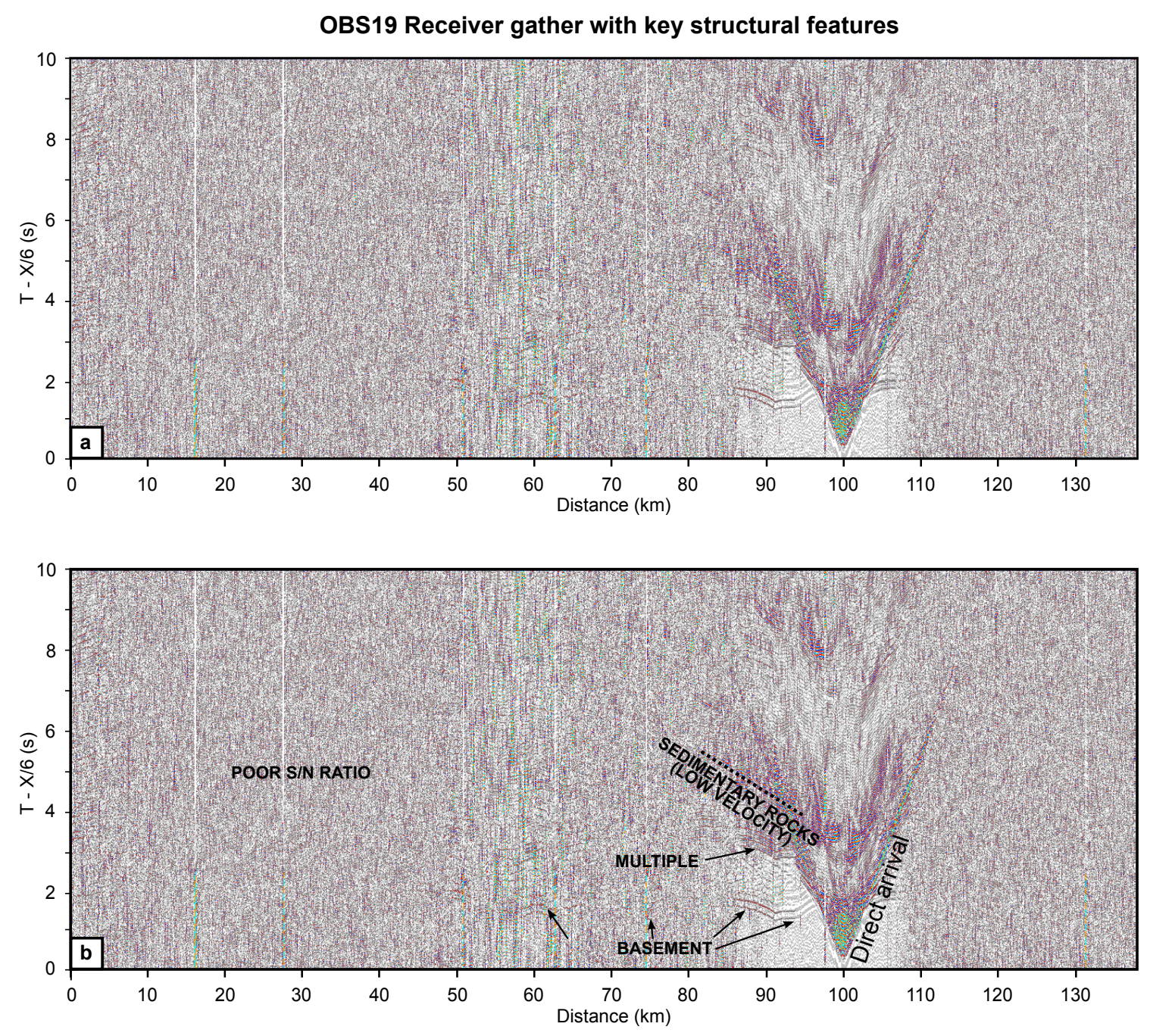

Figure G.3: OBS19 reduced traveltime plot. An uninterpreted (a) and interpreted (b) wide-angle reflection/refraction profile [after Henrys et al., 2013]. Processing: Zero-phase $2-5-10-20 \mathrm{~Hz}$ butterworth bandpass filter; $6 \mathrm{~km} / \mathrm{s}$ linear moveout correction. 

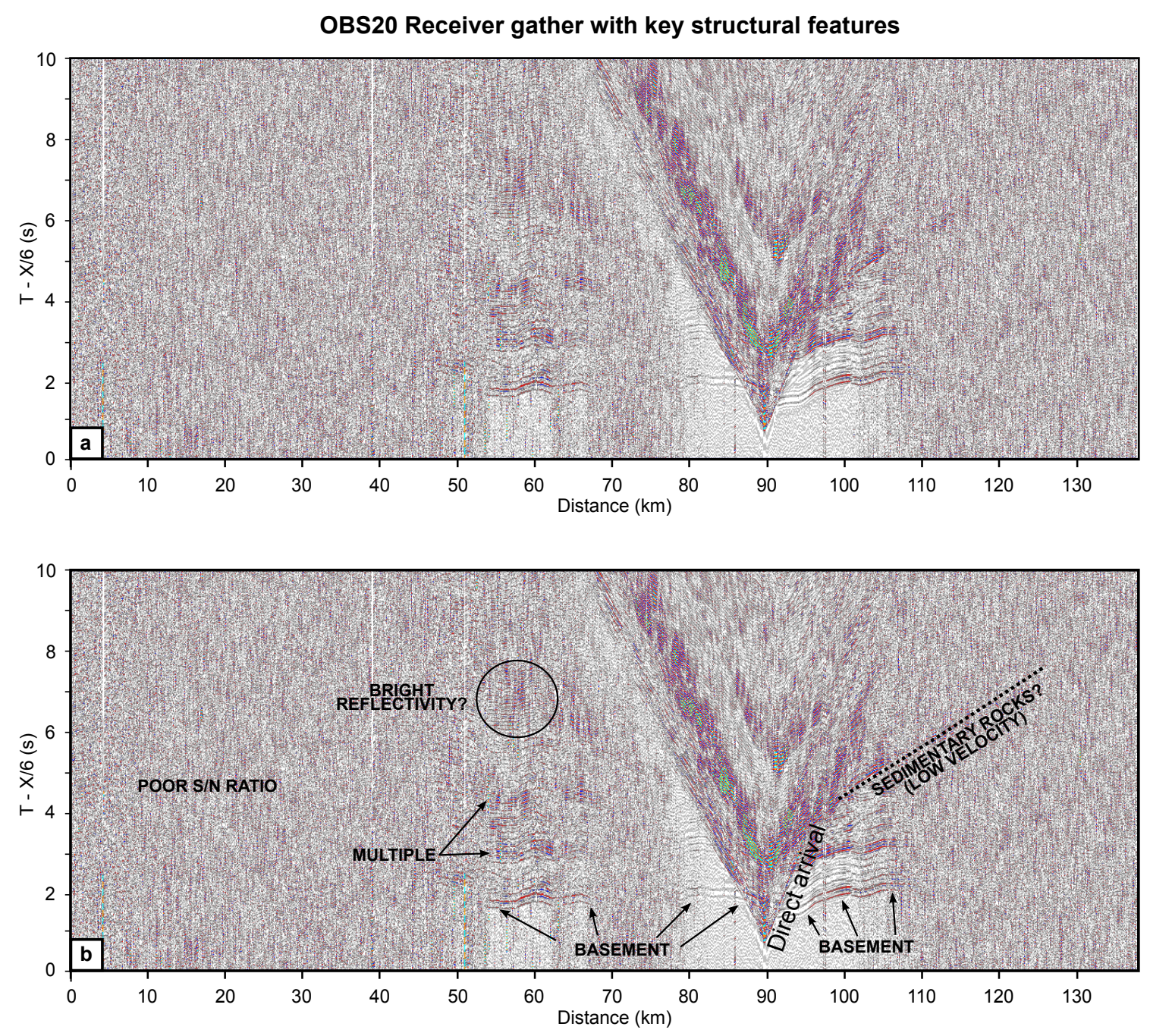

Figure G.4: OBS20 reduced traveltime plot. An uninterpreted (a) and interpreted (b) wide-angle reflection/refraction profile [after Henrys et al., 2013]. Processing: Zero-phase $2-5-10-20 \mathrm{~Hz}$ butterworth bandpass filter; $6 \mathrm{~km} / \mathrm{s}$ linear moveout correction. 


\section{Bibliography}

Abers, G. A., X. Hu, and L. R. Sykes, Source scaling of earthquakes in the Shumagin region, Alaska: Time-domain inversions of regional waveforms, Geophysical Journal International, 123(1), 41-58, 1995.

Aki, K., and P. Richards, Quantitative Seismology: Theory and Methods, vol. 1, WH Freeman \& Co, San Francisco, 1980.

Ammon, C. J., The isolation of receiver effects from teleseismic P waveforms, Bulletin of the Seismological Society of America, 81(6), 2504-2510, 1991.

Ammon, C. J., G. E. Randall, and G. Zandt, On the nonuniqueness of receiver function inversions, Journal of Geophysical Research: Solid Earth, 95(B10), 15,30315,318, 1990.

Anderton, P. W., Structure and evolution of the South Wanganui Basin, New Zealand, New Zealand Journal of Geology and Geophysics, 24(1), 39-63, 1981.

Arnold, R., and J. Townend, A Bayesian approach to estimating tectonic stress from seismological data, Geophysical Journal International, 170(3), 1336-1356, 2007.

Bak, P., and C. Tang, Earthquakes as a self-organized critical phenomenon, J. geophys. Res, 94 (15), 635-15, 1989.

Bannister, S., M. Reyners, G. Stuart, and M. Savage, Imaging the Hikurangi subduction zone, New Zealand, using teleseismic receiver functions: crustal fluids above the forearc mantle wedge, Geophysical Journal International, 169(2), 602-616, 2007.

Beaumont, C., Foreland basins, Geophysical Journal International, 65(2), 291-329, 1981.

Bell, R., R. Sutherland, D. H. Barker, S. Henrys, S. Bannister, L. Wallace, and J. Beavan, Seismic reflection character of the Hikurangi subduction interface, 
New Zealand, in the region of repeated Gisborne slow slip events, Geophysical Journal International, 180(1), 34-48, 2010.

Blakely, R. J., T. M. Brocher, and R. E. Wells, Subduction-zone magnetic anomalies and implications for hydrated forearc mantle, Geology, 33(6), 445-448, 2005.

Boddington, T., C. Parkin, and D. Gubbins, Isolated deep earthquakes beneath the North Island of New Zealand, Geophysical Journal International, 158(3), 972-982, 2004 .

Bormann, P., and E. Wielandt, New Manual of Seismological Observatory Practice 2 (NMSOP2), chap. Seismic Signals and Noise, pp. 1-62, Deutsches GeoForschungZentrum GFZ, Potsdam, 2013.

Bostock, M., The Moho in subduction zones, Tectonophysics, 609, 547-557, 2013.

Bostock, M., R. Hyndman, S. Rondenay, and S. Peacock, An inverted continental Moho and serpentinization of the forearc mantle, Nature, 417(6888), 536-538, 2002.

Bott, M. H. P., The mechanics of oblique slip faulting, Geological Magazine, 96(02), 109-117, 1959.

Boyd, O. S., An efficient Matlab script to calculate heterogeneous anisotropically elastic wave propagation in three dimensions, Computers \& Geosciences, 32(2), 259-264, 2006.

Brewer, J. A., D. H. Matthews, M. R. Warner, J. Hall, D. K. Smythe, and R. J. Whittington, BIRPS deep seismic reflection studies of the British Caledonides, 1983.

Brocher, T. M., T. Parsons, A. M. Tréhu, C. M. Snelson, and M. A. Fisher, Seismic evidence for widespread serpentinized forearc upper mantle along the Cascadia margin, Geology, 31(3), 267-270, 2003.

Bürgmann, R., M. Kogan, V. Levin, C. Scholz, R. King, and G. Steblov, Rapid aseismic moment release following the 5 December, 1997 Kronotsky, Kamchatka, earthquake, Geophysical Research Letters, 28(7), 1331-1334, 2001.

Calvert, A., E. Sandvol, D. Seber, M. Barazangi, S. Roecker, T. Mourabit, F. Vidal, G. Alguacil, and N. Jabour, Geodynamic evolution of the lithosphere and 
upper mantle beneath the Alboran region of the western Mediterranean: constraints from travel time tomography, Journal of Geophysical Research: Solid Earth, 105(B5), 10,871-10,898, 2000.

Cande, S. C., and J. M. Stock, Pacific-Antarctic-Australia motion and the formation of the Macquarie Plate, Geophysical Journal International, 157(1), 399-414, 2004.

Carminati, E., C. Giunchi, A. Argnani, R. Sabadini, and M. Fernandez, PlioQuaternary vertical motion of the Northern Apennines: Insights from dynamic modeling, Tectonics, 18(4), 703-718, 1999.

Carter, N. L., and M. C. Tsenn, Flow properties of continental lithosphere, Tectonophysics, 136(1), 27-63, 1987.

Chen, L., T. Zheng, and W. Xu, A thinned lithospheric image of the Tanlu Fault Zone, eastern China: constructed from wave equation based receiver function migration, Journal of Geophysical Research: Solid Earth (1978-2012), 111(B9), 2006.

Christensen, N. I., Pore pressure, seismic velocities, and crustal structure, Geological Society of America Memoirs, 172, 783-798, 1989.

Christensen, N. I., Serpentinites, peridotites, and seismology, International Geology Review, 46 (9), 795-816, 2004.

Chun, J. H., and C. A. Jacewitz, Fundamentals of frequency domain migration, Geophysics, 46(5), 717-733, 1981.

Clayton, R. W., and R. A. Wiggins, Source shape estimation and deconvolution of teleseismic bodywaves, Geophysical Journal International, 47(1), 151-177, 1976.

Clowes, R., M. Brandon, A. Green, C. Yorath, A. S. Brown, E. Kanasewich, and C. Spencer, LITHOPROBE-southern Vancouver Island: Cenozoic subduction complex imaged by deep seismic reflections, Canadian Journal of Earth Sciences, $24(1), 31-51,1987$.

Constable, S., Treatise on geophysics, chap. Geomatic Induction Studies, pp. 219254, Elsevier, 2015.

Cook, F. A., D. S. Albaugh, L. D. Brown, S. Kaufman, J. E. Oliver, and R. D. Hatcher, Thin-skinned tectonics in the crystalline southern Appalachians; COCORP seismic-reflection profiling of the Blue Ridge and Piedmont, Geology, 7(12), 563-567, 1979. 
Cook, F. A., A. J. Velden, K. W. Hall, and B. J. Roberts, Frozen subduction in Canada's Northwest Territories: Lithoprobe deep lithospheric reflection profiling of the western Canadian Shield, Tectonics, 18(1), 1-24, 1999.

Coombs, D., C. Landis, R. Norris, J. Sinton, D. Borns, and D. Craw, The Dun Mountain Ophiolite Belt, New Zealand, its tectonic setting, constitution, and origin, with special reference to the southern portion, American Journal of Science, 276 (5), 561-603, 1976.

Cope, R. N., The hydrocarbon prospects of the Wanganui Basin, unpublished report, E.P. No. 64, Shell, B.P. and Todd Oil Services Ltd. Petroleum Report Number 459 on open file at GNS Science, 1966.

Cope, R. N., and J. J. Reed, The Cretaceous paleogeology of the Taranaki-Cook Strait area, in Proceedings of the Australasian Institute of Mining and Metallurgy, vol. 222, pp. 63-72, 1967.

Cowie, P. A., C. Vanneste, and D. Sornette, Statistical physics model for the spatiotemporal evolution of faults, Journal of Geophysical Research: Solid Earth, 98(B12), 21,809-21,821, 1993.

Crotwell, H. P., T. J. Owens, and J. Ritsema, The TauP Toolkit: Flexible seismic travel-time and ray-path utilities, Seismological Research Letters, 70 (2), 154-160, 1999.

Darby, D. J., and C. M. Meertens, Terrestrial and GPS measurements of deformation across the Taupo back arc and Hikurangi forearc regions in New Zealand, Journal of Geophysical Research: Solid Earth, 100(B5), 8221-8232, 1995.

Dasgupta, R., and R. A. Clark, Estimation of Q from surface seismic reflection data, Geophysics, 63(6), 2120-2128, 1998.

Davey, F. J., Seismic reflection measurements behind the Hikurangi convergent margin, southern North Island, New Zealand., Geophysical Journal of the Royal Astronomical Society, 89(1), 443-448, 1987.

Davey, F. J., and T. A. Stern, Crystal Seismic observations across the convergent plate boundary, North Island, New Zealand, Tectonophysics, 173(1-4), 283 - 296, siesmic Probing of Continents and their Margins, 1990.

Davy, B., The influence of subducting plate buoyancy on subduction of the Hikurangi-Chatham Plateau beneath the North Island, New Zealand, Geology and Geophysics of Continental Margins. AAPG memoir, 53, 75-92, 1992. 
Davy, B., and R. Wood, Gravity and magnetic modelling of the Hikurangi Plateau, Marine Geology, 118(1), 139-151, 1994.

de Bremond d'Ars, J., C. Lécuyer, and B. Reynard, Hydrothermalism and diapirism in the Archean: gravitational instability constraints, Tectonophysics, 304(1), 29 39, 1999.

Docherty, C., and E. Banda, Evidence for the eastward migration of the Alboran Sea based on regional subsidence analysis: a case for basin formation by delamination of the subcrustal lithosphere?, Tectonics, 14(4), 804-818, 1995.

Douglas, A., J. Beavan, L. Wallace, and J. Townend, Slow slip on the northern Hikurangi subduction interface, New Zealand, Geophysical Research Letters, 32(16), 2005.

Dragert, H., K. Wang, and G. Rogers, Geodetic and seismic signatures of episodic tremor and slip in the northern Cascadia subduction zone, Earth, Planets and Space, 56(12), 1143-1150, 2004.

Dueker, K. G., and A. F. Sheehan, Mantle discontinuity structure from midpoint stacks of converted P to S waves across the Yellowstone hotspot track, Journal of Geophysical Research: Solid Earth (1978-2012), 102(B4), 8313-8327, 1997.

Dueker, K. G., and A. F. Sheehan, Mantle discontinuity structure beneath the Colorado rocky mountains and high plains, Journal of Geophysical Research: Solid Earth (1978-2012), 103(B4), 7153-7169, 1998.

Dvorkin, J., and A. Nur, Dynamic poroelasticity: A unified model with the squirt and the Biot mechanisms, Geophysics, 58(4), 524-533, 1993.

Eberhart-Phillips, D., M. Reyners, M. Chadwick, and J.-M. Chiu, Crustal heterogeneity and subduction processes: 3-D Vp, Vp/Vs and Q in the southern North Island, New Zealand, Geophysical Journal International, 162(1), 270-288, 2005.

Eberhart-Phillips, D., M. Reyners, M. Chadwick, and G. Stuart, Three-dimensional attenuation structure of the Hikurangi subduction zone in the central North Island, New Zealand, Geophysical Journal International, 174(1), 418-434, 2008.

Evans, B. W., Lizardite versus antigorite serpentinite: Magnetite, hydrogen, and life (?), Geology, 38(10), 879-882, 2010. 
Ewig, E., Lithospheric shortening and ductile deformation in a back-arc setting: South Wanganui Basin, New Zealand, Ph.D. thesis, Victoria University of Wellington, 2009.

Faccenna, C., C. Piromallo, A. Crespo-Blanc, L. Jolivet, and F. Rossetti, Lateral slab deformation and the origin of the western Mediterranean arcs, Tectonics, $23(1), 2004$.

Fenaughty, K., GeoNet Earthquake Catalog, 2015.

Fillerup, M. A., J. H. Knapp, C. C. Knapp, and V. Raileanu, Mantle earthquakes in the absence of subduction? Continental delamination in the Romanian Carpathians, Lithosphere, 2(5), 333-340, 2010.

Fleming, C. A., The geology of Wanganui subdivision, Waverley and Wanganui sheet districts (N137 and N138)., New Zealand Geol. Surv. Bull., 52, 1-362, 1953.

Foley, S. F., Rejuvenation and erosion of the cratonic lithosphere, Nature Geoscience, $1(8), 503-510,2008$.

Fowler, C. M. R., The solid earth: an introduction to global geophysics, Cambridge University Press, 1990.

Frassetto, A. M., G. Zandt, H. Gilbert, T. J. Owens, and C. H. Jones, Structure of the Sierra Nevada from receiver functions and implications for lithospheric foundering, Geosphere, 7(4), 898-921, 2011.

Frederiksen, A., and M. Bostock, Modelling teleseismic waves in dipping anisotropic structures, Geophysical Journal International, 141(2), 401-412, 2000.

Frost, B. R., and K. Bucher, Is water responsible for geophysical anomalies in the deep continental crust? A petrological perspective, Tectonophysics, 231(4), 293309, 1994.

Furlong, K. P., and P. J. Kamp, The lithospheric geodynamics of plate boundary transpression in New Zealand: Initiating and emplacing subduction along the Hikurangi margin, and the tectonic evolution of the Alpine Fault system, Tectonophysics, 474 (3-4), 449-462, 2009.

Geiger, L., Herdbestimmung bei Erdbeben aus den Ankunftszeiten, Nachrichten von der Gesellschaft der Wissenschaften zu Göttingen, Mathematisch-Physikalische Klasse, 1910, 331-349, 1910. 
GeoNet, Continuous Waveform Buffer, 2014.

Geotrace, Pegasus, Bounty Trough, Great South Basin and Sahke Processing Report; Ministry of Economic Development New Zealand Unpublished Petroleum Report PR4279, 2010.

Gephart, J. W., Stress and the direction of slip on fault planes, Tectonics, $9(4)$, 845-858, 1990.

Gephart, J. W., and D. W. Forsyth, An improved method for determining the regional stress tensor using earthquake focal mechanism data: application to the San Fernando earthquake sequence, Journal of Geophysical Research: Solid Earth (1978-2012), 89(B11), 9305-9320, 1984.

Gerst, A., and M. K. Savage, Seismic anisotropy beneath Ruapehu volcano: A possible eruption forecasting tool, Science, 306(5701), 1543-1547, 2004.

Gilbert, F., and L. Knopoff, Seismic scattering from topographic irregularities, Journal of Geophysical Research, 65(10), 3437-3444, 1960.

Godfrey, N. J., F. Davey, T. A. Stern, and D. Okaya, Crustal structure and thermal anomalies of the Dunedin region, South Island, New Zealand, Journal of Geophysical Research: Solid Earth, 106(B12), 30,835-30,848, 2001.

Guillot, S., S. Schwartz, B. Reynard, P. Agard, and C. Prigent, Tectonic significance of serpentinites, Tectonophysics, 646, 1-19, 2015.

Guralp, CMG-3ESP Operator's Guide, Tech. rep., Guralp Systems Limited, 2011.

Gurrola, H., J. Minster, and T. Owens, The use of velocity spectrum for stacking receiver functions and imaging upper mantle discontinuities, Geophysical Journal International, 117(2), 427-440, 1994.

Gurrola, H., G. E. Baker, and J. B. Minster, Simultaneous time-domain deconvolution with application to the computation of receiver functions, Geophysical Journal International, 120(3), 537-543, 1995.

Hacker, B. R., G. A. Abers, and S. M. Peacock, Subduction factory 1. Theoretical mineralogy, densities, seismic wave speeds, and H2O contents, Journal of Geophysical Research: Solid Earth, 108(B1), 2003.

Hackert, C. L., and J. O. Parra, Estimating scattering attenuation from vugs or karsts, Geophysics, 68(4), 1182-1188, 2003. 
Hanks, T. C., and H. Kanamori, A Moment Magnitude Scale, Journal of Geophysical Research, 84(B5), 2348-2350, 1979.

Hardebeck, J. L., and P. M. Shearer, A new method for determining first-motion focal mechanisms, Bulletin of the Seismological Society of America, 92(6), 22642276, 2002.

Hasselgren, E. O., and R. M. Clowes, Crustal structure of northern Juan de Fuca plate from multichannel reflection data, Journal of Geophysical Research: Solid Earth (1978-2012), 100(B4), 6469-6486, 1995.

Hatherton, T., Upper mantle inhomogeneity beneath New Zealand: Surface manifestations, Journal of Geophysical Research, 75(2), 269-284, 1970a.

Hatherton, T., Gravity, seismicity, and tectonics of the North Island, New Zealand, New Zealand Journal of Geology and Geophysics, 13(1), 126-144, 1970b.

Hatherton, T., Shallow seismicity in New Zealand 1956-75, Journal of the Royal Society of New Zealand, 10(1), 19-25, 1980.

Havskov, J., and L. Ottemoller, Routine data processing in earthquake seismology: with sample data, exercises and software, Springer Science \& Business Media, 2010 .

Hayes, G., M. Reyners, and G. Stuart, The Waiouru, New Zealand, earthquake swarm: Persistent mid crustal activity near an active volcano, Geophysical Research Letters, 31 (19), 2004.

Henrys, S., et al., SAHKE geophysical transect reveals crustal and subduction zone structure at the southern Hikurangi margin, New Zealand, Geochemistry, Geophysics, Geosystems, 2013.

Hirose, H., and K. Obara, Repeating short-and long-term slow slip events with deep tremor activity around the Bungo channel region, southwest Japan, Earth, Planets and Space, 57(10), 961-972, 2005.

Hirose, H., K. Hirahara, F. Kimata, N. Fujii, and S. Miyazaki, A slow thrust slip event following the two 1996 Hyuganada earthquakes beneath the Bungo Channel, southwest Japan, Geophysical Research Letters, 26(21), 3237-3240, 1999.

Holt, W. E., and T. A. Stern, Subduction, platform subsidence, and foreland thrust loading: The late Tertiary development of Taranaki Basin, New Zealand, Tectonics, 13(5), 1068-1092, 1994. 
Holtzman, B., D. Kohlstedt, M. Zimmerman, F. Heidelbach, T. Hiraga, and J. Hustoft, Melt segregation and strain partitioning: implications for seismic anisotropy and mantle flow, Science, 301 (5637), 1227-1230, 2003.

Horan, S., Borehole stress study of Kupe South \& Toru Fields, PML38146. Unpublished Petroleum Report PR2764, Tech. rep., Ministry of Economic Development New Zealand, 1997.

Horspool, N., M. Savage, and S. Bannister, Implications for intraplate volcanism and back-arc deformation in northwestern New Zealand, from joint inversion of receiver functions and surface waves, Geophysical Journal International, 166(3), 1466-1483, 2006.

Houseman, G., From mountains to basin, Nature, $379(6568)$, 771-772, 1996.

Hunt, T., Stokes magnetic anomaly system, New Zealand Journal of Geology and Geophysics, 21(5), 595-606, 1978.

Hunt, T., Basement structure of the Wanganui Basin, interpreted from gravity data, New Zealand Journal of Geology and Geophysics, 23, 1-16, 1980.

Hurst, A., and P. McGinty, Earthquake swarms to the west of Mt Ruapehu preceding its 1995 eruption, Journal of Volcanology and Geothermal Research, 90(1-2), 19 $-28,1999$.

Hutchinson, D., and M. Lee, Processing and attenuation of noise in deep seismicreflection data from the Gulf of Maine, Marine geophysical researches, 11(1), 51-67, 1989.

Hyndman, R. D., and S. M. Peacock, Serpentinization of the forearc mantle, Earth and Planetary Science Letters, 212(3), 417-432, 2003.

Jackson, J., and D. McKenzie, The relationship between plate motions and seismic moment tensors, and the rates of active deformation in the Mediterranean and Middle East, Geophysical Journal International, 93(1), 45-73, 1988.

Jackson, J., D. McKenzie, K. Priestley, and B. Emmerson, New views on the structure and rheology of the lithosphere, Journal of the Geological Society, 165, 453465, 2008.

Johnson, J. H., M. K. Savage, and J. Townend, Distinguishing between stressinduced and structural anisotropy at Mount Ruapehu volcano, New Zealand, Journal of Geophysical Research: Solid Earth, 116(B12), 2011. 
Johnston, D. H., M. Toksöz, and A. Timur, Attenuation of seismic waves in dry and saturated rocks: II. Mechanisms, Geophysics, 44(4), 691-711, 1979.

Kamp, P. J., et al., Megasequence architecture of Taranaki, Wanganui, and King Country basins and Neogene progradation of two continental margin wedges across western New Zealand, in 2002 New Zealand Petroleum Conference Proceedings, pp. 464-481, 2002.

Kato, N., A possible model for large preseismic slip on a deeper extension of a seismic rupture plane, Earth and Planetary Science Letters, 216(1), 17-25, 2003.

Katz, H., and B. Leask, The South Wanganui Basin - A neglected hydrocarbon prospect Petroleum exploration in New Zealand, Petroleum Exploration New Zealand News, pp. 19-25, 1990.

Kawasaki, I., Silent earthquakes occurring in a stable-unstable transition zone and implications for earthquake prediction, Earth, Planets and Space, 56 (8), 813-821, 2004.

Kearey, P., M. Brooks, and I. Hill, An introduction to geophysical exploration, John Wiley \&amp; Sons, 2013.

Keats, B. S., J. H. Johnson, and M. K. Savage, The Erua earthquake cluster and seismic anisotropy in the Ruapehu region, New Zealand, Geophysical Research Letters, 38(16), 2011.

Kennett, B., E. Engdahl, and R. Buland, Constraints on seismic velocities in the Earth from traveltimes, Geophysical Journal International, 122(1), 108-124, 1995.

King, P. R., Tectonic reconstructions of New Zealand: 40 Ma to the Present, New Zealand Journal of Geology and Geophysics, 43(4), 611-638, 2000.

Knox, G., Taranaki Basin, structural style and tectonic setting, New Zealand Journal of Geology and Geophysics, 25(2), 125-140, 1982.

Kostoglodov, V., S. K. Singh, J. A. Santiago, S. I. Franco, K. M. Larson, A. R. Lowry, and R. Bilham, A large silent earthquake in the Guerrero seismic gap, Mexico, Geophysical Research Letters, 30(15), 2003.

Kostrov, V., Seismic moment and energy of earthquakes, and seismic flow of rock, Izv. Acad. Sci. USSR Phys. Solid Earth, 1, 23-44, 1974. 
Lamb, S., Cenozoic tectonic evolution of the New Zealand plate-boundary zone: A paleomagnetic perspective, Tectonophysics, 509(3-4), 135-164, 2011.

Lamb, S., Kinematics to dynamics in the New Zealand Plate boundary zone: implications for the strength of the lithosphere, Geophysical Journal International, $201(2), 552-573,2015$.

Langston, C. A., Corvallis, Oregon, Crustal and Upper Mantle Receiver Structure from Teleseismic P and S waves, Bulletin of the Seismological Society of America, 67, 713-724, 1977.

Langston, C. A., Structure under Mount Rainier, Washington, inferred from teleseismic body waves, Journal of Geophysical Research: Solid Earth (1978-2012), 84(B9), 4749-4762, 1979.

Le Pourhiet, L., M. Gurnis, and J. Saleeby, Mantle instability beneath the Sierra Nevada mountains in California and Death Valley extension, Earth and Planetary Science Letters, 251(1), 104-119, 2006.

Lienert, B. R., and J. Havskov, A computer program for locating earthquakes both locally and globally, Seismological Research Letters, 66 (5), 26-36, 1995.

Lienert, B. R., E. Berg, and L. N. Frazer, HYPOCENTER: An earthquake location method using centered, scaled, and adaptively damped least squares, Bulletin of the Seismological Society of America, 76(3), 771-783, 1986.

Lin, C.-L., A Review of Receiver Function Techniques for Estimation of OneDimensional Velocity Structures, TAO, 6(2), 181-195, 1995.

Lindenfeld, M., and G. Rümpker, Detection of mantle earthquakes beneath the East African Rift, Geophysical Journal International, 186(1), 1-5, 2011.

Liu, Y., and J. R. Rice, Spontaneous and triggered aseismic deformation transients in a subduction fault model, Journal of Geophysical Research: Solid Earth (19782012), 112(B9), 2007.

Lomax, A., The NonLinLoc Software Guide, version 6.0., 2011.

Lomax, A., J. Virieux, P. Volant, and C. Berge, Probabilistic earthquake location in 3D and layered models: Introduction of a Metropolis-Gibbs method and comparison with linear locations., in Advances in Seismic Event Location, edited by C. Thurber and N. Rabinowitz, pp. 101-134, 2000. 
Lomax, A., A. Michelini, and A. Curtis, Encyclopoaedia of Complexity and Systems Science, chap. Earthquake Location, Direct, Global-Search Methods, 2009.

Lorinczi, P., and G. Houseman, Lithospheric gravitational instability beneath the Southeast Carpathians, Tectonophysics, 474(1), 322-336, 2009.

Lowry, A. R., K. M. Larson, V. Kostoglodov, and R. Bilham, Transient fault slip in Guerrero, southern Mexico, Geophysical Research Letters, 28(19), 3753-3756, 2001.

Maggi, A., J. Jackson, D. Mckenzie, and K. Priestley, Earthquake focal depths, effective elastic thickness, and the strength of the continental lithosphere, Geology, 28(6), 495-498, 2000a.

Maggi, A., J. Jackson, K. Priestley, and C. Baker, A re-assessment of focal depth distributions in southern Iran, the Tien Shan and northern India: do earthquakes really occur in the continental mantle?, Geophysical Journal International, 143(3), 629-661, 2000b.

Matsuzawa, A., T. Tamano, Y. Aoki, and T. Ikawa, Structure of the Japan Trench subduction zone, from multi-channel seismic-reflection records, Marine Geology, $35(1), 171-182,1980$.

Matthews, D., C. A. Flack, R. W. Hobbs, S. L. Klemperer, D. C. Snyder, M. R. Warner, and N. J. White, Progress in BIRPS deep seismic reflection profiling around the British Isles, Tectonophysics, 173(1), 387-396, 1990.

Maunder, D. E., New Zealand Seismological Report 2000: Seismological Observatory Bulletin E-183, Tech. rep., Institute of Geological and Nuclear Sciences, 2002.

May, B., and J. Covey, An inverse ray method for computing geologic structures from seismic reflections-Zero-offset case, Geophysics, 46(3), 268-287, 1981.

McKenzie, D., The relation between fault plane solutions for earthquakes and the directions of the principal stresses, Bulletin of the Seismological Society of America, 59(2), 591-601, 1969.

McKenzie, D., J. Jackson, and K. Priestley, Thermal structure of oceanic and continental lithosphere, Earth and Planetary Science Letters, 233(3), 337-349, 2005.

McNamara, D. E., and R. Boaz, Seismic noise analysis system using power spectral density probability density functions: A stand-alone software package, Citeseer, 2006 . 
McNamara, D. E., and R. P. Buland, Ambient noise levels in the continental United States, Bulletin of the Seismological Society of America, 94(4), 1517-1527, 2004.

Michael, A. J., Determination of stress from slip data: faults and folds, Journal of Geophysical Research: Solid Earth (1978-2012), 89(B13), 11,517-11,526, 1984.

Michael, A. J., Use of focal mechanisms to determine stress: a control study, Journal of Geophysical Research: Solid Earth (1978-2012), 92(B1), 357-368, 1987.

Mildren, S., and J. Meyer, Regional seal evaluation of the north Taranaki Graben, PEP38485. Unpublished Petroleum Report PR3344., Tech. rep., Ministry of Economic Development New Zealand, 2005.

Mildren, S., J. Meyer, and R. Hills, Pohokura ERD Wellbore Stability Study. Unpublished Petroleum Report PR2651, Tech. rep., Ministry of Economic Development New Zealand, 2001.

Milkereit, B., and C. Spencer, Noise suppression and coherency enhancement of seismic data, Statistical Application in the Earth Sciences, 89, 9, 1989.

Miller, M. M., T. Melbourne, D. J. Johnson, and W. Q. Sumner, Periodic slow earthquakes from the Cascadia subduction zone, Science, 295(5564), 2423-2423, 2002.

Miller, V., and M. Savage, Changes in Seismic Anisotropy After Volcanic Eruptions: Evidence from Mount Ruapehu, Science, 293(5538), 2231-2233, 2001.

Mooney, H. M., Upper mantle inhomogeneity beneath New Zealand: Seismic evidence, Journal of Geophysical Research, 75 (2), 285-309, 1970.

Mortimer, N., Metamorphic zones, terranes, and Cenozoic faults in the Marlborough Schist, New Zealand, New Zealand Journal of Geology and Geophysics, 36(3), 357-368, 1993.

Mortimer, N., New Zealand's geological foundations, Gondwana Research, 7(1), 261-272, 2004.

Mortimer, N., A. Tulloch, and T. Ireland, Basement geology of Taranaki and Wanganui Basins, New Zealand, New Zealand Journal of Geology and Geophysics, 40(2), 223-236, 1997.

Mortimer, N., F. Davey, A. Melhuish, J. Yu, and N. Godfrey, Geological interpretation of a deep seismic reflection profile across the Eastern Province and Median 
Batholith, New Zealand: crustal architecture of an extended Phanerozoic convergent orogen, New Zealand Journal of Geology and Geophysics, 45(3), 349-363, 2002.

Nedimović, M. R., R. D. Hyndman, K. Ramachandran, and G. D. Spence, Reflection signature of seismic and aseismic slip on the northern Cascadia subduction interface, Nature, 424(6947), 416-420, 2003.

Neidell, N., and M. T. Taner, Semblance and other coherency measures for multichannel data, Geophysics, 36(3), 482-497, 1971.

Oliver, J., Deep seismic sounding of the continental crust and mantle - a long-term view, Tectonophysics, 286(1), 1-4, 1998.

Olivieri, M., and J. Clinton, An almost fair comparison between Earthworm and SeisComp3, Seismological Research Letters, 83(4), 720-727, 2012.

Oppenheimer, D., Focal Mechanisms, 1996.

Park, J., and V. Levin, Receiver functions from multiple-taper spectral correlation estimates, Bulletin of the Seismological Society of America, 90(6), 1507-1520, 2000 .

Petersen, T., K. Gledhill, M. Chadwick, N. H. Gale, and J. Ristau, The New Zealand national seismograph network, Seismological Research Letters, 82(1), 9-20, 2011.

Peterson, J., Observations and modeling of seismic background noise: Open-File Report 93-322, Tech. rep., US Geological Survey, 1993.

Platt, J. P., and R. Vissers, Extensional collapse of thickened continental lithosphere: a working hypothesis for the Alboran Sea and Gibraltar Arc, Geology, 17(6), 540543, 1989.

Platt, J. P., J.-I. Soto, M. J. Whitehouse, A. J. Hurford, and S. P. Kelley, Thermal evolution, rate of exhumation, and tectonic significance of metamorphic rocks from the floor of the Alboran extensional basin, western Mediterranean, Tectonics, $17(5), 671-689,1998$.

Platt, J. P., W. M. Behr, K. Johanesen, and J. R. Williams, The Betic-Rif arc and its orogenic hinterland: A review, Annual Review of Earth and Planetary Sciences, 41, 313-357, 2013. 
Poulet, T., E. Veveakis, K. Regenauer-Lieb, and D. Yuen, Thermo-poro-mechanics of chemically active creeping faults: 3 . The role of serpentinite in episodic tremor and slip sequences, and transition to chaos, Journal of Geophysical Research: Solid Earth, 2014.

Presti, D., B. Orecchio, G. Falcone, and G. Neri, Linear versus non-linear earthquake location and seismogenic fault detection in the southern Tyrrhenian Sea, Italy, Geophysical Journal International, 172(2), 607-618, 2008.

Price, R. C., R. B. Stewart, J. D. Woodhead, and I. E. M. Smith, Petrogenesis of High-K Arc Magmas: Evidence from Egmont Volcano, North Island, New Zealand, Journal of Petrology, 40(1), 167-197, 1999.

Proust, J.-N., G. Lamarche, S. Nodder, and P. J. Kamp, Sedimentary architecture of a Plio-Pleistocene proto-back-arc basin: Wanganui Basin, New Zealand, Sedimentary Geology, 181 (3-4), 107 - 145, 2005.

Pulford, A., and T. Stern, Pliocene exhumation and landscape evolution of central North Island, New Zealand: the role of the upper mantle, Journal of Geophysical Research: Earth Surface, $109(\mathrm{~F} 1), 2004$.

Raikes, S., and R. White, Measurements of Earth Attenuation from Downhole and Surface Seismic RECORDINGS*, Geophysical Prospecting, 32(5), 892-919, 1984.

Rait, G., F. Chanier, and D. W. Waters, Landward- and seaward-directed thrthrust accompanying the onset of subduction beneath New Zealand, Geology, 19, 230233, 1991.

Ranalli, G., Rheology of the Earth, Springer Science \&amp; Business Media, 1995.

Reilly, W., New Zealand gravity map series, New Zealand Journal of Geology and Geophysics, 15(1), 3-15, 1972.

Reyners, M., A microearthquake study of the plate boundary, North Island, New Zealand, Geophysical Journal of the Royal Astronomical Society, 63(1), 1-22, 1980.

Reyners, M., New Zealand seismicity 1964-87: An interpretation, New Zealand Journal of Geology and Geophysics, 32(3), 307-315, 1989.

Reyners, M., Stress and strain from earthquakes at the southern termination of the Taupo Volcanic Zone, New Zealand, Journal of Volcanology and Geothermal Research, 190(1-2), 82 - 88, 2010. 
Reyners, M., D. Eberhart-Phillips, G. Stuart, and Y. Nishimura, Imaging subduction from the trench to $300 \mathrm{~km}$ depth beneath the central North Island, New Zealand, with Vp and Vp/Vs, Geophysical Journal International, 165(2), 565583, 2006.

Reyners, M., D. Eberhart-Phillips, and G. Stuart, The role of fluids in lower-crustal earthquakes near continental rifts, Nature, 446(7139), 1075-1078, 2007.

Reyners, M., D. Eberhart-Phillips, and S. Bannister, Tracking repeated subduction of the Hikurangi Plateau beneath New Zealand, Earth and Planetary Science Letters, 311(1), 165-171, 2011.

Richter, F. M., Convection and the large-scale circulation of the mantle, Journal of Geophysical Research, 78(35), 8735-8745, 1973.

Richter, F. M., and B. Parsons, On the interaction of two scales of convection in the mantle, Journal of Geophysical Research, 80(17), 2529-2541, 1975.

Ringwood, A., Composition and evolution of the upper mantle, The Earth's Crust and Upper Mantle, pp. 1-17, 1969.

Ristau, J., Comparison of magnitude estimates for New Zealand earthquakes: moment magnitude, local magnitude, and teleseismic body-wave magnitude, Bulletin of the Seismological Society of America, 99(3), 1841-1852, 2009.

Rivera, L., and A. Cisternas, Stress tensor and fault plane solutions for a population of earthquakes, Bulletin of the Seismological Society of America, 80(3), 600-614, 1990.

Robertson, E., and W. Reilly, Bouguer anomaly map of New Zealand, New Zealand journal of geology and geophysics, 1(3), 560-564, 1958.

Salmon, M. L., Crust and Upper Mantle Inhomogeneities Beneath Western North Island, New Zealand: Evidence from Seismological and Electromagnetic Data, Ph.D. thesis, Victoria University of Wellington, 2008.

Salmon, M. L., T. A. Stern, and M. K. Savage, A major step in the continental Moho and its geodynamic consequences: the Taranaki-Ruapehu line, New Zealand, Geophysical Journal International, 186(1), 32-44, 2011.

Savage, M. K., J. Park, and H. Todd, Velocity and anisotropy structure at the Hikurangi subduction margin, New Zealand from receiver functions, Geophysical Journal International, 168(3), 1034-1050, 2007. 
Schmidt, J., NIWA Open Data License, 2015.

Schwartz, S., P. Allemand, and S. Guillot, Numerical model of the effect of serpentinites on the exhumation of eclogitic rocks: insights from the Monviso ophiolitic massif (Western Alps), Tectonophysics, 342(1), 193-206, 2001.

Schwartz, S. Y., and J. M. Rokosky, Slow slip events and seismic tremor at circumPacific subduction zones, Reviews of Geophysics, 45(3), 2007.

Seber, D., M. Barazangi, A. Ibenbrahim, and A. Demnati, Geophysical evidence for lithospheric delamination beneath the Alboran Sea and Rif-Betic mountains, Nature, 379, 785-790, 1996.

Segall, P., A. M. Rubin, A. M. Bradley, and J. R. Rice, Dilatant strengthening as a mechanism for slow slip events, Journal of Geophysical Research: Solid Earth (1978-2012), 115(B12), 2010.

Seward, A., S. Greve, T. Stern, and M. Savage, P-wave travel time residuals across the western North Island: Implications for variations in thickness of the mantle lithosphere, Poster presented at the annual meeting of the Geological Society of New Zealand, Oamaru, Otago., 2009a.

Seward, A., C. Henderson, and E. Smith, Models of the upper mantle beneath the central North Island, New Zealand, from speeds and anisotropy of subhorizontal P waves (Pn), Journal of Geophysical Research: Solid Earth, 114(B1), 2009b.

Sherburn, S., and R. S. White, Crustal seismicity in Taranaki, New Zealand using accurate hypocentres from a dense network, Geophysical Journal International, 162(2), 494-506, 2005.

Sherburn, S., and R. S. White, Tectonics of the Taranaki region, New Zealand: Earthquake focal mechanisms and stress axes, New Zealand Journal of Geology and Geophysics, 49:2, 269-279, 2006.

Sherburn, S., R. S. White, and M. Chadwick, Three-dimensional tomographic imaging of the Taranaki volcanoes, New Zealand, Geophysical Journal International, $166(2), 957-969,2006$.

Sheriff, R. E., Encyclopedic Dictionary of Applied Geophysics, Society of Exploration Geophysicists Tulsa, OK, 2002.

Sheriff, R. E., and L. P. Geldart, Exploration Seismology, Cambridge University Press, 1995. 
Smith, D., Antigorite peridotite, metaserpentinite, and other inclusions within diatremes on the Colorado Plateau, SW USA: implications for the mantle wedge during low-angle subduction, Journal of Petrology, 51(6), 1355-1379, 2010.

Stein, S., and M. Wysession, An Introduction to Seismology, Earthquakes, and Earth Structure, John Wiley \& Sons, 2009.

Stern, T. A., and F. J. Davey, Crustal Structure and Origin of Basins Formed Behind the Hikurangi Subduction Zone, New Zealand, pp. 73-85, American Geophysical Union, 1989.

Stern, T. A., and F. J. Davey, Deep seismic expression of a foreland basin: Taranaki Basin, New Zealand, Geology, 18(10), 979-982, 1990.

Stern, T. A., E. G. C. Smith, F. J. Davey, and K. J. Muirhead, Crustal and upper mantle structure of the northwestern North Island, New Zealand, from seismic refraction data, Geophysical Journal of the Royal Astronomical Society, 91(3), 913-936, 1987.

Stern, T. A., G. M. Quinlan, and W. E. Holt, Basin formation behind an active subduction zone: three-dimensional flexural modelling of Wanganui Basin, New Zealand, Basin Research, 4(3-4), 197-214, 1992.

Stern, T. A., S. Kleffmann, D. Okaya, M. Scherwath, and S. Bannister, Low seismicwave speeds and enhanced fluid pressure beneath the Southern Alps of New Zealand, Geology, 29(8), 679-682, 2001.

Stern, T. A., W. R. Stratford, and M. L. Salmon, Subduction evolution and mantle dynamics at a continental margin: Central North Island, New Zealand, Reviews of Geophysics, 44(4), 2006.

Stern, T. A., G. Houseman, M. Salmon, and L. Evans, Instability of a lithospheric step beneath western North Island, New Zealand, Geology, 2013.

Stern, T. A., S. Henrys, D. Okaya, J. Louie, M. Savage, S. Lamb, H. Sato, R. Sutherland, and T. Iwasaki, A seismic reflection image for the base of a tectonic plate, Nature, 518(7537), 85-88, 2015.

Stratford, W. R., Lithospheric Structure of a Continental Back-Arc: Central Volcanic Region, New Zealand, Ph.D. thesis, Victoria University of Wellington, 2006. 
Stratford, W. R., and T. A. Stern, Crust and upper mantle structure of a continental backarc: central North Island, New Zealand, Geophysical Journal International, $166(1), 469-484,2006$.

Szeliga, W., T. I. Melbourne, M. M. Miller, and V. M. Santillan, Southern Cascadia episodic slow earthquakes, Geophysical Research Letters, 31(16), 2004.

Tarantola, A., and B. Valette, Inverse Problems = Quest for Information, Journal of Geophysics, 50(3), 159-170, 1982.

Townend, J., S. Sherburn, R. Arnold, C. Boese, and L. Woods, Three-dimensional variations in present-day tectonic stress along the Australia-Pacific plate boundary in New Zealand, Earth and Planetary Science Letters, 353-354(0), 47 - 59, 2012 .

Townsend, D., A. Vonk, and P. J. J. Kamp, Geology of the Taranaki area: scale 1:250,000, Tech. rep., GNS Science, 2008.

Tozer, B., Crustal Structure of Wanganui Basin: Implications for Back-Arc Basin Formation, Master's thesis, Victoria University of Wellington, 2013.

Turcotte, D. L., and G. Schubert, Geodynamics: Applications of continuum physics to geological problems, 450 pp., John Wiley, New York, 1982.

Ulmer, P., and V. Trommsdorff, Serpentine stability to mantle depths and subduction-related magmatism, Science, 268(5212), 858-861, 1995.

Vasudevan, K., S. Eckel, F. Fleischer, V. Schmidt, and F. Cook, Statistical analysis of spatial point patterns on deep seismic reflection data: a preliminary test, Geophysical Journal International, 171(2), 823-840, 2007.

Walcott, R., Reconstructions of the New Zealand region for the Neogene, Palaeogeography, Palaeoclimatology, Palaeoecology, 46(1-3), 217 - 231, 1984.

Wallace, L. M., and J. Beavan, Diverse slow slip behavior at the Hikurangi subduction margin, New Zealand, Journal of Geophysical Research: Solid Earth, $115(\mathrm{~B} 12), 2010$.

Wallace, L. M., J. Beavan, R. McCaffrey, and D. Darby, Subduction zone coupling and tectonic block rotations in the North Island, New Zealand, Journal of Geophysical Research: Solid Earth, 109 (B12), 2004. 
Wallace, L. M., P. Barnes, J. Beavan, R. Van Dissen, N. Litchfield, J. Mountjoy, R. Langridge, G. Lamarche, and N. Pondard, The kinematics of a transition from subduction to strike-slip: an example from the central New Zealand plate boundary, Journal of Geophysical Research: Solid Earth (1978-2012), 117(B2), 2012 .

Wallace, R. E., Geometry of shearing stress and relation to faulting, The Journal of Geology, pp. 118-130, 1951.

Wallner, H., and H. Schmeling, Rift induced delamination of mantle lithosphere and crustal uplift: a new mechanism for explaining Rwenzori Mountains' extreme elevation?, International Journal of Earth Sciences, 99(7), 1511-1524, 2010.

Walsh, D., Directional Statistics, Bayesian Methods of Earthquake Focal Mechanism Estimation, and their Application to New Zealand Seismicity Data, Master's thesis, Victoria University of Wellington, Wellington, 2008.

Walsh, D., R. Arnold, and J. Townend, A Bayesian approach to determining and parametrizing earthquake focal mechanisms, Geophysical Journal International, $176(1), 235-255,2009$.

Warner, M., Migration-why doesn't it work for deep continental data?, Geophysical Journal International, 89(1), 21-26, 1987.

Warner, M., Basalts, water, or shear zones in the lower continental crust?, Tectonophysics, $173(1)$, 163-174, 1990.

Watson, J., and D. Allen, Compilation of seismic results in the Wanganui Basin, Shell, BP and Todd Oil Services report EP, 53, 1964.

White, R., The accuracy of estimating Q from seismic data, Geophysics, 57(11), 1508-1511, 1992.

Williams, C. A., D. Eberhart-Phillips, S. Bannister, D. H. N. Barker, S. Henrys, M. Reyners, and R. Sutherland, Revised Interface Geometry for the Hikurangi Subduction Zone, New Zealand, Seismological Research Letters, 84 (6), 1066-1072, 2013.

Wilson, C. K., C. H. Jones, P. Molnar, A. F. Sheehan, and O. S. Boyd, Distributed deformation in the lower crust and upper mantle beneath a continental strike-slip fault zone: Marlborough fault system, South Island, New Zealand, Geology, 32, 837-840, 2004. 
Wirth, E. A., and J. Korenaga, Small-scale convection in the subduction zone mantle wedge, Earth and Planetary Science Letters, 35\%, 111-118, 2012.

Wolfe, C. J., P. G. Okubo, and P. M. Shearer, Mantle fault zone beneath Kilauea volcano, Hawaii, Science, 300(5618), 478-480, 2003.

Wood, R., and V. Stagpoole, Validation of tectonic reconstructions by crustal volume balance: New Zealand through the Cenozoic, Geological Society of America Bulletin, 119(7-8), 933-943, 2007.

Yilmaz, Ö., Seismic Data Analysis, vol. 1, Society of Exploration Geophysicists Tulsa, OK, 2001.

Zandt, G., and C. J. Ammon, Continental crust composition constrained by measurements of crustal Poisson's ratio, Nature, 374 (6518), 152-154, 1995.

Zandt, G., H. Gilbert, T. J. Owens, M. Ducea, J. Saleeby, and C. H. Jones, Active foundering of a continental arc root beneath the southern Sierra Nevada in California, Nature, 431(7004), 41-46, 2004.

Zhou, H.-W., Practical Seismic Data Analysis, Cambridge University Press, 2014.

Zoeppritz, K., Erdbebenwellen VII, Nachrichten von der Gesellschaft der Wissenschaften zu Göttingen, Mathematisch-Physikalische Klasse, 1919, 57-65, 1919. 